\title{
TESTS AND EVALUATION OF UPGRADED FLAT-PLATE AND WAFFLE-SLAB FLOOR SYSTEMS
}

\author{
by \\ Stanley C. Woodson, Mark K. McVay \\ Structures Laboratory
}

U. S. Army Engineer Waterways Experiment Station

P. O. Box 631, Vicksburg, Miss. 39180
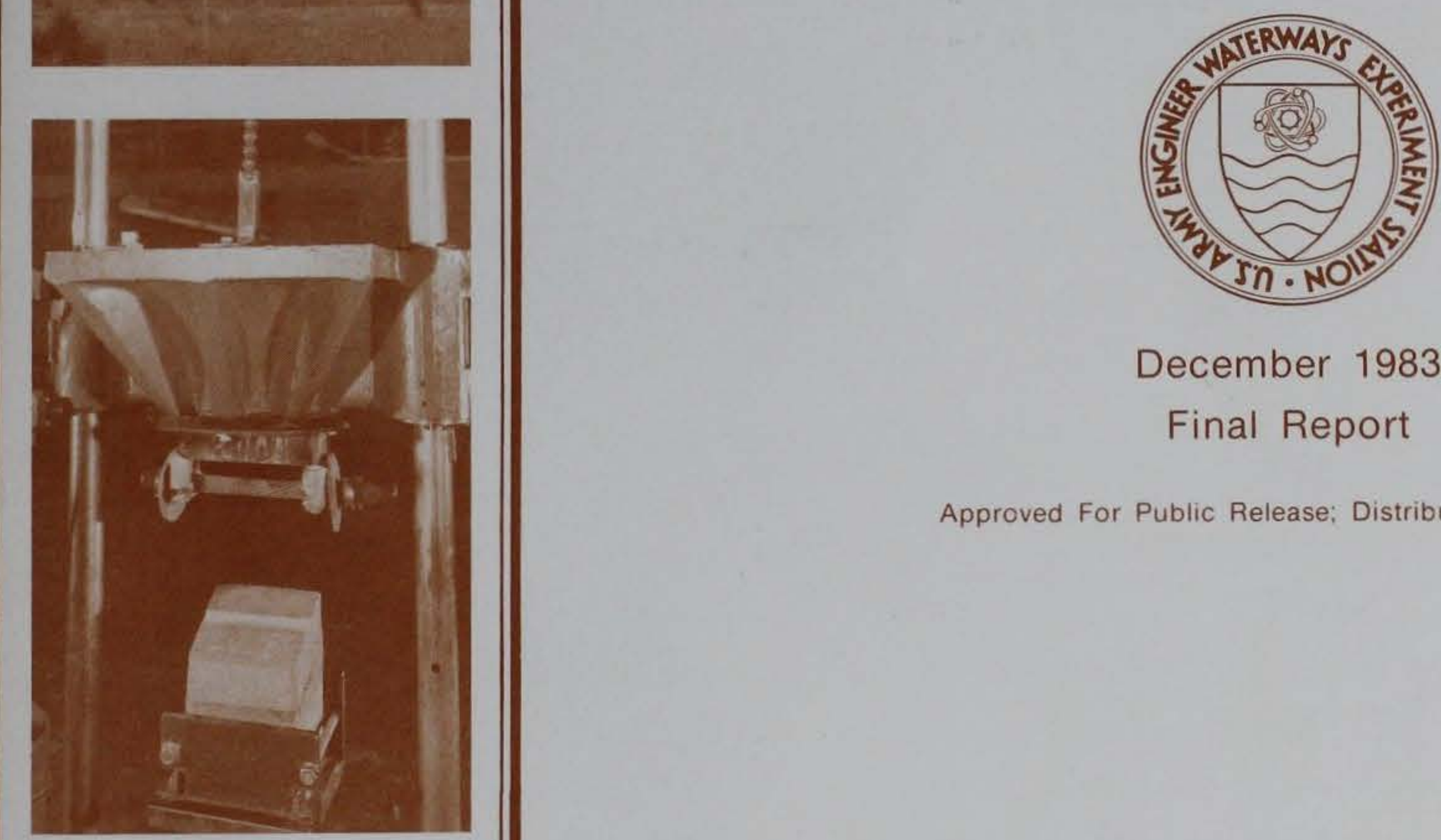

December 1983

Final Report

Approved For Public Release; Distribution Unlimited

Prepared for Federal Emergency Management Agency Washington, D. C. 20472 
TESTS AND EVAULATION OF UPGRADED

FLAT-PLATE AND WAFFLE-SLAB FLOOR SYSTEMS

This report describes the research program consisting of several tests performed at the Waterways Experiment Station (WES) for the Federal Emergency Management Agency (FEMA). The tests were conceived and recommended by Scientific Services Incorporated (SSI) to provide information for use in the Shelter Upgrading Manuals being prepared for FEMA.

The program consisted of tests on individual 19- and 30-in.-square panels taken from waffle slabs, 19-in. panels taken from one-way ribbed joist slabs, two center portions of a waffle slab, and the center portion of a flat plate. Also included were tests to determine the punching strength of 4-in.-thick basement slabs on grade.

The individual 19- and 30-in. waffle panels and the 19-in. one-way slab panels were $3 \mathrm{in.} \mathrm{thick,} \mathrm{which} \mathrm{is} \mathrm{the} \mathrm{minimum} \mathrm{thickness} \mathrm{used} \mathrm{in} \mathrm{standard}$ construction. Each panel was cast as the center portion of a 46-in.-diameter by 11-in.-thick concrete disk and statically loaded to failure with water pressure in the Small Blast Load Generator (SBLG).

Two 4-in.-thick basement slabs on grade were cast inside 46-3/4-in.diameter steel rings and on top of a polyurethane sheet covering 6 in. of compacted gravel on top of $18 \mathrm{in}$. of soil compacted to 95 percent optimum density. The slabs were tested by pushing a 7- by 7-in. wooden post, composed of four 4- by 4-in. posts nailed together, into the center of the slab with the 200-kip loader. One test was performed statically and one dynamically.

The two center portions of a waffle slab and the one center portion of a flat plate were designed with the maximum diameters that would allow placement inside the 22-ft 10-in.-diameter Large Blast Load Generator (LBLG). The flatplate test specimen was constructed to include the positive moment area from a 22-ft-square slab designed according to the Third Edition of the CRSI Handbook. The waffle-slab specimens were constructed to include positive moment areas from $24-\mathrm{ft}$-square slabs. An 8 -in.-thick wall, $8 \mathrm{ft}$ tall, supported the slabs along their perimeters, and wooden posts were wedged in place under each specimen where SSI predicted upgrading supports would be needed in an actual slab. It should be noted that these test specimens were not under boundary conditions similar to those in actual structures. However, SSI was 
interested in testing the response of the slabs' center portions where upgrading supports were applied.

The static overpressure load-bearing capacity of the 19-in.-square by 3-in.-thick waffle-slab panel was in the range of 900 to 1000 psi. The structural behavior was characteristic of deep slabs, with failure occurring due to shearing action.

The static overpressure capacities of the 19- by $19-$ by $3-i n$. one-way slab panel and the $30-$ by $30-$ by $3-i n$. waffle-slab panel were approximately 445 and 347 psi, respectively. The load-bearing capacities of the panels are of magnitude great enough to insure that the panels will not be vulnerable components of upgraded floor systems.

The wooden posts punched through the 4-in.-thick slabs on grade under a peak static load of approximately $79.0 \mathrm{kips}$ and a peak dynamic load of approximately 135.0 kips. Utilizing results of the statically tested slab on grade, the ultimate dynamic punching load for the slab was computed to be approximately 106.4 kips. The dynamic punching load of 106.4 kips was approximately 48 percent of the maximum dynamic load of 220 kips sustained by the upgrading columns during the dynamic tests on the waffle-slab floor center portion. Therefore, in the case of Crisis Relocation Planning implementation involving the upgrading of floor systems, allowances must be made to avoid the punching of upgrading columns into the basement (shelter) floor.

Although the waffle-slab center portion specimens did not properly model the center portion of a waffle-slab floor as it would exist in a building, the lack of punching shear failure at the waffle joists indicated that the upgrading of waffle slabs may be feasible. Due to upgrading column buckling, allowing collapse of the slab primarily through shear failure, the maximum static and dynamic load-carrying capacities of the waffle-slab system were near 44 and 34 psi, respectively.

The flat-plate specimen did not properly model the center portion of a flat-plate floor as it would exist in a building, due to differences in boundary conditions. However, the absence of punching shear initiation at the upgrading columns in the test does indicate that punching shear would not occur at upgrading columns in a complete flat-plate floor, having similar upgrading column spacing, before column buckling or other failure occurred. Due to column buckling, the maximum static average overpressure load-carrying capacity of the upgraded flat-plate specimen was 38 psi. 


\title{
TESTS AND EVALUATION OF UPGRADED FLAT-PLATE AND WAFFLE-SLAB FLOOR SYSTEMS
}

\author{
by \\ Stanley C. Woodson, Mark K. McVay \\ Structures Laboratory \\ U. S. Army Engineer Waterways Experiment Station \\ P. O. Box 631, Vicksburg, Miss. 39180
}

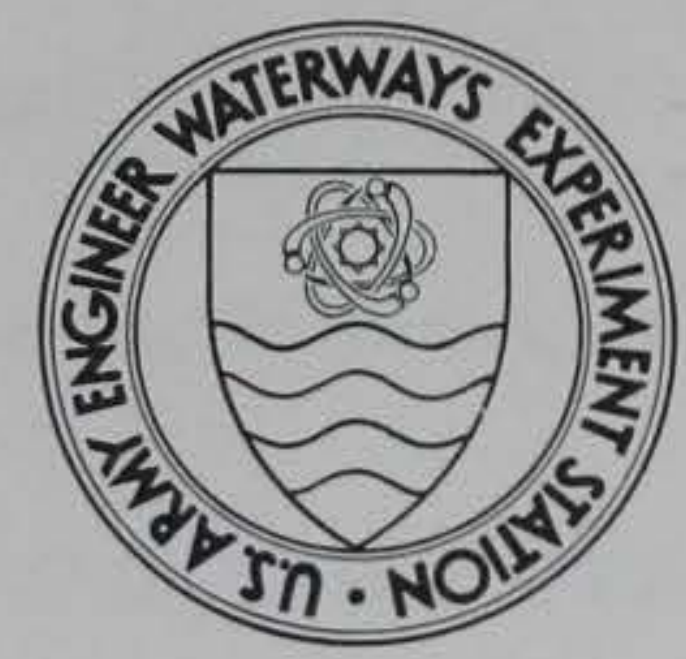

December 1983

Final Report

Approved for Public Release; Distribution Unlimited

This report has been reviewed in the Federal Emergency Management Agency and approved for publication. Approval does not signify that the contents necessarily reflect the views and policies of the Federal Emergency Management Agency. 
Unclassified

SECURITY CLASSIFICATION OF THIS PAGE (When Date Entered)

\begin{tabular}{|c|c|}
\hline REPORT DOCUMENTATION PAGE & $\begin{array}{c}\text { READ INSTRUCTIONS } \\
\text { BEFORE COMPLETING FORM } \\
\end{array}$ \\
\hline $\begin{array}{l}\begin{array}{l}\text { 1. REPORT NUMBER } \\
\text { Technical Report SL- } 83-7\end{array} \\
\text { 2. GOVT ACCESSION NO. }\end{array}$ & 3. RECIPIENT'S CATALOG NUMBER \\
\hline \multirow{2}{*}{$\begin{array}{l}\text { 4. TITLE (and Subtitie) } \\
\text { TESTS AND EVALUATION OF UPGRADED FLAT-PLATE } \\
\text { AND WAFFLE-SLAB FLOOR SYSTEMS }\end{array}$} & $\begin{array}{l}\text { 5. TYPE OF REPORT \& PERIOD COVERED } \\
\text { Final report }\end{array}$ \\
\hline & 6. PERFORMING ORG. REPORT NUMBER \\
\hline $\begin{array}{l}\text { 7. AUTHOR(s) } \\
\text { Stanley C. Woodson } \\
\text { Mark K. McVay }\end{array}$ & 8. CONTRACT OR GRANT NUMBER(s) \\
\hline $\begin{array}{l}\text { 9. PERFORMING ORGANIZATION NAME AND ADDRESS } \\
\text { U. S. Army Engineer Waterways Experiment Station } \\
\text { Structures Laboratory } \\
\text { P. O. Box } 631 \text {, Vicksburg, Miss. } 39180\end{array}$ & $\begin{array}{l}\text { 10. PROGRAM ELEMENT, PROJECT, TASK } \\
\text { AREA \& WORK UNIT NUMBERS } \\
\text { Interagency Agreement } \\
\text { No. EMW-E-00337 }\end{array}$ \\
\hline \multirow{2}{*}{$\begin{array}{l}\text { 11. CONTROLLING OFFICE NAME AND ADDRESS } \\
\text { Federal Emergency Management Agency } \\
1725 \text { I. St. N. W. (M. Bldg) } \\
\text { Washington, D. C. } 20472\end{array}$} & $\begin{array}{l}\text { 12. REPORT DATE } \\
\text { December } 1983\end{array}$ \\
\hline & $\begin{array}{l}\text { 13. NUMBER OF PAGES } \\
158\end{array}$ \\
\hline \multirow[t]{2}{*}{ 14. MONITORING AGENCY NAME \& ADDRESS(if different from Controlling Office) } & $\begin{array}{l}\text { 15. SECURITY CLASS. (of thia roport) } \\
\text { Unclassified }\end{array}$ \\
\hline & $\begin{array}{l}\text { 15a. DECLASSIFICATION/DOWNGRADING } \\
\text { SCHEDULE }\end{array}$ \\
\hline
\end{tabular}

\section{DISTRIBUTION STATEMENT (of thIo ROpOrt)}

Approved for public release; distribution unlimited.

17. DISTRIBUTION STATEMENT (of the abstract ontered in Block 20, if different froch Report)

\section{SUPPLEMENTARY NOTES}

Available from National Technical Information Service, 5285 Port Royal Road, Springfield, Va. 22161

$\begin{array}{ll}\text { 19. KEY WORDS (Continue on reverse side If nocessary and ldentlfy by block number) } \\ \text { Buildings } & \text { Reinforced concrete } \\ \text { Concrete } & \text { Slabs } \\ \text { Deep slabs } & \text { Slabs on grade } \\ \text { Dynamic loads } & \text { Upgrading } \\ \text { Flat plate } & \text { Waffle slabs }\end{array}$

20. ABSTRACT (Contimue an reverso of if necesany and tdentify by block number)
Several tests were performed at the Waterways Experiment Station (WES) for the Federal Emergency Management Agency (FEMA). The tests were conceived and recommended by Scientific Services Incorporated (SSI) to provide information for use in the Shelter Upgrading Manuals being prepared for FEMA by SSI.

The program consisted of tests on individual 19- and 30-inch-square panels taken from waffle slabs, 19-inch panels taken from one-way ribbed joist slabs,

(Continued) 


\section{ABSTRACT (Continued).}

two center portions of a waffle slab, and the center portion of a flat plate. Also included were tests to determine the punching strength of 4 -inch-thick basement slabs on grade.

The individual 19- and 30-inch waffle panels and the 19-inch one-way slab panels were 3 inches thick, which is the minimum thickness used in standard construction. Each panel was cast as the center portion of a 46-inch-diameter by 11 -inch-thick concrete disk and statically loaded to failure with water pressure in the Small Blast Load Generator (SBLG).

Two 4-inch-thick basement slabs on grade were cast inside 46-3/4-inchdiameter steel rings and on top of a polyurethane sheet covering 6 inches of compacted gravel on top of 18 inches of soil compacted to 95 percent optimum density. The slabs were tested by pushing a 7 - by 7 -inch wooden post, composed of four 4- by 4-inch posts nailed together, into the center of the slab with the 200-kip loader. One test was performed statically and one dynamically.

The two center portions of a waffle slab and the one center portion of a flat plate were designed with the maximum diameters that would allow placement inside the 22-foot 10-inch-diameter Large Blast Load Generator (LBLG). The flat-plate test specimen was constructed to include the positive moment area from a 22-foot-square slab designed according to the Third Edition of the CRSI Handbook. The waffle-slab specimens were constructed to include positive moment areas from 24-foot-square slabs. An 8-inch-thick wall, 8 feet tall, supported the slabs along their perimeters, and wooden posts were wedged in place under each specimen where SSI predicted upgrading supports would be needed in an actual slab. It should be noted that these test specimens were not under boundary conditions similar to those in actual structures. However, SSI was interested in testing the response of the slabs' center portions where upgrading supports were applied.

The 19-inch-square by 3-inch-thick waffle-slab panel failed in shear under a peak pressure of $900 \mathrm{psi}$ and at a peak displacement of 0.15 inch. The 19-inch-long by 3-inch-thick one-way ribbed joist panel failed in shear at an average peak pressure of $400 \mathrm{psi}$ and a displacement of 0.054 inch. The 30-inch-square by 3 -inch-thick waffle panels failed at an average peak pressure of $320 \mathrm{psi}$ and a deflection of $0.087 \mathrm{inch}$. The wooden posts punched through the 4-inch-thick slabs on grade under a peak static load of 79.0 kips and a peak dynamic load of 135.0 kips. After punching through the slabs, the wooden posts were still capable of supporting load. The static load capacity of the center portion of an upgraded waffle slab under the given boundary conditions was $44.0 \mathrm{psi}$. Failure seemed to be caused by collapse of the wooden columns and then shearing of the slab around the rigid boundary. The dynamic load capacity of an identical slab was near an average pressure of $34 \mathrm{psi}$. Movies of the underside of the slab indicated that the wooden columns failed and the slab collapsed at nearly the same time. The static load capacity of the center portion of an upgraded flat plate was $38.0 \mathrm{psi}$. The wooden columns collapsed allowing the slab to deflect.

These test results will be incorporated into the manuals SSI is preparing on upgrading of shelters. 


\section{PREFACE}

Personnel of the U. S. Army Engineer Waterways Experiment Station (WES) Structures Laboratory (SL) conducted tests from May 1980 through February 1982 on specimens designed by Scientific Services, Incorporated, for the Blast Upgrading Shelter--Experimental Study Area project. The Federal Emergency Management Agency sponsored the work under Interagency Agreement EMW-E-0337.

SL personnel performed the work under the general supervision of Mr. Bryant Mather, Chief, SL, and Mr. J. R. Ballard, Chief, Structural Mechanics Division. Mr. W. L. Huff managed the project. Mr. M. K. McVay planned and supervised the experiments and Mr. S. C. Woodson analyzed the test results and prepared this report. Mr. C. D. Norman assisted in the analyses.

COL Tilford C. Creel, CE, was Commander and Director of WES during the course of the investigation; Mr. F. R. Brown was Technical Director. 
PREFACE

LIST OF ILLUSTRATIONS

CONVERSION FACTORS, INCH-POUND TO METRIC (SI) UNITS OF MEASUREMENT

CHAPTER 1 INTRODUCTION .

1.1 BACKGROUND . . . . . . . . . . . . . . . . . . . . . . . . . . . . . . 7

1.2 OBJECTIVE . . . . . . . . . . . . . . . . . . . . . . 8

1.3 APPROACH . . . . . . . . . . . . . . . . . . . . . . . . . . . . 9

CHAPTER 2 EXPERIMENTS . . . . . . . . . . . . . . . . . . . . . . . . . . . . . . . 10

2.1 DESCRIPTION OF TEST SPECIMENS . . . . . . . . . . . . . . . . . . . . 10

2.1.1 19 - by 19 - by 3 -Inch Waffle-Slab Panel . . . . . . . . . . . 10

2.1.2 19- by 19- by 3-Inch One-Way Slab . . . . . . . . . . . . . 10

2.1.3 30- by 30 - by 3 -Inch Waffle-Slab Panel . . . . . . . . . . . 11

2.1.4 Punching Strength of 4-Inch-Thick Slab on Grade . . . . . . 11

2.1.5 Center Portion of 24-Foot-Square Waffle-Slab Floor . . . . . 12

2.1.6 Center Portion of 22-Foot-Square Flat Plate . . . . . . . . 13

2.2 LOADING DEVICES . . . . . . . . . . . . . . . . . . . . . . . . 13

2.2.1 Small Blast Load Generator (SBLG) . . . . . . . . . . . . . 14

2.2 .2 200-Kip Loader . . . . . . . . . . . . . . . . . . . . . . 14

2.2.3 Large Blast Load Generator (LBLG) . . . . . . . . . . . . . 14

2.3 PLACEMENT OF STRUCTURES . . . . . . . . . . . . . . . . . . . . . . . . . . 15

2.3.1 Individual Panel Specimens . . . . . . . . . . . . . . . . . 15

2.3.2 4-Inch-Thick Slabs on Grade . . . . . . . . . . . . . . . . 15

2.3.3 Slab Center Portions . . . . . . . . . . . . . . . . . 15

2.4 INSTRUMENTATION . . . . . . . . . . . . . . . . . . . . . . . . . . . . 16

2.4.1 Individual Panel Specimens . . . . . . . . . . . . . . . . . 16

2.4.2 4-Inch-Thick Slabs on Grade . . . . . . . . . . . . . . . . 17

2.4.3 Center Portion of a 24-Foot-Square Waffle-Slab Floor . . . . 17

2.4.4 Center Portion of a 22-Foot-Square Flat Plate . . . . . . . 18

2.5 TEST PROCEDURES . . . . . . . . . . . . . . . . . . . . . . . . 19

2.5.1 Individual Panel Specimens . . . . . . . . . . . . . . . . . 19

2.5.2 4-Inch-Thick Slabs on Grade .. . . . . . . . . . . . . . . 19

2.5.3 Center Portions of a 24-Foot-Square Waffle-Slab Floor
and a 22-Foot-Square Flat Plate . . . . . . . . 20

CHAPTER 3 EXPERIMENTAL RESULTS . . . . . . . . . . . . . . . . . . 57

3.1 19- BY 19- BY 3-INCH WAFFLE-SLAB PANEL . . . . . . . . . . . . 57

3.2 19- BY 19- BY 3-INCH ONE-WAY SLAB . . . . . . . . . . . . . 57

$3.330-$ BY $30-$ BY 3-INCH WAFFLE-SLAB PANEL . . . . . . . . . . 57

3.4 PUNCHING STRENGTH OF A 4-INCH-THICK SLAB ON GRADE . . . . . . . 58

3.4.1 Static Test . . . . . . . . . . . . . . . . . . 58

3.4.2 Dynamic Test . . . . . . . . . . . . . . . . . . . 58

3.5 CENTER PORTION OF A 24-FOOT-SQUARE WAFFLE-SLAB FLOOR . . . . . . 58

3.5.1 Static Test . . . . . . . . . . . . . . . . . . . 58

3.5.2 First Dynamic Test . . . . . . . . . . . . . . . . . . 59

3.5.3 Second Dynamic Test . . . . . . . . . . . . . . . . . . . . 59

3.6 CENTER PORTION OF A 22-FOOT-SQUARE FLAT PLATE . . . . . . . . 60 
CHAPTER 4 DISCUSSION OF TEST RESULTS . . . . . . . . . . . . 72

4.1 19- BY 19- BY 3-INCH WAFFLE-SLAB PANEL . . . . . . . . . . . 72

4.2 19- BY 19- BY 3-INCH ONE-WAY SLAB . . . . . . . . . . . . . . . 74

4.330 - BY 30 - BY 3-INCH WAFFLE SLAB . . . . . . . . . . . . 77

4.4 PUNCHING STRENGTH OF A 4-INCH-THICK SLAB ON GRADE . . . . . . . 77

4.4.1 Static Test . . . . . . . . . . . . . . . . . . . 77

4.4.2 Dynamic Test . . . . . . . . . . . . . . . . . . . . . 79

4.5 CENTER PORTION OF A 24-FOOT-SQUARE WAFFLE-SLAB FLOOR . . . . . . 80

4.5.1 Static Test . . . . . . . . . . . . . . . . . . . . 80

4.5.2 First Dynamic Test . . . . . . . . . . . . . . . . . 82

4.5.3 Second Dynamic Test . . . . . . . . . . . . . . . . . . 85

4.6 CENTER PORTION OF A 22-FOOT-SQUARE FLAT PLATE . . . . . . . . 88

CHAPTER 5 CONCLUSIONS AND RECOMMENDATIONS . . . . . . . . . . . . 92

5.1 19- BY 19- BY 3-INCH WAFFLE-SLAB PANEL . . . . . . . . . . . . 92

5.2 19- BY 19- BY 3-INCH ONE-WAY SLAB . . . . . . . . . . . . . . 92

5.3 30- BY 30- BY 3-INCH WAFFLE-SLAB PANEL . . . . . . . . . . . . . . 92

5.4 PUNCHING STRENGTH OF A 4-INCH-THICK SLAB ON GRADE . . . . . . . 93

5.5 CENTER PORTION OF A 24-FOOT-SQUARE WAFFLE-SLAB FLOOR . . . . . . 93

5.6 CENTER PORTION OF 22-FOOT-SQUARE FLAT PLATE . . . . . . . . . 95

5.7 RECOMMENDATIONS . . . . . . . . . . . . . . . . . . . . . . . . 96

REFERENCES . . . . . . . . . . . . . . . . . . . . . . . . . . . . . . . . 98

APPENDIX A TEST DATA, 19- BY 19- BY 3-INCH WAFFLE-SLAB PANELS, 19- BY 19- BY 3-INCH ONE-WAY SLABS, AND 30- BY 30-

BY 3-INCH WAFFLE-SLAB PANELS . . . . . . . . . . . . 99

APPENDIX B TEST DATA, STATIC AND DYNAMIC PUNCHING STRENGTH TESTS

ON 4-INCH-THICK SLABS ON GRADE . . . . . . . . . . 105

APPENDIX C STATIC AND DYNAMIC TESTS ON WAFFLE-SLAB CENTER PORTIONS . . 111

APPENDIX D TEST DATA, FLAT PLATE CENTER PORTION . . . . . . . . . 147 
Figure

$2.119-$ by $19-$ by 3 -inch waffle-slab panel

2.219 - by 19 - by 3 -inch waffle-slab panel formwork and reinforcing steel

Center portion of waffle slab . . . . . . . . . . . . . 35

Reinforcing steel and formwork for waffle-slab center

portion

Casting concrete for waffle-slab center portion.

Test in the 200-kip loader of the punching strength of a typical 4-inch-thick slab on grade 
3.2 Posttest topside view of 19 - by 19 - by 3 -inch waffle-slab panel

3.4 Posttest bottomside view of 30 - by 30 - by 3 -inch waffle-slab

3.5 Wooden column punched into 4 -inch-thick slab on grade due to static loading

3.6 Posttest topside view of dynamically punched 4-inch-thick slab on grade

3.7 Posttest bottomside view of dynamically punched 4-inch-thick slab on grade....... . . . . . . . . . . . . . . .

3.9 Sheared waffle boundary of statically tested waffle-slab center portion

Second dynamic test on waffle slab after removal of water sealing membrane

3.17 Second dynamic test on waffle slab after removal of slab sand overburden . . . . . . . . . . . . . . . . . . . . . .

3.18 Sheared waffle slab after second dynamic test . . . . . . . .

3.19 Topside posttest view of statically tested upgraded flat

3.21 Bottomside posttest view of statically tested flat-plate center portion .... . . . . . . . . . . . . . 71

4.1 One-way slab comparison . . . . . . . . . . . . . . . . . 90

4.2 Pinned end column subjected to a harmonic axial load of frequency 
Inch-pound units of measurement used in this report can be converted to metric (SI) units as follows:

Multiply

feet

inches

kips (force)

pounds (force)

pounds (force) per square foot

pounds (force) per square inch

pounds (mass)

pounds (mass) per cubic foot

square inches
By

0.3048

2.54

4.4482

4.4482

47.88026

6.8947

0.4535924

16.01846

6.4516
To Obtain

metres

centimetres

kilonewtons

newtons

pascals

kilopascals

kilograms

kilograms per cubic metre square centimetres 


\section{TESTS AND EVALUATION OF UPGRADED FLAT-PLATE}

AND WAFFLE-SLAB FLOOR SYSTEMS

CHAPTER 1

INTRODUCTION

\subsection{BACKGROUND}

The Federal Emergency Management Agency (FEMA) has the responsibility of maintaining an appropriate civil defense program for the United States. The current civil defense program is Crisis Relocation Planning (CRP). CRP would call for the following actions by FEMA during a time of developing international crisis when a nuclear war is imminent:

1. Move the majority of the population away from potential target areas into surrounding host areas within 2 to 3 days before the expected attack.

2. Initially move people into public and private buildings in the host areas; then, if necessary, move them into shelters (mostly expedient-type shelters).

3. Direct keyworkers and officials to stay in the target areas to operate important industries and perform government functions until just before an attack, then to take cover in a hardened shelter that is within quick access of the target area.

The study reported herein is related to Part 3 of the CRP. Researchers have estimated that a hardened shelter within quick access of a target area would be in an overpressure range of $50 \mathrm{psi}$ or less. Several concepts for developing hardened shelters for keyworkers have been proposed. One is "Upgrading," in which basements in existing buildings are upgraded with additional structural members in order to withstand a peak overpressure of 50 psi. Another concept is "Slanting," in which the government provides funds for the additional design and construction costs incurred in strengthening a new building to withstand a peak overpressure of $50 \mathrm{psi}$. The newest concept requires the development of a dedicated shelter system. Under this concept, specially designed blast shelters would be constructed near keyworkers. Very

* A table of factors for converting inch-pound units of measurement to metric (SI) units is presented on page 6 . 
few existing civil defense shelters are strong enough to withstand 50 psi overpressure. Over the past few years the development of upgrading methods that could be used immediately to implement CRP in the event of a nuclear war has been emphasized.

Some early studies with simple slabs showed that upgrading was possible if proper methods were used. Results of tests conducted on small, one-way reinforced concrete (R/C) floor slabs at the U. S. Army Engineer Waterways Experiment Station (WES) indicated that the load capacities of one-way slabs could be increased by factors of 4 to 7 by providing expedient supports of various types at the midspan of slabs (Reference 1). After these encouraging results, WES continued to study the design of upgrading systems for actual one-way slabs. WES developed two upgrading methods that (a) used readily available materials, (b) were easy to construct, and (c) increased the load-carrying capacities of shelters to $50 \mathrm{psi}$ or greater (Reference 2). One method was designated the wooden-post method and the other, the steel-beam method. The increased load capacities resulting from these upgrading methods were verified by conducting dynamic tests on three identical full-scale sections of a typical one-way R/C slab floor system. The load capacity of the typical section was increased by about 5.0 times with the steel-beam method and 7.0 times with the wooden-post method. The load capacities of approximately 80 to 90 psi and 113 psi achieved by the steel-beam and wooden-post upgrading methods, respectively, were much greater than the desired minimum of $50 \mathrm{psi}$.

Currently, WES is developing upgrading methods for two-way R/C slab-floor systems. The first half of the development program, which was the testing of several structural components from potential upgraded shelters, is the subject of this report. Scientific Services, Incorporated (SSI), designed the tests and requested FEMA to have them conducted at WES. SSI has an ongoing contract with FEMA to prepare Shelter Upgrading Manuals for use by the general public in the quick upgrading of the blast resistance of buildings. SSI has incorporated the results of most of the previous studies into the manuals; however, the manuals lack information verifying the increased load capacities of upgraded two-way slabs. Therefore, SSI requested these tests to provide information for use in the manuals.

\subsection{OBJECTIVE}

This study was conducted to verify the load capacities of several 
structural elements from potential upgraded shelters.

\subsection{APPROACH}

SSI provided the design of the test specimens and the test plans. WES constructed the test specimens and tested them according to SSI's specifications with a few modifications. The test specimens consisted of: 19- by 19by 3 -inch waffle-slab panels, 19- by 3-inch one-way panels from ribbed joist construction, 30 - by 30 - by 3 -inch waffle-slab panels, a composite column of four 4- by 4-inch wooden posts driven into a slab on grade, two center portions of a 24-foot-square waffle slab, and the center portion of a 22-footsquare flat plate.

The individual waffle panels and the one-way panels were statically loaded to failure in the WES Small Blast Load Generator (SBLG). The 200-kip loader was used to drive the wooden columns into the slabs on grade. One test. was performed statically and one was performed dynamically. The center portions of the two 24-foot-square waffle slabs and the 22-foot-square flat plate were loaded to failure in the WES Large Blast Load Generator (LBLG). One center portion of the waffle slab was tested statically and the other, dynamically. The flat plate was loaded statically.

Appropriate measurements were made during each test with electronic gages and were recorded on magnetic tape. The data records on tape were then digitized, and plots were drawn by a computer. Detailed photographs of each test were also taken. Copies of the data and photographs were sent to SSI for their use and are included in this report also. 


\section{EXPERIMENTS}

\subsection{DESCRIPTION OF TEST SPECIMENS}

WES built and tested the test specimens according to plans provided by SSI. All of the test specimens were structural elements of various types of floor systems that could potentially be upgraded. As stated previously, the test specimens consisted of 19- by 19- by 3-inch waffle-slab panels, 19- by 3-inch one-way panels, 30- by 30- by 3-inch waffle-slab panels, wooden upgrading posts driven into slabs on grade, center portions of 24-foot-square waffle slabs, and the center portion of a 22-foot-square flat plate. Each specimen is described below.

\subsubsection{9- by $19-$ by $3-$ Inch}

Waffle-Slab Panel

These test specimens represented single 19- by 19- by 3-inch panels taken from a waffle-slab floor system and cast in the middle of 46-inch-diameter by 11-inch-thick circular slabs so they could be tested in the SBLG; see Figure 2.1. Since 3-inch-thick waffle-slab panels are the thinnest commonly made, these tests were conducted to determine the load capacity of the weakest common 19-inch-square waffle-slab panel. From these results one could tell if the panels are the weak points in a waffle-slab floor system with 19-inchsquare panels. The actual compressive strength of the concrete was 5,270 psi on test day. The welded wire mesh was 70 grade steel, and the No. 4 reinforcing bars were 60 grade steel. Figure 2.2 shows the formwork and reinforcing steel. Figure 2.3 shows the top and bottom of one of the completed test specimens.

\subsubsection{9- by $19-$ by $3-$ Inch \\ One-Way Slab}

These test specimens were single strips taken from panels in one-way ribbed joist floor systems and cast in the middle of 46 -inch-diameter by 11-inch-thick circular slabs so they could be tested in the SBLG; see Figure 2.4. Since 3-inch-thick panels are about the thinnest panels commonly made, the implication is that they would be the weakest component of a shelter with one-way ribbed joist construction. Therefore, these tests were conducted to determine the load capacities of the one-way panels. The test specimens 
were constructed identical to the $19-$ by $19-$ by 3 -inch waffle-slab panels and were then cut along two sides of the panel to impose one-way action. The average compressive strength of the concrete was 5,090 psi. The welded wire mesh was 70 grade steel, and the No. 4 reinforcing bars were 60 grade steel. Figure 2.5 shows one of the test specimens.

\section{$2.1 .330-$ by $30-$ by 3 -Inch}

Waffle-Slab Panel

The 30-inch-square waffle panel is another common sized waffle panel used in modern construction. The design of the test specimens is shown in Figure 2.6. Since 3-inch-thick panels are about the thinnest waffle panels commonly built, they are the weakest that would likely be in a shelter. These tests were conducted to determine if the individual panels would be the weakest part of a waffle-slab-floor system with 30-inch-square panels. The average compressive strength of the concrete was 4,300 psi. The welded wire mesh was 70 grade steel, and the No. 4 reinforcing bars were 60 grade steel. Figure 2.7 shows the formwork and reinforcing steel for one of the test specimens. Figure 2.8 shows a finished test specimen.

\subsubsection{Punching Strength of 4-Inch-}

Thick Slab on Grade

SSI expressed some concern that large overpressures might punch upgrading columns downward through the basement floor, which would be a slab on grade, and ordered tests to examine the punching shear capacity of a 4-inch-thick concrete slab on top of a polyurethane sheet covering 6 inches of compacted gravel on top of 18 inches of soil compacted to 95 percent optimum density. The slab was loaded with a 7-inch-square wooden column; see Figure 2.9. Two test specimens were constructed inside 46-3/4-inch inside diameter steel confining rings. One specimen was tested statically and the other dynamically.

A gradation curve and a compaction curve for the gravelly sand soil are shown in Figures 2.10 and 2.11, respectively. The soil was placed in 5-1/2-inch loose lifts and compacted to 4-1/2-inch lifts with four passes of a pneumatic tamper at $100 \mathrm{psi}$ to achieve 95 percent maximum density. One dry density reading and one moisture content measurement were taken at the 9-inch compacted depth in both of the test specimens. The soil in both test specimens had identical dry densities and water contents of $129 \mathrm{lb} / \mathrm{ft}^{3}$ and 6.8 percent, respectively. Uniaxial strain tests were conducted on the soil and the results are shown in Figure 2.12. The gravel was washed river gravel, 
$1 / 4$ inch to 2 inches in size. In each test specimen, the gravel was placed in one 6-inch lift and hand-tamped two passes. A sheet of polyurethane was placed over the gravel, a standard construction practice. The reinforcing wire was $4-$ by 4 -inch W 2.9 by W 2.9 welded wire fabric, made of Grade 70 steel. One of the test specimens before concrete was placed is shown in Figure 2.13. The average compressive strengths of the concrete in the static and dynamic test specimens were 3,590 and $4,090 \mathrm{psi}$, respectively. One of the finished test specimens is shown in Figure 2.14.

The wooden upgrading columns were composed of four 4- by 4-inch-wooden timbers nailed together. The timbers were No. 2 quality fir, readily available in most lumber stores. The wooden columns in the static and dynamic tests were 4 feet 10 inches and 4 feet 6-3/4 inches long, respectively. The wooden upgrading column used in the dynamic test weighed $61-1 / 2$ pounds.

\subsubsection{Center Portion of 24-Foot-Square Waffle-Slab Floor}

These test specimens were designed by SSI to have the maximum diameters that would allow placement inside the 22-foot 10-inch diameter LBLG, and to include the center portion of a 24-foot-square waffle-slab floor upgraded with wooden columns; see Figure 2.15. The wooden columns were wedged in place under the center portions where SSI predicted upgrading supports would be needed under an actual slab. The purpose of these tests was to determine the increased load capacity of the center portion of a waffle slab upgraded with wooden columns. WES personnel built two test specimens, one for a static test and one for a dynamic test. In these tests, the center portion of a 24-footsquare waffle-slab floor contained the area where two perpendicular middle strips, described in the American Concrete Institute (ACI) Building Code (Reference 3), overlapped each other plus one row of waffle panels on each side; see Figure 2.16. Therefore, the specimens mostly contained the positive steel, although the negative steel extended into its edges a few inches. The center portions were designed in accordance with the design of a waffle-slab floor given in the Concrete Reinforcing Steel Institute (CRSI) Handbook (Reference 4), with 24-foot spans, 19- by 19- by 8-inch indentions, 3-inch-thick slabs, 11-inch-deep joists, 4,000-psi designed concrete strength, 60 grade steel, and a factored live load of $200 \mathrm{lb} / \mathrm{ft}^{2}$. The four solid areas on each side of the center portion were left 11 inches thick and were heavily reinforced in the top and bottom. The bottom and top reinforcing steel layouts 
are shown in Figures 2.17 and 2.18, respectively, and the entire layout before casting the concrete is shown in Figure 2.19. The yield strengths of the reinforcing steel used in both models were $65,083,62,500$, and 68,064 psi for the No. 3,4 , and 5 bars, respectively. The concrete was obtained from a local ready-mix company. Figure 2.20 shows the concrete being placed. The average compressive strengths of the concrete in the static and dynamic test specimens were 4,410 and 5,580 psi, respectively. The top and bottom of one of the finished test specimens are shown in Figures 2.21 and 2.22, respectively.

The wooden columns were made of four 4- by 4-inch posts strapped together. The " 4 by 4 's" were used because they are the largest size wooden timbers readily available in large quantities at most lumber companies. The wood was a No. 2 quality fir.

\subsubsection{Center Portion of 22-Foot- \\ Square Flat Plate}

This test specimen, a large circular slab 22 feet 9 inches in diameter and 8 inches thick, was designed by SSI to include as much as possible of a 22-foot-square-flat plate floor upgraded with wooden columns that would fit into the 22-foot 10-inch-diameter LBLG; see Figure 2.23. In this case, the center portion of a flat plate included all of the positive moment area and some of the negative moment areas but did not contain the areas near the columns. The design for the test specimen was taken from a flat-plate design in the CRSI Handbook (Reference 4) using 22-foot spans, 8 inches thick, 4,000-psi. concrete, 60 grade steel, and a factored live load of $200 \mathrm{lb} / \mathrm{ft}^{2}$. The bottom and top reinforcing steel layouts are shown in Figures 2.24 and 2.25, respectively. The yield strengths of the No. 4, 5, and 7 steel reinforcing bars were $62,500,68,064$, and $65,083 \mathrm{psi}$, respectively. The reinforcing steel and formwork before the concrete was cast are shown in Figure 2.26. The concrete was obtained from a local ready-mix company and had an average compressive strength of 5,783 psi.

Wooden upgrading columns were wedged under the test specimen, where SSI predicted upgrading supports would be needed under an actual slab. The wooden columns were composite columns of four 4 by $4^{\prime}$ s strapped together. The wood was No. 2 quality fir.

\subsection{LOADING DEVICES}

The loading devices used in this study are described below. A more 
detailed discussion of the test devices is contained in Reference 5 .

\subsubsection{Small Blast Load Generator (SBLG)}

Each of the 19- by 19- by 3-inch waffle-slab panels, 19- by 3-inch oneway panels, and $30-$ by 30 - by 3 -inch waffle-slab panels was tested in the SBLG.

The SBLG can produce static pressures up to 1,000 psi. The generator has a steel cylindrical shell and an elliptical dome top called the bonnet. The shell is composed of a series of stacked rings (46-3/4-inch ID) of various depths that are bolted together to allow the depth of a soil sample or test specimen to be varied. Figure 2.27 shows the SBLG with instrumentation cables attached prior to a test.

\section{2 .2 200-Kip Loader}

The two 4-inch-thick slabs on grade were tested in the 200-kip loader. The 200-kip loader (Figure 2.28) is capable of applying a concentrated load over a maximum stroke of 6 inches and of testing structural shapes with loading rates varying from slow static loads to those at which the maximum load is reached in a very few milliseconds. The 200-kip loader is designed to apply forces varying from 10,000 to $200,000 \mathrm{lb}$ in either tension or compression.

\subsubsection{Large Blast Load Generator (LBLG)}

The two center portions of the 24-foot-square waffle slabs and the center portion of the 22-foot-square flat plate were tested in the LBLG.

The LBLG (Figure 2.29) is a large, three-dimensional device designed primarily to test underground protective structures subjected to pressures simulating those generated by both kiloton and megaton nuclear devices. Pressures up to about $500 \mathrm{psi}$, having rise times and durations similar to megaton-size nuclear weapons, can be reproduced in the generator. Static loads up to 1,000 psi can be sustained. The LBLG has two basic components: the central firing station and the test chambers. The central firing station is a massive, posttensioned, prestressed concrete reaction structure designed to resist the dynamic or static loads generated in the test chamber. The two test chambers are cylindrical steel bins having a 23-foot OD and a 22-foot 10-inch ID that contain the test media and test structures. A test chamber consists of three $C$ rings that stack to a height of 10 feet, one $B$ ring that is capable of 
containing 15 firing tubes during dynamic loadings, and one A ring that is a telescoping-type lid.

\subsection{PLACEMENT OF STRUCTURES}

\subsubsection{Individual Panel Specimens}

The 19- by 19 - by 3 -inch waffle-slab panels, 19- by 3-inch one-way slabs, and 30 - by 30 - by 3 -inch waffle-slab panels were all tested in the SBLG. A 6-inch-thick concrete ring was cast inside the SBLG rings to support the test specimens; see Figure 2.30. The first step in the installation of each test specimen was to place a thin layer of high-strength grout on top of the support rings. Then the test specimen was placed on the grout before it hardened to allow uniform contact at the support. Finally, high-strength grout was poured between the sides of the test specimen and the SBLG ring. This placement and the geometry of the test specimens made the boundary conditions of the various panels fixed-fixed, which is close to the conditions in an actual slab without the axial forces. The various test specimens placed inside the SBLG are shown in Figures 2.31 through 2.33 .

\subsubsection{4-Inch-Thick Slabs on Grade}

The punching strengths of 4 -inch basement slabs on grade, subjected to the loadings from 7- by 7-inch wooden upgrading columns, were tested in the 200-kip loader. The test specimens were cast inside the 46-3/4-inch ID steel rings of the SBLG facility, as described in paragraph 2.1.4. A 1/2-inch-thick steel plate was bolted across the bottom of the rings so one could lift the test specimens. The test specimens were moved by an overhead crane into the pit below the 200-kip loader and then pulled into position with come-alongs.

The wooden columns were placed exactly in the middle of the test specimens, and the ram of the 200-kip loader was lowered onto the top of the column. A very small load was initially applied to the column to hold it securely in place, as would occur with an upgraded column wedged into place. The test setup is shown in Figure 2.34. The test specimens were made large enough to prohibit influence of edge effects upon the punching action.

\subsubsection{Slab Center Portions}

The two center portions of the 24-foot-square waffle-slab floors and the 
center portion of the 22-foot-square flat plate were all tested in the LBLG. An 8-inch-thick concrete ring was cast along the inside of the LBLG rings to support the test specimens; see Figure 2.35. Several 1/4-inch-thick spacers were placed on top of the concrete support ring, preceding a test specimen being lowered upon it. Then the 1/4-inch crack between the specimen and the support ring was filled by allowing high-strength grout to flow downward between the side of the specimen and the LBLG ring, and laterally into the 1/4-inch space. The placement of grout was continued until the grout began to fill the space between the specimen and the LBLG ring. When the grout's surface was approximately 1 inch above the bottom edge of the 11-inch-thick slab, the grouting procedure was discontinued.

Composite wooden columns were made by strapping together four No. 2 quality fir 4 by $4^{\prime}$ s per column. Five 3/4-inch steel straps were used per column. Figures 2.15 and 2.23 show the locations where the wooden columns were wedged into place underneath the waffle slabs and the flat plate, respectively. Photographs of the wooden upgrading columns in place for the waffle slabs and the flat plate are shown in Figures 2.36 and 2.37, respectively. Each upgrading column was approximately 7 feet 10-1/2 inches in length while the wedges filled a gap of about 1-1/2 inches.

The final step in the placement of the waffle slabs and the flat plate involved the placing of sand cover on the specimens. After the proper instrumentation had been placed, as described in paragraph 2.4, the lid of the entranceway was closed, and a fairly uniform sand was spread on top of the specimen to a depth of 18 inches. The soil surface was then sealed, as required for the type of test to follow, which is discussed in paragraph 2.5 .

\subsection{INSTRUMENTATION}

\subsubsection{Individual Panel Specimens}

Each of the 19- by 19- by 3-inch waffle-slab panels, 19- by 3-inch oneway panels, and $30-$ by 30 - by 3 -inch waffle-slab panels was instrumented similarly. One Trans-Tek linear variable displacement transducer was placed under the center of the specimen to measure deflections. Figure 2.30 shows the deflection gage mount inside the SBLG. The deflection gage was connected to the mount at the correct height to insure contact with the underside of the specimen. The magnitude of the applied load during the static test was measured 
with two pressure gages mounted on the inside surface of the SBLG's pressure bonnet. Two interface pressure gage mounts were also installed in the specimen to house interface pressure gages. However, after the first test revealed that the interface pressure gages and the pressure gages in the bonnet measured almost identical pressures, the use of interface pressure gages was discontinued.

\subsubsection{4-Inch-Thick Slabs on Grade}

Although one 4-inch-thick slab on grade was tested statically and one was tested dynamically, the two slabs were similarly instrumented. Figure 2.38 shows the instrumentation layout for the slabs on grade. Seven Trans-Tek linear variable displacement transducers were mounted on a bar which spanned the diameter of the top SBLG ring to measure deflection of the slab on grade. One load cell was mounted above the loading head to determine the magnitude of the load applied to the composite wooden post. By correlating the deflections of the slab with the applied load at any point in time, SL personnel could determine the punching strength of the 4 -inch-thick slab on grade.

\subsubsection{Center Portion of a 24-Foot- \\ Square Waffle-Slab Floor}

Figure 2.39 shows the instrumentation layout for the waffle-slab specimens. As noted in Figure 2.39, the instrumentation of the dynamically tested slab differed from that of the statically tested slab by requiring five airblast gages to measure airblast pressures applied to the structure; otherwise, the two slabs were instrumented identically with various types of transducers strategically located on and within the specimen. Excluding the airblast gages, a total of 42 transducers were used per specimen.

2.4.3.1 Deflection Measurements. Fourteen Trans-Tek linear variable displacement transducers were mounted on a structure specifically built for that purpose as shown in Figure 2.40. The displacement transducers measured the vertical deflection of the specimen at the locations shown in Figure 2.39.

2.4.3.2 Pressure Measurements. Two pressure gages were mounted in the B ring of the LBLG to measure the applied pressure in the cavity above the specimen.

2.4.3.3 Soil-Stress Measurements. Eight soil-stress gages were placed on a 1-inch soil layer on top of the specimen before placement of the 18-inch soil cover. The soil-stress gages measured the magnitude of overpressures 
applied at the eight locations in order to allow investigation of load transfer through the soil cover.

2.4.3.4 Strain Measurements. Sixteen strain gages were placed on the reinforcement steel of the specimen at the locations shown in Figure 2.39. The strain gages were placed in pairs with one gage on a top reinforcement bar and one on a nearby bottom reinforcement bar in parallel alignment. The strain gages were bonded to the bar with a heat-curing epoxy after the bar had been cleaned and lightly sanded. Lead wires were then attached to the strain gages, and the locations were waterproofed with synthetic rubber compounds.

2.4.3.5 Load Measurements. Two 200,000-1b-capacity load cells were used to measure the vertical load applied to two of the wooden upgrading columns as further confirmation of the load applied to the specimen.

\subsubsection{Center Portion of a 22-Foot- Square Flat Plate}

Figure 2.41 shows the instrumentation layout for the flat-plate specimen. A total of 36 transducers were used to investigate the specimen's behavior during static loading.

2.4.4.1 Deflection Measurements. Eight Trans-Tek linear variable displacement transducers were mounted on a structure similar to the one used in the waffle-slab tests, shown in Figure 2.40. The displacement transducers measured the vertical deflection of the specimen at the locations shown in Figure 2.41.

2.4.4.2 Pressure Measurements. Two pressure gages were mounted in the B ring of the LBLG to measure the static pressure above the soil cover.

2.4.4.3 Soil-Stress Measurements. Eight soil-stress gages were placed on a 1-inch soil layer on top of the specimen before placement of the 18-inch soil cover. The soil-stress gages measured the magnitude of the overpressures applied at the eight locations shown in Figure 2.41 to allow investigation of load transfer through the soil cover.

2.4.4.4 Strain Measurements. Eighteen strain gages were placed on the reinforcement steel of the specimen at the locations shown in Figure 2.41. The strain gages were placed in pairs, with one gage on a top reinforcement bar and one on a nearby bottom reinforcement bar in parallel alignment. The strain gages were bonded to the bar with a heat-curing epoxy after the bar had been cleaned and lightly sanded. Lead wires were then attached to the strain gages, and the locations were waterproofed with synthetic rubber compounds. 
2.4.4.5 Load Measurements. Two 200,000-pound-capacity load cells were used to measure the vertical load applied to two of the wooden upgrading columns.

\subsection{TEST PROCEDURES}

After the specimens had been placed in their respective loading devices, as described in paragraph 2.3, the tests were performed in accordance with the following procedures.

\subsubsection{Individual Panel Specimens}

The 19- by 19- by 3-inch waffle-slab panels, the 19- by 3-inch oneway slabs, and the 30 - by 30 - by 3 -inch waffle-slab panels were all statically tested in the SBLG. For the static tests, water pressure was used to apply a uniform load. Water pressure loading was chosen instead of air pressure loading, since it allows a better determination of the deflection-resistance curve. Air pressure loading often causes a sudden failure due to air expansion when the resistance of the specimen begins to decrease.

Final steps in preparation for testing included placement of a 3/32-inchthick neoprene rubber diaphragm over the specimen's surface to prevent loss of pressure when the slab deflected and cracked. The diaphragm extended across the specimen and across the flange of the top ring of the SBLG. Between the neoprene and specimen, an unsecured 6-mil-thick sheet of polyethylene was placed and covered with powder to provide a low-friction surface for the neoprene diaphragm to slide on. The pressure bonnet was bolted to the flange of the top ring, thereby sealing the SBLG and securing the diaphragm's edge between the flanges of the bonnet and the top ring. The air void above the model was then filled with water. Immediately before the water pressure was applied, calibration steps for the instrumentation transducers were recorded.

Water pressure for loading was obtained from an air-driven pump. The load was applied at a pressure increase of approximately $80 \mathrm{psi} / \mathrm{min}$. Water flow was continued until total loss of pressure or diaphragm rupture occurred. Posttest photographs were taken of each test slab with a still camera. The specimen was removed from the support ring which was then prepared for the next specimen.

\subsubsection{4-Inch-Thick Slabs on Grade}

The 4-inch-thick slabs on grade were tested in the 200-kip loader. 
Although one slab was loaded statically and one was loaded dynamically, the two tests were conducted similarly with the exception of rate of load application. Immediately preceding load initiation, calibration steps for the instrumentation transducers were recorded.

At the start of the test, equal pressures were maintained on both sides of the loader's main loading piston. To load the specimen in compression, an unbalanced pressure was caused by releasing oil from below the piston and allowing it to flow through a variable orifice which controlled the rise-time characteristics of the applied load.

\subsubsection{Center Portions of a 24-Foot- \\ Square Waffle-Slab Floor and a \\ 22-Foot-Square Flat Plate}

The one flat plate and the two waffle-slab center portions were tested in the LBLG. The flat-plate specimen and one waffle-slab specimen were tested statically, and the remaining waffle-slab specimen was tested dynamically.

\subsubsection{Static Tests. Water pressure was used to apply a uniform load} for the static tests. As mentioned in paragraph 2.3, it was necessary to seal the specimen and soil cover from the water. A 6-mil-thick layer of polyethylene was placed over the soil surface and taped to the sides of the chamber. A 0.035 -inch-thick polyurethane diaphragm was placed atop the polyethylene and glued to the chamber's side to form a water seal.

After the water seal had been completed, the top ring and lid of the test chamber were installed and the chamber was moved into the Central Firing Station (CFS). The air void above the model was then filled with water.

Water pressure for loading was obtained by passing tap water through a pressure regulator. The water pressure in the water mains at the time of testing was approximately $80 \mathrm{psi}$. Before the pressure was applied, calibration steps were recorded for the instrumentation transducers. Water pressure was then applied to the specimen at a rate of approximately $6 \mathrm{psi} / \mathrm{min}$ until the water-sealing membrane ruptured. One water-pressure transducer, one slabdeflection transducer, and one Bourdon-type mechanical pressure gage connected to the water chamber above the model were monitored throughout the test.

The test chamber was then rolled out of the CFS so that the top ring, lid, and sealing membranes could be removed. After removal of the soil cover, the specimen was examined and photographed. The slab was then removed from the reaction wall and chamber. 
2.5.3.2 Dynamic Test. Primacord explosive was used to apply a dynamic load to the waffle slab. A 6-mil-thick layer of polyethylene was placed over the soil surface and taped to the sides of the chamber to serve as a barrier to prevent the airblast pressure from entering the sand layer. Approximately 1 inch of sand was placed over the polyethylene to protect it from heat.

Before the top ring and lid were placed on the test chamber, the amount of Primacord explosive necessary to produce the desired pressure, based on calibration curves and past use of the LBLG, was strung in the firing tubes atop the specimen. With the top ring's exhaust ports open, the chamber was then closed and placed in the CFS.

Overpressure was generated by detonation of the Primacord after the calibration of the transducers had been completed.

The chamber was then rolled out of the CFS so that the top rings and lid could be removed. Examination of the specimen revealed that only slight damage had occurred. Therefore, after detailed photographs had been taken, the specimen and chamber were prepared for another testing in the same manner as before.

An overpressure greater in magnitude than that of the first testing was generated by detonation of Primacord. The chamber was then rolled out of the CFS and opened so that the final examination and detailed photography on the specimen could be performed. 

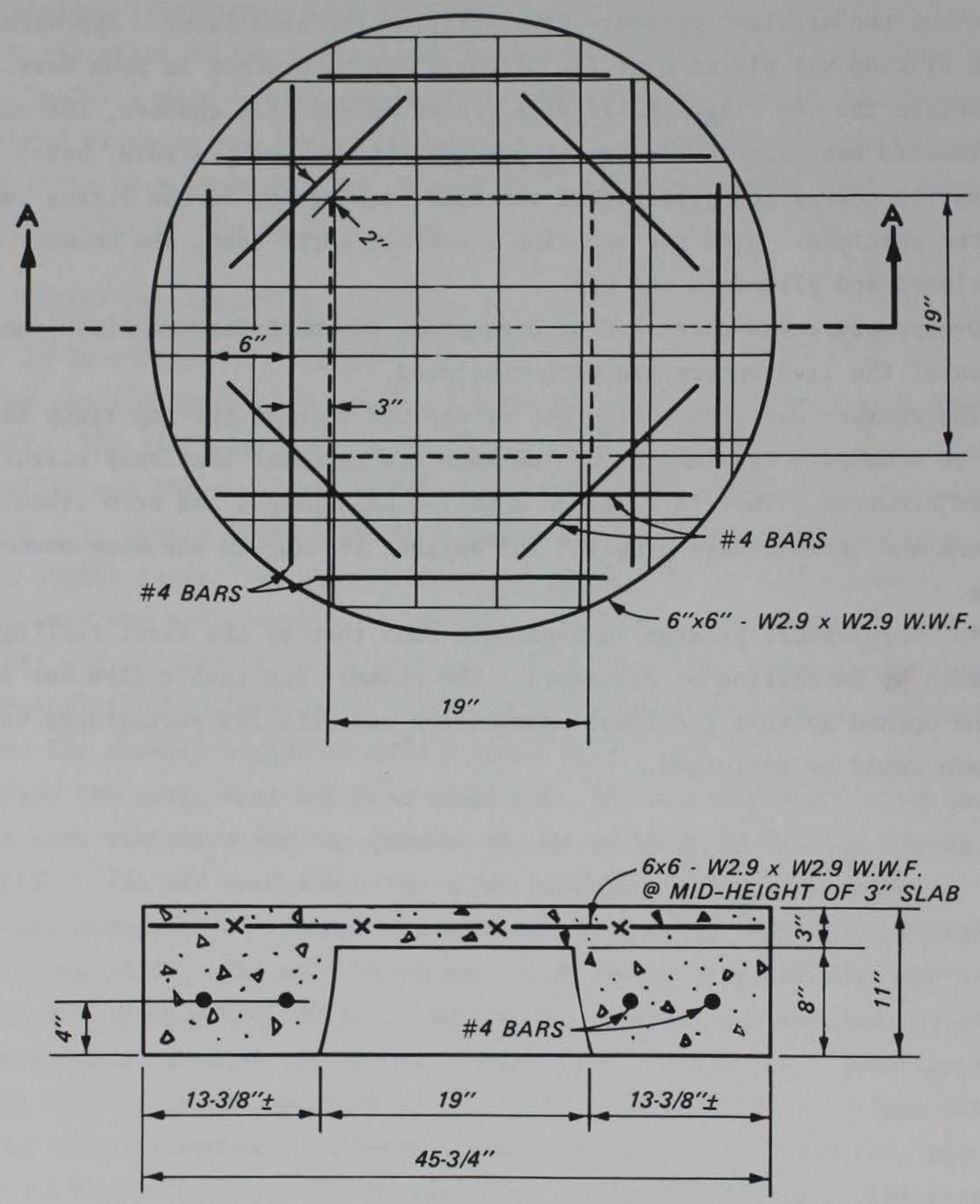

SECT. A-A

Figure 2.119 - by 19 - by 3 -inch waffle-slab panel. 


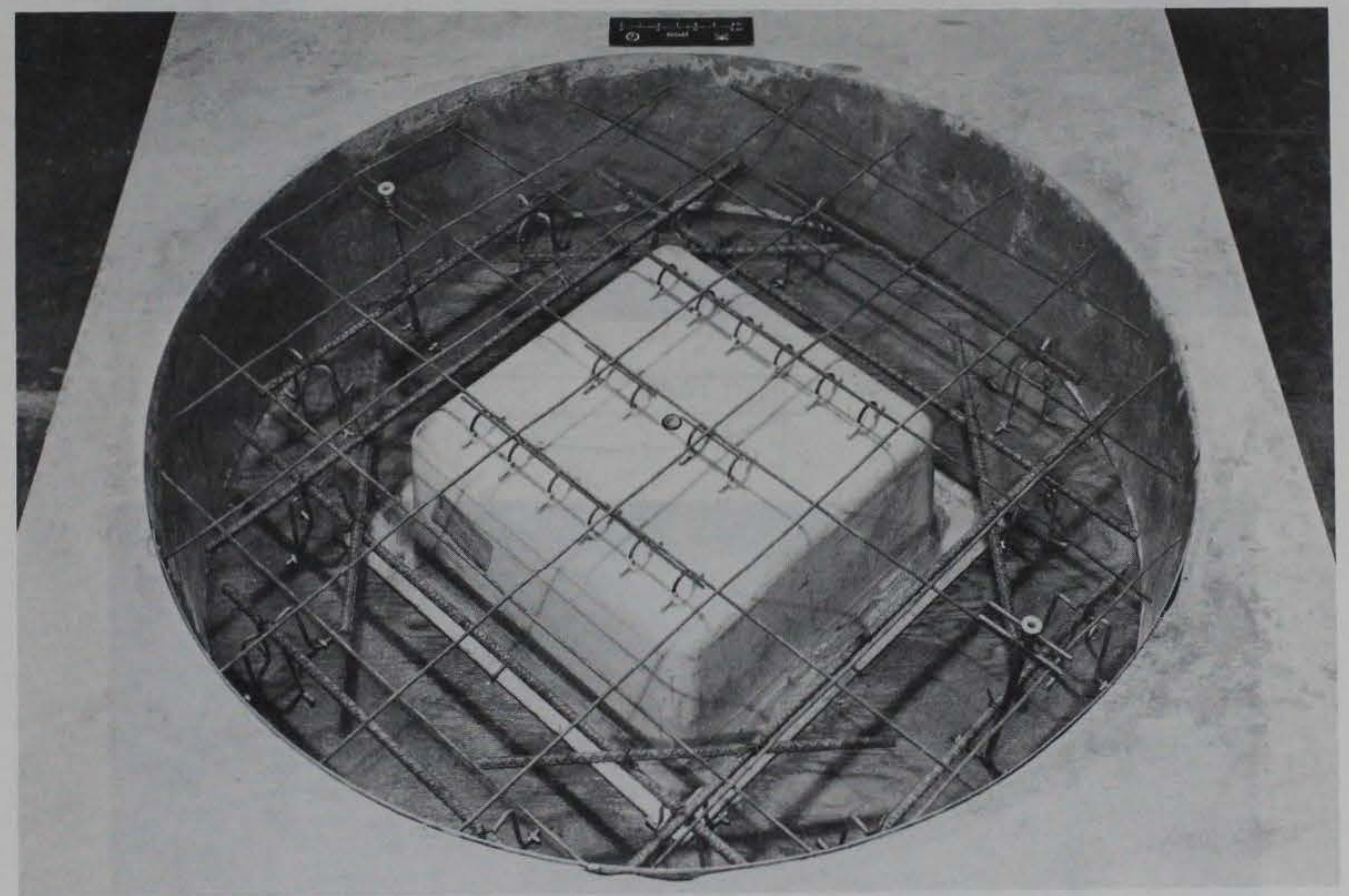

Figure 2.219 - by 19 - by 3 -inch waffle-slab panel formwork and reinforcing steel. 


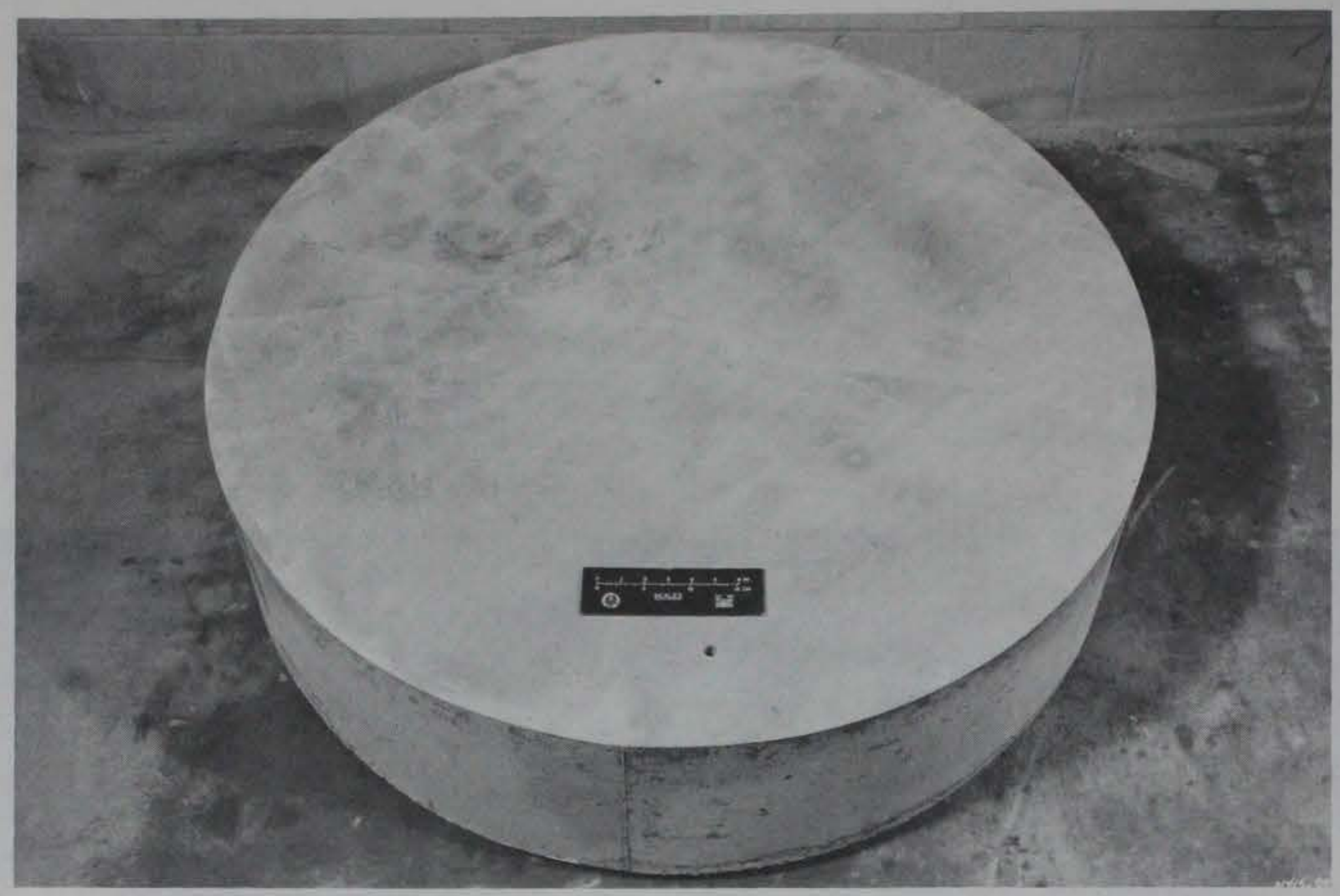

Top.

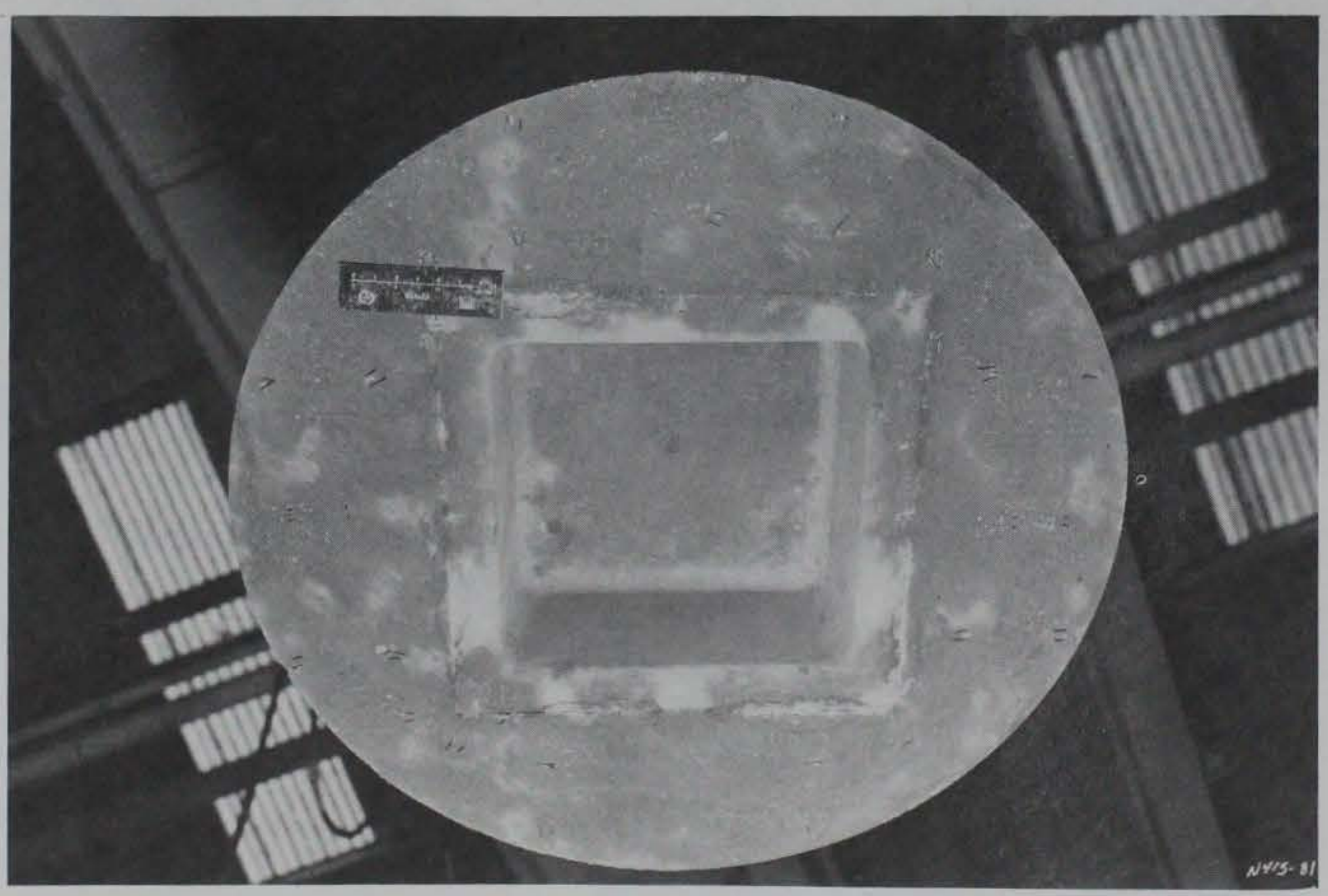

Bottom.

Figure 2.3 Completed 19- by 19- by 3-inch waffle-slab panel. 

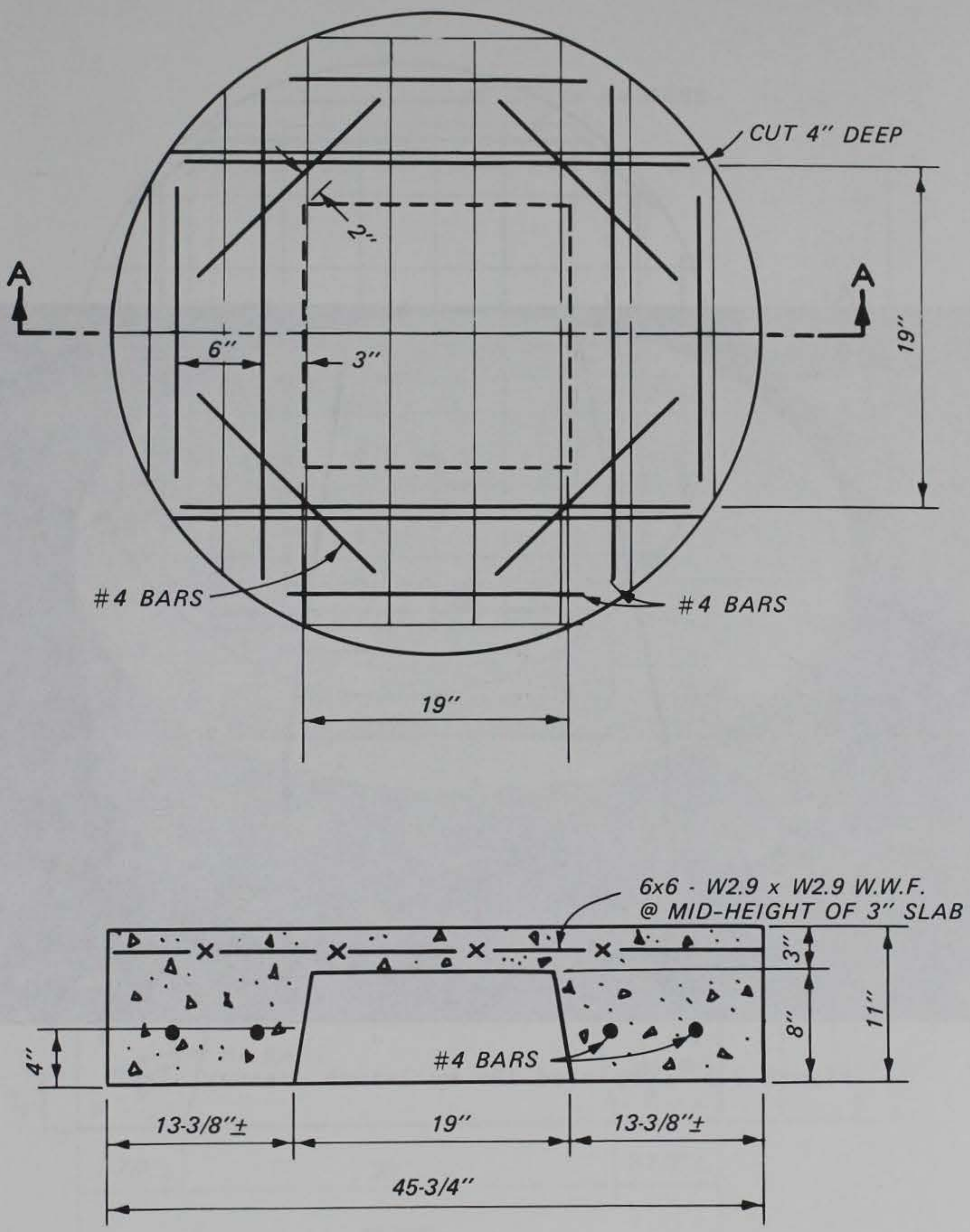

SECT. A-A

Figure 2.419 - by 3 -inch one-way slab. 


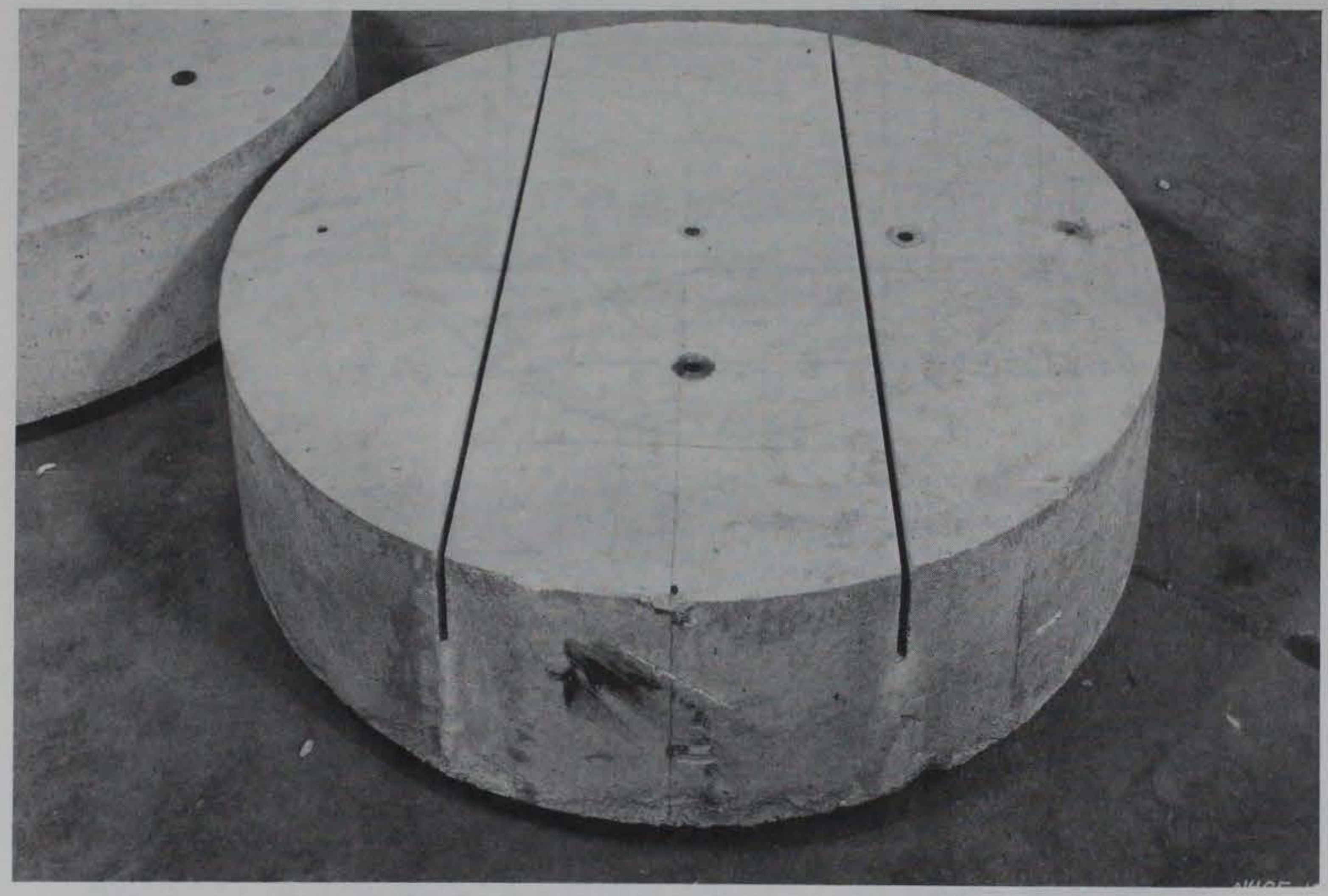

Figure 2.5 Completed 19 - by 3 -inch one-way slab. 

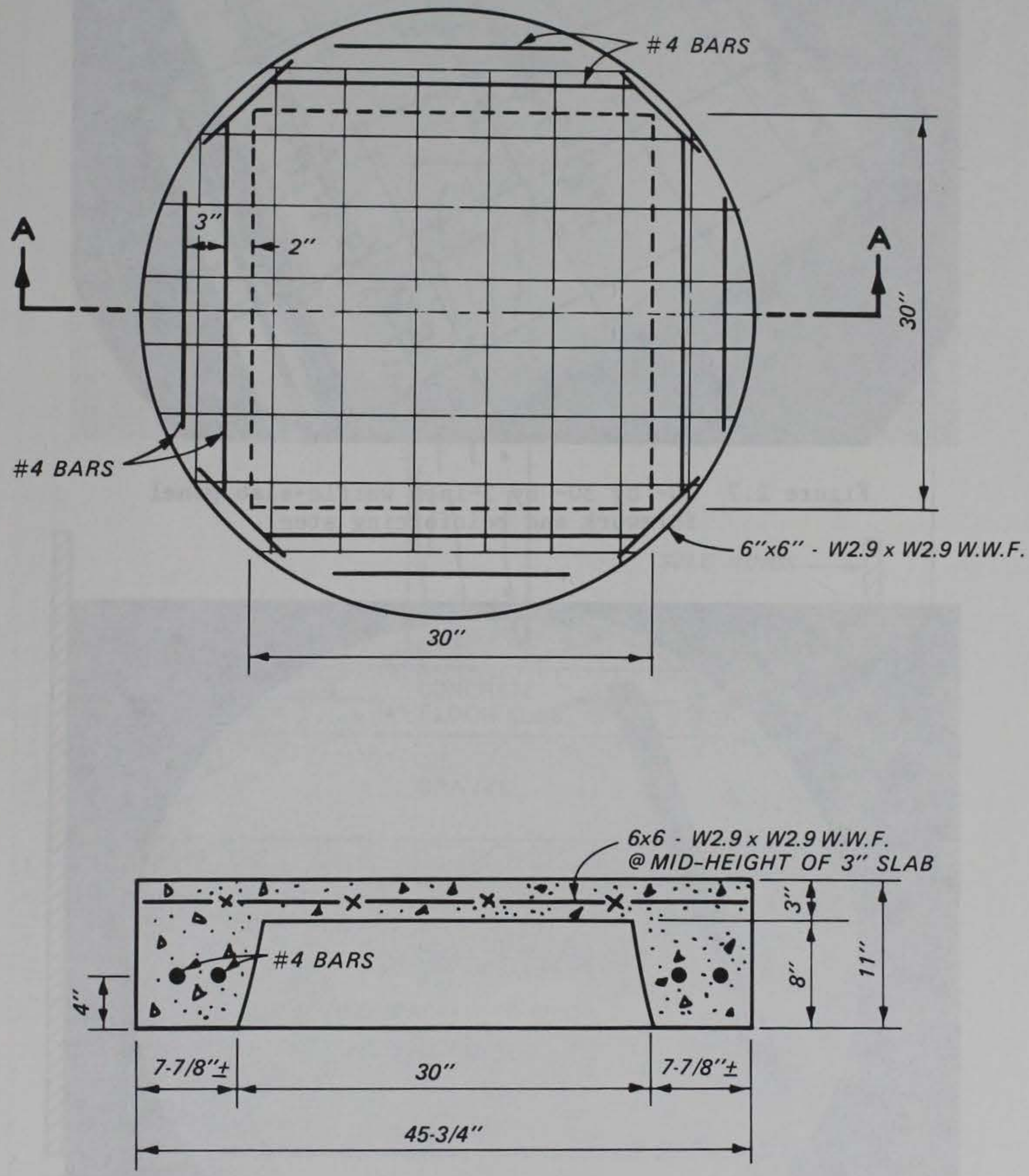

SECT. A-A

Figure 2.630 - by 30 - by 3 -inch waffle-slab panel. 


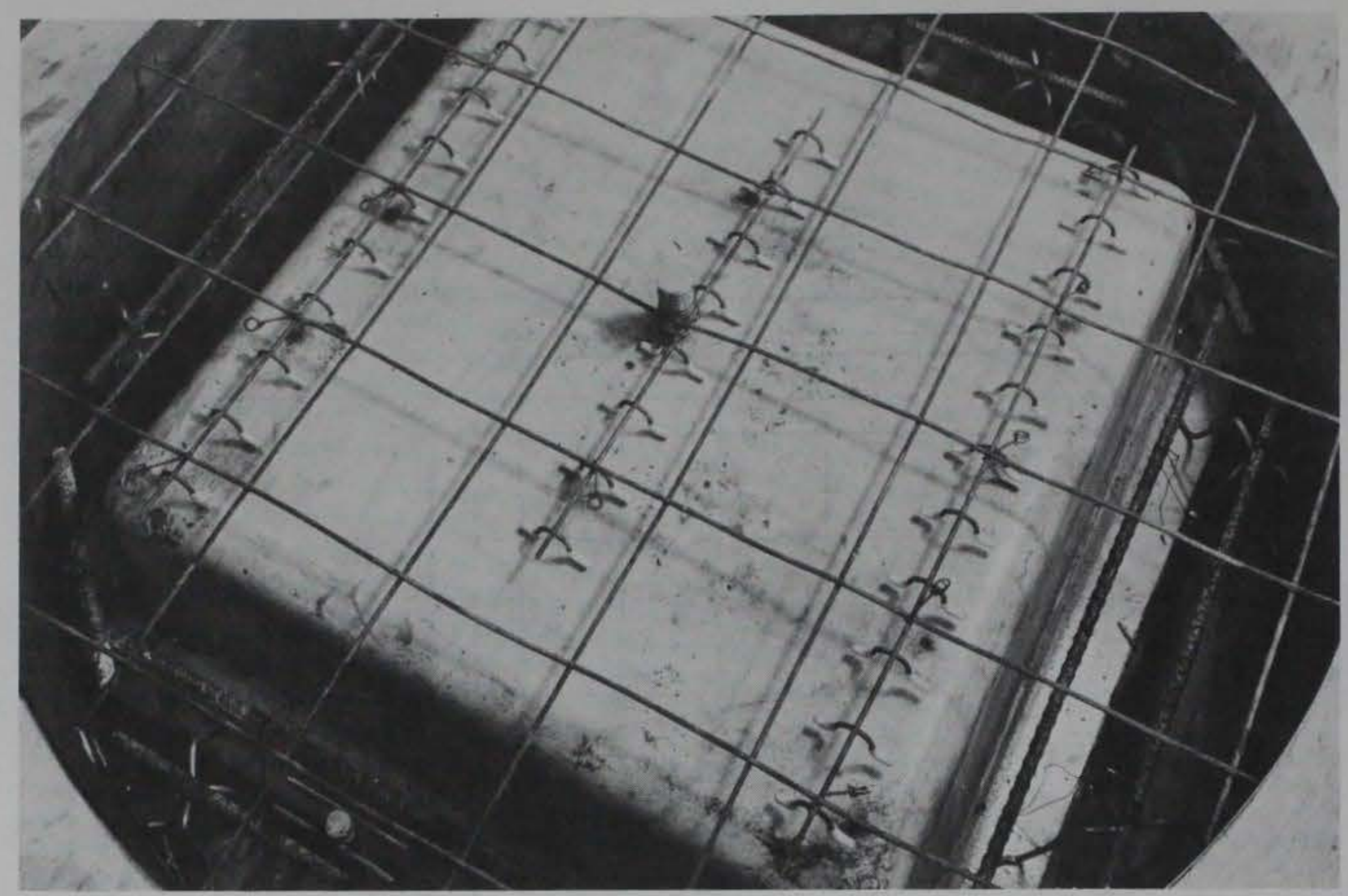

Figure 2.730 - by 30 - by 3 -inch waffle-slab panel formwork and reinforcing steel.

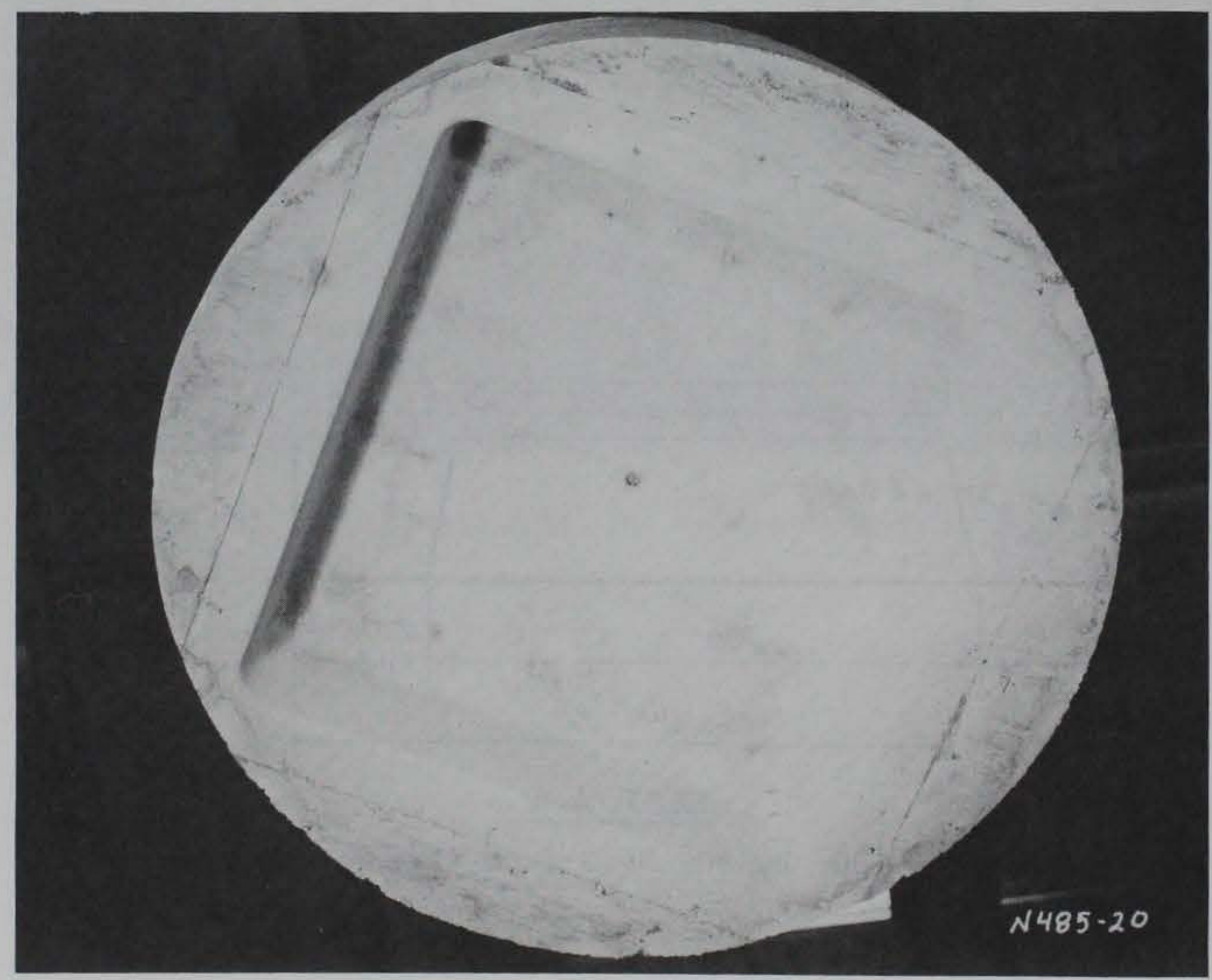

Figure 2.8 Bottom of 30 - by 30 - by 3 -inch waffle-slab panel. 


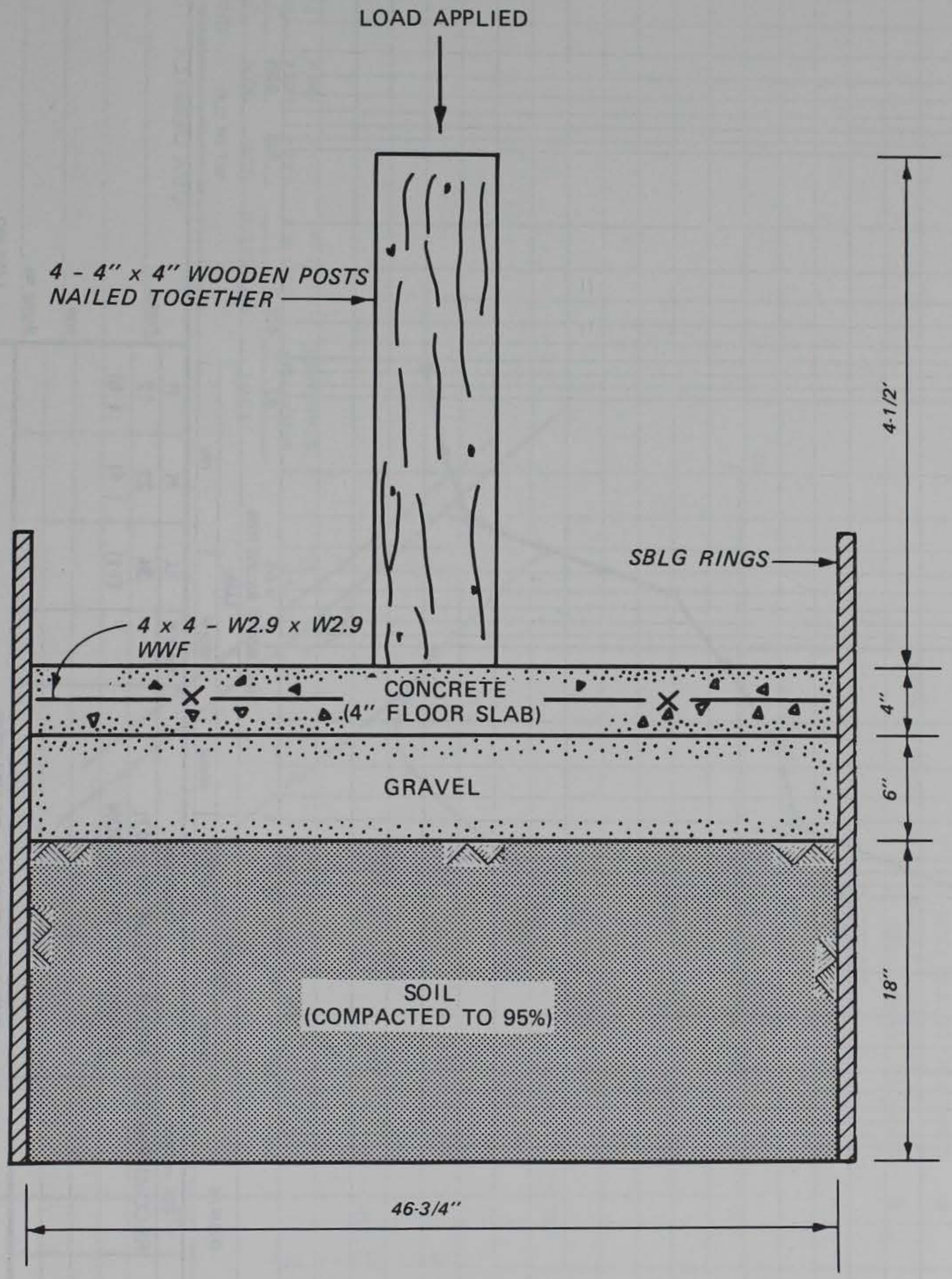

Figure 2.9 Punching strength of a 4-inch-thick slab on grade. 


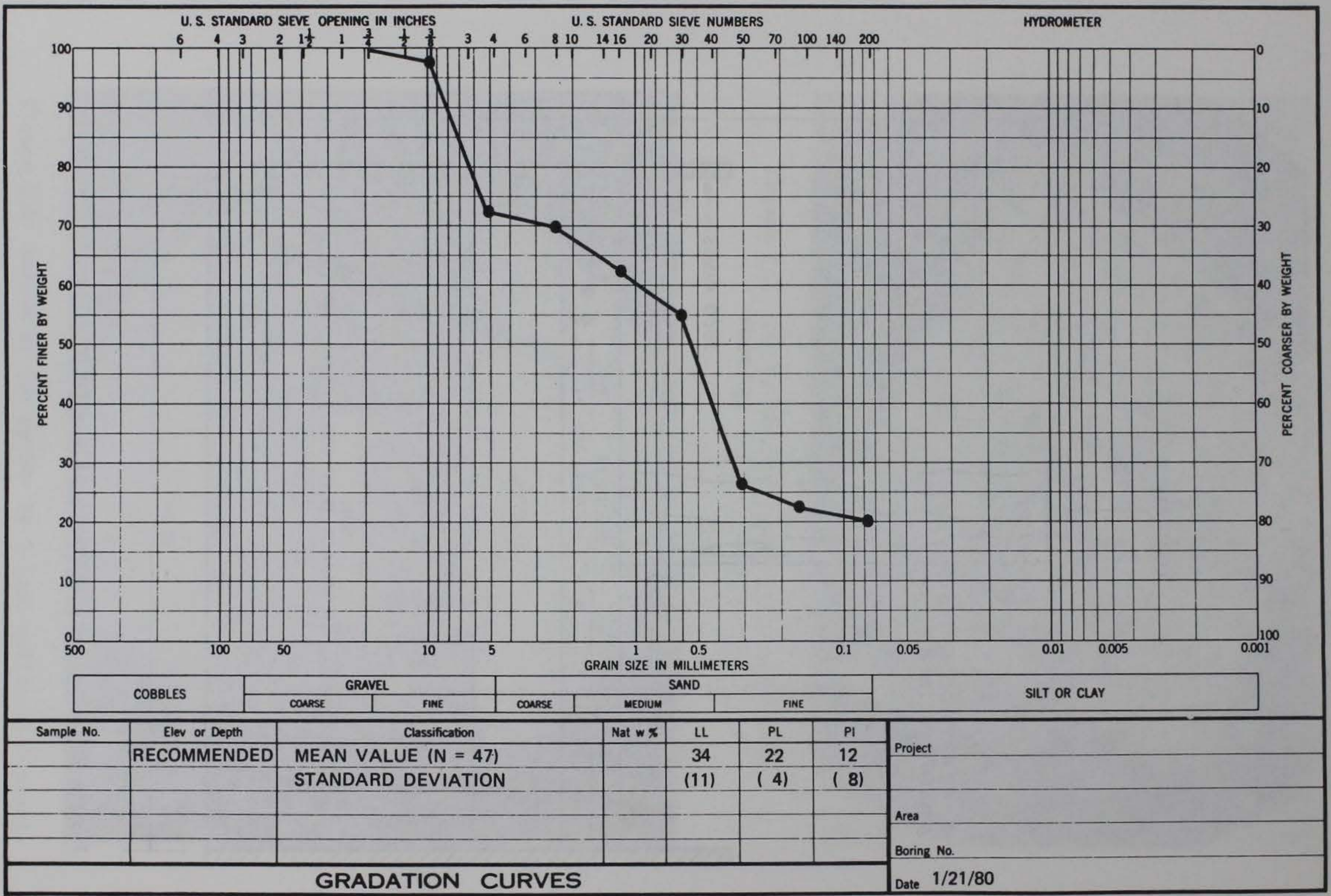

Figure 2.10 Gradation curve of soil used in test specimens. 


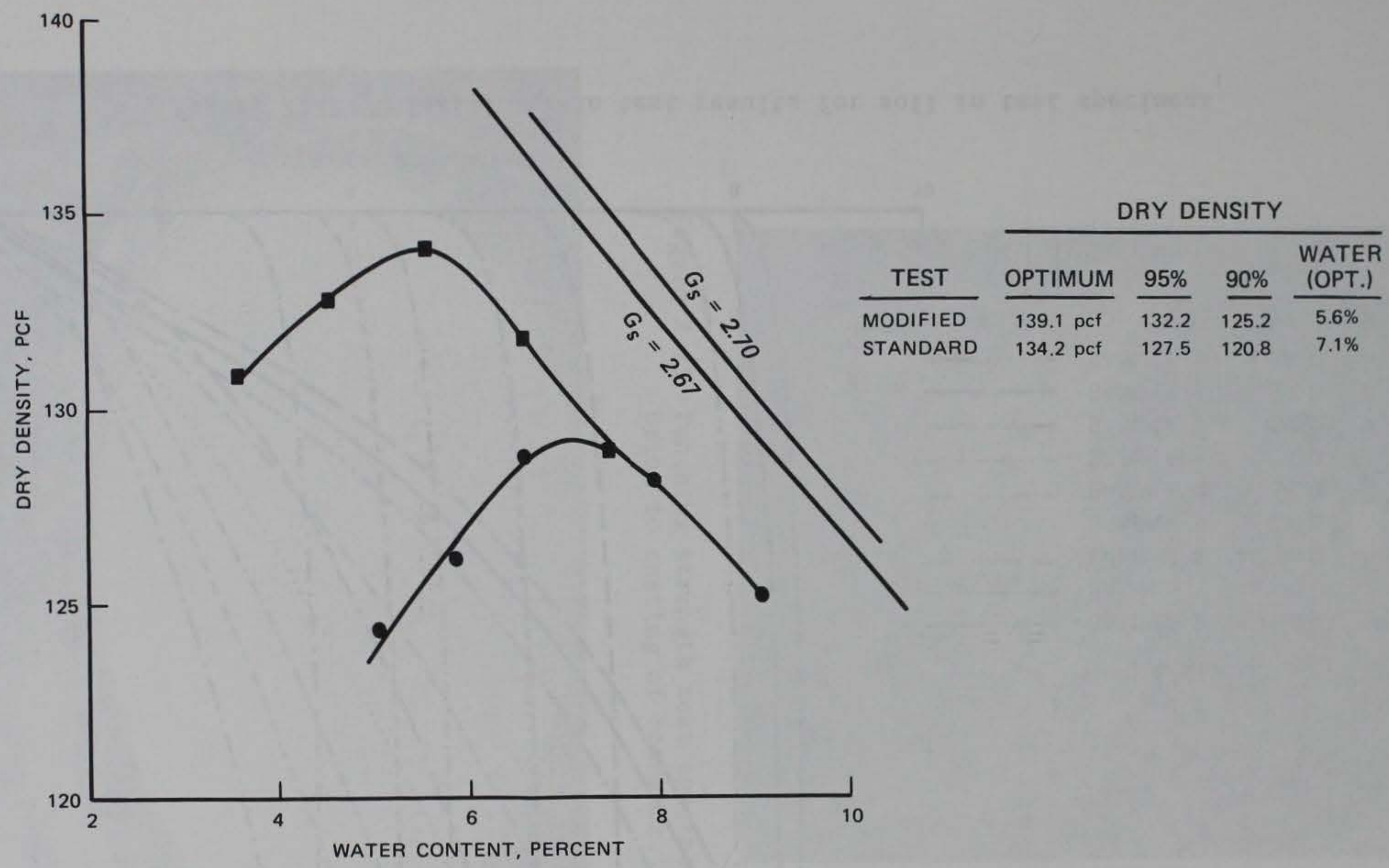

\section{LEGEND}

- MODIFIED COMPACTION

56 BLOWS/5 LAYERS/10\#/18" DROP/6" MOLD

- STANDARD COMPACTION

56 BLOWS/3 LAYERS/5.5\#/12" DROP/6" MOLD

Figure 2.11 Compaction test results for soil in test specimens. 


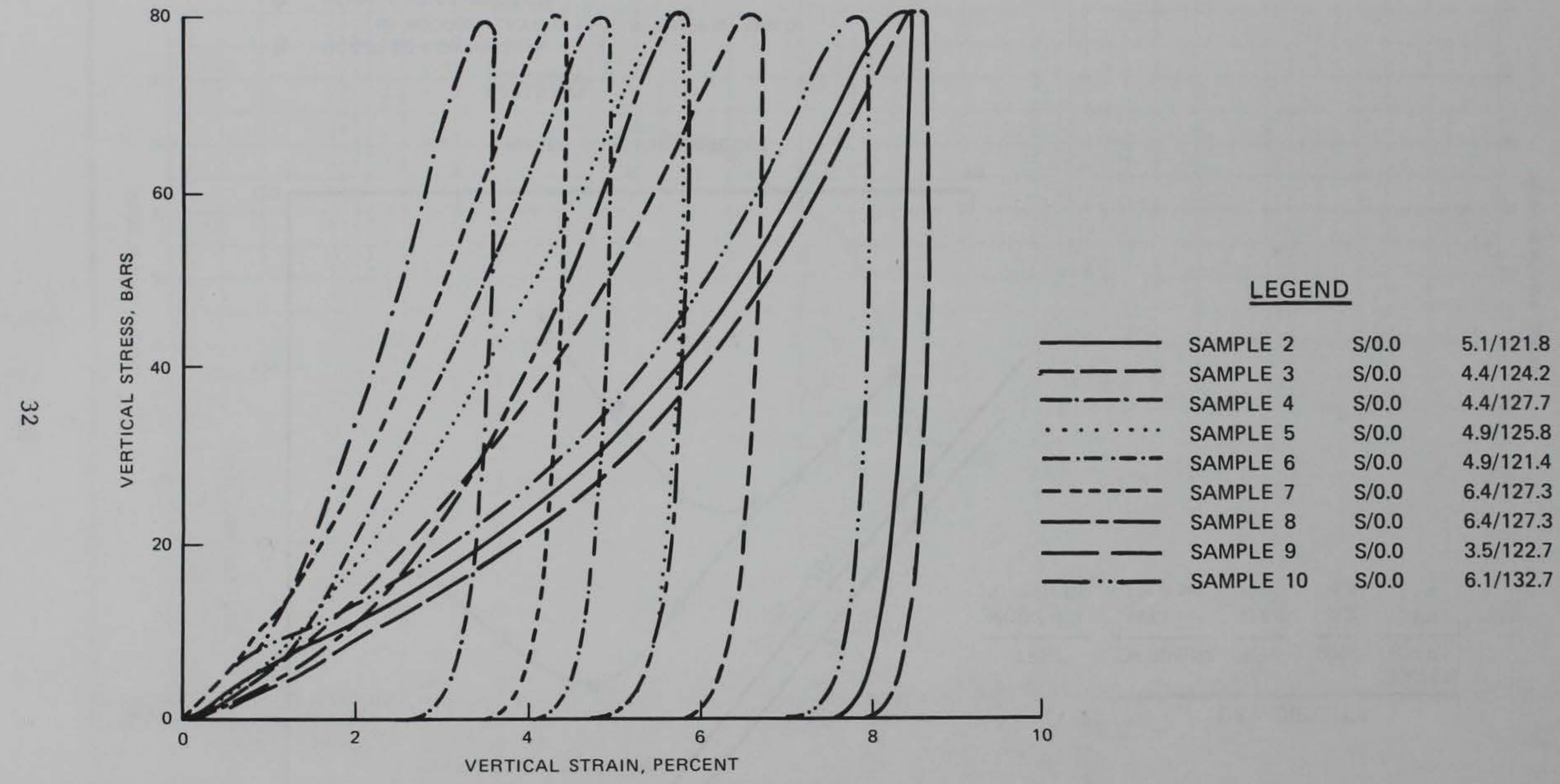

Figure 2.12 Uniaxial strain test results for soil in test specimens. 


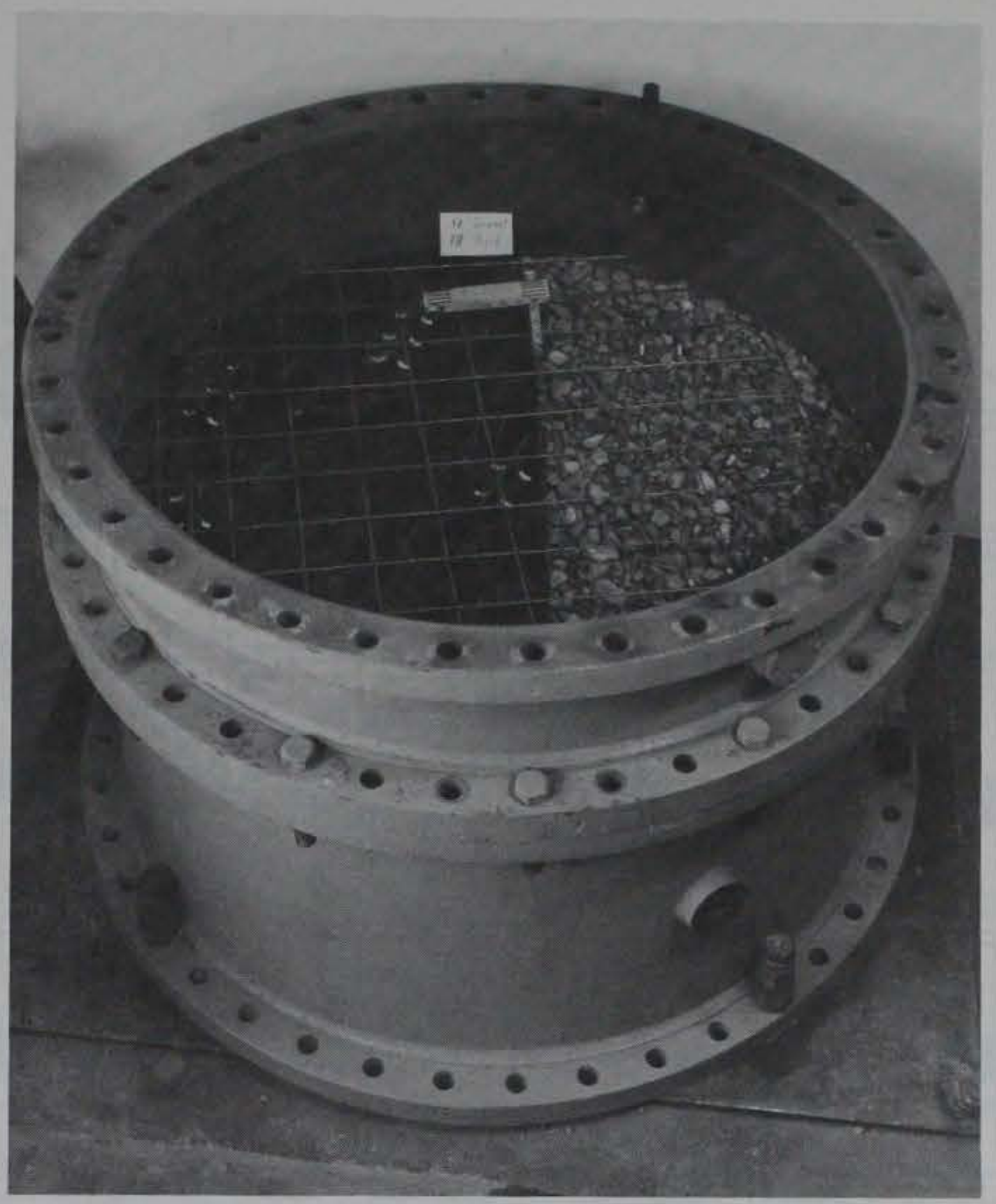

Figure 2.13 Punching strength test specimen prior to casting of concrete.

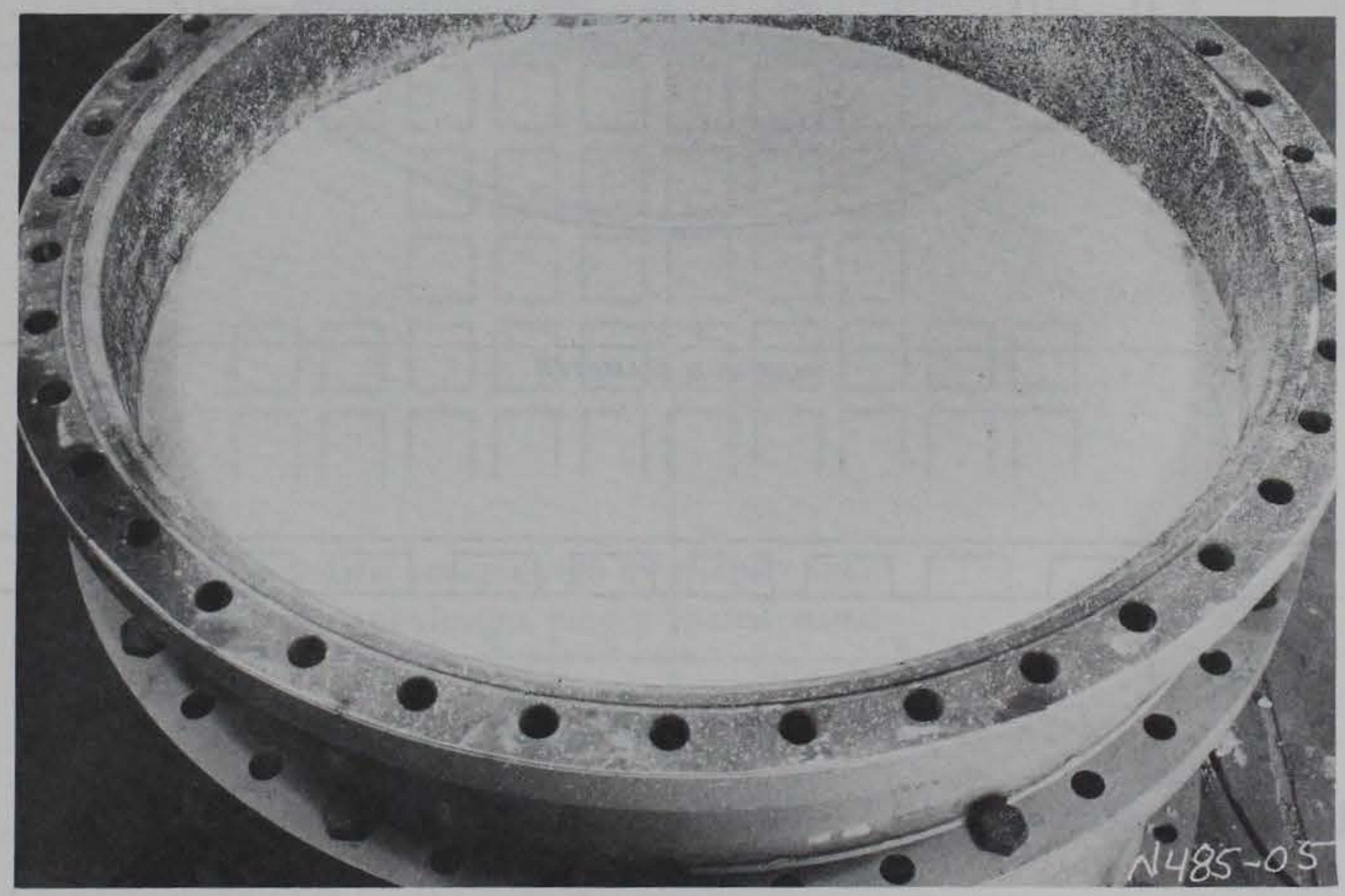

Figure 2.14 Completed punching strength test specimen. 

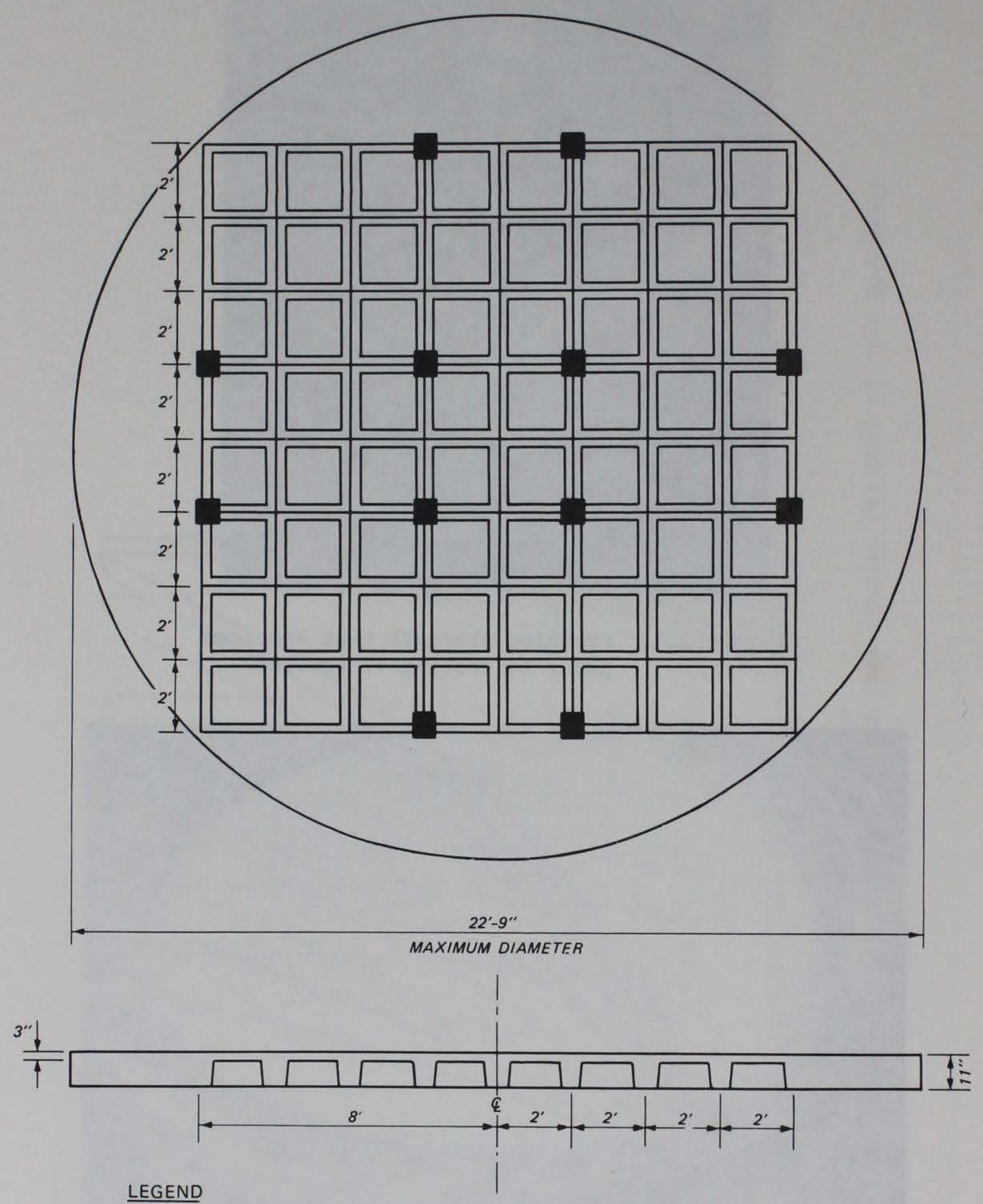

WOODEN UPGRADING
COLUMN

Figure 2.15 Center portion of a waffle-slab floor. 


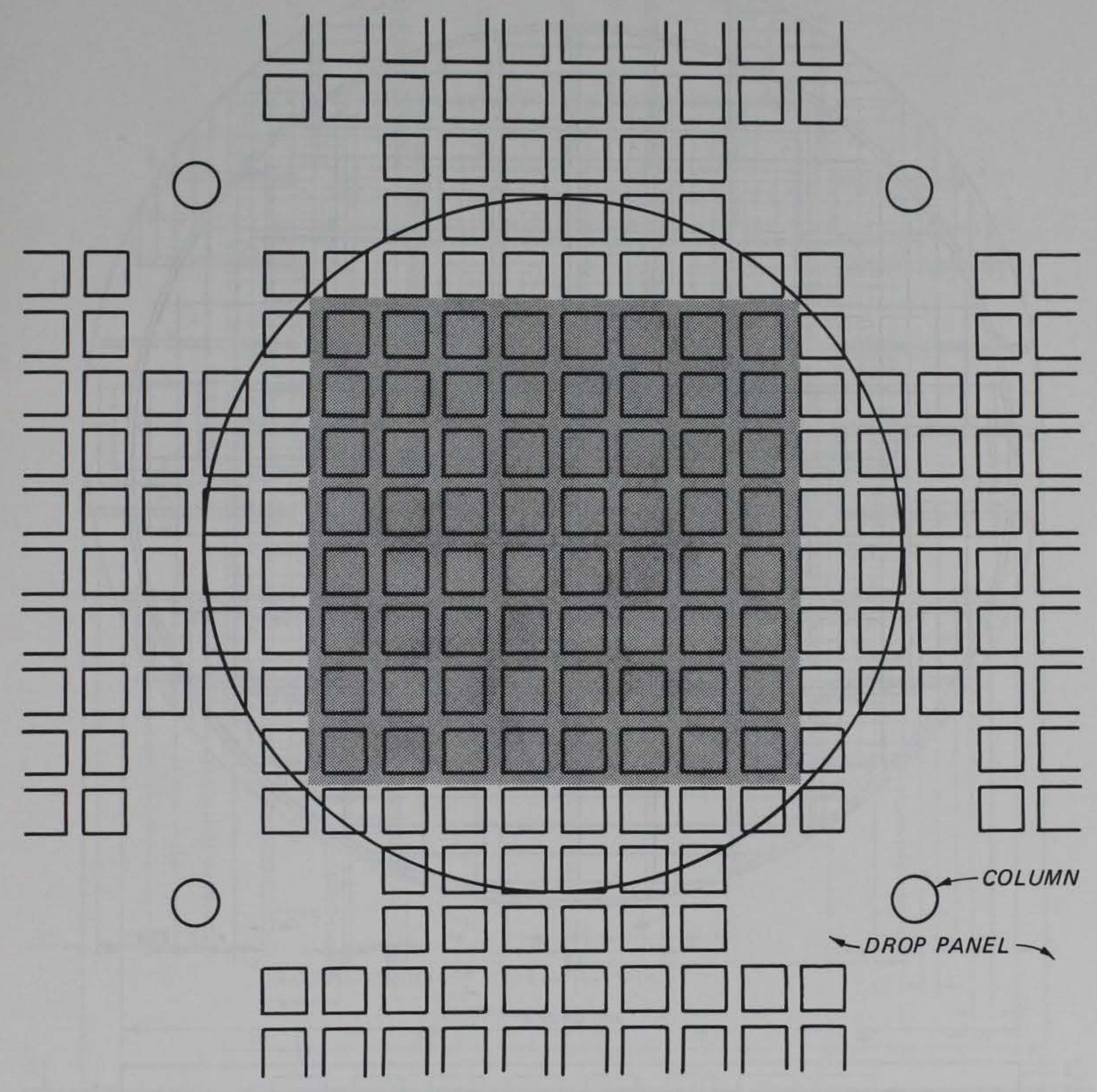

NOTE: TEST SPECIMEN REPRESENTED BY SHADED AREA. REMAINING AREA INSIDE CIRCLE TRANSFORMED TO RIGID SUPPORT.

Figure 2.16 Center portion of waffle slab. 


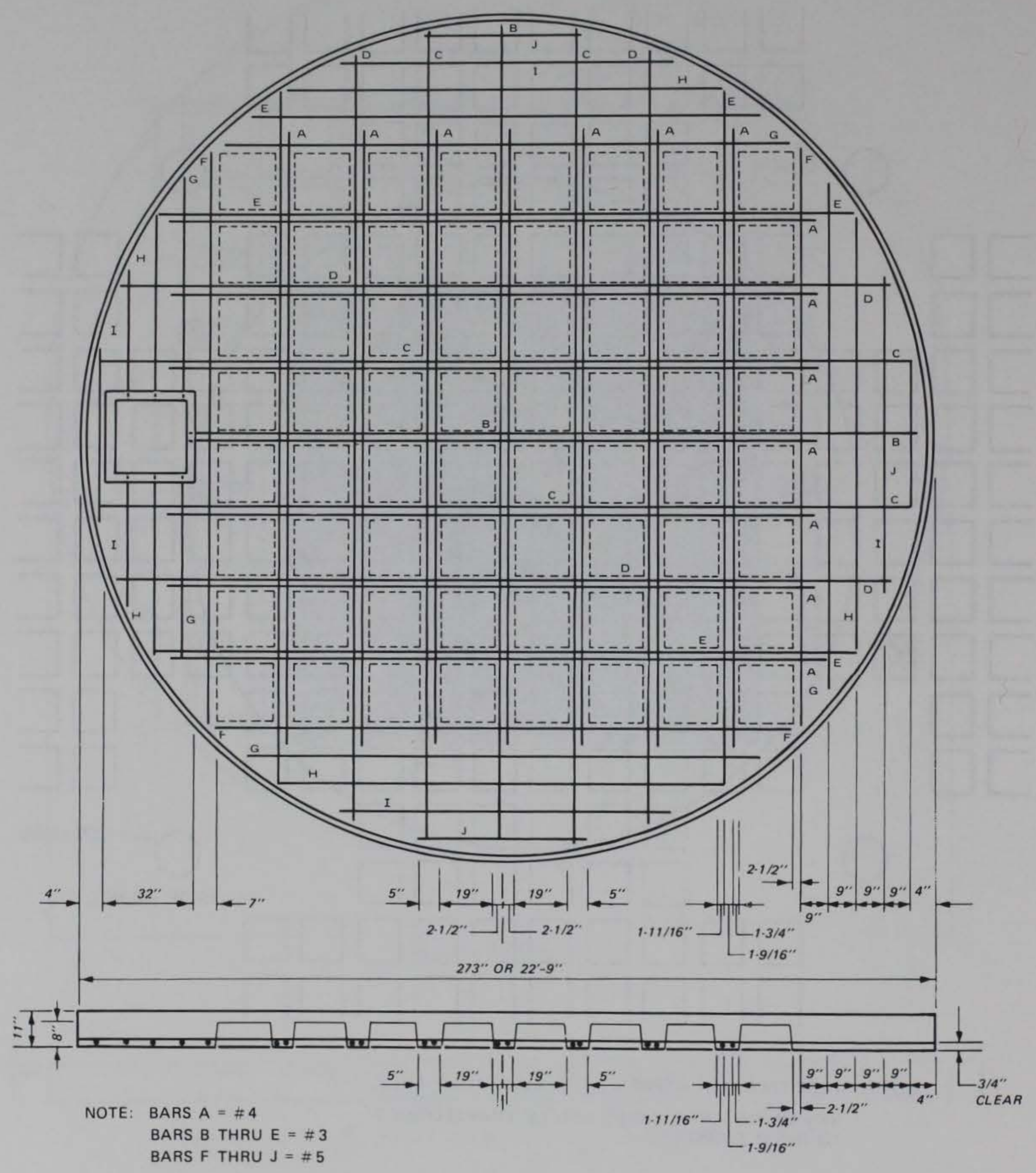

Figure 2.17 Waffle-slab bottom reinforcing steel. 


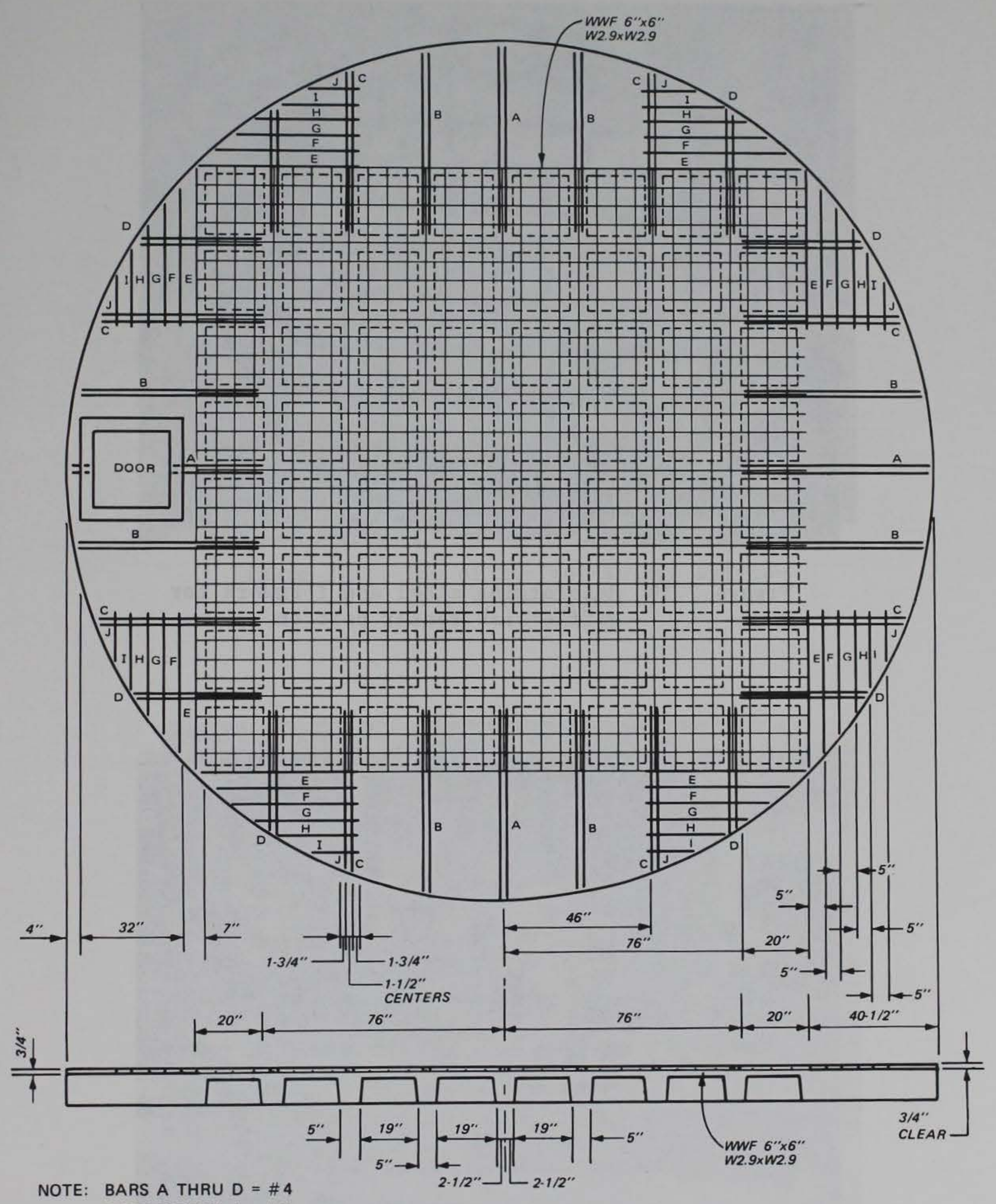

BARS E THRU $\mathrm{J}=\# 5$

Figure 2.18 Waffle-slab top reinforcing steel. 


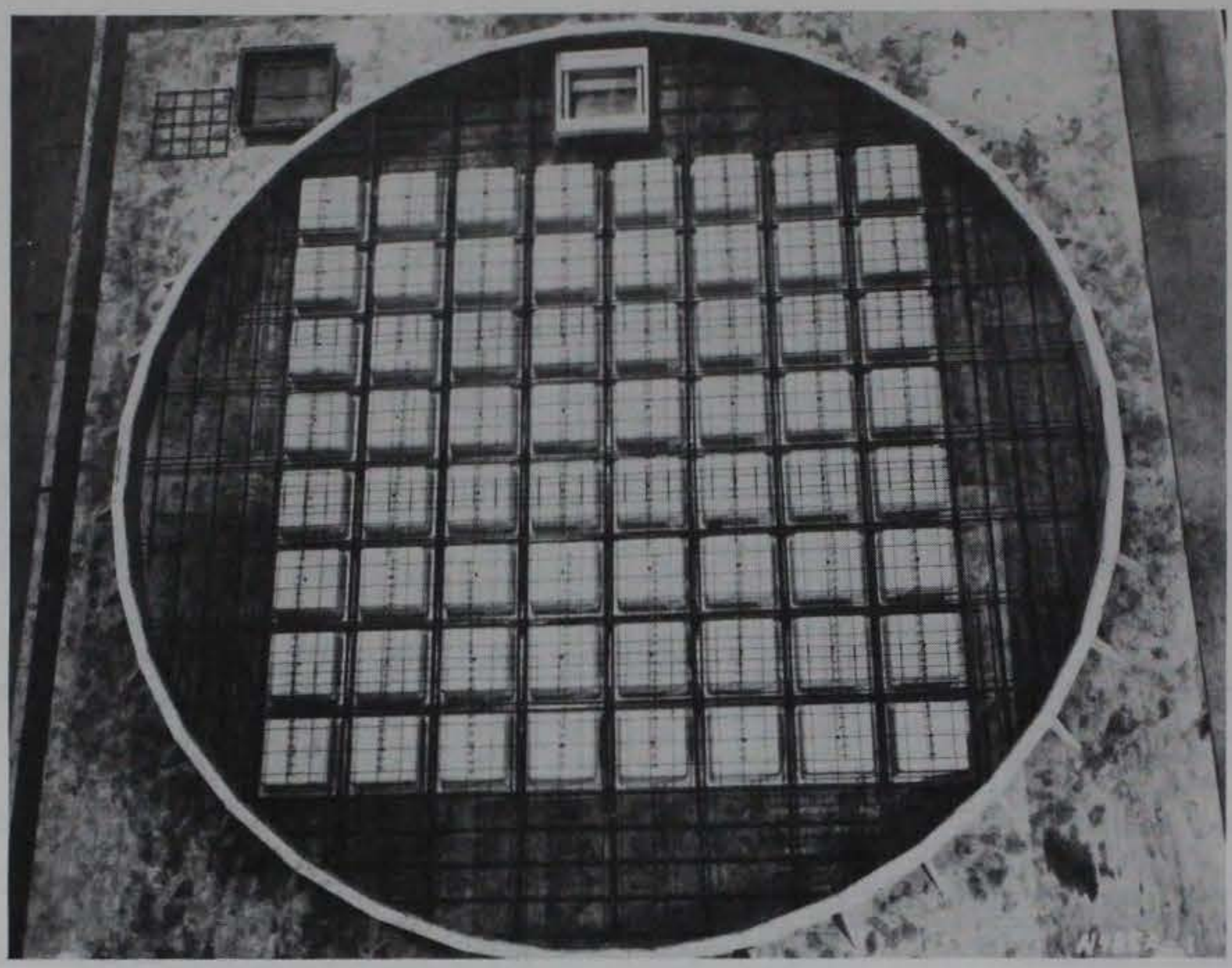

Figure 2.19 Reinforcing steel and formwork for waffle-slab center portion.

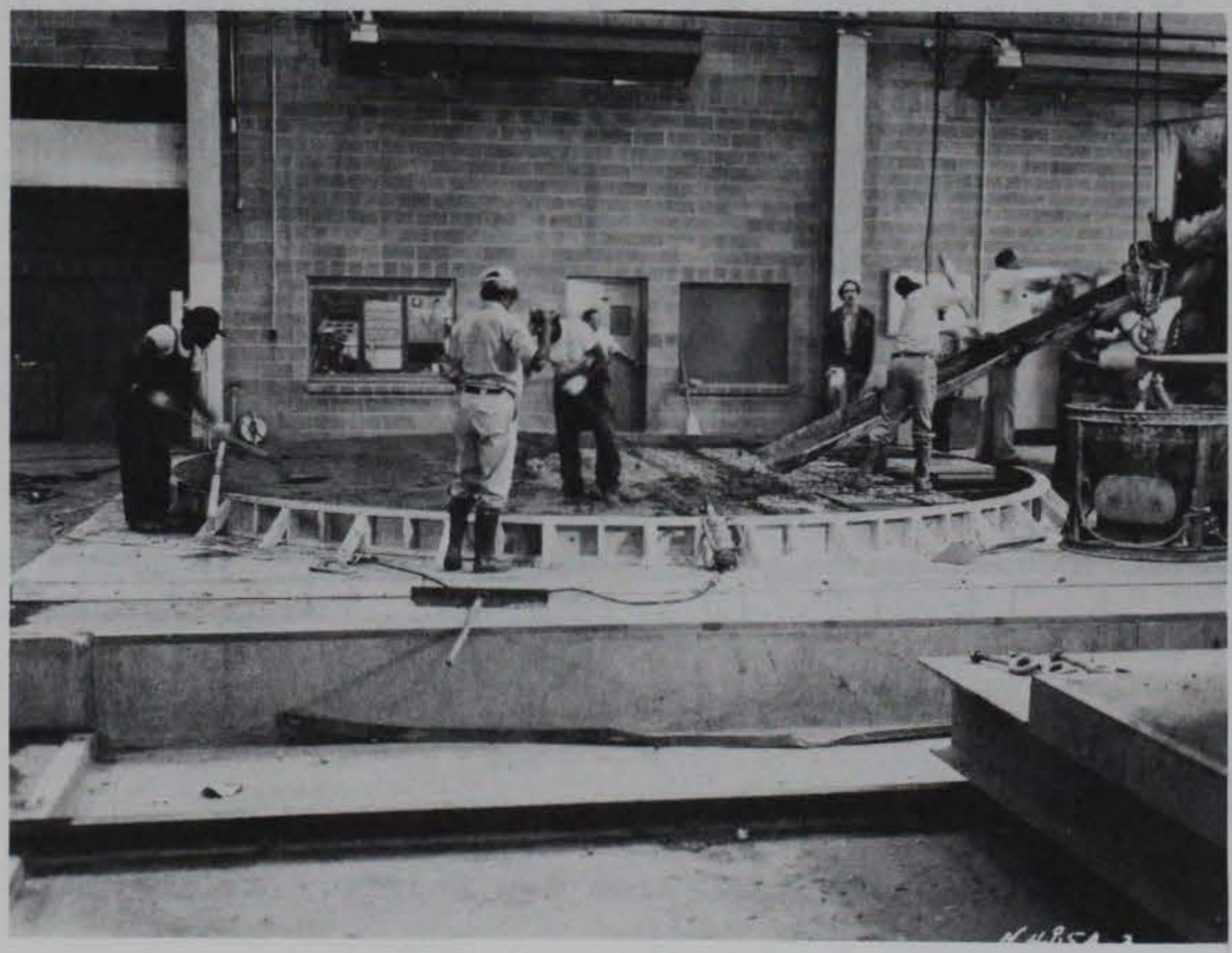

Figure 2.20 Casting concrete for waffle-slab center portion. 


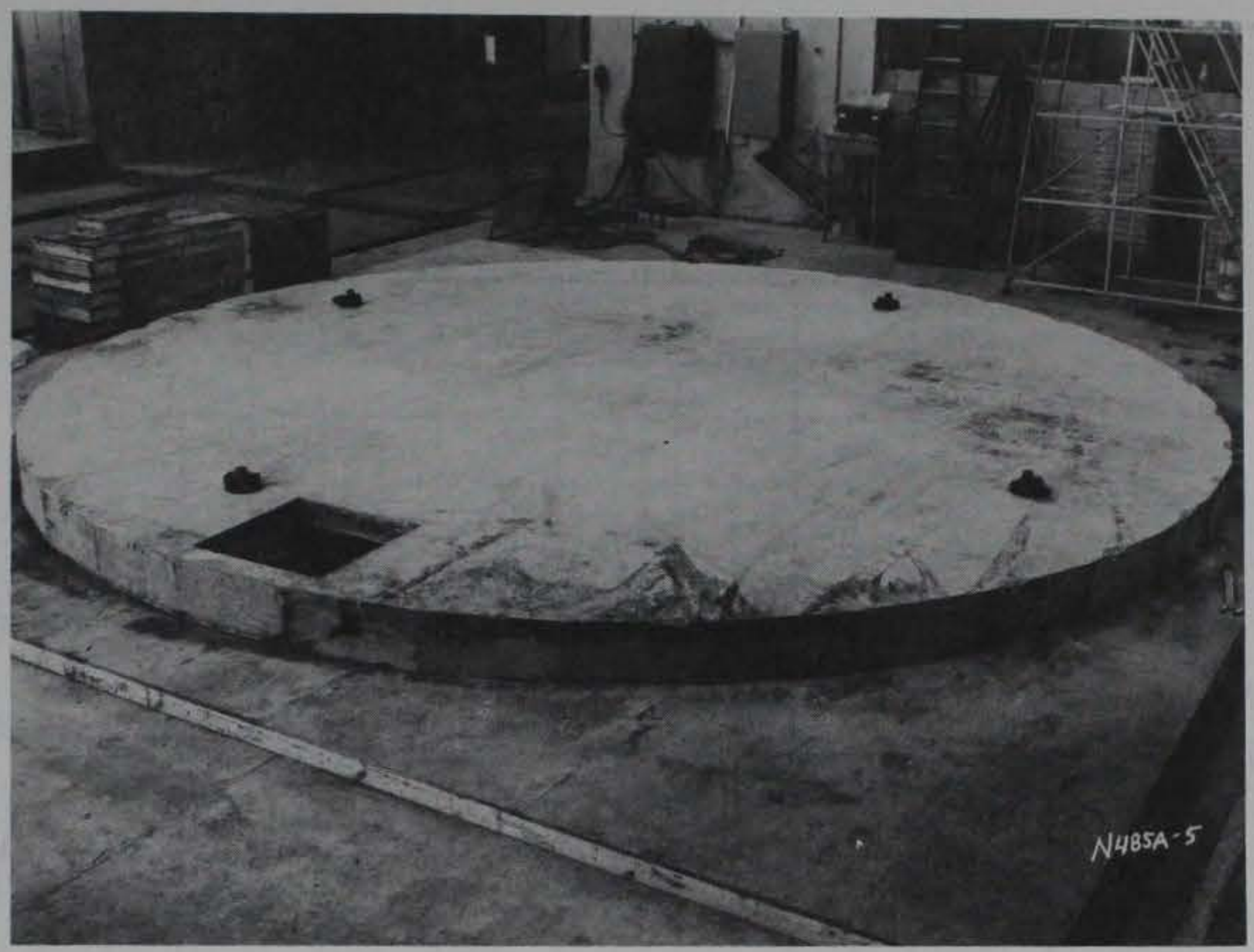

Figure 2.21 Top of 24-foot-square waffleslab center portion.

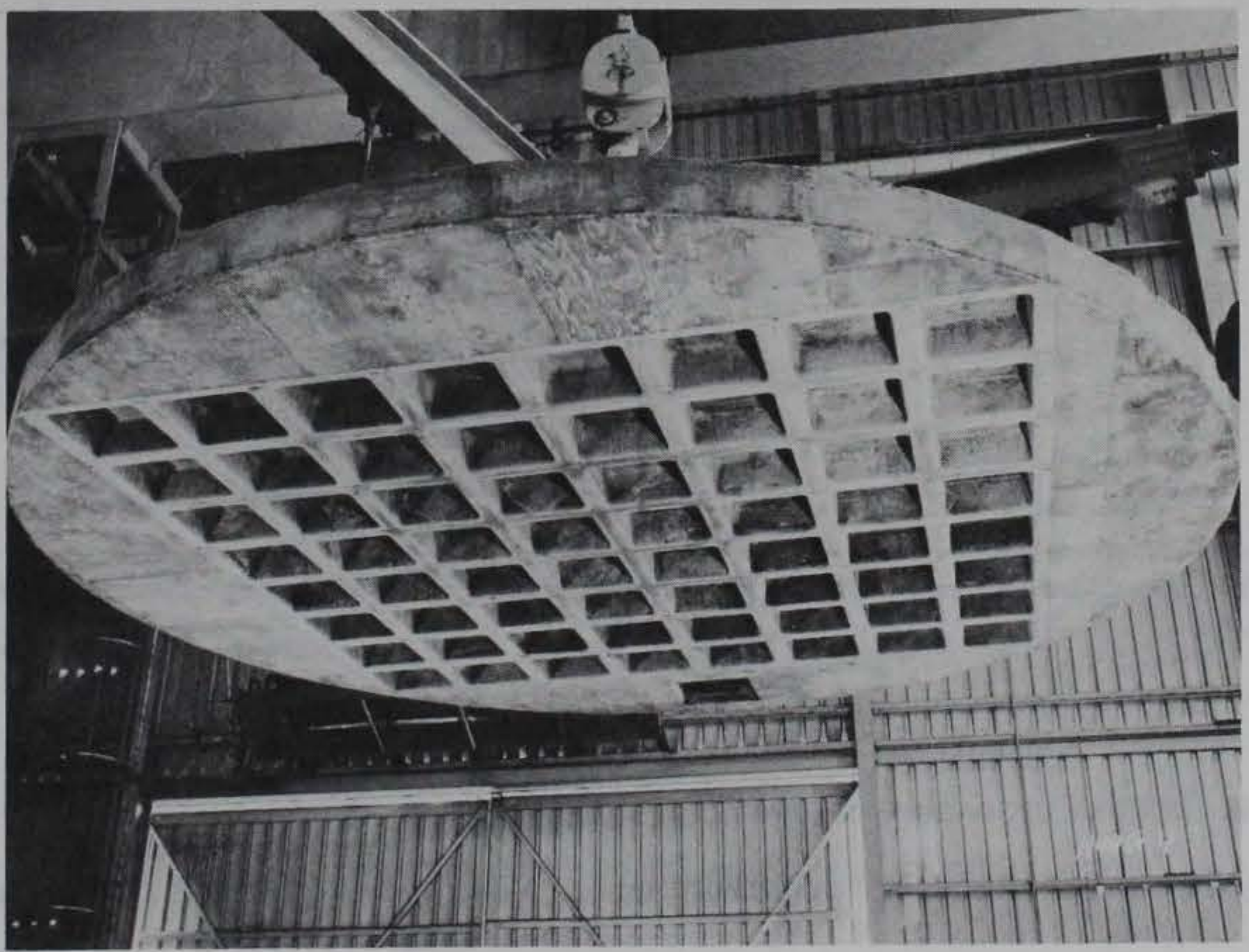

Figure 2.22 Bottom of 24-foot-square waffleslab center portion. 


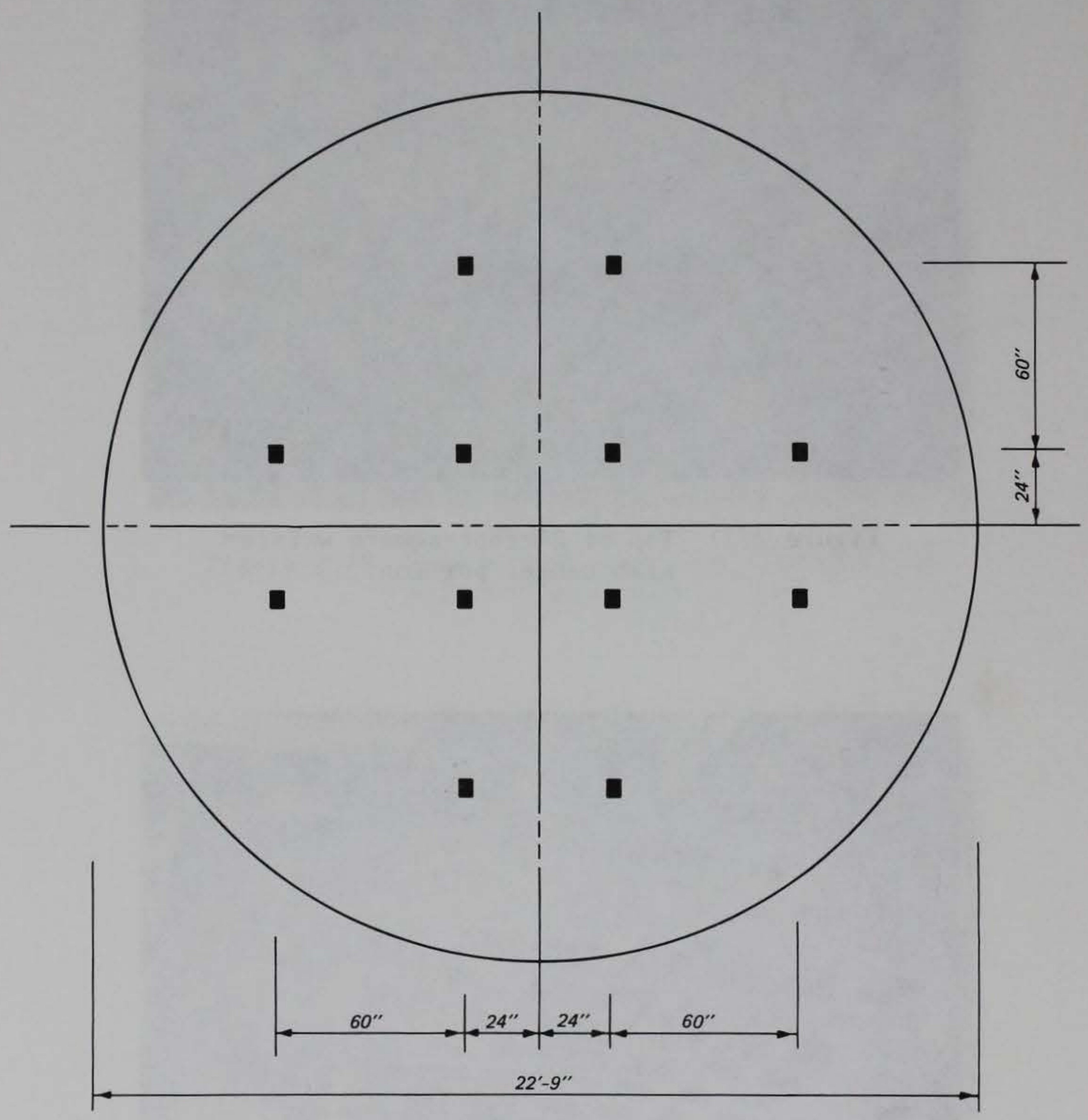

\section{LEGEND}

- WOODEN UPGRADING COLUMN

Figure 2.23 Center portion of a 22-foot-square flat plate. 


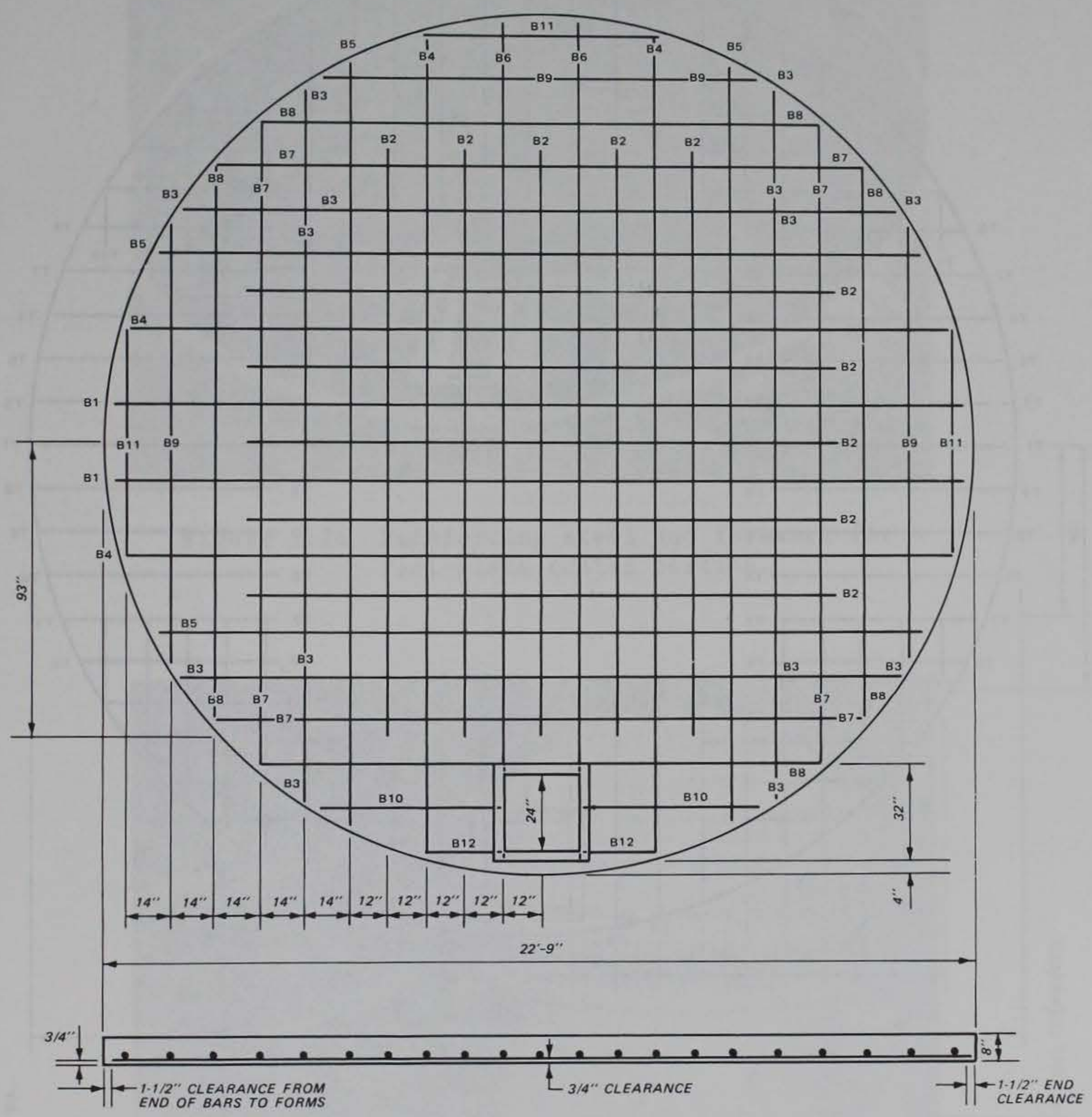

NOTE: $B 1, B 2, B 4, B 5, \& B 6=\# 4$ BARS.

B3,B7 THROUGH B12 = \#5 BARS.

USE 3/4" CHAIRS.

Figure 2.24 Flat-plate bottom reinforcing steel. 


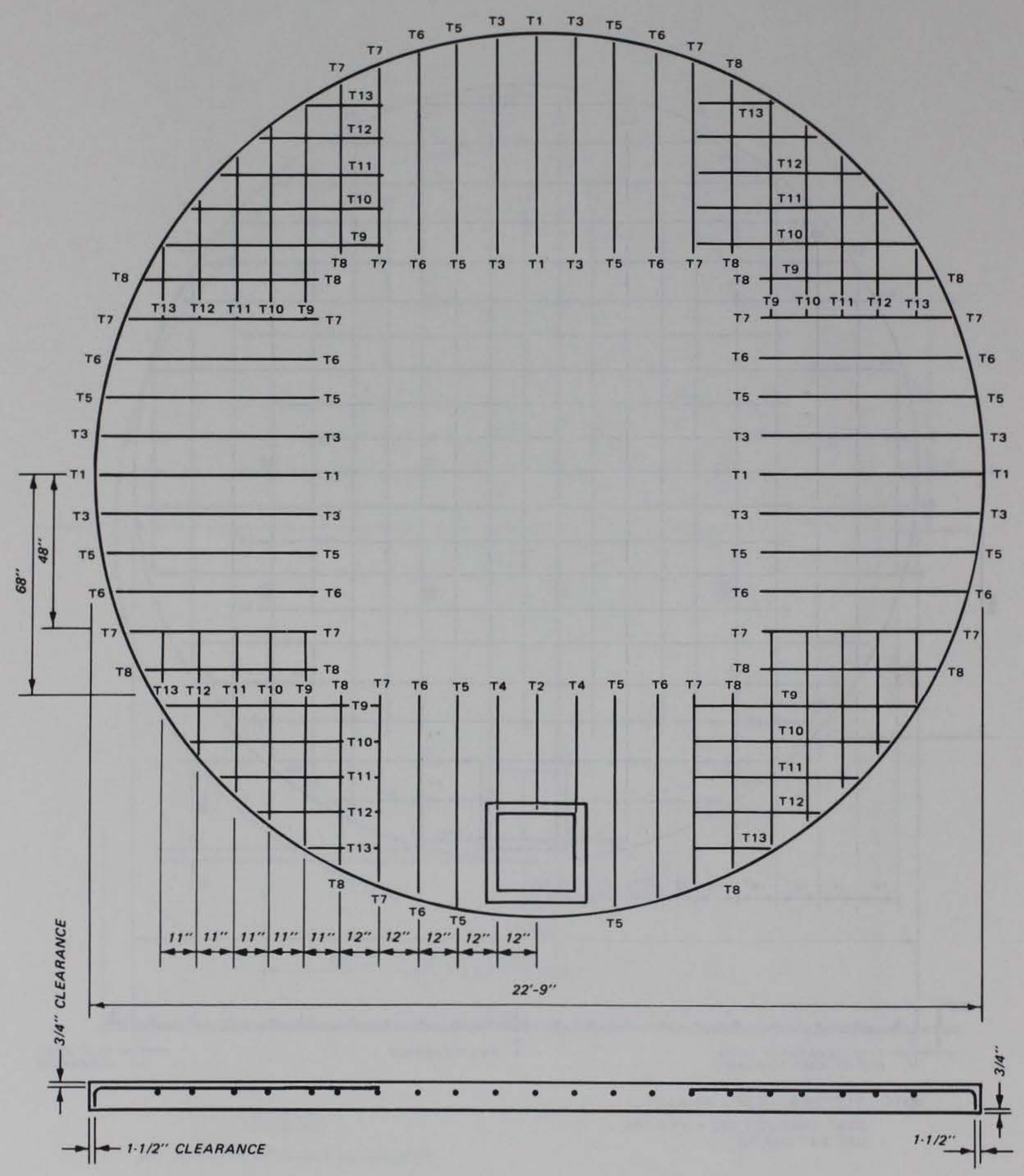

NOTE: T1 THRU T8 $=$ 4 BARS.

T9 THRU T13 = \#7 BARS.

Figure 2.25 Flat-plate top reinforcing steel. 


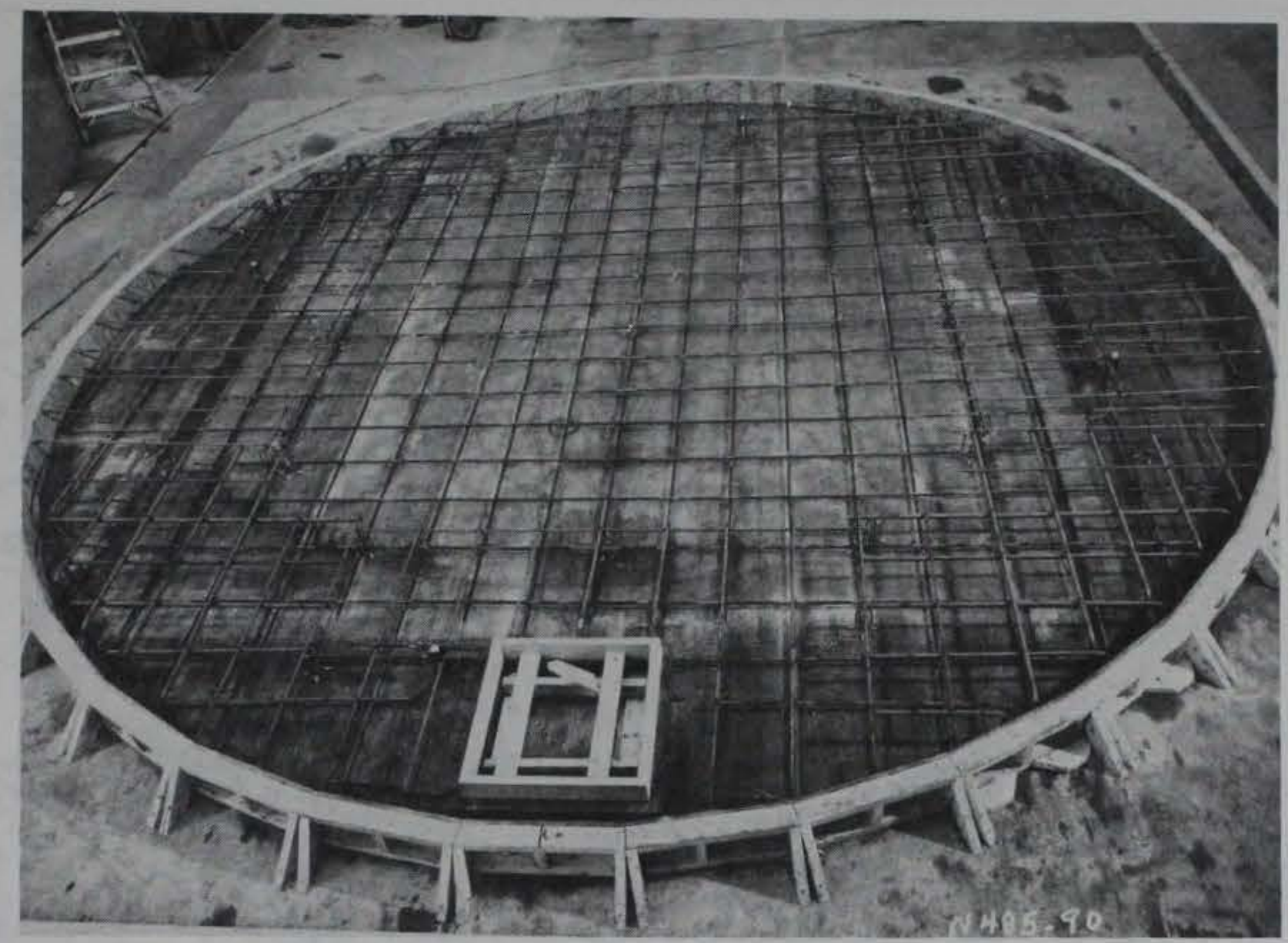

Figure 2.26 Reinforcing steel and formwork for flat-plate center portion.

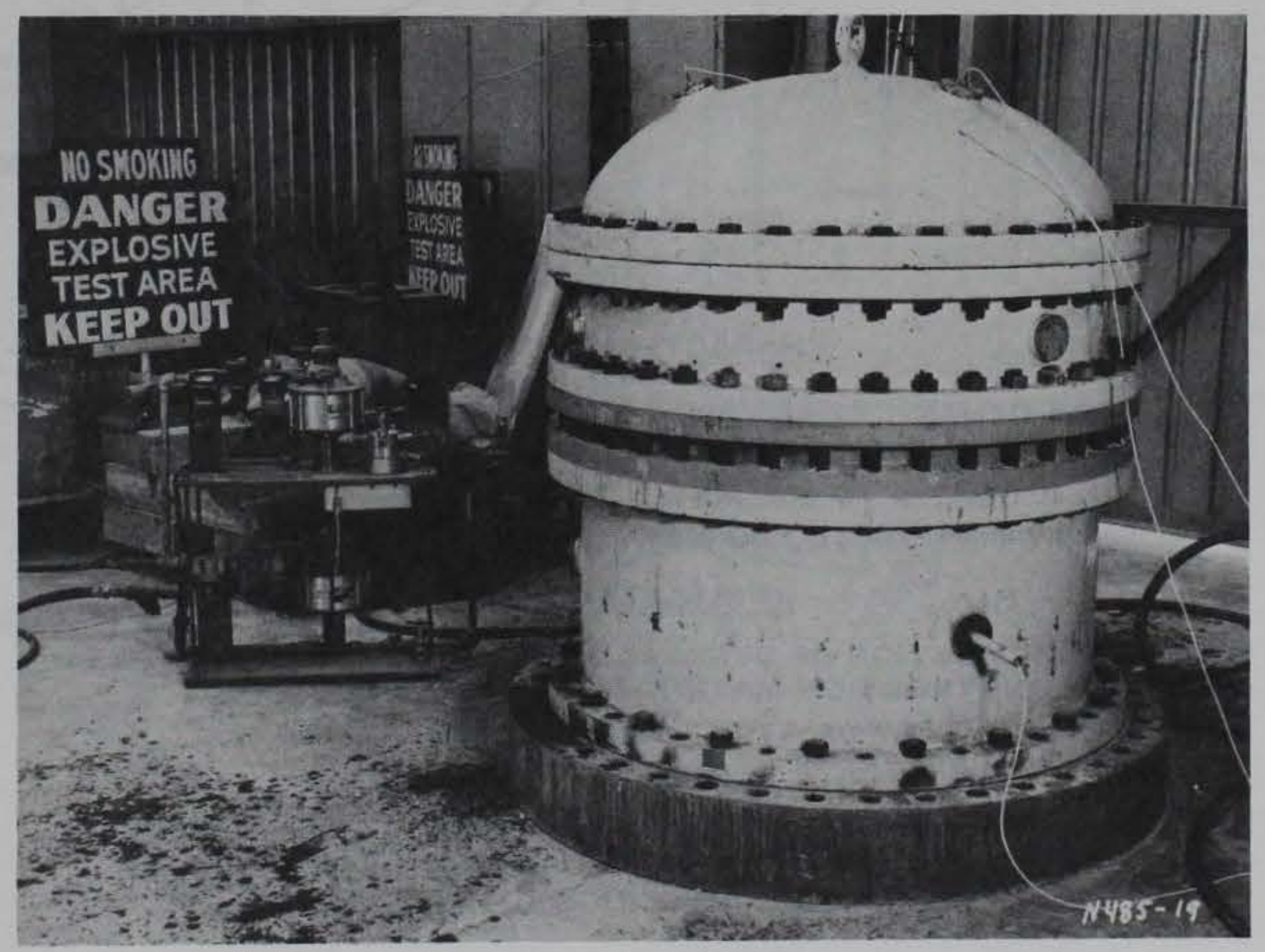

Figure 2.27 Small blast load generator (SBLG). 


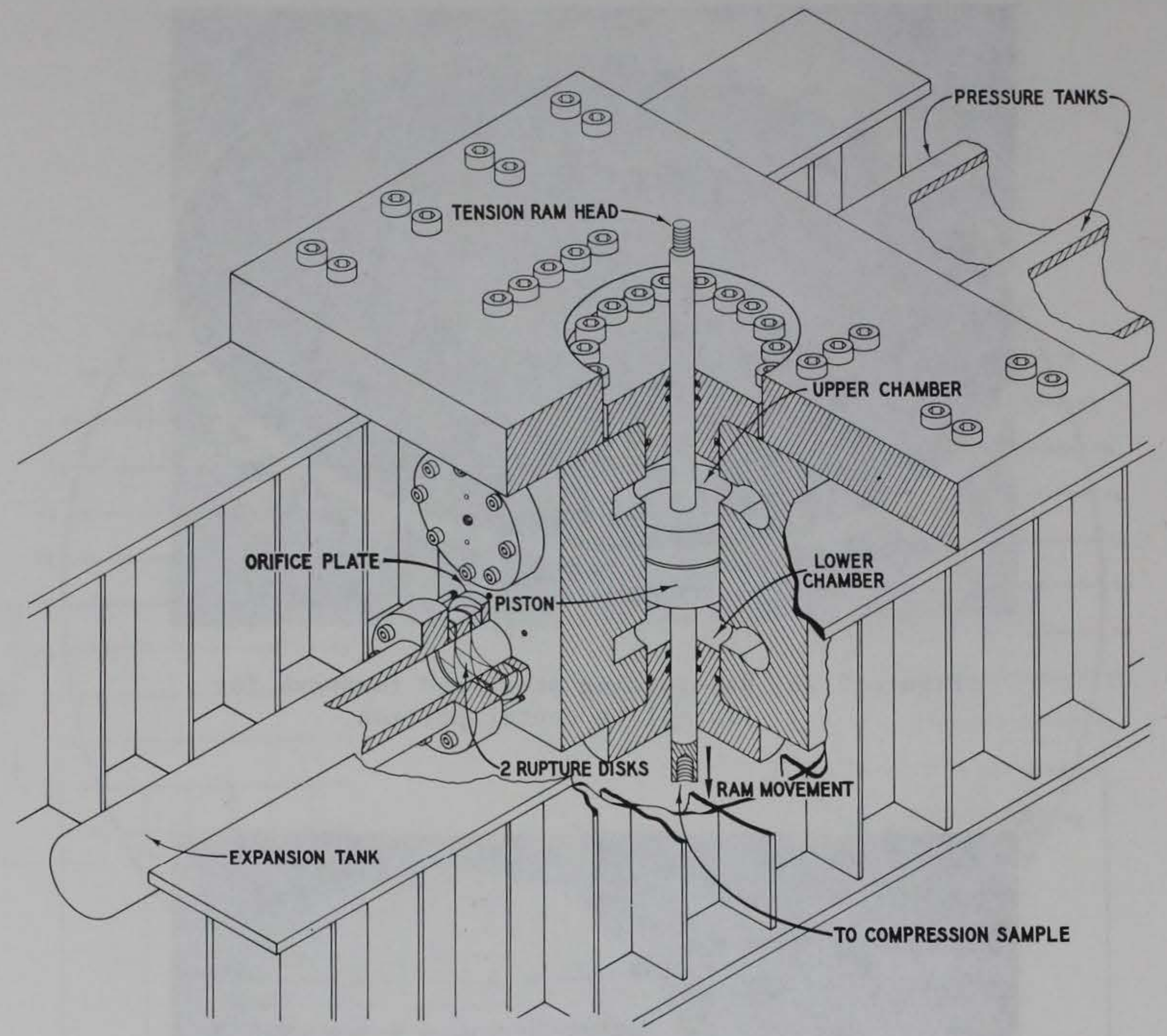

CHARACTERISTICS

1. PEAK DYNAMIC LOAD: 200,000 LB IN LESS THAN 2 MSEC.

2. RISE TIME: 1 TO 200 MSEC.

3. HOLD TIME: O TO 200 MSEC.

4. DELAY TIME: 15 TO 500 MSEC.

\section{APPLICATIONS}

1. DETERMINATION OF DYNAMIC STRESS-STRAIN PROPERTIES OF CONSTRUCTION MATERIALS.

2. DYNAMIC TEST OF STRUCTURAL ELEMENTS:

a. BEAMS UP TO 18 FEET IN LENGTH.

b. COLUMNS UP TO 8 FEET IN LENGTH.

c. TENSILE SPECIMENS UP TO 3 FEET IN LENGTH.

d. STRUCTURAL CONNECTIONS AND FRAMES.

Figure 2.28 200-kip loading device. 


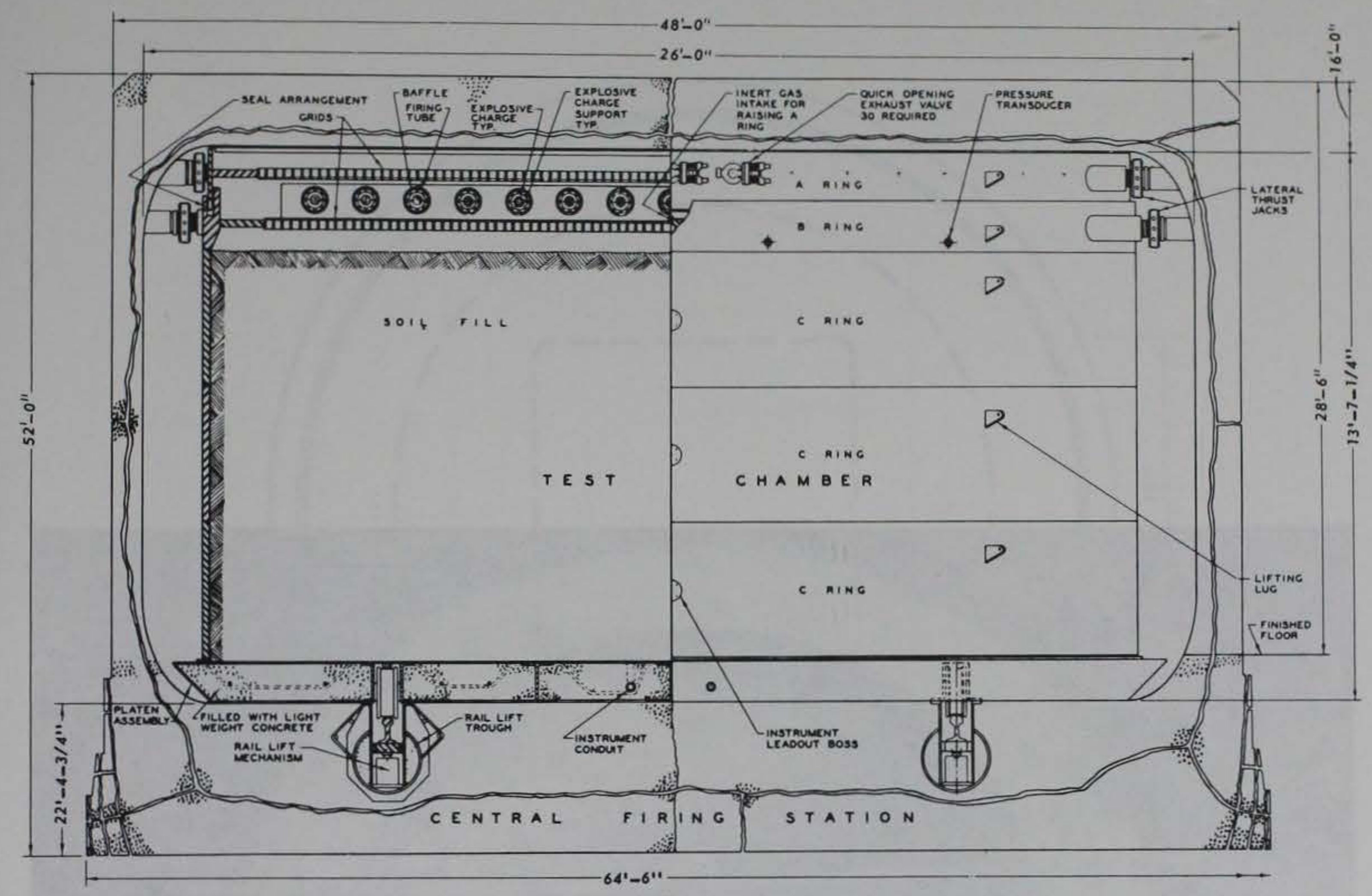

a. Half section of the LBLG.

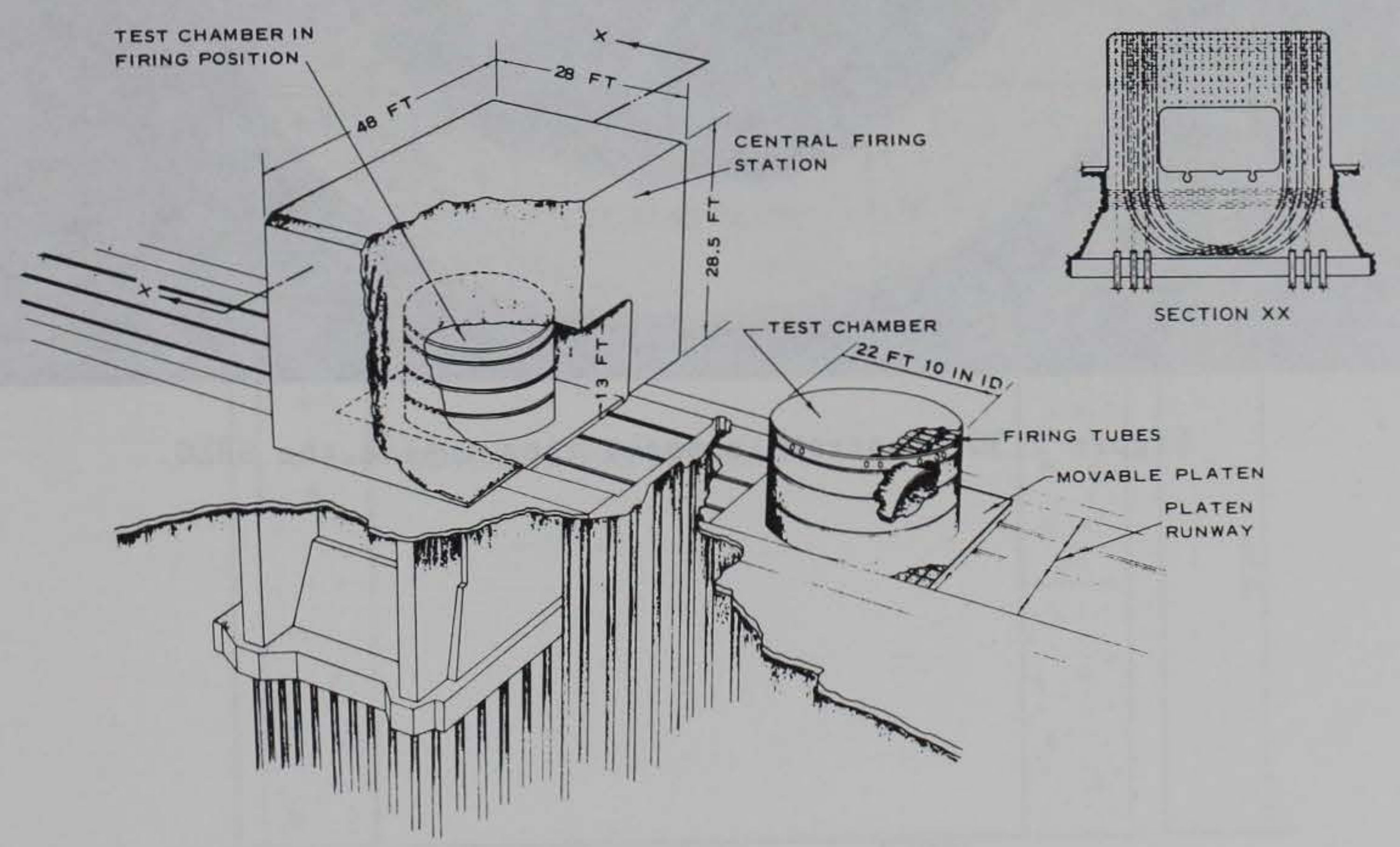

b. Cutaway view of the LBLG.

Figure 2.29 Large blast load generator (LBLG). 


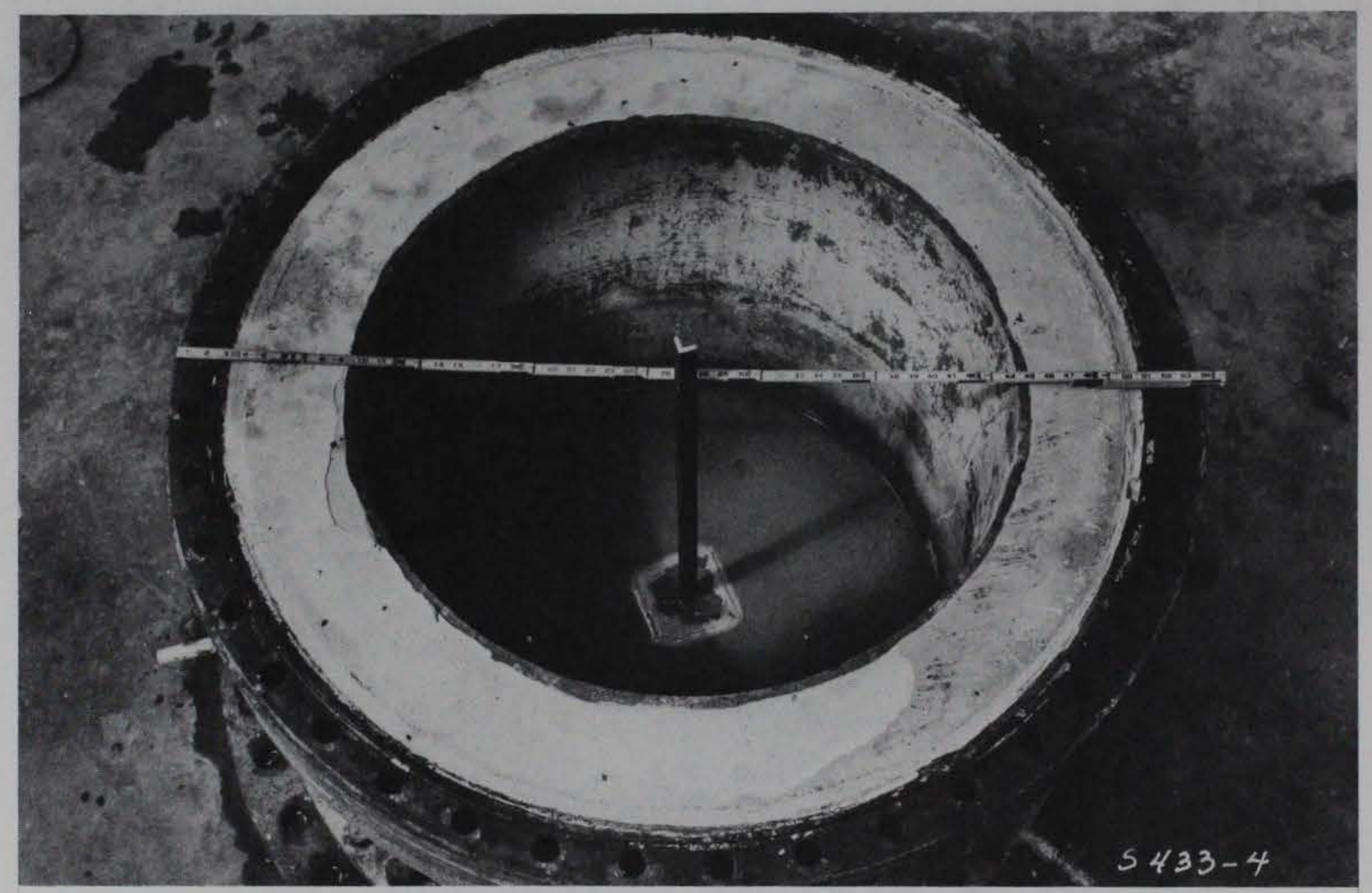

Figure 2.30 Concrete support ring inside the SBLG. 

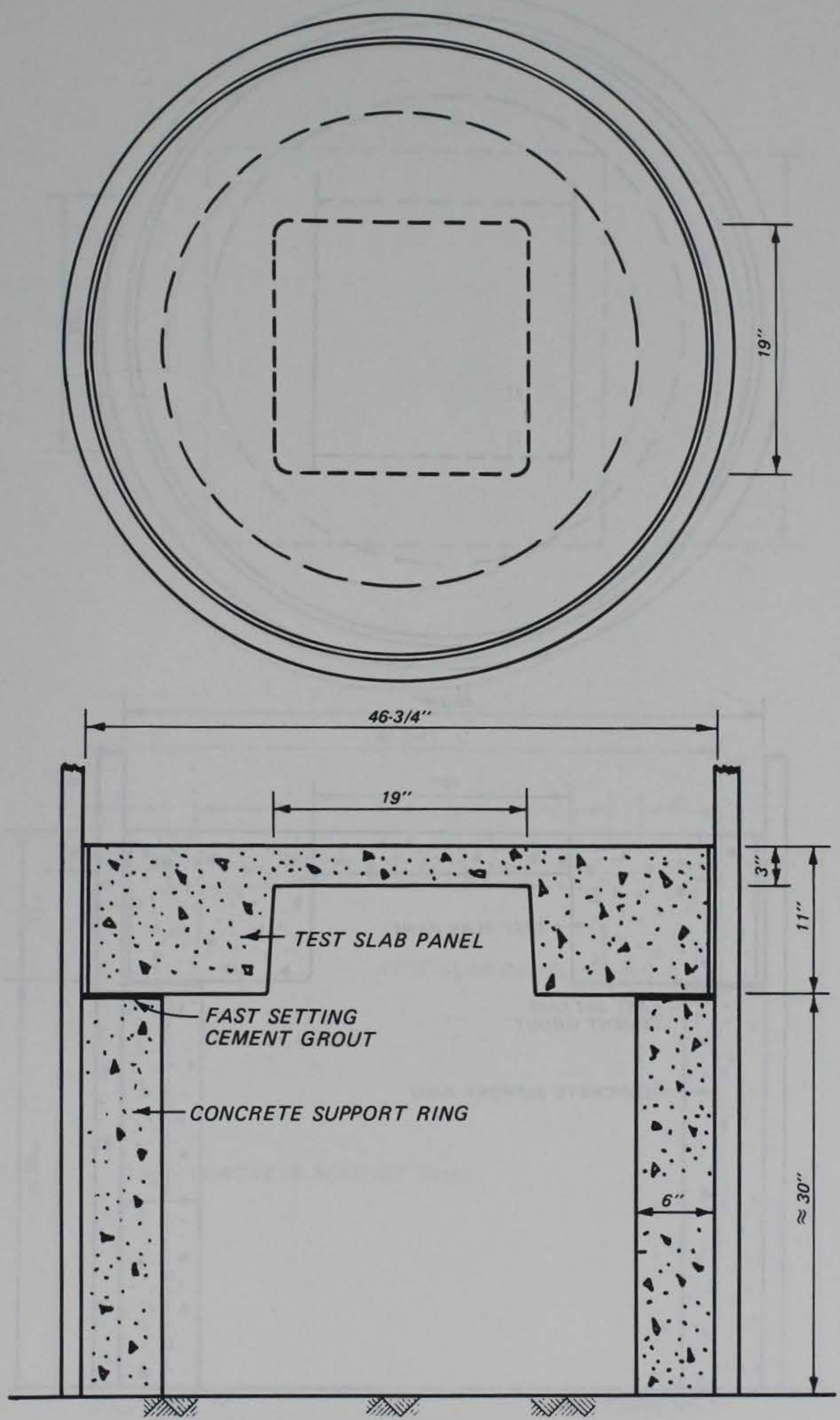

Figure 2.31 Test in SBLG of 19-inch-square waffle-slab panel. 


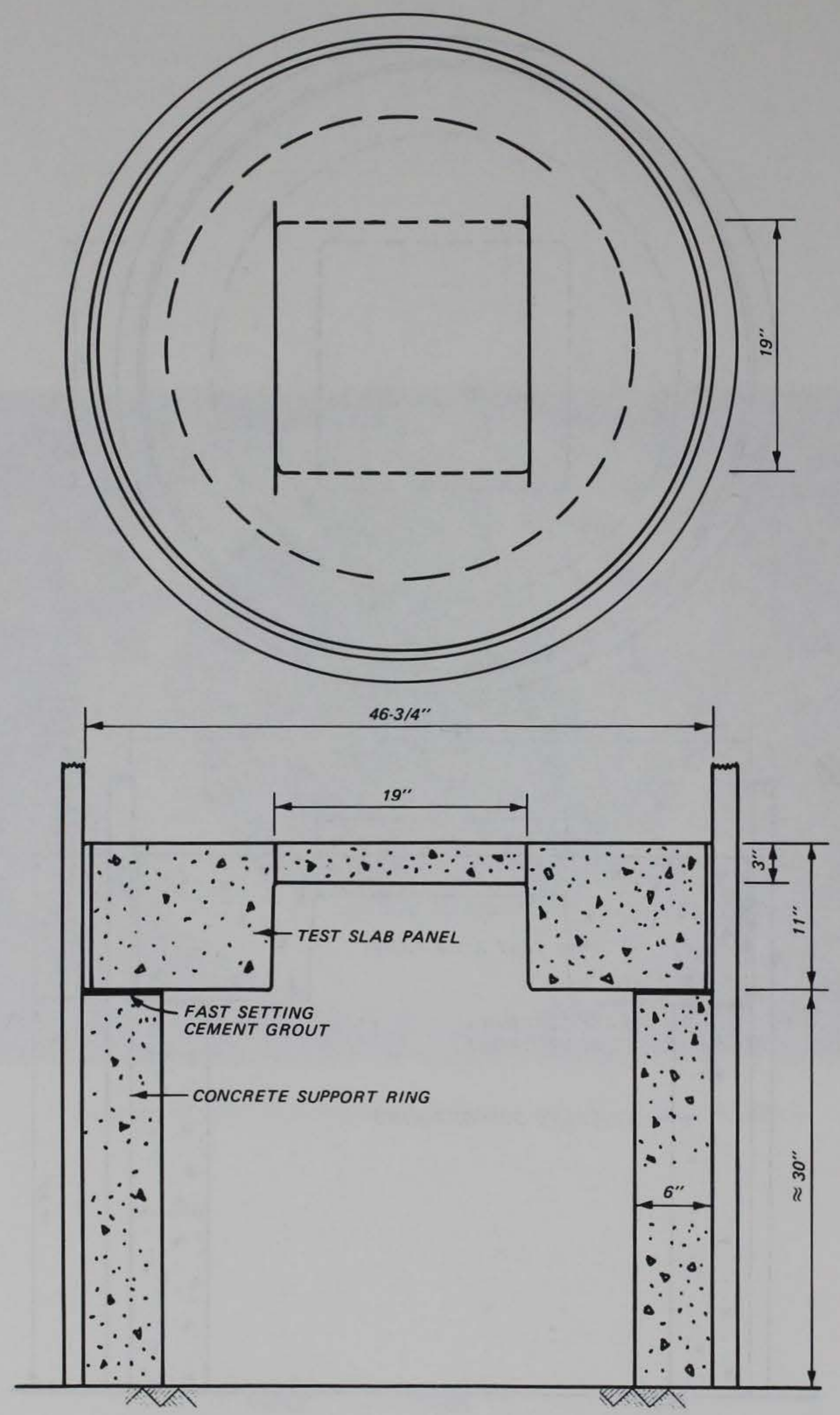

Figure 2.32 Test in SBLG of 19-inch-square one-way slab panel. 

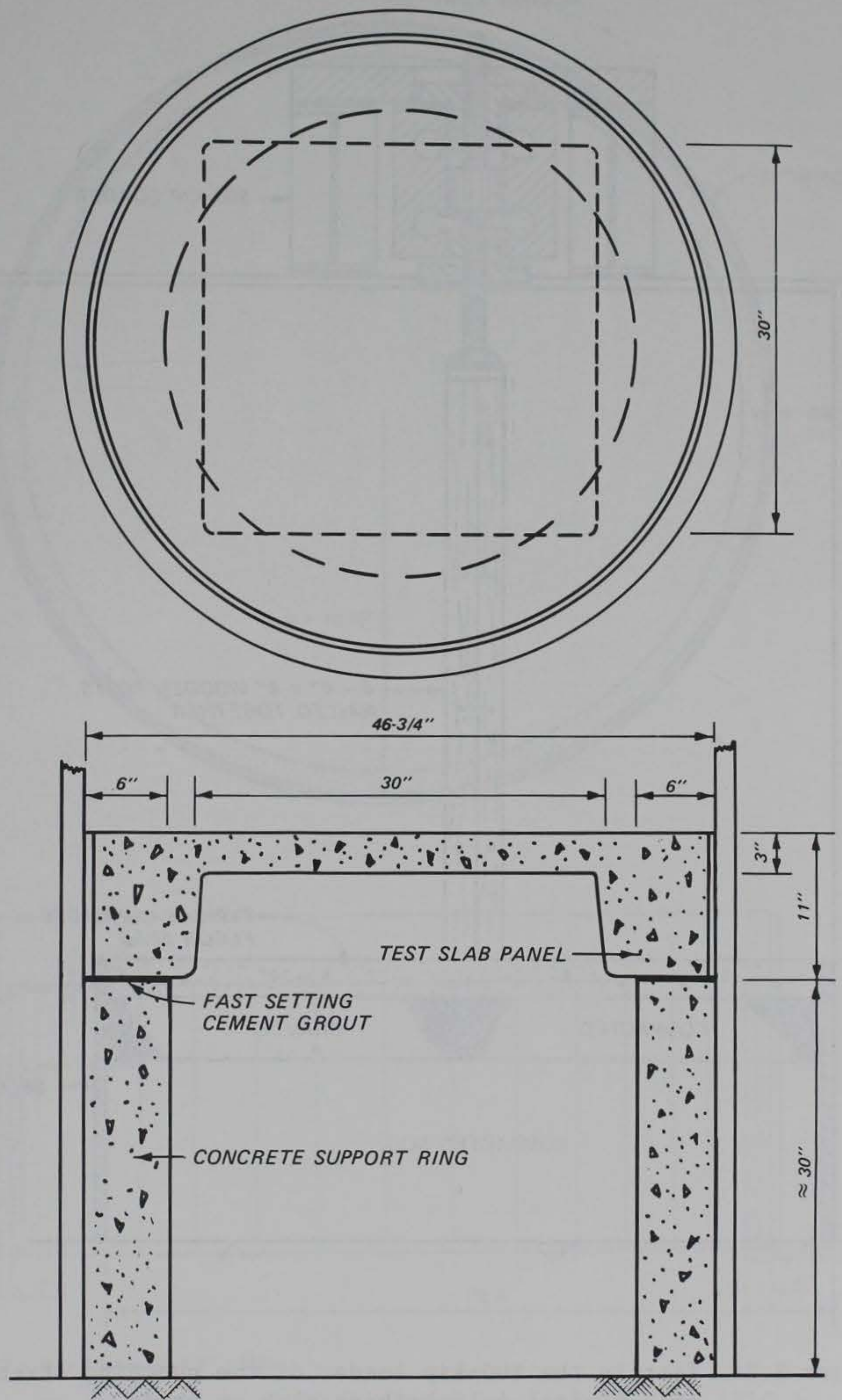

Figure 2.33 Test in SBLG of 30-inch-square waffle-slab panel. 


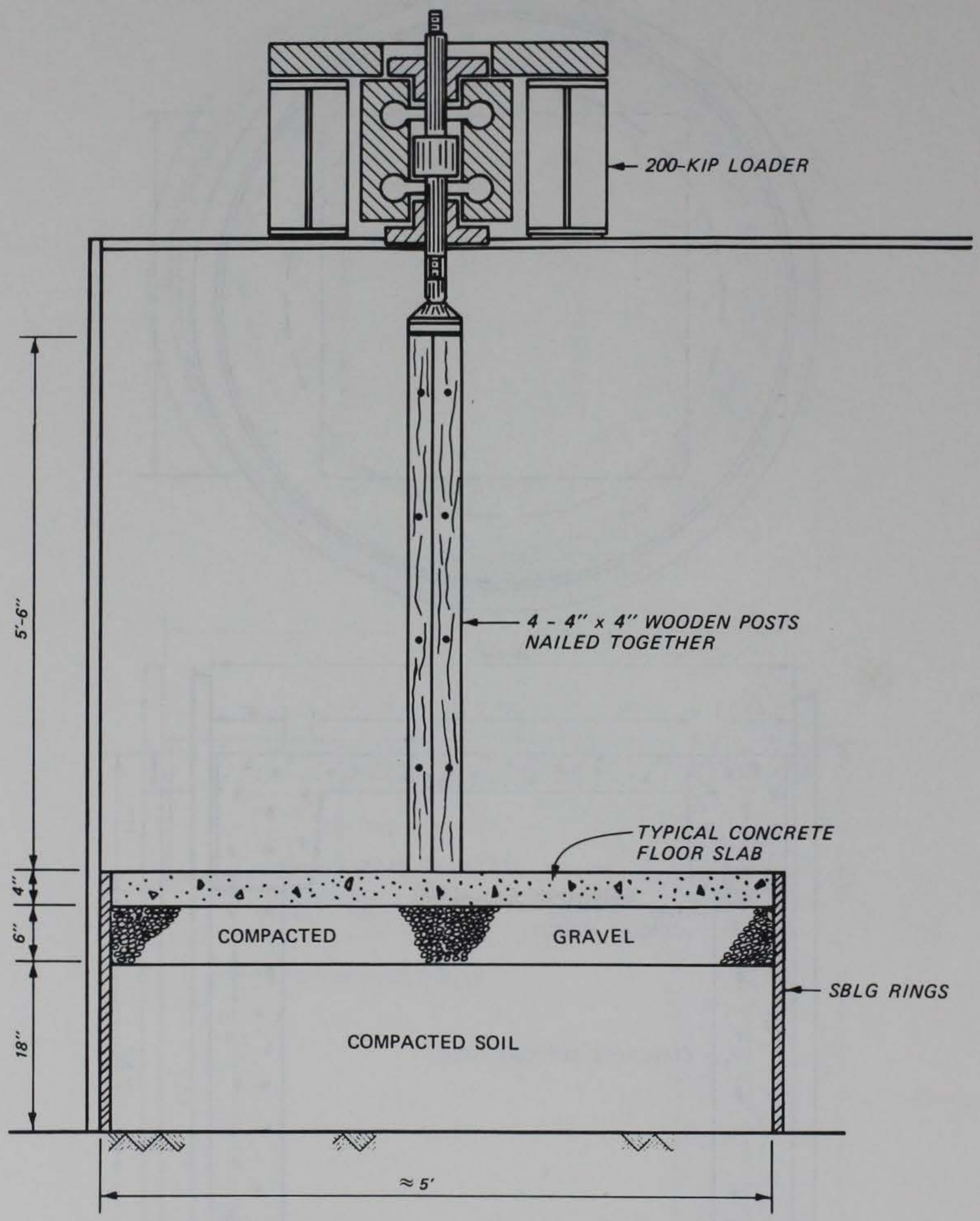

Figure 2.34 Test in the 200-kip loader of the punching strength of a typical 4-inch-thick slab on grade. 

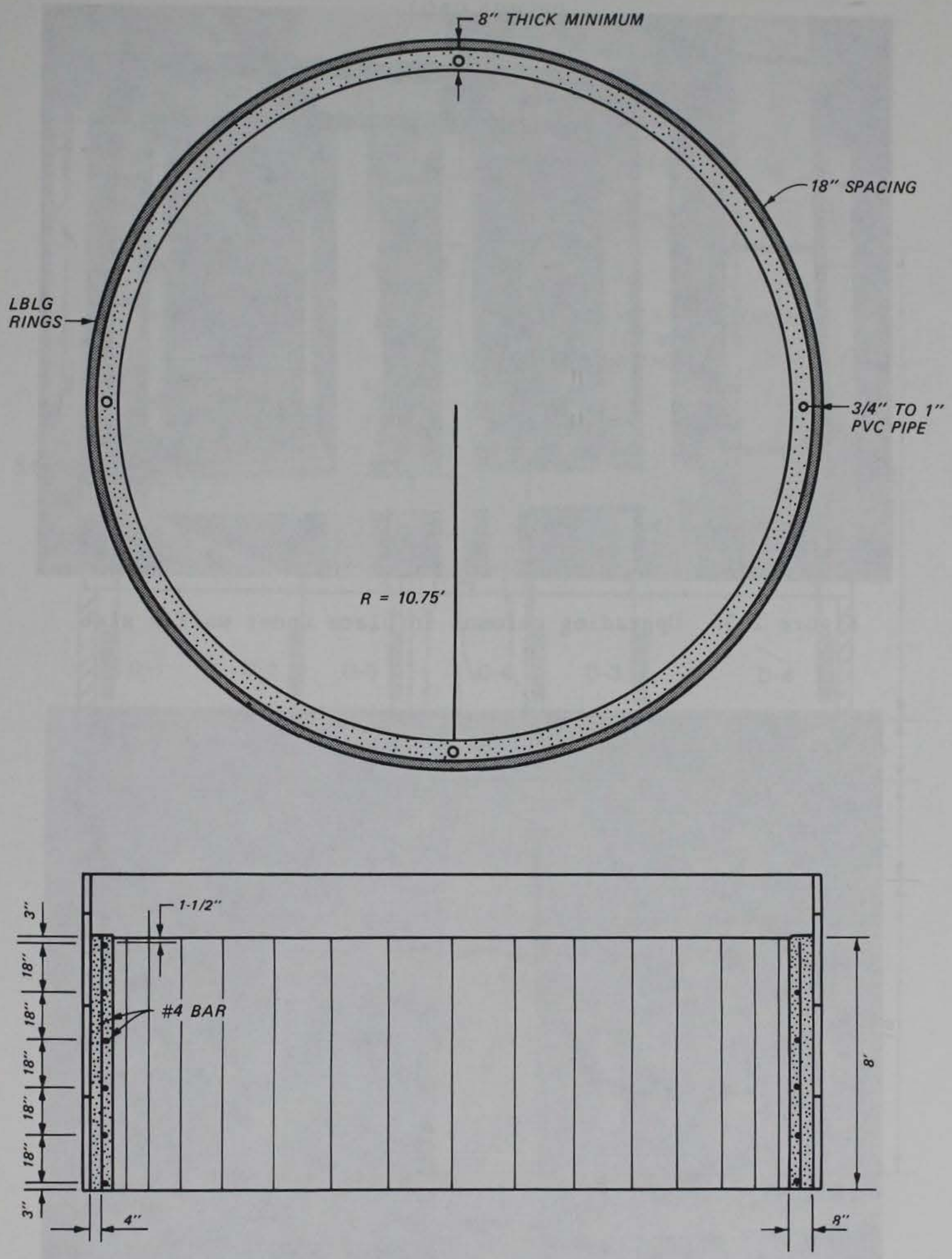

NOTE: 48-\# 4 BAR-94-1/2" LONG

Figure 2.35 Concrete support ring inside the LBLG. 


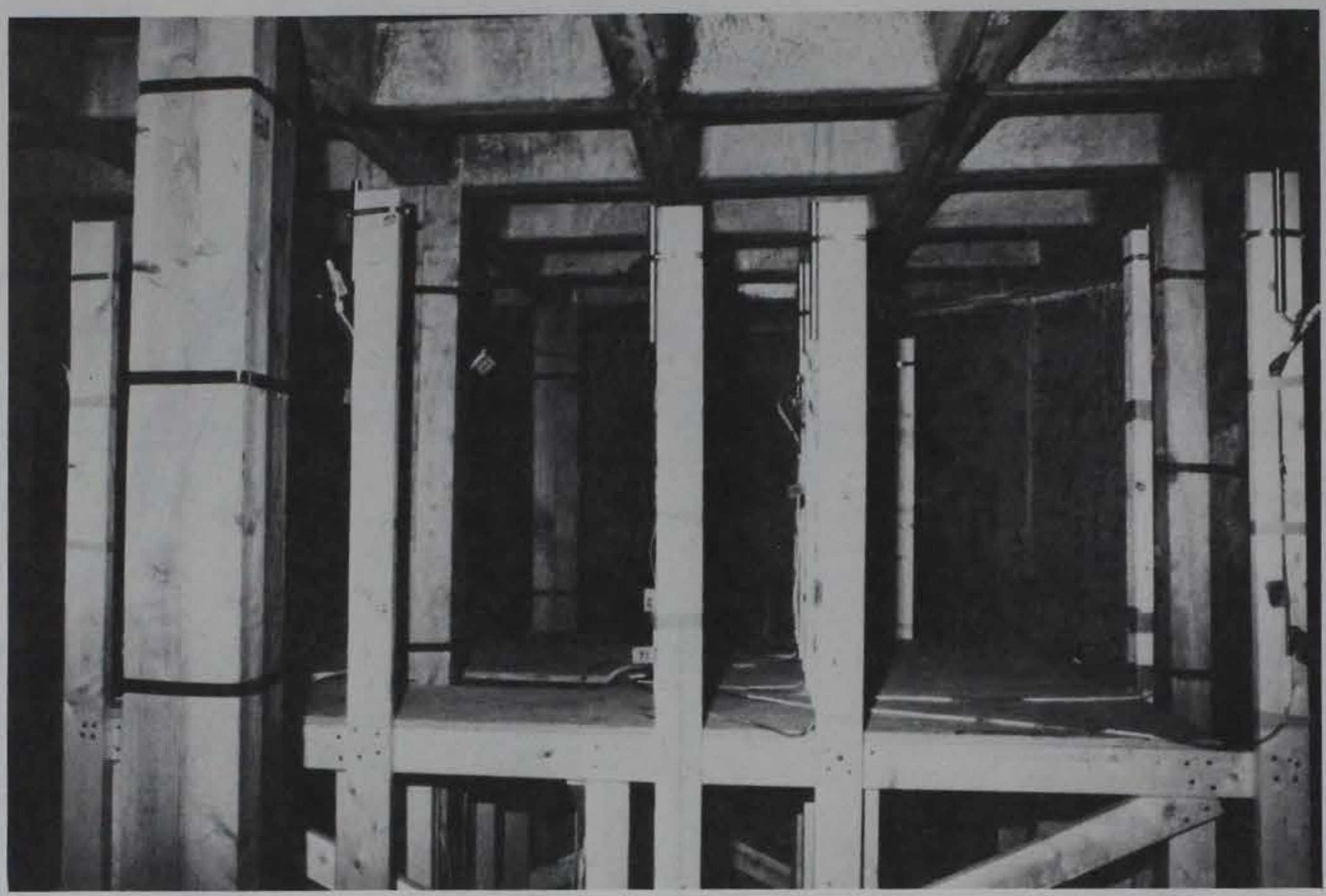

Figure 2.36 Upgrading columns in place under waffle slab.

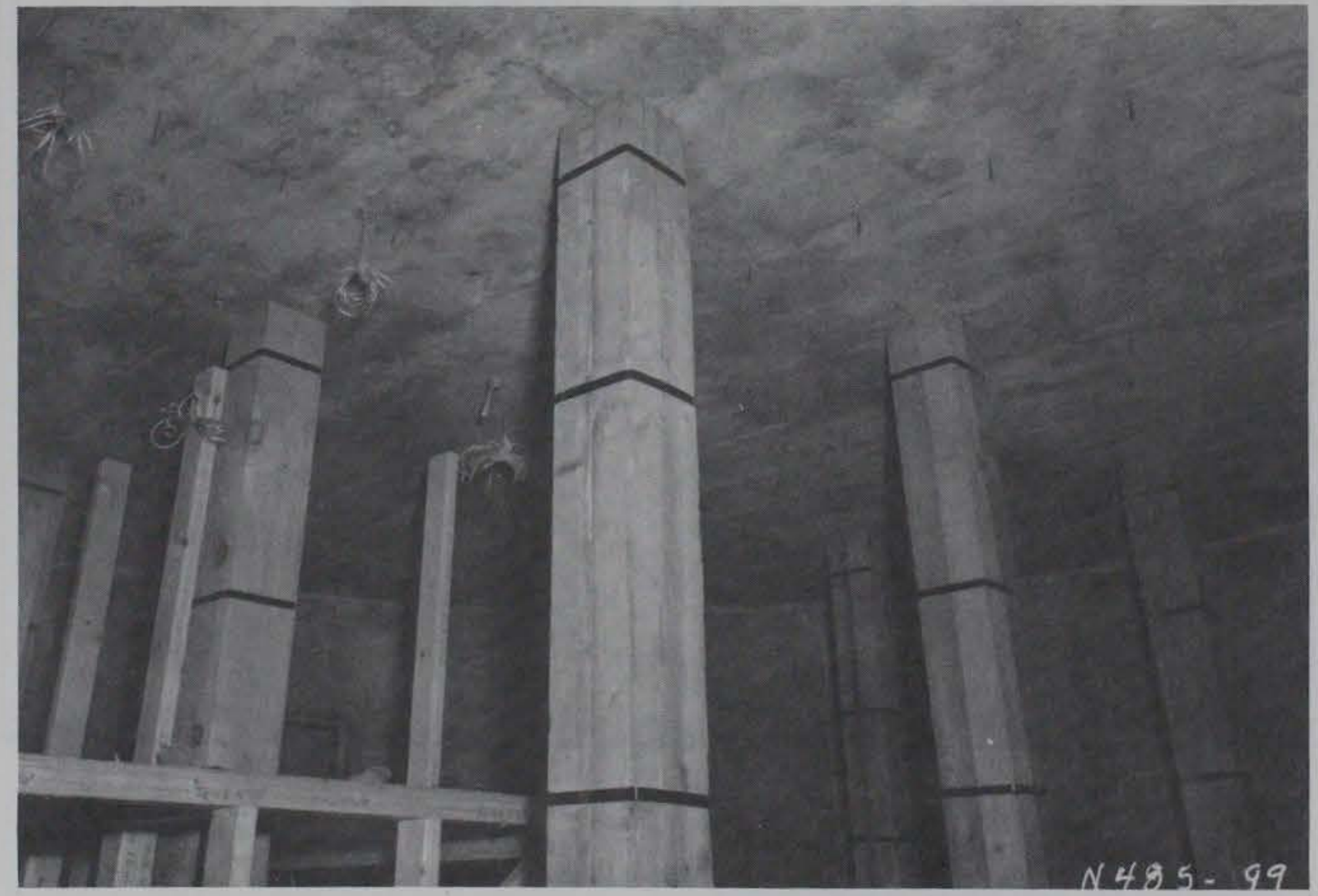

Figure 2.37 Upgrading columns in place under flat plate. 


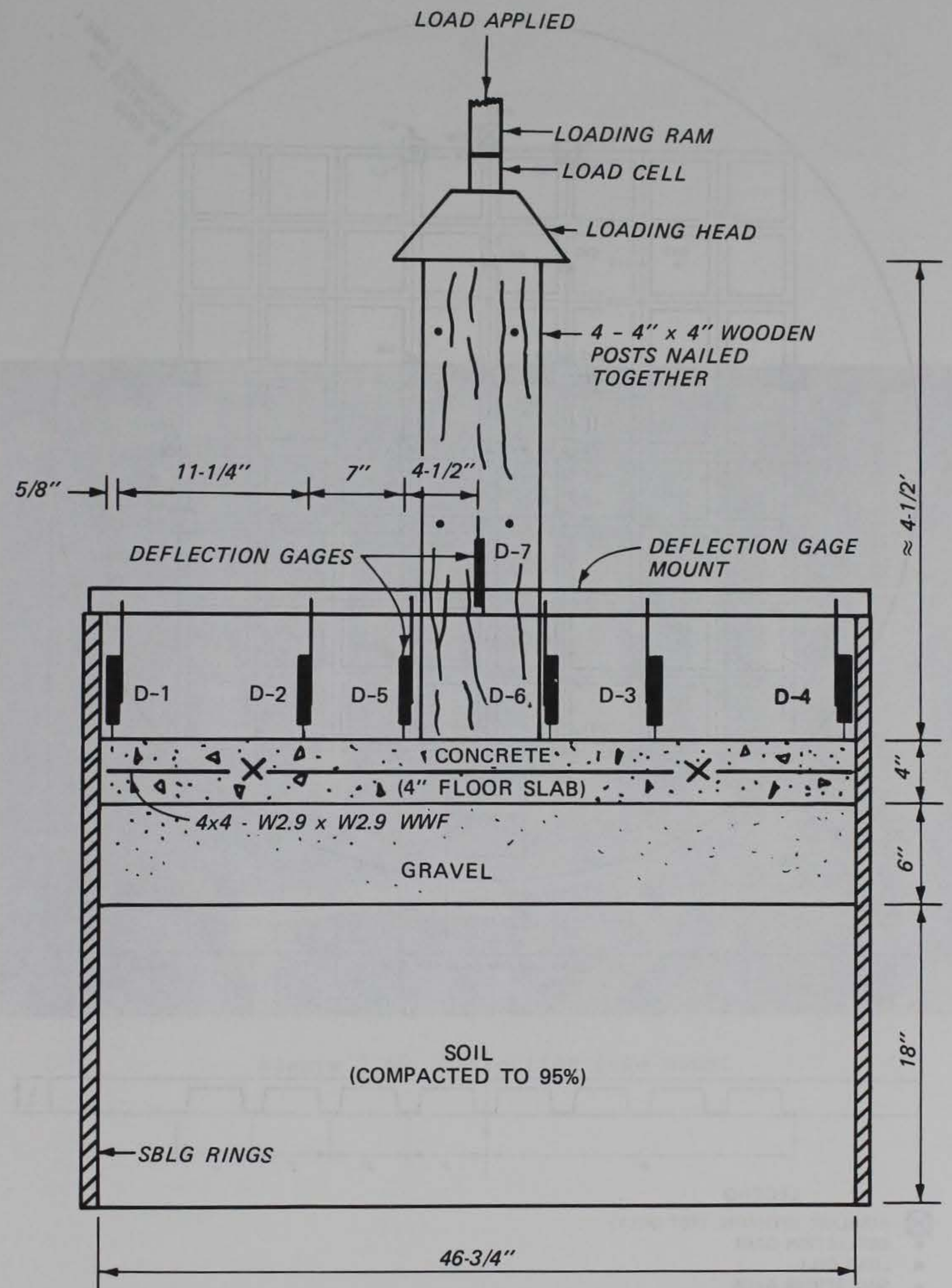

Figure 2.38 Instrumentation of slabs on grade. 

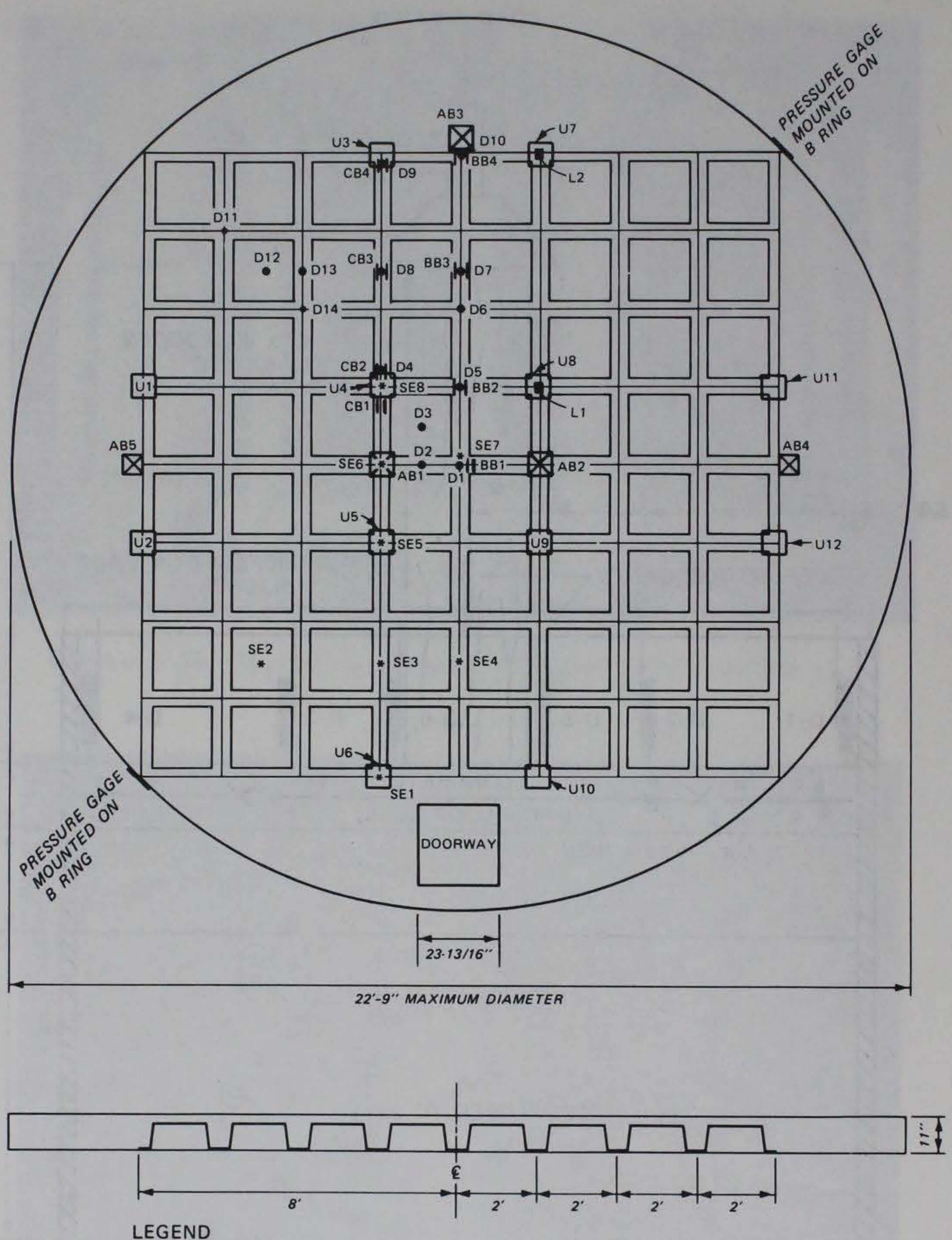

$\bigotimes$ AIRBLAST (DYNAMIC TEST ONLY)

DEFLECTION GAge

- LOAD CELl

* soil stress gage

II STRAIN GAGE PAIR

$\square$ UPGRADING POST

Figure 2.39 Instrumentation of center portion of a waffle slab. 


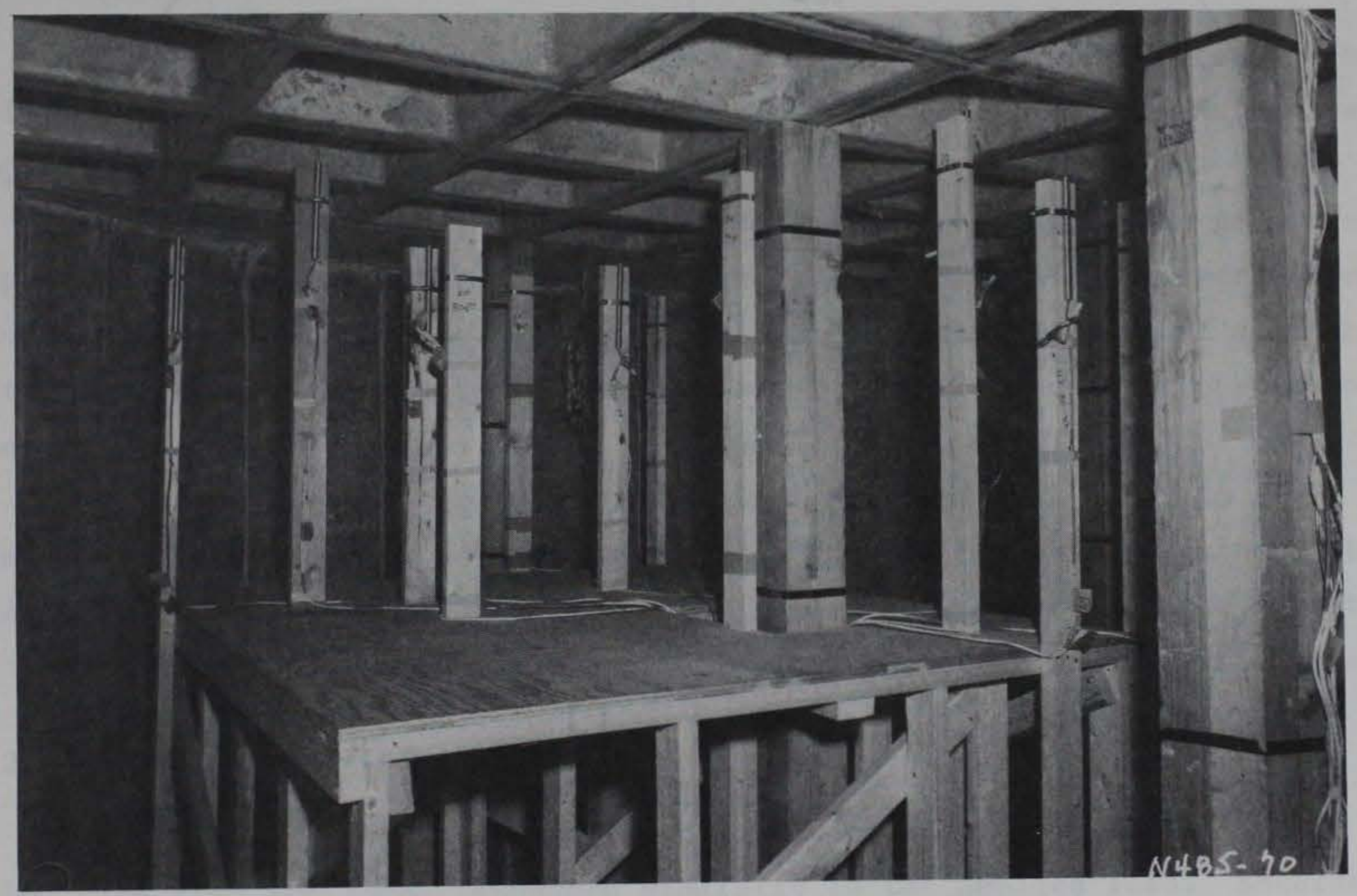

Figure 2.40 Deflection gage mount. 


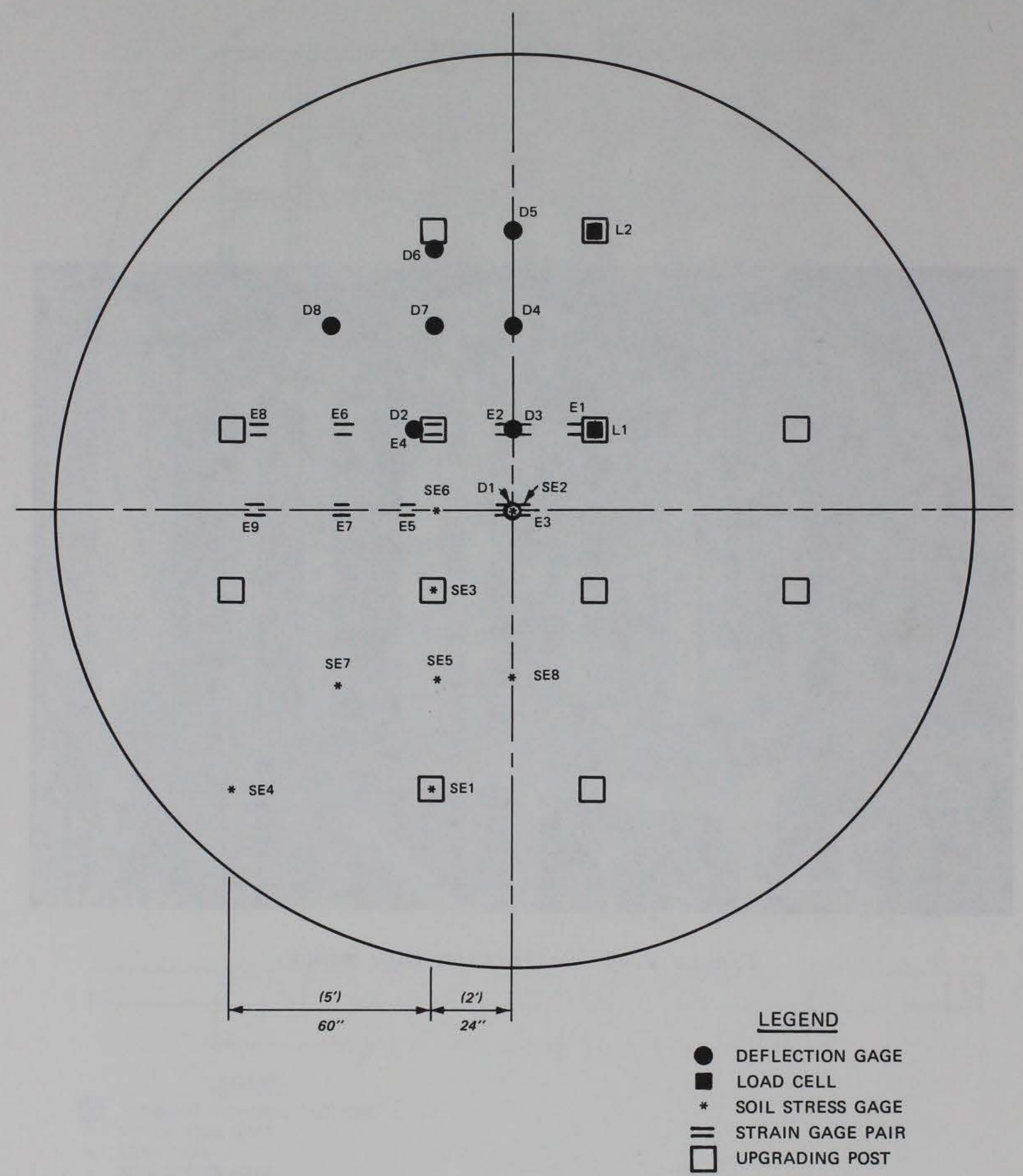

Figure 2.41 Instrumentation of center portion of a flat plate. 


\section{EXPERIMENTAL RESULTS}

The results of the experiments are presented in this chapter and in the appendices. A general description of the data produced and of the performance of each specimen and accompanying instrumentation is presented herein. Further discussion and analyses of the results are presented in Chapter 4 .

\subsection{9- BY 19- BY 3-INCH \\ WAFFLE-SLAB PANEL}

One 19 - by 19 - by 3 -inch waffle-slab panel was statically tested in the SBLG. Recorded data from the panel test are presented in Figures A.1-A.3 of Appendix A.

The pressure on the panel was continually increased until the pressure supported by the specimen reached approximately $970 \mathrm{psi}$. The pressure then suddenly decreased, and the test was terminated as the waffle panel and the water-sealing membrane ruptured allowing water to enter the lower portion of the test chamber.

A posttest view of the waffle-slab panel bottomside is shown in Figure 3.1. The panel sheared at an angle of approximately 45 degrees near the panel's perimeter forming a near-circular shaped rupture area with a diameter of approximately 15 inches, as shown in the posttest topside view in Figure 3.2.

\subsection{9- BY 19- BY 3-INCH ONE-WAY SLAB}

Five 19 - by 19 - by 3 -inch one-way slabs were statically tested in the SBLG. The five specimens responded similarly to the applied load. Recorded data from a typical slab test are presented in Figures A.4-A.6 of Appendix A.

The pressure on the specimen was continually increased until it reached an approximate value of $445 \mathrm{psi}$. The pressure suddenly decreased when a flexural three-hinged mechanism formed causing the slab to collapse and the watersealing membrane to rupture. Figure 3.3 is a posttest view of the one-way $\mathrm{slab}$.

\section{$3.330-$ BY $30-$ BY 3-INCH \\ WAFFLE-SLAB PANEL}

Two $30-$ by $30-$ inch waffle-slab panels were statically tested in the SBLG. 
Figures A.7-A.9 in Appendix A present data typical of the tests.

The applied pressure supported by the specimen was continually increased until it approached an approximate value of $347 \mathrm{psi}$. A sudden decrease in the applied pressure then occurred. Figure 3.4 is a posttest view of the panel showing the ruptured area with initiation of a 45-degree shear plane angle along the panel's inside perimeter.

\subsection{PUNCHING STRENGTH OF A 4-INCH- THICK SLAB ON GRADE}

One specimen was tested statically, and one was tested dynamically.

\subsubsection{Static Test}

Recorded data from the static test are presented in Figures B.1-B.8 in Appendix B. The load forcing the composite wooden column against the slab was continually increased until it reached a value of 79.4 kips. The magnitude of the load then suddenly decreased, indicating that the column had punched into the slab as shown in Figure 3.5 .

\subsubsection{Dynamic Test}

Recorded data from the dynamic test are presented in Figures B.9-B.14 in Appendix B. The peak dynamic load of 135 kips transferred to the slab by the composite wooden post was reached in a period of $200 \mathrm{msec}$. Figures 3.6 and 3.7, respectively, show the posttest topside and bottomside views of the slab.

\subsection{CENTER PORTION OF A 24-FOOT- SQUARE WAFFLE-SLAB FLOOR}

One waffle-slab specimen was tested statically and one was tested dynamically in the LBLG. The dynamically tested slab was dynamically loaded twice before structural collapse occurred. The two dynamic loadings are referred to as the "First Dynamic Test" and the "Second Dynamic Test."

\subsubsection{Static Test}

Recorded data from the static test are presented in Figures C.1-C.37 in Appendix C. The static pressure applied to the specimen was continually increased until it reached an approximate value of $44.0 \mathrm{psi}$. Large deflections of the slab, resulting in a sudden decrease in pressure as the water-sealing 
membrane ruptured, caused termination of the test.

The slab model as it appeared after removal of the sealing membrane and sand cover is shown in Figure 3.8. The shearing of the slab along the waffled boundary was responsible for most of the model slab's displacement as shown in Figure 3.9. The sheared slab did not collapse to the test chamber's floor due to the immediate relief from loading pressure when the sealing membrane ruptured. Therefore, the model slab remained supported only by reinforcement steel along the waffle boundary as shown in Figure 3.10. Figure 3.11 shows the model's buckled composite wooden upgrading posts on the test chamber's floor, unable to help support the posttest slab.

Apparent flexural deflection and flexural cracks of the waffle slab are visible in Figure 3.12 .

\subsubsection{First Dynamic Test}

Recorded data from the first dynamic test are presented in Figures C.38C.84 in Appendix C. A peak dynamic pressure loading of approximately 34.0 psi was applied to the waffle slab.

The dynamic loading produced minor structural damage to the upgraded $\mathrm{slab}$ system. Upgrading post U9 fell to the floor of the test chamber (refer to Figure 2.39). The applied load caused the upgrading post to compress the wooden wedges beneath the post, resulting in the loss of surface contact between the upgrading post and the waffle slab. Upgrading post U5 experienced some surface contact loss with the waffle slab, resulting in a tilt of the post before contact was regained. Figure 3.13 shows upgrading post U9 on the test chamber's floor with post U5 in the background.

Noticeable hairline cracks in the slab were located in one region of the specimen. The cracks formed along one row of the waffle-slab's panels during the test as shown in Figure 3.14. The waffle-slab edge parallel to the row of cracked panels, as shown in Figure 3.14, is located next to the specimen's entryway hatch. In reference to Figure 2.37, the waffle-slab's southwest corner panel also experienced cracking as shown in Figure 3.15. The described cracks were darkened with a black marker to make them more visible in their respective photographs.

\subsubsection{Second Dynamic Test}

Recorded data from the second dynamic test are presented in 
Figures C.85-C.131 in Appendix C. A peak dynamic pressure loading of approximately $61.1 \mathrm{psi}$ was applied to the slab system.

Extensive structural damage occurred to the upgraded waffle-slab system. Figure 3.16 is a posttest view of the test chamber with collapsed specimen after removal of the water sealing membrane. Figure 3.17 allows a more visible view of the specimen's debris after removal of most of the sand cover.

The waffle slab sheared along its perimeter at an approximate angle of 45 degrees as shown in the slab corner view in Figure 3.18. Some of the wooden upgrading columns located along the slab's waffle perimeter remained in position after the test, although spalling occurred on surrounding concrete.

\subsection{CENTER PORTION OF A 22-FOOT- SQUARE FLAT PLATE}

The center portion of the 22-foot-square upgraded flat plate was statically tested in the LBLG. Recorded data from the static test are presented in Figures D.1-D.37 in Appendix D. The static pressure applied to the specimen was continually increased until it reached an approximate value of $38.0 \mathrm{psi}$. Collapse of the wooden columns allowed the slab to deflect 3.0 inches. Figure 3.19 shows the topside of the damaged flat plate. Some of the collapsed upgrading columns are shown on the test chamber floor in Figure 3.20 .

Numerous cracks, ranging in size from hairline cracks to highly visible cracks, developed on the bottomside of the specimen as it deflected. Figure 3.21 shows the bottomside cracks of the tested flat plate suspended from a crane. 


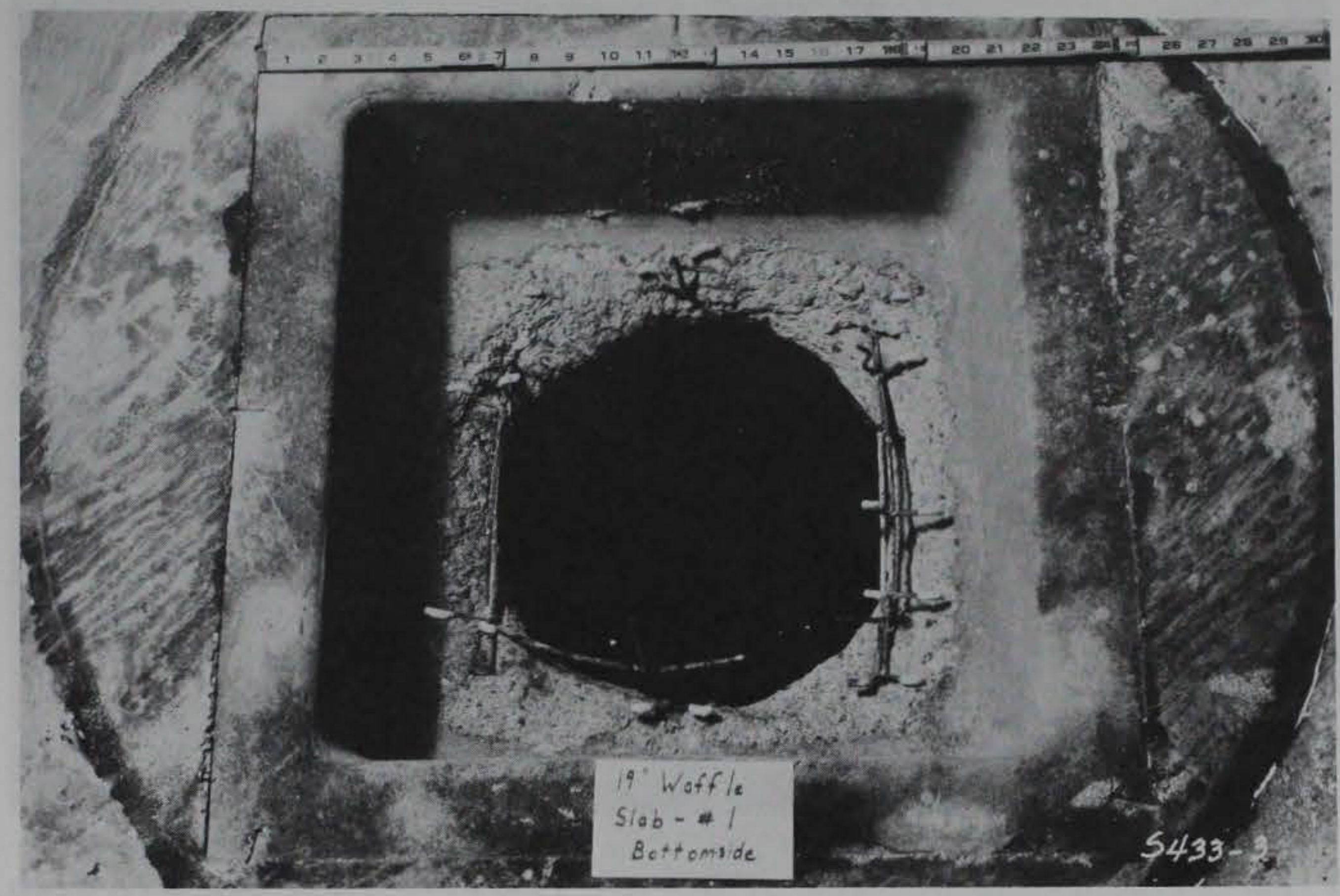

Figure 3.1 Posttest bottomside view of 19 - by 19 - by 3 -inch waffle-slab panel.

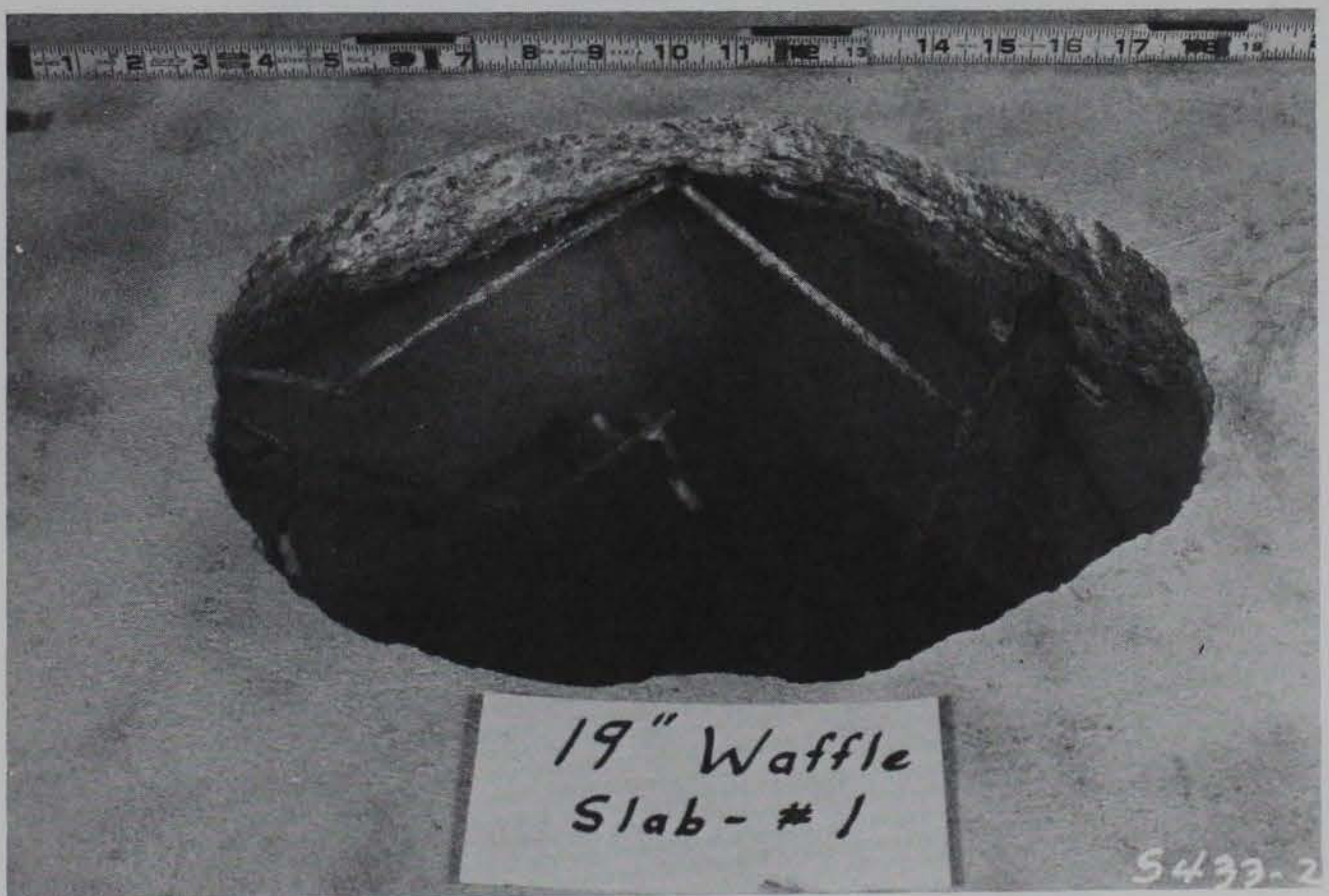

Figure 3.2 Posttest topside view of 19 - by 19 - by 3 -inch waffle-slab panel. 


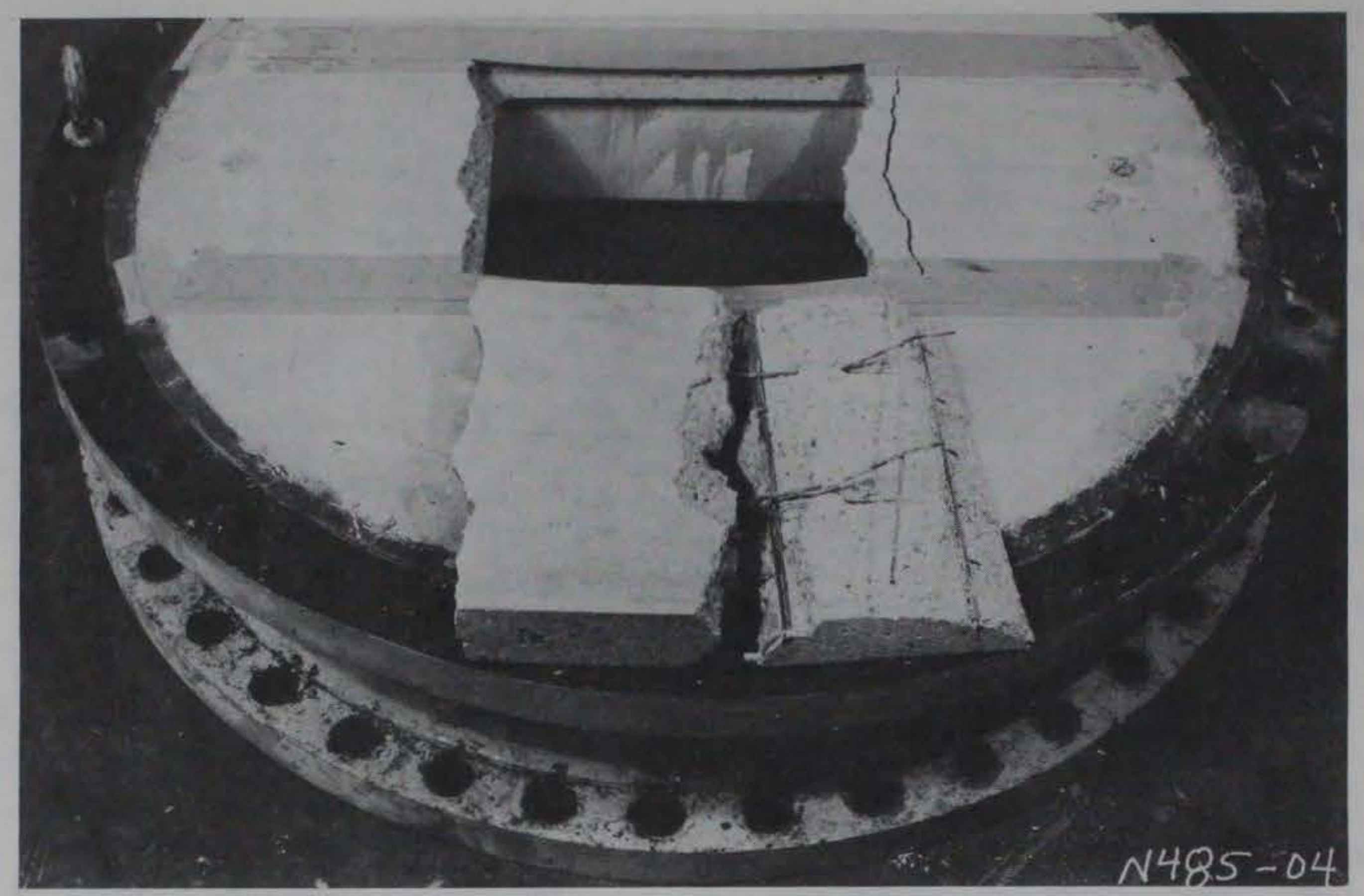

Figure 3.3 Posttest view of 19 - by 19 - by 3 -inch one-way slab.

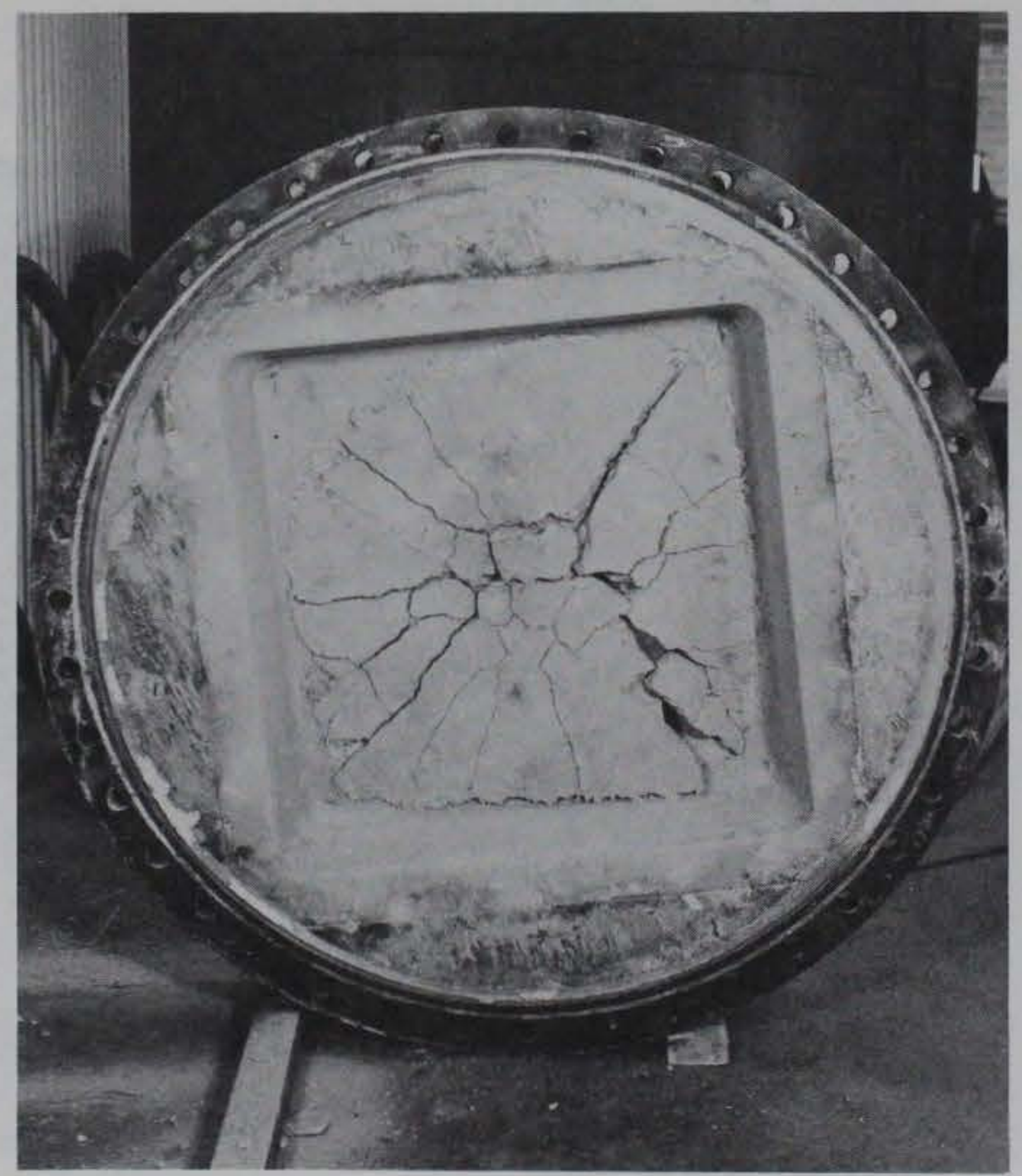

Figure 3.4 Posttest bottomside view of 30 - by 30 - by 3 -inch waffleslab panel. 


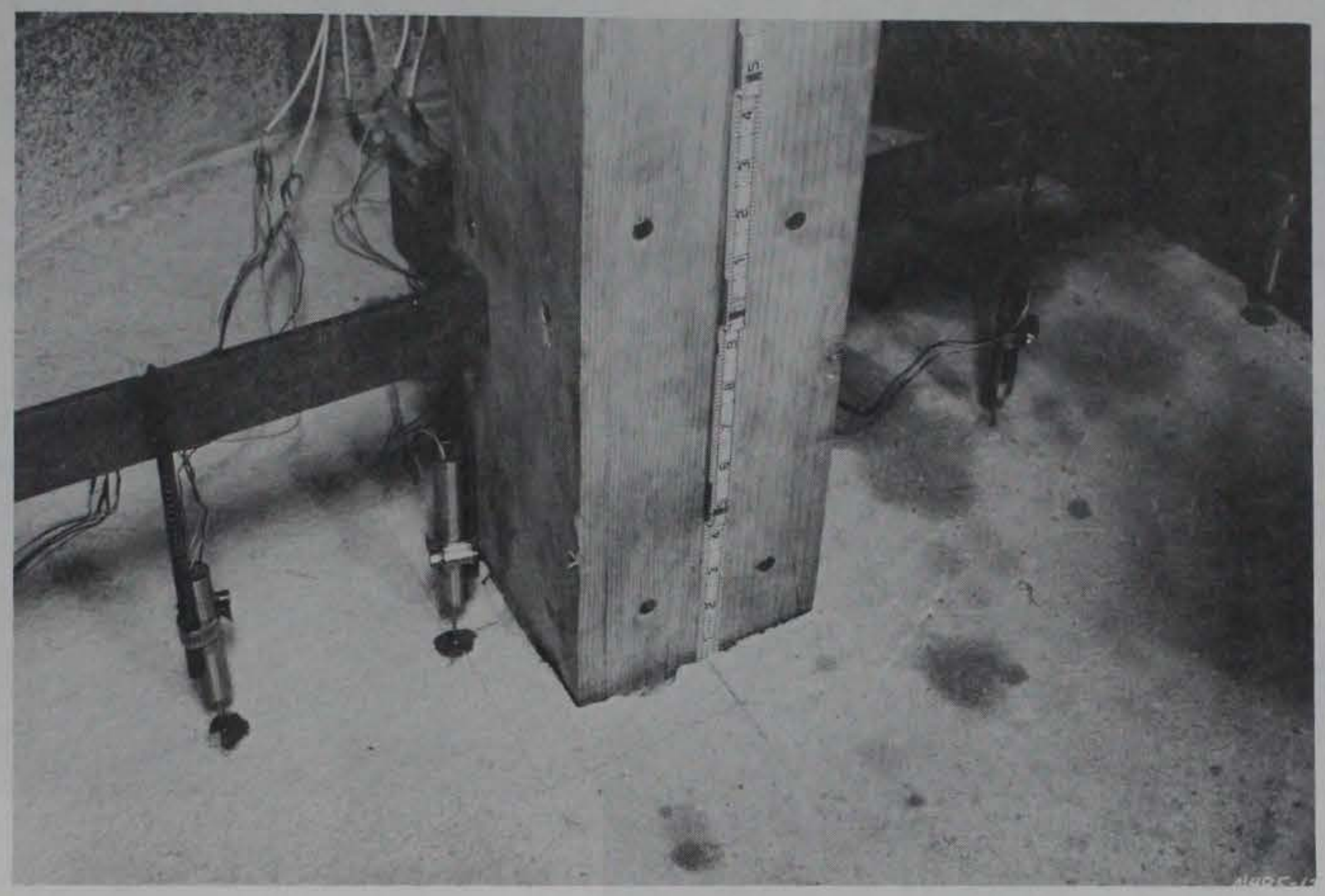

Figure 3.5 Wooden column punched into 4-inch-thick slab on grade due to static loading.

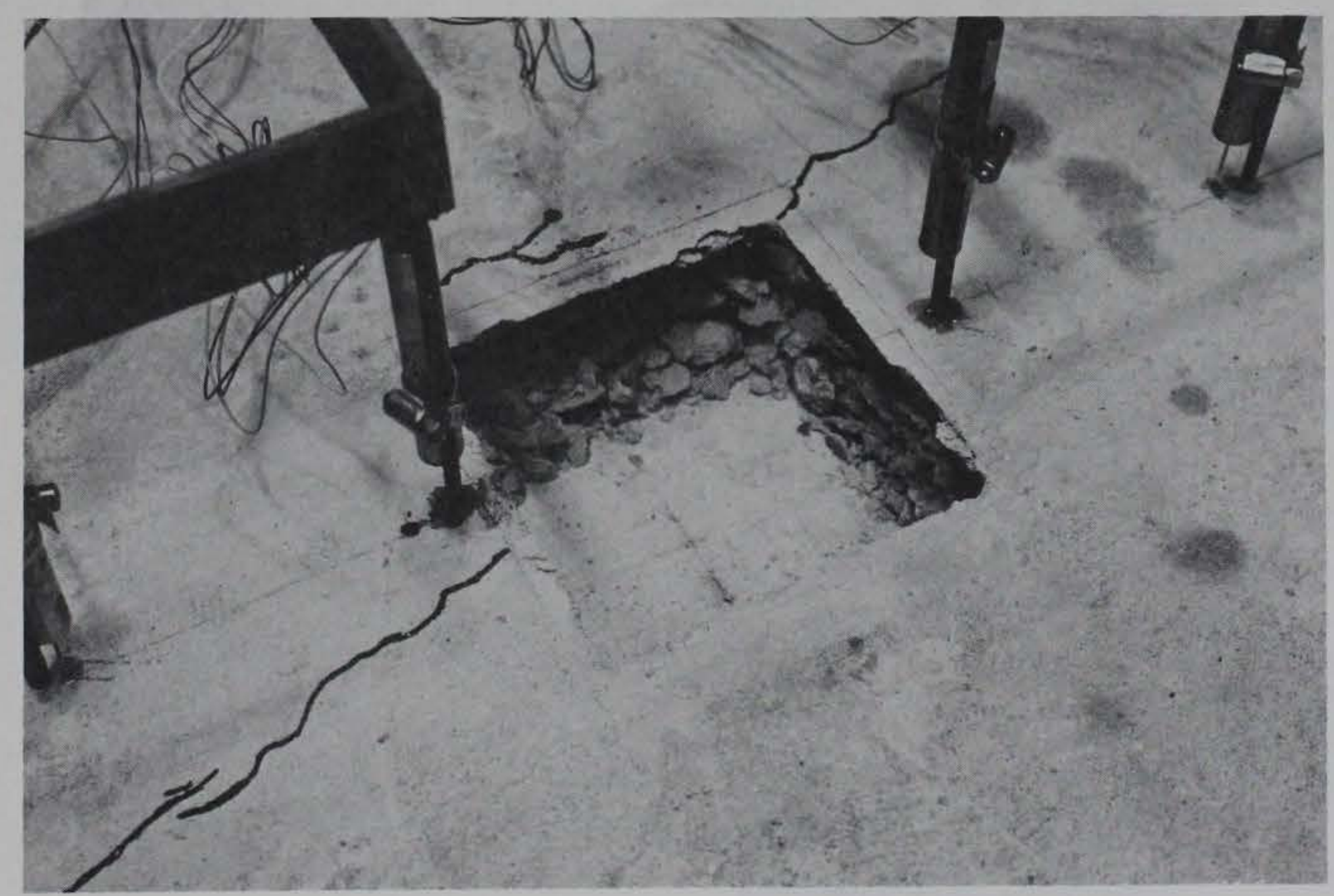

Figure 3.6 Posttest topside view of dynamically punched 4-inch-thick slab on grade. 


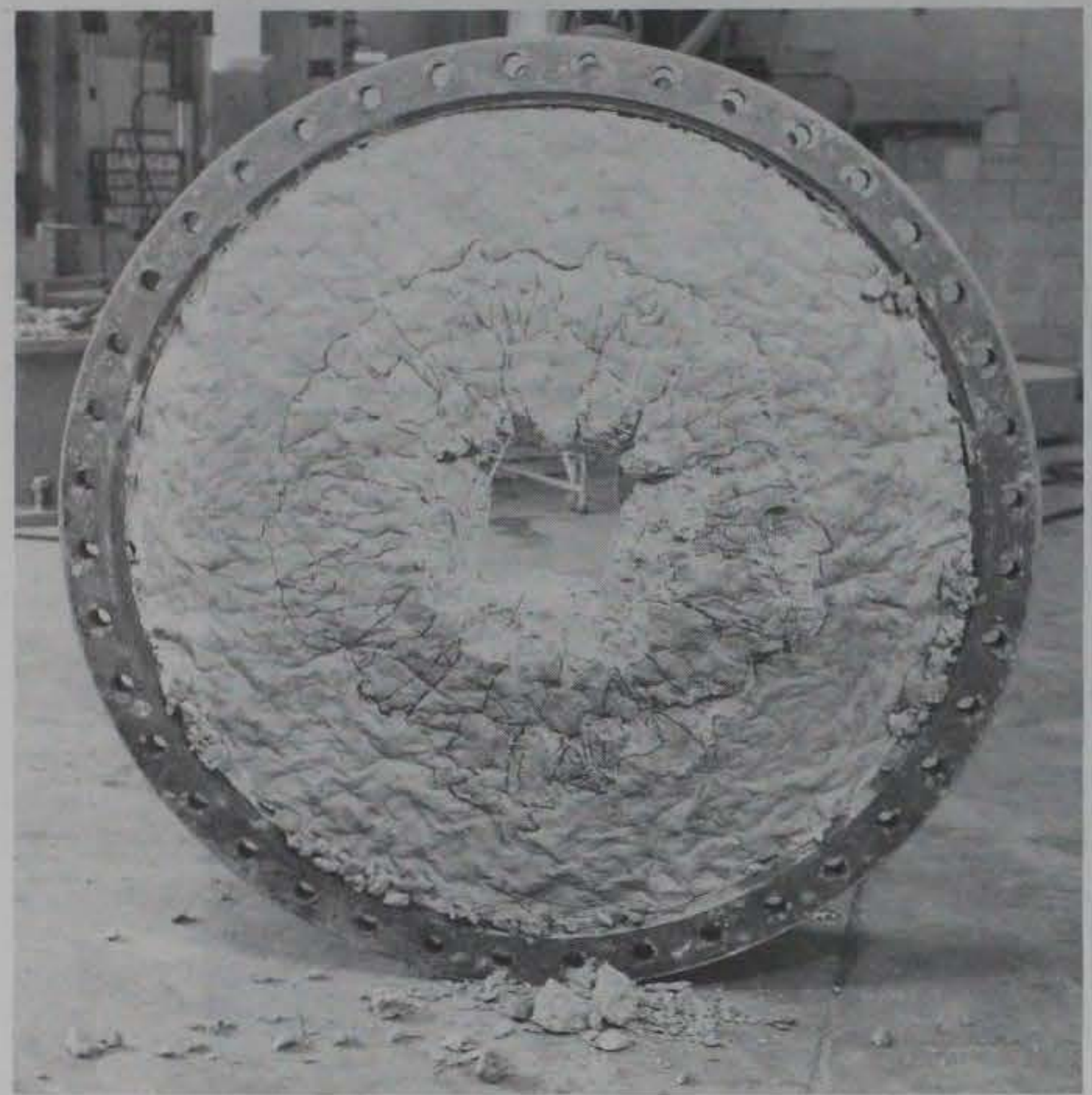

Figure 3.7 Posttest bottomside view of dynamically punched 4-inch-thick slab on grade.

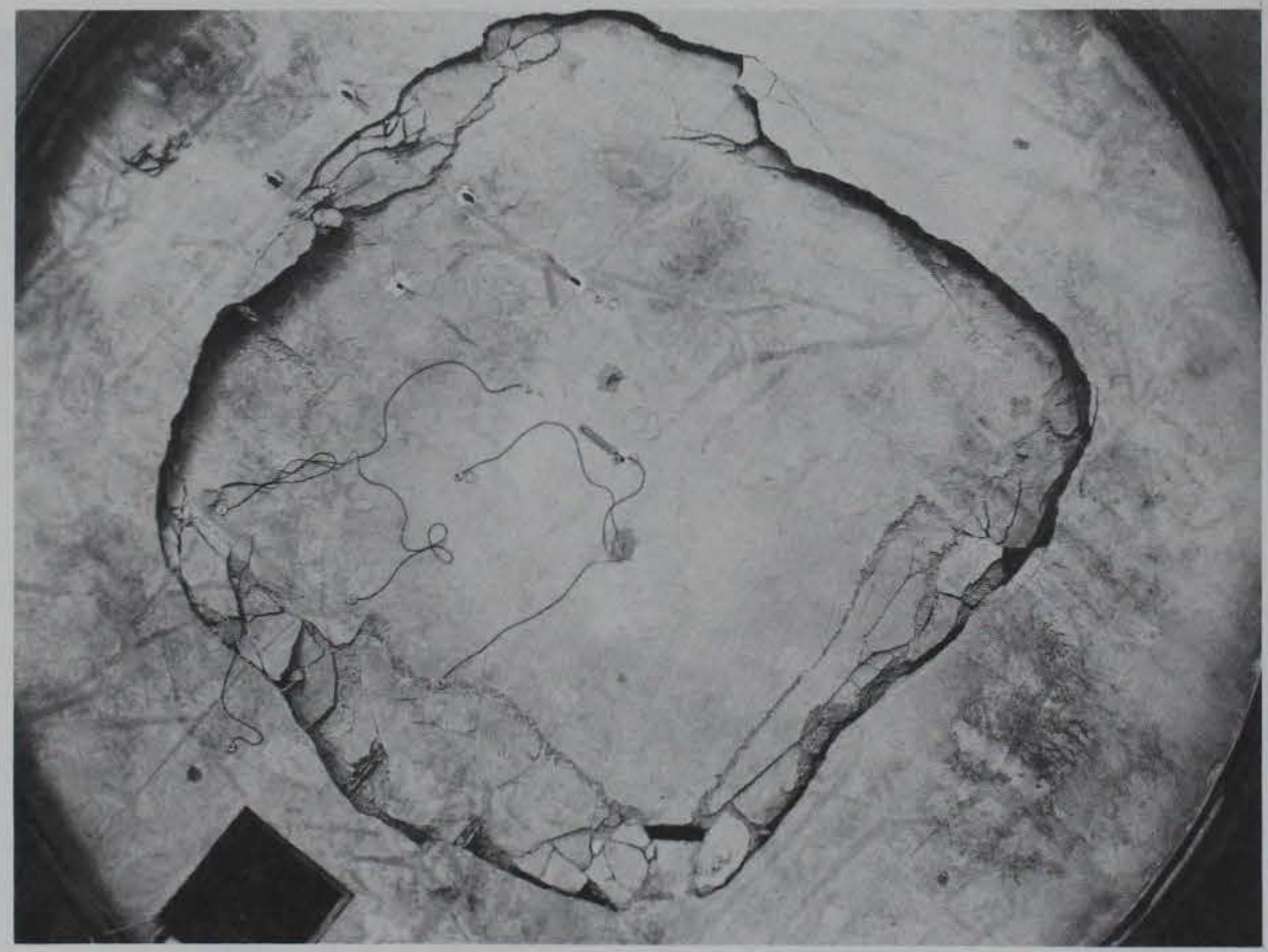

Figure 3.8 Statically tested waffle slab in test chamber. 


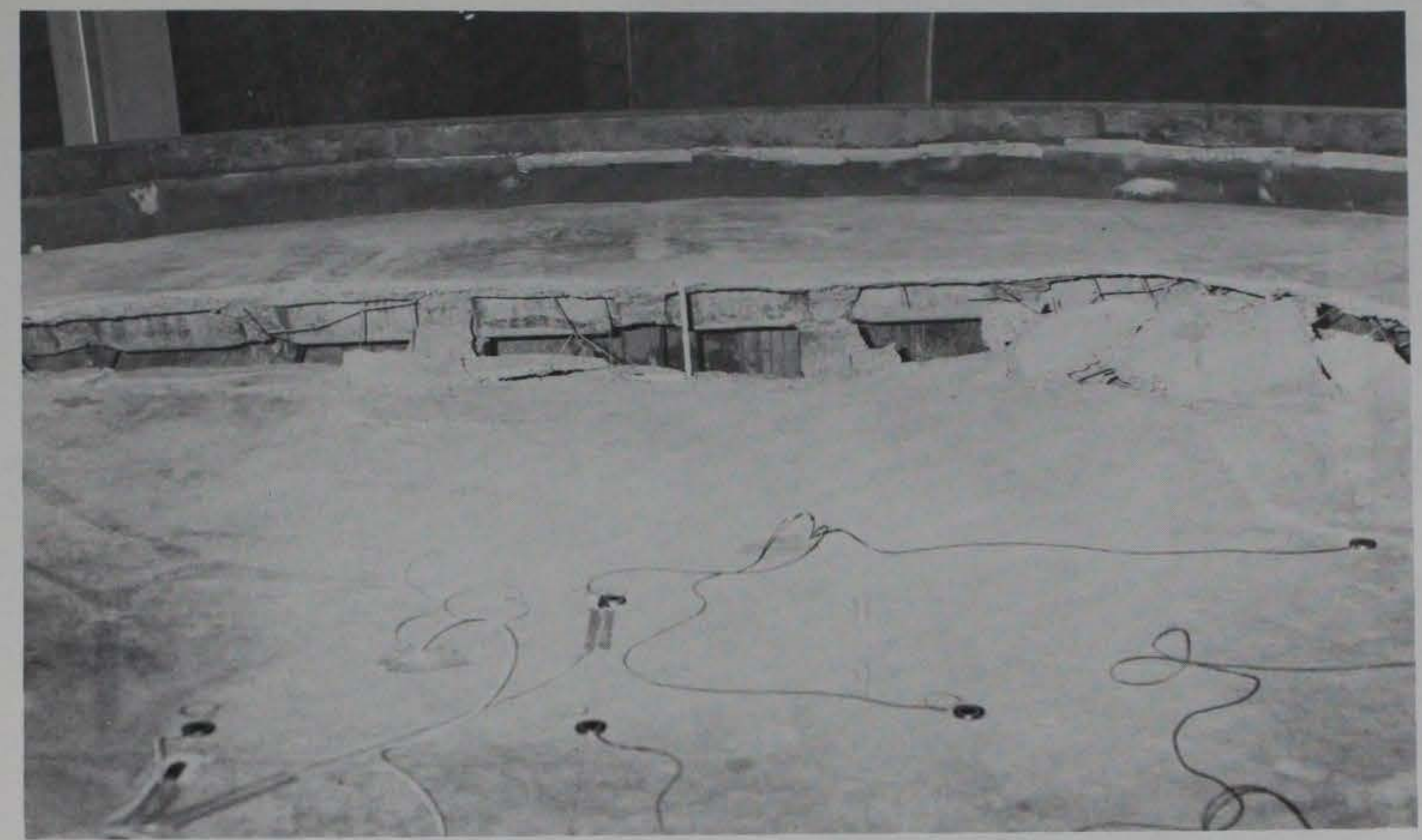

Figure 3.9 Sheared waffle boundary of statically tested waffle-slab center portion.

Figure 3.10 Sheared slab supported by steel reinforcement.

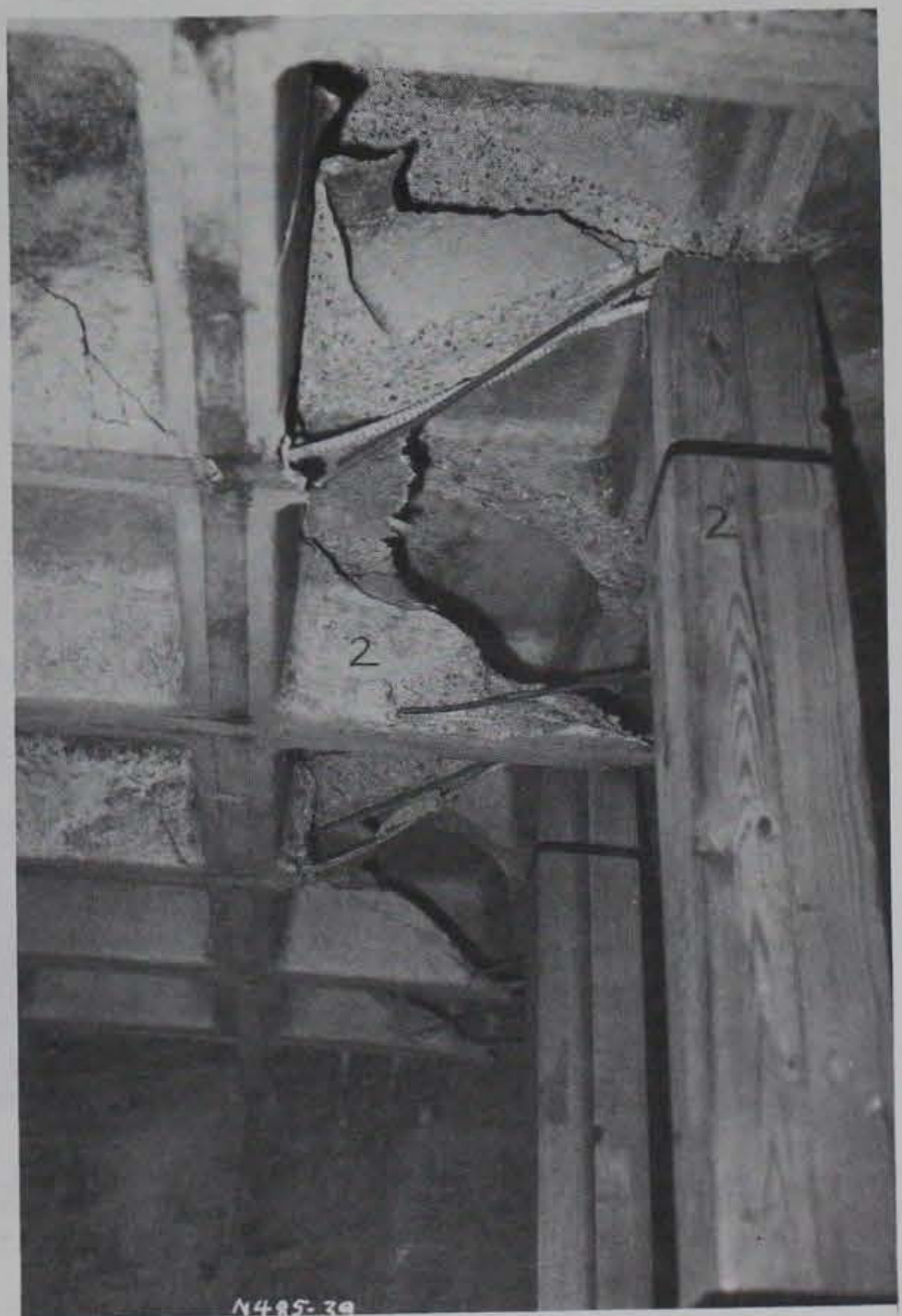




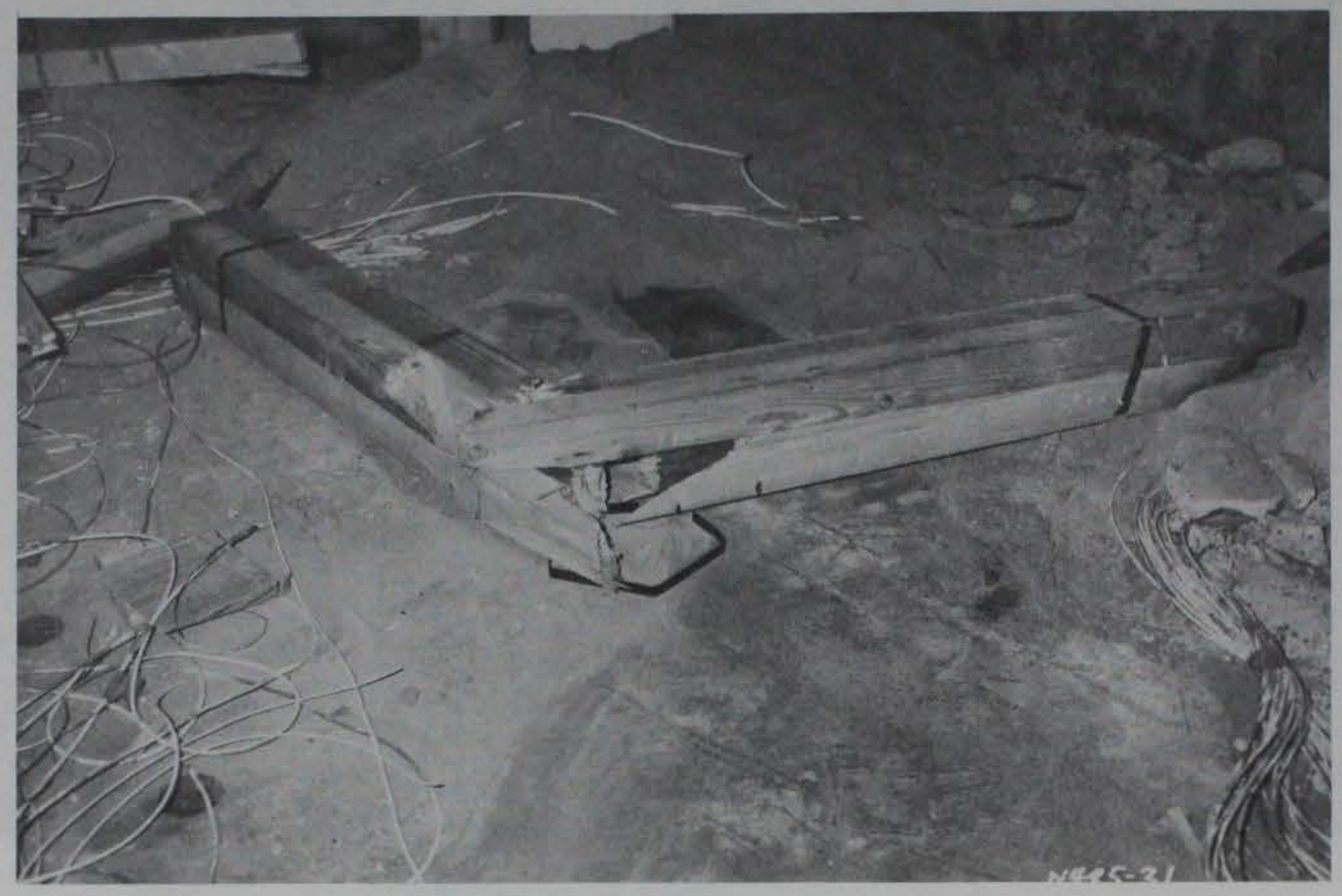

Figure 3.11 Buckled upgrading column from static waffle-slab test.

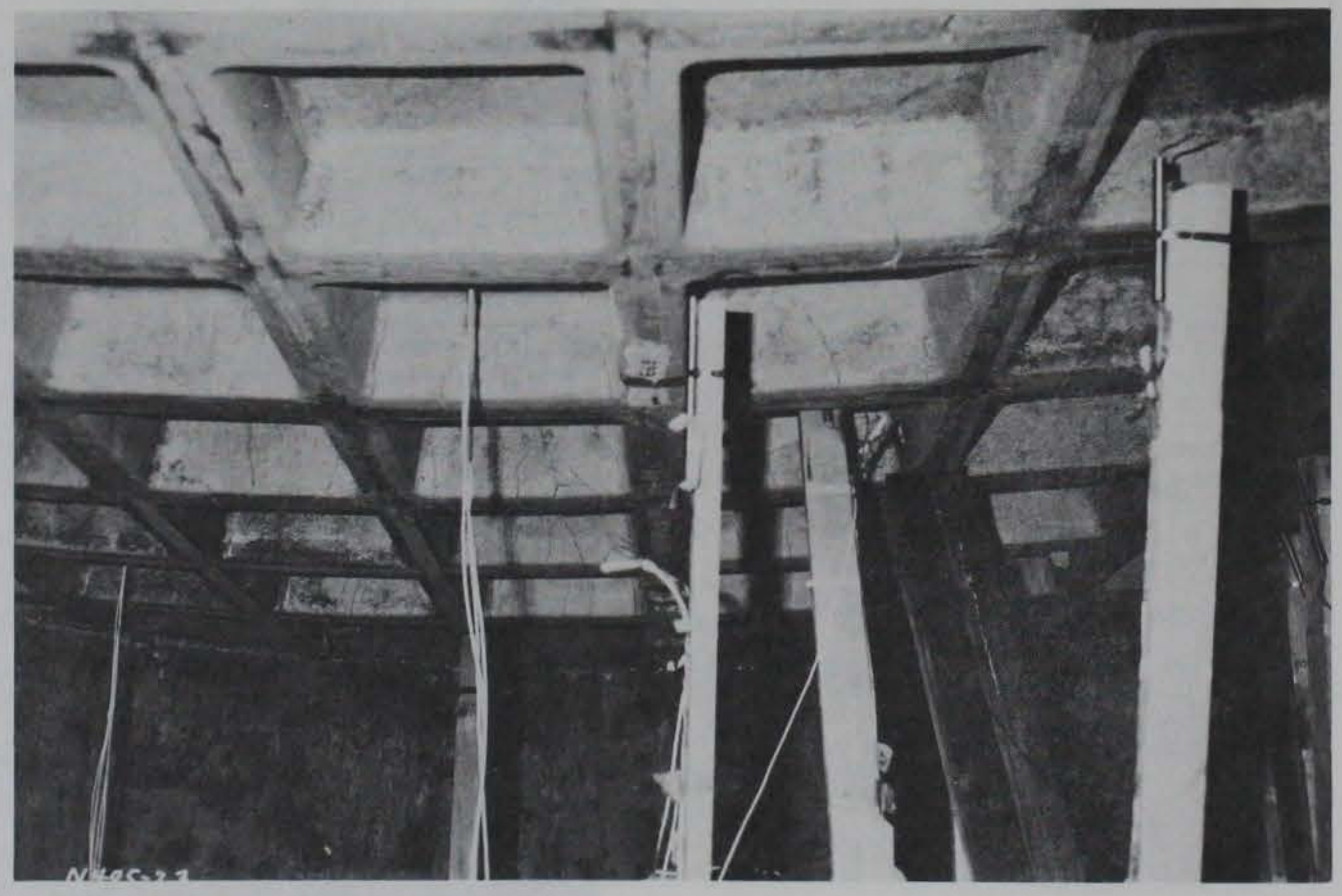

Figure 3.12 Posttest bottomside view of statically tested waffle slab. 
Figure 3.13 Displaced upgrading columns in first dynamic waffle-slab test.
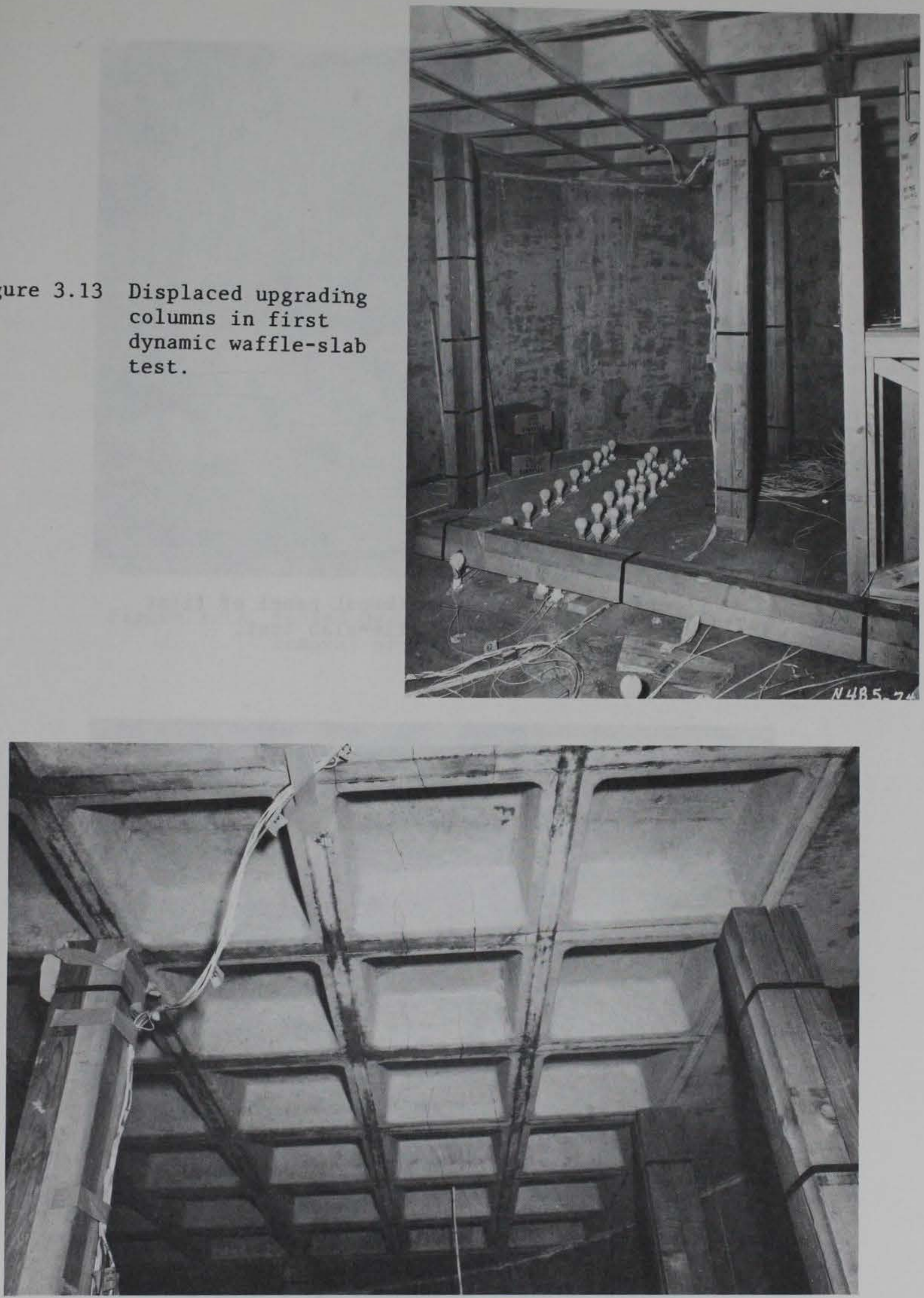

Figure 3.14 Hairline cracks of first dynamic waffle-slab test. 


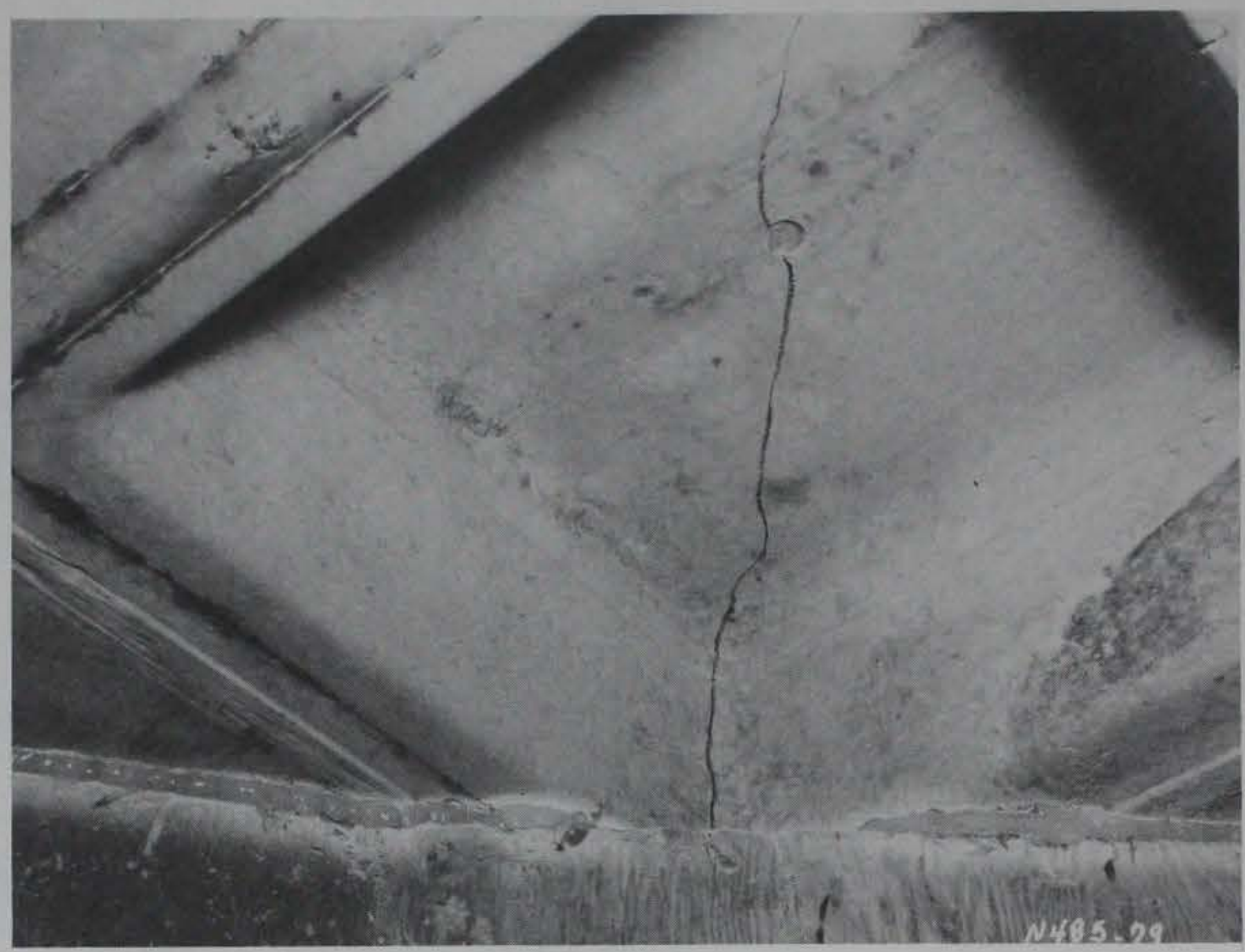

Figure 3.15 Cracked southwest panel of first dynamic waffle-slab test.

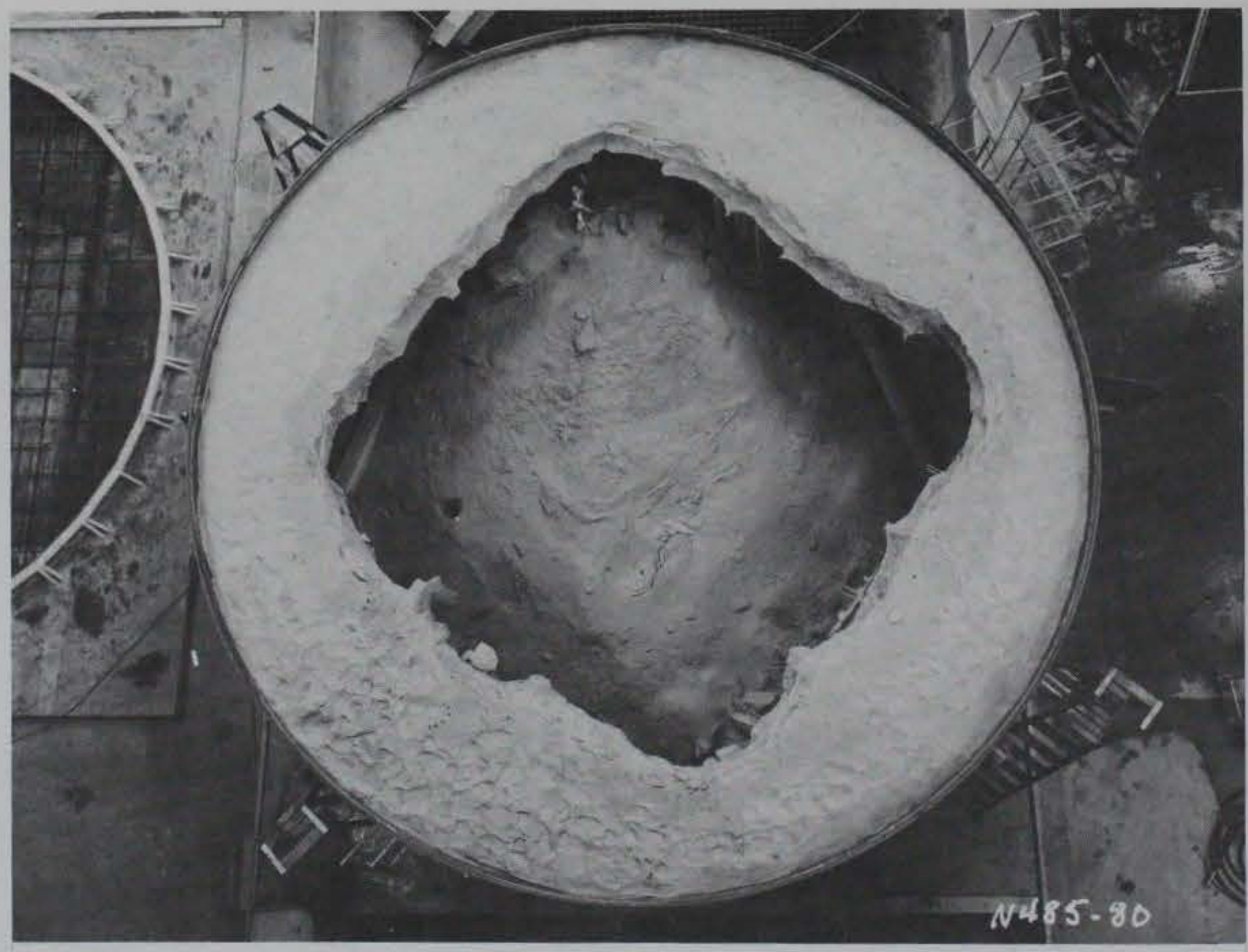

Figure 3.16 Second dynamic test on waffle slab after removal of water sealing membrane. 


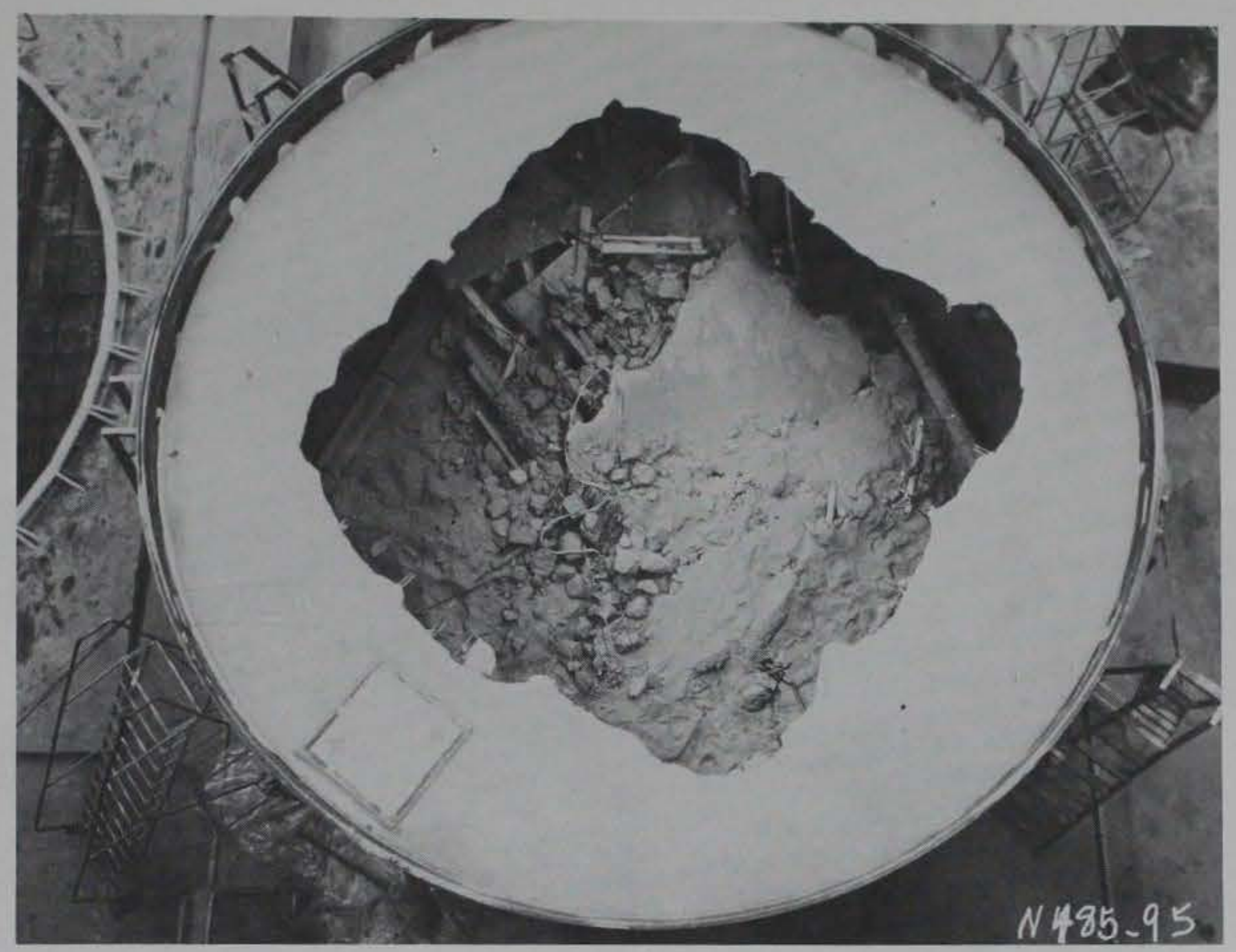

Figure 3.17 Second dynamic test on waffle slab after removal of slab sand overburden.

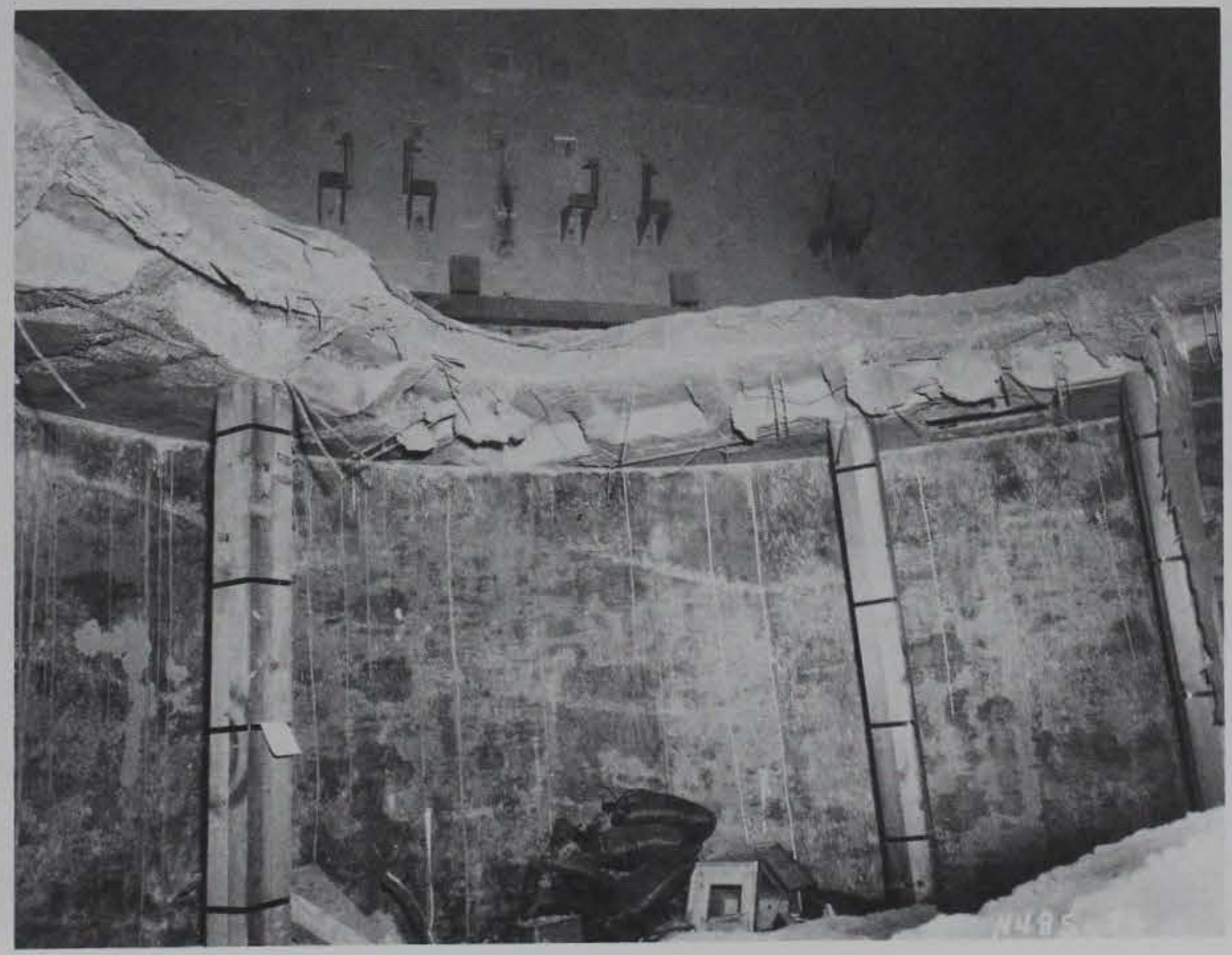

Figure 3.18 Sheared waffle slab after second dynamic test. 


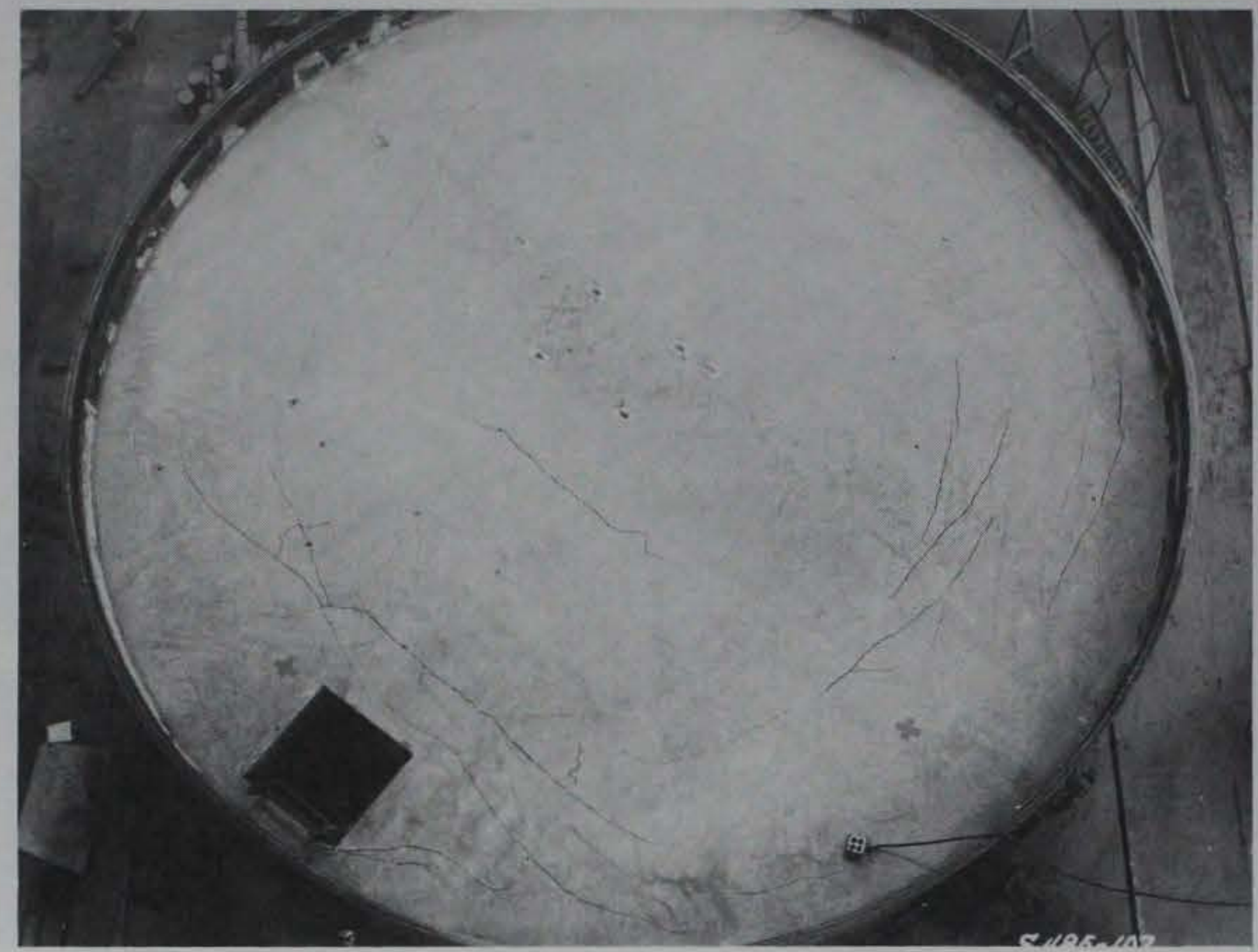

Figure 3.19 Topside posttest view of statically tested upgraded flat plate.

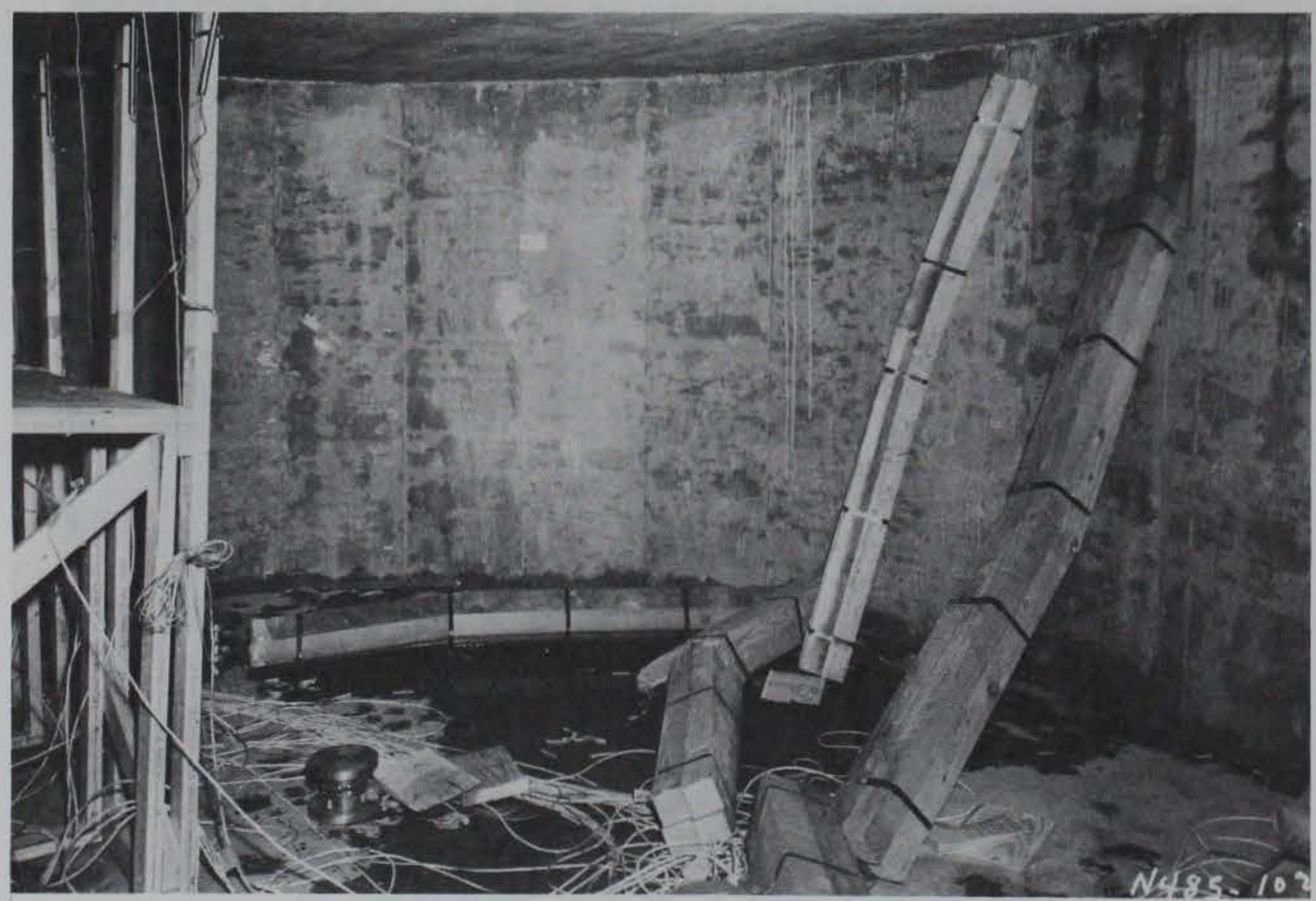

Figure 3.20 Collapsed upgrading columns beneath flat plate specimen. 


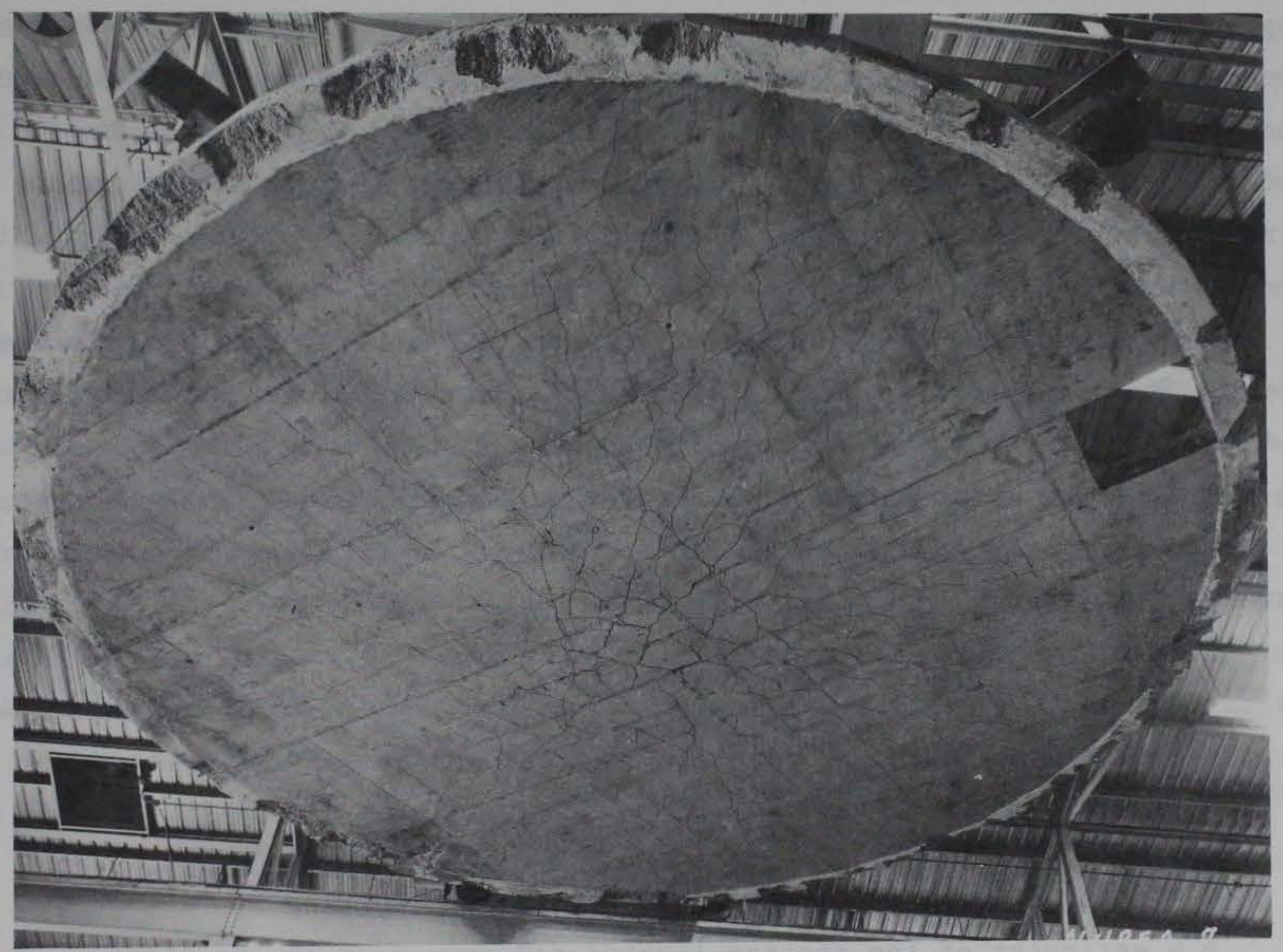

Figure 3.21 Bottomside posttest view of statically tested flat-plate center portion. 


\section{DISCUSSION OF TEST RESULTS}

\subsection{9- BY 19- BY 3-INCH}

WAFFLE-SLAB PANEL

The original test program called for several tests to be performed on 19by 19 - by 3 -inch waffle panels. Since the waffle panels were expected to be a weak component of a waffle-slab system, the test would include techniques for upgrading the panels. However, the first waffle test resulted in a sustained overpressure considerably greater than expected. SL personnel then concluded that the 19-inch waffle panels would not be a probable weak component of a waffle-slab system. Therefore, the remaining 19- by 19-inch waffle panels were properly sawed to transform them into 19- by 19-inch one-way slabs which are discussed in paragraph 4.2 .

The primary mode of structural response for the waffle-slab panels was shear. The panel specimens had a span/thickness ratio of 6.3 , indicating that the panels are susceptible to behaving as deep slabs.

The average shear stress of a typical waffle-slab panel can be computed on the basis of the ordinary equation for average shear stress in a reinforced concrete member:

$$
v_{u}=\frac{v}{b d}
$$

where

$$
\begin{aligned}
& v_{u}=\text { unit shear stress } \\
& v=\text { total shear force transferred through the section } \\
& b=\text { perimeter of the section located } d / 2 \text { away from the reaction area } \\
& d=\text { effective depth of the section }
\end{aligned}
$$

Using Equation 4.1 with $d$ equal to the total panel thickness of 3 inches, an analysis of the shear stresses for the maximum attained experimental load of 970 psi gives a unit shear stress of 854 psi. The waffle-slab panel was reinforced at midheight with $6 \times 6-$ W2.9 $\times$ W2.9 welded wire fabric, giving a steel ratio of 0.00305 for a $d$ value of 1.5 inches. The use of an effective depth value equal to 1.5 inches in Equation 4.1 would yield a unit shear stress value of $1,708 \mathrm{psi}$ as compared to the previously mentioned value of 854 psi for a $d$ value of 3 inches. 
The formulation of Equation 4.1 considers the effective depth $d$ to be the depth of the tension steel in a reinforced concrete member, and a minimum amount of concrete cover beneath the steel is expected to exist in standard practice. Since midheight of a concrete member is not deep into the zone of tension and a relatively large amount of concrete cover exists beneath the steel, the use of an effective depth value of 1.5 inches in Equation 4.1 for the waffle panel is unwarranted. An effective depth equal to the total panel thickness is a more logical value for use in Equation 4.1, especially since the equation concerns shear. An effective depth of 3 inches yields a steel ratio of 0.00153 as compared to the previously mentioned value of 0.00305 for an effective depth of 1.5 inches.

Gamble et al. (Reference 6) discusses several slabs tested by Brotchie et al. (Reference 7) in which the span/thickness ratio was as low as 5.0 , while the span/thickness ratio is 6.3 in the present study. The slabs were square or rectangular, and the lower edges were restrained against lateral movement during most of the tests to simulate friction between the slab and the support. The primary mode of failure in ten square slabs with a span/ thickness ratio of 5.0 was shear failure. The average ultimate shear stresses at the face of the support ranged from $830 \mathrm{psi}$ in an unreinforced slab to $1,900 \mathrm{psi}$ in a slab with a tension steel ratio of 0.02 . A slab with a tension steel ratio of 0.03 was resisting an average shear stress of 2,350 psi when the loading membrane broke. An edge detail failure occurred in a similar slab when the average shear stress reached $1,670 \mathrm{psi}$. The concrete strengths were in the range of 3,000 to $4,000 \mathrm{psi}$.

The testing of the 19- by 19 - by 3 -inch waffle-slab panels in this study is comparable to the testing by Brotchie et al., since the span/thickness ratios were similar and the edges were restrained against lateral movement. The concrete strengths of the panels were in the range of 5,000 psi. The 0.00153 steel ratio of a panel is relatively closer to that of Brotchie's unreinforced slab than his slab having an 0.02 tension steel ratio. The physical similarities in the waffle panel and the unreinforced slab resulted in similar structural response to applied load. The specimens experienced shear failure with average ultimate shear stresses of $854 \mathrm{psi}$ and $830 \mathrm{psi}$ for the waffle panel and Brotchie's unreinforced slab, respectively.

Gamble and others (Reference 6) developed the first empirical equation applicable to deep slabs. The span/thickness ratios of Brotchie's slab and 
the waffle panels of the present study approach that which is associated with the term "deep slab." Gamble's equation was developed from test data on 1/14-scale deep circular slabs having a span/thickness ratio of 3.5 . The circular slabs were supported flat over a circular opening and subjected to static overpressure. The primary mode of failure in Gamble's slabs was shear. It was shown that a high frictional force developed between the slab and its support structure causing compressive in-plane forces, preventing flexural failure.

Gamble found that for deep circular slabs, the ultimate shear stress is a function of $f_{c}^{\prime}$ and is represented by

$$
v_{u}=k \sqrt{f_{c}^{\prime}}
$$

where

$$
\begin{aligned}
v_{u} & =\text { ultimate shear stress } \\
k & =\text { an empirical constant } \\
f_{c}^{\prime} & =\text { compressive strength of concrete }
\end{aligned}
$$

The ultimate shear stress was found to occur on a section equal to the full slab thickness $t$ and located a distance $t$ from the face of the support. The empirical constant $k$ was determined to have values ranging from 9.0 to 13.5 with an average value of 11.2 for the circular deep slabs.

Application of Equation 4.2 to the waffle-slab panel experimental data yields an empirical constant $k$ value of 11.8 , which is comparable to the 11.2 average value for Gamble's circular slabs.

\subsection{9- BY 19- BY 3-INCH ONE-WAY SLAB}

The primary mode of structural response for the one-way slab was flexural bending. The slab was supported at the ends under fixed-fixed conditions with characteristics of an indeterminate member.

Crawford and others (Reference 8) present expressions for flexural capacity of indeterminate members, assuming the formation of plastic hinges at the supports and midspan. The one-way indeterminate slab in the present study collapsed after the formation of plastic hinges, as assumed by Crawford. The expression presented by Crawford for the flexural capacity of a one-way member with fixed supports resisting a uniform load is 


$$
P_{f}^{a}=7.2\left(P_{c}+P_{e}\right) f_{y} b\left(\frac{d}{L}\right)^{2}
$$

where

$P_{f}=$ uniform load resistance of member based on flexural capacity

$a=$ width of contributary load area

$\mathrm{P}_{\mathrm{c}}=$ tensile steel ratio at midspan

$\mathrm{P}_{\mathrm{e}}=$ tensile steel ratio at the end

$f_{y}=$ steel yield stress

$\mathrm{b}=$ beam width

$\mathrm{d}=$ depth to center of steel

$\mathrm{L}=$ span length

The location of the reinforcing steel in the one-way slab presents a problem of uncertainty in comparative analysis with standard one-way members. Since the steel is located at midheight throughout the slab, it does not lie deep enough into the tension zone to be completely effective in flexural resistance at either midspan or at the supports.

An adequate amount of test data exists verifying the validity of Equation 4.3. The equation includes the tension steel ratios at midspan and at the supports as a factor in determining the flexural capacity of a one-way member. Reference 3 includes the effective depth $d$ in the computation of tension reinforcement by the equation

$$
\mathrm{p}=\frac{\mathrm{A}_{\mathrm{s}}}{\mathrm{bd}}
$$

where

$\mathrm{p}=$ ratio of tension reinforcement

$A_{s}=$ area of tension reinforcement

$\mathrm{b}=$ width of member

$d=$ distance from extreme compression fiber to centroid of tension reinforcement

The effective depth also appears in Equation 4.3 as part of the term $(d / L)^{2}$. The remaining factors $\left(a, b, L, f_{y}\right)$ in Equation 4.3 are as applicable to the oneway slab of this study as to any typical one-way reinforced concrete member.

Therefore, the effective depth is the only factor of Equation 4.3 which has an unusual value in the one-way slab in this study, since it is equivalent to the 
midheight of the slab. Hence, Equation 4.3 may be useful to this study in determining the effectiveness of locating reinforcement steel at midheight in the slab for the purpose of flexural resistance.

The use of Equation 4.3 in determining the effectiveness of the reinforcement steel requires that the equation be solved for the effective depth d . Since the slab in this study has reinforcement steel at the ends that is identical to that at midspan and is also located at the slab's midheight, the term $\left(P_{c}+P_{e}\right)$ should be substituted by $2 A_{s} / b d$. The substitution is based on the assumption that the slab may be modeled by a typical one-way slab which has positive bending steel at midspan and negative bending steel at the ends, as shown in Figure 4.1. The substitution and algebraic manipulation results in the following equation:

$$
d=\frac{P_{f} \mathrm{fL}^{2}}{14.4 \mathrm{~A}_{\mathrm{s}} \mathrm{f}}
$$

where

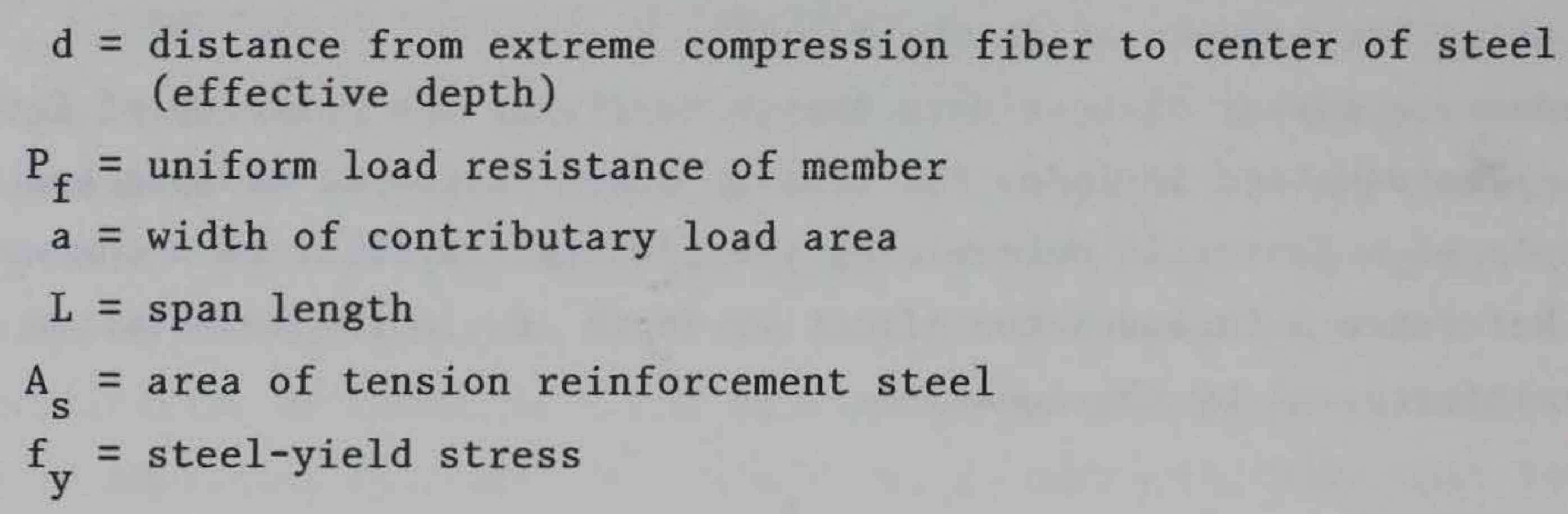

Equation 4.5 yields an effective depth of 2.14 inches when the value of the factor $P_{f}$ is assumed to be $445 \mathrm{psi}$, as was determined from test data to be the uniform load resistance of the slab in this study. Reference 3 requires a minimum concrete cover of $3 / 4$ inch for reinforcement steel in slabs of the type under discussion. Considering the radius of the reinforcement steel welded wire, the value of effective depth recommended by Reference 3 is 2.15 inches. The closeness of the two effective depth values implies that the computed effective depth of 2.14 inches may be used in Equation 4.4 to determine the effective tension steel ratios for the one-way $\mathrm{slab}$. Under these circumstances, Equation 4.4 yields a tension steel ratio of 0.002140 . This ratio applies to the midspan as well as the ends of the slab.

Since the effective depth computed on the basis of a uniform load resistance of 445 psi conforms with standards of a common slab, the experimentally 
obtained load of $445 \mathrm{psi}$ appears to be valid. However, it should not be assumed that a one-way slab with steel reinforcement located at midheight must behave as a slab with reinforcement located as recommended by the ACI code in Reference 3. It is common engineering practice to assume the contrary.

\subsection{0- BY 30- BY 3-INCH WAFFLE SLAB}

The primary mode of structural response for the waffle-slab panel was shear. The span/thickness ratio of the waffle-slab panel was 10.0. Unlike the 19- by 19 - by 3 -inch panels discussed in paragraph 4.1 , the 30 - by 30 - by 3-inch panels would not be expected to behave as deep slabs. However, as discussed by Brotchie (Reference 7), the ultimate load capacity of a slab is improved by external restraint. Even laterally restrained, unreinforced slabs are stronger than unrestrained, conventionally reinforced slabs. Brotchie indicates that, essentially, the full capacity of the concrete in compression is utilized when the slab is restrained. Before cracking, the effect of external restraint is to increase stiffness by less than 100 percent. After cracking, but before the crushing of concrete, the effect of external restraint is to cause an increase in stiffness of the order of one to several hundred percent.

Using Equation 4.1 with an effective depth of 3 inches, as discussed in paragraph 4.1, the maximum attained experimental load of 347 psi gives a unit shear stress of $617 \mathrm{psi}$. Application of this unit shear stress value to Equation 4.2 yields an empirical constant $k$ value of 9.4 , which is comparable to the 9.0 minimum value for Gamble's deep circular slabs. Since a deep slab is usually characterized by span/thickness ratios between 1 and 6 , the slab under discussion exhibited greater shear resistance than normally expected for a slab having a span/thickness ratio of 10 .

\subsection{PUNCHING STRENGTH OF A 4-INCH-} THICK SLAB ON GRADE

\subsubsection{Static Test}

The maximum static load applied to the slab by the 7- by 7-inch wooden post was 79.4 kips. The compacted soil beneath the slab had a load-bearing capacity of approximately $190 \mathrm{psi}$. In terms of a resultant force, the soil's load-bearing capacity was approximately 327 kips for the bearing area equivalent to the entire underside surface area of the slab. The resultant force of the soil's load-bearing capacity for the bearing area equivalent to the 
underside surface area of the punched conical section of the slab was approximately 43 kips. Therefore, the applied force of $79.4 \mathrm{kips}$ is the actual force at which punching shear occurred in the slab, since it is greater than the load-bearing capacity of the soil under the punched conical section.

Use of Equation 4.1 produces a unit shear stress value of 451.1 psi. This shear stress value is considerably greater than the shear value of 239.7 psi computed from the expression $v_{u}=4 \sqrt{f_{c}^{\prime}}$ given in paragraph 11.11.2 of the ACI code (Reference 3) for shear stress at a critical section located d/2 away from the column. An empirical expression of the same form as the ACI code expression that is compatible with the unit shear stress value of $451.1 \mathrm{psi}$ is $v_{\mathrm{u}}=7.5 \sqrt{\mathrm{f}_{\mathrm{c}}^{i}}$, which is an increase of the ACI expression by 88 percent.

Criswell (Reference 9) reported that the expression $v_{u}=4 \sqrt{f_{c}^{\prime}}$ underestimates shear failure resistance by 25 percent for a slab-column connection having an $r / d$ ratio less than 2 where $r$ equals side dimension of a square column and $d$ equals effective depth of the slab. The $r / d$ ratio in the current study is 1.75 . Therefore, an underestimate of 25 percent may be expected by the expression $v_{u}=4 \sqrt{f_{c}^{\prime}}$. However, an underestimate of 47 percent actually occurred. The difference in the percentage of underestimation by $v_{u}=4 \sqrt{f_{c}^{\prime}}$ between the slab in the current study and those studied by Criswell is partially due to support conditions. Criswell's slabs were simply supported along the edges, whereas the slab on grade was-uniformly supported by the soil.

Criswell reported that punching shear failure occurred at a center deflection of from 0.7 to 2.0 percent of the span of the specimen. However, the slab on grade in the current study experienced punching shear at a center deflection of approximately 0.02 percent of the span of the specimen. The uniform support beneath the slab on grade was responsible for maintaining the small flexural deflection. The deflections at which punching shear failure occurred in Criswell's specimens with a reinforcement steel ratio of 0.0075 were slightly over twice those of the specimens with a reinforcement steel ratio of 0.0150 . Also, the specimens with a reinforcement steel ratio of 0.0075 sustained a maximum connection resistance force that was approximately 60 percent of the force carried by the specimens with a steel ratio of 0.0150 . Therefore, Criswell's simply supported slabs showed that deflections decrease and resistance increases as the steel ratio increases. Such behavior related 
to reinforcement steel ratio is expected in a simply supported member.

The reinforcement steel ratio of the slab on grade in the current study was 0.001551 , which is considerably less than the lowest steel ratio in Criswell's study. The uniform resistance of the compacted soil beneath the slab on grade hindered deflection of the slab, causing a shear stress value of which the expression $v_{u}=4 \sqrt{f_{c}^{\prime}}$ underestimates by 22 percent more than it underestimates a slab simply supported along the edges. Since the reinforcement steel ratio of the slab on grade was considerably low compared to Criswell's specimens, and slab deflections remained extremely small, it is implied that the reinforcement steel ratio of a slab on grade contributes little to punching shear resistance. However, the current study does not contain multiple experiments to support the insignificance of the reinforcement steel. Also, it should be noted that there must be an upper limit at which the steel ratio becomes great enough that the quantity of steel is proportional to the quantity of concrete to such a degree that the shearing load is basically resisted by the steel, leaving little purpose for the concrete. Such steel ratios are impractical.

\subsubsection{Dynamic Test}

A peak dynamic load of approximately 135 kips was transferred to the slab on grade by the 7- by 7-inch wooden post. This load caused the wooden post to punch into the slab and induce shearing of a conical section beneath the post in a manner similar to the punching of the statically tested slab on grade. However, the vast difference in loading rates for the two slabs creates a need for further discussion.

The compressive strength of the concrete composing the dynamically tested slab was $4,090 \mathrm{psi}$ as compared to $3,590 \mathrm{psi}$ for the statically tested slab. Use of the empirical expression, $v_{u}=7.5 \sqrt{f_{c}^{\prime}}$, of which the constant was developed from the statically tested $\mathrm{slab}$, yields a unit shear stress value of 480 psi for the dynamically tested slab. Based upon results of the statically tested slab, a static load of 84.4 kips would be required to produce the 480-psi stress.

Criswell (Reference 9) reported that the shear strength of the slabcolumn connections in his simply supported specimens increased slightly more than the flexural strength with rapid loading. The increase in strength with rapid loading averaged 26 percent for Criswell's slabs failing in shear. A 
26 percent increase in the assumed static shear strength of the dynamically tested slab on grade results in a dynamic load of 106.4 kips applied by the 7by 7 -inch wooden post.

\subsection{CENTER PORTION OF A 24-FOOT- SQUARE WAFFLE-SLAB FLOOR}

Comparison of the waffle-slab floor center portion with a typical waffleslab floor that may exist in a bay of a building reveals some physical differences that could alter structural behavior. The differences are the boundary conditions related to the support of the slab. The center portion tested in the LBLG had an 11-inch-thick reinforced concrete boundary which reached to the supportive concrete wall along the inside surface of the test chamber.

The reinforced concrete boundary supported the waffle area in a more rigid manner than that which typically occurs in waffle-slab building construction. A typical waffle-slab floor is supported by columns at the four corners of a bay. Between the columns, the waffle slab monolithically joins the waffle slabs of the surrounding bays. Under uniform loading conditions of a nonupgraded waffle-slab floor, the load is transferred to the columns as the waffle slab deflects flexurally. The waffle slabs of the surrounding bays deflect similarly and do not behave as rigid supports to each other.

The waffle slab tested in the LBLG was upgraded with twelve 8-ft-long wooden columns to increase its load-carrying capacity. SSI determined the spacing between the upgrading columns. In the determination of the upgrading column spacing, it was desirable to determine a spacing that would utilize both flexural strength and shear strength of the slab to obtain the maximum load-carrying capacity. Eight of the twelve upgrading columns (boundary columns) were located along the boundary of the waffle slab, while the remaining four columns (inner columns) were located near the center of the slab. Load cells were placed under one of the boundary columns and under one of the inner columns for the purpose of measuring applied load.

\subsubsection{Static Test}

Both load cells indicated that the columns had sustained a load of approximately 120 kips when failure of the upgraded slab system occurred. Figures C. 2 and C. 3 in Appendix C show the loading patterns of the two columns, as the uniform pressure applied to the slab increased. Figure C.2 indicates 
that the load-carrying capacity of the inner column decreased to zero after the loading on the slab reached 44 psi. However, Figure C.3 shows that the load carried by the column on the waffle-slab boundary continued to increase until the large deflections of the slab caused a loss of loading pressure.

The initial deflections of the slab at the columns were allowed by the compression of the wedges beneath the columns. The compression of the wedges absorbed some of the loading energy and may have induced a redistribution of the stresses in the slab by allowing some flexural response at the slab-column connection. However, as the overpressure increased and the compression of the wedges neared a maximum, the columns were loaded until buckling occurred.

Posttest observation revealed that all four inner columns buckled, although all eight of the boundary columns remained in place. The existence of the boundary columns increased the rigidity of the 11-inch-thick reinforced concrete boundary as the waffle slab sheared along the boundary.

The soil-stress gage data presented in Figures C.18-C.25 reveal that the phenomenon of soil arching did occur during the test. Soil arching often occurs in shallow-buried structures when relatively small deflections develop. Soil arching should act to decrease the load over the flexible portion of the roof, provided a high shear strength backfill material is used. The decrease in load over the flexible area should result in an increase in load at the stiffer or hardened areas of the slab. The upgrading column locations of the statically tested slab system served as hardened areas which received a greater maximum load than flexible portions of the slab, thereby helping to minimize slab deflections and enhancing the concept of slab upgrading. It is debatable as to which action occurred first: buckling of the four inner columns or shearing of the waffle slab. It is evident that one action immediately followed the other, since the recorded data reveal a sudden change in slab deflections and column loading at the 44-psi overpressure level.

Assuming that the slab sheared and caused the inner columns to buckle, a sudden increase in load applied to the inner column would be expected. However, Figure C.2 reveals only a decrease in applied load at the 44-psi overpressure level. Based on the absence of increased column loading immediately preceding test termination, it appears that the inner columns buckled, leaving the center portion of the waffle slab nonupgraded and susceptible to immediate shearing action.

After the shearing of the waffle slab, the load cell beneath the boundary 
column indicated an increase in load applied to the boundary column, as shown in Figure C.3. This increase was due to the absence of support to the slab system by the buckled inner columns. The boundary column sustained a load of approximately 173 kips, although the current discussion implies that the similarly constructed inner column buckled at approximately 120 kips. A series of static axial load tests were performed on similar wooden columns in the WES 200-kip loader, resulting in a critical buckling load of 153 kips. A possible explanation for premature buckling of the inner column is the probable existence of eccentric loading conditions in the column. The likelihood of eccentric forces in the column is considerably great since the load cell was beneath the column in perhaps a slightly off-center position. Also, greater deflections of the slab above the inner columns, as compared to slab deflections at the boundary columns, could be responsible for inducing eccentric forces in all four inner columns. However, there is no explanation for the ability of the boundary column to surpass the experimentally attained buckling load of 153 kips except for possible material and loading variances.

\subsubsection{First Dynamic Test}

The dynamic loading producing a peak dynamic pressure of 34 psi caused only minor structural damage as presented in paragraph 3.5.2. The peak pressure of $34 \mathrm{psi}$ was approximately 77 percent of the static pressure of $44 \mathrm{psi}$ that "failed" the statically tested slab systems.

The cracks which formed on the underside of the slab were of a flexural nature. No evidence of shear initiation was observed during the posttest examination. Most of the cracks were on the waffle joists at midspan of the distance between upgrading columns where maximum positive bending would be expected. The upgrading columns between which the cracks developed were 6 feet apart as compared to the 4-foot distance between inner columns. However, cracks did not form in other regions of the slab that were similar to the region with cracks. The existence of cracks in one region, along with the absence of cracks in similar regions, indicates that the applied pressure was near the level that would impend cracking in many regions of the slab.

The soil-stress data in Figures C.47-C.54 in Appendix C indicate that soil arching occurred within the slab's overburden during the dynamic test. The degree to which soil arching occurred may have varied slightly from one region of the slab to another, although the regions were physically identical. 
The probable existence of variation in the effect of soil arching may have been associated with the nonuniformity of crack formation in similar regions of the slab.

The crack which occurred in the panel shown in Figure 3.15 may have been due to the boundary conditions. The corner of the panel was positioned on top of the supportive concrete wall. A poor surface contact between the panel's corner joists and concrete wall could have been responsible for increased stresses at the corner.

Figures C.40 and C.41 in Appendix C show the recorded data from the load cells located beneath the two upgrading columns. The loading pattern applied to the inner column is shown in Figure C.40. A peak dynamic load of approximately 220 kips was applied to the inner column without the occurrence of buckling. The peak load was an increase over the maximum load applied to the inner column during the static test discussed in paragraph 4.5 .1 of approximately 83 percent. Malfunctions in the instrumentation system prohibited the collection of data from the load cell beneath the boundary column, as indicated in Figure C.41.

Peak deflections occurring during the dynamic test ranged from 41 to 120 percent of the maximum deflections attained at similar locations during the static test when rupture of the statically tested slab was impending. This range includes data from the deflection gage D3, which was located at the center of a panel. The deflection indicated by the D3 gage in the static test was approximately 50 percent of the deflections measured by deflection gages D1, D2, D4, and D5, which were located on joists surrounding the panel. It is apparent that the data obtained from the D3 gage are incorrect. However, even if the data from the D3 gage were not included in the percentage range, the range's upper bound would only decrease from 120 percent to 112 percent.

The range of 41 to 112 percent may be divided into an upper region and a lower region. Deflections measured near the boundary of the waffle slab were responsible for the upper region of the range and were from about 80 to 112 percent of the static deflections. Deflections measured near the center of the waffle slab composed the lower region of 41 to 71 percent of the static deflections. Therefore, peak dynamic deflections near the boundary were similar to the maximum prerupture boundary deflections measured in the static test. However, deflection magnitudes near the slab's center were considerably less than those near the statically tested slab's center. 
A more appropriate comparison of deflections is the comparison of the dynamic deflections at the peak dynamic pressure of 34-psi pressure level with the deflections of the statically tested slab at the 34-psi pressure level. The dynamically tested slab deflections ranged from 62 percent to 192 percent of the statically tested slab deflections. However, except for two gages, D7 and D11, which were, respectively, responsible for the lower and upper limits of the percentage range, the range was from 82 percent to 124 percent.

The response of the dynamically tested slab may be considered more uniform than that of the statically tested slab. This is evident from calculations producing the sample standard deviation of the deflection data. The sample standard deviation of the deflection data of the statically tested slab at the 34-psi pressure level was 0.224 . The sample standard deviation of the deflection data of the dynamically tested slab at the 34-psi pressure level was 0.138 . The value for the dynamic test was only 62 percent of the value for the statically tested slab, indicating a lesser degree of variation among measured deflections.

The permanent deflections of the dynamically tested slab ranged from 18 percent to 83 percent of the peak dynamic deflections, with an average of 43 percent. The sample standard deviation for the residual deflections was 0.0938 , which was 42 percent of that for the peak dynamic deflections. The compression of the wedges beneath the columns accounted for deflections of the slab at the columns, causing loss of surface contact between some of the upgrading columns and the rebounded $\mathrm{slab}$ as reported in paragraph 3.5.2.

Increased buckling resistance in the upgrading columns of the dynamic test (as compared to that of the static test) was due to rapid application of the load. This phenomenon is often quantitized by the concept known as the dynamic load factor (DLF) discussed in Reference 10. High speed movies taken during the test revealed that considerable vibration of the upgrading columns occurred, although the degree of instability was not great enough to induce buckling. Since large column loads were allowed while slab deflections were considerably uniform, and perhaps the wedges were not fully compressed, buckling of the inner columns was avoided. If a greater peak dynamic overpressure had been applied and uniformity in the slab deflections existed, the columns may have buckled due to the reaching of the dynamic value of the critical buckling load without the existence of eccentrical loads. Buckling would also 
be expected to occur in the boundary columns if uniformity in the slab deflections existed at the greater pressure.

\subsubsection{Second Dynamic Test}

Extensive structural damage occurred during the second dynamic test on the waffle slab due to the peak dynamic pressure of $61.1 \mathrm{psi}$, as presented in paragraph 3.5.3. The peak pressure of 61.1 psi was an increase of approximately 80 percent over the peak pressure of the first dynamic test and was an increase of approximately 39 percent over the maximum slab overpressure sustained during the static test.

Figure C.87 in Appendix C reveals that the maximum load measured by the load cell beneath the inner column was approximately 220 kips. Figure C. 88 indicates that a malfunction in the instrumentation system prohibited the collection of data from the load cell beneath the boundary column.

High-speed movies which monitored the underside of the slab indicated that the entire slab fell to the test chamber's floor as a unit which was demolished at floor contact. Only the portion of the slab that fell on the deflection-gage mount structure remained as a large piece; see Figure 3.17. Contrary to the behavior observed during the static test and the first dynamic test, many precollapse deflections near the boundary were slightly larger than those near the inner region of the slab for locations other than those at upgrading columns. The deflection measured at a boundary column by deflection gage D9 was 75 percent of the deflection measured at an inner column by deflection gage D4. In the first dynamic test, the deflection at D9 was only 49 percent of that at $\mathrm{D} 4$.

Since little damage was observed in the first dynamic test and failure occurred in the second dynamic test, it is not obvious where the critical overpressure lies. An analysis must be performed to determine whether the critical overpressure was slightly greater than $34 \mathrm{psi}$, slightly less than $61 \mathrm{psi}$, or any other value within the domain. It is reasonable to assume that the load-carrying capacity of the wooden upgrading columns strongly influences the load-carrying capacity of the overall structure.

To determine the dynamic buckling load, a pinned-end column subjected to a harmonic axial load of frequency $\Omega$ was investigated (Figure 4.2a). Timoshenko (Reference 11) discusses the stability of bars under varying axial forces. Experience has shown that a slender bar can withstand a maximum 
pulsating force which is larger than the Euler load. Timoshenko states that at certain values of the frequency of the pulsating force, violent lateral vibrations of the bar are produced so that the bar is unstable. In studying the lateral vibrations, Timoshenko used the following differential equation of motion:

$$
\text { EI } \frac{\partial^{4} y}{\partial x^{2}}+(S \cos \Omega t) \frac{\partial^{2} y}{\partial x^{2}}+m \frac{\partial^{2} y}{\partial t^{2}}=0
$$

where

$$
\begin{aligned}
& \mathrm{E}=\text { modulus of elasticity } \\
& \mathrm{I}=\text { moment of inertia } \\
& \mathrm{S}=\text { amplitude of pulsating force } \\
& \Omega=\text { radian frequency of pulsating force } \\
& \mathrm{t}=\text { time } \\
& \mathrm{m}=\text { ratio of mass per length of bar }
\end{aligned}
$$

The solution which satisfies Equation 4.6 for the conditions of a bar with pinned ends is in the form

$$
y=A f(t) \sin \frac{\pi x}{\ell}
$$

where

$$
\begin{aligned}
& A=\text { amplitude of the sine function } \\
& \ell=\text { length of bar }
\end{aligned}
$$

Substituting Equation 4.7 into Equation 4.6, Timoshenko obtained the following equation:

$$
\frac{\partial^{2} f(\tau)}{d \tau^{2}}+(a+b \cos \tau) f(\tau)=0
$$

where

$$
\begin{aligned}
\tau & =\Omega \mathrm{t} \\
\mathrm{a} & =w_{0}^{2} / \Omega^{2} \\
\mathrm{~b} & =\left(-w_{0}^{2} / \Omega^{2}\right) \mathrm{s} \\
w_{0} & =\begin{array}{l}
\text { fundamental radian frequency of lateral vibration of a pinned-end } \\
\text { column with no axial load }
\end{array} \\
\mathrm{s} & =\mathrm{s} \ell^{2} / \pi^{2} \mathrm{EI}
\end{aligned}
$$


Timoshenko presents a graphical interpretation of Equation 4.8 based upon the determination of the parameters $a$ and $b$, as shown in Figure 4.2b. In Figure $4.2 \mathrm{~b}$, the shaded areas indicate regions of stability. The unshaded areas represent regions of instability, indicating the occurrence of buckling.

Application of Figure $4.2 b$ to the inner column in the first dynamic waffle-slab test requires the computation of $I$, the column's moment of inertia. As discussed in paragraph 4.5.1, the critical buckling load of $\mathrm{P}_{\mathrm{cr}}=153$ kips was determined from tests using the WES 200-kip loader. Assuming a first mode Euler buckling load for a pinned-end column,

$$
P_{c r}=\frac{\pi^{2} E I}{\ell^{2}}
$$

where

$$
\begin{aligned}
& \mathrm{E}=\text { modulus of elasticity } \\
& \mathrm{I}=\text { moment of inertia } \\
& \ell=\text { unsupported length of column }
\end{aligned}
$$

Using an $E$ value of $1.7 \times 10^{6}$ psi, an effective I value of 73.9 inches $^{4}$ can be determined for the wooden column with a mass per unit length of $0.00251 \mathrm{~b}-\sec ^{2} / \mathrm{in}^{2}$.

When structural damping is considered, the dashed lines in Figure 4.2b are used as the boundary of stable solutions. If the frequency $\Omega$ is taken as the frequency observed in the load cell (Figure C.40), the value of a is determined as

$$
a=\frac{\omega_{0}^{2}}{\Omega^{2}}=1.27
$$

For this value of $a$, use of the dashed curve in Figure $4.2 b$ yields a value of $b=1.8$. Therefore, the dynamic harmonic load at which buckling would occur can be determined as

$$
\begin{aligned}
& \mathrm{S}=\frac{\mathrm{b}}{\mathrm{a}} \mathrm{P}_{\mathrm{cr}}=\frac{1.8}{1.27} 153 \mathrm{kips} \\
& \mathrm{S}=217 \mathrm{kips}
\end{aligned}
$$

The value of 217 kips is very near the approximate value of 220 kips measured by the column load cells in both dynamic tests. 


\subsection{CENTER PORTION OF A 22-FOOT- \\ SQUARE FLAT PLATE}

As in the case of the waffle-slab floor specimens discussed in paragraph 4.5, the boundary conditions of the flat-plate specimen varied from those which would exist in a typical building. The boundary conditions may have caused structural response different from that of a flat plate in a building floor system.

When the average overpressure loading reached approximately 38 psi, a sudden increase in magnitude of measured deflections occurred, and overpressure loading decreased due to the sudden volume increase accompanying the deflections. The load cells located beneath one inner column and one boundary column indicated an abrupt change in column loading at the 38-psi pressure level (see Figures D. 3 and D.4 in Appendix D). The maximum load carried by the inner column was approximately 120 kips, while the boundary column sustained a load of approximately 85 kips at the 38-psi overpressure level.

The inner columns buckled under the load of 120 kips as did the inner columns in the waffle-slab static test discussed in paragraph 4.5.1. Buckling of the columns allowed the sudden increase in slab deflections. When the column loading of 120 kips occurred in the flat plate inner column, the overpressure was approximately 86 percent of the waffle-slab static test overpressure that produced an inner column loading of 120 kips.

Apparent malfunctions occurred in deflection gages D2 and D6, as respectively shown in Figures D.31 and D.35 in Appendix D. Other portions of the deflection data indicated that deflections along the boundary were similar to maximum prerupture boundary deflections of the statically tested waffle slab. Deflections at the inner region of the flat plate and at regions near the boundary, but not on the boundary, measured approximately 71 percent and 122 percent, respectively, of waffle slab prerupture deflections at similar locations.

The thickness of the flat plate was uniform and equal to the thickness of the rigid supportive boundary, producing a greater resistance to shear along the boundary than that of the waffle slab. However, negative bending yield lines did develop along the boundary and along the span between two inner columns (Figure 3.19).

Load cell data indicated that the boundary column load was approximately 71 percent of the inner column load at the 38-psi average overpressure level. 
Figures D.5 through D.12 reveal that soil arching did occur in the sand overburden. Figure D.5 shows the soil-stress data for gage SE-1 which was located above a boundary upgrading column. Figure D.5 indicates that soil arching acted to increase the slab loading at the column. The SE-3 gage plot, shown in Figure D.7, did not produce reasonable data, resulting in the absence of soil arching data for the inner column location. Soil stress gages at all other locations on the flat-plate slab produced data characteristic of the soil-stress data of the waffle-slab static test. Therefore, the soil-stress measurement at the inner column would be expected to be characteristic of the waffle-slab inner column location soil-stress measurement, indicating similarity in loading behavior of the two slabs. By the same reasoning, the slab loading at the boundary column having a maximum column load of 85 kips would be expected to be similar to the slab loading at the boundary column where soil-stress gage SE-1 was located. However, the low column load of 85 kips at the 38-psi average overpressure level implies that symmetry in the soil arching action may not have existed.

Figure D. 4 may be approximated by a straight-line function which changes slope at the 20-psi overpressure value. The slope of the line from the 20-psi value to $35-p s i$ value is approximately 2.7 times that of the line below the 20 -psi value. The steeper slope of the line reveals that the change in overpressure was considerably greater than the change in column load when compared to the relationship of change in overpressure to change in column load below the 20-psi level. A straight-line approximation of Figure D.3 reveals a slight decrease in slope of about 17 percent at the 22-psi overpressure value for the load cell data at the inner column. A straight-line approximation of the waffle-slab static test boundary column load data presented in Figure C. 3 reveals that the slope above the $30-p s i$ overpressure value is approximately 2.4 times that of the line below the 30-psi value. The magnitudes of the slope changes were similar for the boundary column data of the two tests. However, the slope change in the waffle-slab test occurred at a considerably higher overpressure and column load than that of the flat-plate test. The indication is that each upgrading column of the upgraded slab systems was loaded in a unique manner, influenced by variances in parameters such as column material property, slab type, and soil arching. 


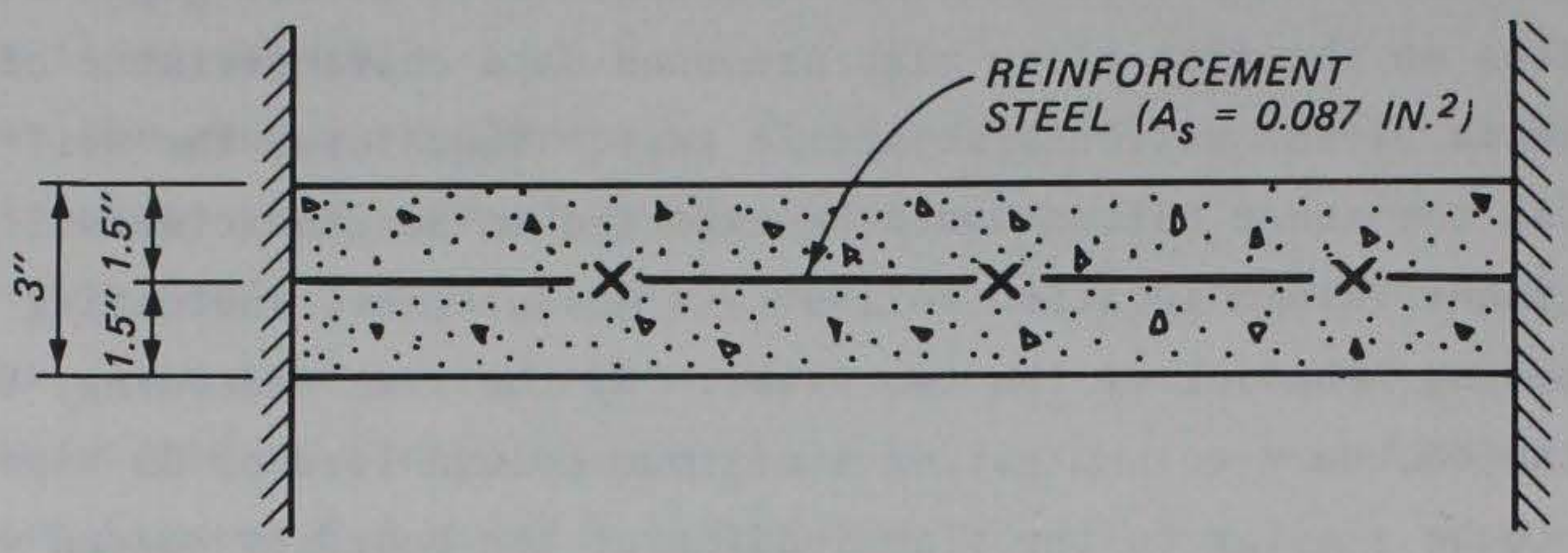

ONE-WAY SLAB WITH MIDHEIGHT REINFORCEMENT

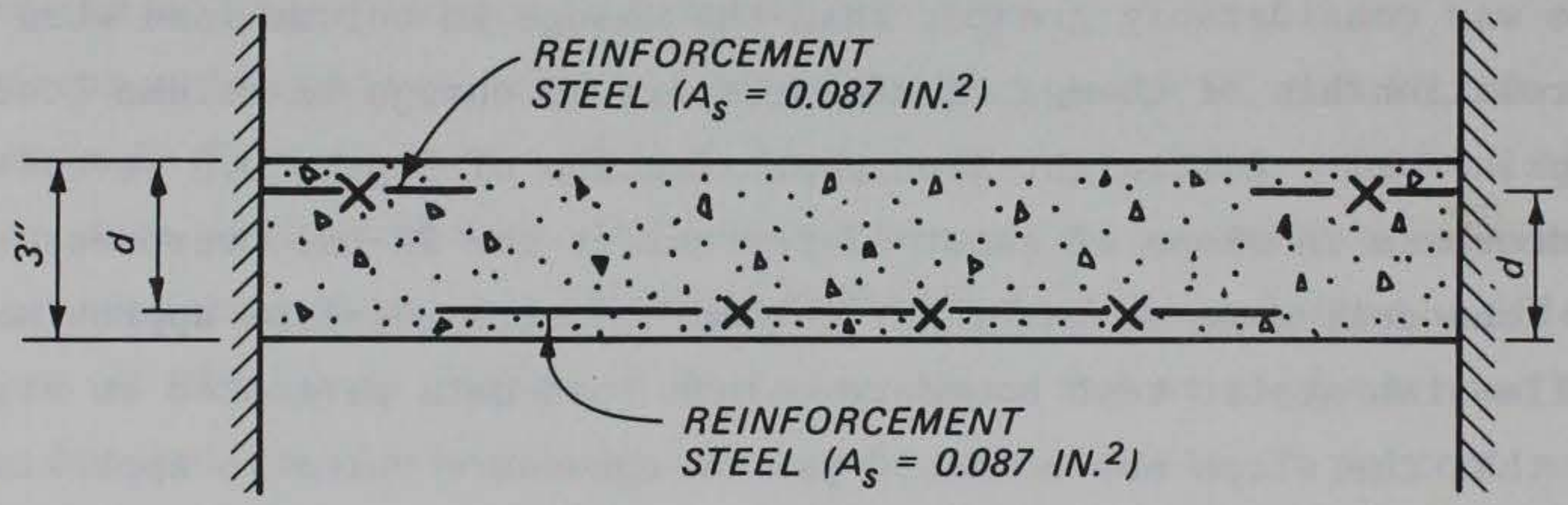

EQUIVALENT TYPICAL ONE-WAY SLAB

Figure 4.1 One-way slab comparison. 


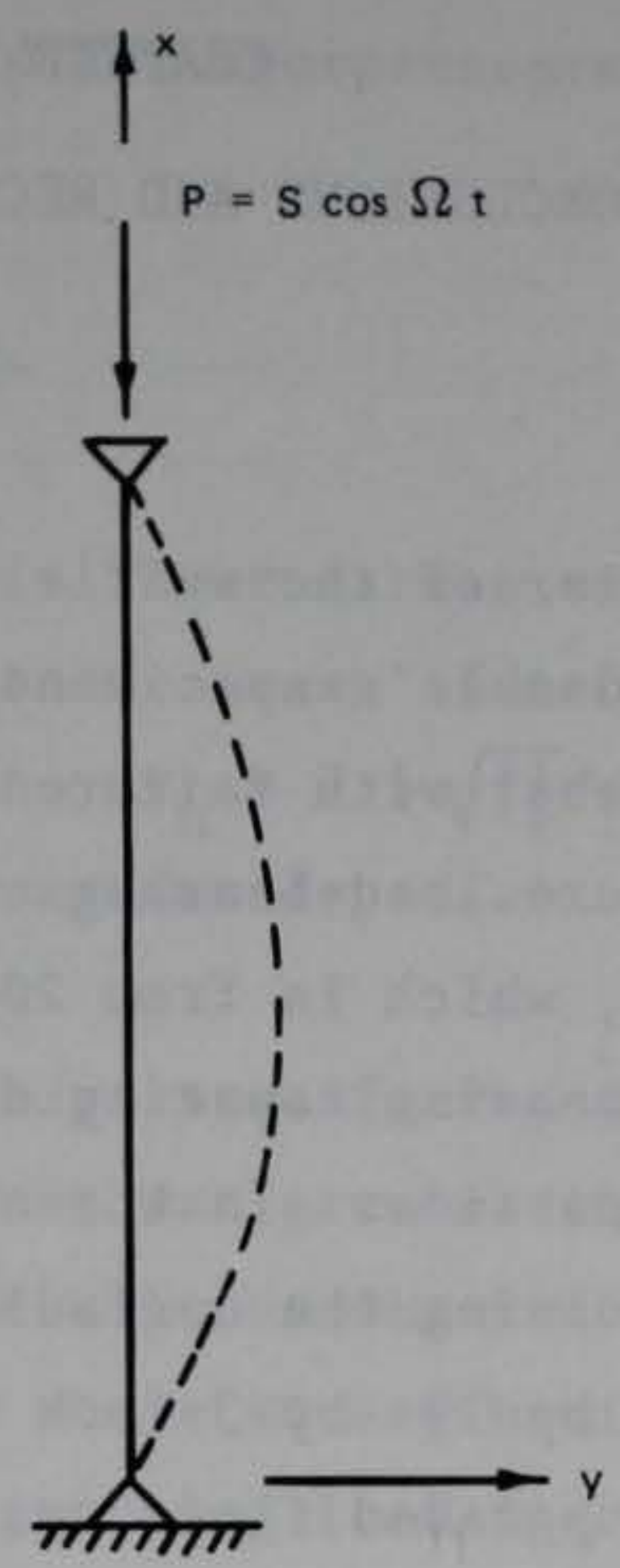

(a)

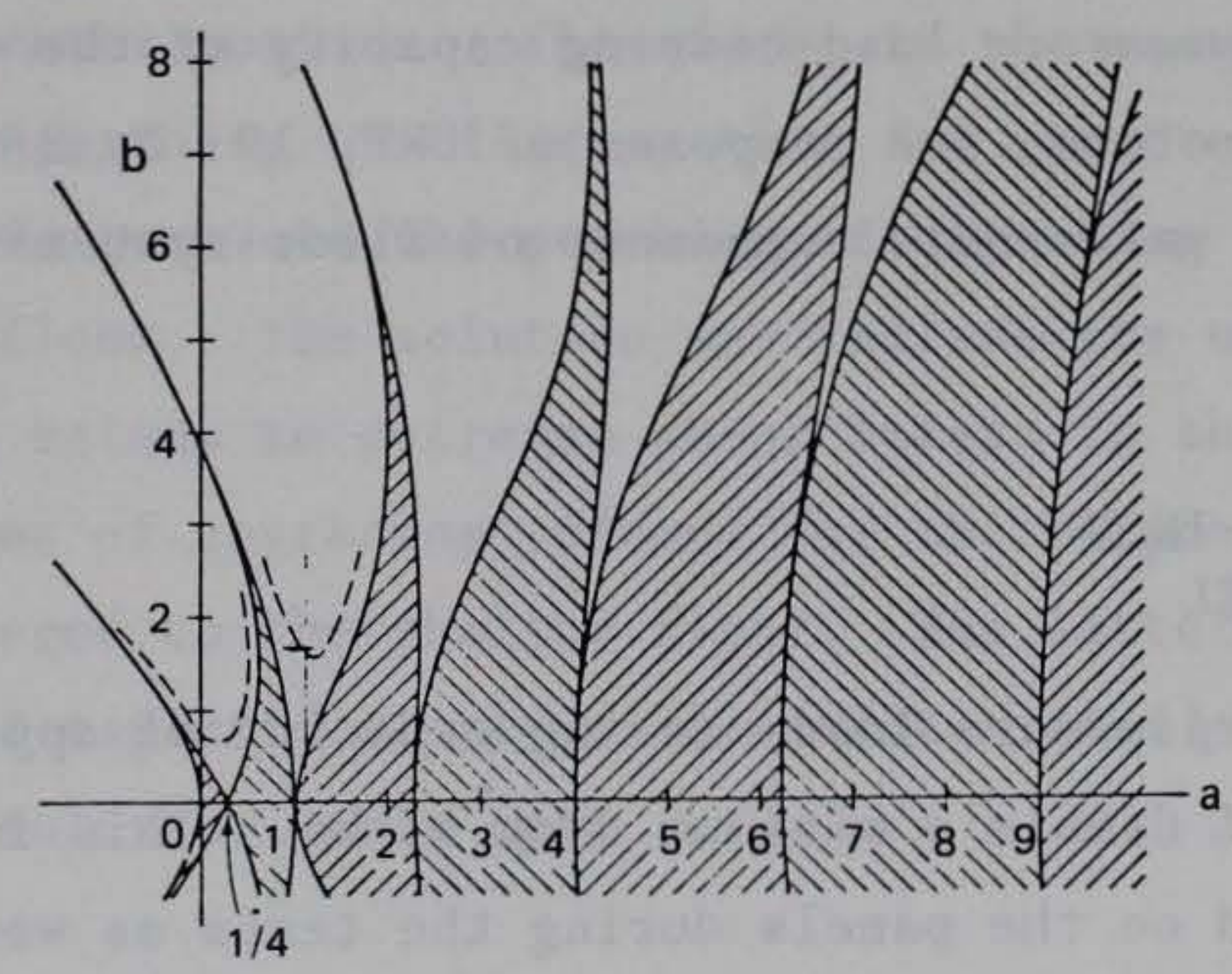

(b)

Figure 4.2 Pinned end column subjected to a harmonic axial load of frequency $\Omega$. 


\subsection{9- BY 19- BY 3-INCH \\ WAFFLE-SLAB PANEL}

The structural behavior of the waffle panels was similar to that of Brotchie's specimens and Gamble's specimens. The structural behavior was characteristic of deep slabs, with failure occurring due to shearing action.

The static overpressure load-bearing capacity of the panels was in the range of 900 to $1,000 \mathrm{psi}$, which is from 20 to 23 times greater than the static overpressure load-bearing capacity of the statically tested upgraded waffle-slab floor center portion. In the case of Crisis Relocation Planning (CRP), implementation involving the upgrading of waffle-slab floors for resisting overpressure, 19 - by 19 - by 3-inch waffle panels will not be a vulnerable component of the upgraded floor system.

\subsection{9- BY 19- BY 3-INCH ONE-WAY SLAB}

Although the reinforcement steel is located at midheight, the overpressure load-bearing capacity of the slabs may be accurately predicted by Crawford's equation, assuming an effective depth value which complies with the 1977 ACI code.

The static overpressure load-bearing capacity of the slabs was approximately 445 psi. Therefore, for purposes of CRP, 19- by 3-inch one-way slab panels will not be a vulnerable component of floor systems upgraded for overpressure resistance.

\subsection{0- BY 30- BY 3-INCH}

WAFFLE-SLAB PANEL

The panels' overpressure load-bearing capacity of approximately 347 psi is similar to that of Gamble's minimum deep slabs. This is due to the external restraint imposed on the panels during the tests as would be expected to occur in a waffle slab composed of similar panels.

The load-bearing capacity of the panels is of magnitude great enough to insure that 30 - by 30 - by 3 -inch panels will not be a vulnerable component of 
a waffle-slab floor system upgraded for overpressure resistance in CRP implementation.

\subsection{PUNCHING STRENGTH OF A 4-INCH- \\ THICK SLAB ON GRADE}

The 1977 ACI code ultimate unit shear stress expression, $v_{u}=4 \sqrt{f_{c}^{\prime}}$, underestimated the ultimate unit shear stress that occurred during the static test by 47 percent. The expression, $v_{u}=7.5 \sqrt{f_{c}^{\prime}}$, more accurately represented the ultimate unit shear stress developed at $d / 2$ away from the face of the column exerting punching action.

The peak dynamic load of 135 kips transferred to the slab on grade by the wooden column during the dynamic test was greater than the ultimate punching strength of the slab. Utilizing results of the statically tested slab on grade and Criswell's comparison of shear strengths in specimens loaded slowly and rapidly, the ultimate dynamic punching load for the slab was computed to be approximately 106.4 kips.

The ultimate static punching load of 79.4 kips was approximately 66 percent of the maximum static load of 120 kips sustained by the upgrading columns during the tests on the waffle-slab floor and flat-plate floor center portions discussed in this report. The computed ultimate dynamic punching load of 106.4 kips was approximately 48 percent of the maximum dynamic load of 220 kips sustained by the upgrading columns during the dynamic tests on the waffle-slab floor center portion. Therefore, in the case of CRP implementation involving the upgrading of floor systems for expected overpressures, allowances must be made to avoid the punching of upgrading columns into the basement (shelter) floor. The solution may include the use of a baseplate beneath the upgrading column to decrease shear stress in the shelter floor, or an increase in number of upgrading columns for the purpose of reducing maximum column loads transfered to the shelter floor. The latter solution may alter the failure mode and capacity of the slab (shelter roof) being upgraded, whereas the former solution would not.

\subsection{CENTER PORTION OF A 24-FOOT-SQUARE WAFFLE-SLAB FLOOR}

Due to the boundary conditions, the waffle-slab specimens did not properly model the center portion of a waffle-slab floor as it would exist in a 
building. However, punching shear failure of the waffle joists did not occur at the upgrading columns, indicating that the upgrading of waffle slabs may be feasible. It is apparent that the optimum spacing of upgrading columns for a waffle-slab floor cannot be determined from the three waffle-slab tests. Also, the effectiveness of the column spacing scheme used in this test series when applied to a complete waffle-slab floor cannot be determined from these tests.

Soil arching did occur in the overburden during the three waffle-slab tests. The arching of the soil acted to reduce the load applied to flexible portions of the slabs by transferring part of the load to the boundary or to upgrading columns.

The wedges beneath the columns compressed under loading, allowing initial flexural slab response to occur at the upgrading column locations. This action would occur in the case of a complete waffle-slab floor in a building. In the case of a waffle-slab floor in a building, shearing action may occur at the concrete columns before it occurs at the upgrading columns, even though the concrete columns would provide a greater shear resistance area,

Each composite wooden upgrading column had overall cross-sectional dimensions of 7 by 7 inches. From the experimentally attained static Euler buckling load of 153 kips and the Euler buckling equation, WES personnel determined the effective cross-sectional dimensions of a column to be approximately 5.5 by 5.5 inches. Considering the static buckling load of 120 kips incurred during the static waffle-slab test, WES determined the effective crosssectional dimensions of a column to be approximately 5.1 by 5.1 inches.

During the static test and the second dynamic test, the inner columns buckled, allowing the slab to shear along the boundary. The approximate buckling load of 220 kips in the second dynamic test was an increase of 83 percent over the buckling load of $120 \mathrm{kips}$ in the static test. This increase was due to the rapid application of the load in the dynamic test. Eccentric loading conditions caused the inner columns in the static test to buckle prematurely at a load of 120 kips rather than the experimentally attained static buckling load of 153 kips.

An analytical method developed by Timoshenko reveals that the dynamic buckling load is near the value of $220 \mathrm{kips}$, as measured in the second dynamic test. Since the first dynamic test's maximum applied column load of 220 kips did not buckle the columns but did induce considerable column vibrations, it 
is apparent that accompanying dynamic slab overpressure was near that which would cause buckling of the columns and probable collapse of the waffle slab.

Due to column buckling, allowing collapse of the slab primarily through shear failure, the maximum static and dynamic load-carrying capacities of the waffle-slab system were near $44 \mathrm{psi}$ and $34 \mathrm{psi}$, respectively.

\subsection{CENTER PORTION OF 22-FOOT-SQUARE \\ FLAT PLATE}

The flat-plate specimen did not properly model the center portion of a flat-plate floor as it would exist in a building, due to differences in boundary conditions. However, the absence of punching shear initiation at the upgrading columns in the test does indicate that punching shear would not occur at upgrading columns in a complete flat-plate floor, having similar upgrading column spacing, before column buckling or other failure occurred. Compression of the wooden wedges beneath the upgrading columns allowed flexural slab behavior at the column locations, decreasing the slab's susceptibility to punching shear. Punching shear action may occur at the concrete columns in the case of a complete building flat-plate floor system, since the concrete columns would not be supported by wedges and characteristically would be without capitals and drop panels.

Soil arching occurred in the overburden of the flat plate, causing a redistribution of the load applied to the slab. The inner upgrading columns buckled at a column load of 120 kips. However, the boundary column load was 71 percent of the inner column load at the 38-psi average overpressure level. Due to column buckling, the maximum static average overpressure load-carrying capacity of the upgraded flat-plate specimen was $38 \mathrm{psi}$.

Comparison of the column loadings of the flat-plate slab with the column loadings of the statically tested waffle slab reveals that loading of upgrading columns may vary considerably, even among columns located symmetrically within the same slab system. Accurate methods of predicting probable variances, particularly for the case of a complete floor system of a building, cannot be developed from this test series. However, it is apparent that the column load variances were due to variations in upgrading column material properties, slab type, and soil arching. 


\subsection{RECOMMENDATIONS}

Research is needed to develop techniques for increasing the buckling resistance of a composite wooden upgrading column. The tests in this series revealed that the columns responded as 5.1 - by 5.1 -inch columns rather than 7by 7 -inch columns, in respect to buckling resistance of static loads. Various construction techniques, such as gluing together the individual members of a composite column and the use of other binding methods, should be investigated for effectiveness in increasing composite action.

The development of an upgrading column baseplate is needed for the purpose of preventing punching shear failure in the floor of an upgraded basement. In order to utilize maximum column load-carrying capacity, the baseplate must be capable of distributing the column buckling load over an area large enough to avoid punching action.

One upgrading column lost contact with the rebounding waffle slab during the first dynamic test and fell to the test chamber's floor. Another column experienced movement but did not fall. It is recommended that future tests involving the use of upgrading columns also include efforts to determine the minimum bracing required to avoid excessive column movement when surface contact with the upgraded $\mathrm{slab}$ is lost.

The waffle-slab floor and flat-plate floor center portion models consisted mainly of positive moment areas and did not include concrete columns. Additional research is required for proper simulation of an upgraded floor system as it would exist in a building. Proper boundary conditions and areas having negative moment steel as well as the areas of positive moment steel could be simulated by models having nine bays with concrete columns. A ninebay model would consist of a floor system center bay, four corner bays, and four center-side bays, allowing investigation of bay interaction and concrete column response. During the time required to publish this report, work was initiated for the testing of $1 / 4-$ scale nine-bay models.

The test series discussed in this report concerned the upgraded slab only and not the walls of the basement shelter. In the development of upgraded basements in existing buildings for use as keyworker shelters, research is needed to evaluate the bahavior of basement walls when loaded and the effect of the wall behavior on the upgraded slab. Similarly, interaction of the upgraded slab with the aboveground structure should be investigated. During the time required to publish this report, plans were being made by FEMA to 
investigate the interaction of the basement walls and aboveground structure with the upgraded slab. 


\section{REFERENCES}

1. W. L. Huff; "Static and Dynamic Tests of Small Upgraded One-Way Slabs." (In Preparation); U. S. Army Engineer Waterways Experiment Station, CE, Vicksburg, Miss.

2. Mark K. McVay; "Test and Analysis of Upgraded One-Way Reinforced Concrete Floor Slabs," Technical Report SL-81-4, April 1981; U. S. Army Engineer Waterways Experiment Station, CE, Vicksburg, Miss.

3. American Concrete Institute; Building Code Requirements for Reinforced Concrete; ACI 318-77, 1977, Detroit, Mich.

4. Concrete Reinforcing Steel Institute; CRSI Handbook Based Upon the 1977 ACI Building Code; 3rd Edition, 1978; Chicago, Ill.

5. W. L. Huff; "Test Devices Blast Load Generator Facility," Miscellaneous Paper N-69-1, April 1969, U. S. Army Engineer Waterways Experiment Station, CE, Vicksburg, Miss.

6. W. L. Gamble and others; "A Study of Launch Facility Closures"; SAMSO-TR-67-15, November 1967, Space and Missile Systems Organization, Air Force Systems Command, Norton Air Force Base, Calif.; prepared by Department of Civil Engineering, University of Illinois, Urbana, Ill.; Unclassified.

7. John F. Brotchie, Amnon Jacobson, and Sadaji Okubo; "Effect of Membrane Action on Slab Behavior," Report R 65-25, August 1965, Massachusetts Institute of Technology, Department of Civil Engineering.

8. R. E. Crawford, C. J. Higgins, E. H. Bultman; "The Air Force Manual for Design and Analysis of Hardened Structures," Report AFWL-TR-74-102, October 1974, Air Force Weapons Laboratory, Kirtland Air Force Base, N. Mex.

9. M. E. Criswell; "Strength and Behavior of Reinforced Concrete SlabColumn Connections Subjected to Static and Dynamic Loadings," Technical Report N-70-1, December 1970, U. S. Army Engineer Waterways Experiment Station, CE, Vicksburg, Miss.

10. J. M. Biggs; Structural Dynamics, McGraw-Hill Inc., 1964.

11. S. P. Timoshenko and J. M. Gere; Theory of Elastic Stability, Second Edition, McGraw-Hill Inc., 1961, pp 158-161. 


\section{APPENDIX A}

TEST DATA, 19- BY 19- BY 3-INCH WAFFLE-SLAB PANELS, 19- BY 19- BY 3-INCH ONE-WAY SLABS, AND 30- BY 30- BY 3-INCH WAFFLE-SLAB PANELS 
Data from the tests on the 19- by 19- by 3-inch waffle-slab panels, 19by 19 - by 3 -inch one-way slabs, and 30 - by 30 - by 3 -inch waffle-slab panels are presented in this appendix. Labels on the plots indicate the following: Line 1: Test name

Line 2: Gage symbol

Line 3: Maximum value and calibration data

Line 4: Filter (if any)

Lines 5 and 6: Bookkeeping data. 


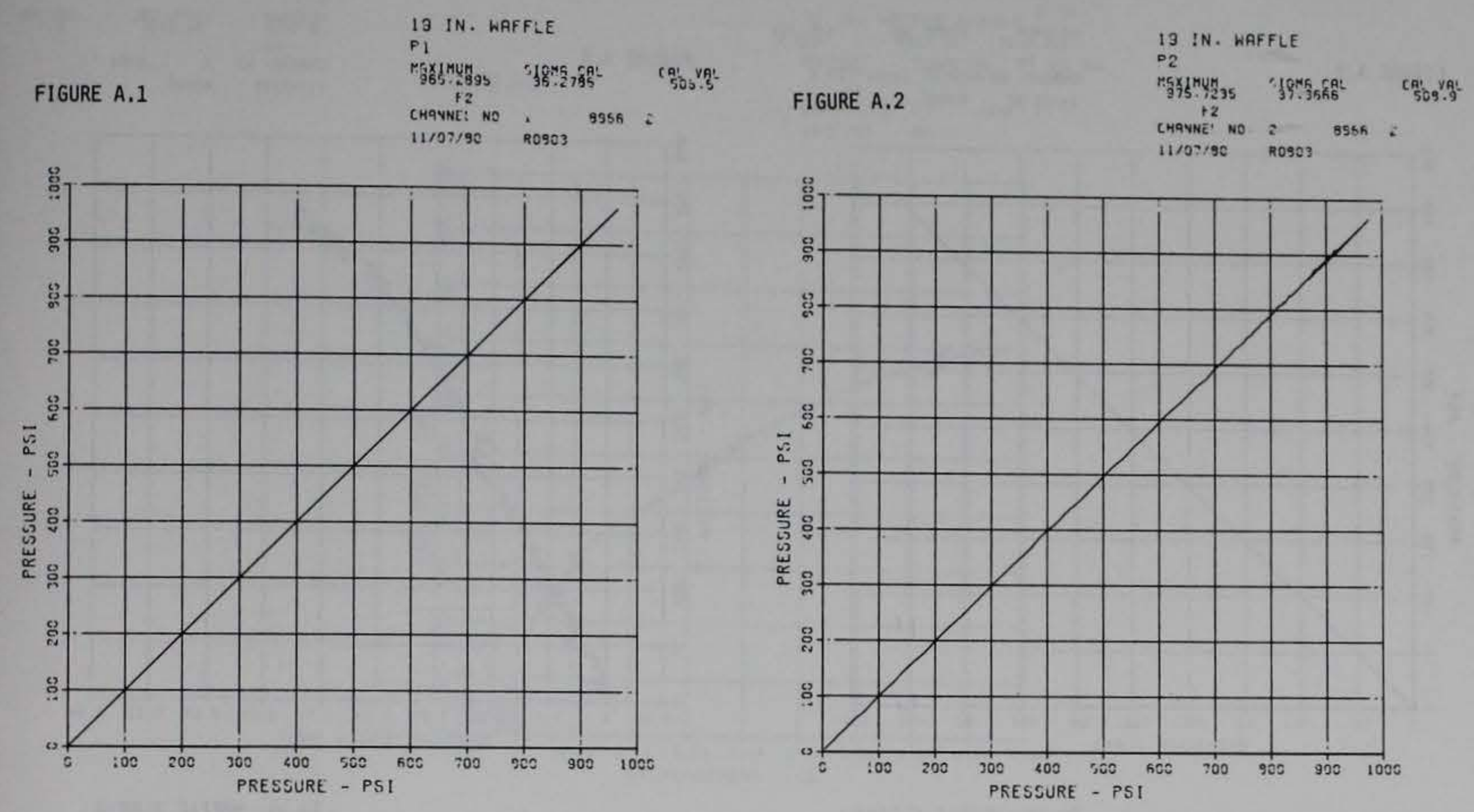

19 IN. WAFFLE

0

FIGURE A.3

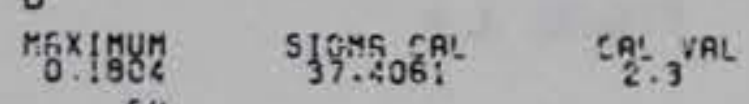
CHANNEI NO ? B956 : $11 / 07 / 9 C$ ROSE3

FIGURE A.4

13 IN. ENE-WAY JUIST

iP - i

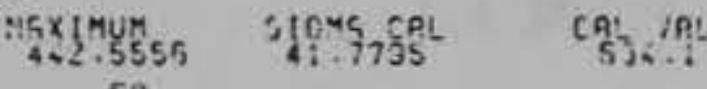
F2
CHOVNE: N9 POPOC
I1/12/96 :
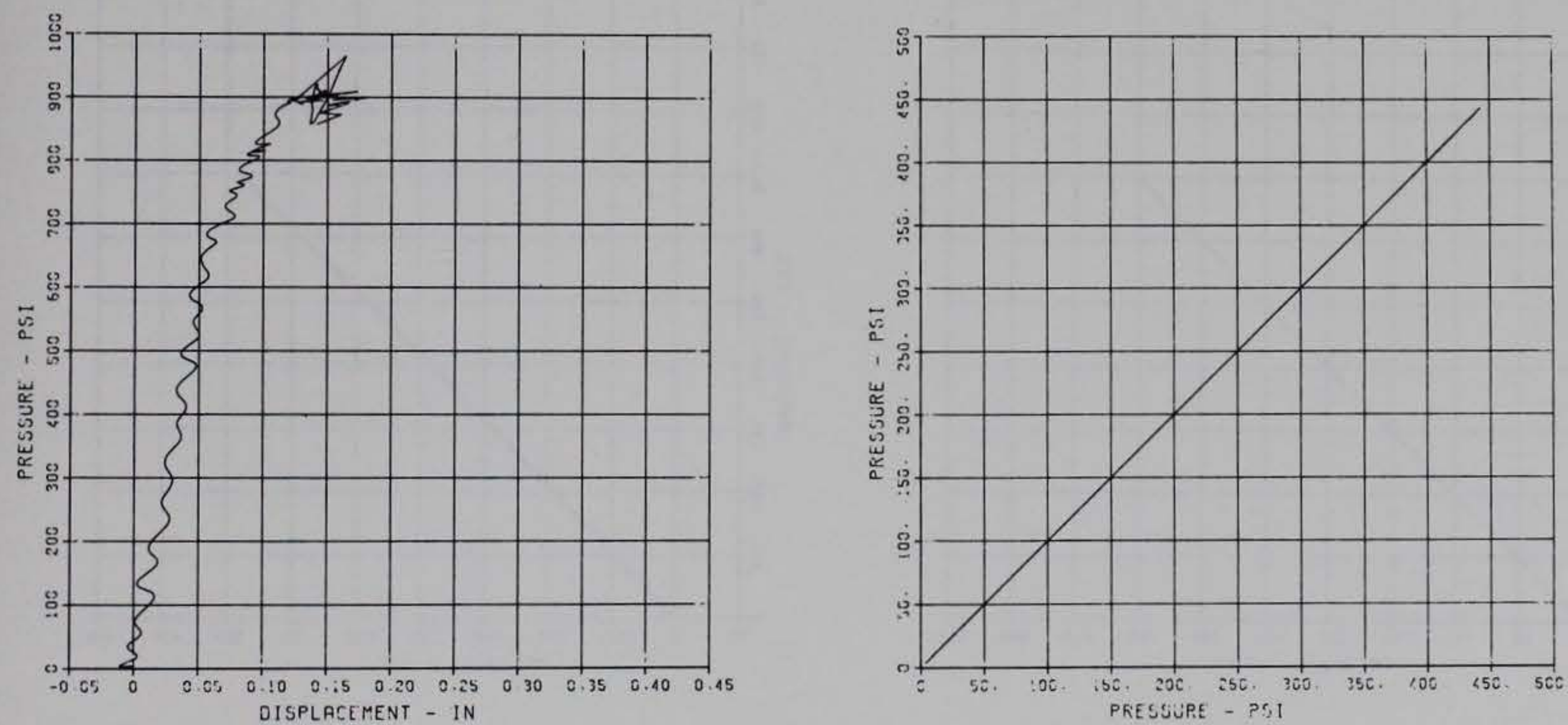
IG IN. ONE-WAY JOIST

!P. 2

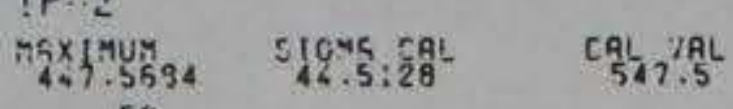

FIGURE A. 5

F2
CHANEE NO
$11 / 12 / 80$ ROS9O

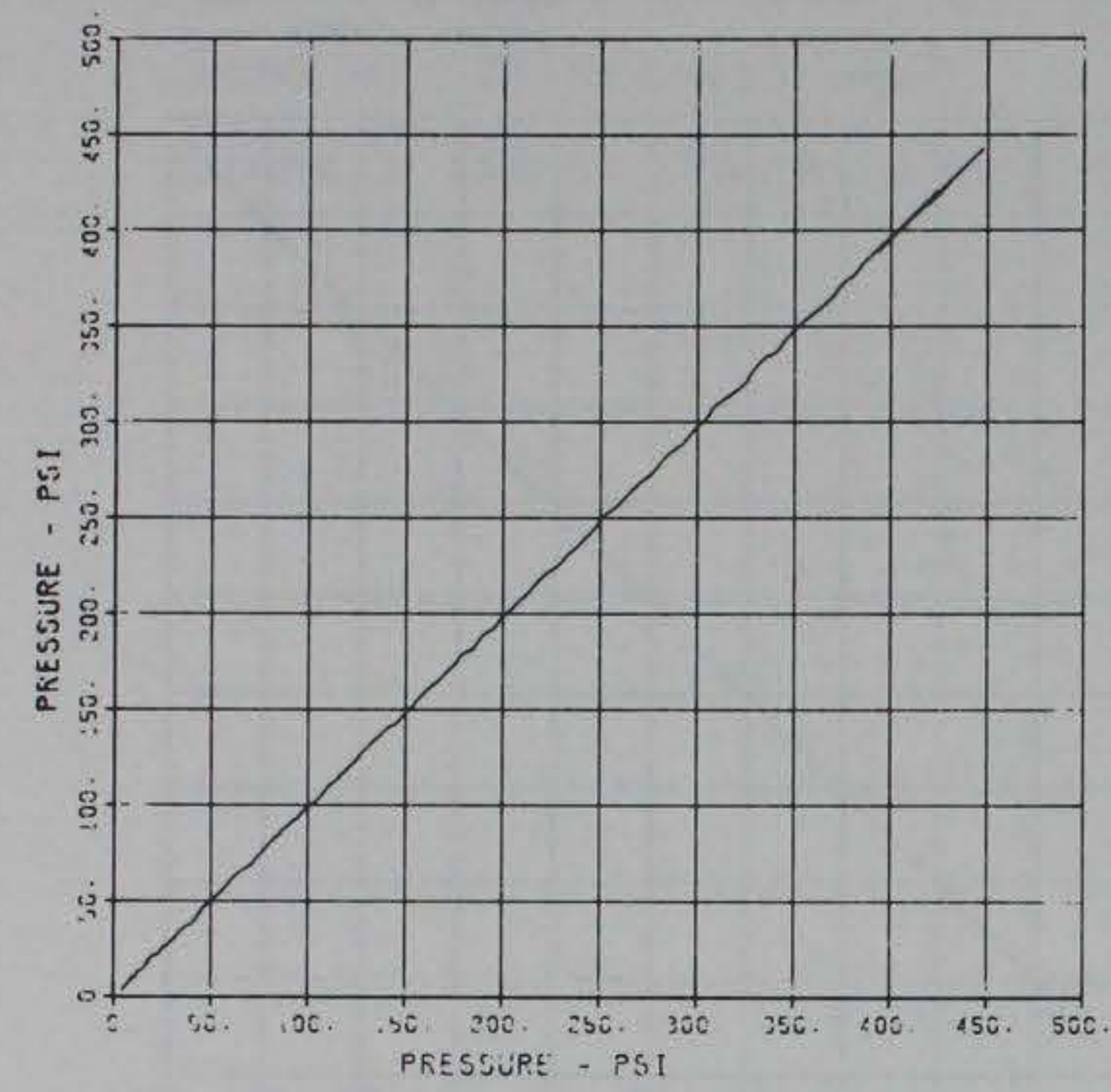

30 IN. WAFFLE. SLAB-2

$P 1$

MGXJMUM शुCMA CAL 350.9795 CAL VAL

FIGURE $A .7$

CHANNE: NO : 1979 ।

$11 / 28 / 80 \quad$ R0097

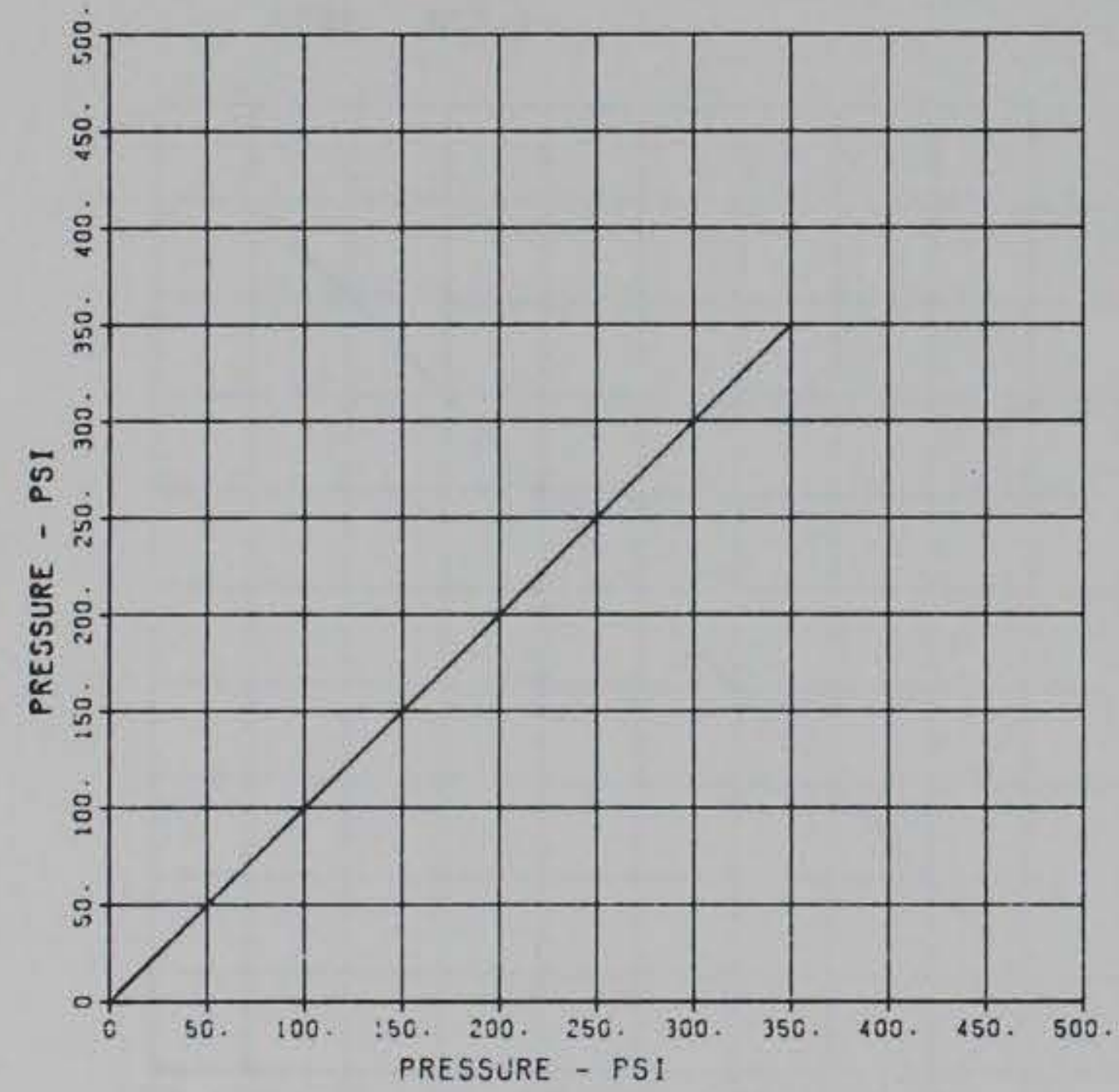

19 IN. CNE-WAY JOIST

D-1

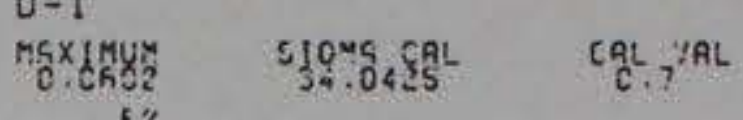

CHANNE: NO 2 12769 I

$11 / 12 / 80$ R0990

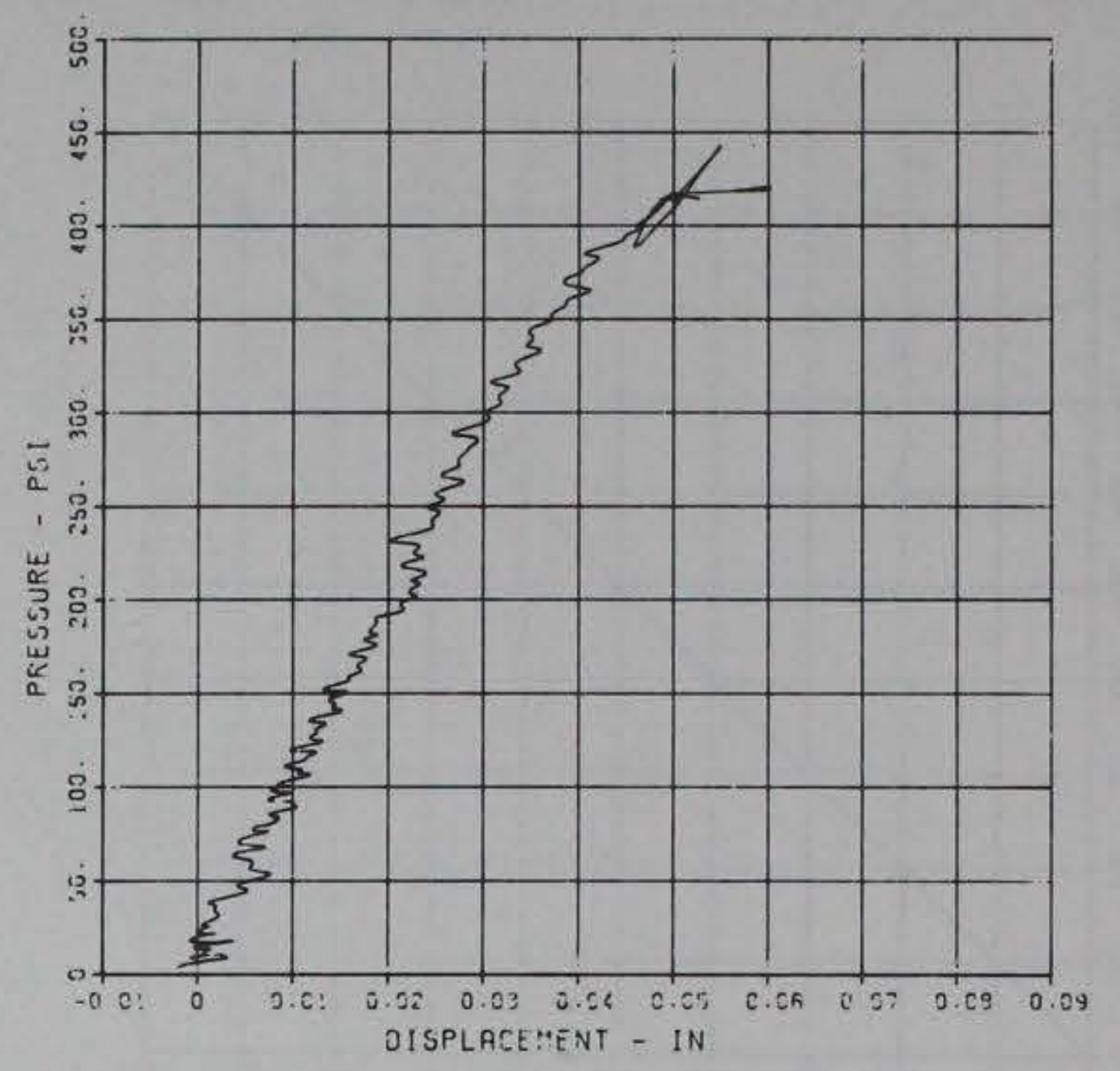

30 IN. WAFFLE SLAB-2

MAXIMUM 51 JMA CAL

CHANNEL NO. 2 1978 1

$11 / 28 / 80$ R0097

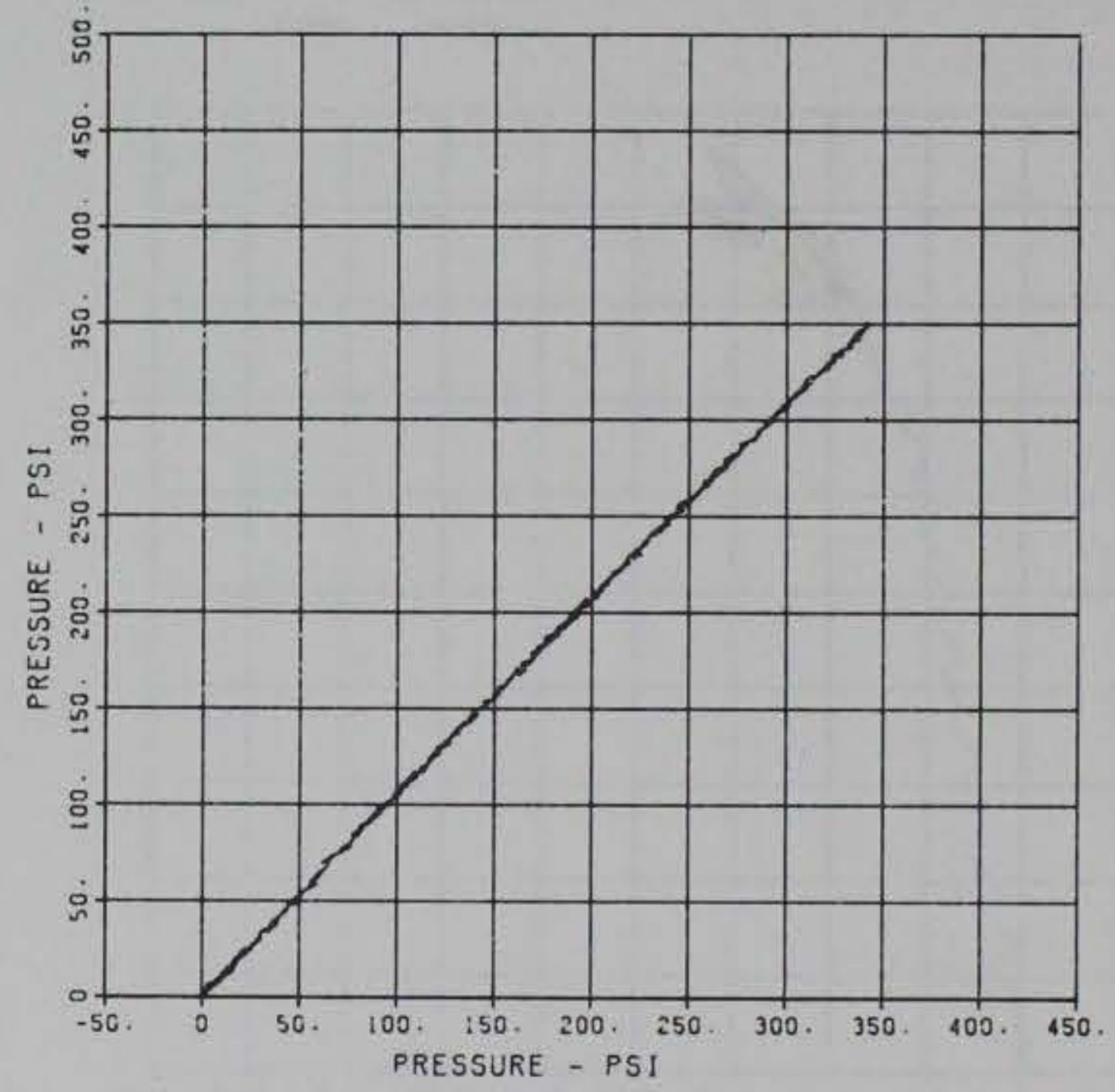



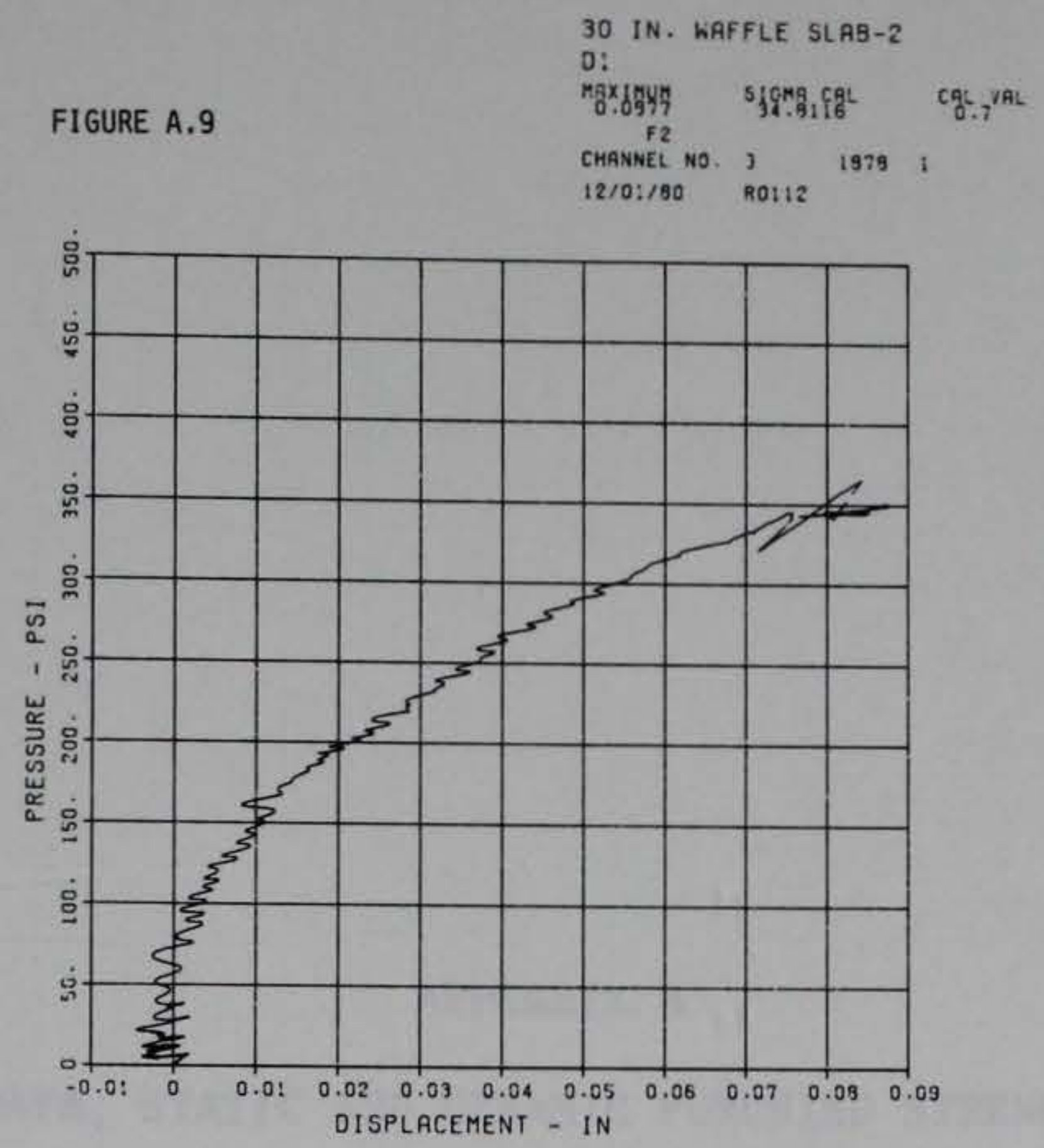
APPENDIX B

TEST DATA, STATIC AND DYNAMIC PUNCHING STRENGTH TESTS ON 4-INCH-THICK SLABS ON GRADE 
Data from the static and dynamic punching strength tests on 4-inch-thick slabs on grade are presented in this appendix. Labels on the static test plots (Figures B.1-B.8) indicate the following:

Line 1: Test name

Line 2: Gage symbol

Line 3: Maximum value and calibration data

Line 4: Filter (if any)

Lines 5 and 6: Bookkeeping data.

Labels on the dynamic test plots (Figures B.9-B.14) indicate the following:

Line 1: Test name

Line 2: Gage symbol

Line 3: Digitizing rate and calibration curve

Line 4: Filter (if any)

Line 5: Bookkeeping data. 


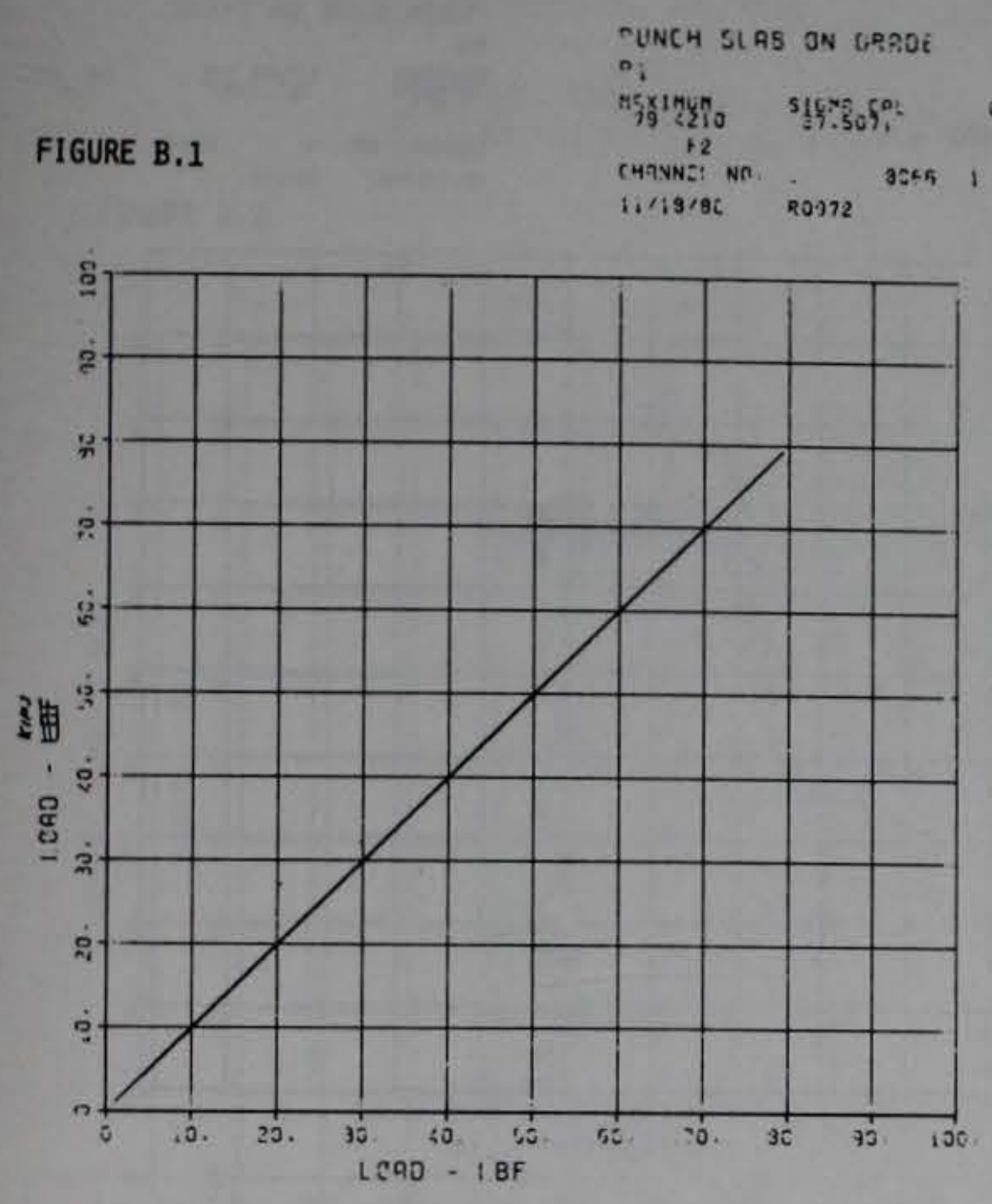

DUNCH SL AS JN GRADE

$\mathrm{O} 2$

FIGURE B.2

PUNCH SLAS ON GRROK

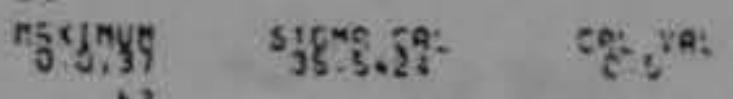

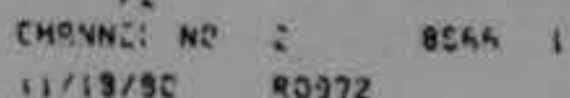

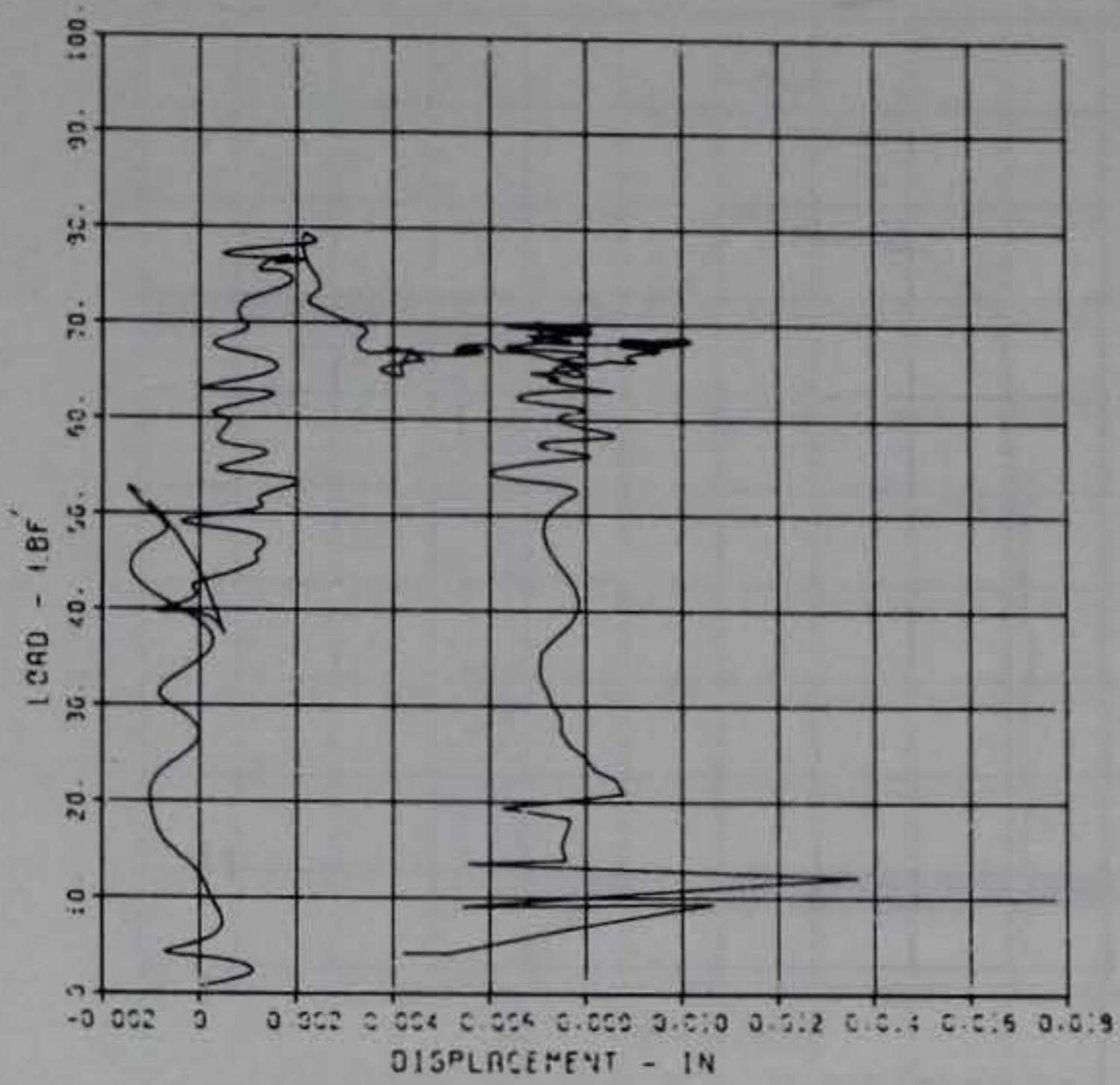

PUNCH SLAS ON GRAOL

O3

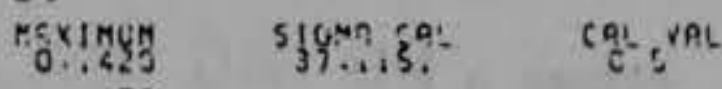

CHOVNẼL NO. \& S9K, :

li/:9/96 R0372

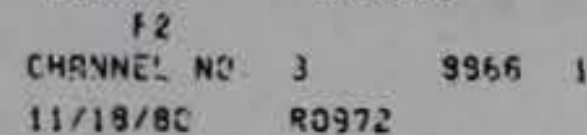

FIGURE B.4
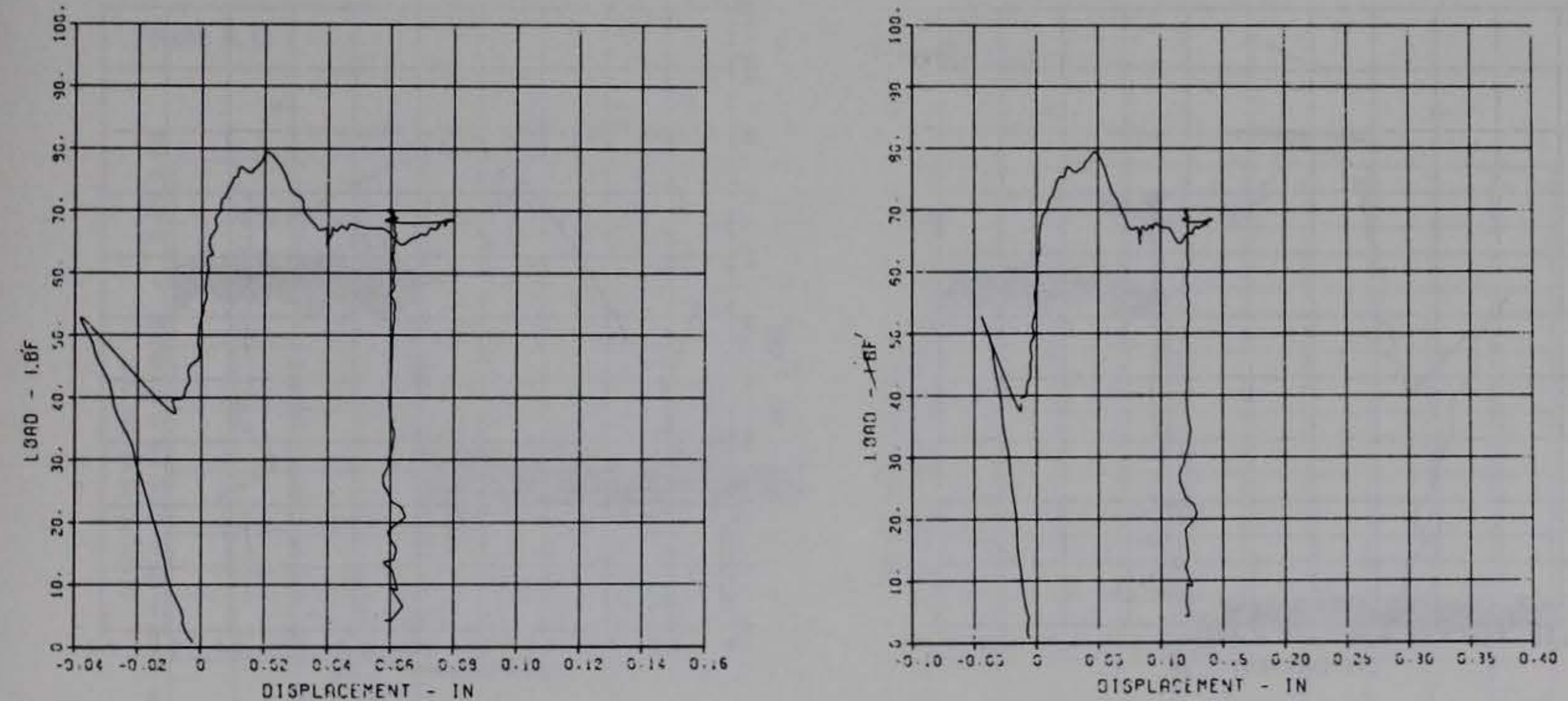


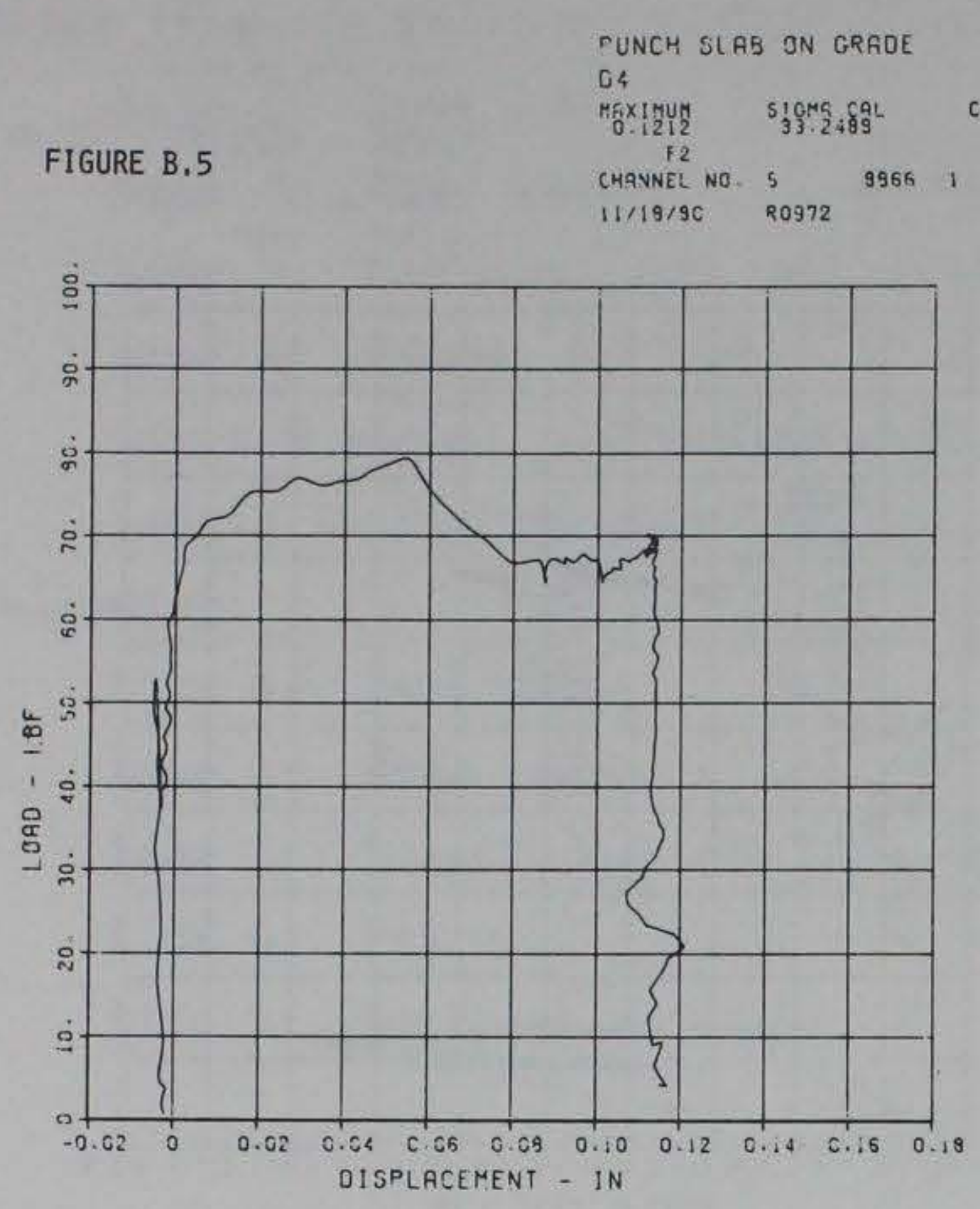

PUNCH SLAB ON GRADE

OG

MaxinUM SुgMa CPL CAL VRL

FIGURE B.7

$\begin{array}{llll}\text { F2 } & \\ \text { CHANNE! NO. ? } & 9866 \quad \text { I } \\ \text { II/1B/BC RO972 } & & \end{array}$

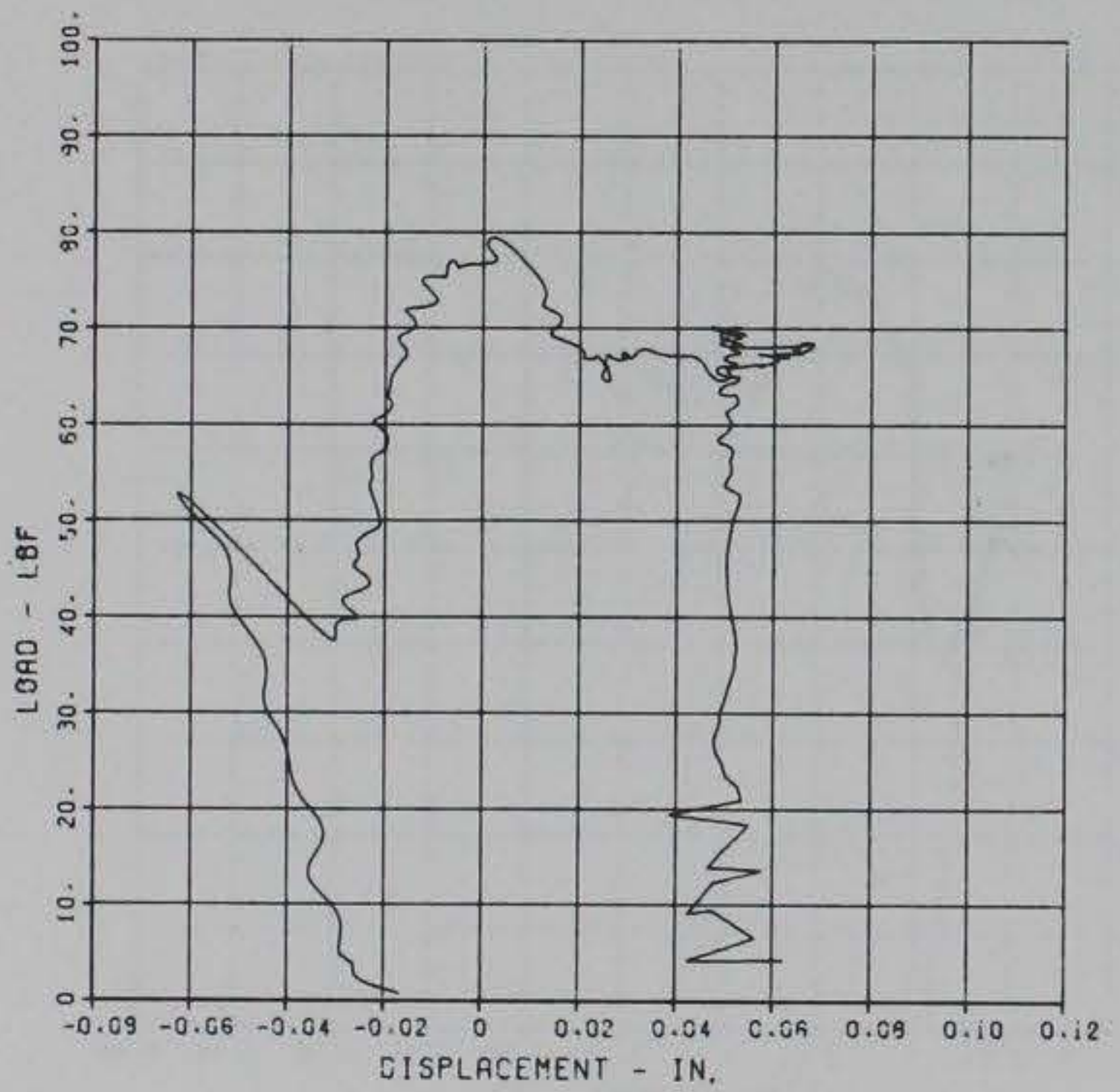

PUNCH SLAS ON GRADE

DS

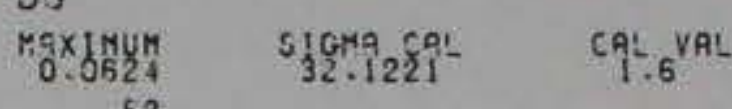

CHQNNEL NO . 5 \$966 ।

$11 / 19 / 90 \quad$ R0972

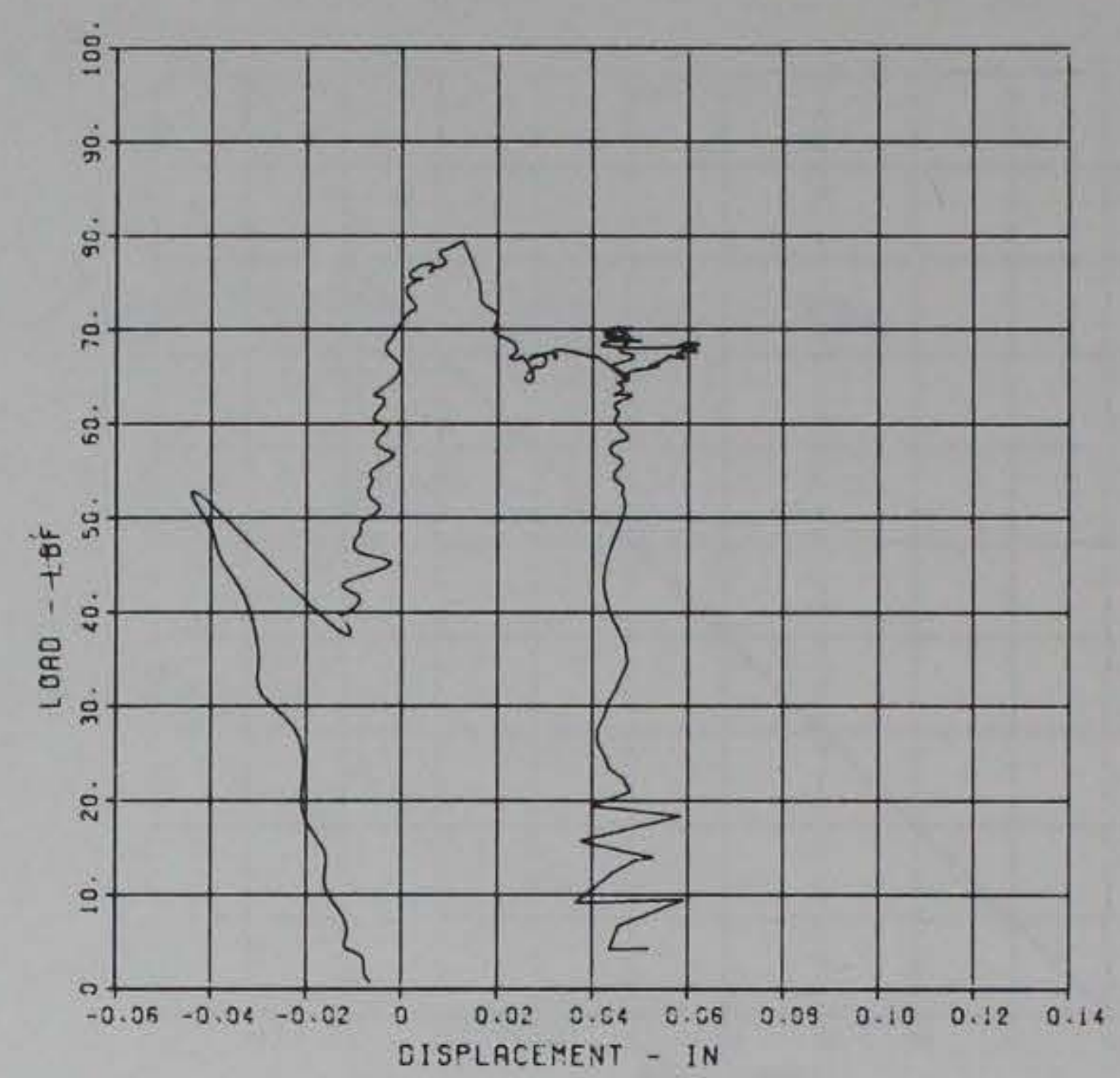

PUNCH SLAS ON GRADE

07

MSXIMUM S1GM9GRL CAL VAL CHANNEL NB. 3 8966 $11 / 18 / 9 C \quad R 0972$

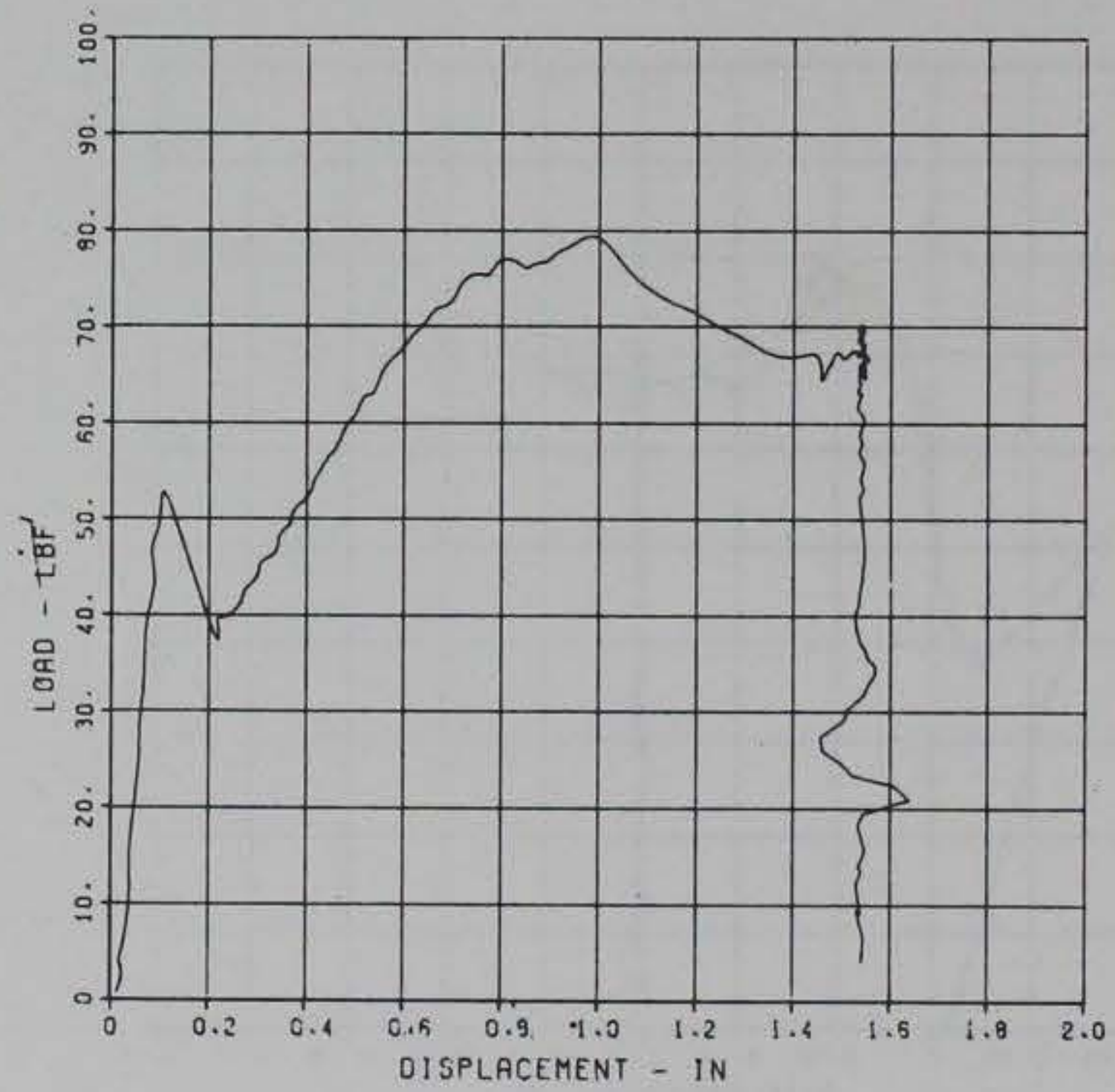




\section{DYN PUNCH SLAB ON GR$$
L-1
$$

$$
\begin{aligned}
& \text { 10000. HZ CAL }=170.3 \\
& \text { LP4 70\% CUTOFF }=450.0 \mathrm{HZ}
\end{aligned}
$$

FIGURE B. 9

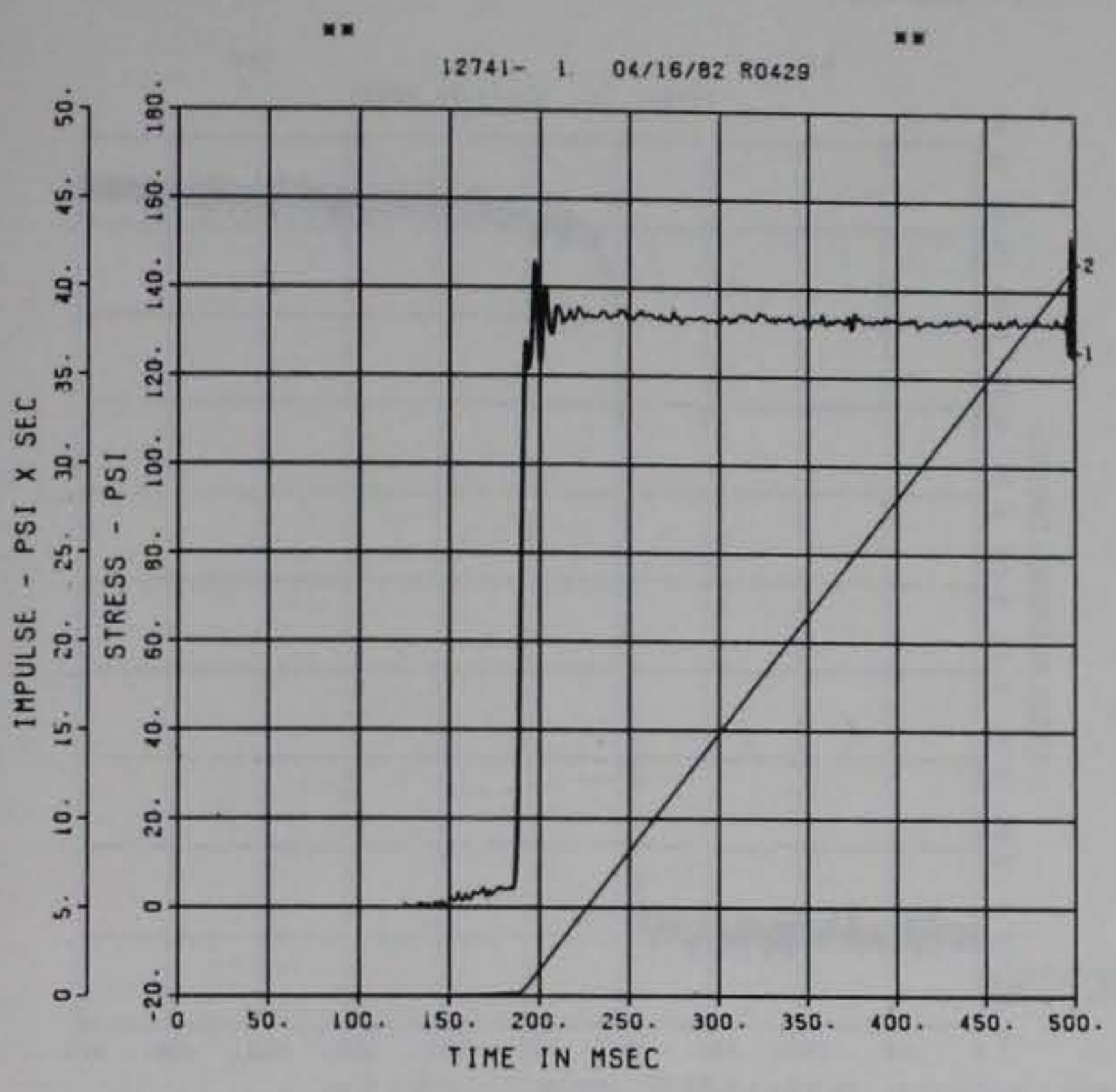

DYN PUNCH SLAB ON GR

$$
D-3
$$

10000. $\mathrm{HZ} \quad \mathrm{CAL}=0.280$

FIGURE B. 11

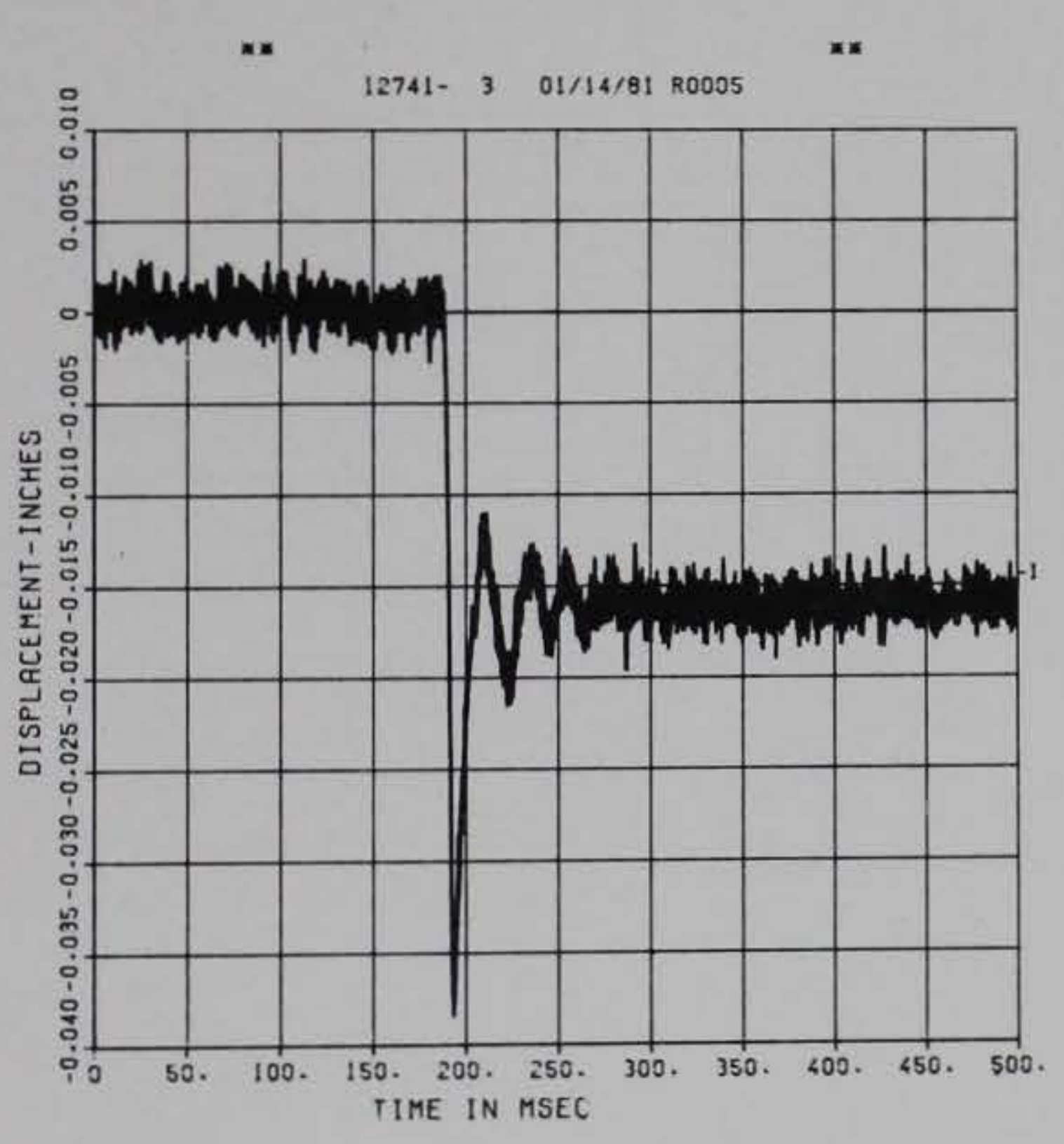

DYN PUNCH SLAB ON GR

$$
\mathrm{D}-2
$$

10000. HZ CAL $=0.240$

FIGURE B. 10

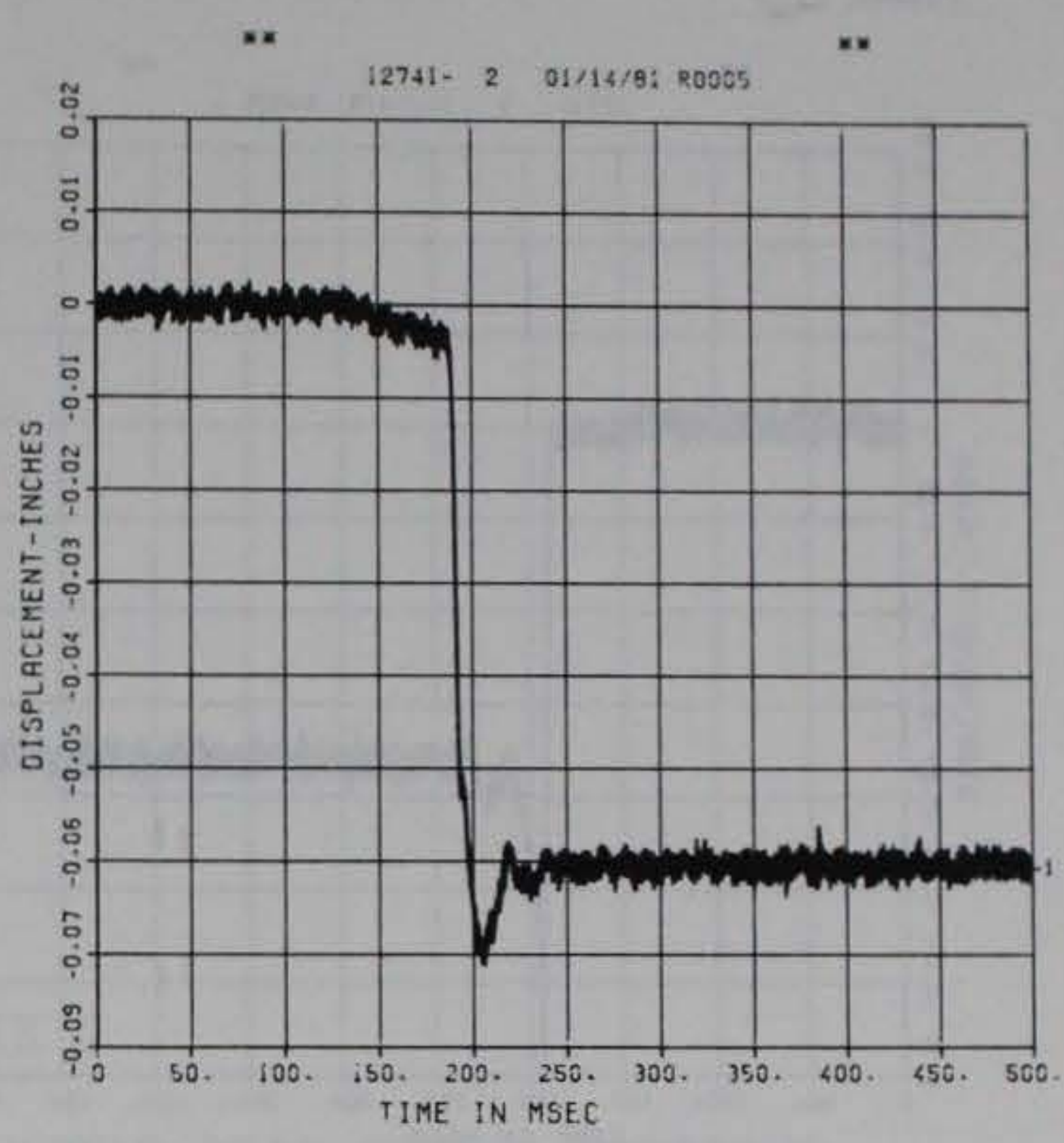

DYN PUNCH SLAB ON GR

$$
D-5
$$

10000. $\mathrm{HZ} \quad \mathrm{CAL}=0.340$

FIGURE B. 12

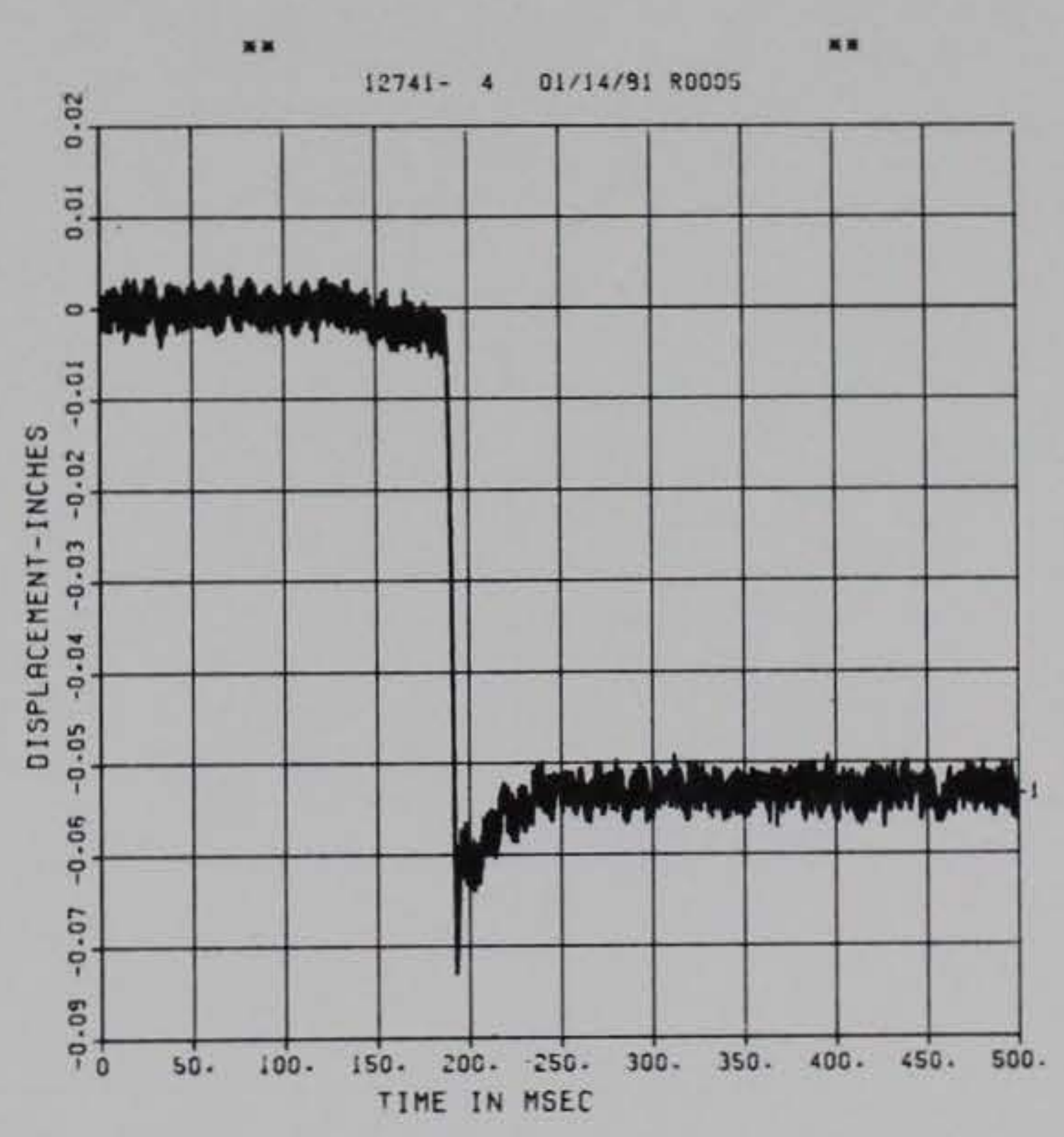


DYN PUNCH SLAB ON GR

$$
D-6
$$

10000. $\mathrm{HZ} \quad \mathrm{CAL}=0.360$

FIGURE B. 13

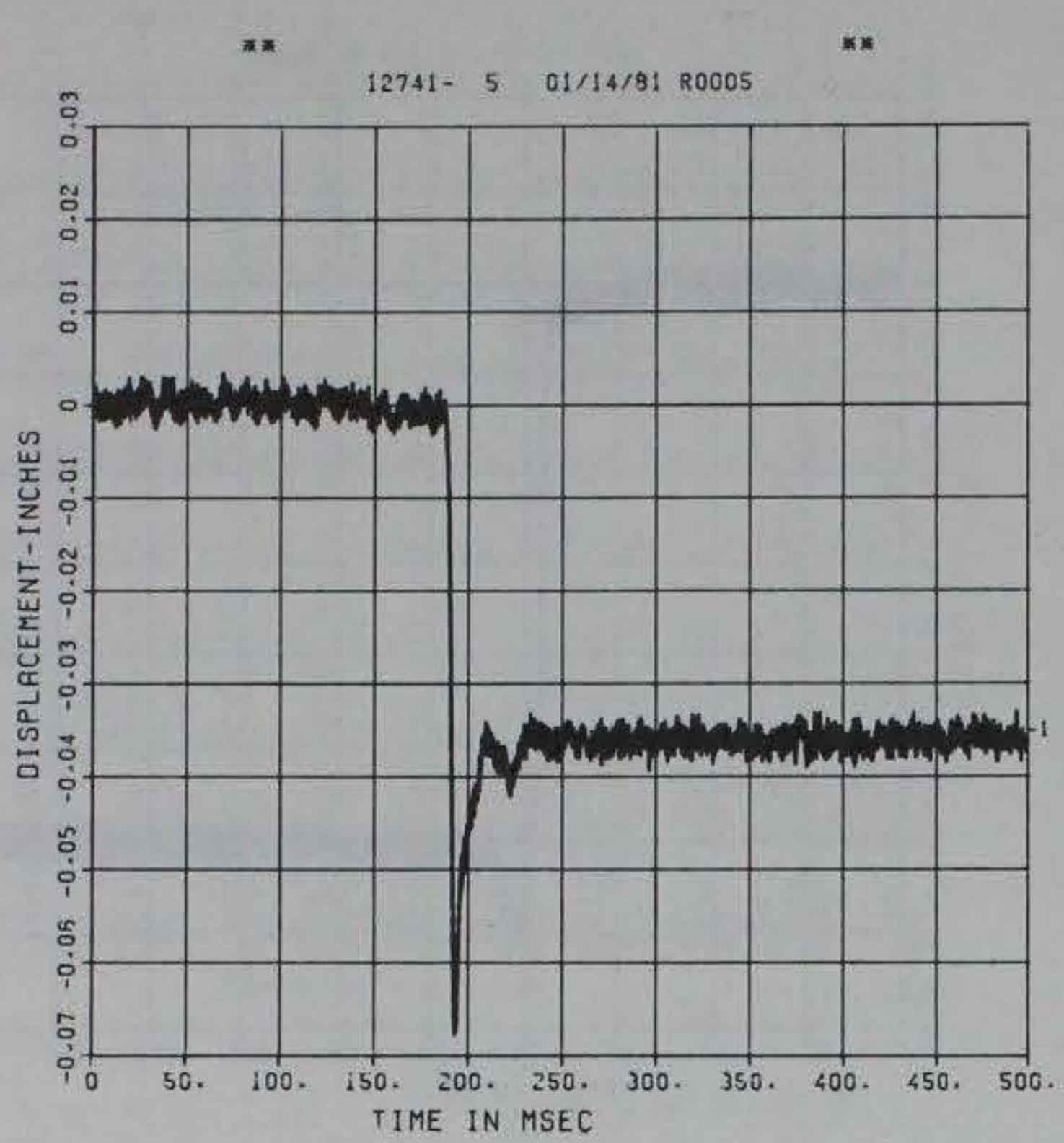

DYN PUNCH SLAB ON GR D-7

10000. $\mathrm{HZ} \quad \mathrm{CAL}=1.690$

FIGURE B. 14

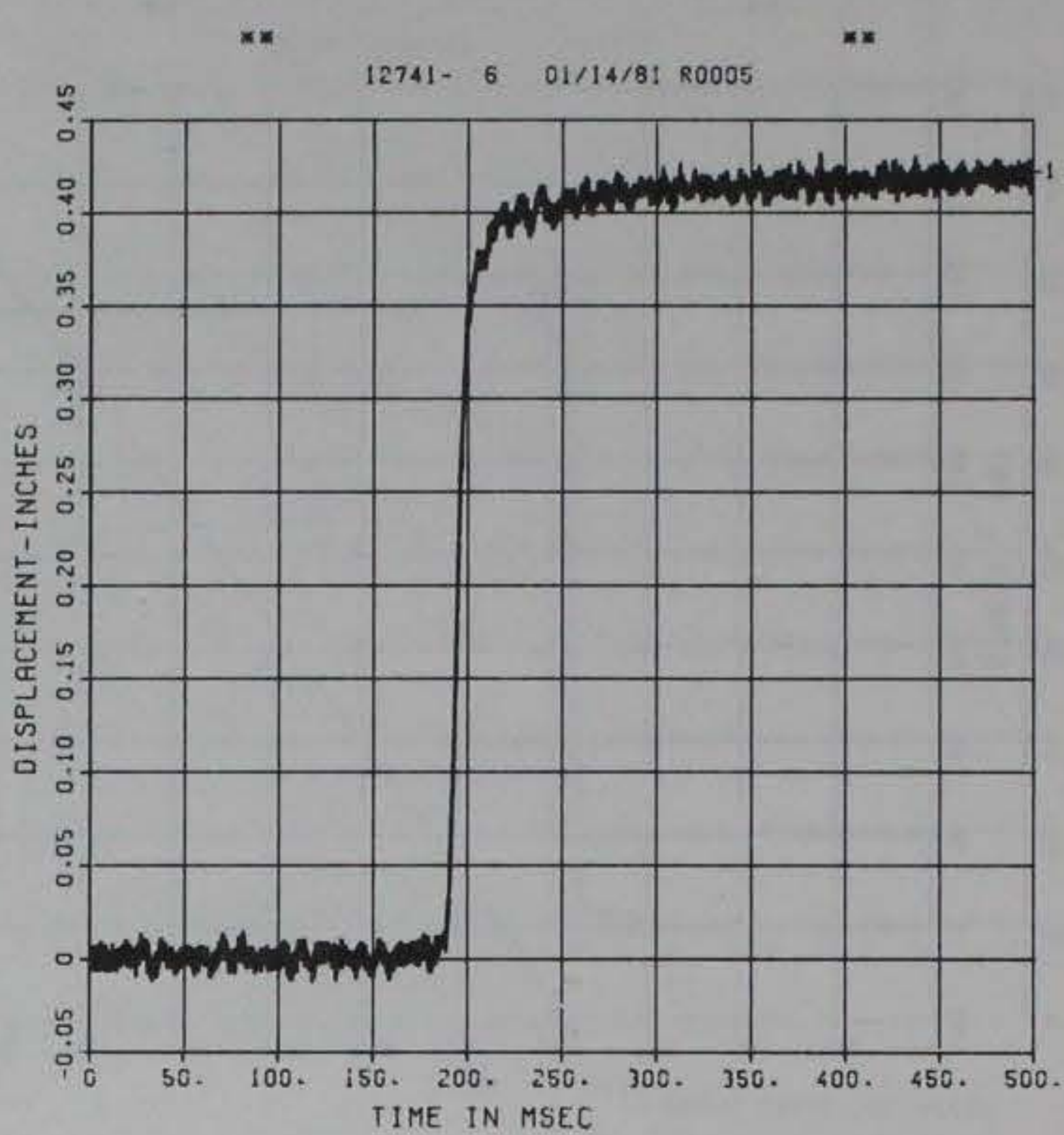




\section{APPENDIX C}

STATIC AND DYNAMIC TESTS ON WAFFLE-SLAB CENTER PORTIONS 
Data from the static and dynamic tests on the waffle-slab center portions are presented in this appendix. Labels on the static test plots (Figures C.IC.37) indicate the following:

Line 1: Test name

Line 2: Gage symbol

Line 3: Maximum value and calibration data

Line 4: Filter (if any)

Lines 5 and 6: Bookkeeping data.

Labels on the dynamic test plots (Figures C.38-C.131) indicate the following:

Line 1: Test name

Line 2: Gage symbol

Line 3: Digitizing rate and calibration curve

Line 4: Filter (if any)

Line 5: Bookkeeping data. 


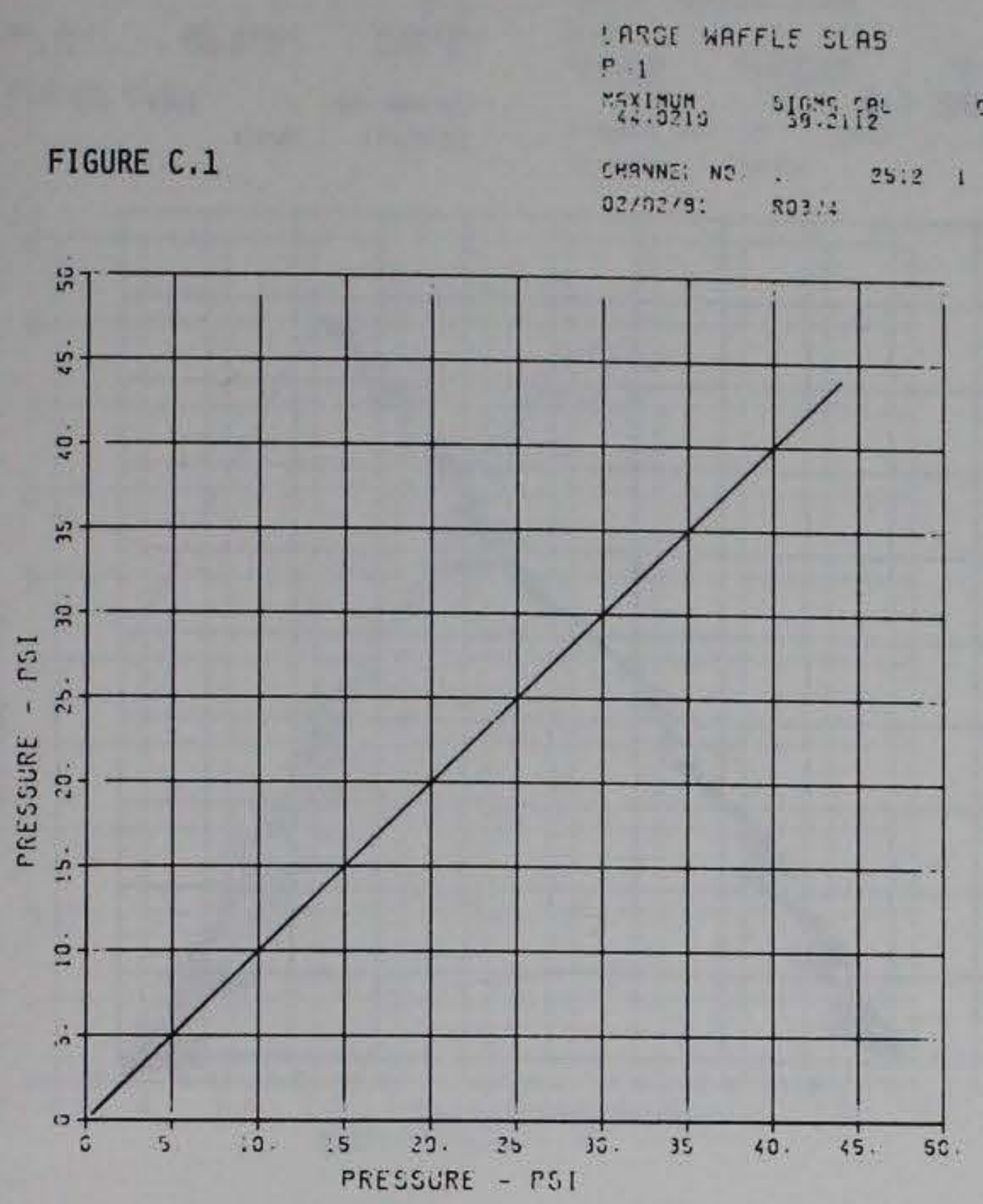

32.2

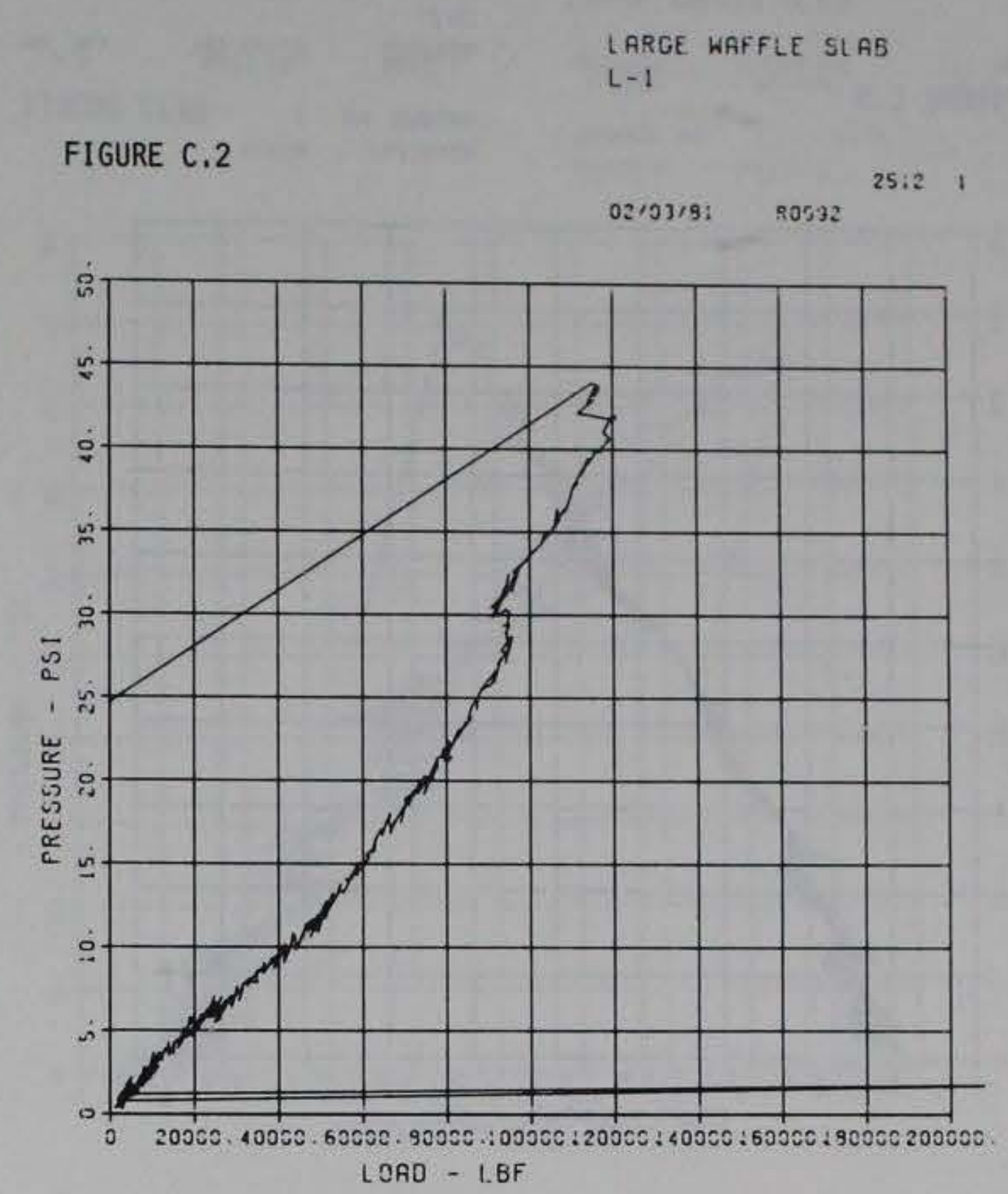

IARGE WAFFLE SLAS

$L-2$

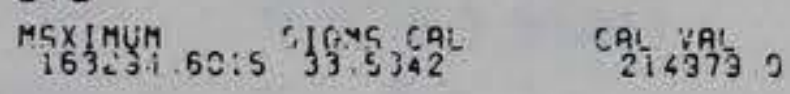

FIGURE C. 3

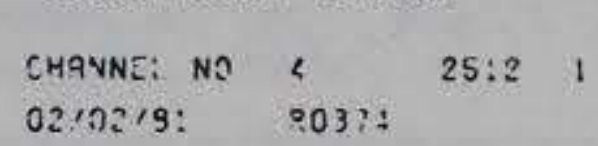

FIGURE $C .4$

LARGE WAFFLE SLAB

$0-1$

MAX
1.5920

$\begin{array}{llll}\text { CHANNEL NO. } 5 & 25: 2 \quad 1\end{array}$
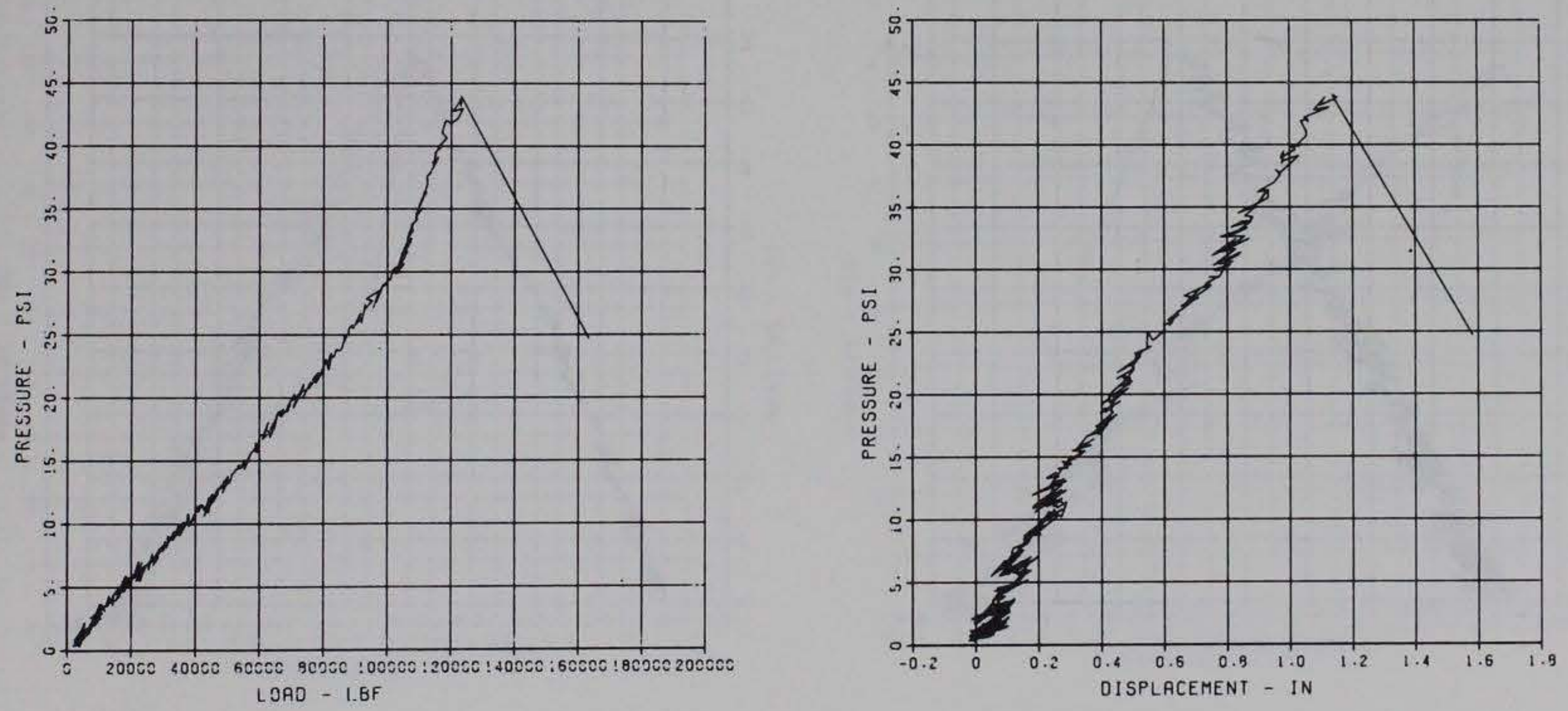
FIGURE C. 5
LARGE WAFFLE SLAB

MAXIMUM SG MA CAL CAL VAL

LARGE WAFFLE SLAB

DO

MEX.

FIGURE C. 6

$\begin{array}{llll}\text { CHANNEL NO. } 7 & 75: 2 \quad 1 \\ 03 / 02 / 91 & \text { R0374 }\end{array}$

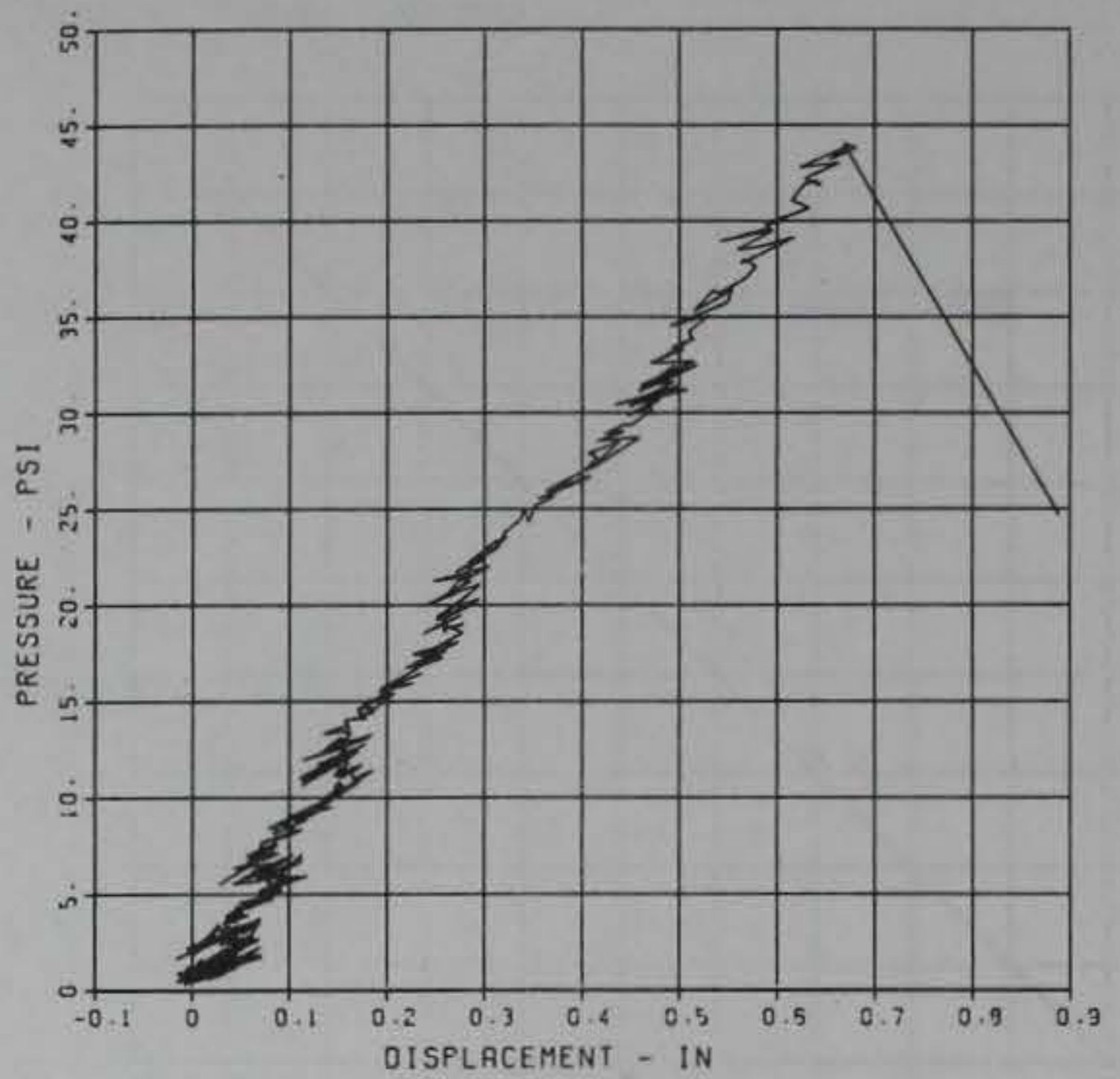

LARGE WAFFLE SLAB

LARGE WAFFLE SLAB

MAXIMUM गुOMG

FIGURE C.7 $\begin{array}{llll}\text { CHANNEL NE } & ? & 25: 2 \quad \\ 02 / 02 / 9: & \text { R0374 } & & \end{array}$

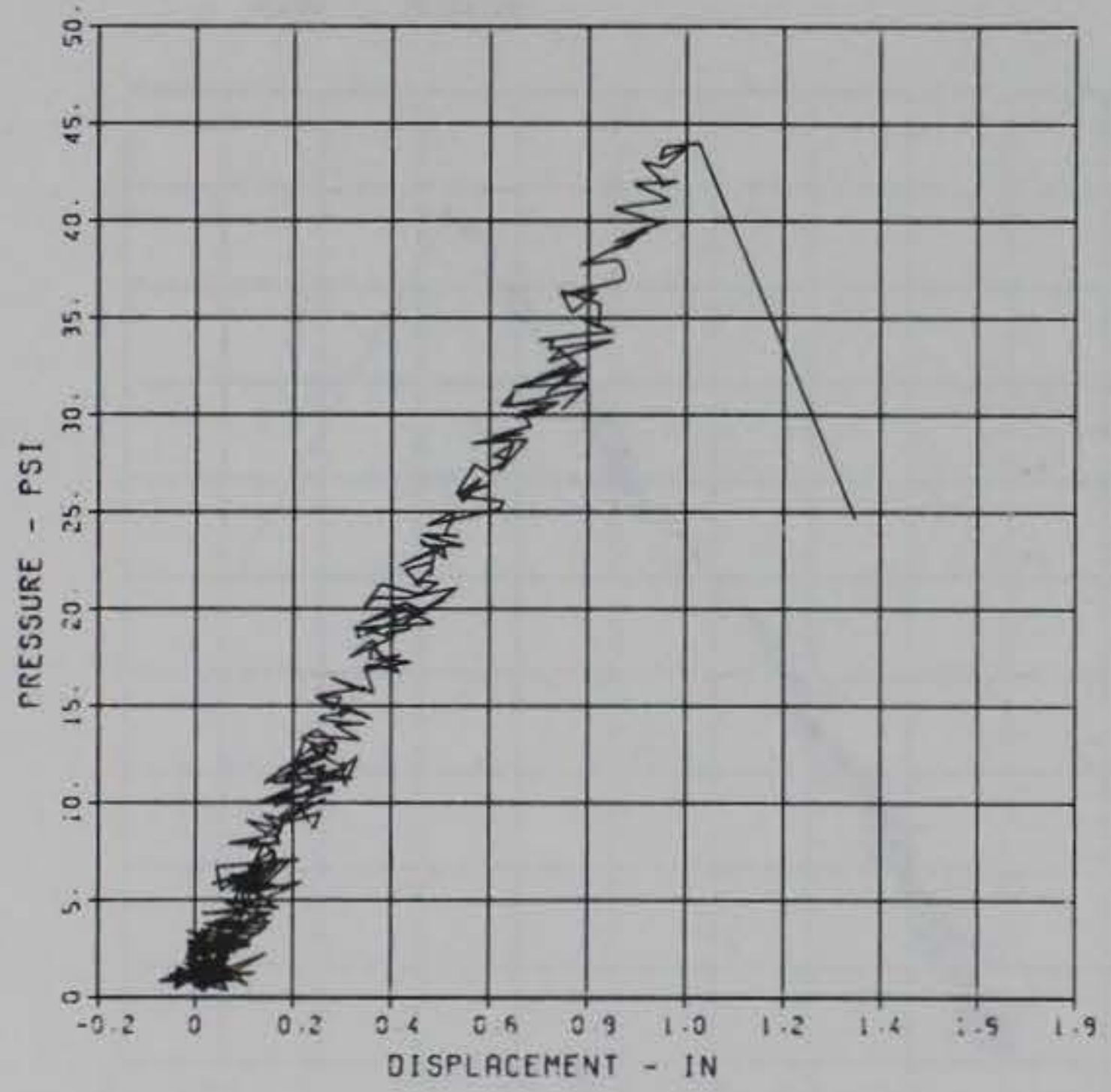

DO

FIGURE C. 8 $\begin{array}{llll}\text { CHANNEL NO } & 9 & 25: 2 & 1 \\ \text { O2/02/91 } & \text { R0374 } & & \end{array}$

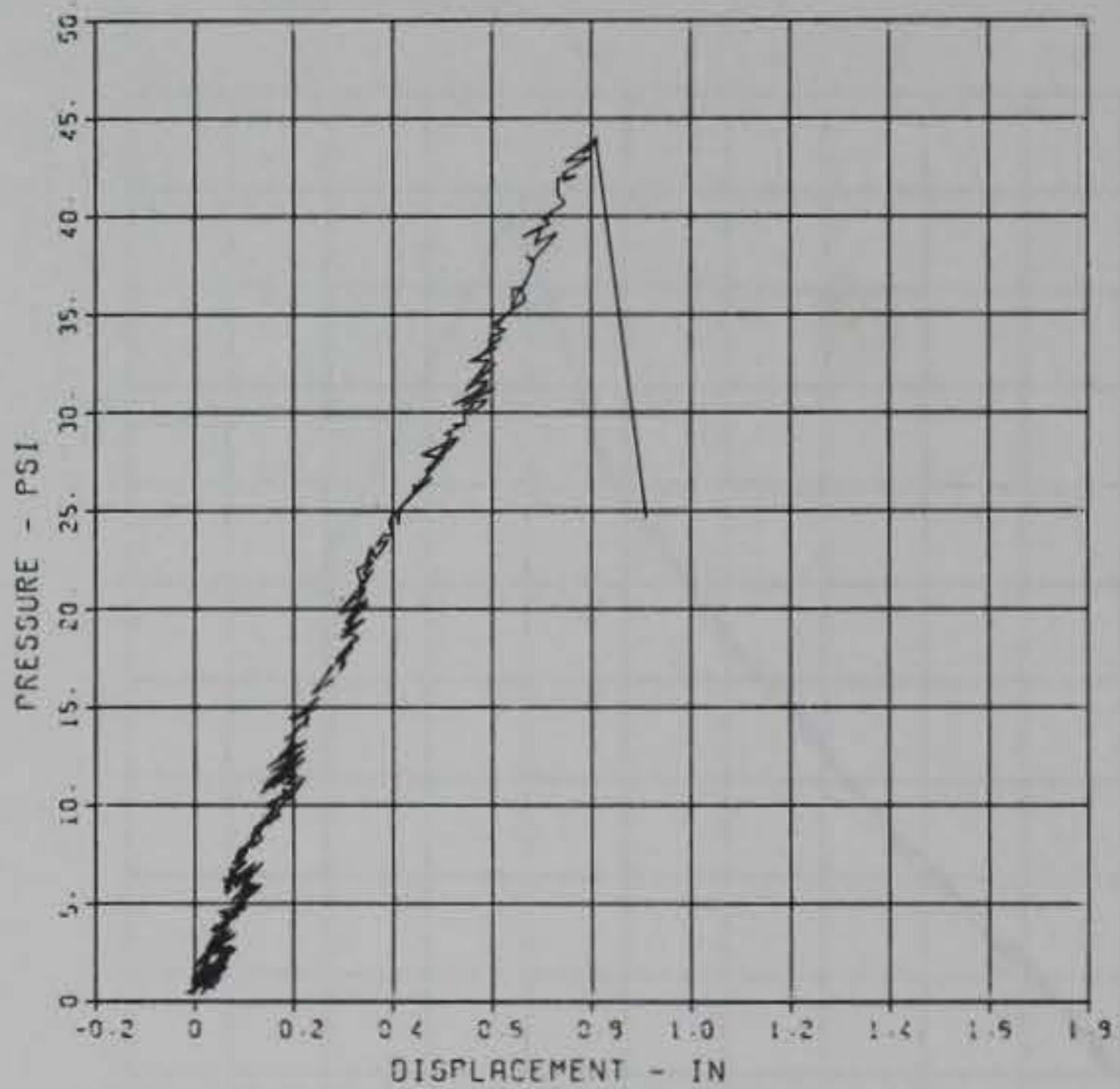

114 


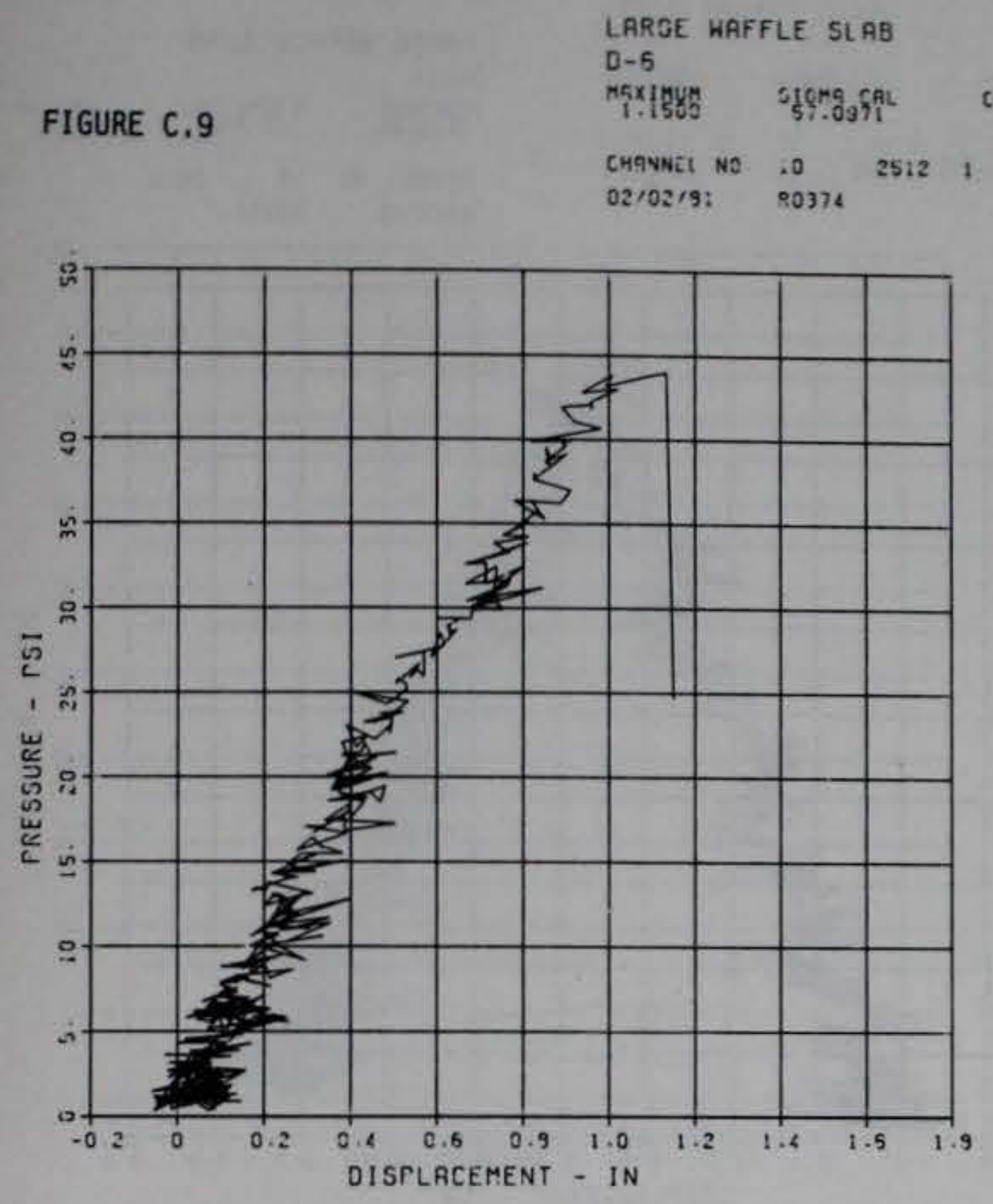

FIGURE C. 10

LARGE WAFFLE SLAG

$0-?$

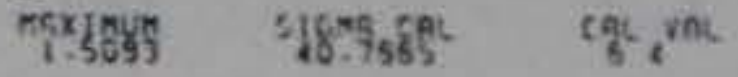

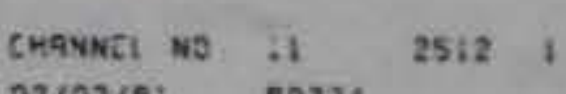

02/92/8: 80374

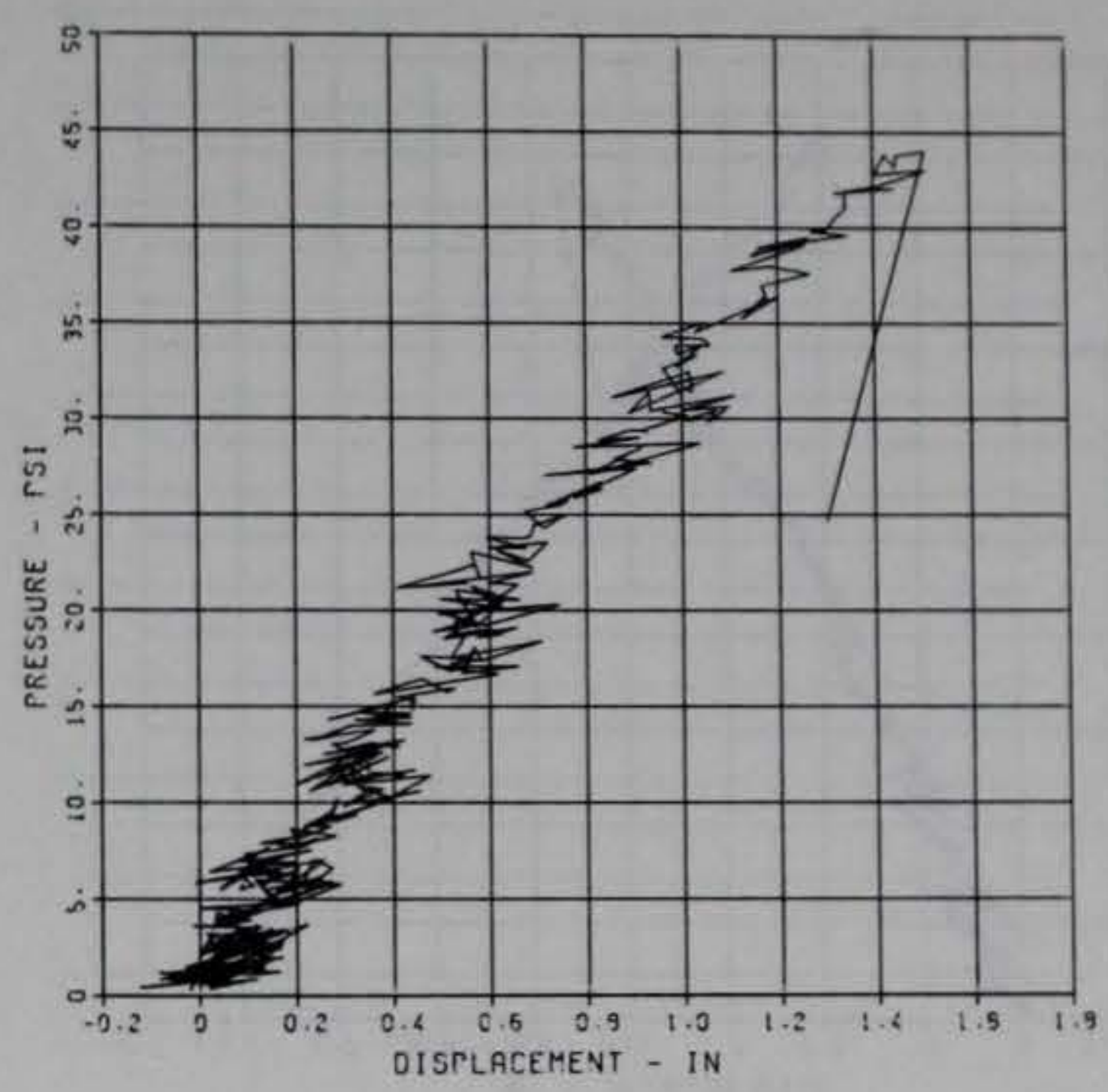

LARGE. WAFFLE SLAB

$D-9$

MgXIMUM

FIGURE C. 11

IRRGE WAFFLE SLAB

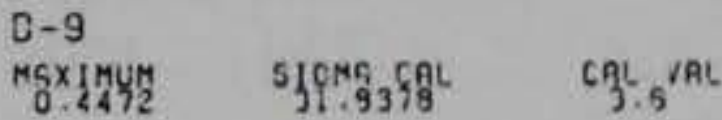

CHANNEL NO :2 $25: 2$ ।

CHANNEL NO : 3 25:2 ।

$02 / 02 / 91 \quad R 0374$
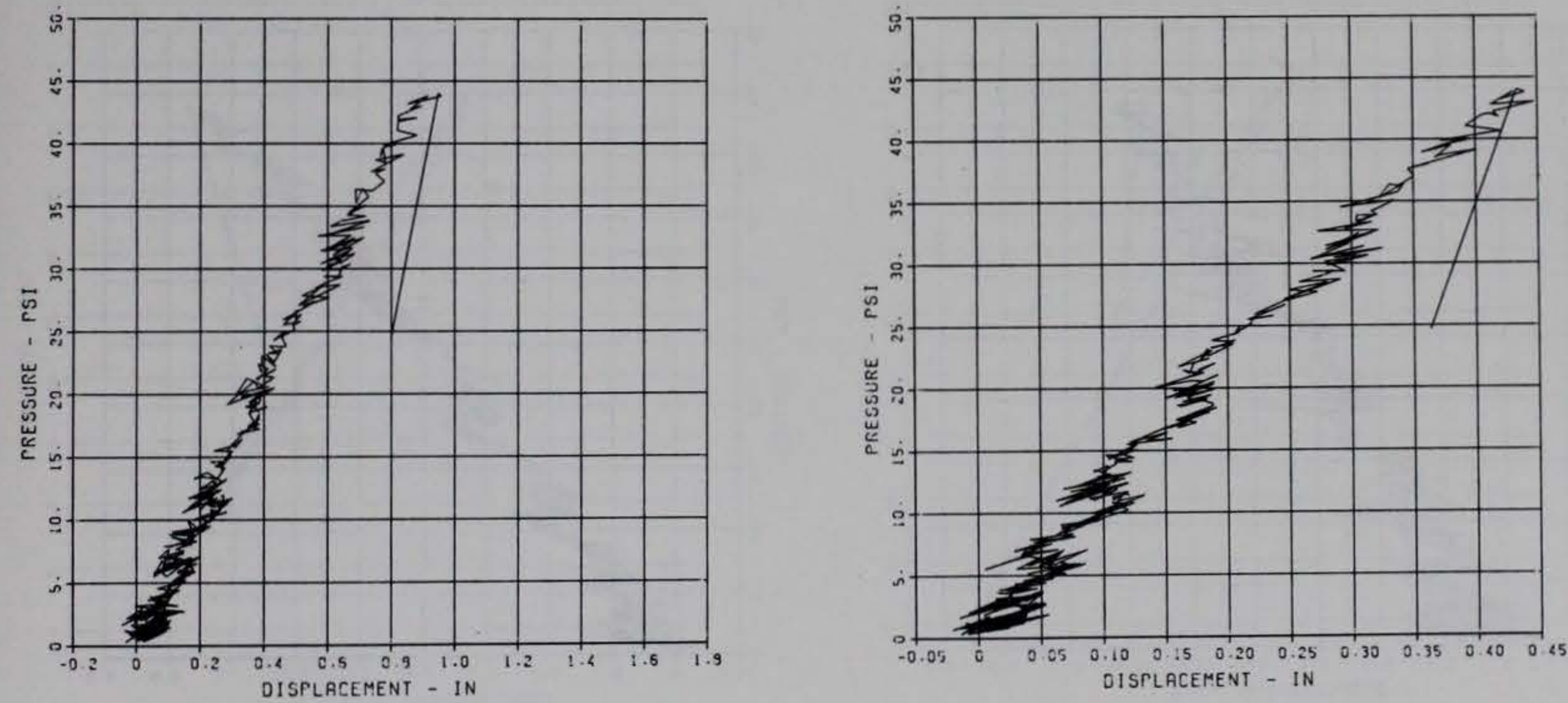
LARGE WAFFLE SLAB

$\mathrm{C}-10$

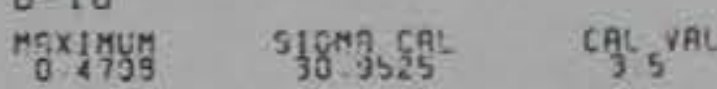

FIGURE C.13

CHONNEI NO IS 2S:2 1

$02 / 02 / 91$ R0374

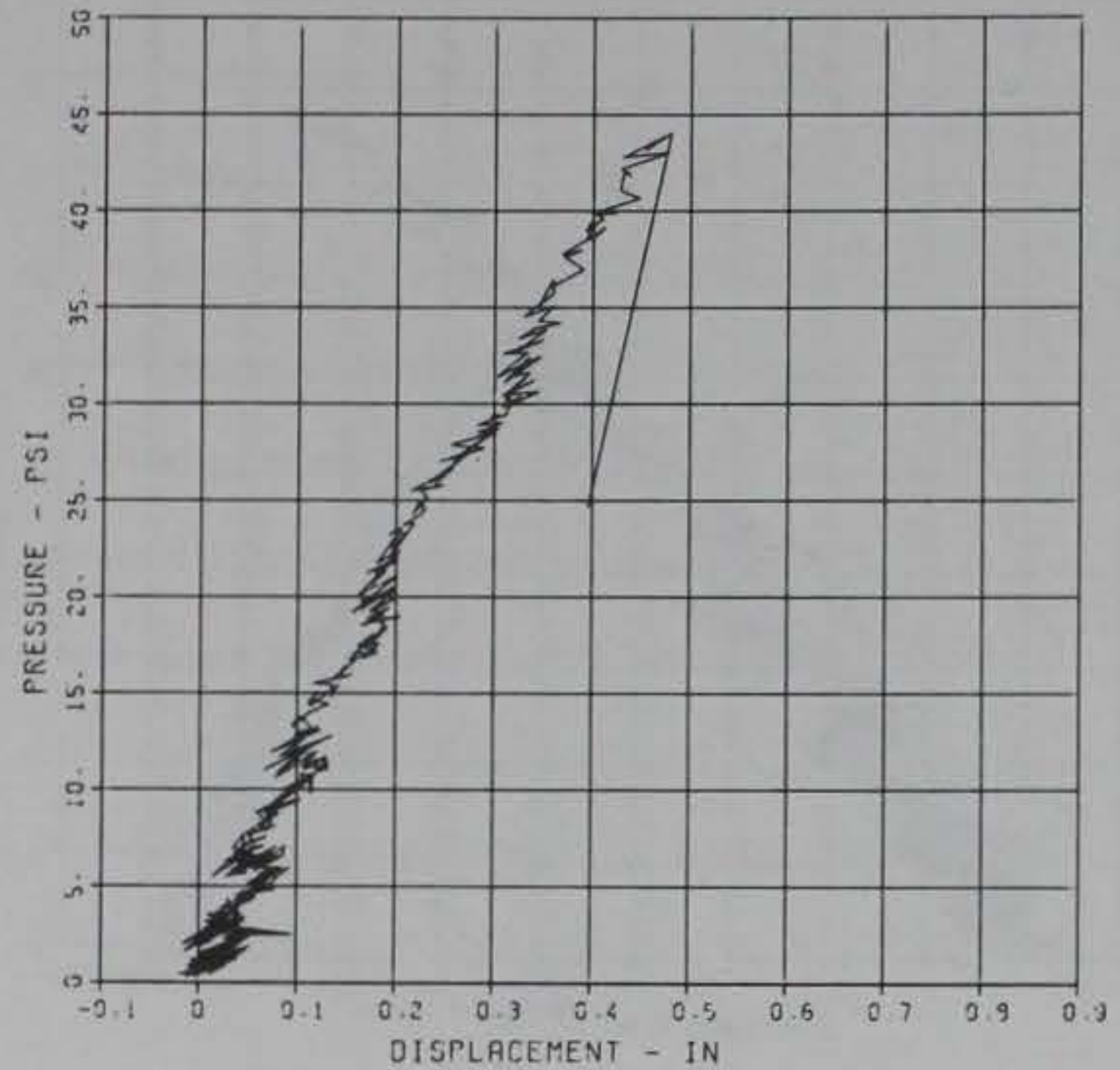

LARGE WAFFLE SLAB

$0-12$

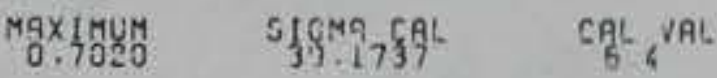

$\begin{array}{llll}\text { CHANNEL NO } & : 5 & 25: 2 & 1 \\ \text { O2/02/9: } & \text { R0374 } & & \end{array}$

FIGURE C.15

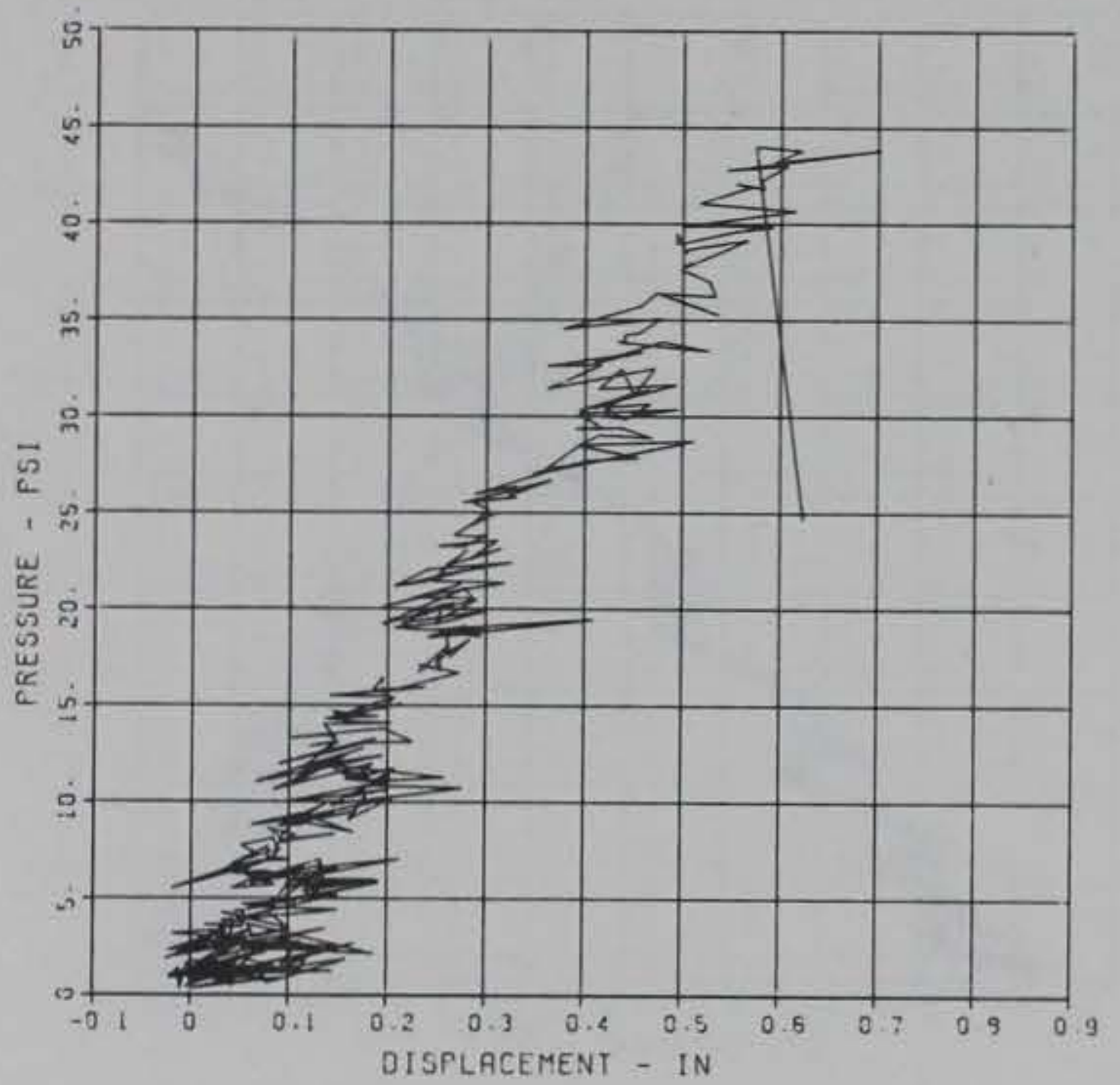

LARGE. WAFFLE SLAB

$0-11$

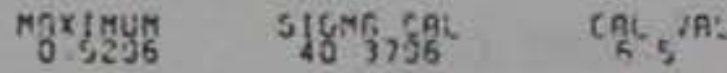

CHRNALI NO IS $25: 21$

02/02/3: R०374

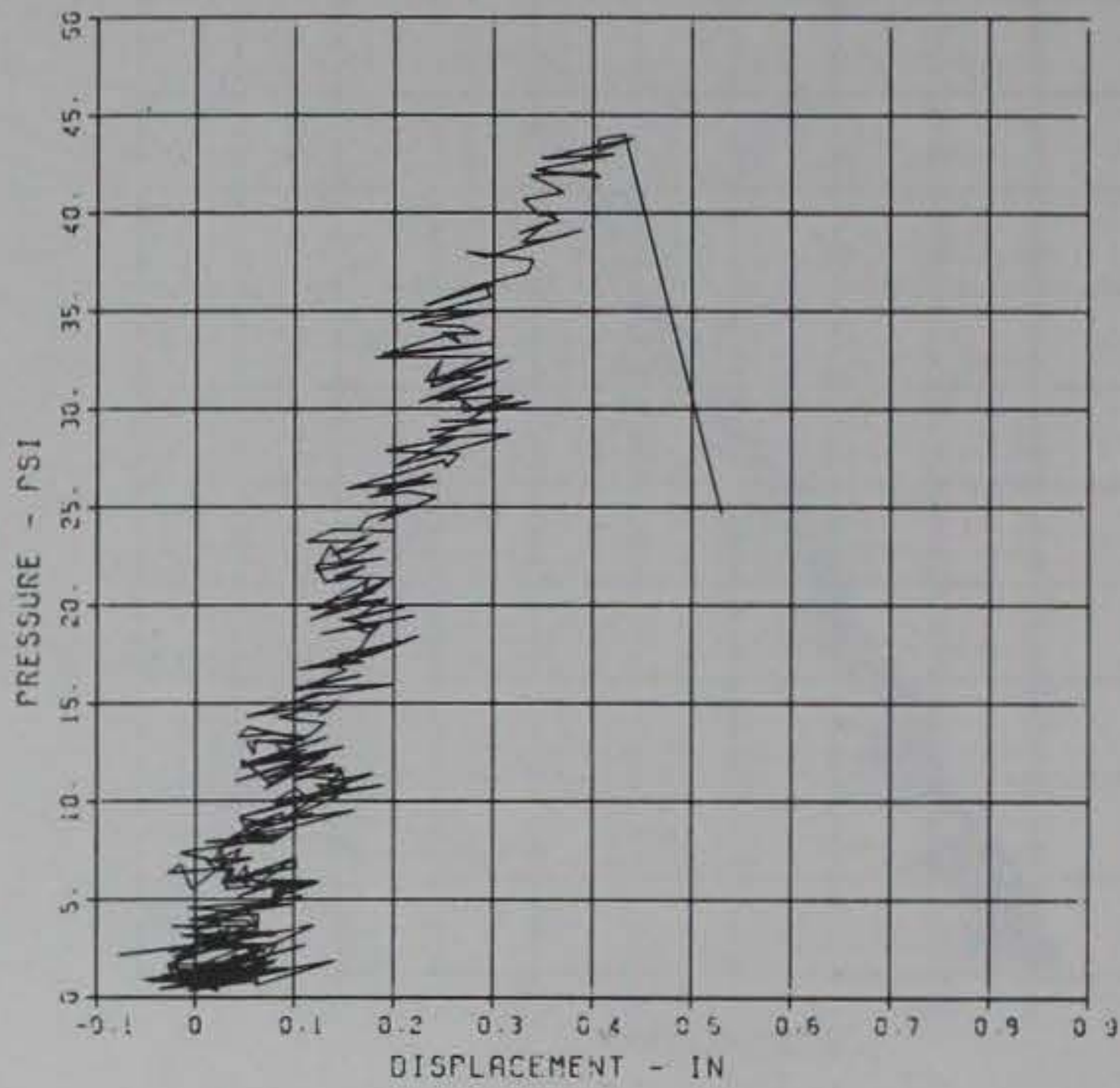

LARGE WAFFLE SLAB

$D-13$

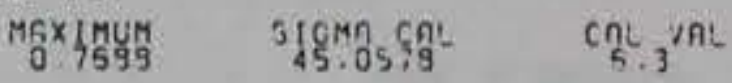

CHANNE: NO : $77 \quad 25: 2$

$02 / 02 / 81 \quad$ R0374

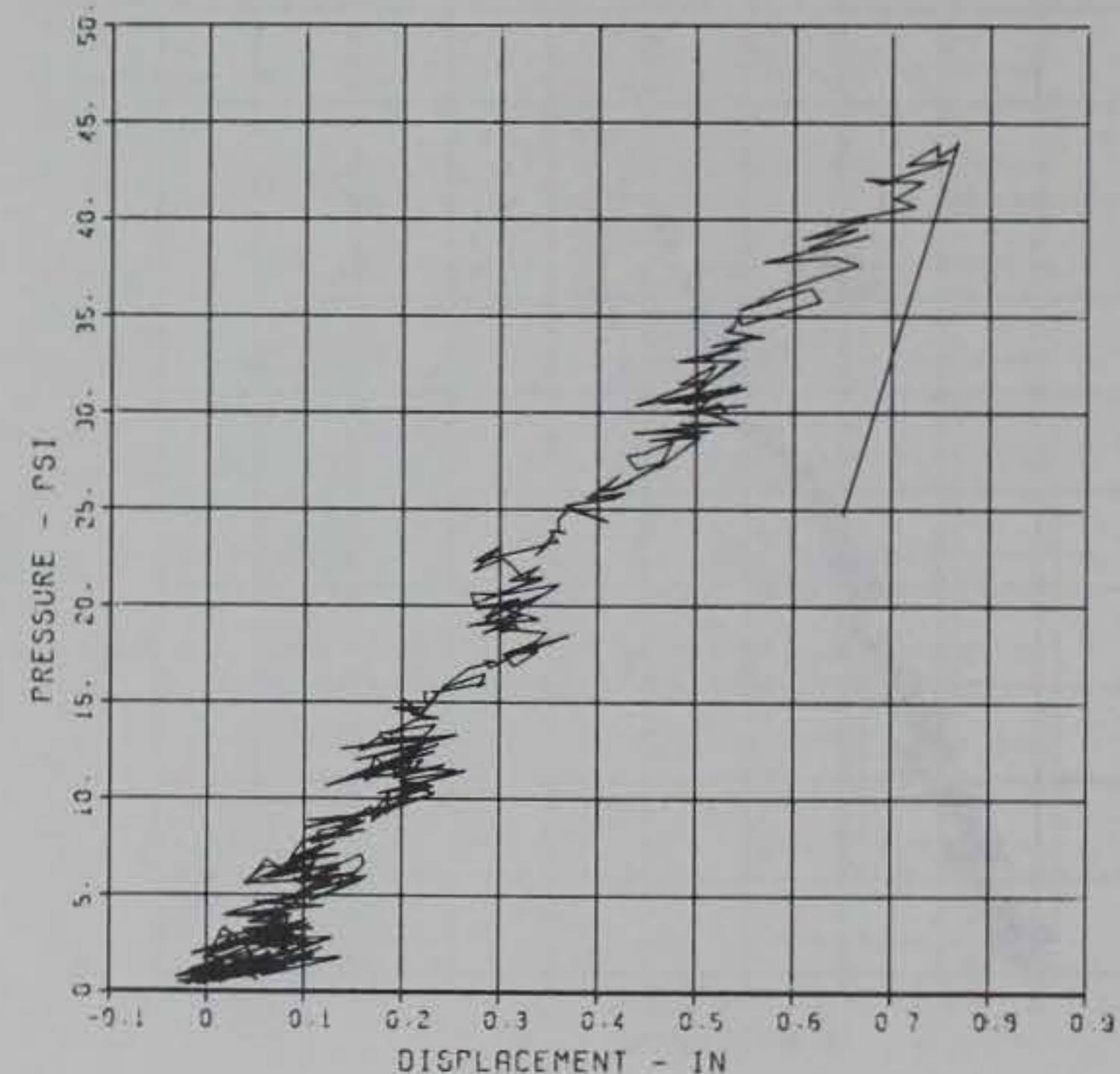




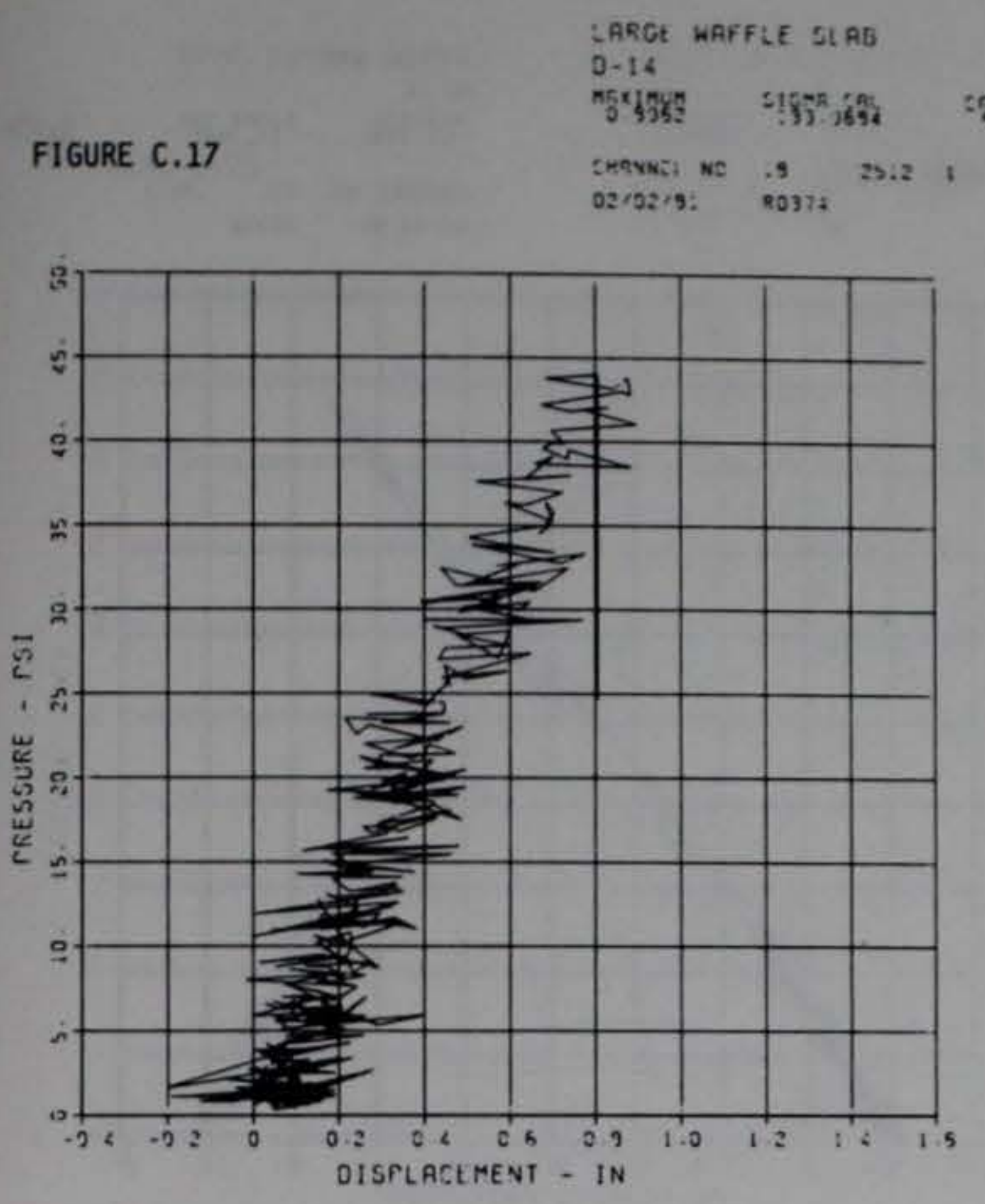

F1GURE C.18

ISTSE WAFFLE SIRS

$5 t-1$

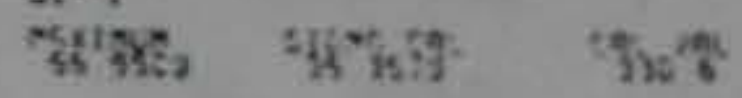

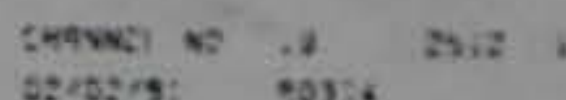

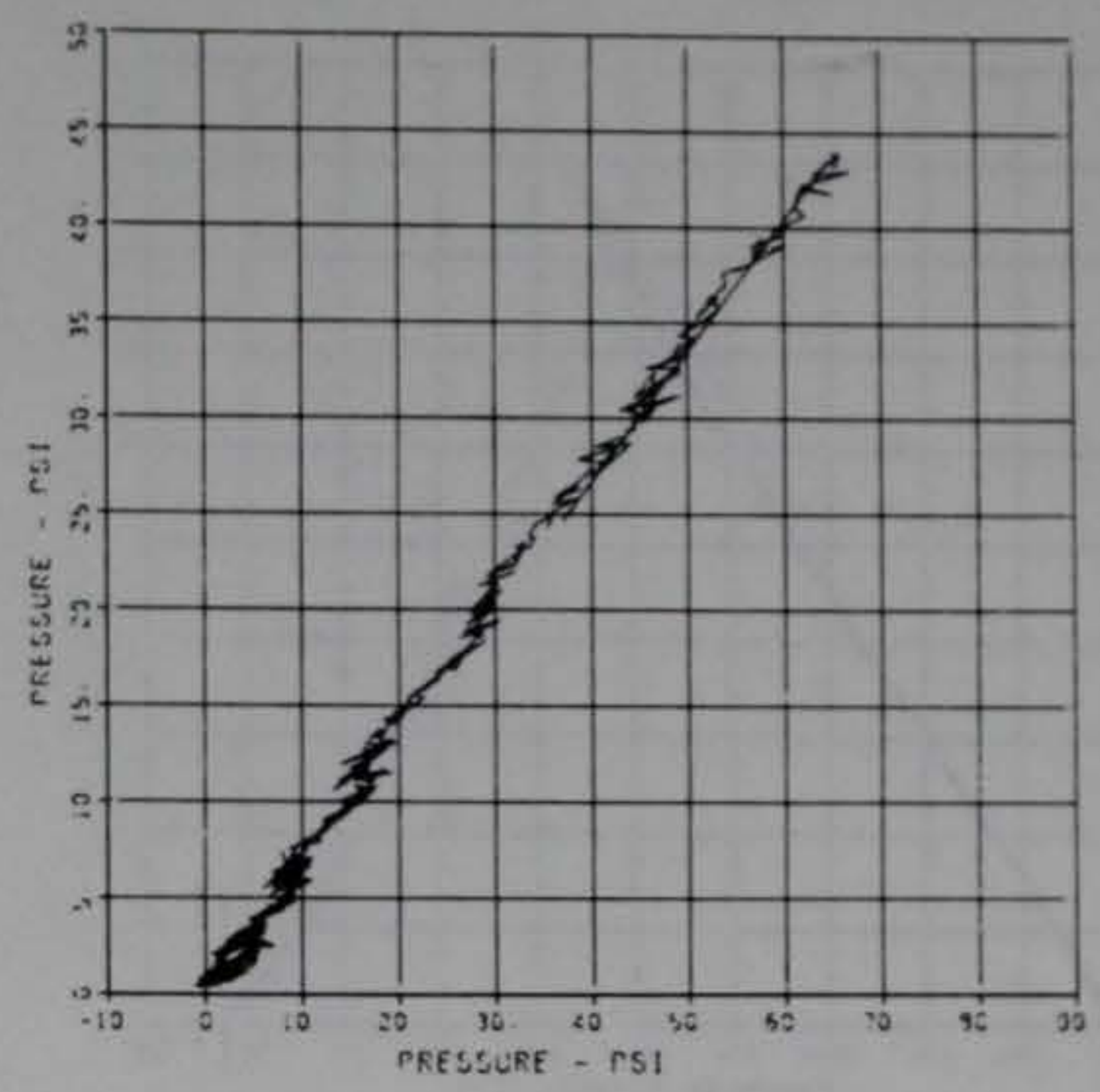

I ARGE WAFFLE SIAB

St -2

APOF WAFFLF SIAD

Sf -3

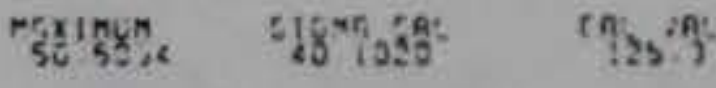

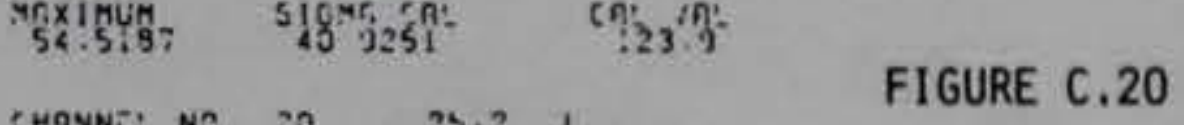

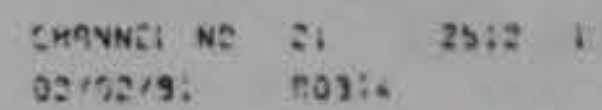

02/08/9: R0374 23.2
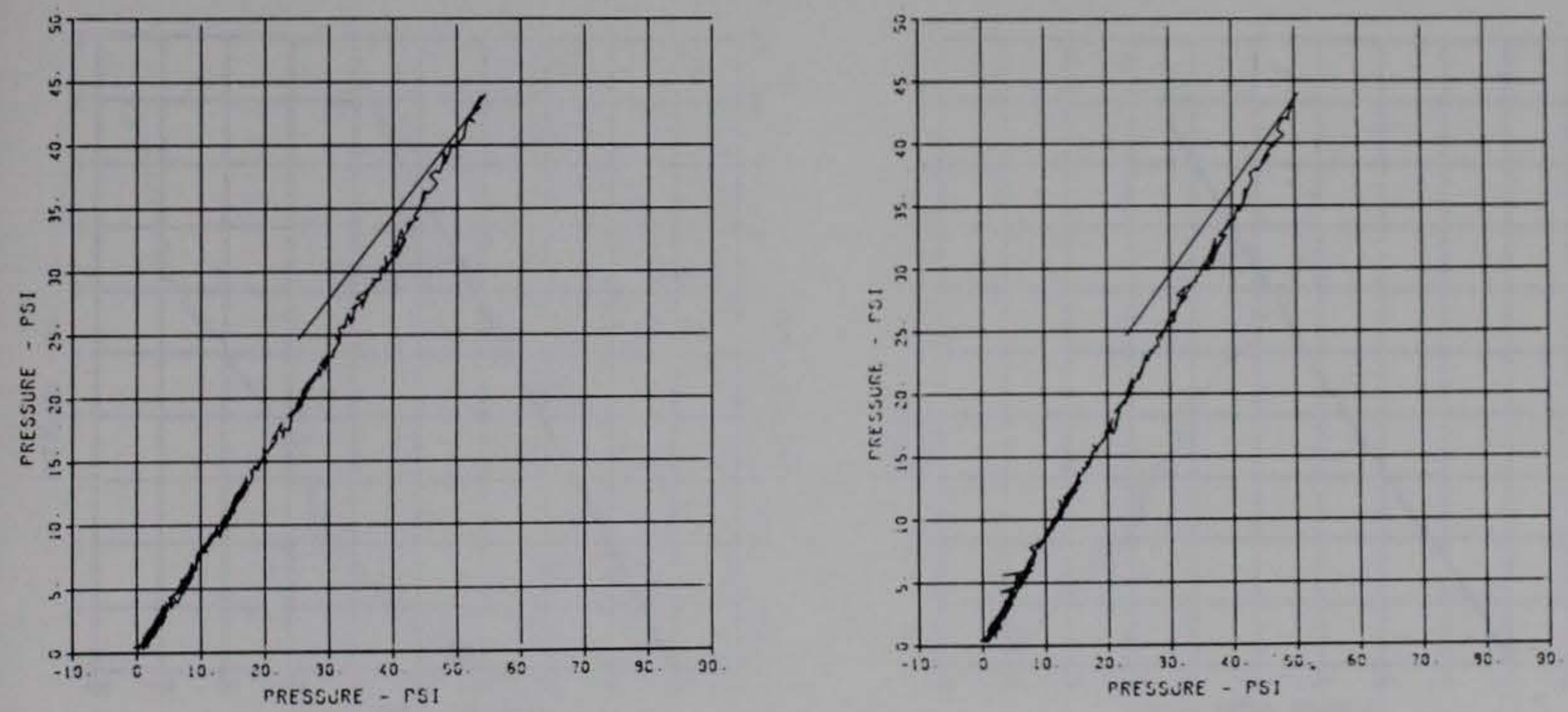
LARGE WAFFLE SLAB

SE -1

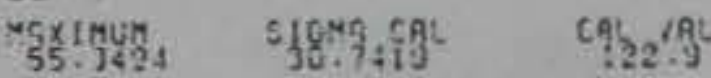

CHRVNEI NC $22 \quad 25: 2 \quad 1$

02/02/9: 80374

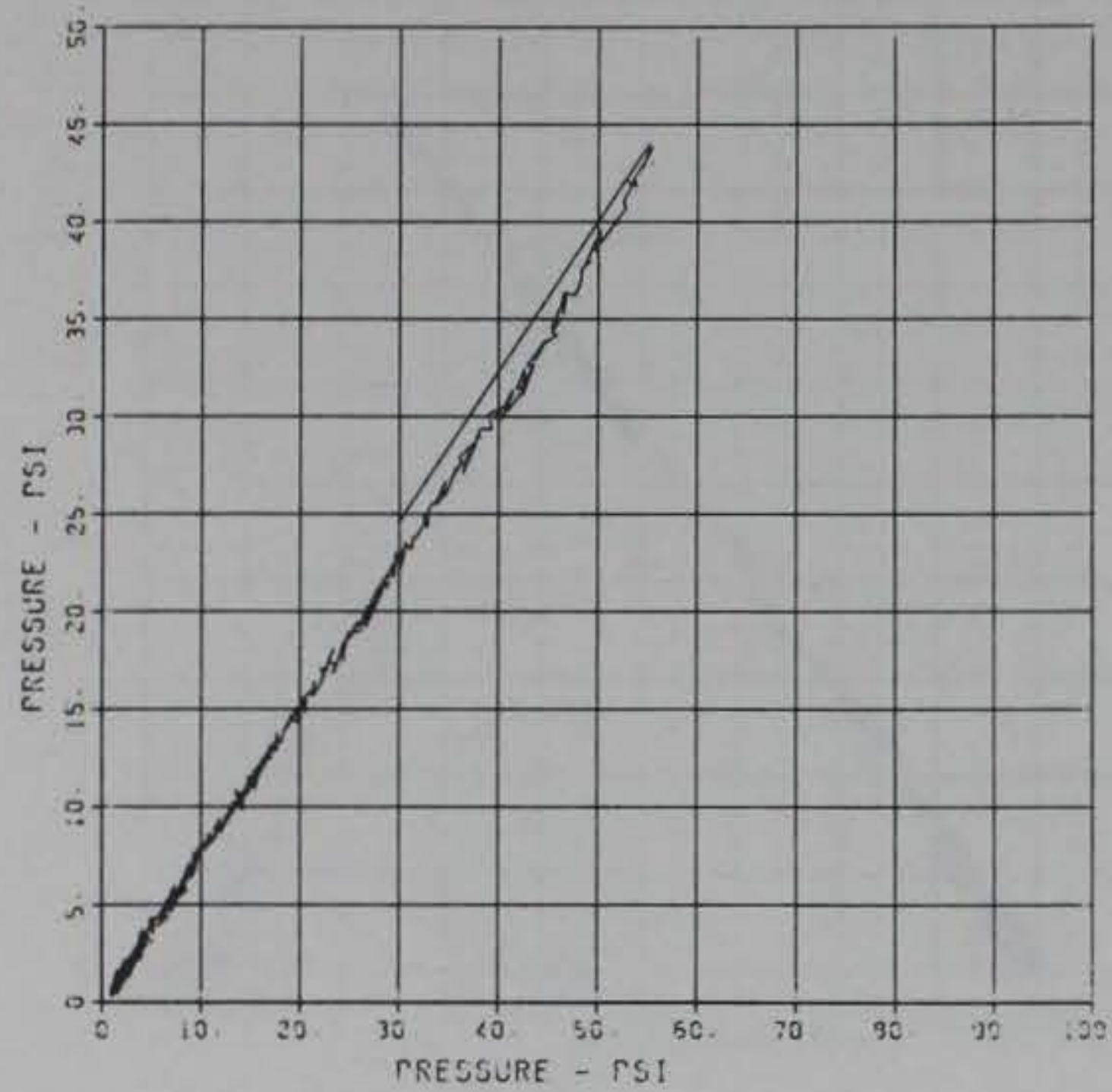

LARGE WAFFLE SLAS

SE -6

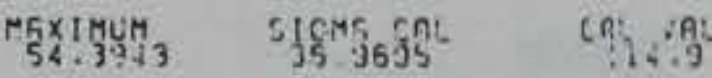

CHANNEL NE 24 2S:2 । 02/02/9: R0374

FIGURE C.23

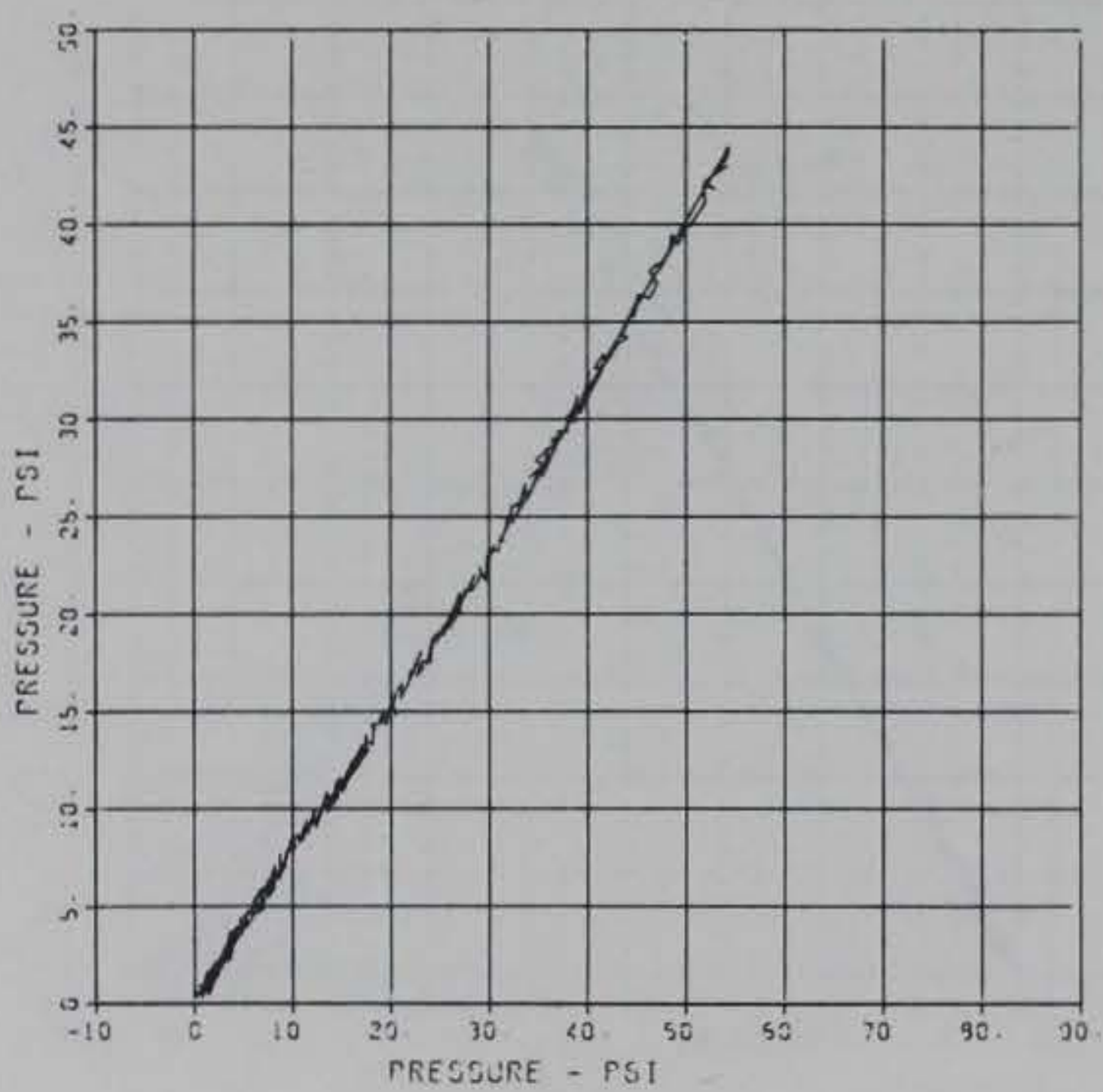

FIGURE C.22

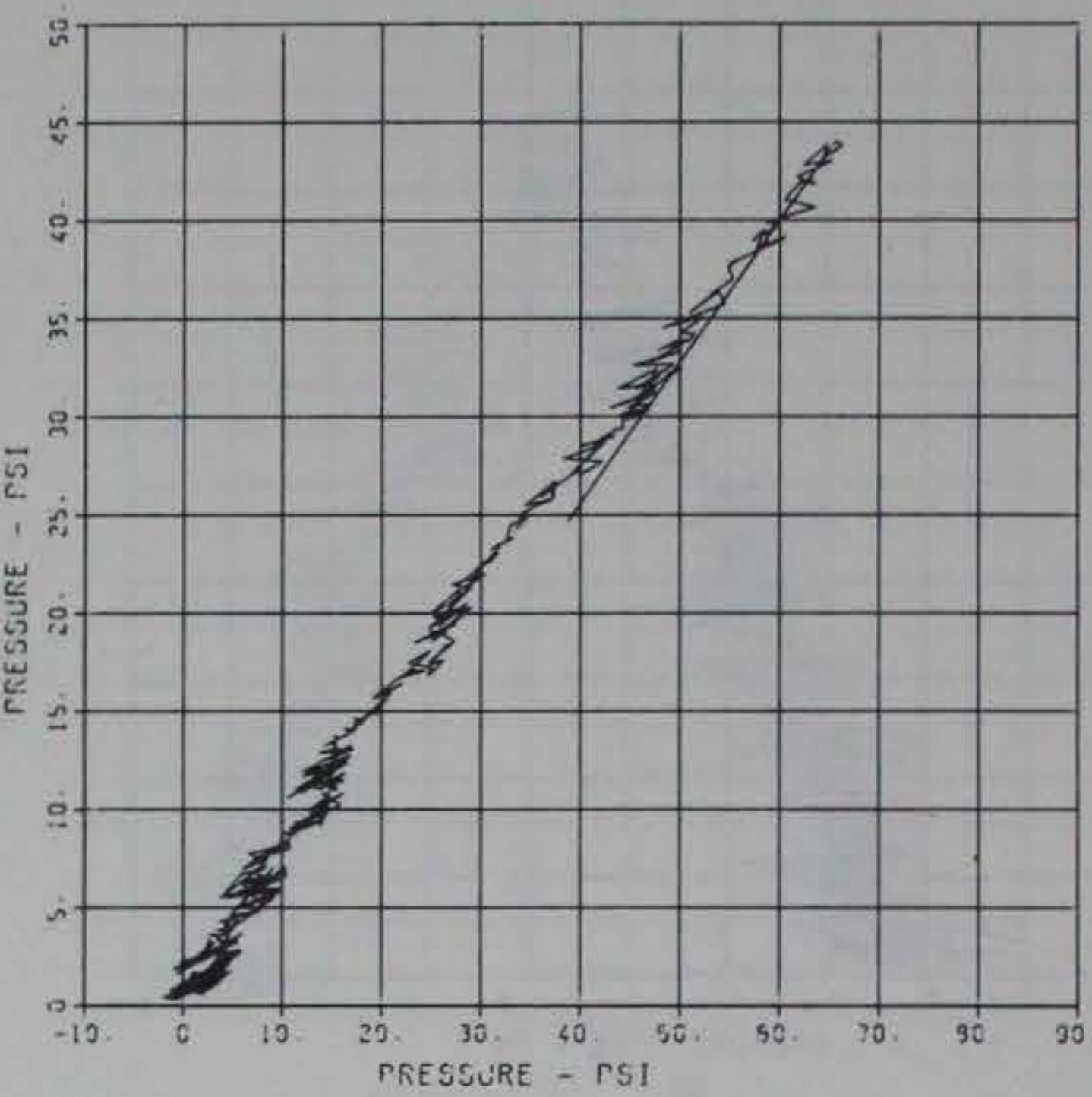

LARGE WAFFLE SIAB SE -7

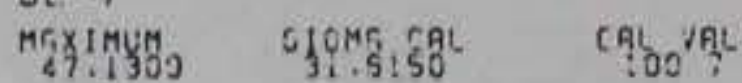

CHONNEI NO 25 25:2 ।

$02 / 0219: \quad 90374$

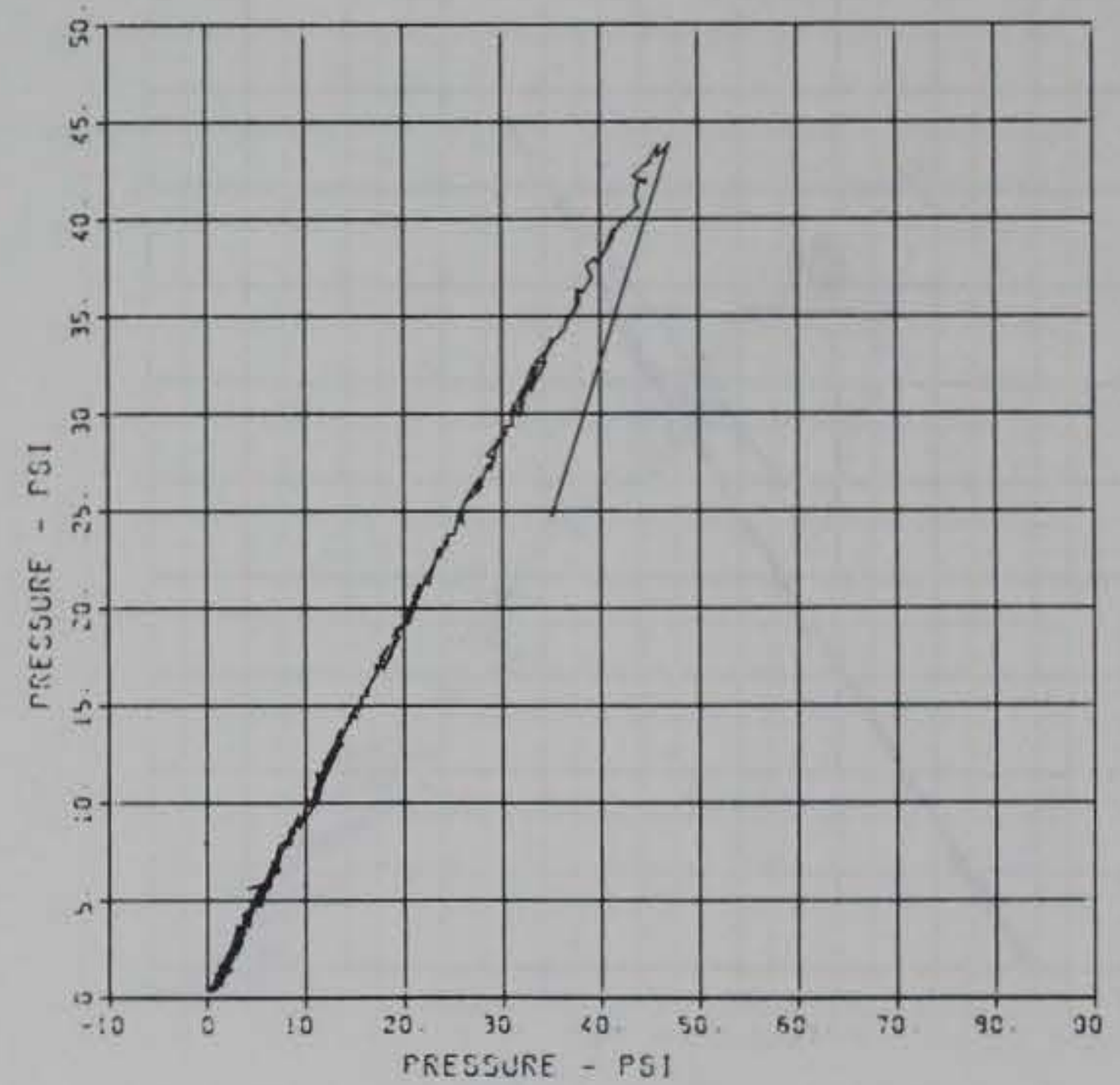



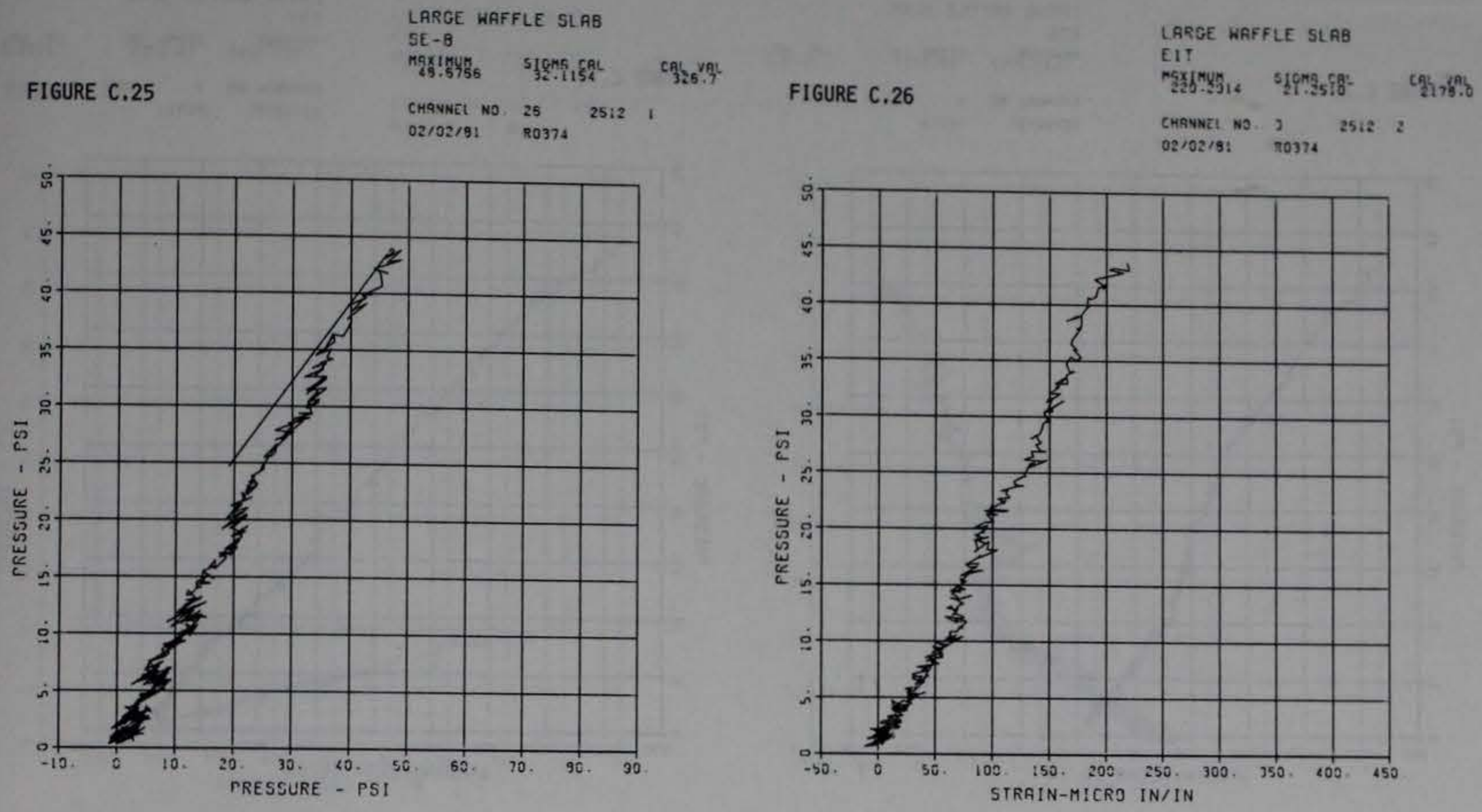

LARGE WAFFLE SLAB

E18

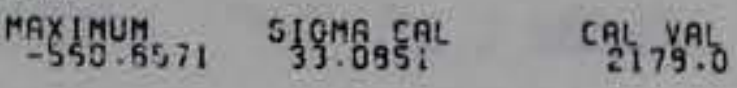

CHANNEL NO. $4 \quad 25: 2 \quad 2$

$02 / 02 / 91$ R0374

FIGURE C.28

LARGE WAFFLE SIAB

E2T

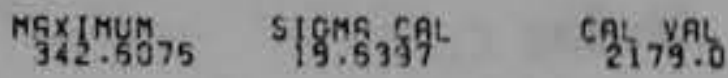

CHANNEL NO 5 25:2

02/02/3

R0374

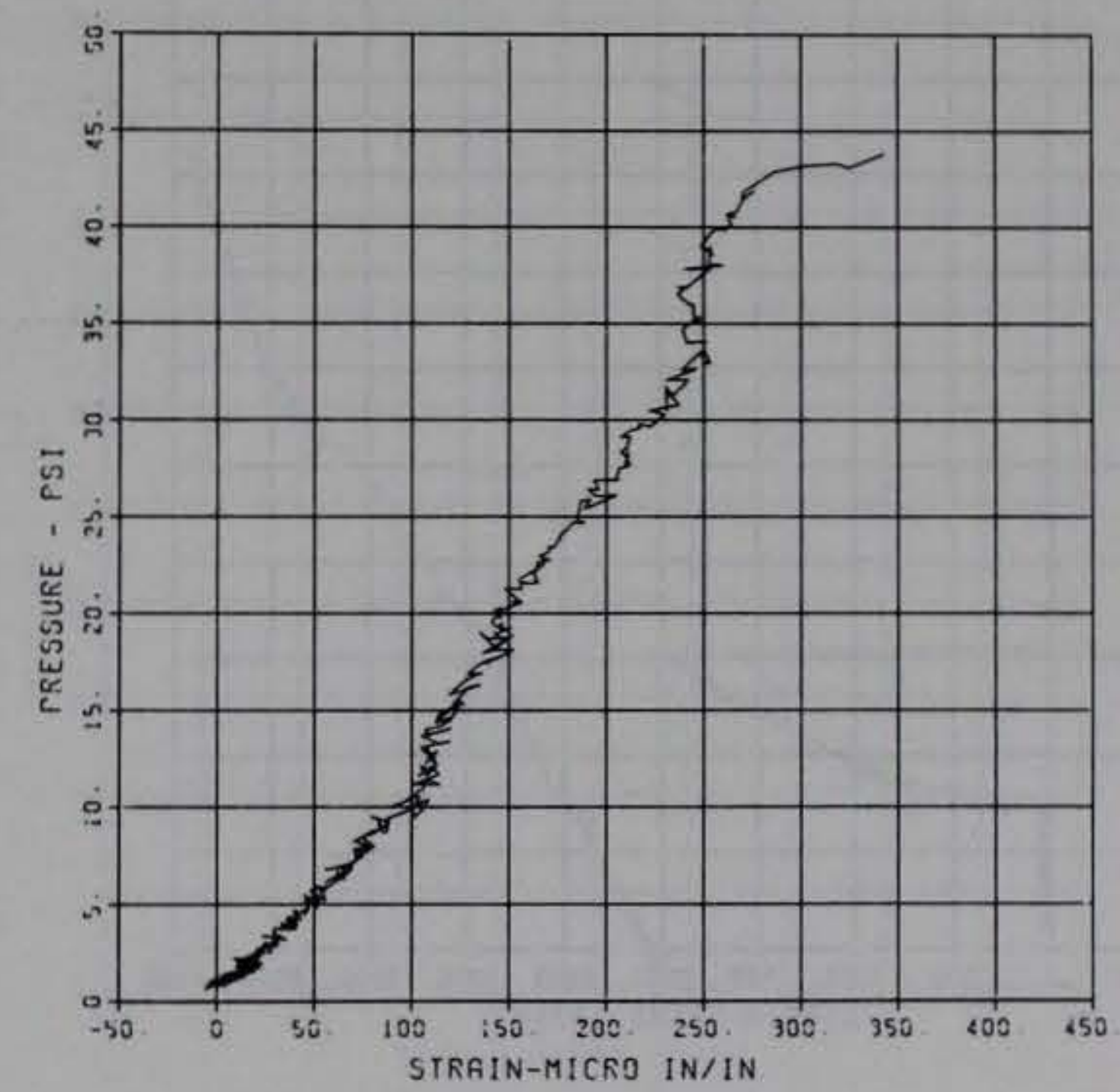


LARGE WAFFLE SLAB

E.25

FIGURE $C .29$

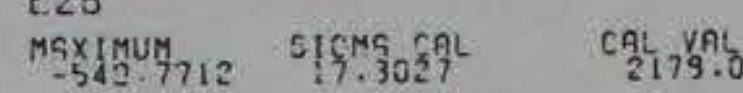

CHQYNEL NO \& $2512 \quad 2$

02/02/9: R0374

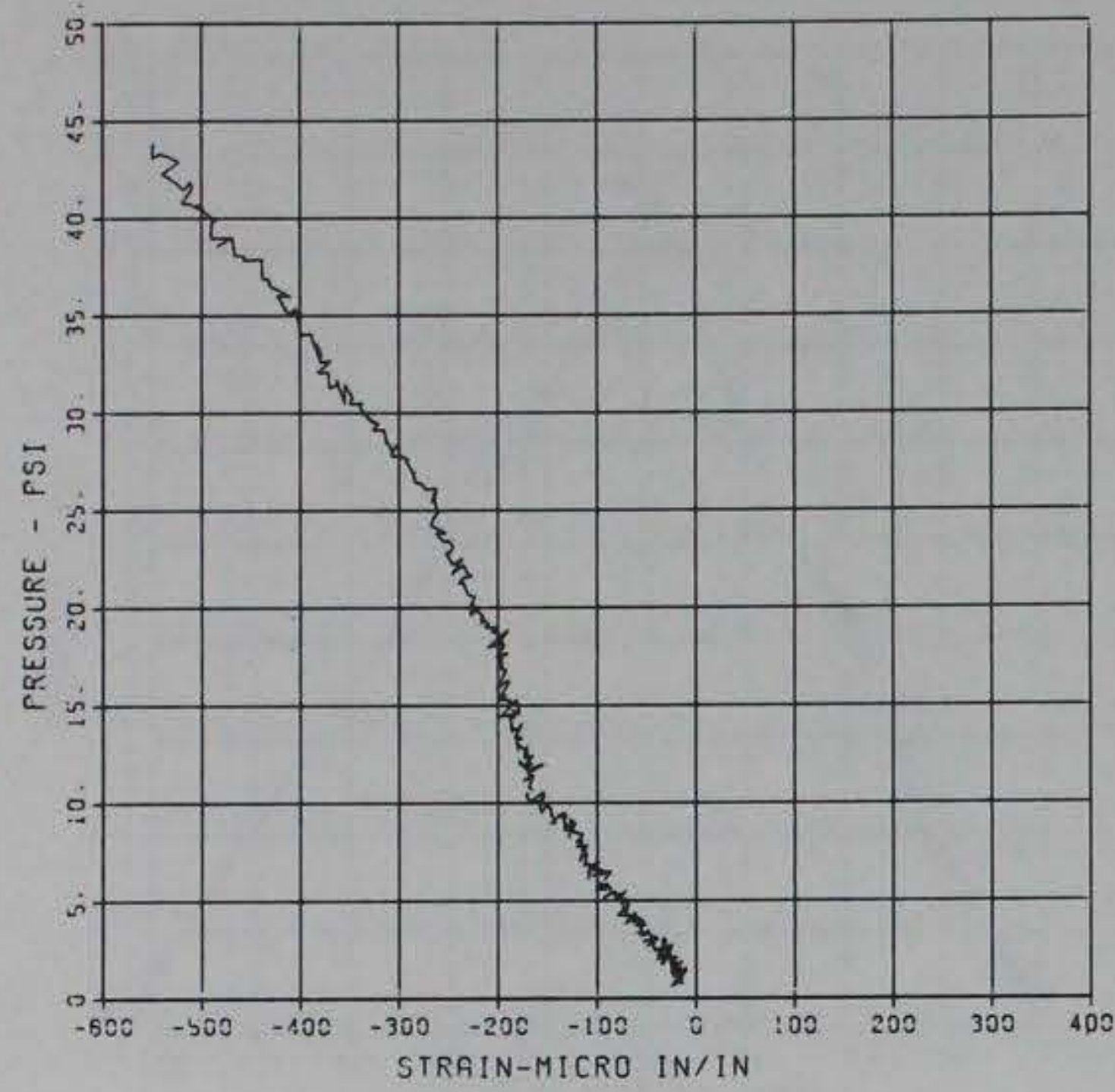

LARGE WAFFLE SLAB

E.3B

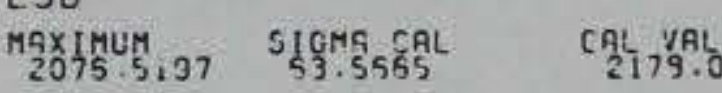

FIGURE $C .31$

CHQNNEI NE. $925: 2=$

O2/02/8i R0374

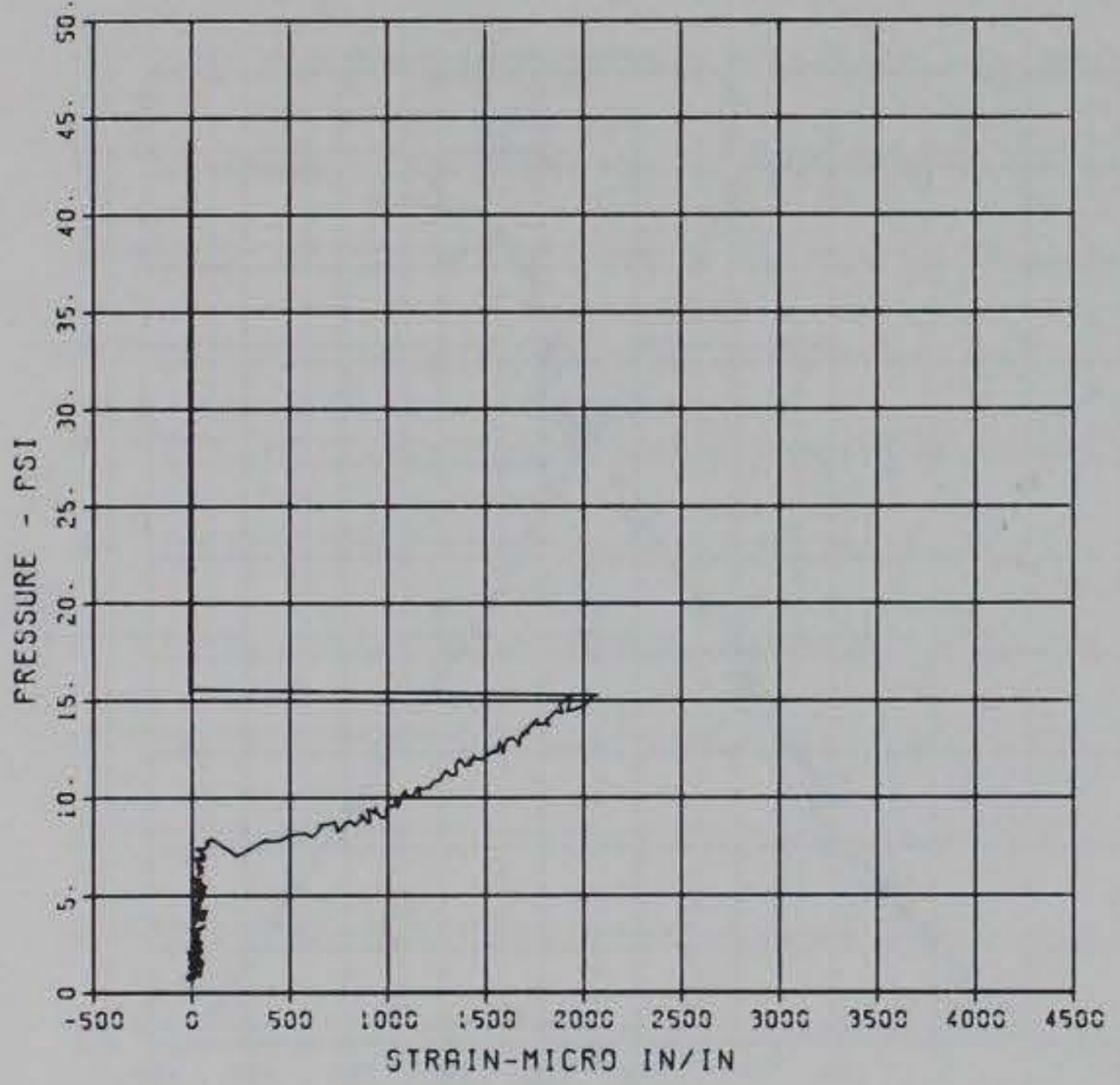

FIGURE C. 30

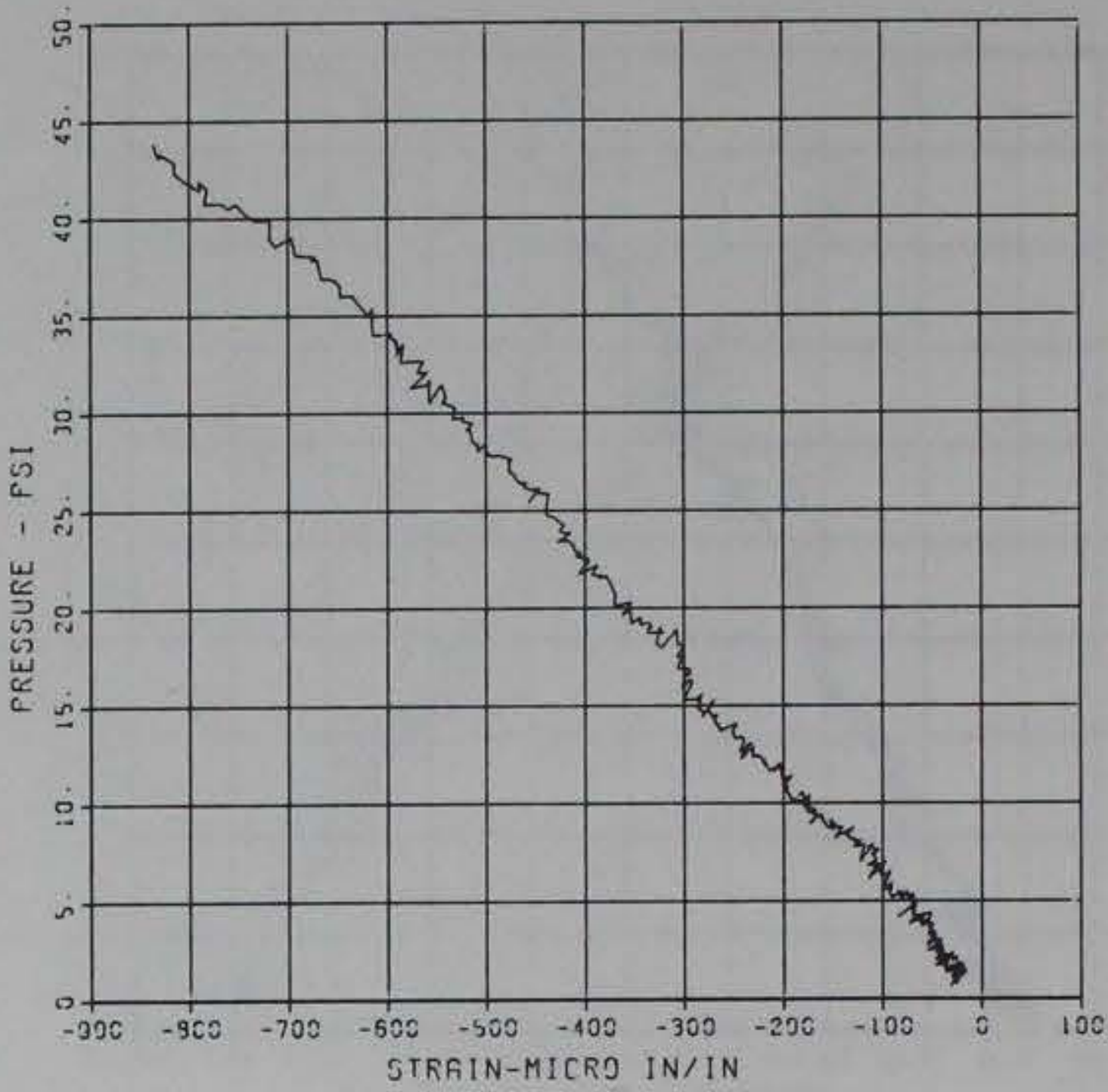

LARGE. WAFFLE SLAB

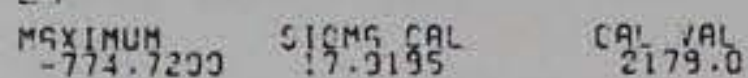

CHAYNEI NO $3 \quad 25: 2=$

$02 / 02 / 9: \quad R 0374$

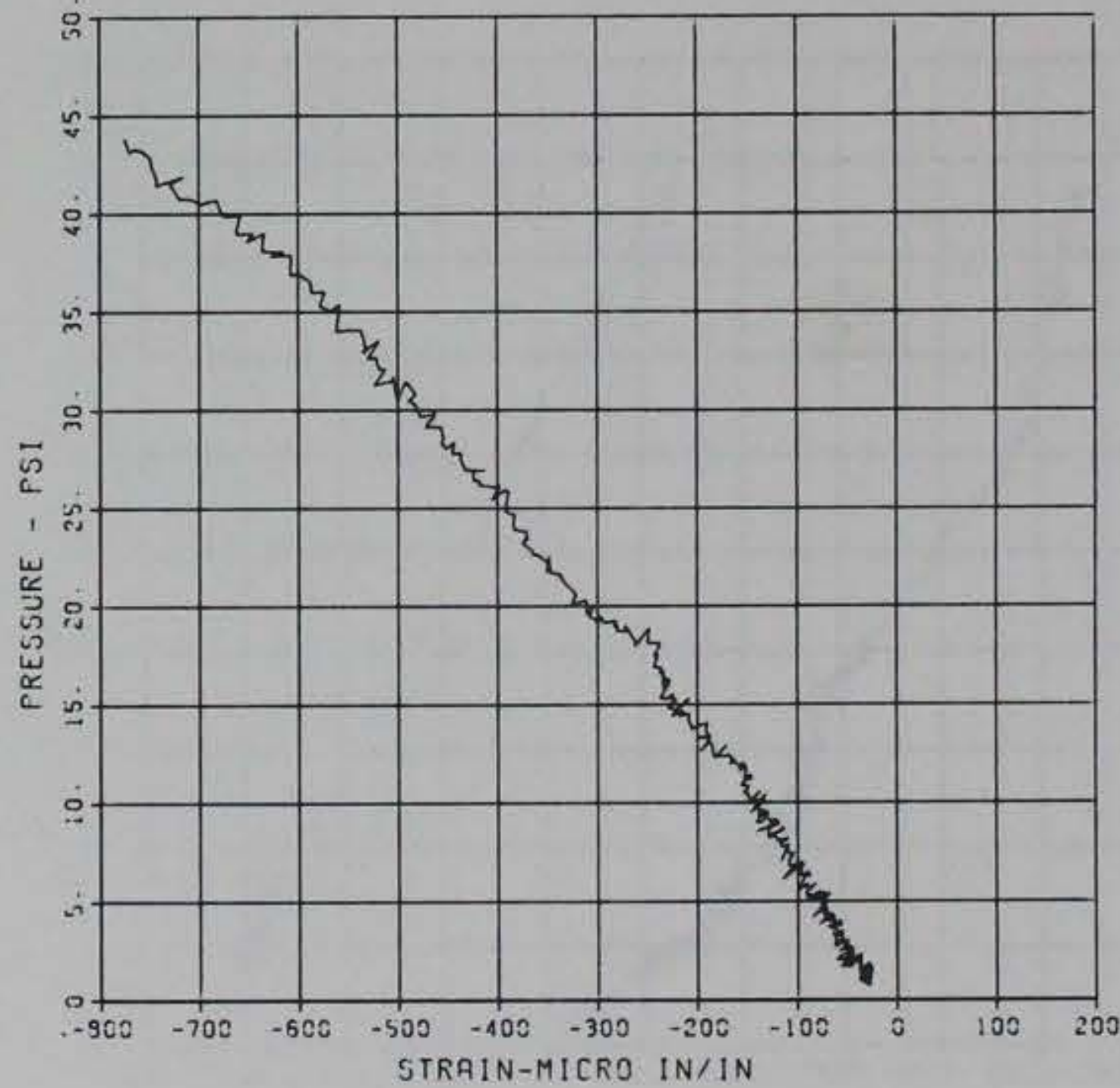



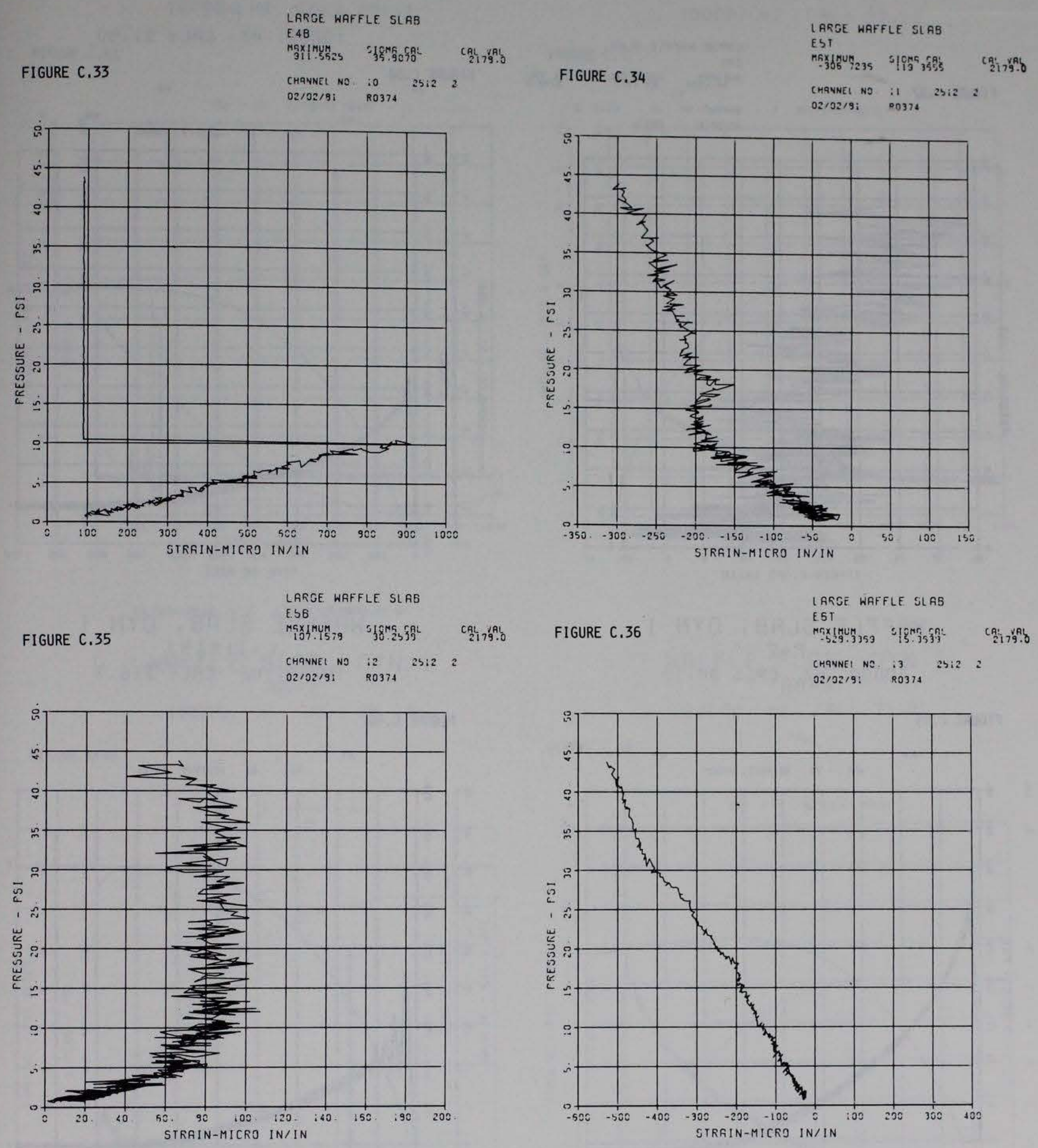
LARGE WAFFLE SLAB

E6B

FIGURE $\quad$ C.37

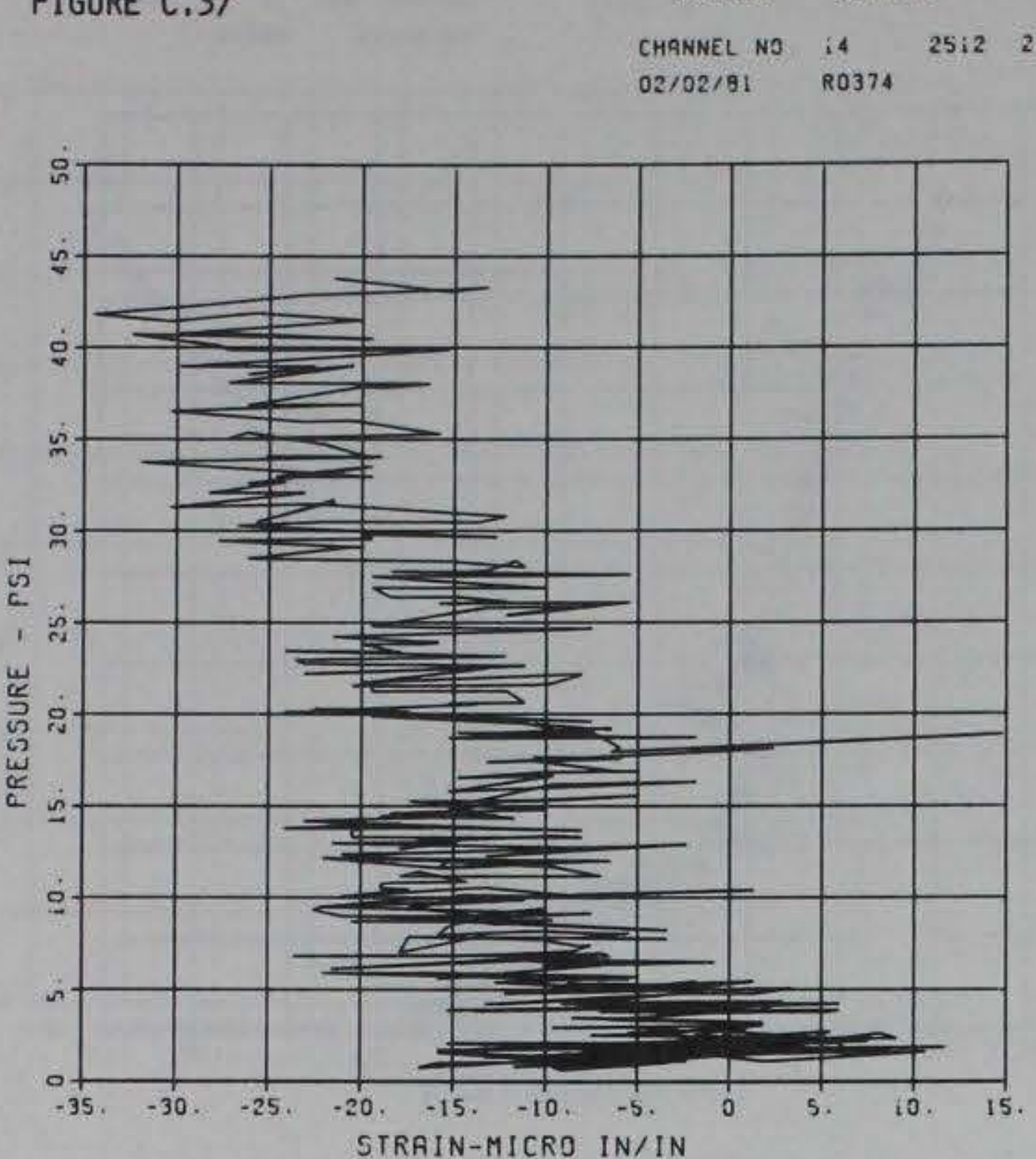

$$
\text { WAFFLE } \underset{\substack{\text { SLAB } \\ P-2}}{\operatorname{DYN} 1}
$$$$
\text { 10000. } \mathrm{HZ} \quad \mathrm{CAL}=88.10
$$

FIGURE C.39

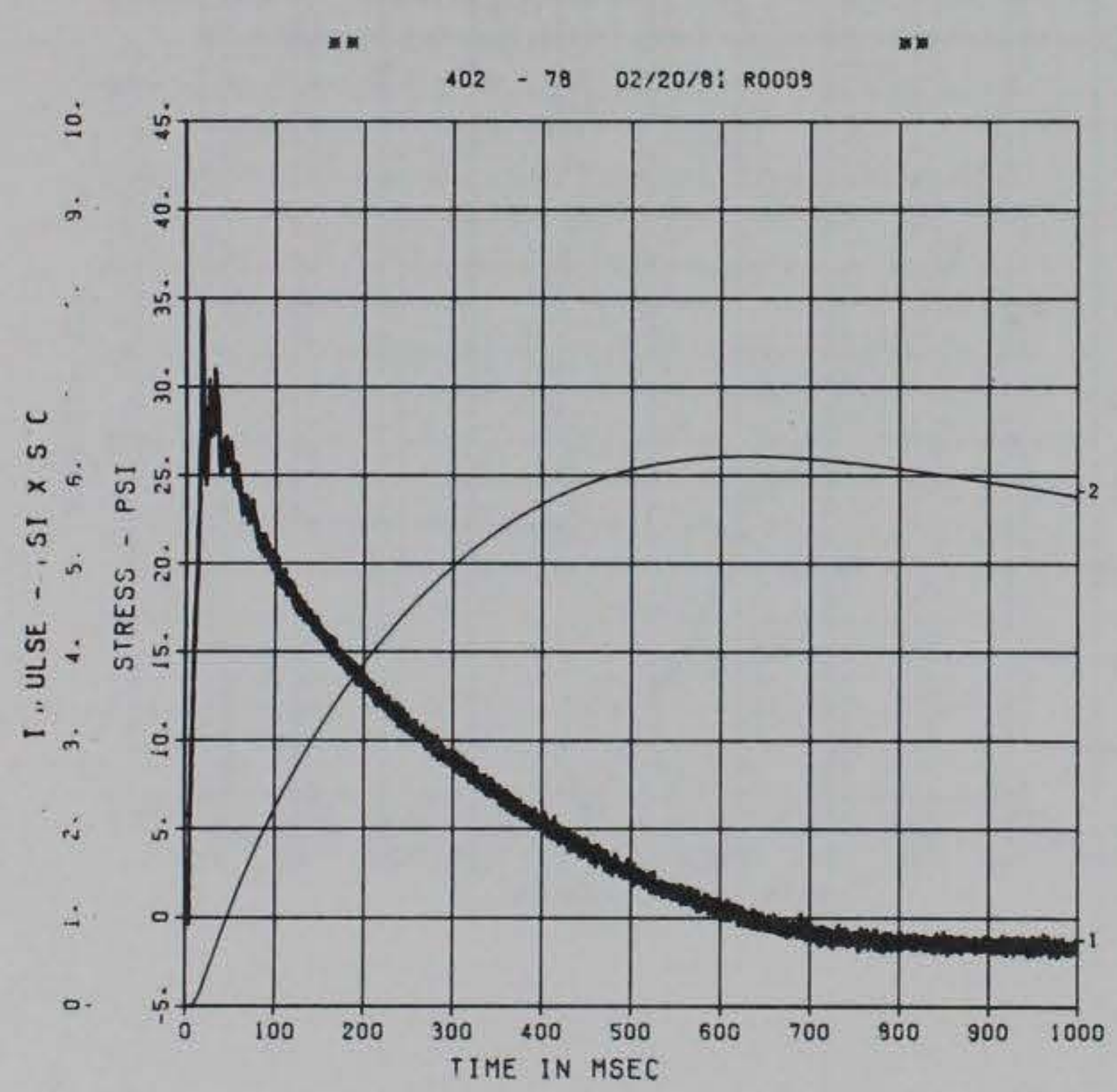

WAFFLE SLAB, DYN 1

$$
P-1
$$$$
\text { 10000. } \mathrm{HZ} \quad \mathrm{CAL}=91.80
$$

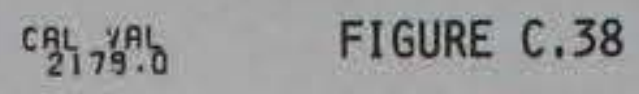

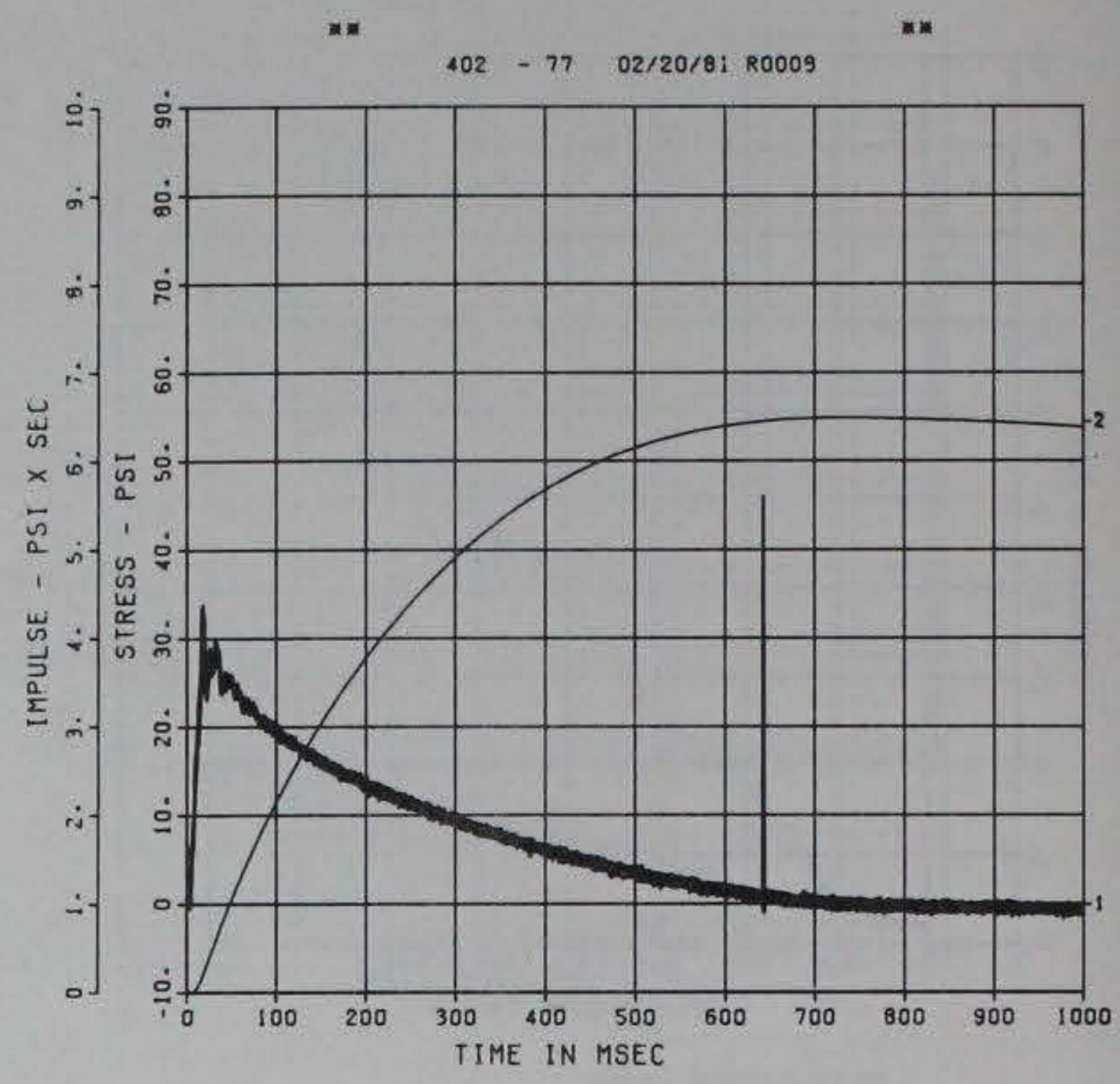

WAFFLE SLAB, DYN 1

$$
L-1 \text { (KIP) }
$$

10000. $\mathrm{HZ} \quad \mathrm{CAL}=216.7$

FIGURE C. 40

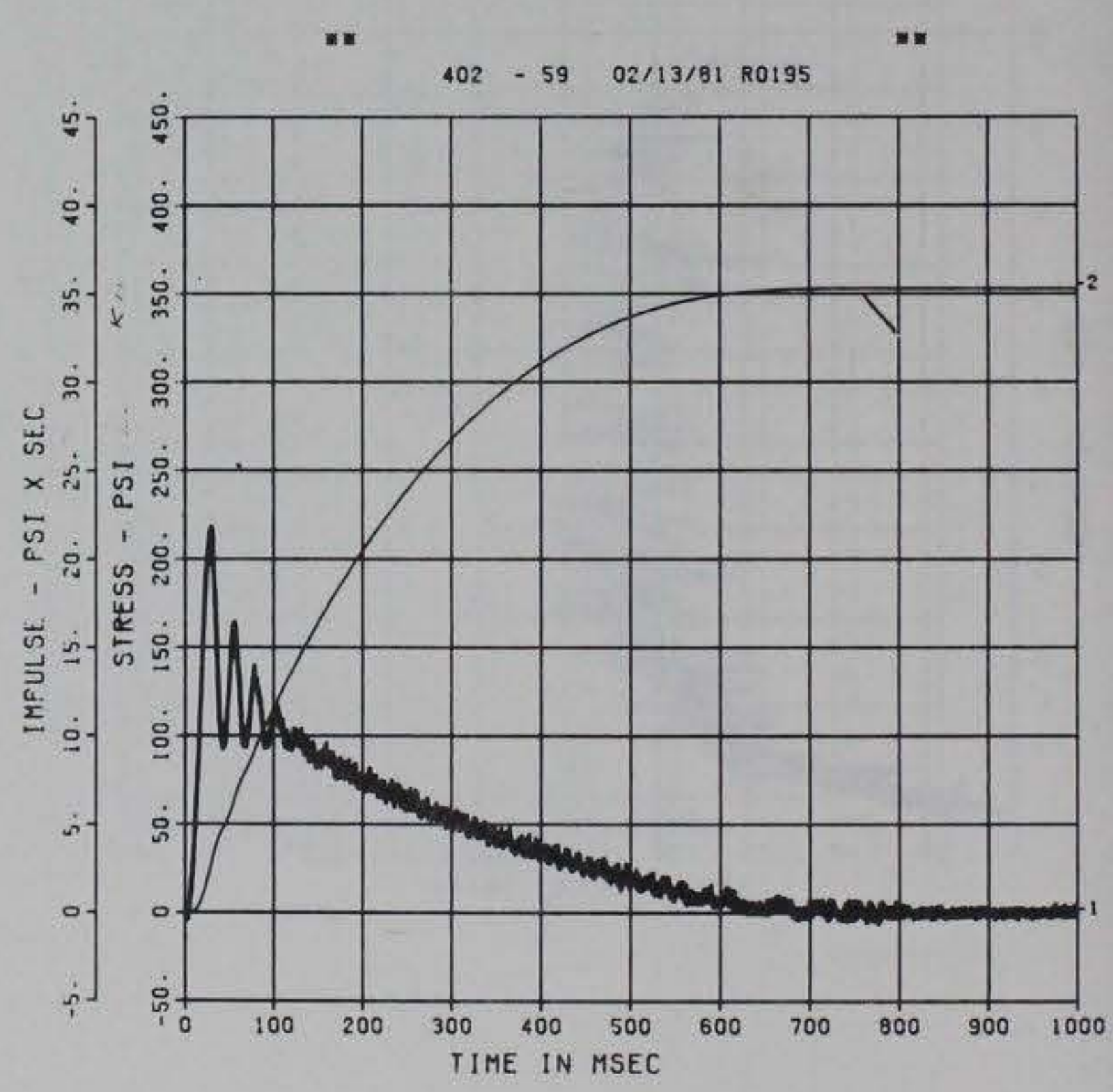

\#. peak value is i \% over calibration .. 


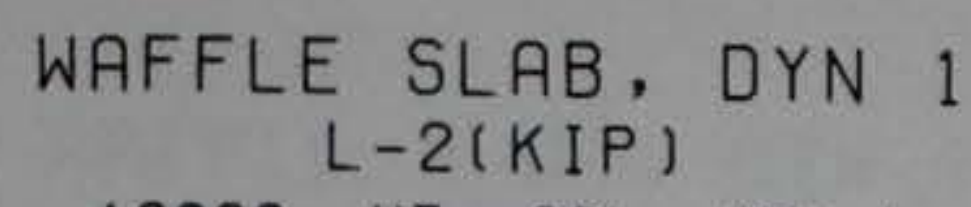

10000. $\mathrm{HZ} \quad \mathrm{CAL}=201.1$

FIGURE C. 41

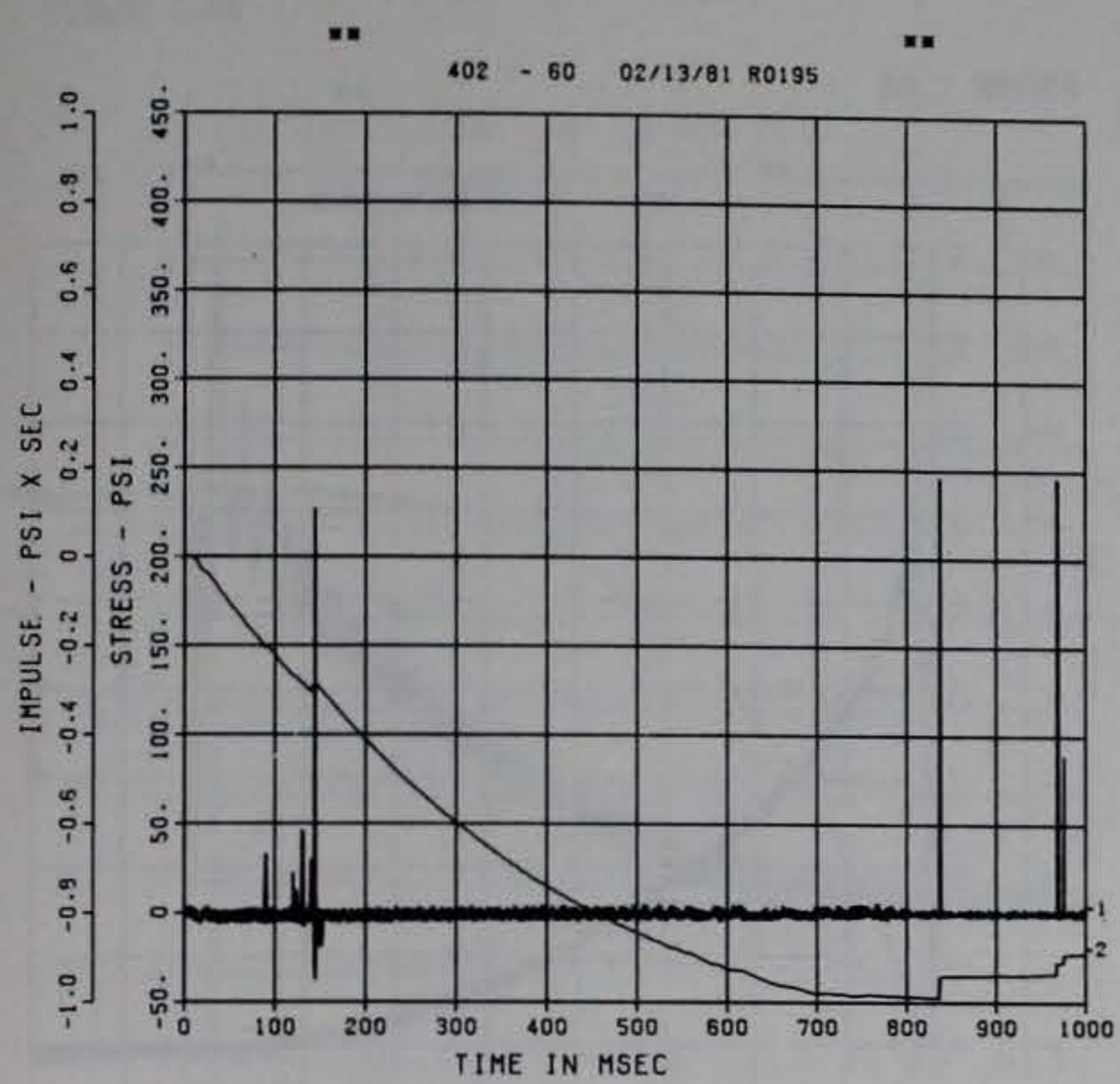

w. Peak valije is 22 \% over calibration *

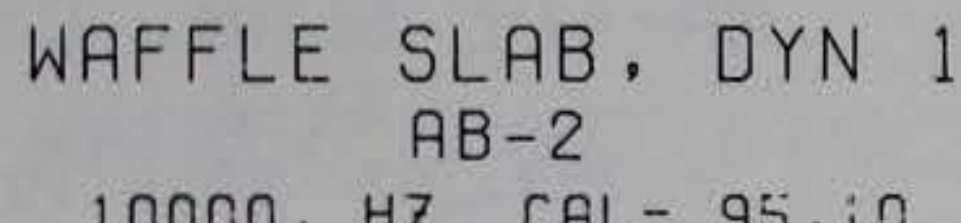

FIGURE $C .43$

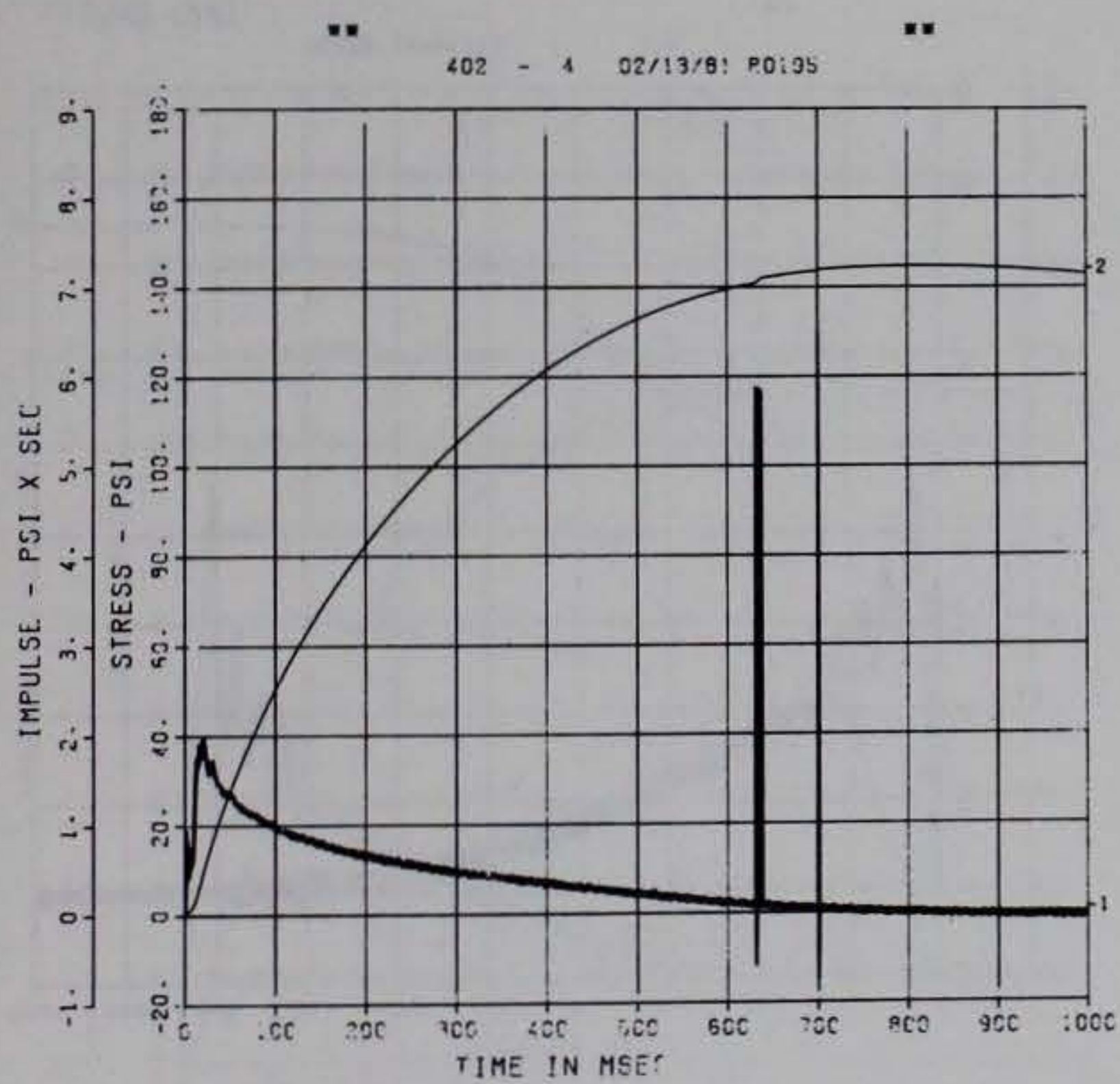

-. peak value is 37 \% over calibration *
WAFFLE SLAB, DYN 1

10000. $\mathrm{HZ} \quad \mathrm{CAL}=93.10$

FIGURE C.42

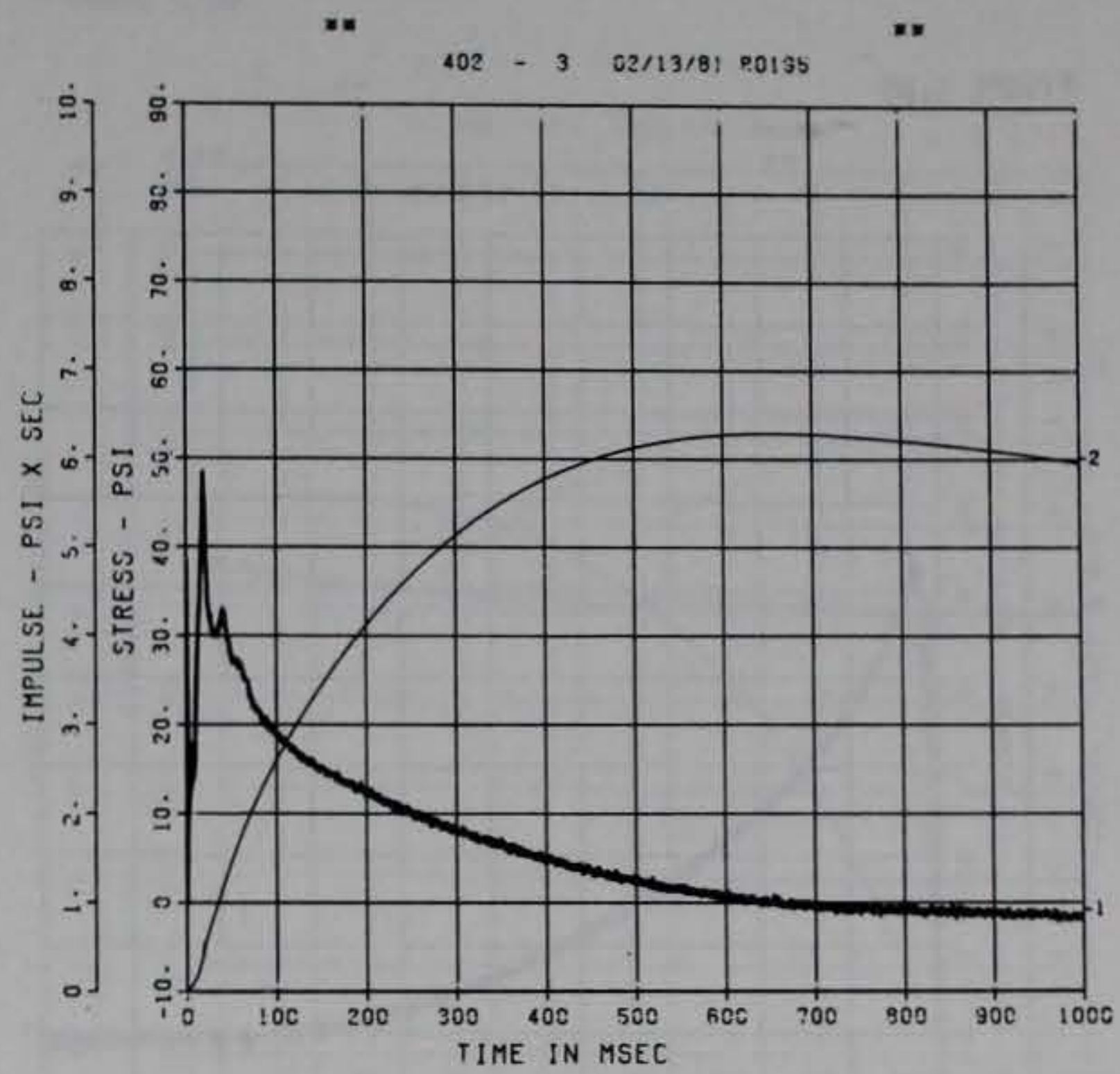

WAFFLE SLAB, DYN 1 $A B-3$

10000. $\mathrm{HZ} \quad \mathrm{CAL}=75.5 \mathrm{C}$

FIGURE $C .44$

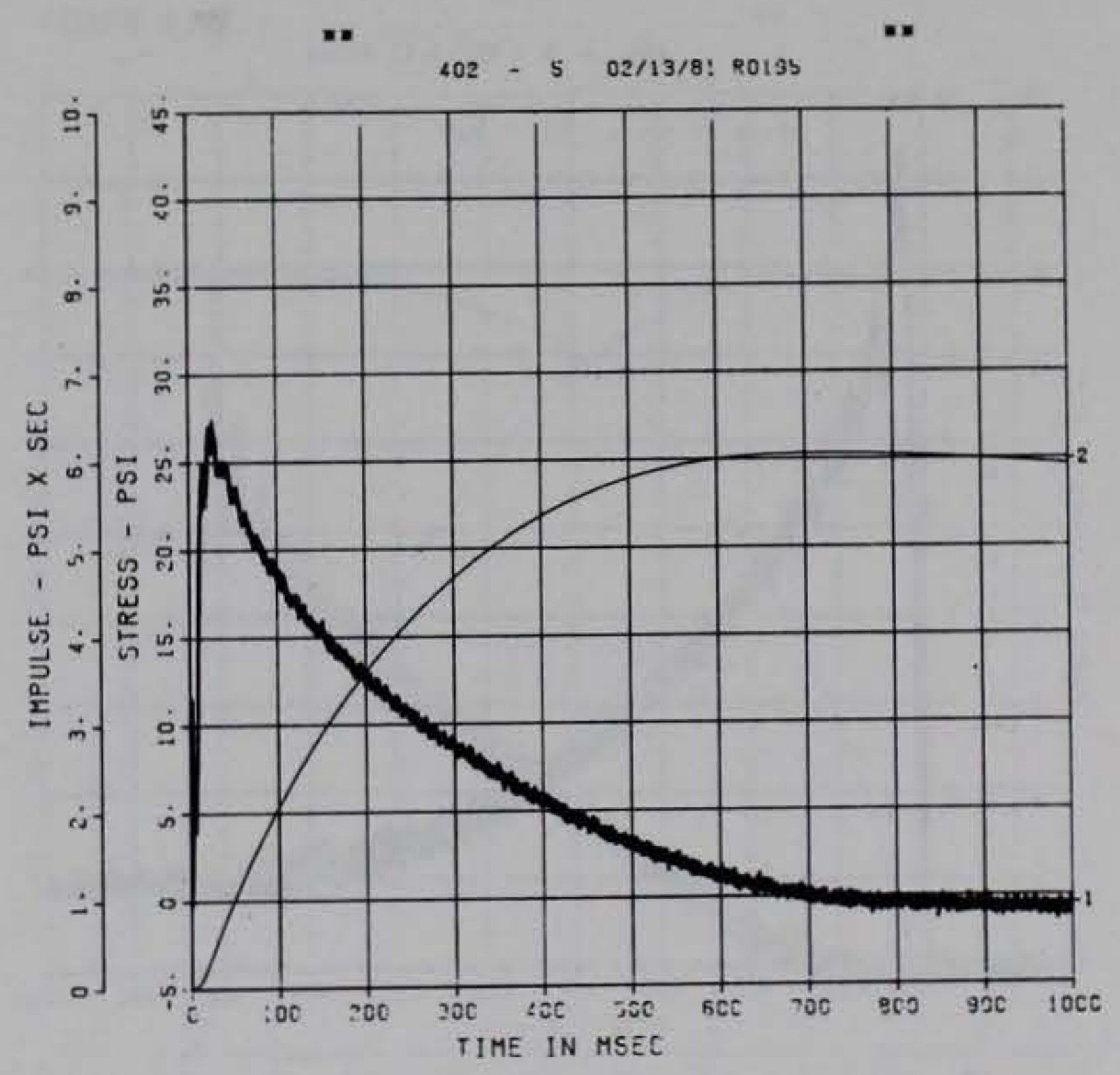




$$
\begin{gathered}
\text { WAFFLE SLAB, DYN 1 } \\
\begin{array}{c}
\text { AB-4 } \\
10000 . \\
\mathrm{HZ} \quad C A L=76.80
\end{array}
\end{gathered}
$$

FIGURE 0.45

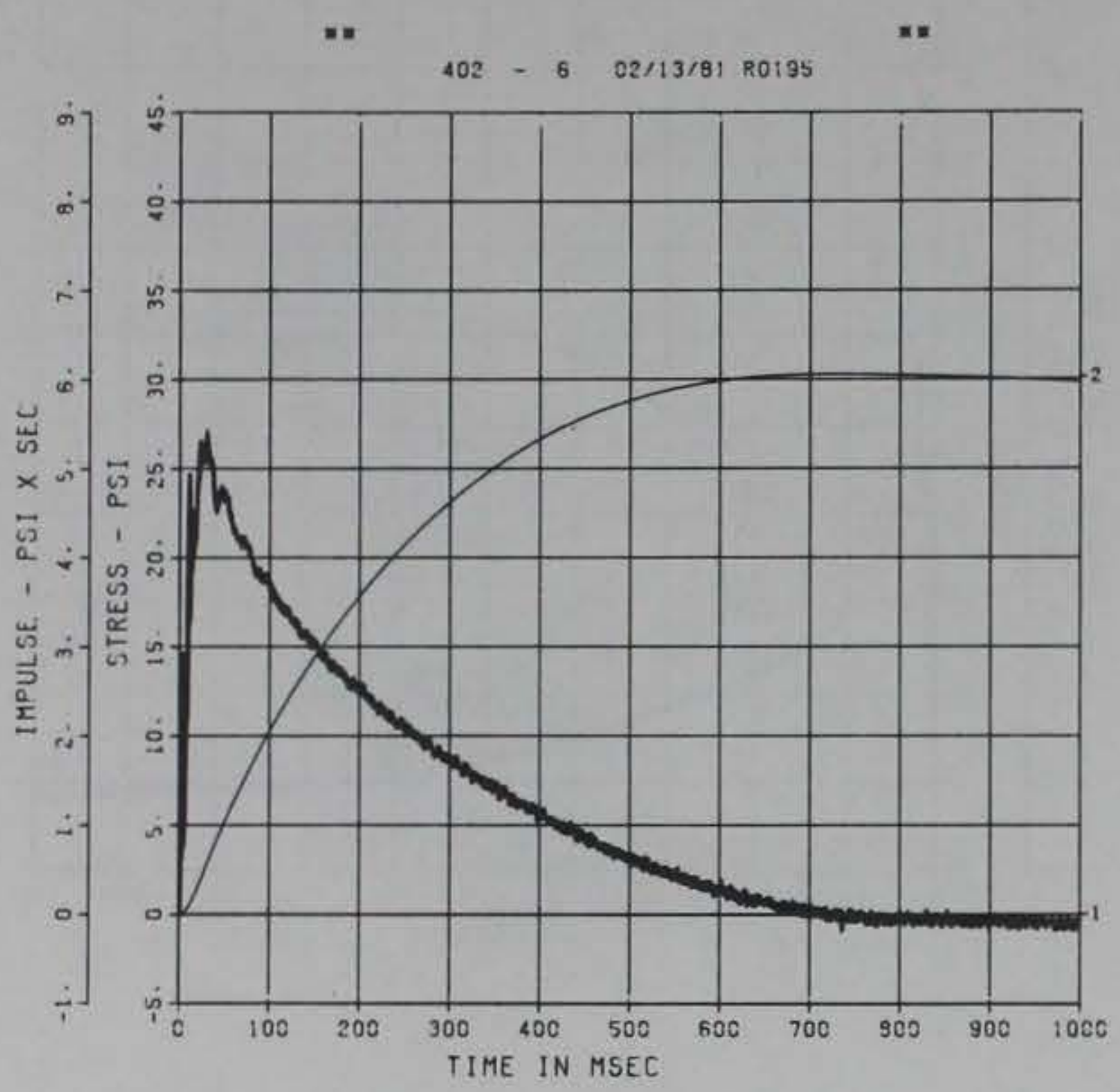

$$
\text { WAFFLE } \underset{S E-1}{S L A B, ~ D Y N ~} 1
$$$$
\text { 10000. } \mathrm{HZ} \quad \mathrm{CAL}=111.4
$$

FIGURE $C .47$

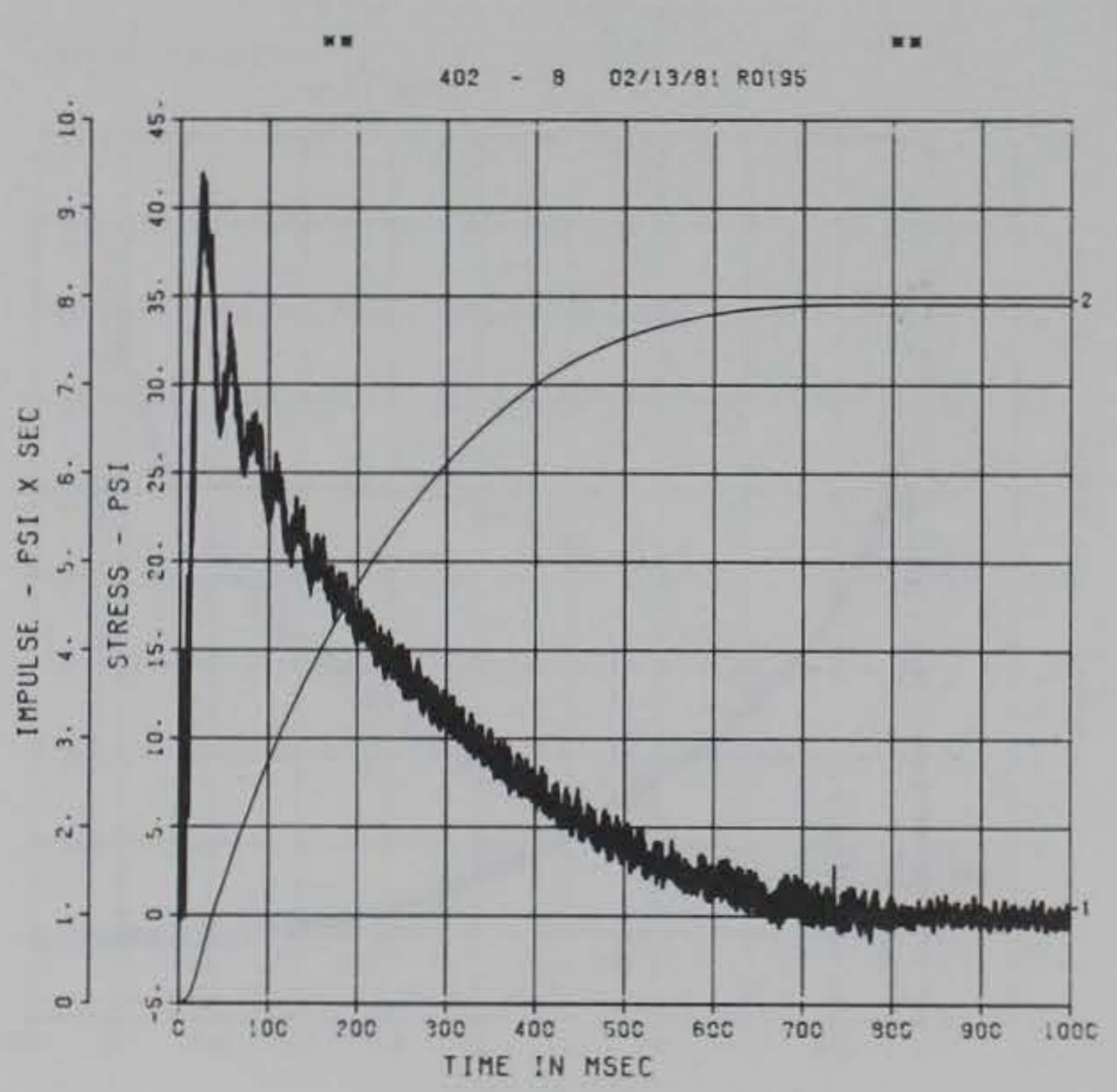

WAFFLE SLAB, DYN 1 $A B-5$

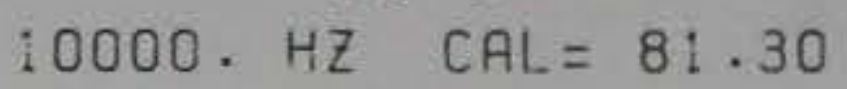

FIGURE C. 46

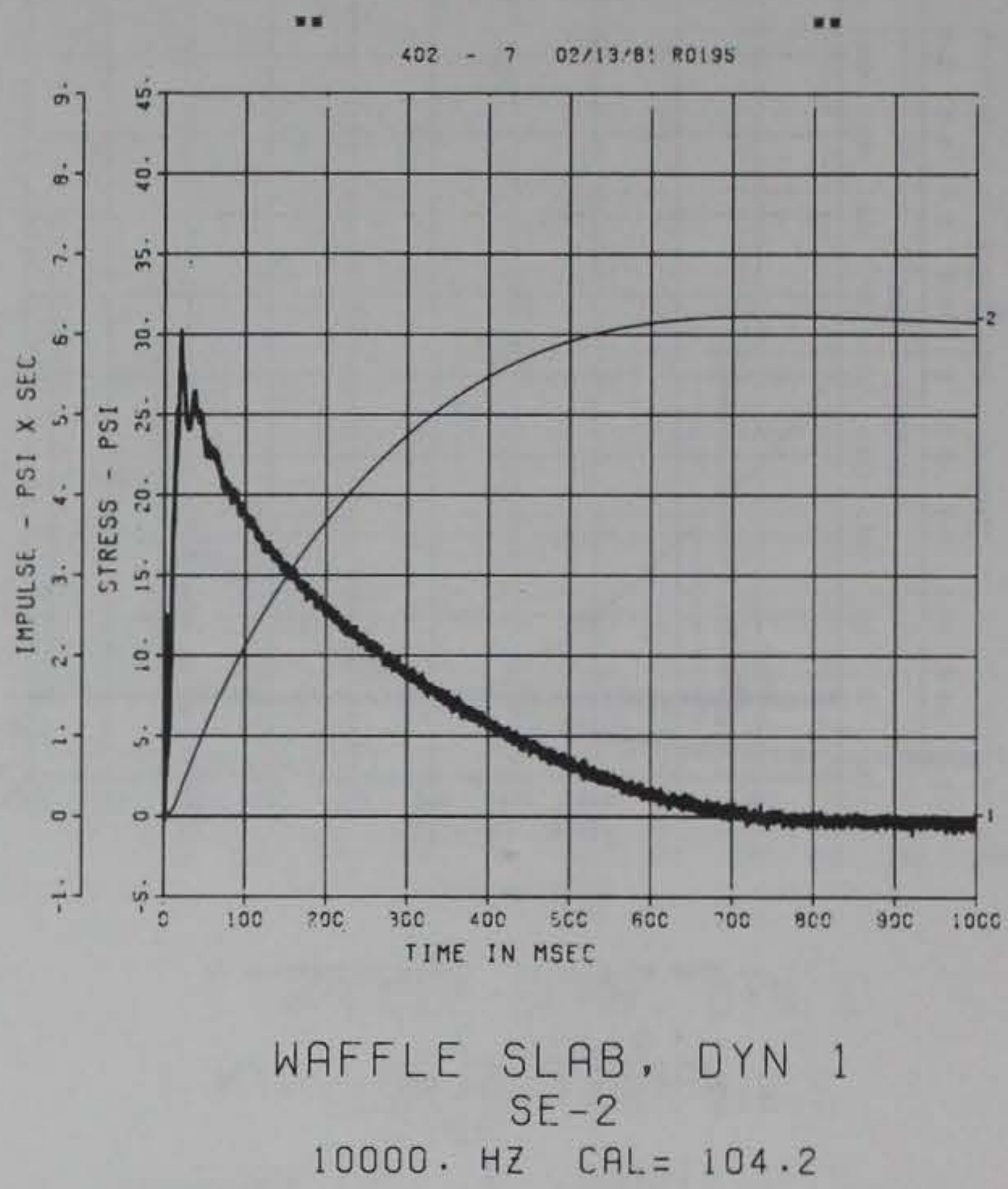

FIGURE C. 48

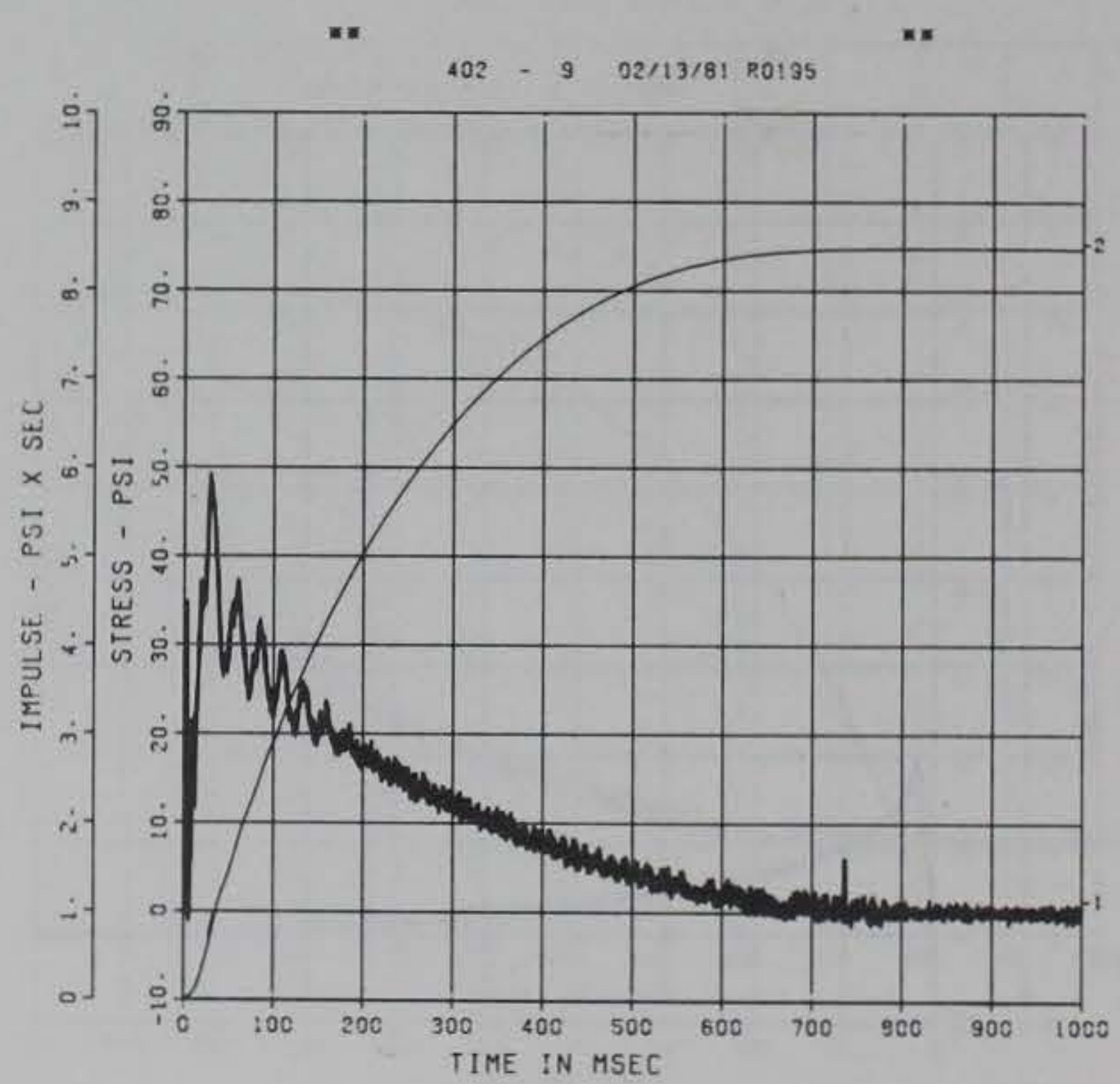




$$
\text { WAFFLE SLAB, DYN } 1
$$$$
\text { i0000. } \mathrm{HZ} \quad \mathrm{CA} \mathrm{L}=-125 \cdot 3
$$

FIGURE $C .49$
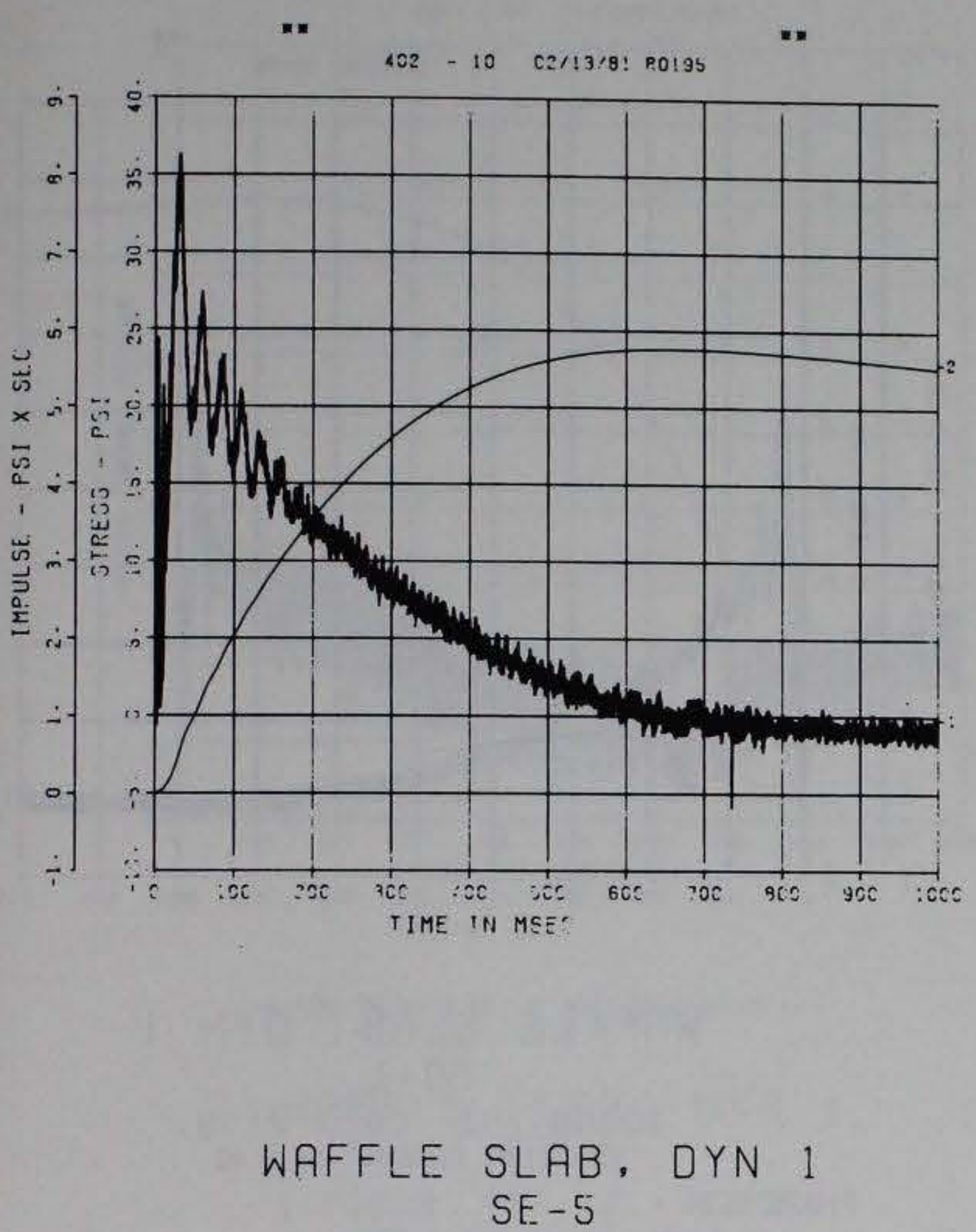

FIGURE C. 51

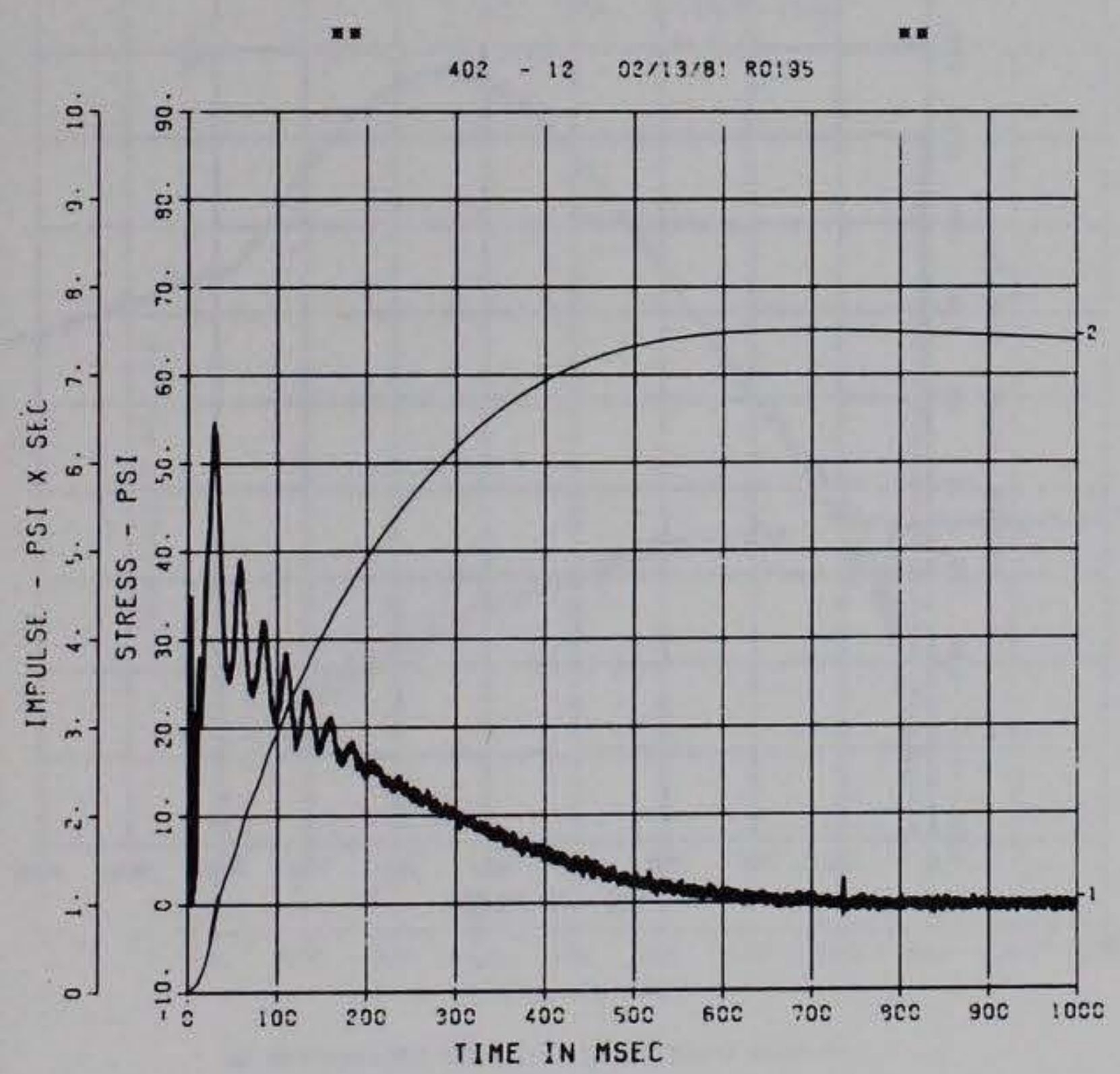

WFFFLE SLAB, DYN 1 $\mathrm{SE}-4$

10000. $\mathrm{HZ} \quad C A L=122.9$

FIGURE $C .50$

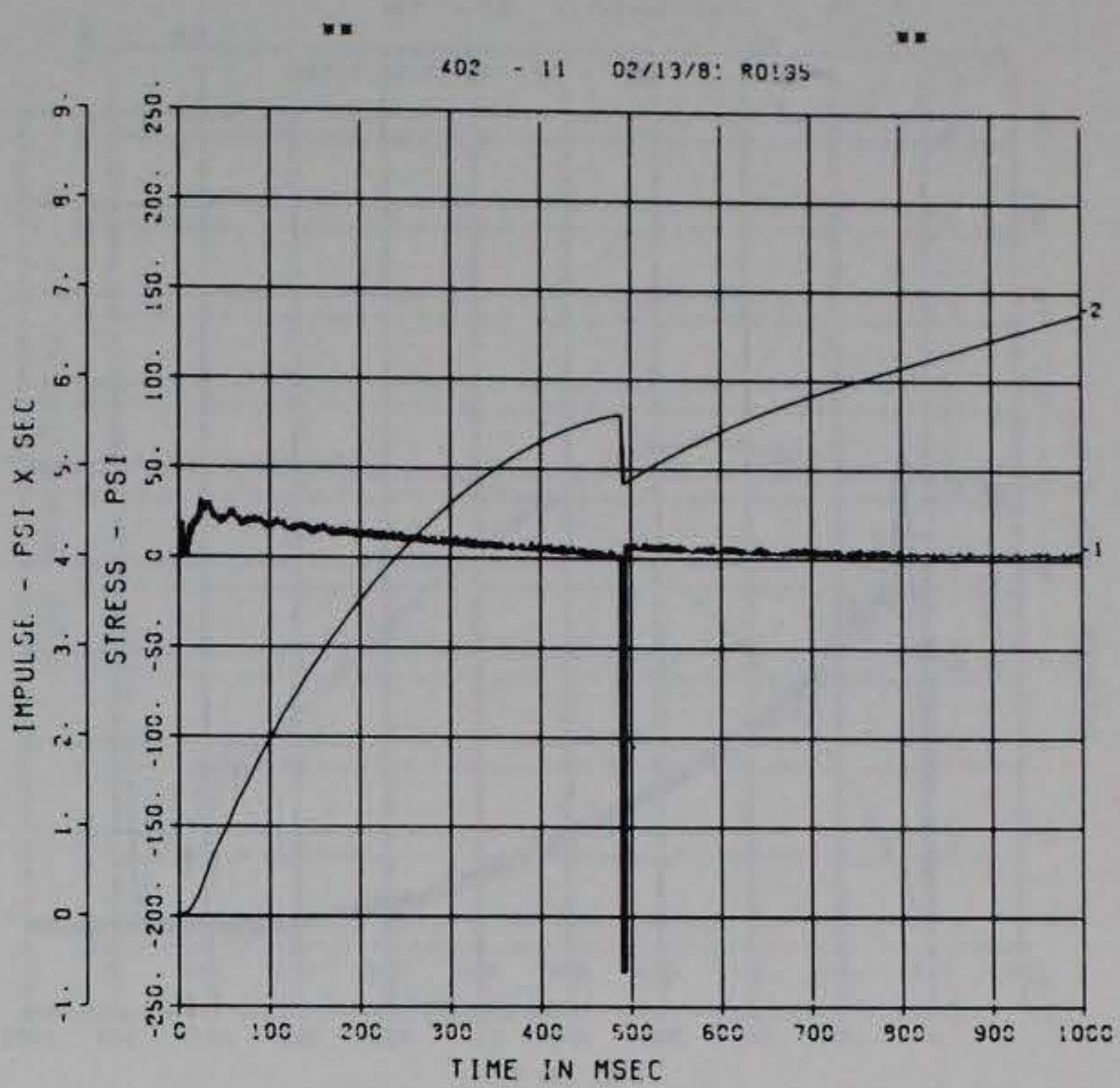

a. PEQK VRLLE IS 35 Y OVEP CALIGRATION =

$$
\begin{gathered}
\text { WAFFLE } \begin{aligned}
\text { SLAB, DYN } 1 \\
\text { SE-6 }
\end{aligned} \\
10000 \cdot \mathrm{HZ} \quad \text { CAL }=114.9
\end{gathered}
$$

FIGURE C.52

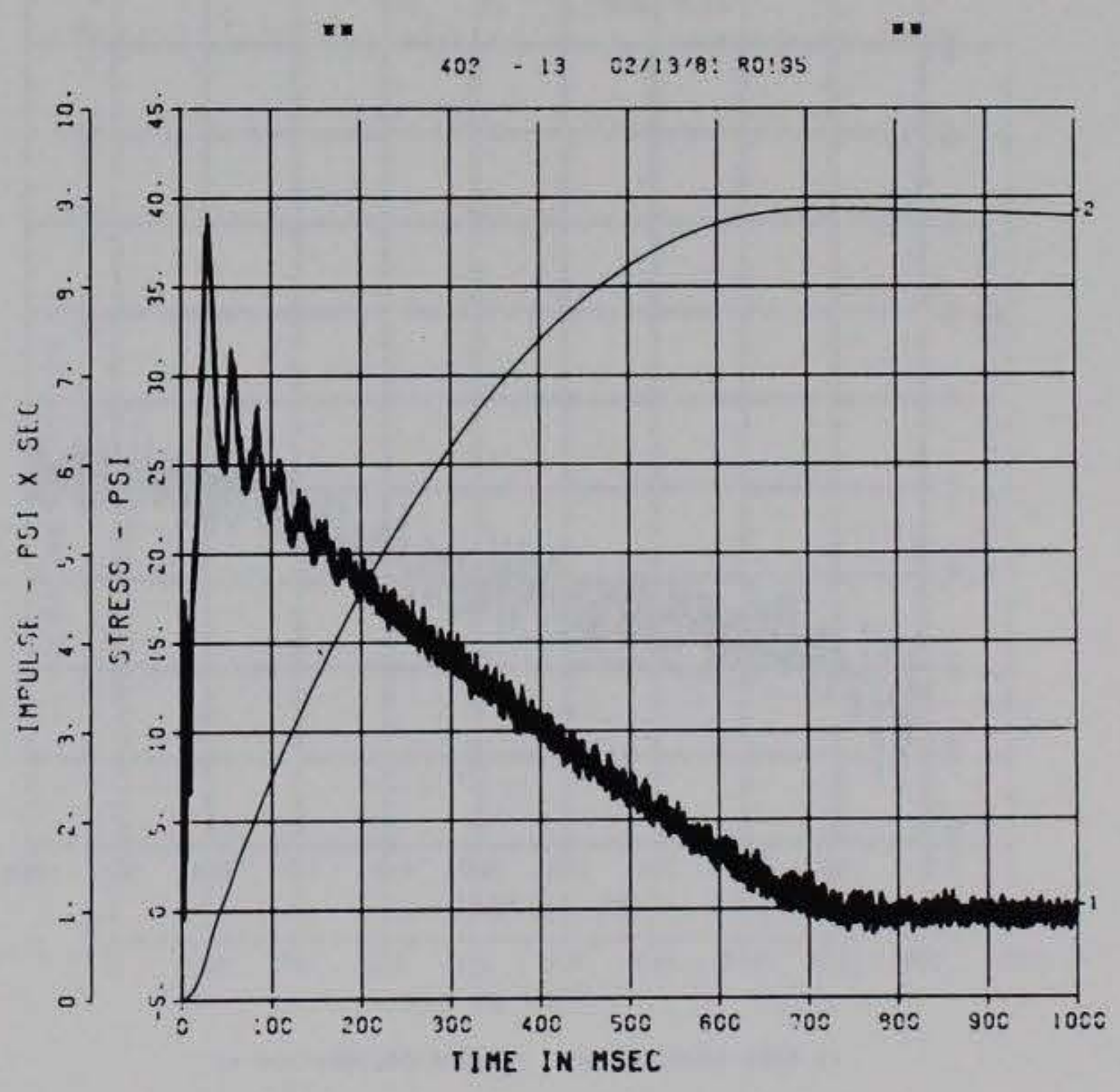




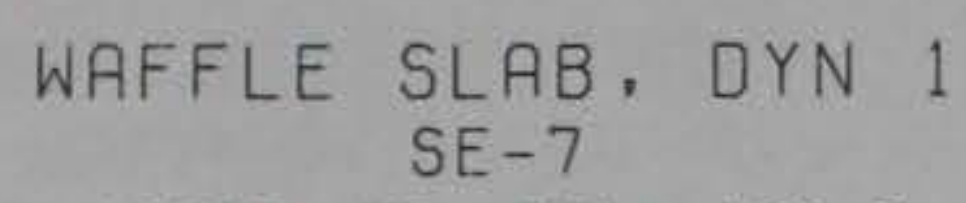

10000. $\mathrm{HZ} \quad \mathrm{CAL}=100.7$

FIGURE 0.53

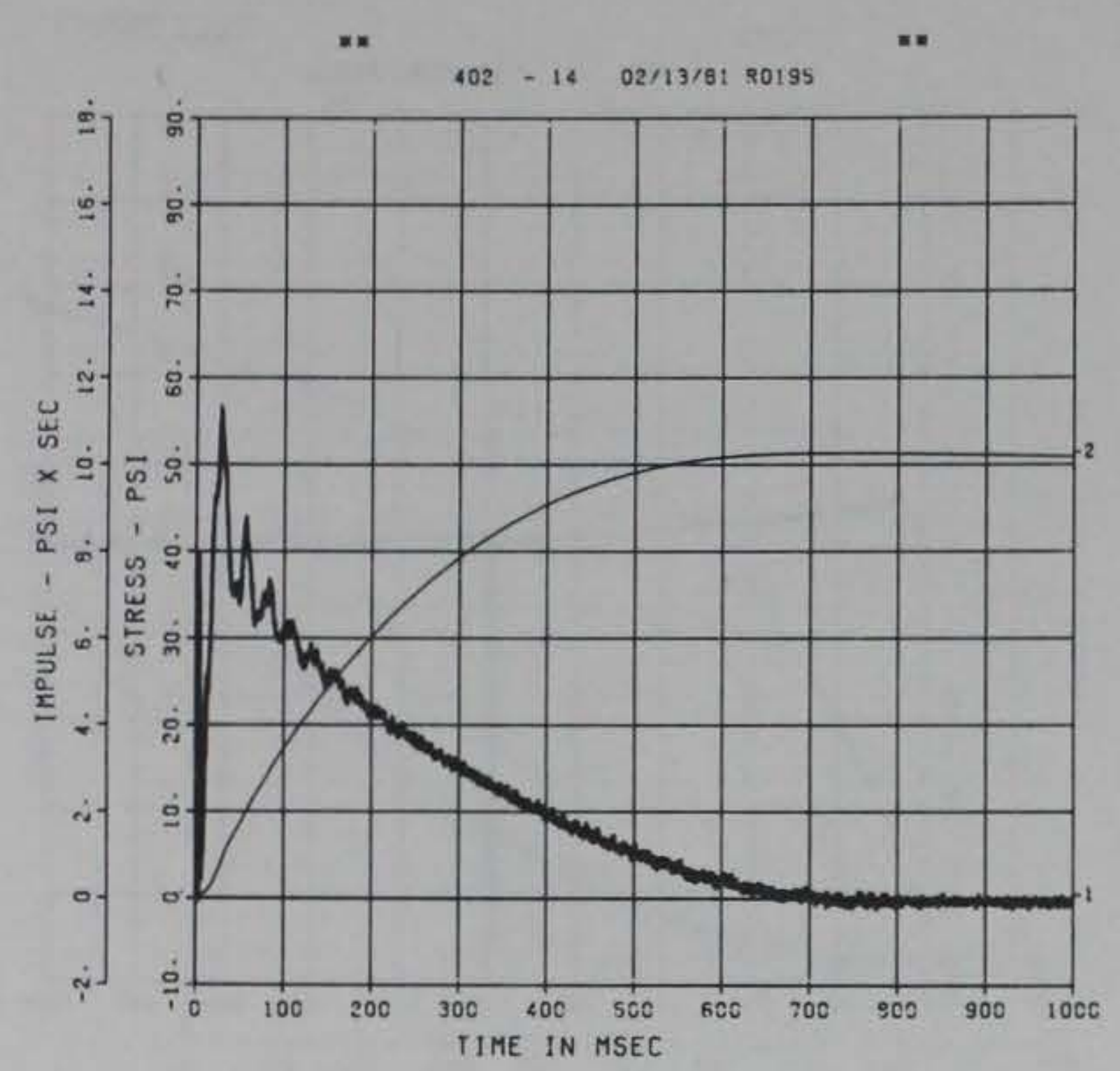

WAFFLE SLAB, DYN 1 $B T-1$

10000. $\mathrm{HZ} \quad \mathrm{CAL}=2178$.

LP $4 / 070 \%$ CUTOFF $=450.0 \mathrm{HZ}$

FIGURE C. 55

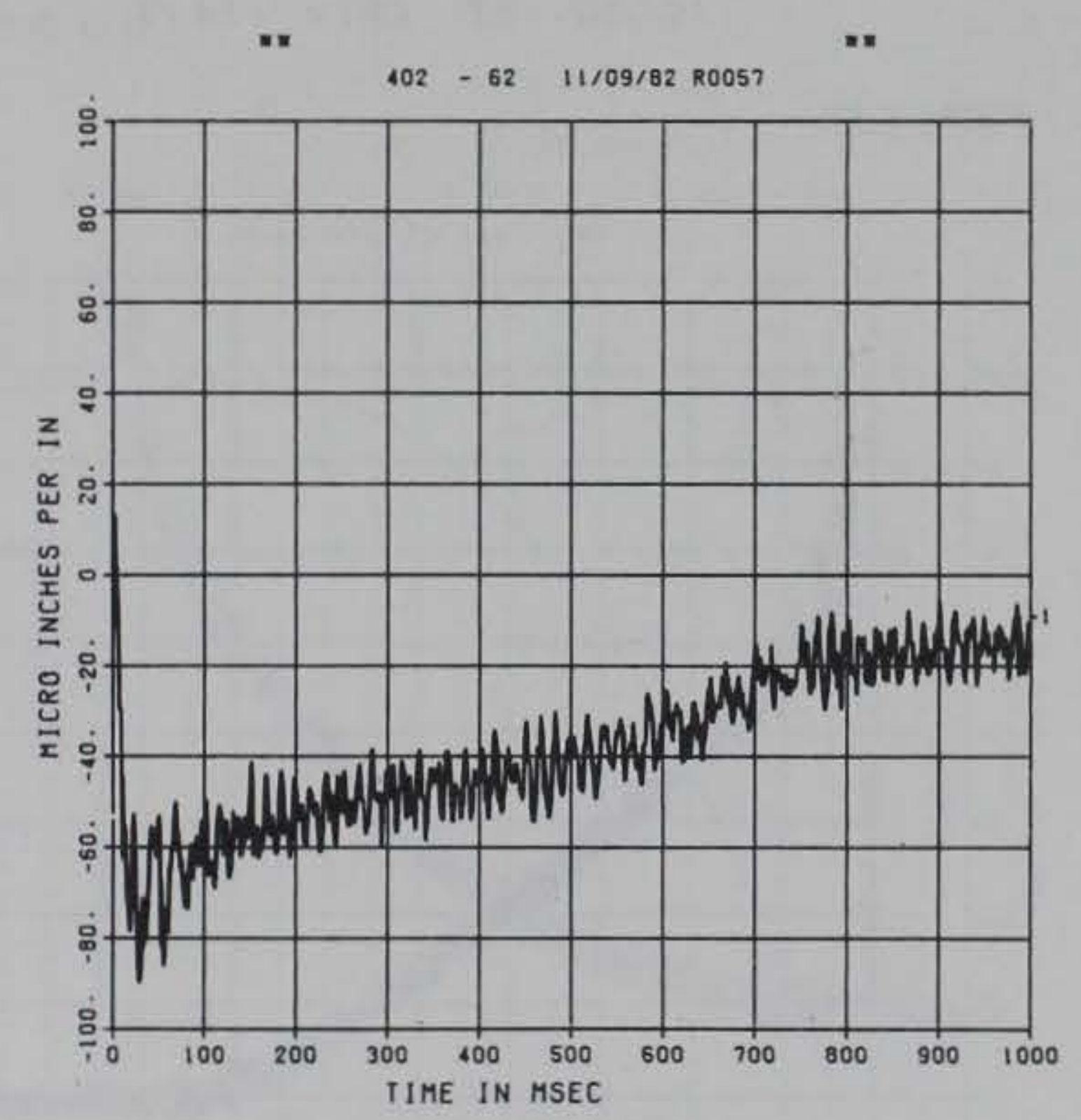

. peak value is 96 \% under calibration ..
WAFFLE SLAB, DYN 1

$$
\text { SE- } 8
$$

10000. $\mathrm{HZ} \quad \mathrm{CAL}=110 . \mathrm{i}$

FIGURE C. 54

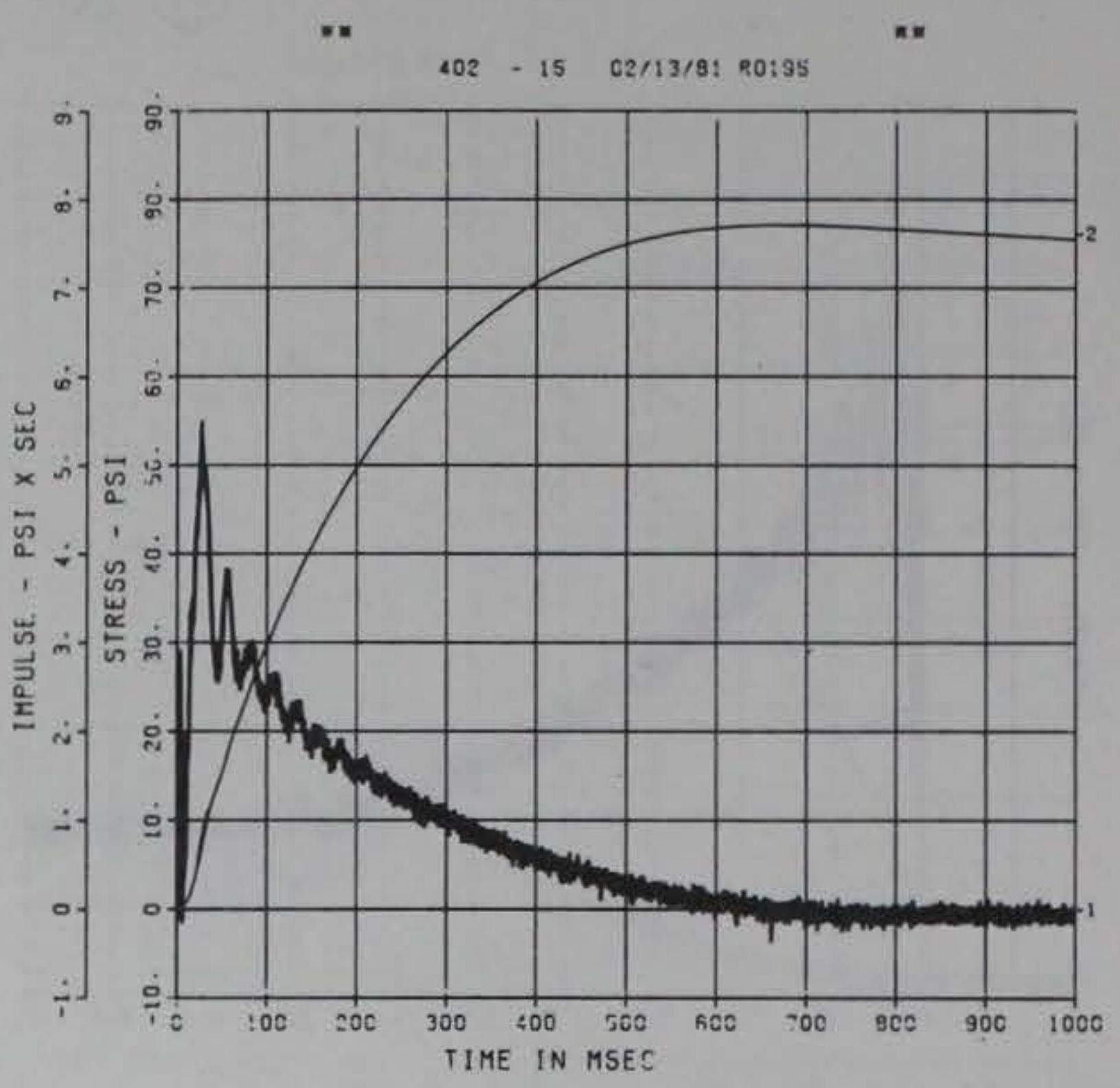

WAFFLE SLAB, DYN 1 $B B-1$

10000. $\mathrm{HZ} \quad \mathrm{CAL}=2178$.

LP4/0 70\% CUTOFF $=450.0 \mathrm{HZ}$

FIGURE C.56

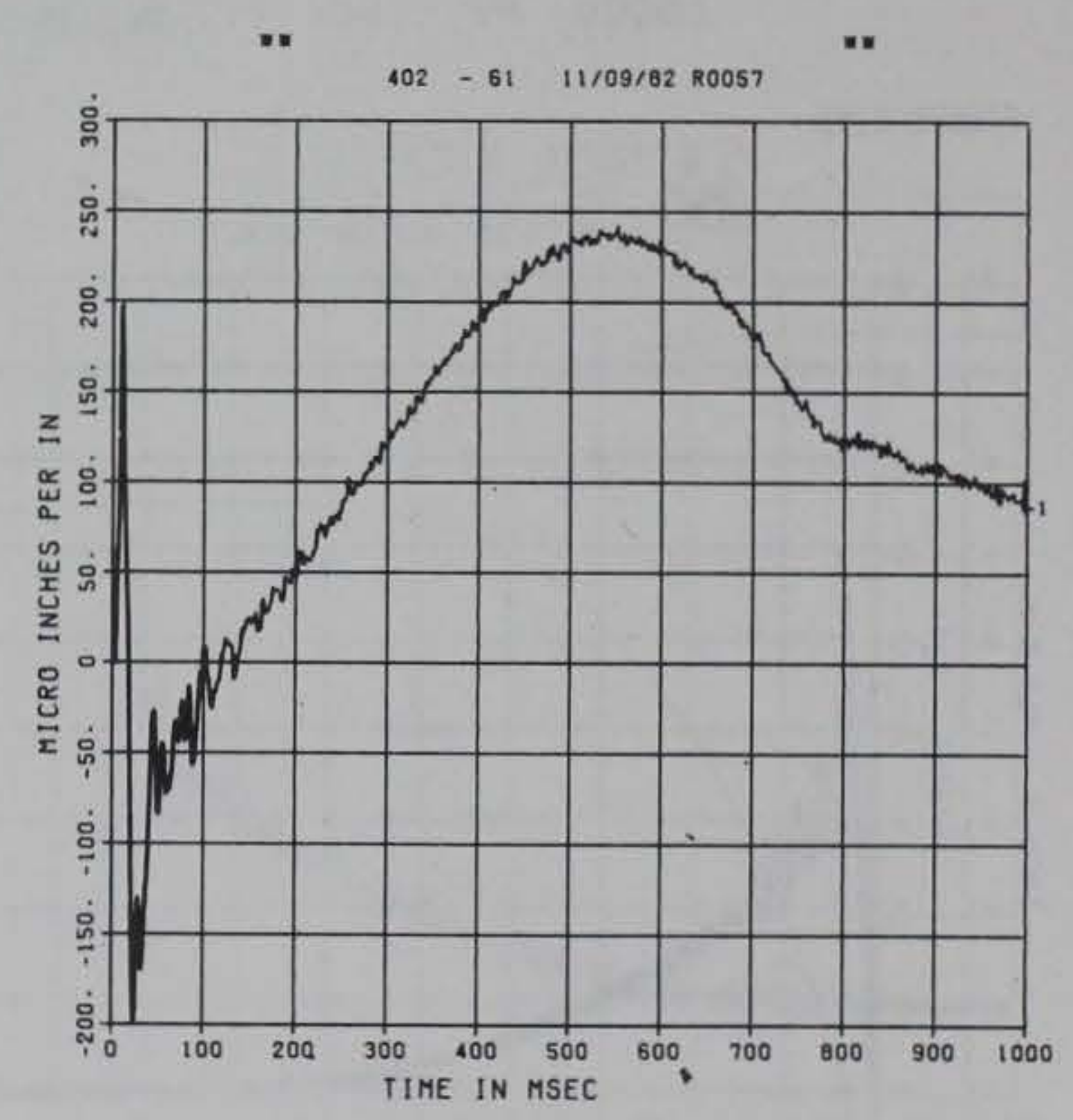

* Peak value is b9 \% under calliration .. 
WAFFLE SLAB, DYN 1
BT-2

10000. HZ CAL $=2178$.

LP $4 / 070 \%$ CUTOFF $=450.0 \mathrm{~Hz}$

FIGURE C.57

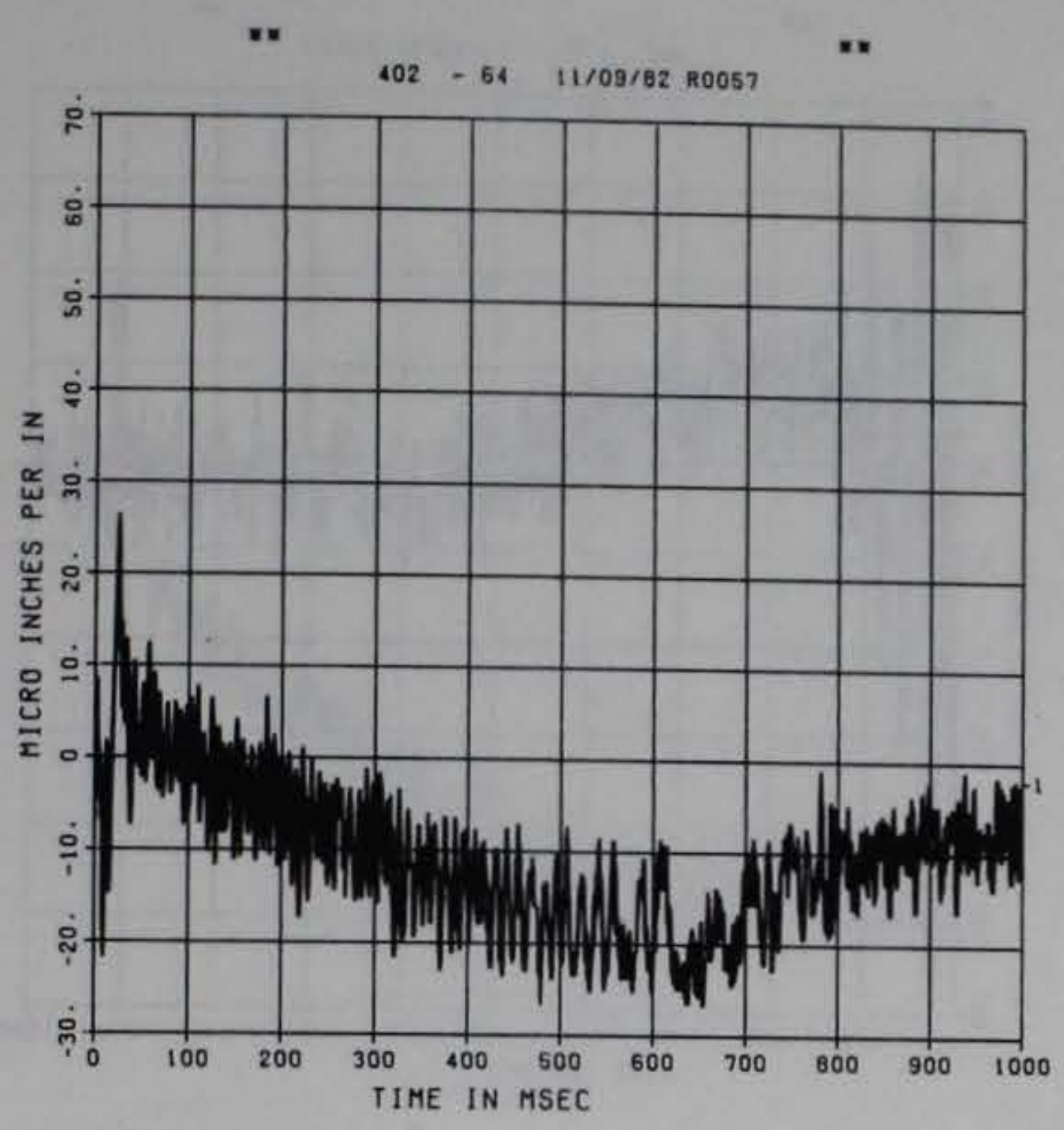

*. PEAK VALUE IS $99 \quad \%$ UNDER CaL IBRatION ..

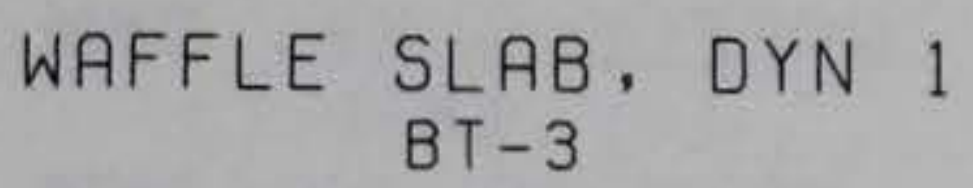

10000. $\mathrm{HZ} \quad \mathrm{CAL}=2178$.

LP $4 / 070 \%$ CUTOFF $=450.0 \mathrm{HZ}$

FIGURE C.59

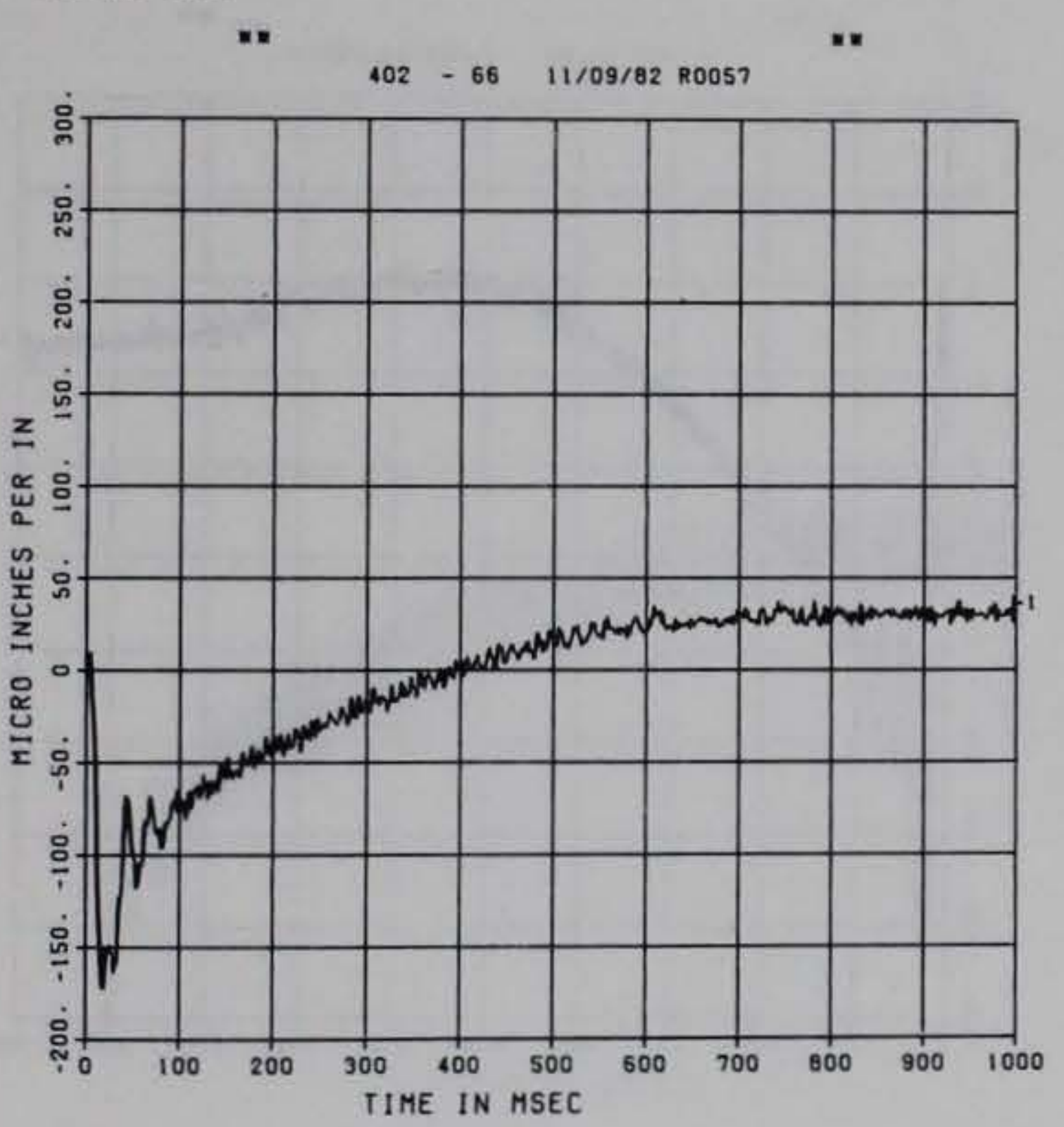

*. Peak value is $92 \%$ under callibration *.
WAFFLE SLAB, OYN 1

10000. $\mathrm{HZ} \quad \mathrm{CAL}=2178$.

LP $4 / 070 \%$ CUTOFF $=450.0 \mathrm{~Hz}$

FIGURE C. 58

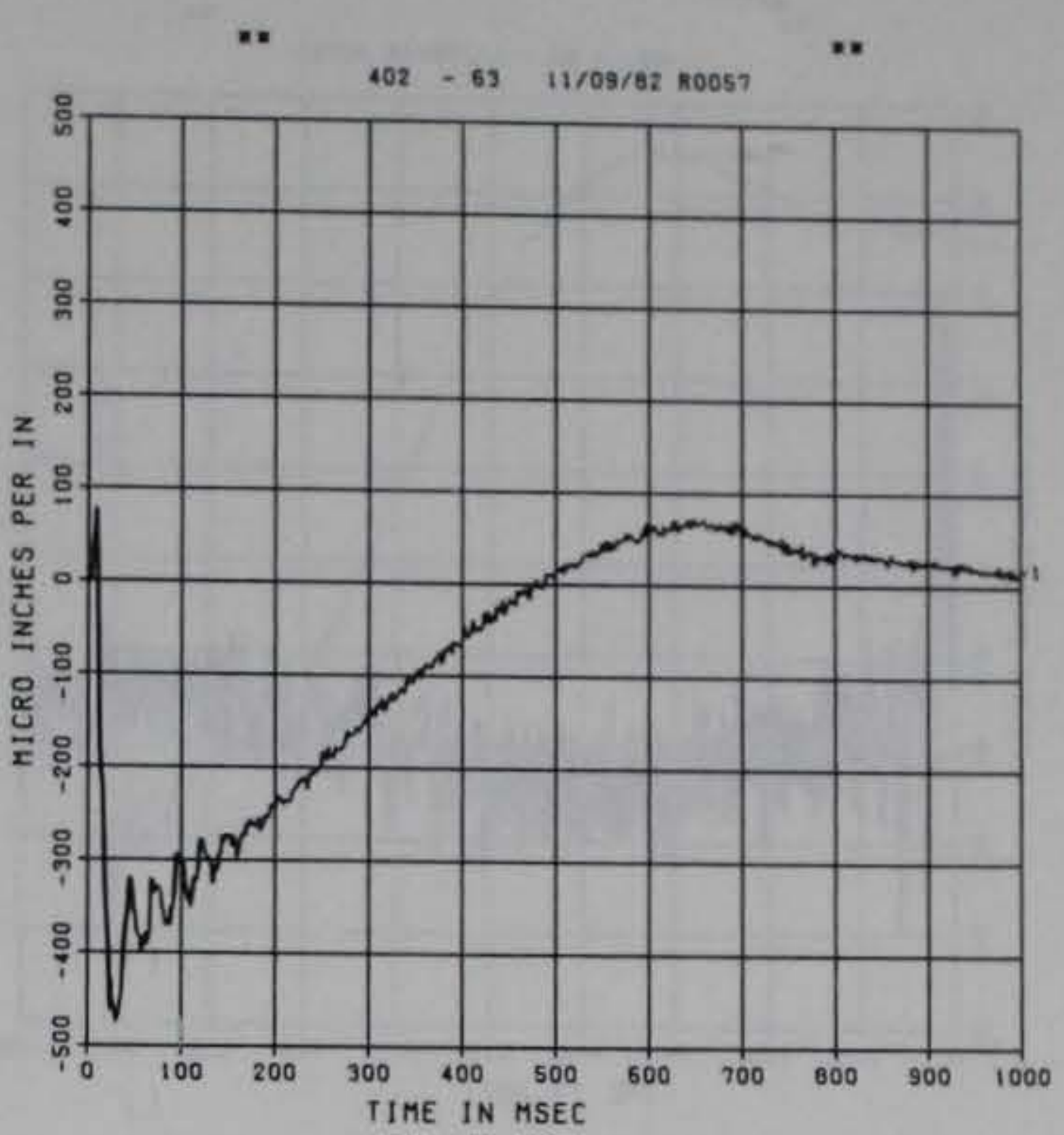

WAFFLE SLAB, OYN 1 $B B-3$

10000. $\mathrm{HZ} \quad \mathrm{CAL}=2178$.

LP $4 / 070 \%$ CUTOFF $=450.0 \mathrm{~Hz}$

FIGURE C. 60

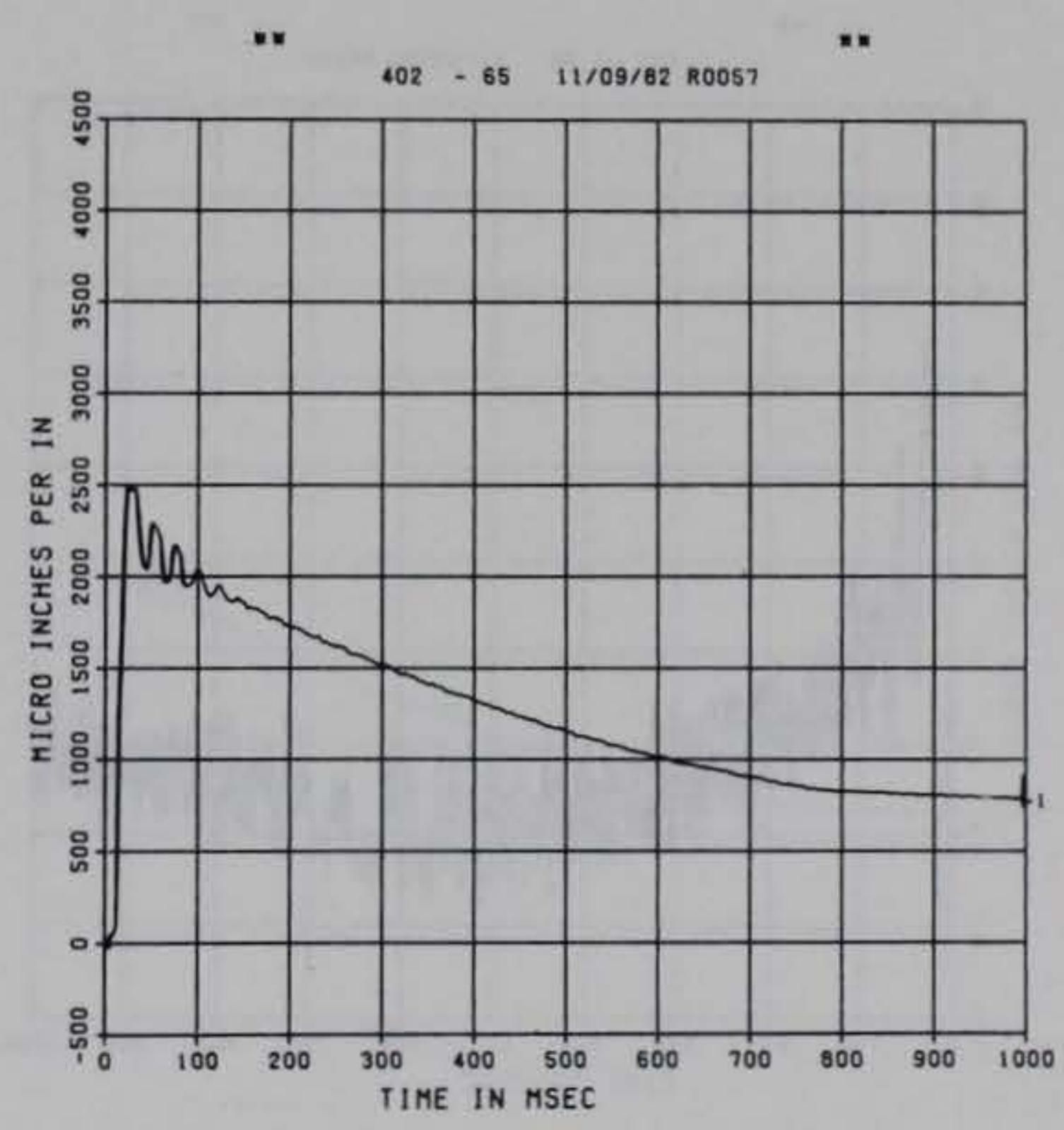

\#. Peak value is is z over caltbration .. 
WAFFLE SLAB, DYN 1

10000. $\mathrm{HZ} \quad \mathrm{CAL}=2178$.

LP $4 / 070 \%$ CUTOFF $=450.0 \mathrm{HZ}$

FIGURE $C .61$

$402-68 \quad 11 / 09 / 82 \quad R 0057$

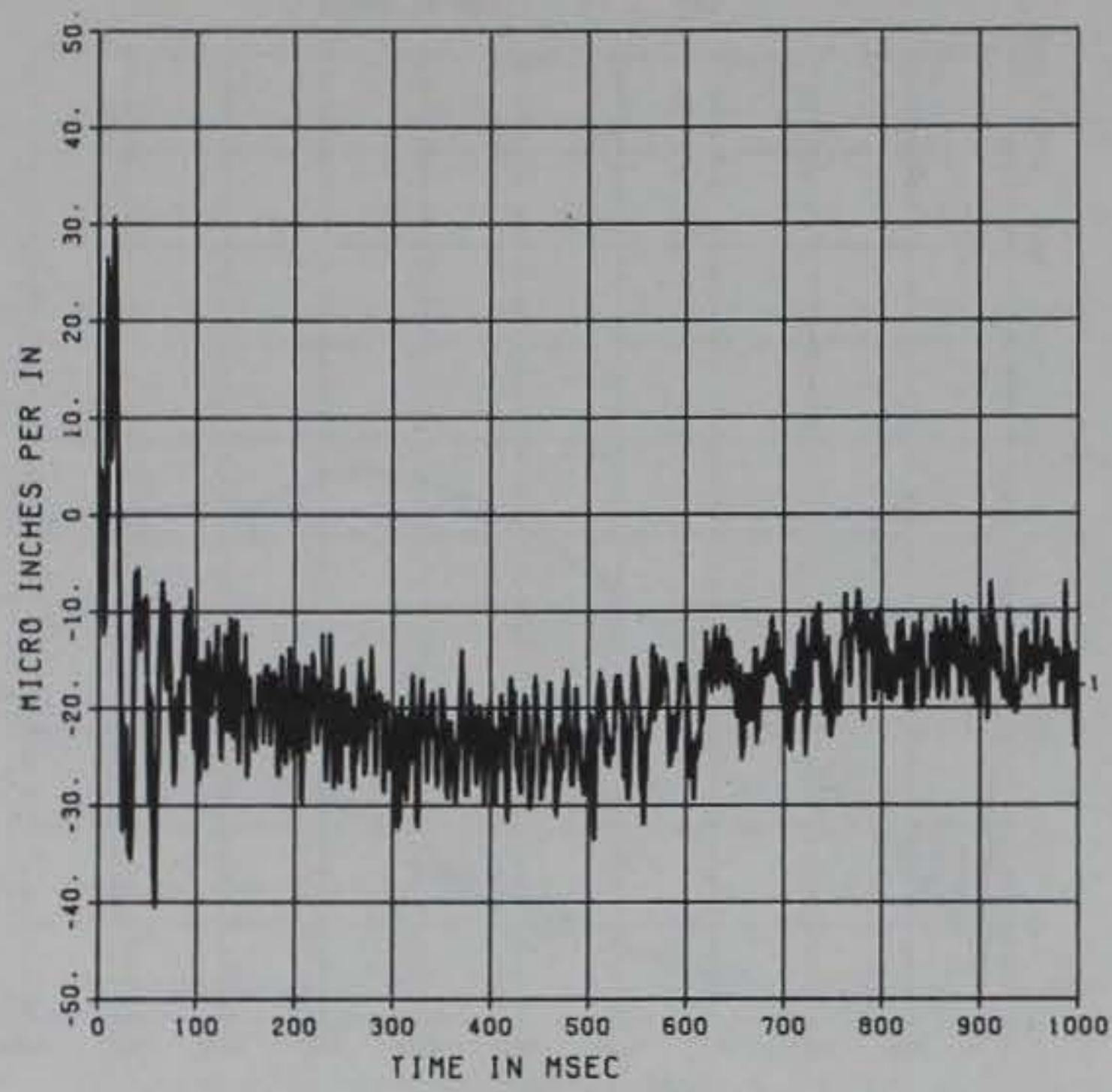

* PEAK VALUE IS 98 \% UNOER CALIBRATION *

$$
\begin{gathered}
\text { WAFFLE SLAB, DYN } 1 \\
\text { CT-1 } \\
\text { 10000. HZ CAL }=2178 .
\end{gathered}
$$$$
\text { LP } 4 / 070 \% \text { CUTOFF }=450.0 \mathrm{HZ}
$$

FIGURE C.63

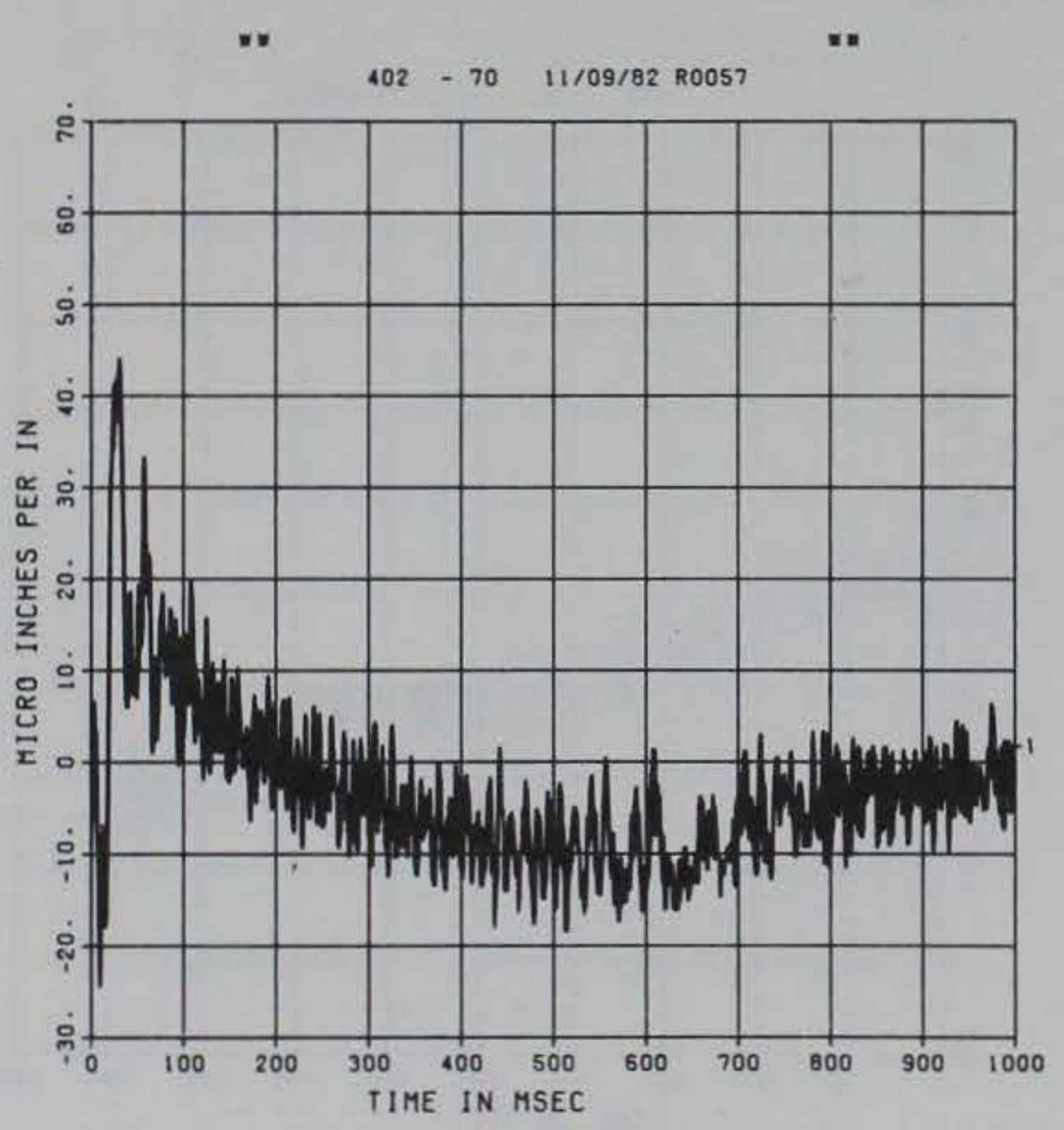

\# PEaK value is 98 $\chi$ under callaration \#.
WAFFLE SLAB, DYN 1

$$
\mathrm{BB}-4
$$

10000. $\mathrm{HZ} \quad C A L=2178$.

LP $4 / 070 \%$ CUTOFF $=450.0 \mathrm{HZ}$

FIGURE C. 62

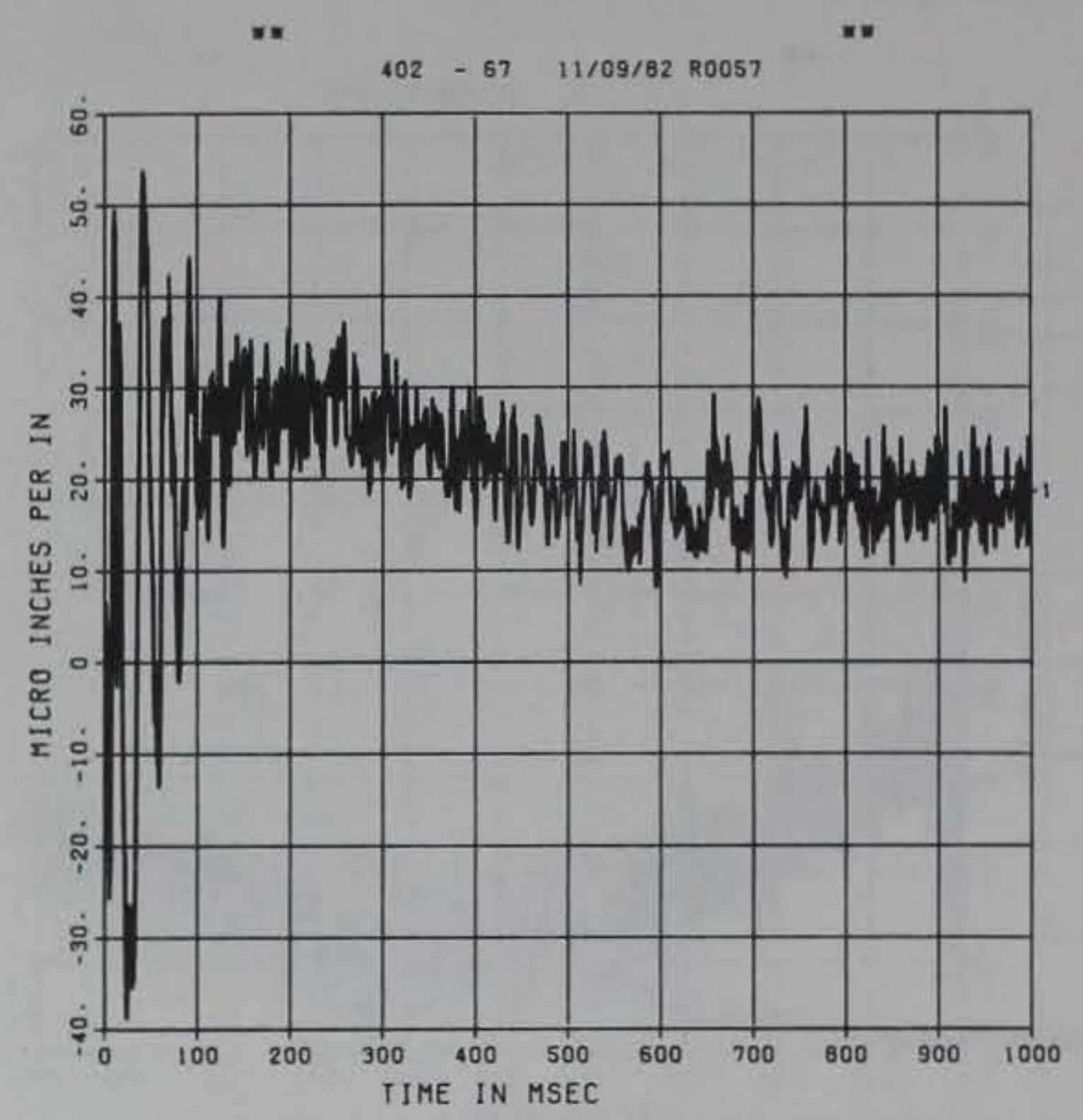

* peak value is 98 \% under calibration ..

WAFFLE SLAB, DYN 1

$$
C B-1
$$

10000. $\mathrm{HZ} \quad \mathrm{CAL}=2178$.

LP $4 / 070 \%$ CUTOFF $=450.0 \mathrm{HZ}$

FIGURE C.64

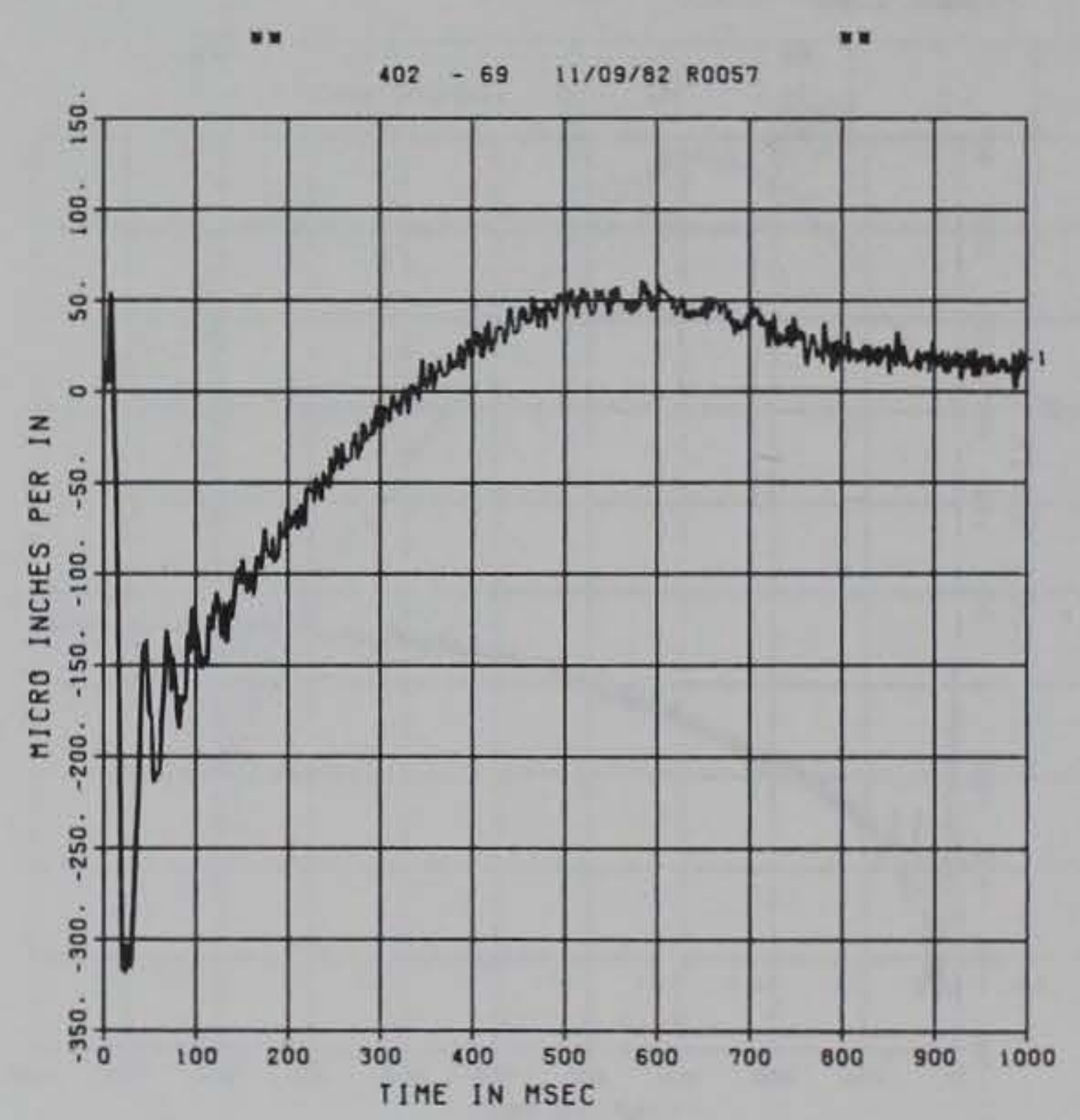

* peak value is 85 \% under cal ibration a. 
WAFFLE SLAB, OYN 1

10000. $\mathrm{HZ} \quad \mathrm{CAL}=2178$.

LP $4 / 070 \%$ CUTOFF $=450.0 \mathrm{HZ}$

FIGURE C.65

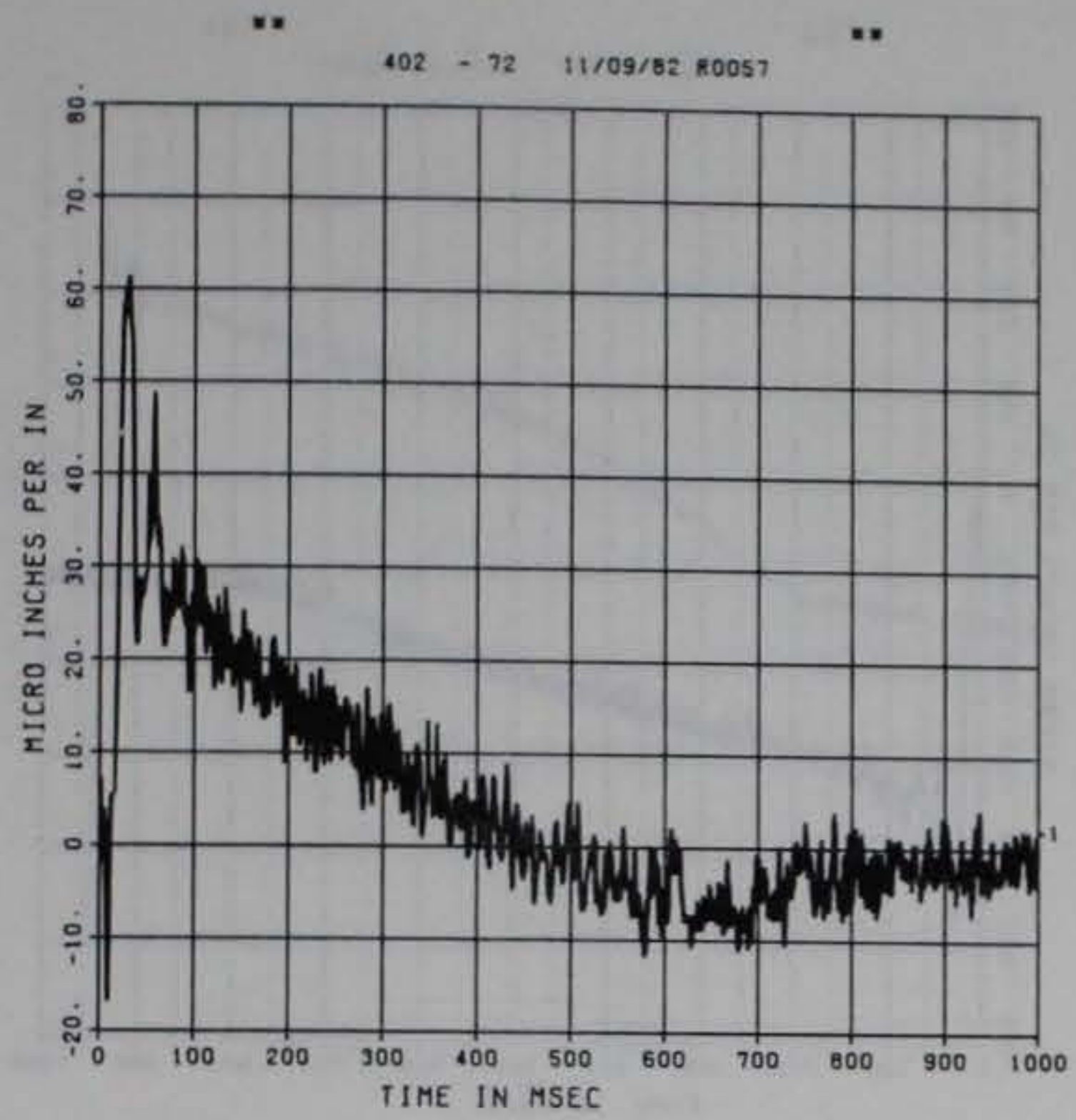

*. PEak value is 97 z under calibration ..

WAFFLE SLAB, DYN 1

CT-3(CAL EST)

10000. $\mathrm{HZ} \quad \mathrm{CAL}=2178$.

$P_{4} / 070 \%$ CUTOFF $=450.0 \mathrm{~Hz}$

FIGURE C.67

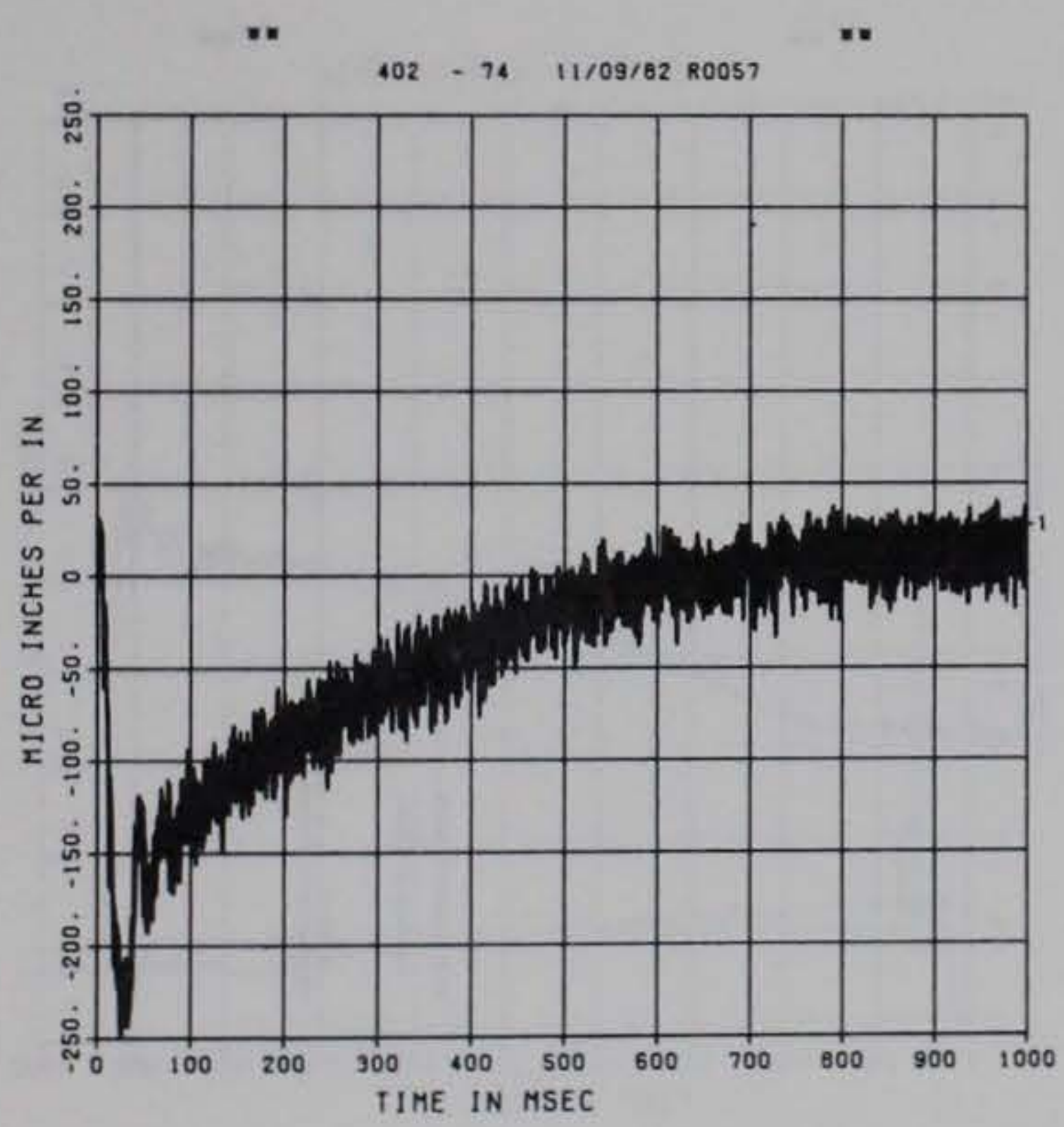

WAFFLE SLAB, DYN 1 CB-2

10000. HZ CAL $=2178$.

$P 4 / 0702$ CuTOFF $=450.0 \mathrm{~Hz}$

FIGURE C.66

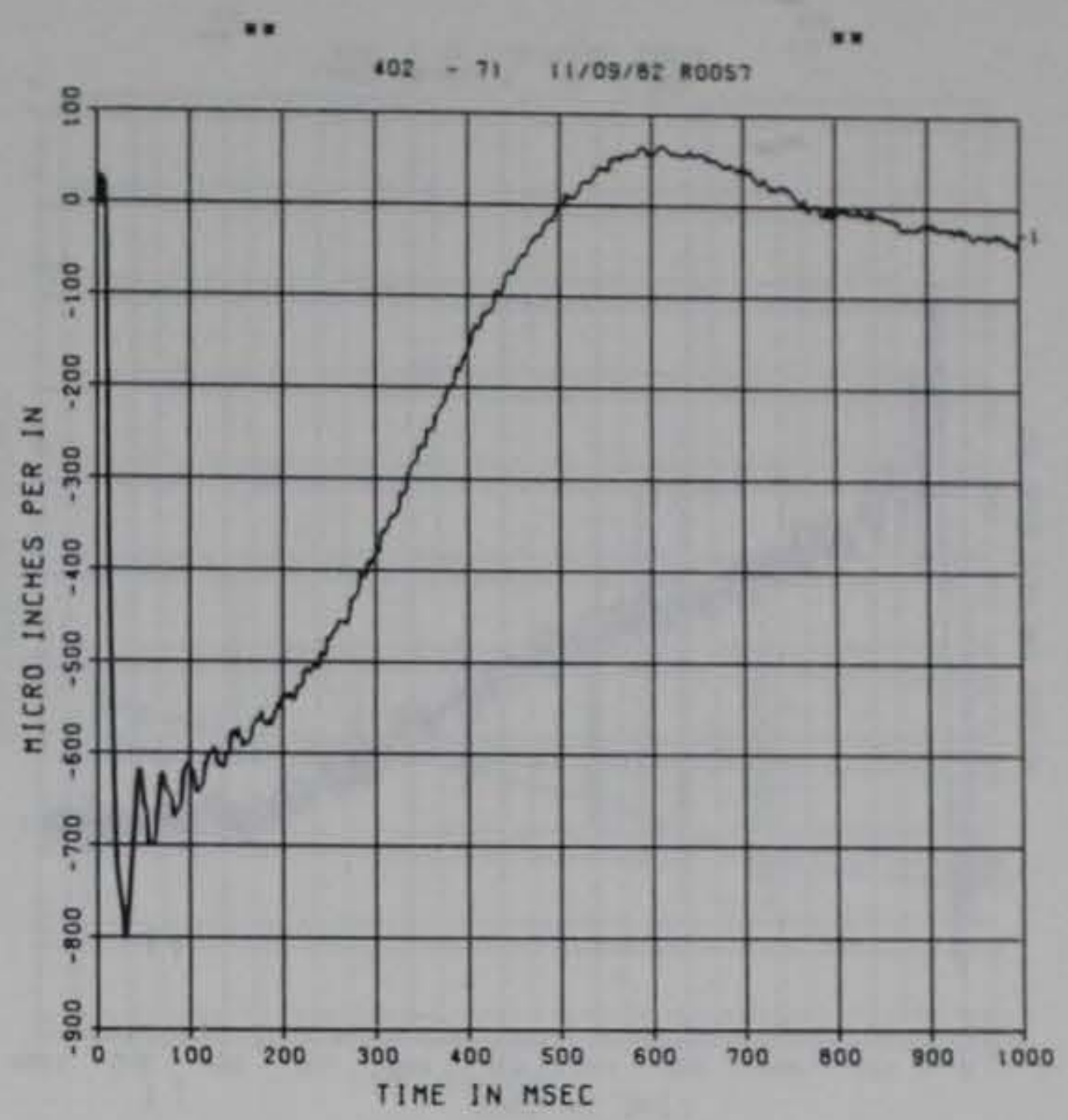

WAFFLE SLAB, DYN 1

10000. $\mathrm{HZ} \quad \mathrm{CAL}=2178$.

LP $4 / 070 \%$ CUTOFF $=450.0 \mathrm{HZ}$

FIGURE C.68

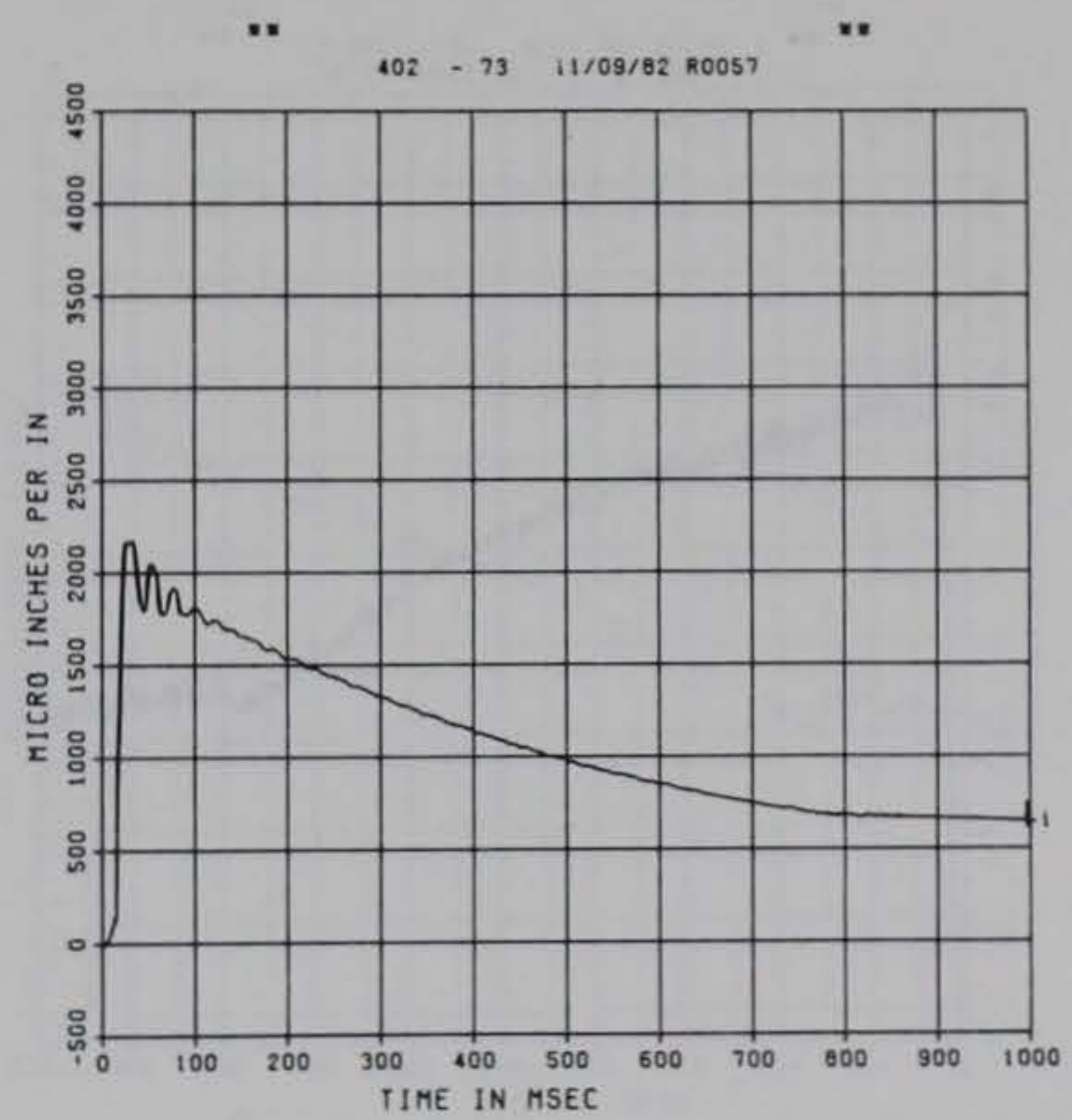


WAFFLE SLAB, DYN 1

CT-4 (CAL EST)

10000. $\mathrm{HZ} \quad \mathrm{CAL}=2178$.

LP $4 / 070 \%$ CUTOFF $=450.0 \mathrm{HZ}$

FIGURE C.69

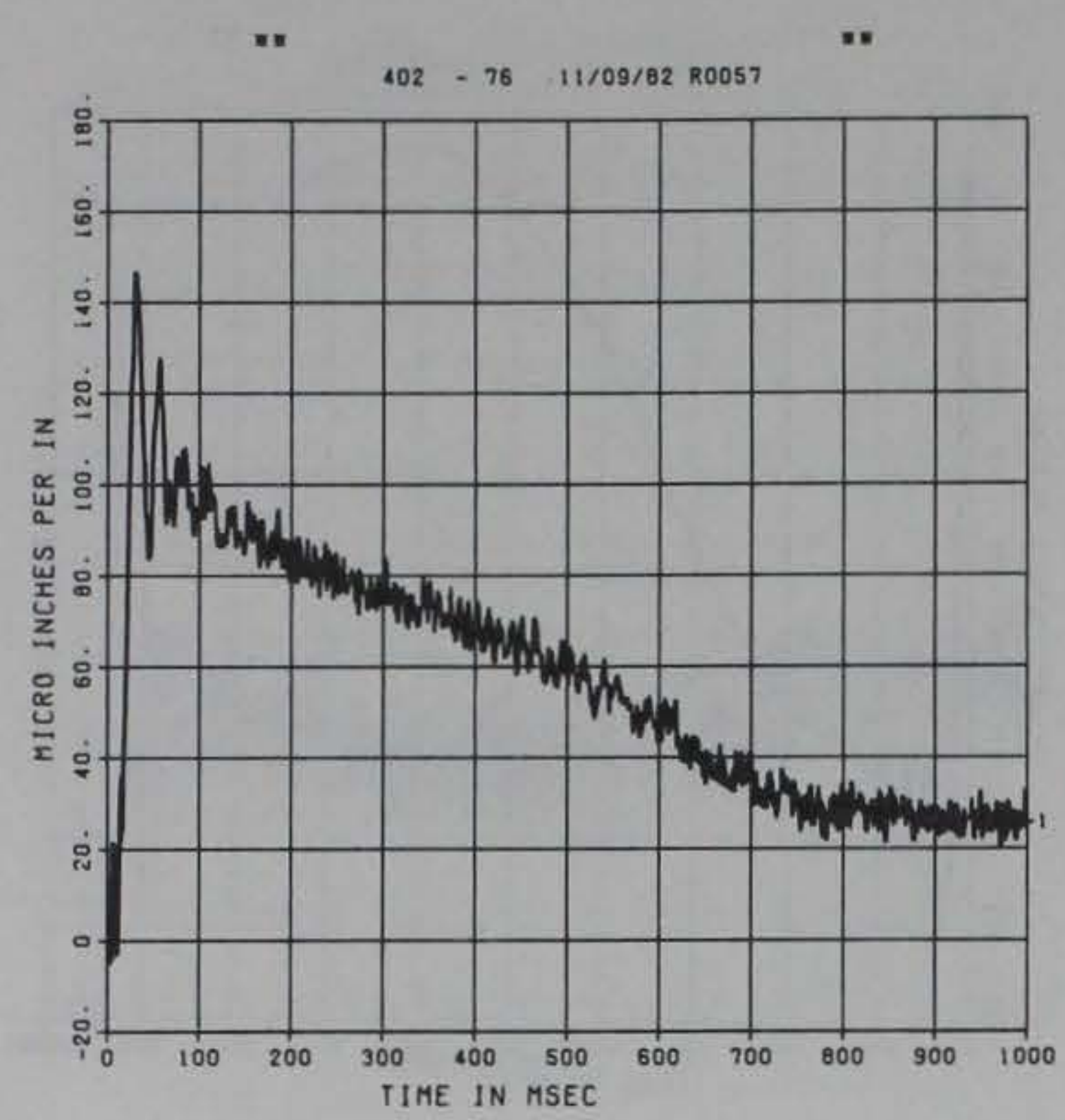

\#. peak value is 93 \% under cal ibration ..

$$
\begin{gathered}
\text { WAFFLE SLAB, DYN } 1 \\
D-1 \\
10000 . \mathrm{HZ} \quad \mathrm{CAL}=6.300 \\
\text { LP4 70\% CUTOFF }=450.5 \mathrm{HZZ}
\end{gathered}
$$

FIGURE C.71

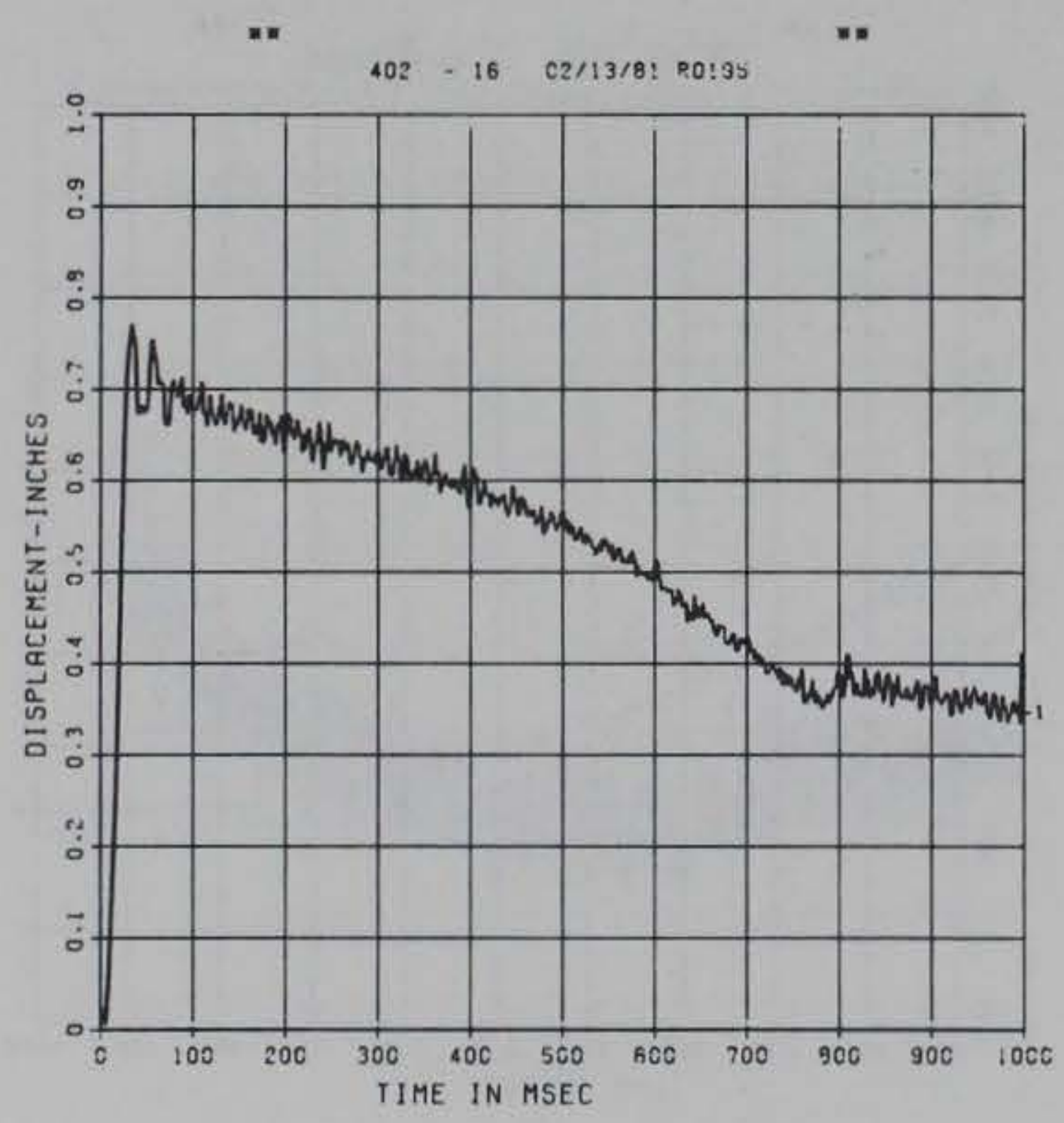

WAFFLE SLAB, DYN 1

CB-4 (CAL EST)

10000. $\mathrm{HZ} \quad \mathrm{CAL}=2178$.

LP $4 / 070 \%$ CUTOFF $=450.0 \mathrm{HZ}$

FIGURE C.70

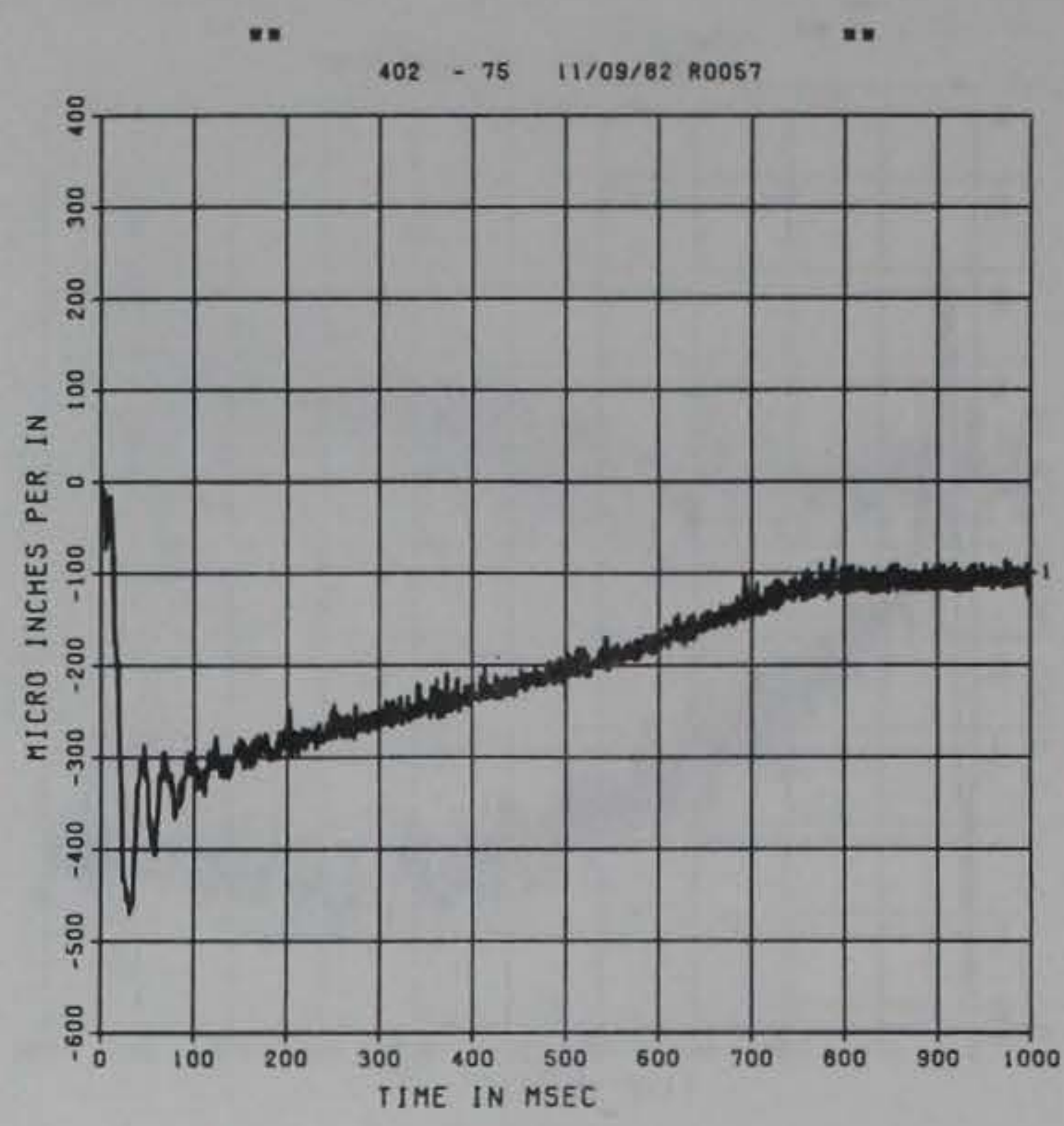

$$
\begin{gathered}
\text { WAFFLE } \begin{array}{c}
\text { SLAB , DYN } 1 \\
D-2
\end{array} \\
10000 . \mathrm{HZ} \quad \mathrm{CAL}=6.300 \\
\text { LP4 70\% CUTOFF }=450.0 \mathrm{~Hz}
\end{gathered}
$$

FIGURE $C .72$

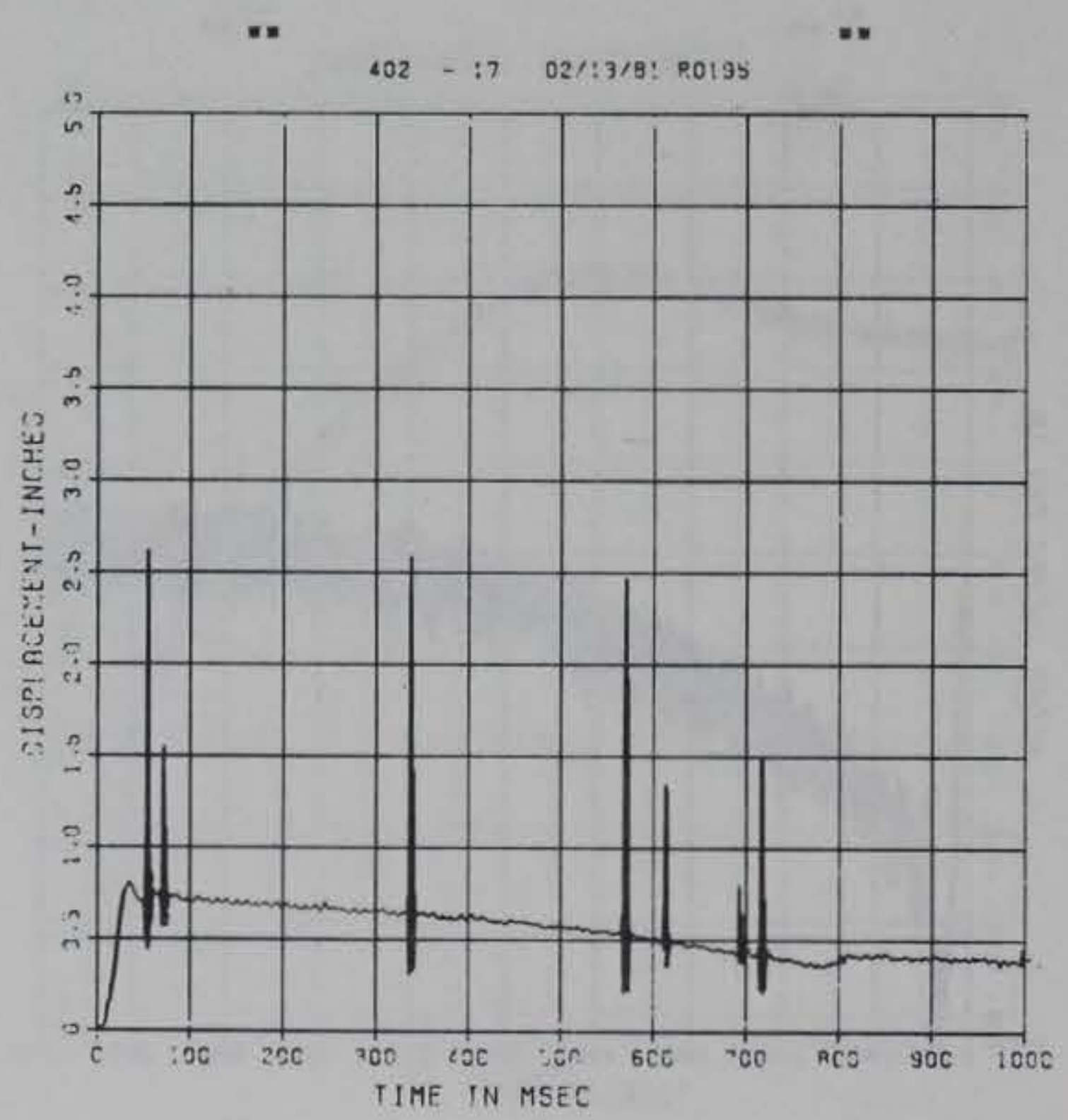



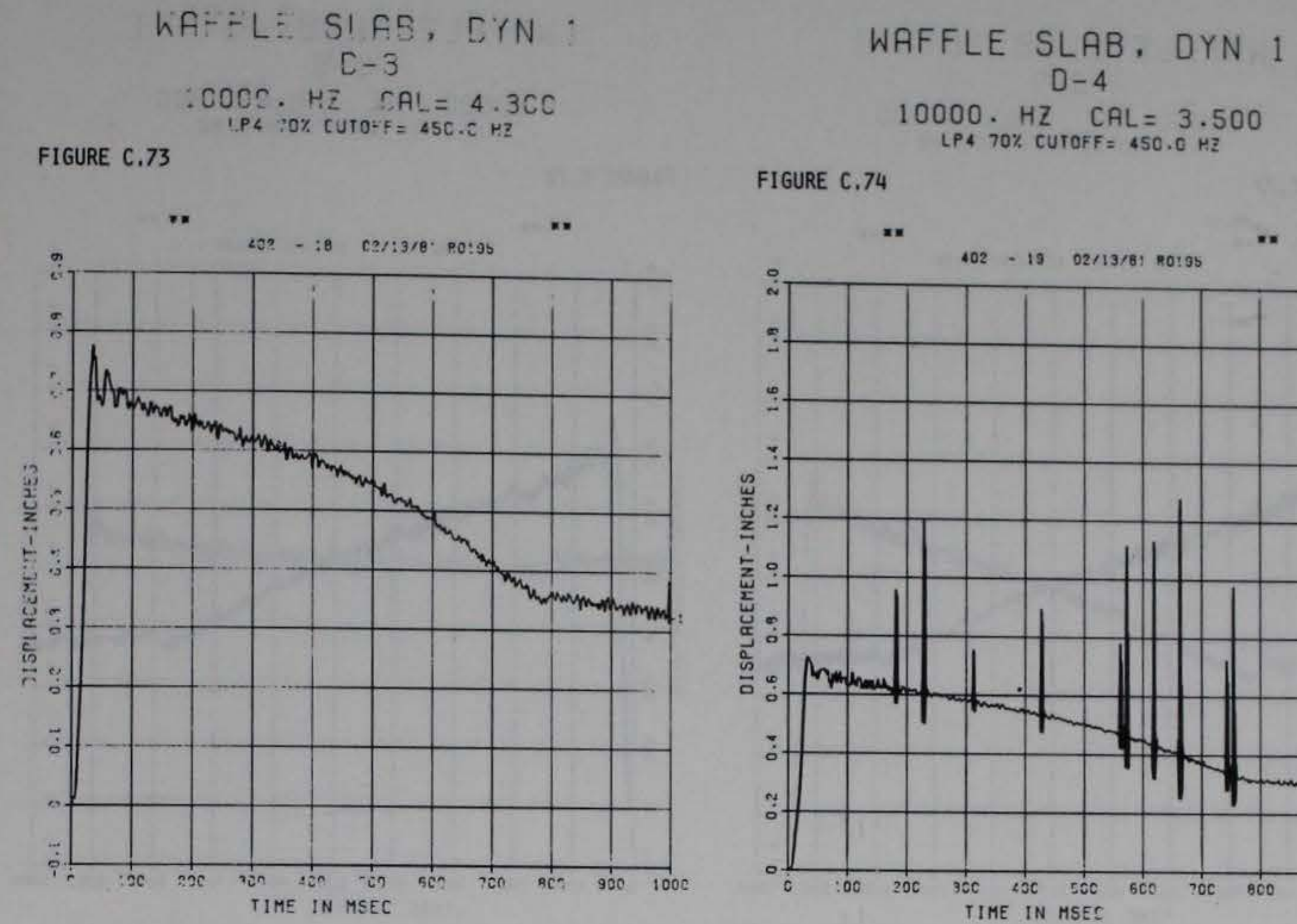

FIGURE C.74

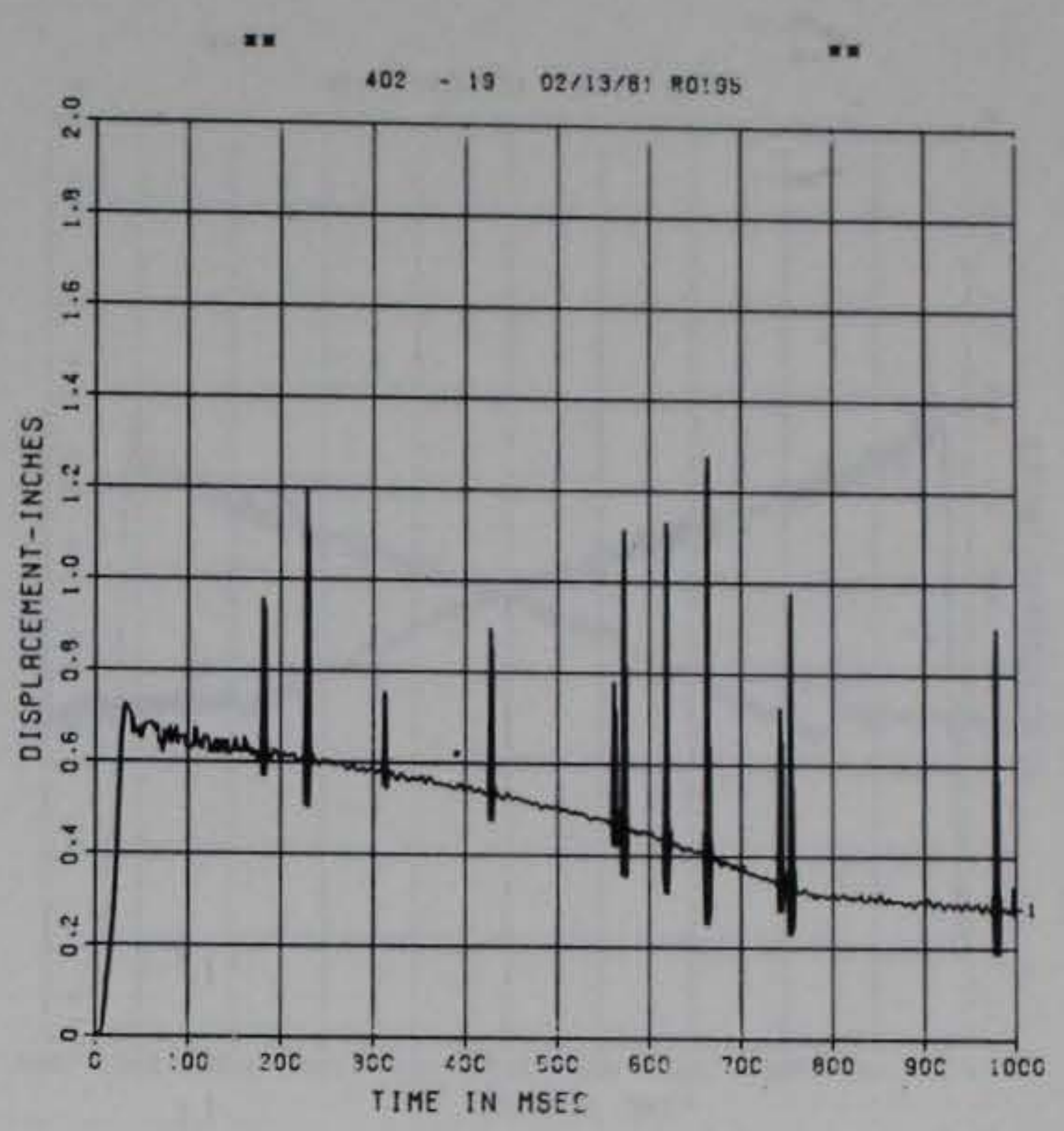

\#. Peak value is 62 * under calibration *

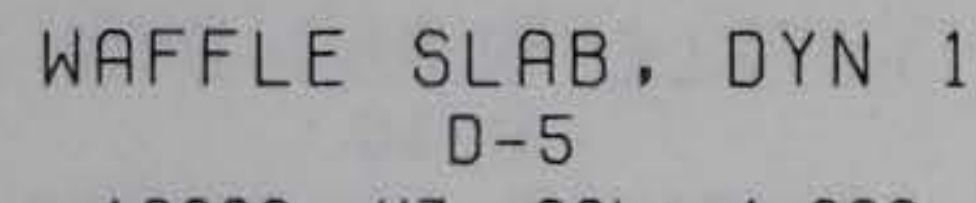

10000. $\mathrm{HZ} \quad \mathrm{CAL}=4.300$

LP4 $70 \%$ CUTOFF $=450.0 \mathrm{HZ}$

FIGURE C.75
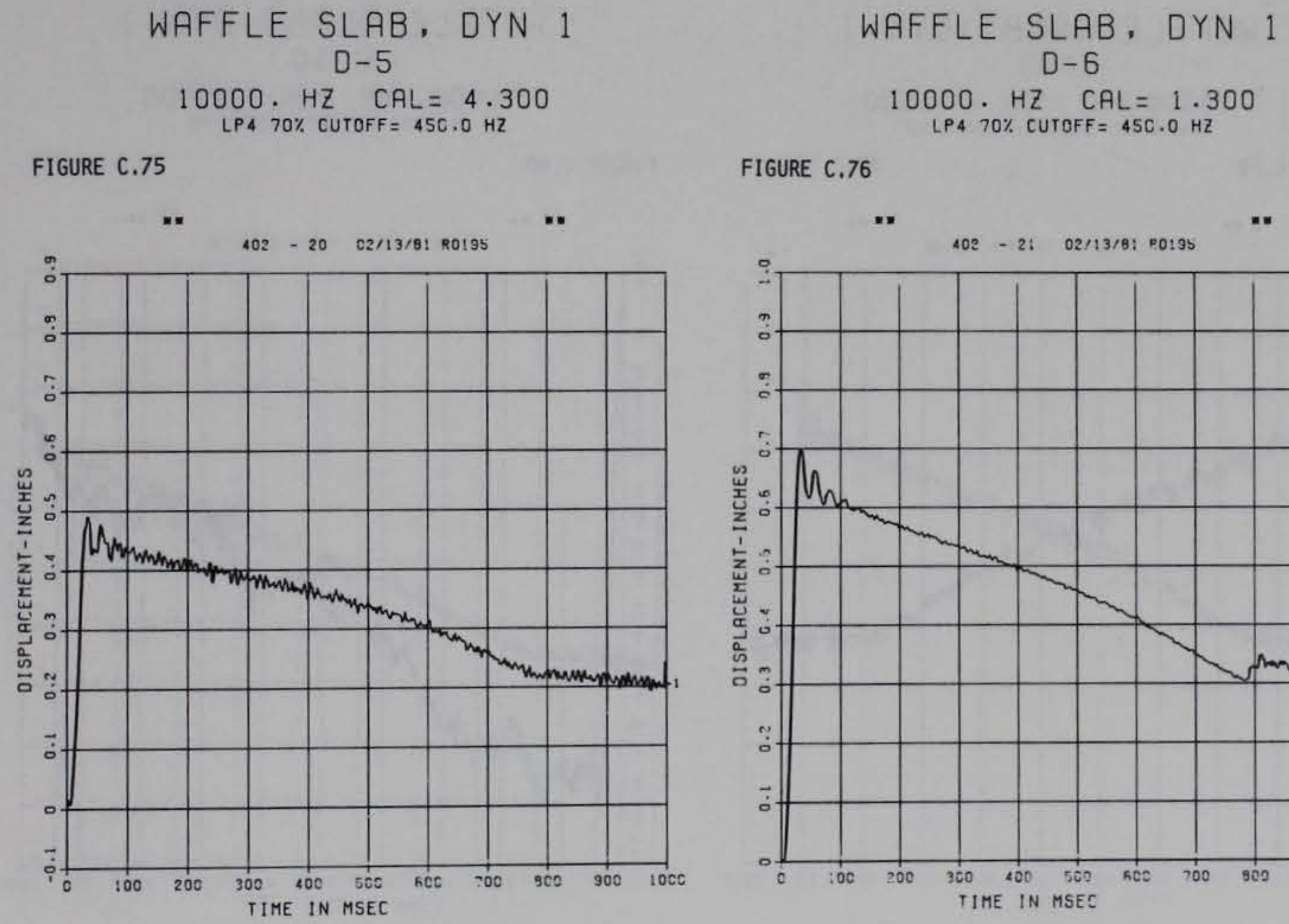

FIGURE C.76

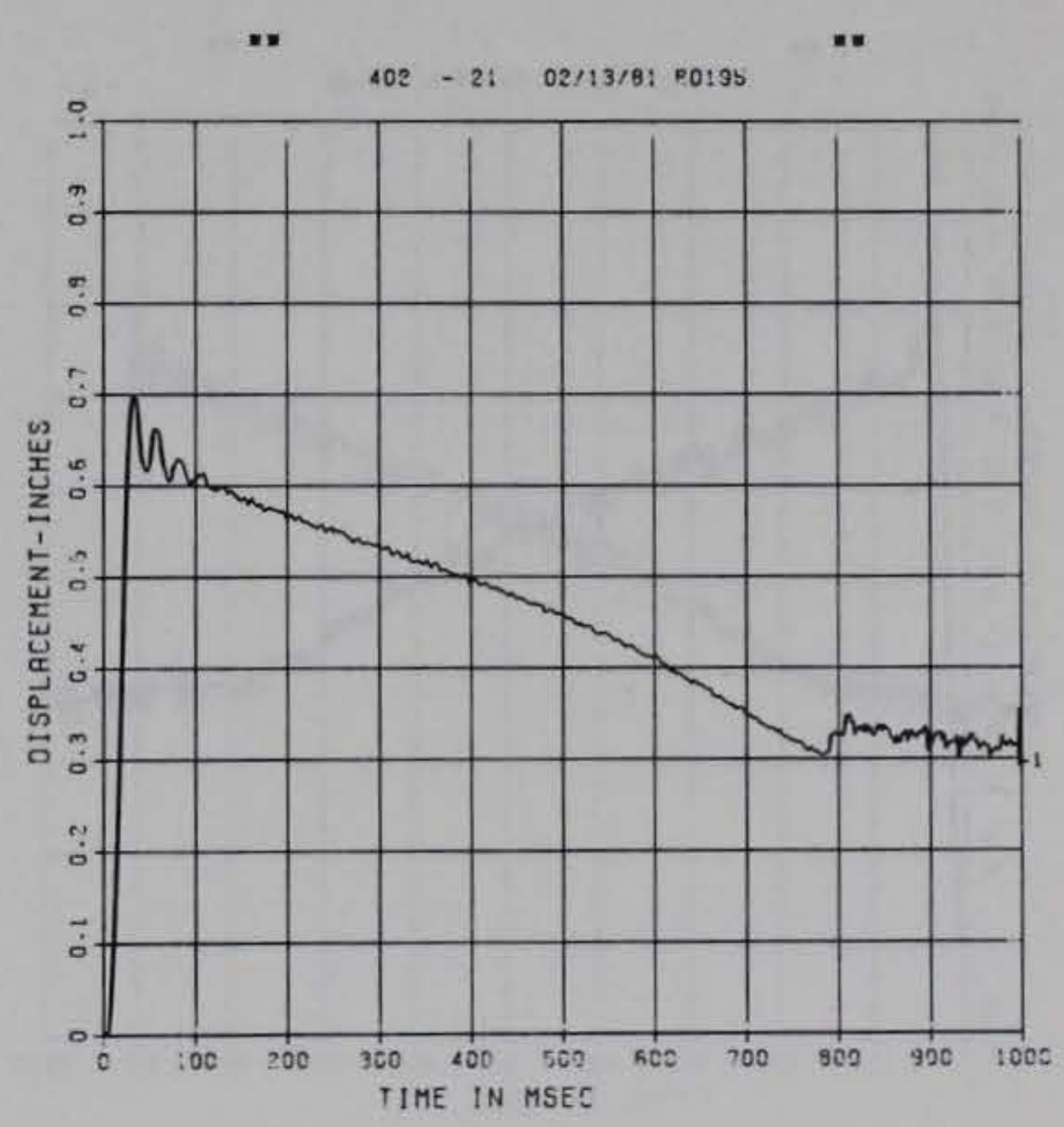

n. Peak value is g9 " unger calibration ** 
WAFFLE SLAB, DYN 1

$$
D-7
$$

10000. $\mathrm{HZ} \quad \mathrm{CAL}=6.300$

LP4 $70 \%$ CUTOFF $=450.0 \mathrm{HZ}$

FIGURE C.77

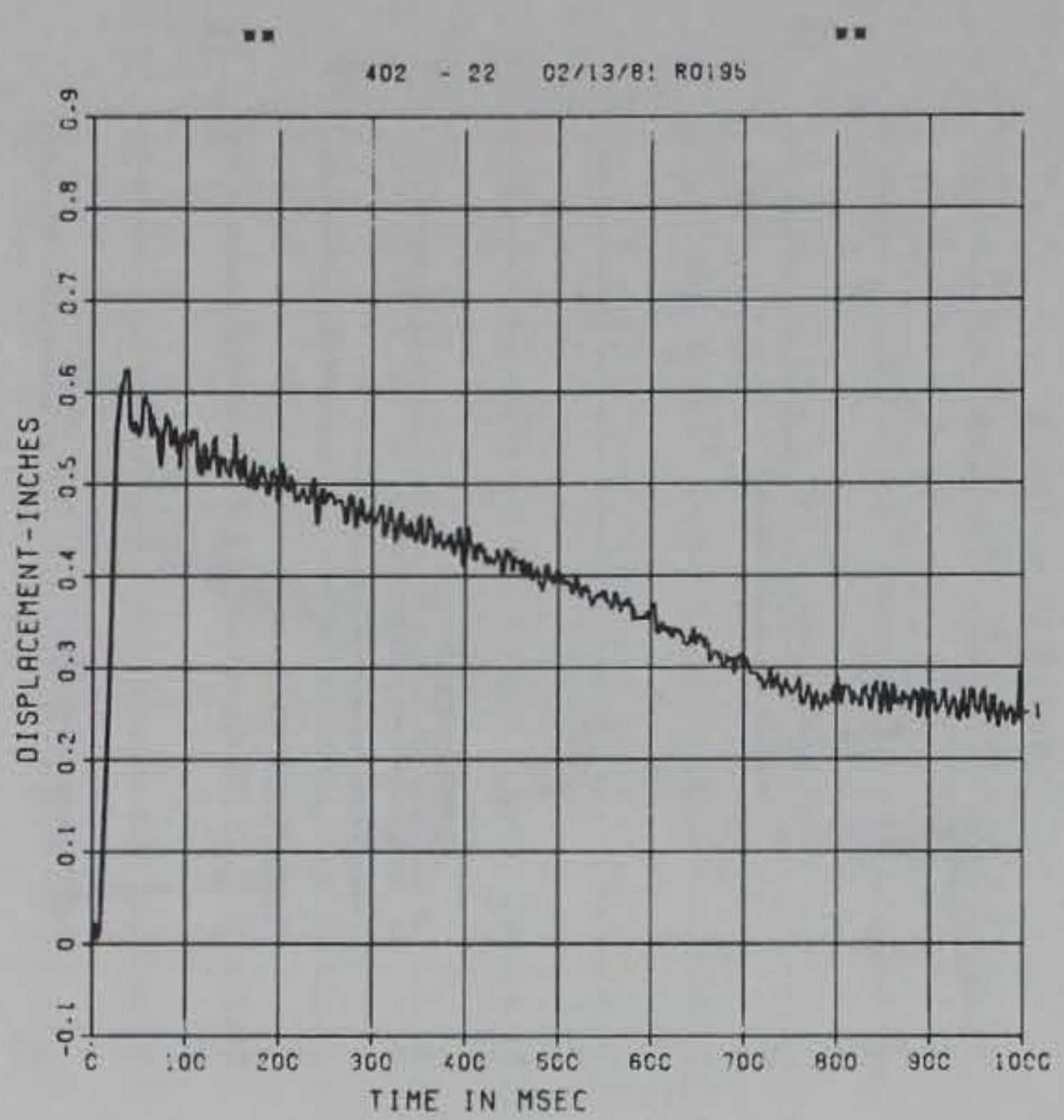

m. PEAK VALUE IS $90 \quad$ ₹ UNCER CALIBRATION *

$$
\begin{gathered}
\text { WAFFLE SLAB, DYN } 1 \\
\begin{array}{c}
\text { D-9 } \\
10000 . \mathrm{HZ} \quad \mathrm{CAL}=3.600
\end{array}
\end{gathered}
$$

LP4 $70 \%$ CUTOFF $=450.0 \mathrm{HZ}$

FIGURE $C .79$

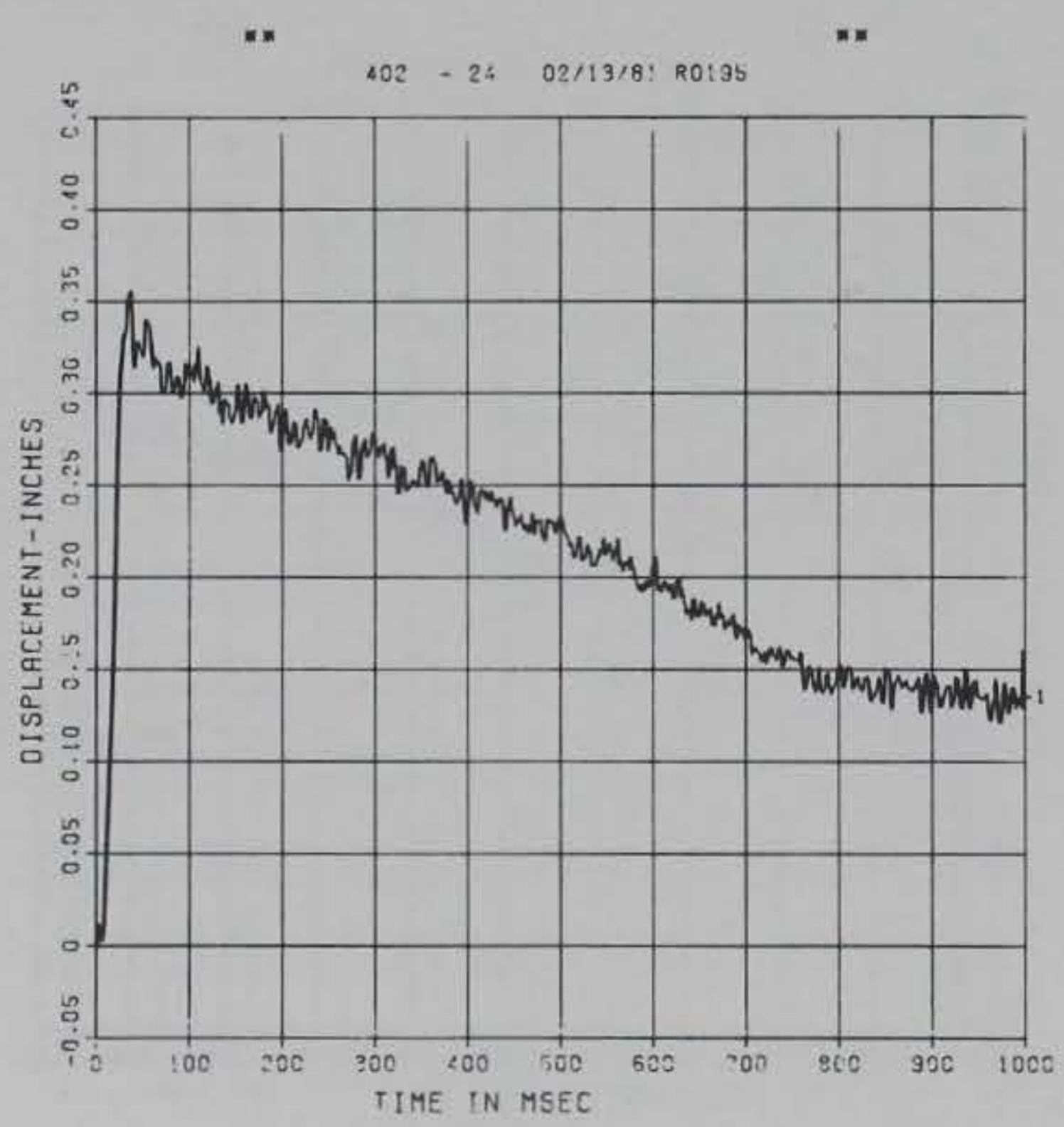

n PEAK VALUE IS $90 \%$ UNDER CALIBRATION \#
WAFFLE SLAB, DYN 1

$$
\text { D-8 }
$$

10000. $\mathrm{HZ} \quad \mathrm{CAL}=6.300$

LP4 $70 \%$ CUTOFF $=45 C .0 \mathrm{HZ}$

FIGURE C. 78

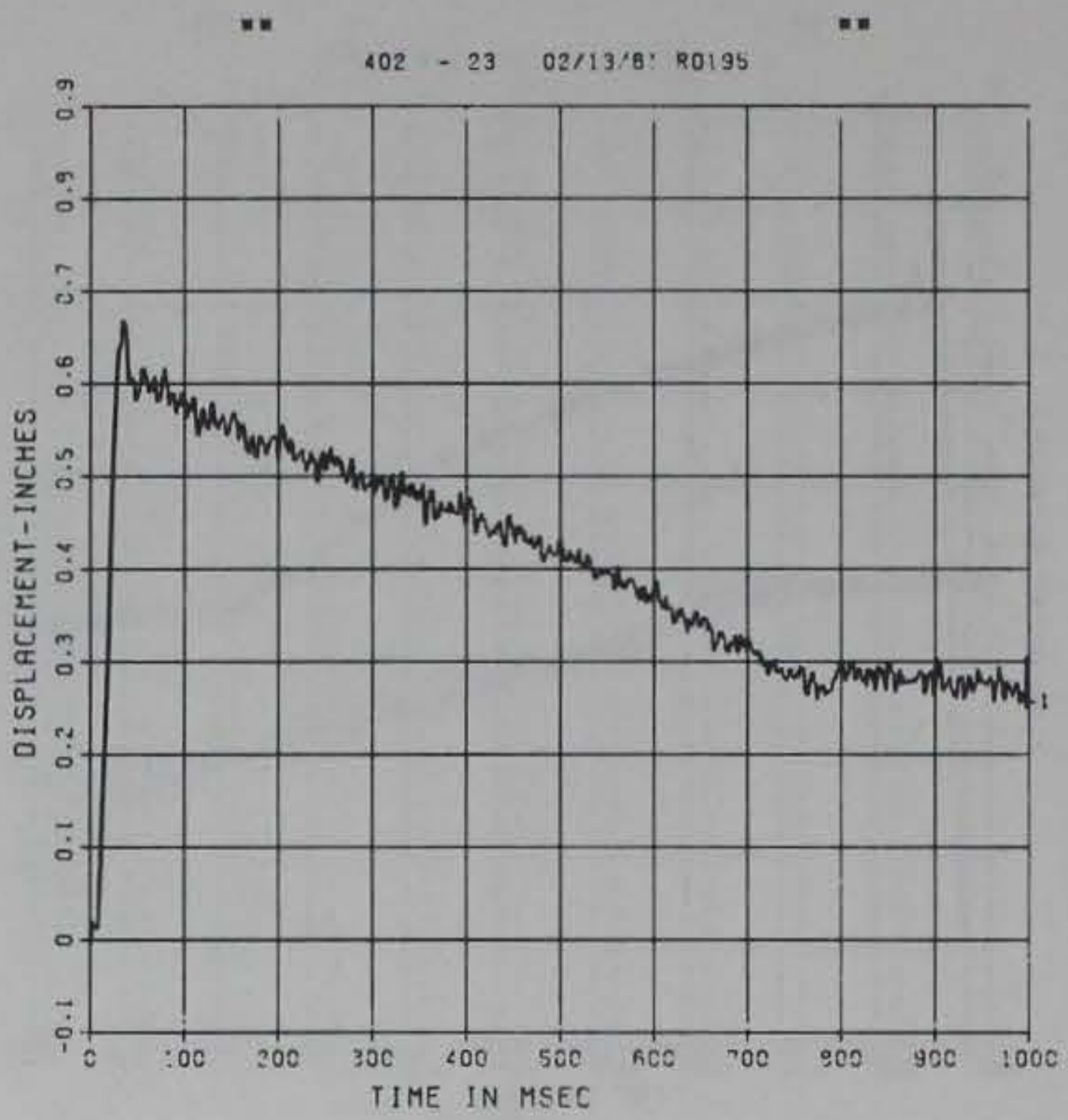

n. Peak value is 89 \% unGer CaLIBration ..

$$
\begin{aligned}
& \text { WAFFLE SLAB, DYN } 1 \\
& D-10 \\
& \text { 10000. HZ CAL }=2.800 \\
& \text { LP4 } 70 \% \text { CUTOFF }=450.0 \mathrm{~Hz}
\end{aligned}
$$

FIGURE C. 80

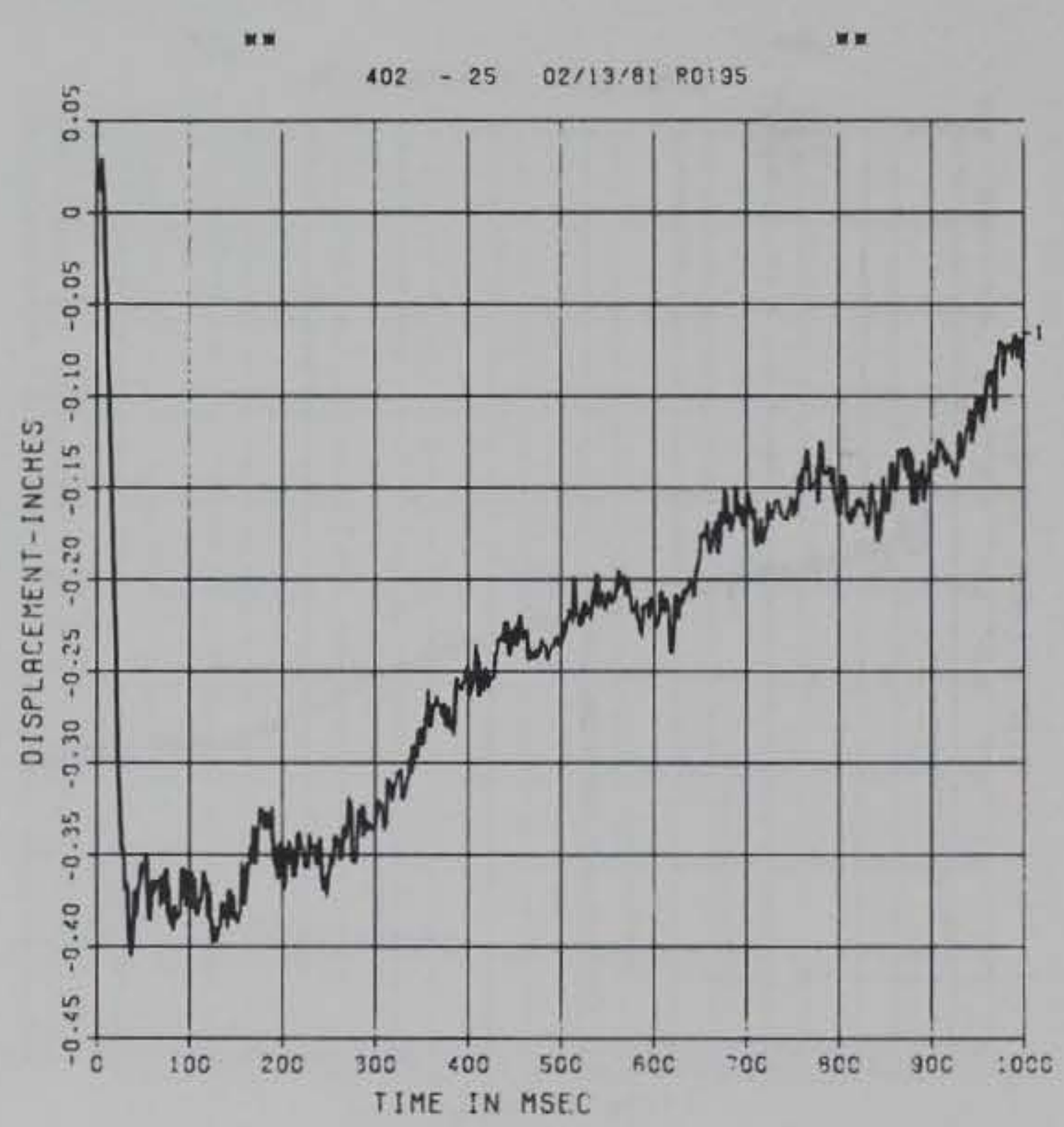

* PEAK VALUE IS $95 \%$ UNOER CALIBRATION * 


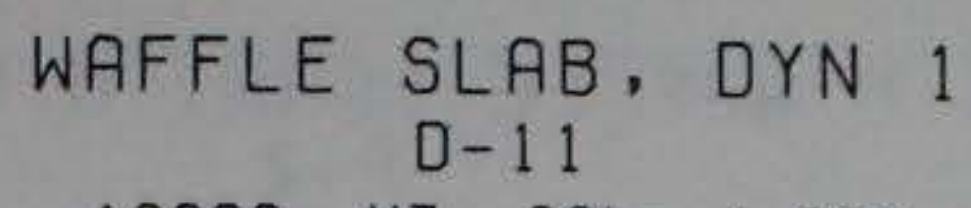

$$
\begin{aligned}
& \text { 10000. HZ CAL }=4.300 \\
& \text { LP4 } 70 \% \text { CUTOFF }=450.0 \mathrm{HZ}
\end{aligned}
$$

FIGURE $C .81$

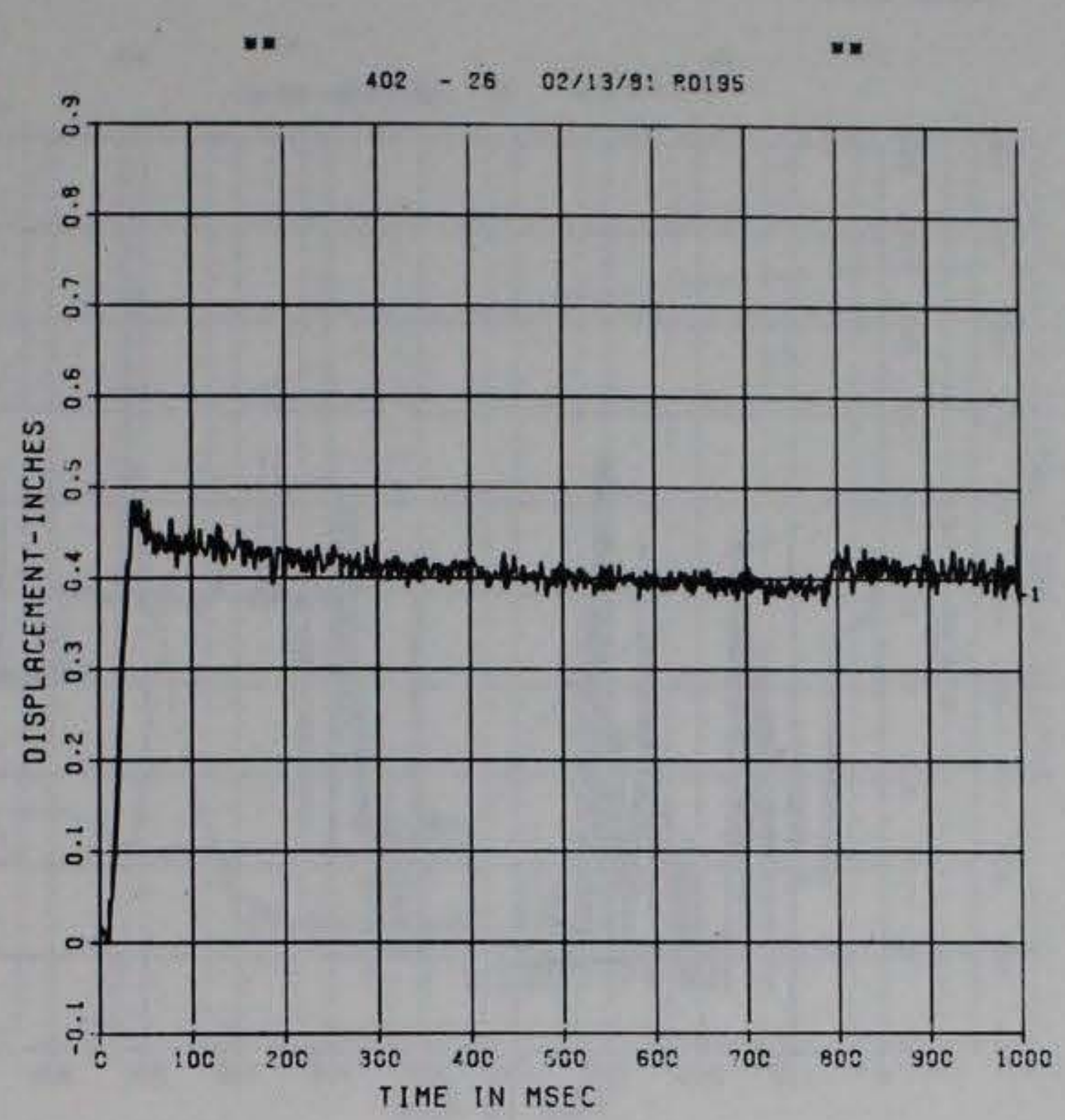

*. PEAK VALUE IS 99 \% UNCER CALIBRATION \#

$$
\text { WAFFLE } \begin{aligned}
& \text { SLAB, DYN } 1 \\
& D-13
\end{aligned}
$$$$
\text { 10000. } \mathrm{HZ} \quad C A L=6.200
$$

LP4 $70 \%$ CUTOFF $=450.0 \mathrm{HZ}$

FIGURE $C .83$

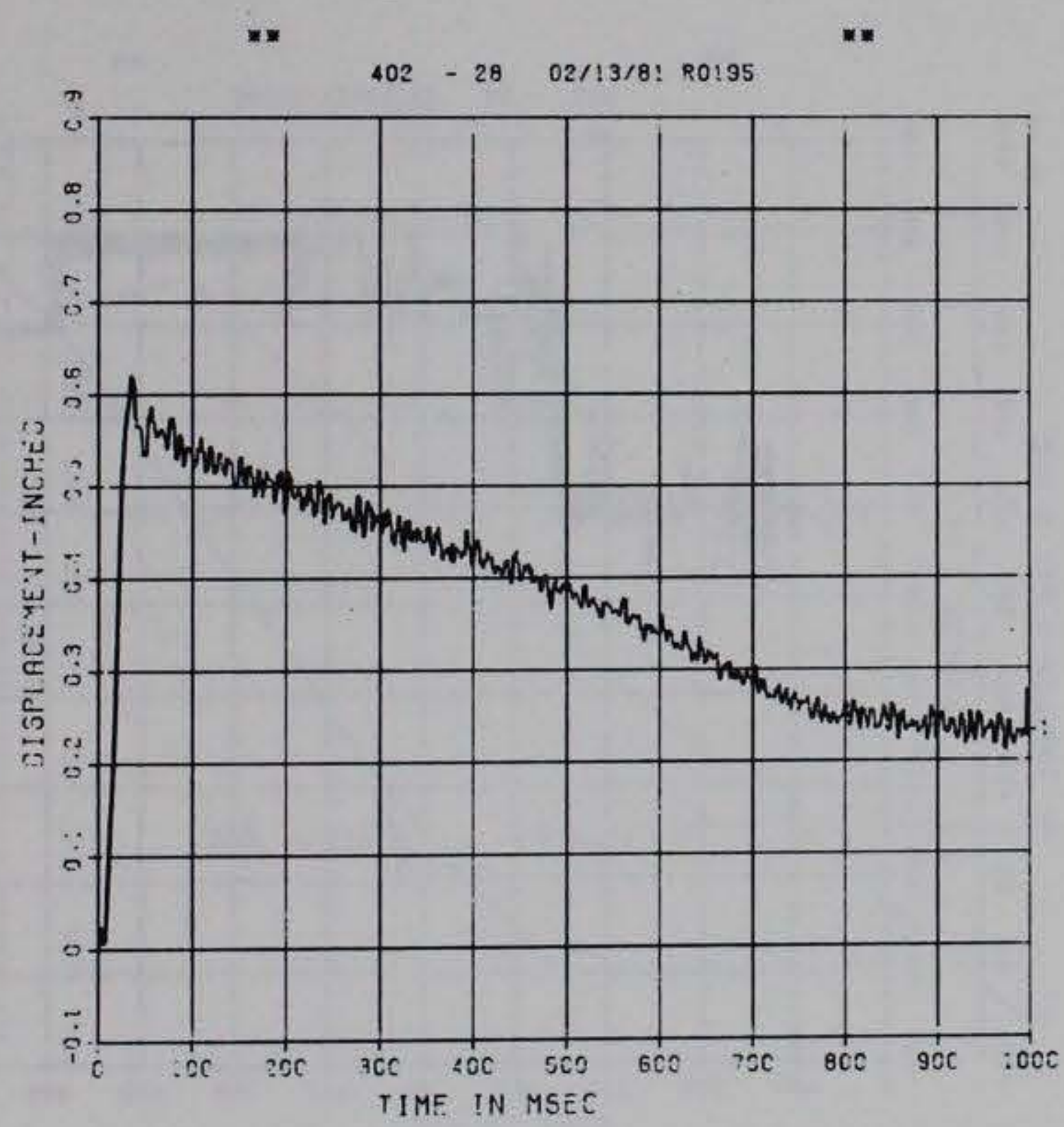

n. PEAK VALUE IS 90 \% unger CaLIBRation =
WAFFLE $\underset{\substack{\text { SLAB, } \\ \mathrm{D}-12}}{\mathrm{DYN} 1}$

10000. $\mathrm{HZ} \quad \mathrm{CAL}=6.300$

LP4 $70 \%$ CUTOFF $=450.0 \mathrm{HZ}$

FIGURE C. 82

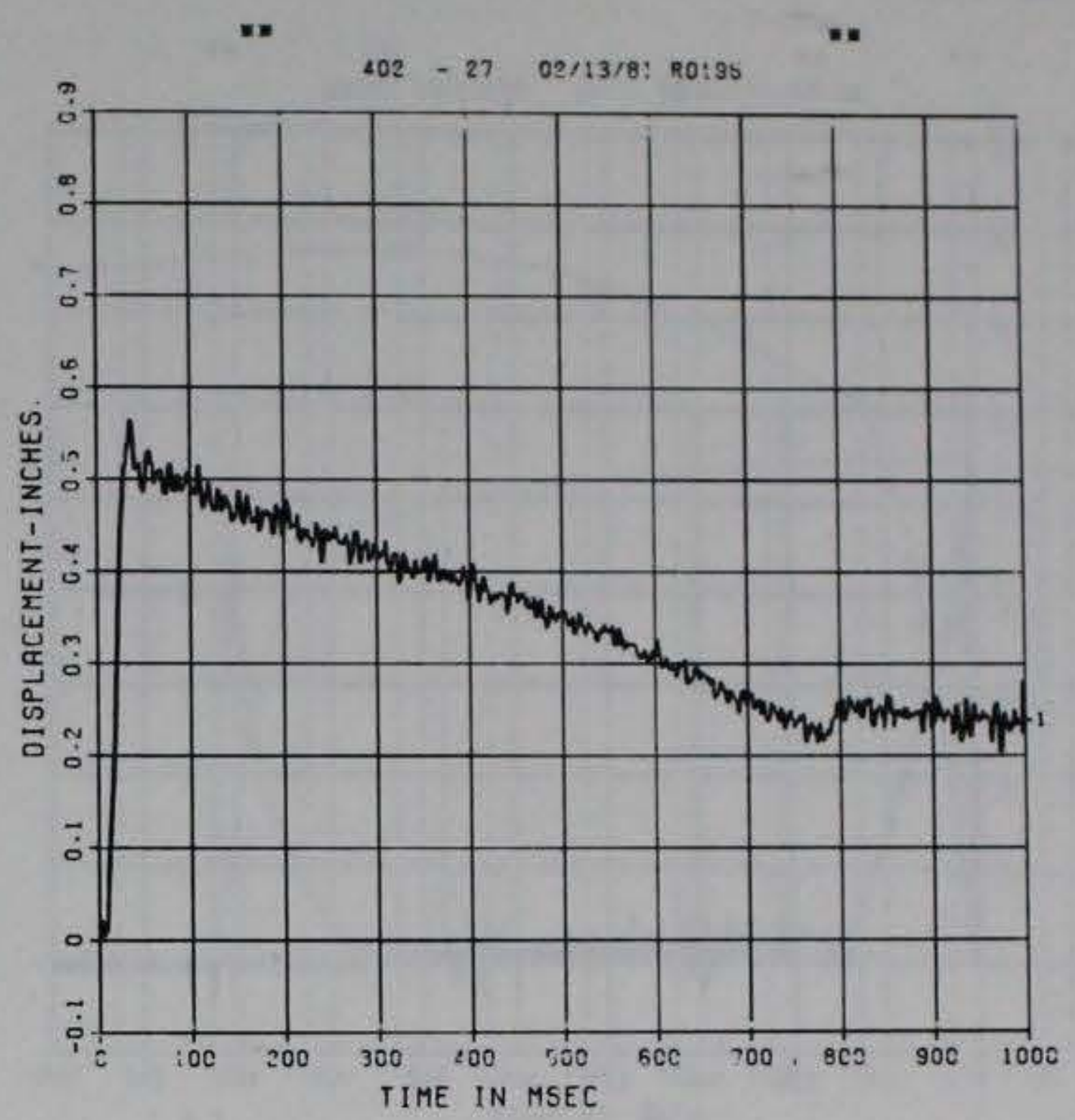

* * PEAK VALUE IS 91 \% UNCER CALIBRATION *

WAFFLE SI.AB, SYN ? D- $-i:$

10000. HZ CAL $=6.30 \mathrm{C}$

I.P4 $70 \%$ CUTOFF $=450 . \mathrm{C} \mathrm{HZ}$

FIGURE C.84

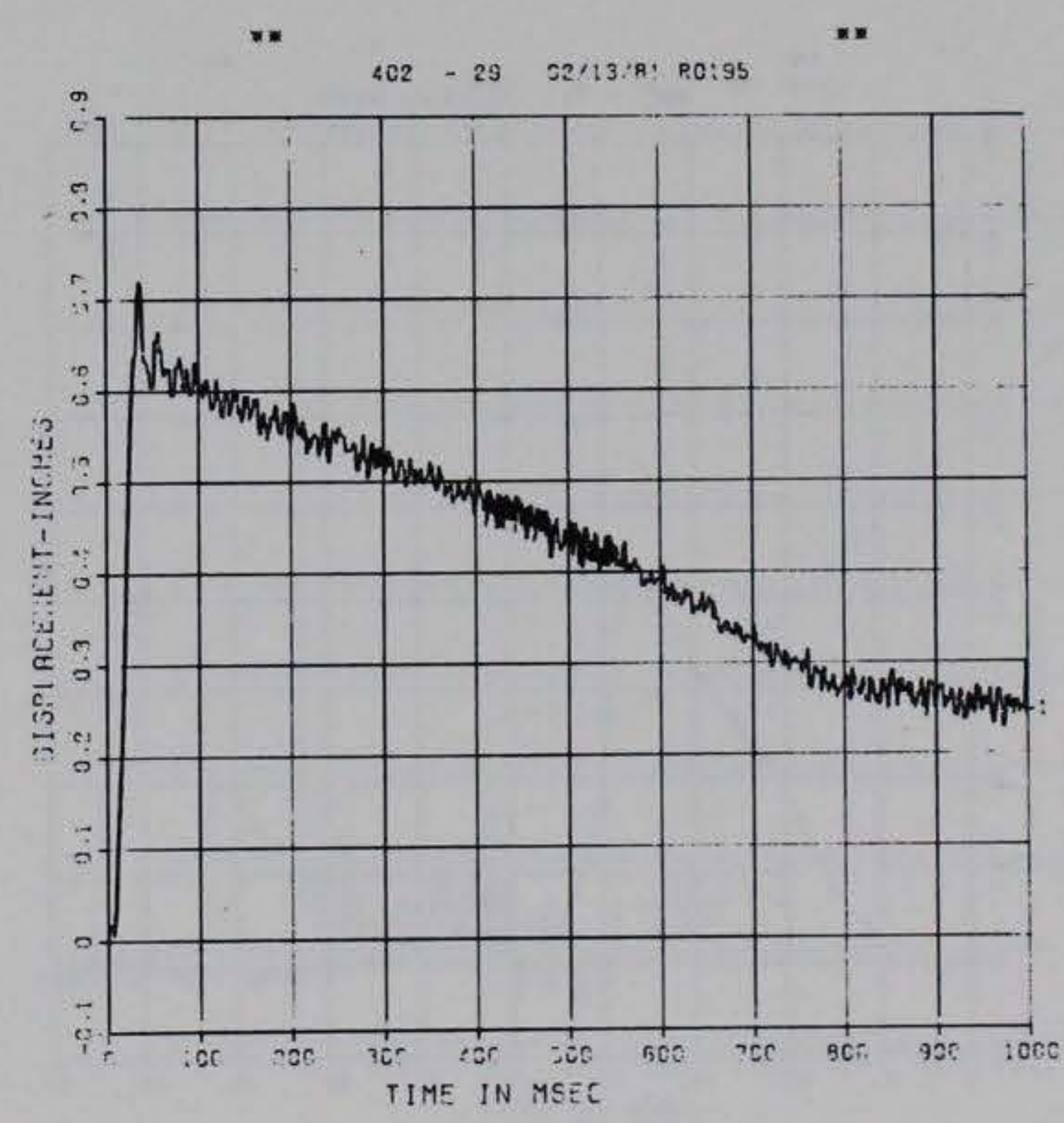

n* PEAK VALJE IS 99 \% UNOER CALIBRATION \# 


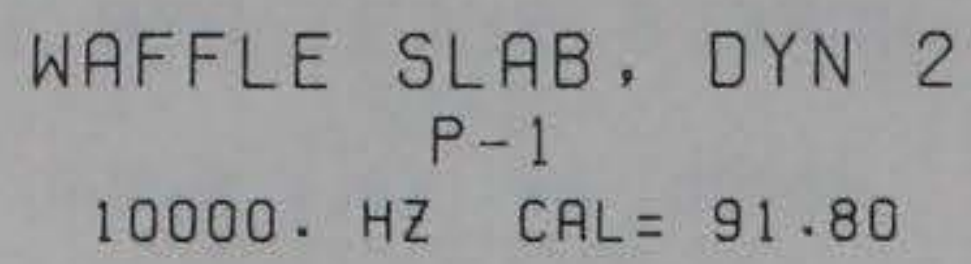

FIGURE $C .85$

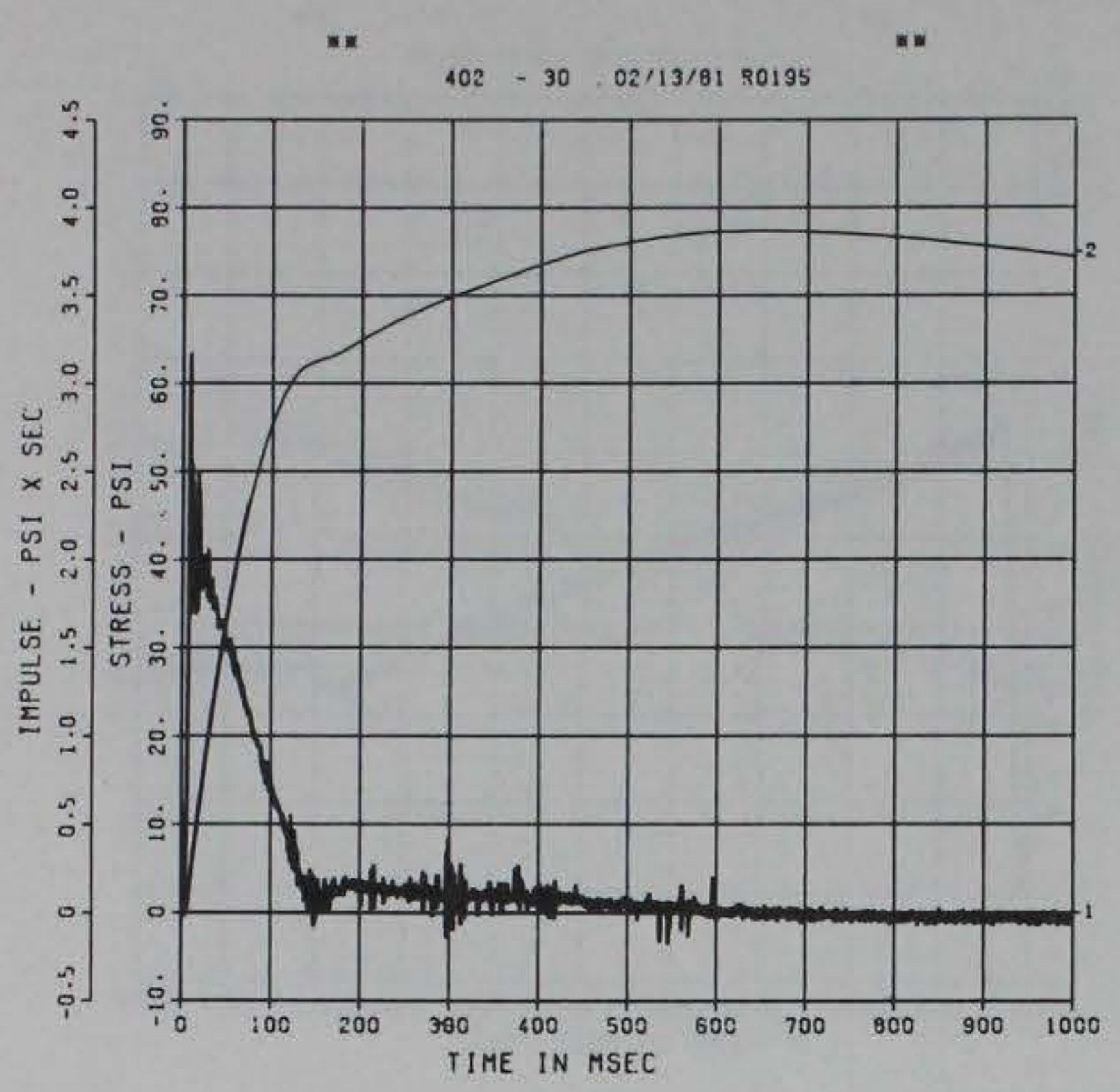

WAFFLE SLAB, DYN 2 $L-1$ (KIP)

10000. $\mathrm{HZ} \quad \mathrm{CAL}=216.7$

FIGURE C. 87

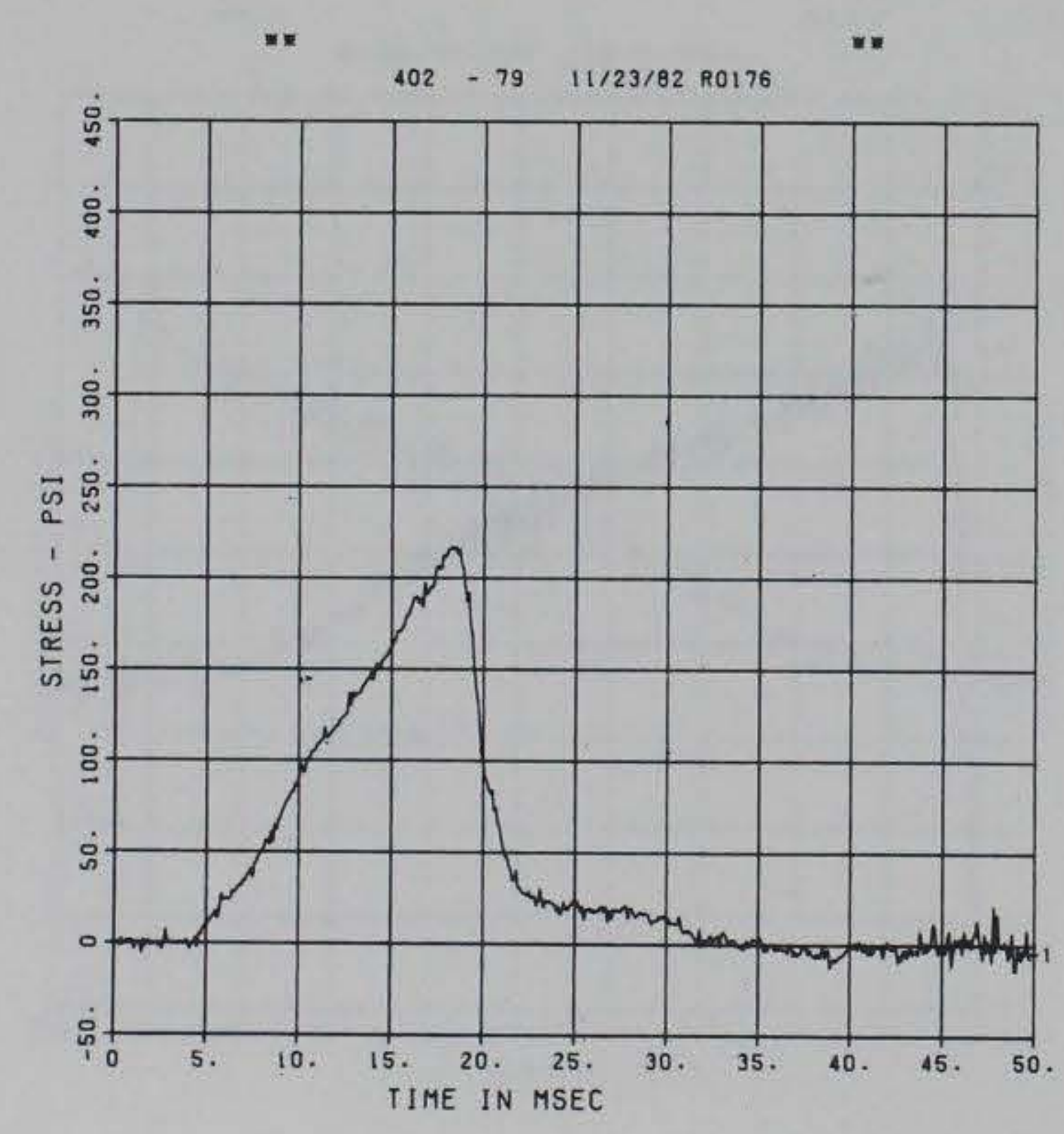

WAFFLE SLAB, DYN 2 $P-2$

10000. $\mathrm{HZ} \quad \mathrm{CAL}=88.10$

FIGURE C. 86

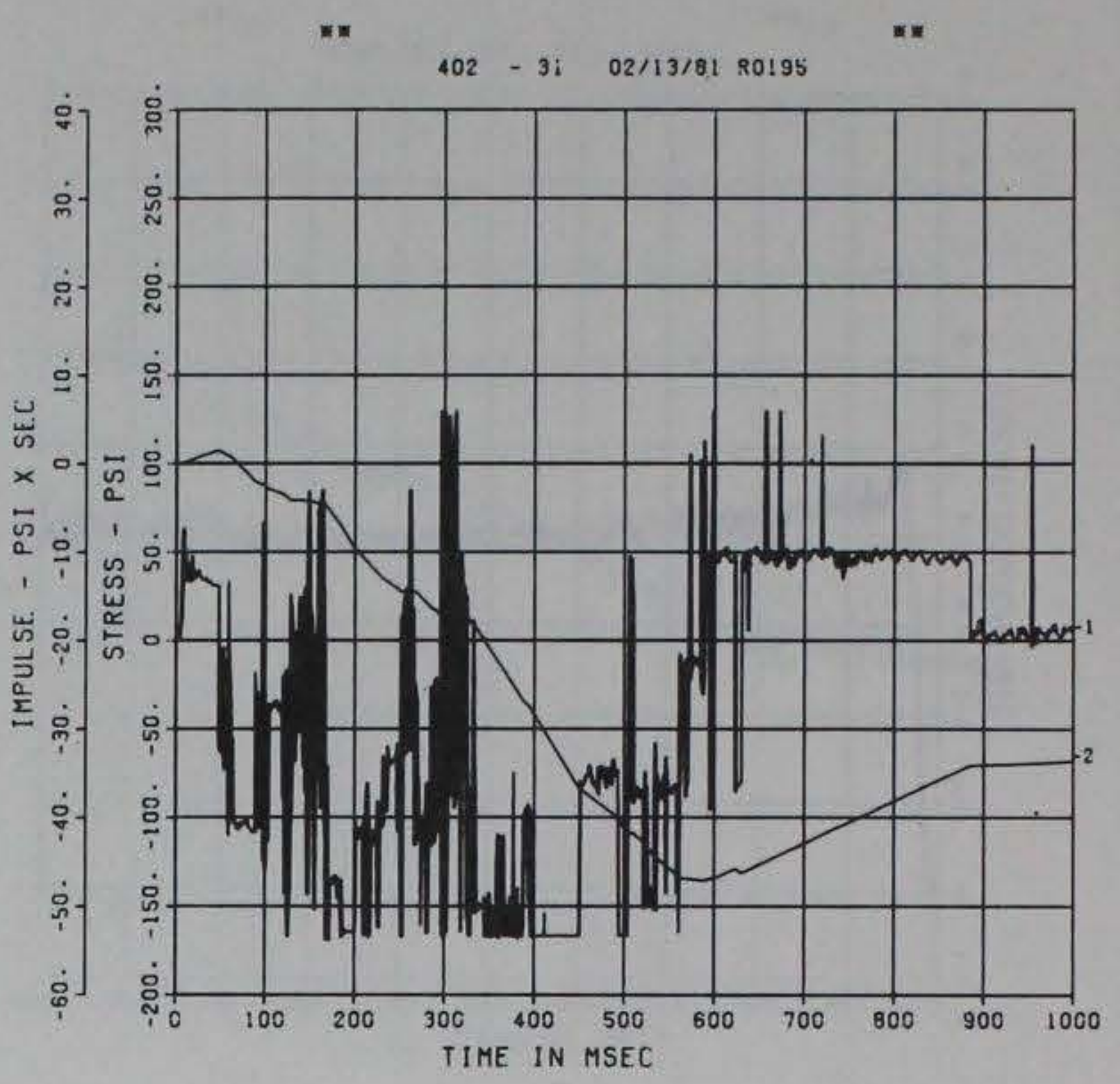

-. peak value is 92 x over calibration .*

WAFFLE SLAB, DYN 2 $L-2$ ( KIP)

10000. $\mathrm{HZ} \quad \mathrm{CAL}=201.1$

FIGURE $C .88$

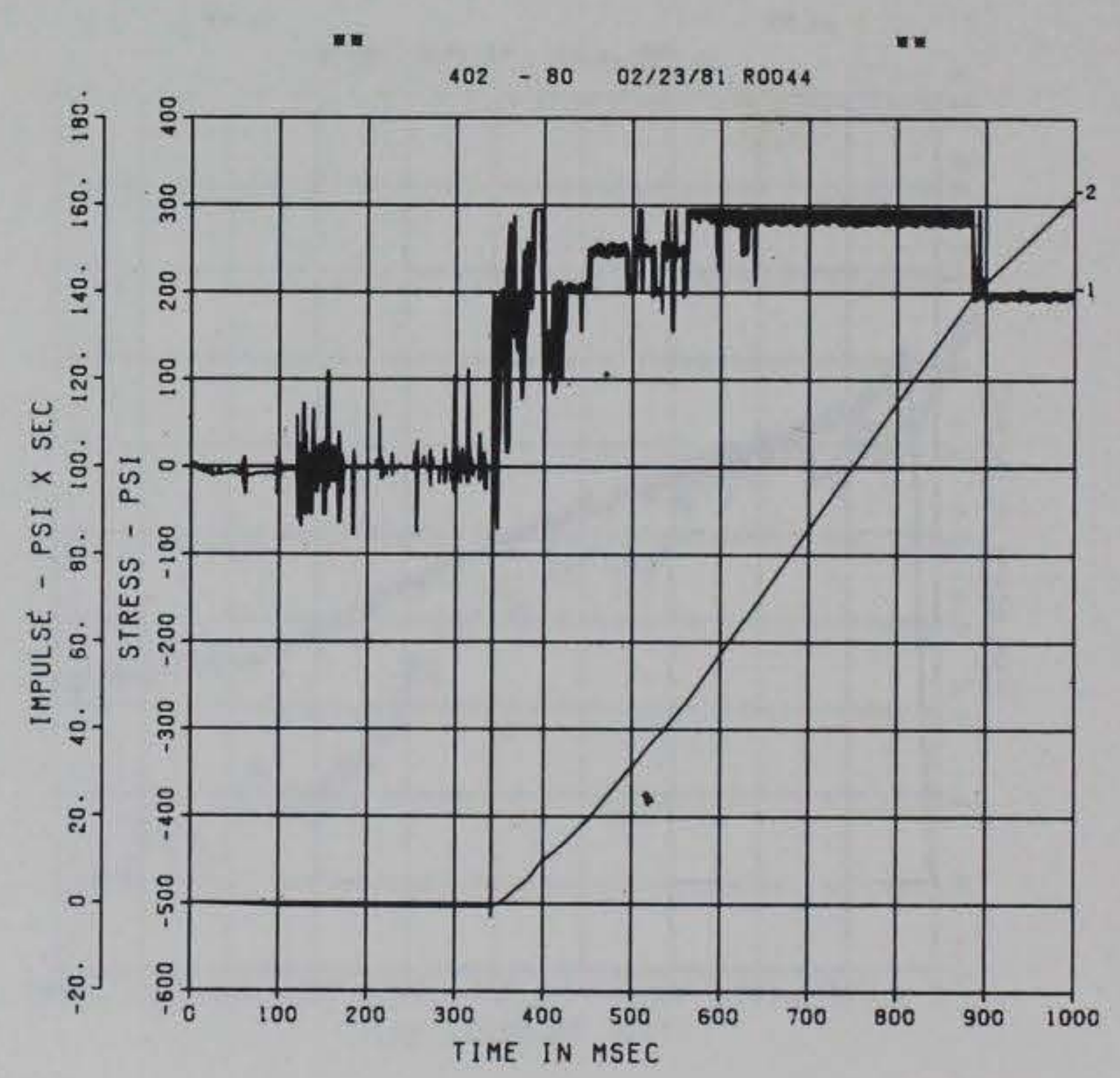

". peak value is 156 \% OVer calibration =" 


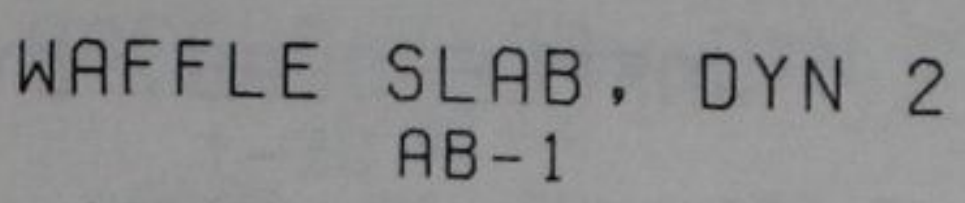

10000. $\mathrm{HZ} \quad \mathrm{CAL}=93.10$

FIGURE $\quad$. 89

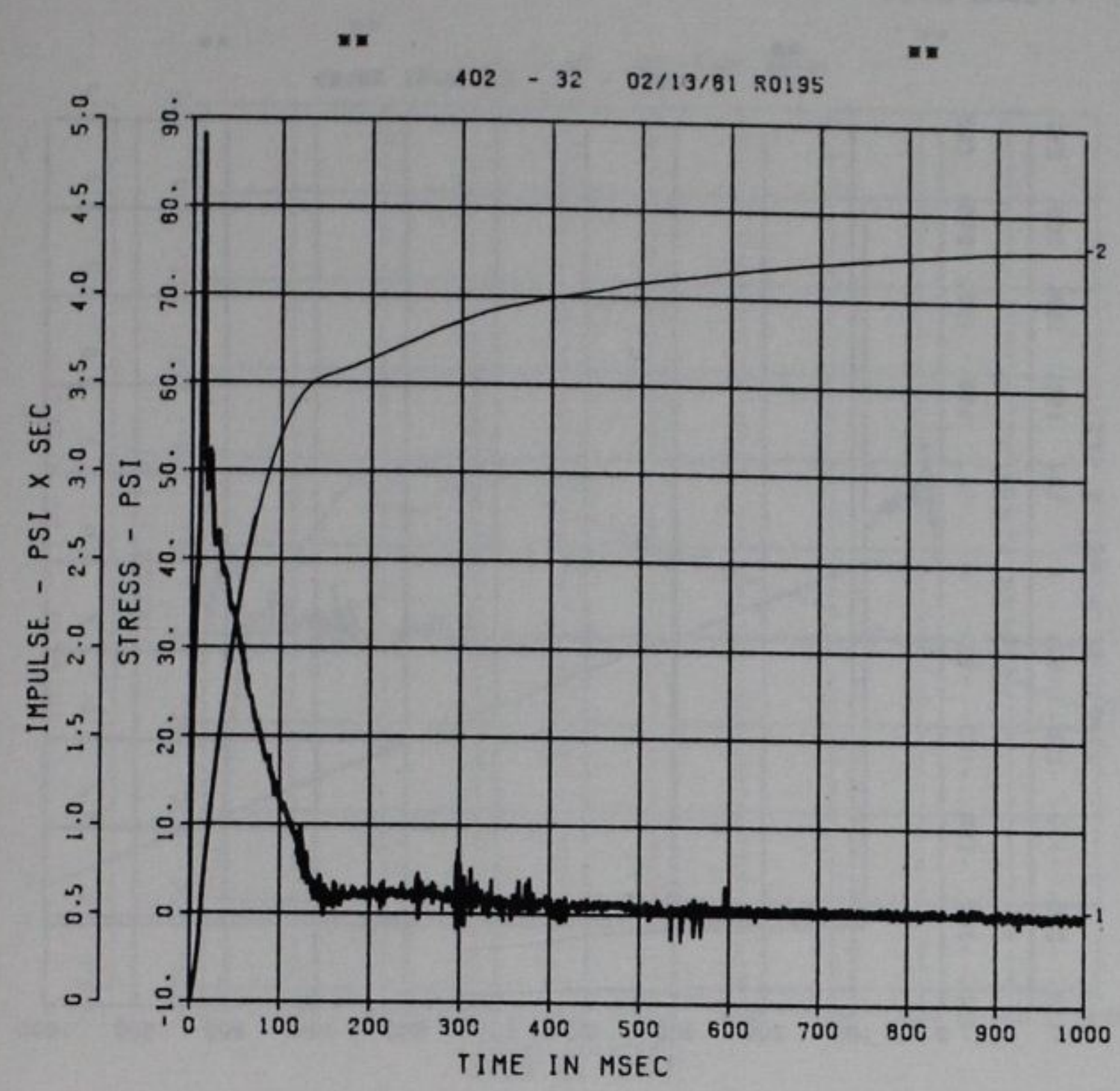

WAFFLE SLAB, DYN 2
AB-3
10000. HZ CAL $=75.50$

FIGURE C.91

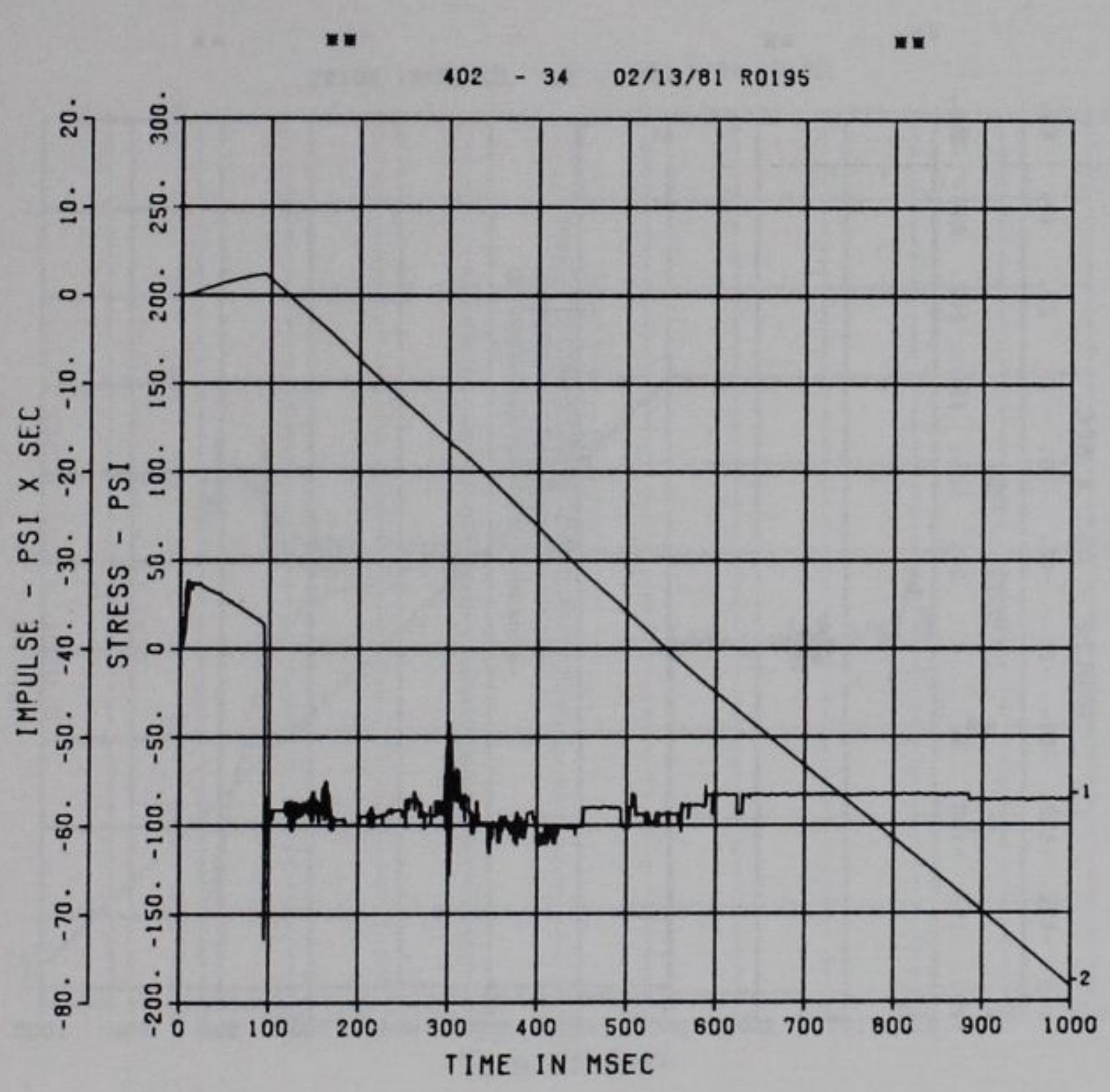

WAFFLE SLAB, DYN 2

$A B-2$

10000. $\mathrm{HZ} \quad \mathrm{CAL}=95.10$

FIGURE C.90

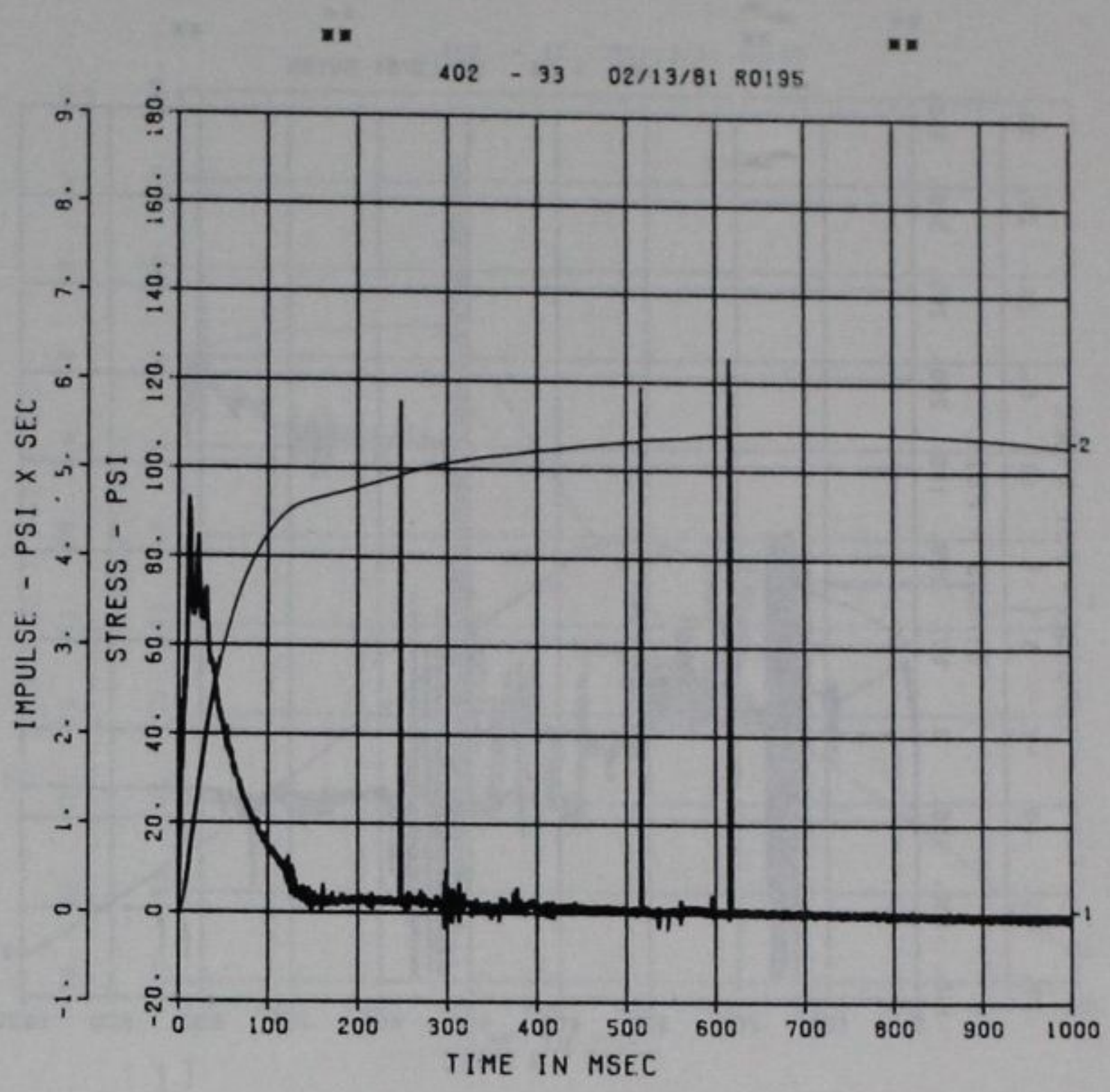

-2 peak value is 32 \% over calibration .

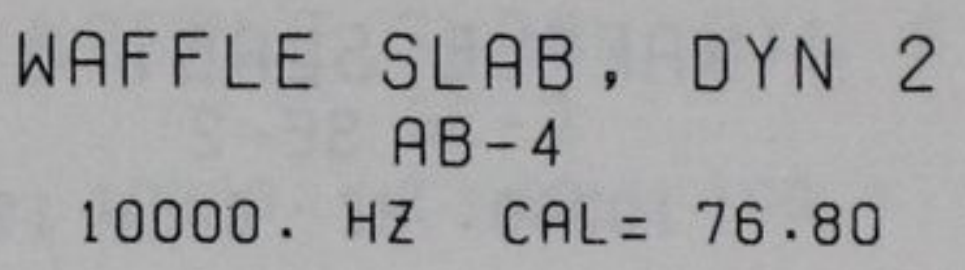

FIGURE C.92

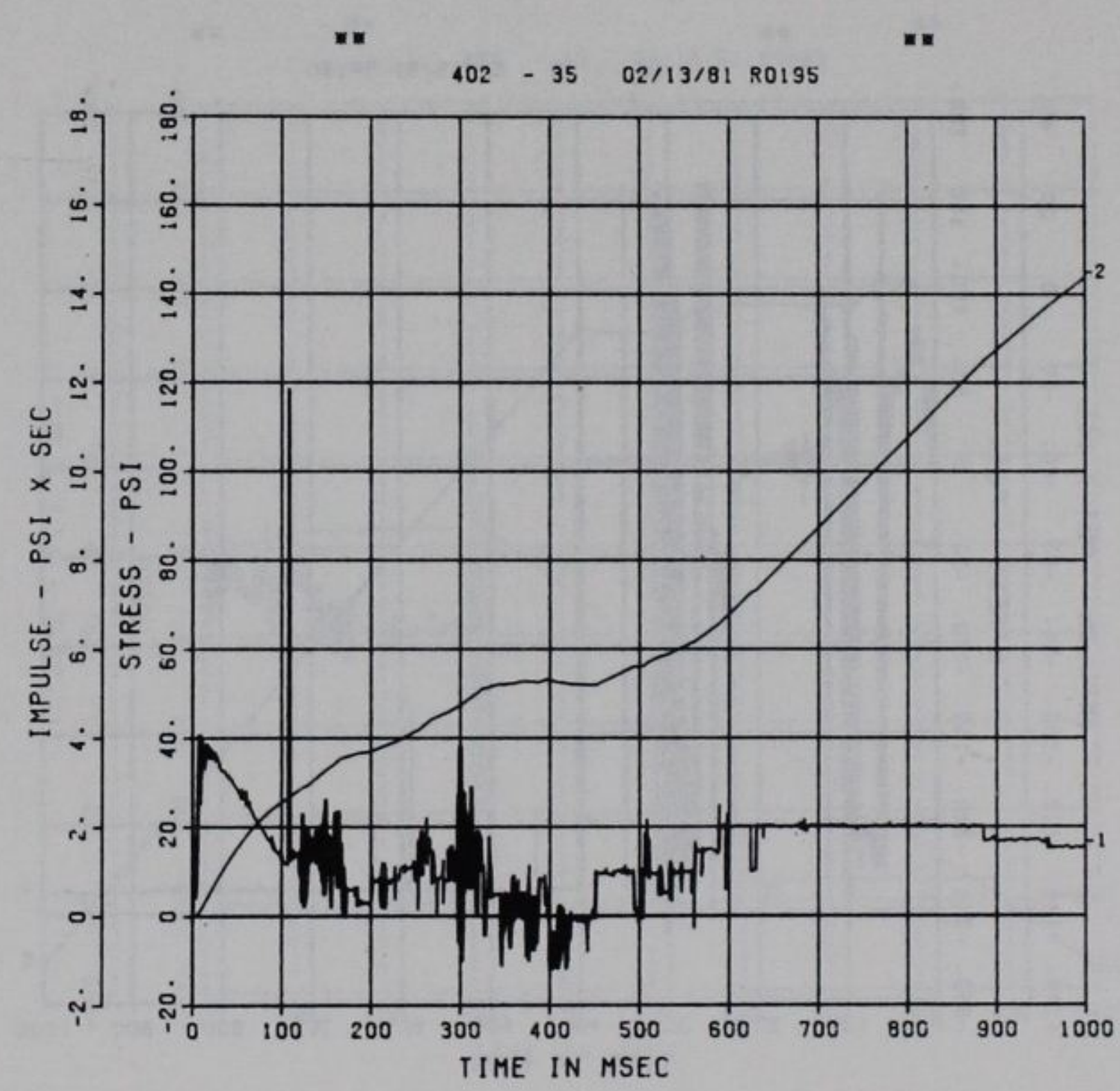



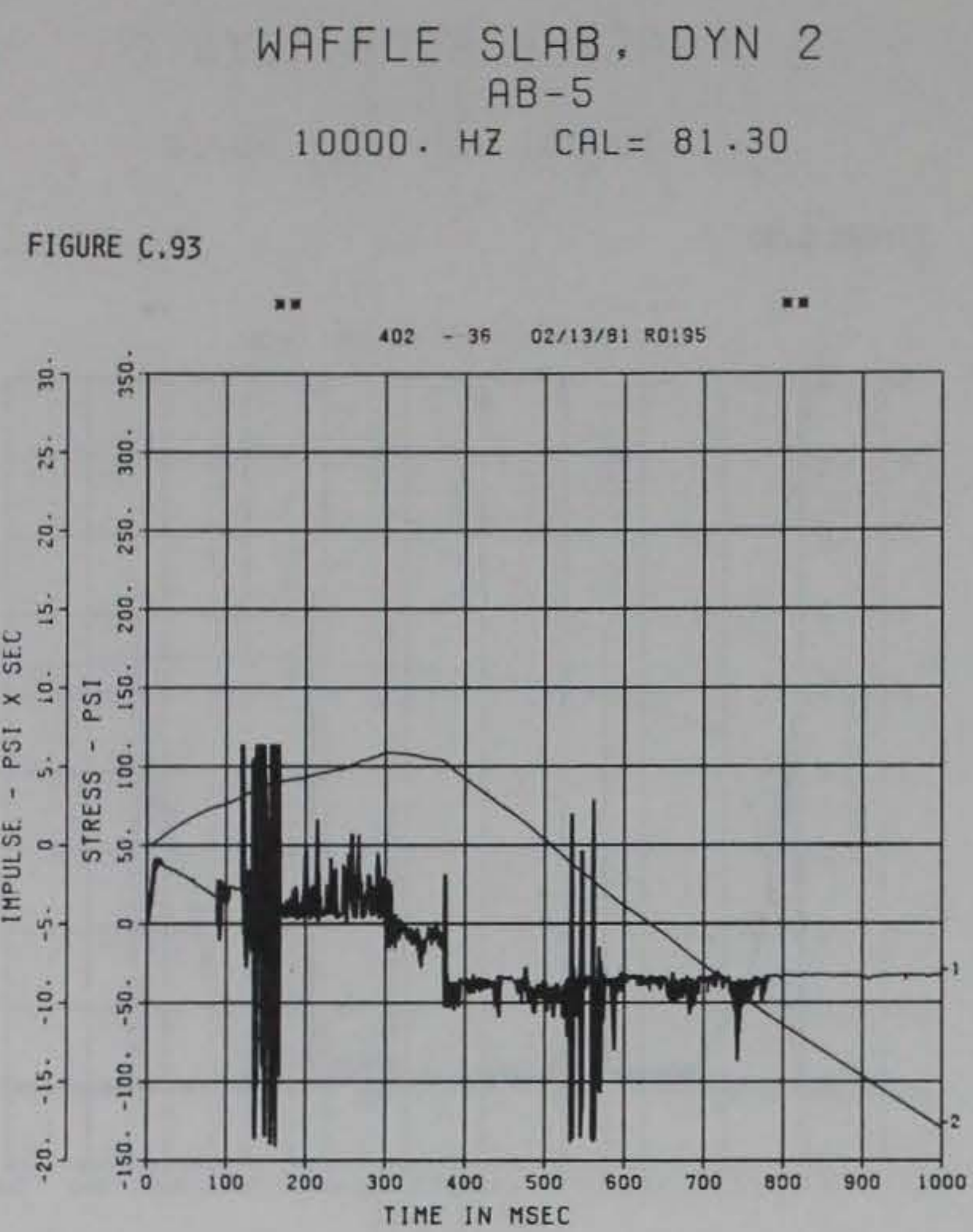

*. PEAK value is 73 \% over callbration *.

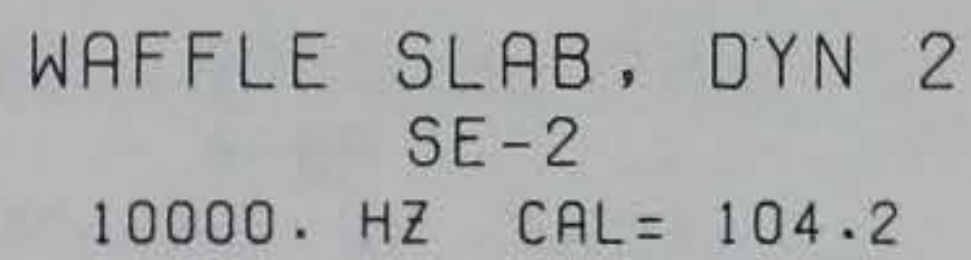

FIGURE C.95

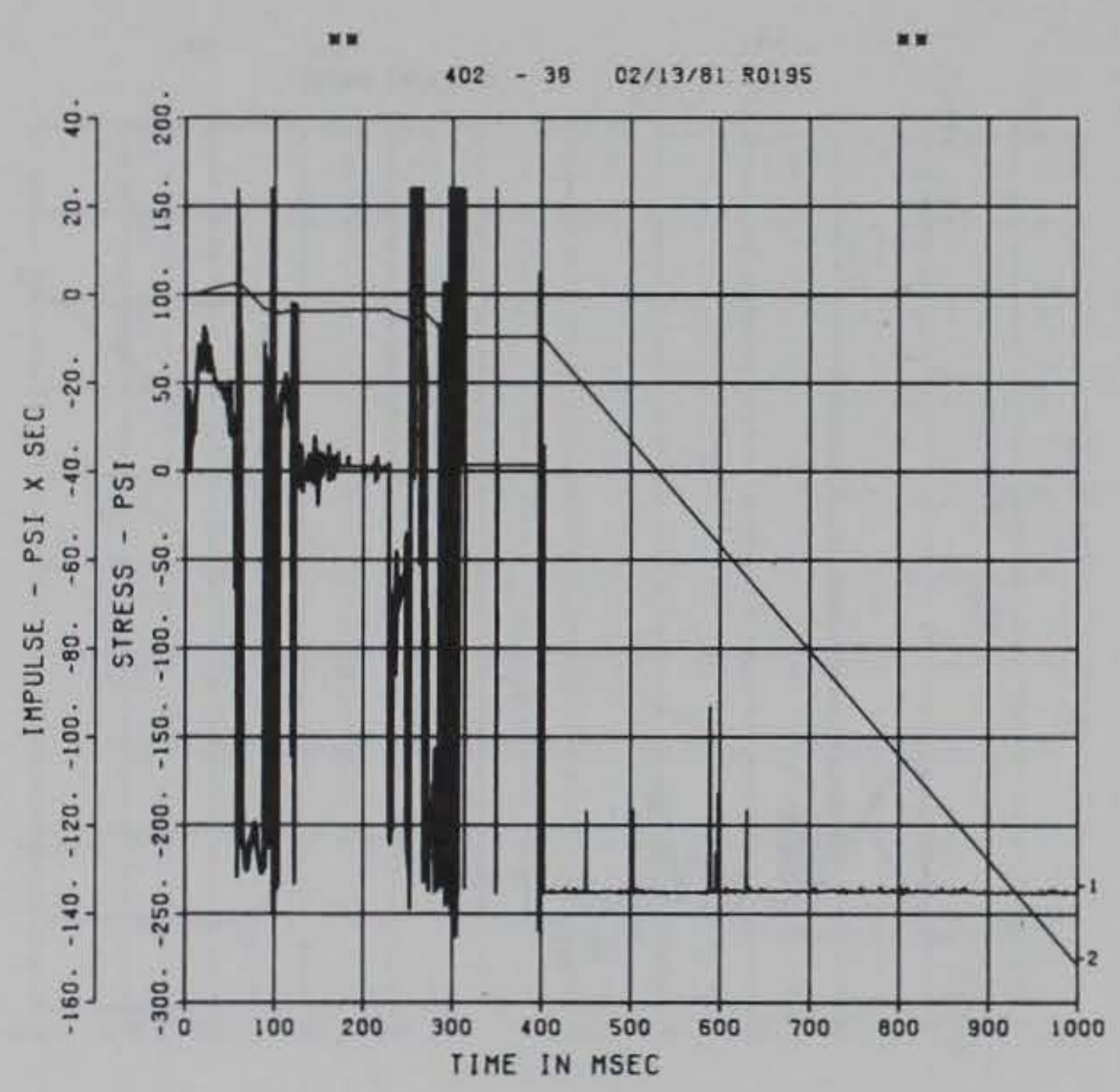

\#. Peak value is 152 \% over caltbration ..

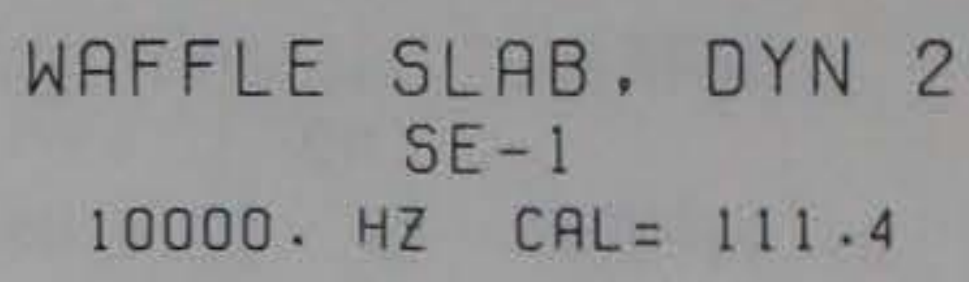

WAFFLE SLAB, DYN 2 SE-1

10000. $\mathrm{HZ} \quad \mathrm{CAL}=111.4$

FIGURE C. 94

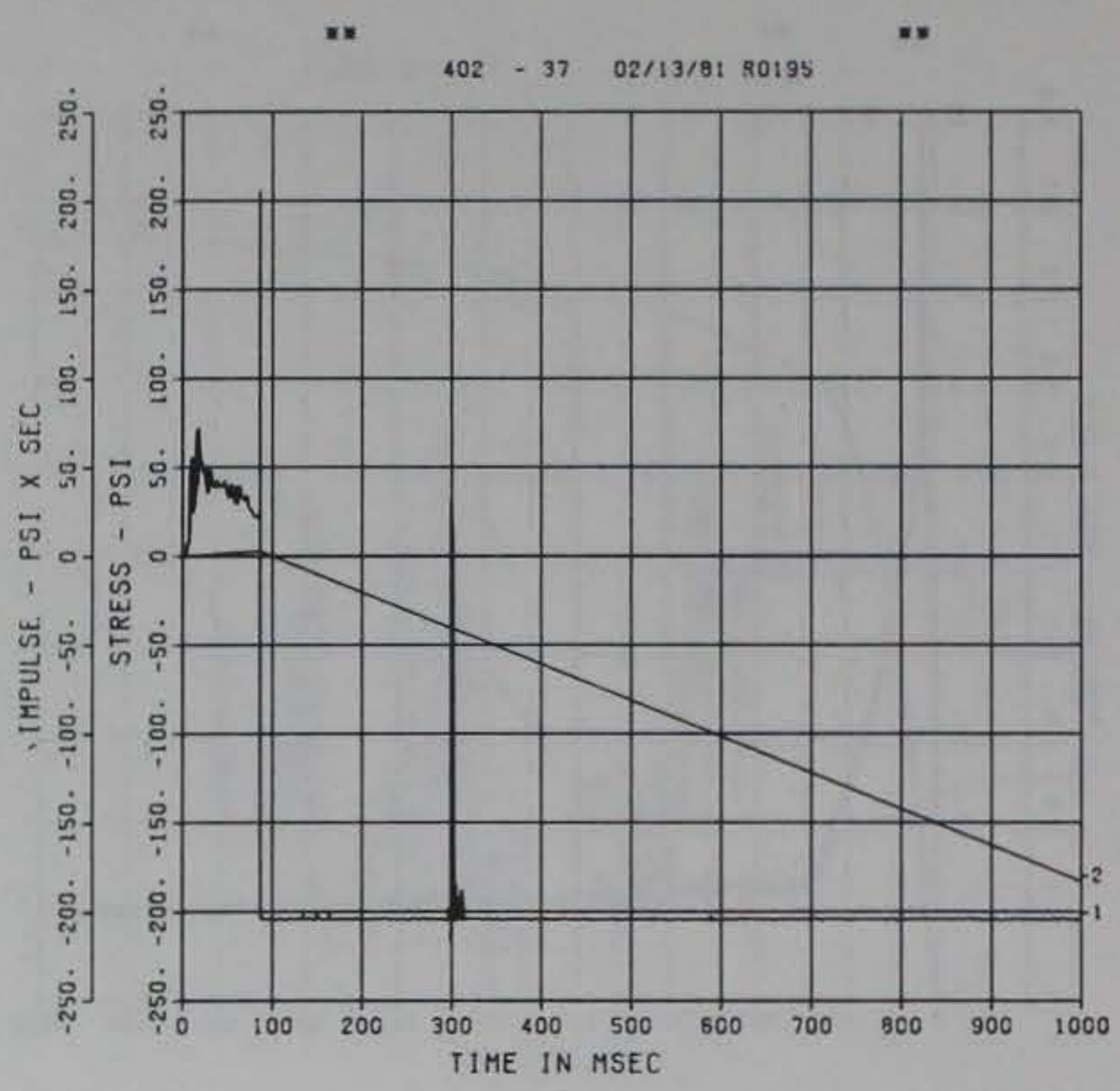

- peak value is ga \% over calibration ..

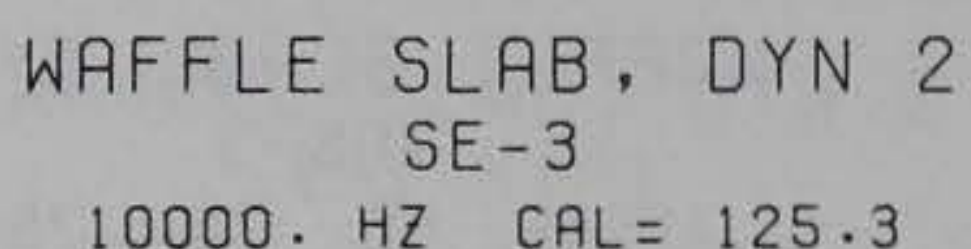

FIGURE C. 96

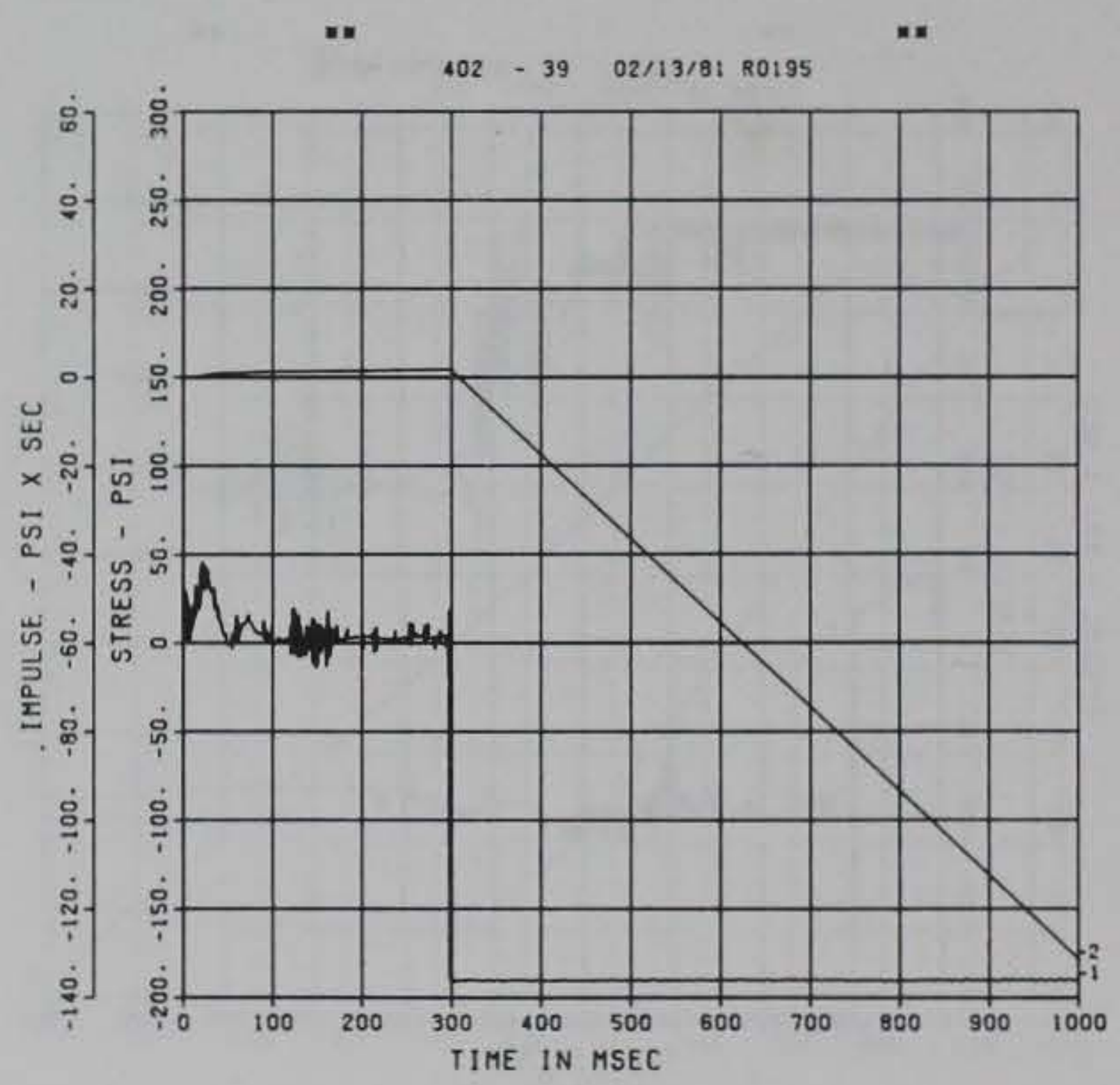

\#* Peak value is 52 z OVer caltaration * 


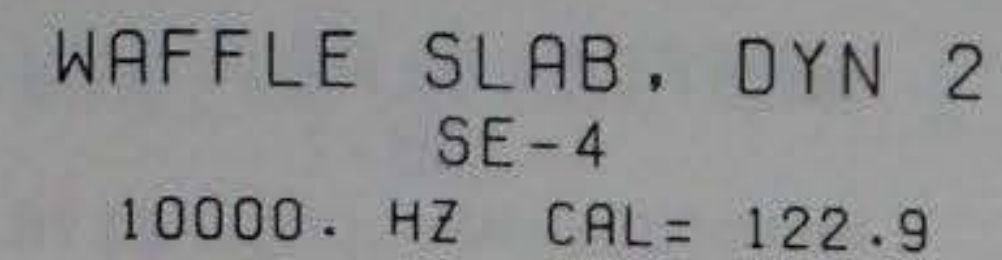

FIGURE $C .97$

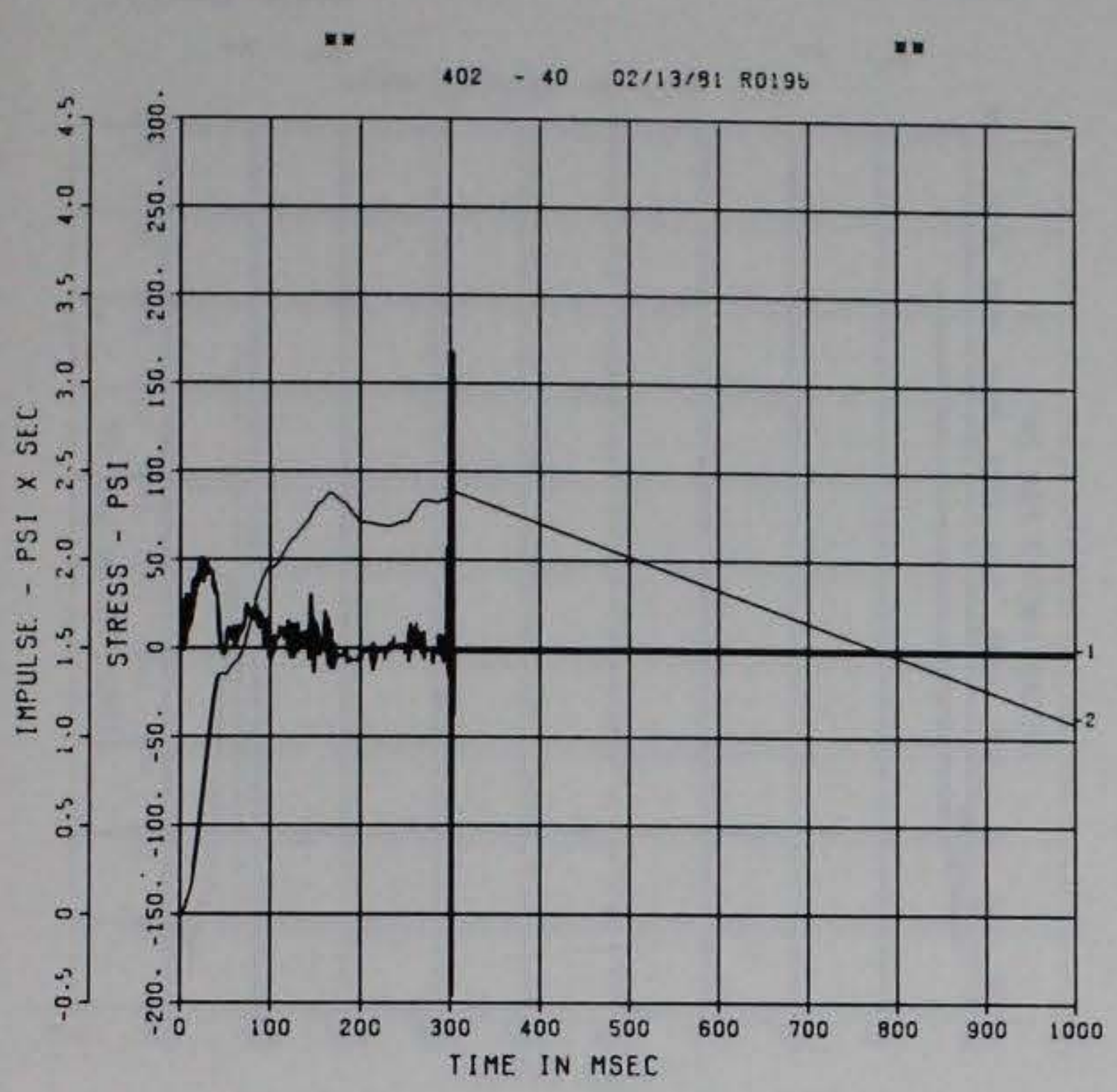

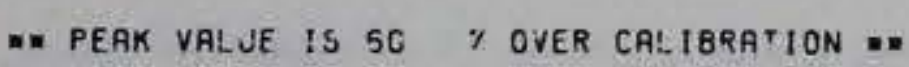

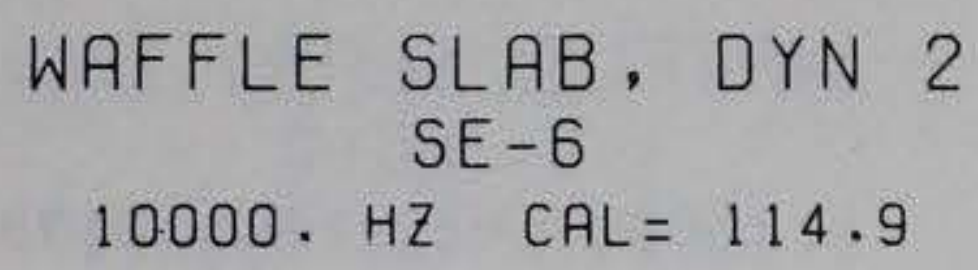

FIGURE C.99

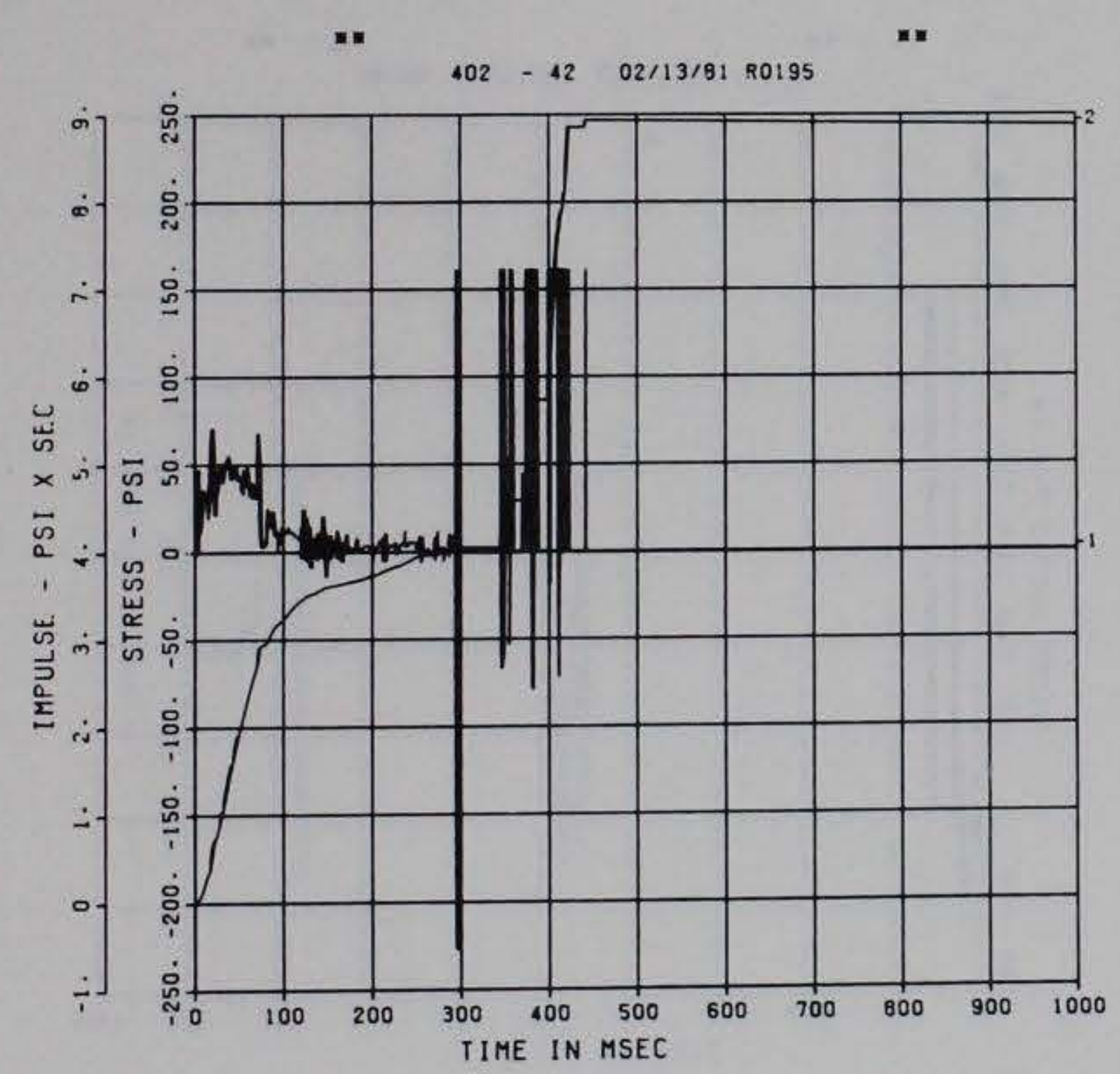

- PEAK Value IS 97 \% OVER CaLIBRation ..
WAFFLE $\underset{S E-5}{S L A B}$, DYN 2

10000. $\mathrm{HZ} \quad \mathrm{CAL}=117.6$

FIGURE C.98

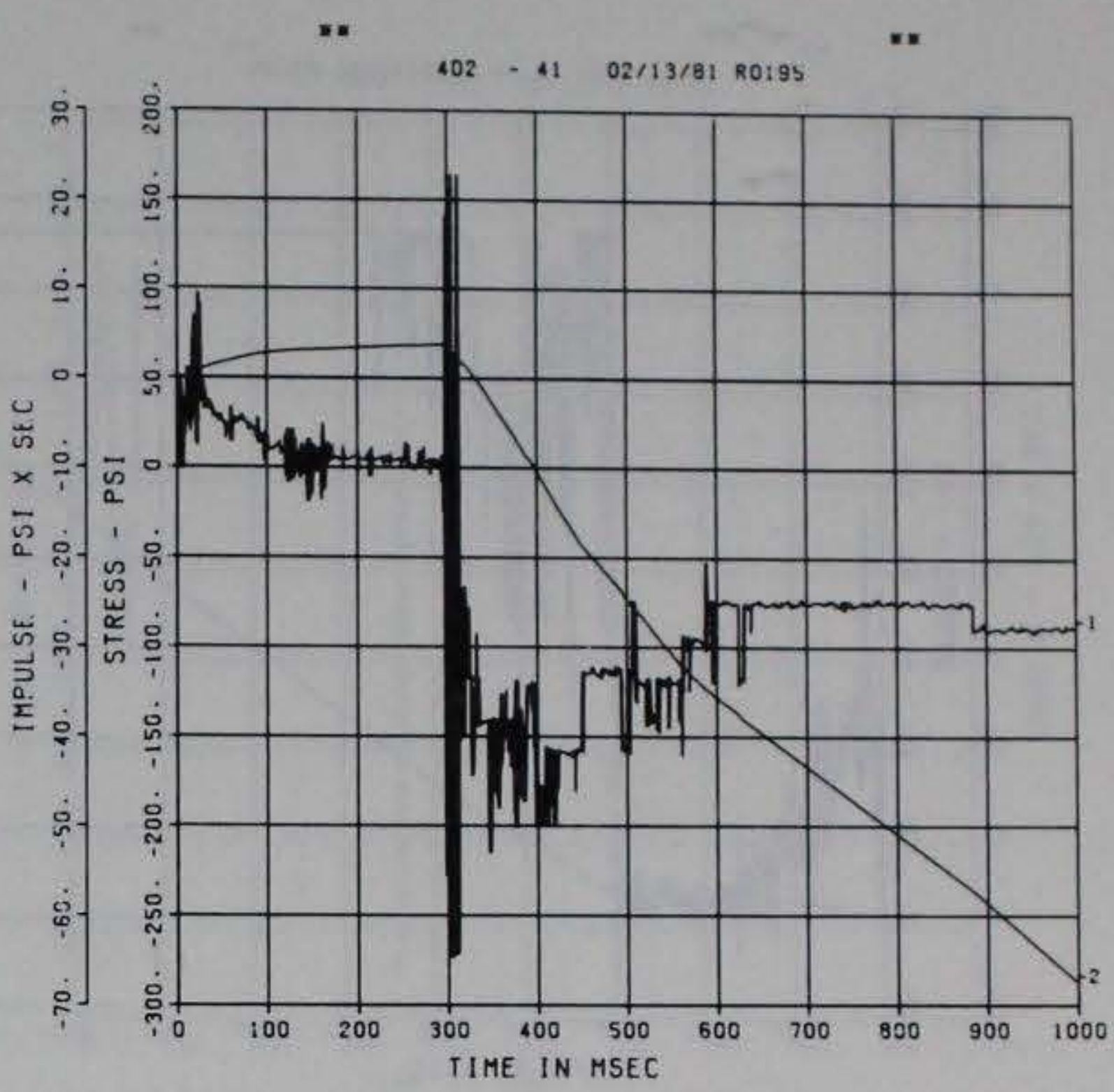

n. PEAK VALLE IS 132 y OVER CALIBration a.

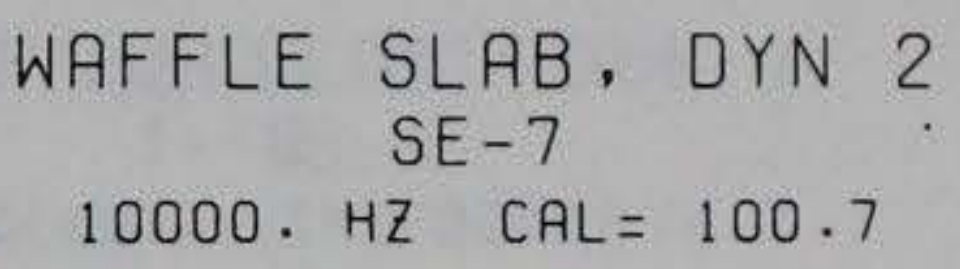

WAFFLE SLAB, OYN 2 $S E-7$

10000. $\mathrm{HZ} \quad \mathrm{CAL}=100.7$

FIGURE C.100

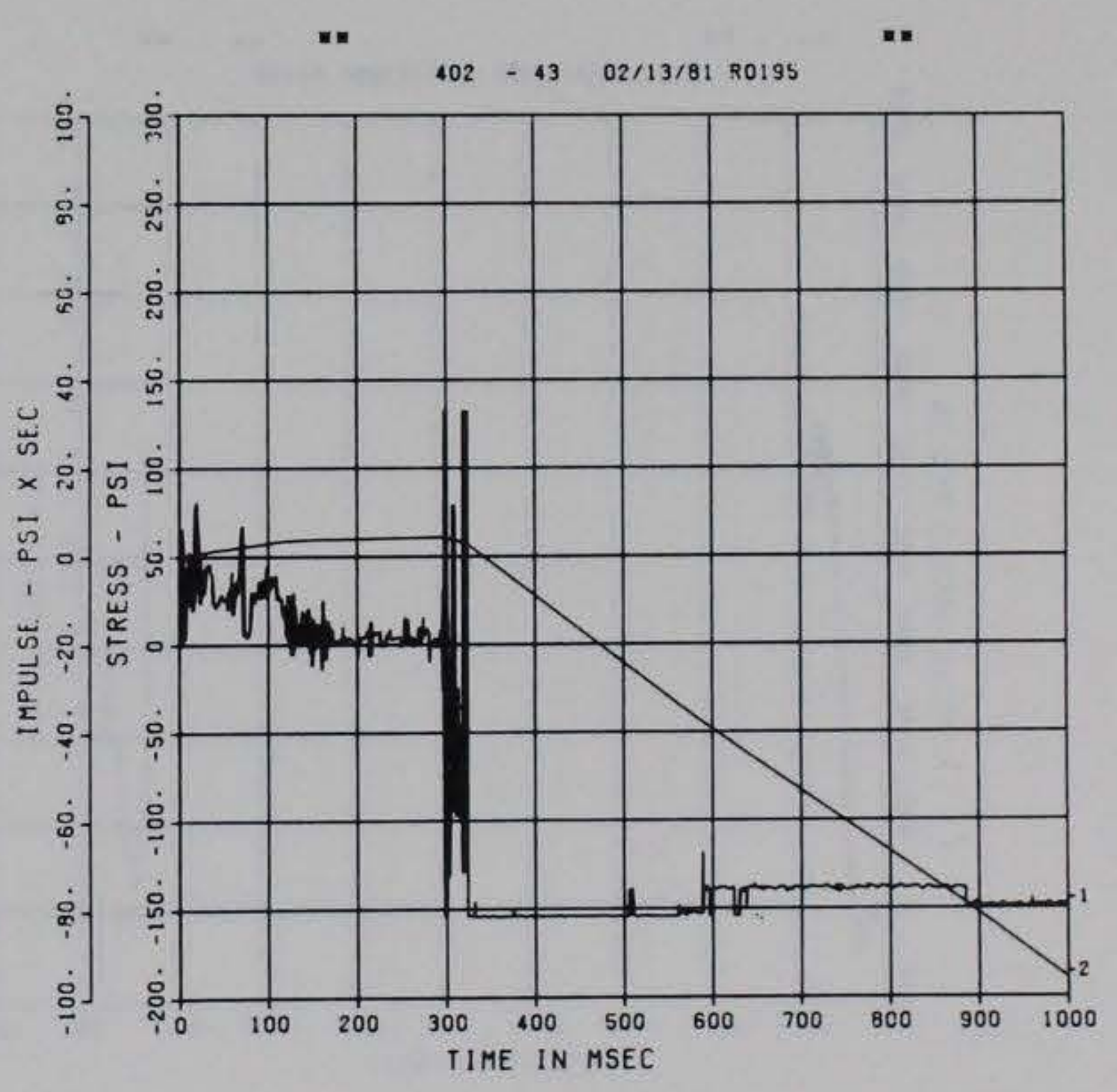

.. peak value is 54 , over calibration .. 


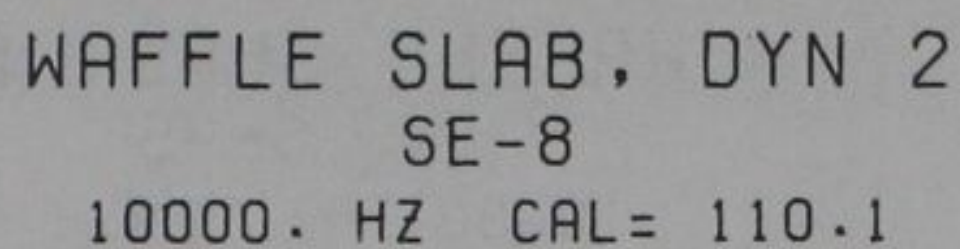

FIGURE C.101

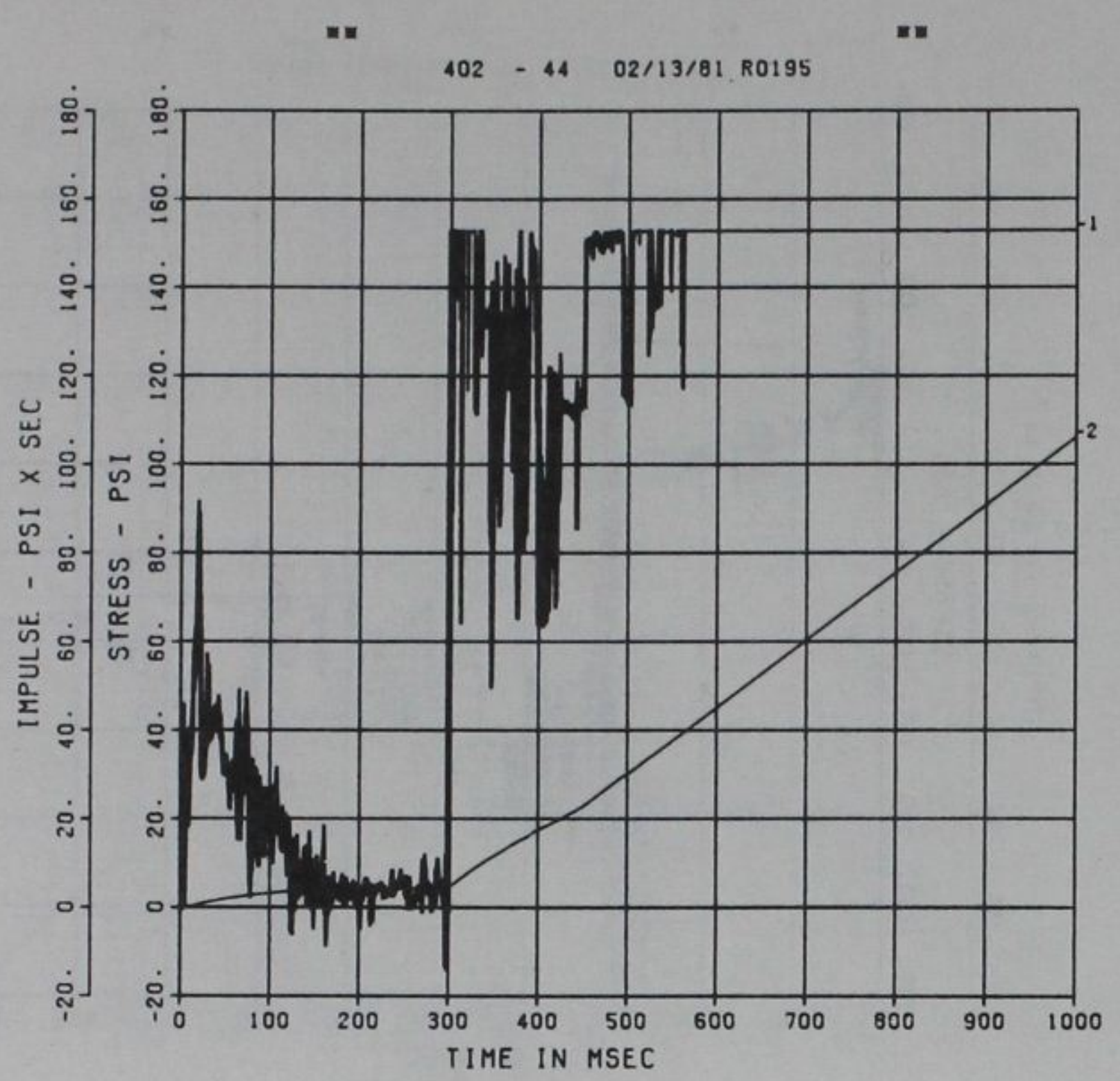

I. PEak value is 39 \% over calibration ..
WAFFLE SLAB, DYN 2 $B T-1$
10000. $\mathrm{HZ} \quad \mathrm{CAL}=2178$.

FIGURE C. 103

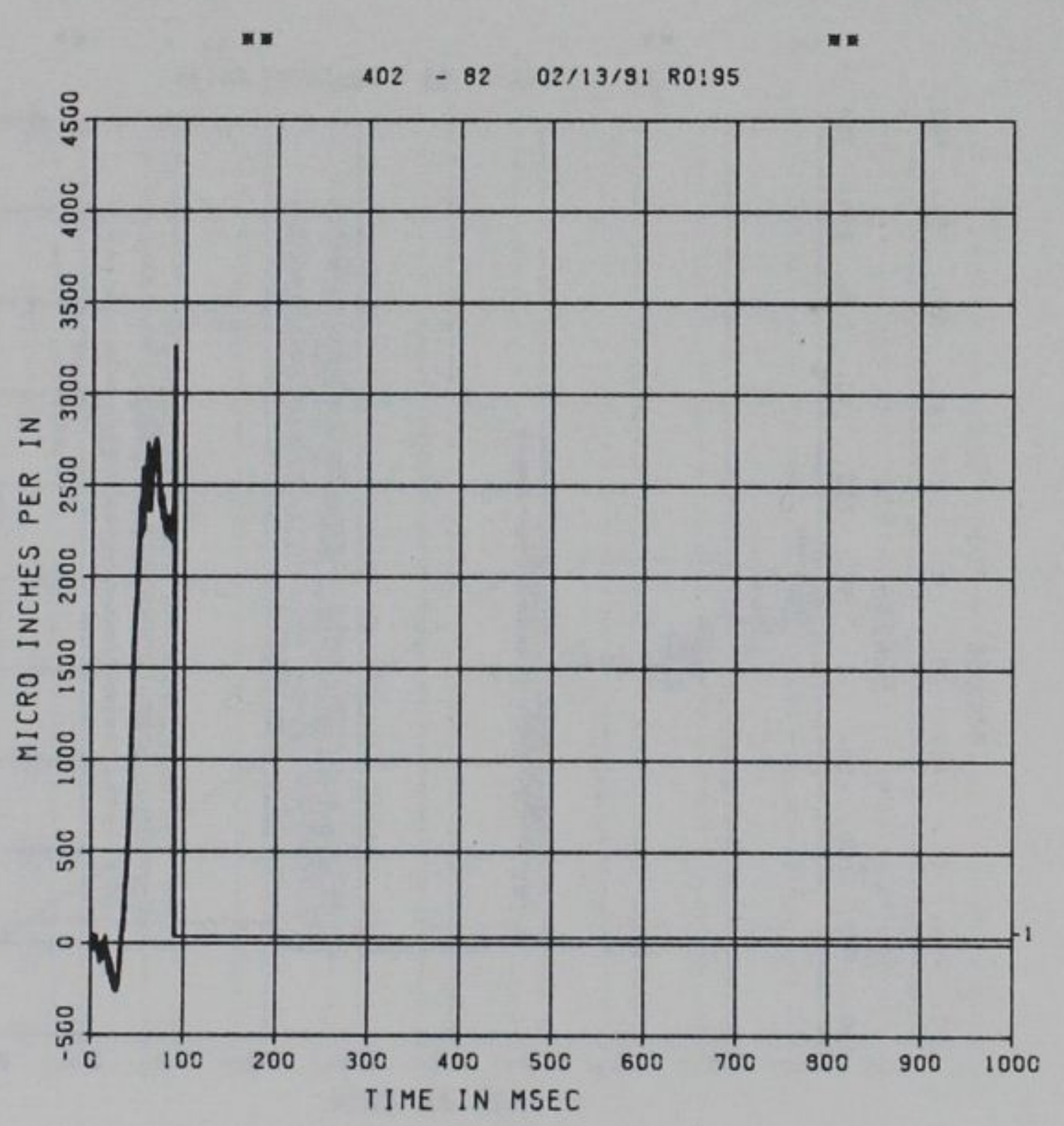

2. PEak val.je is 50 \% OVER Calibration ..
WAFFLE SLAB, DYN 2 $B B-1$

10000. $\mathrm{HZ} \quad \mathrm{CAL}=2178$.

FIGURE C.102

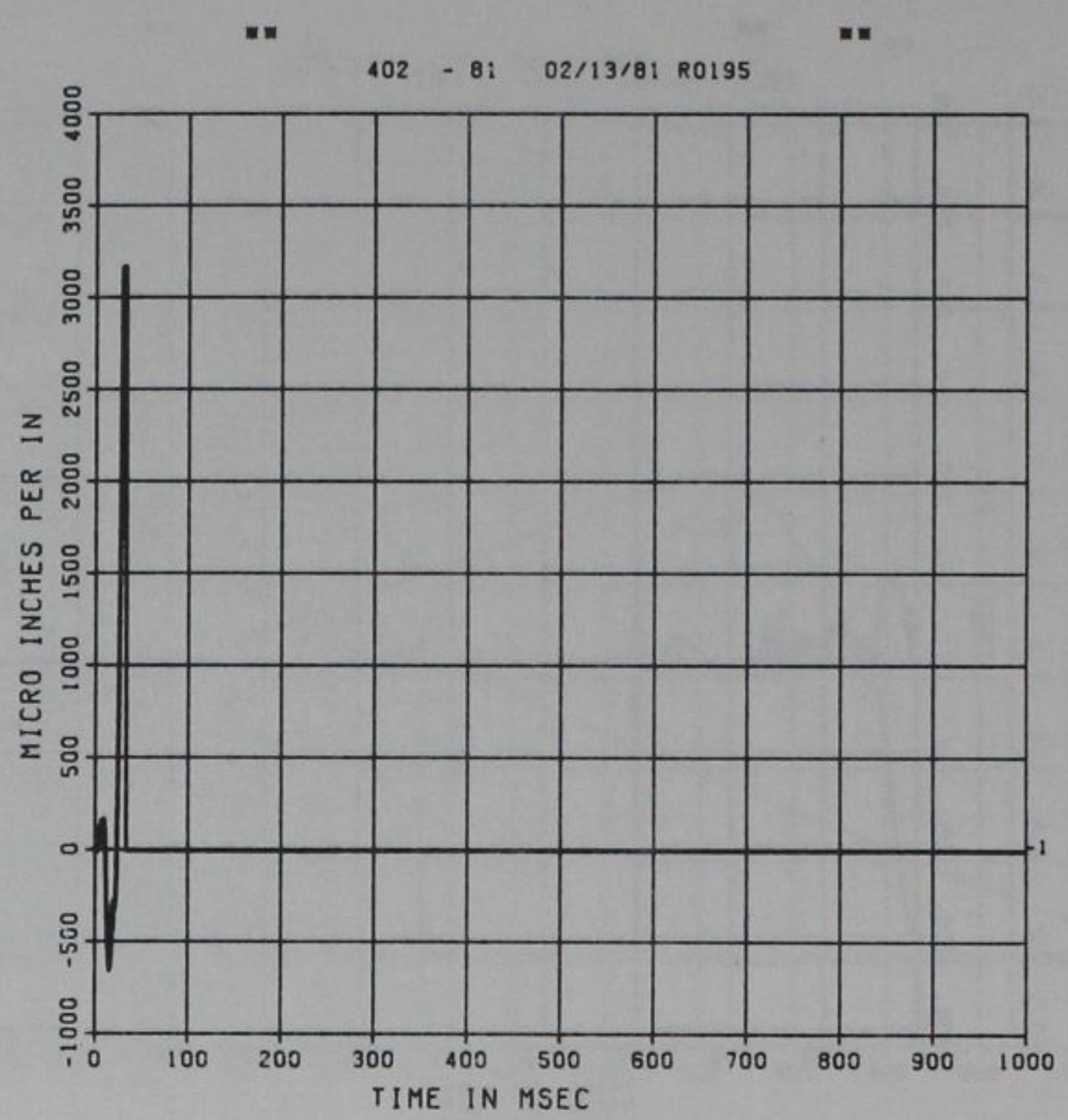

n. peak value is 46 \% over calibration .-

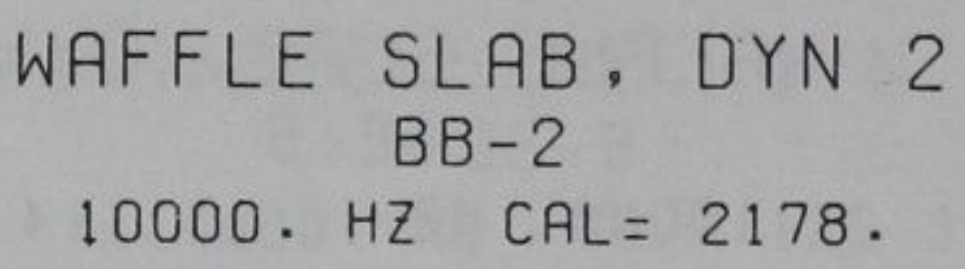

WAFFLE SLAB, DYN 2 $B B-2$

10000. $\mathrm{HZ} \quad \mathrm{CAL}=2178$.

FIGURE C.104

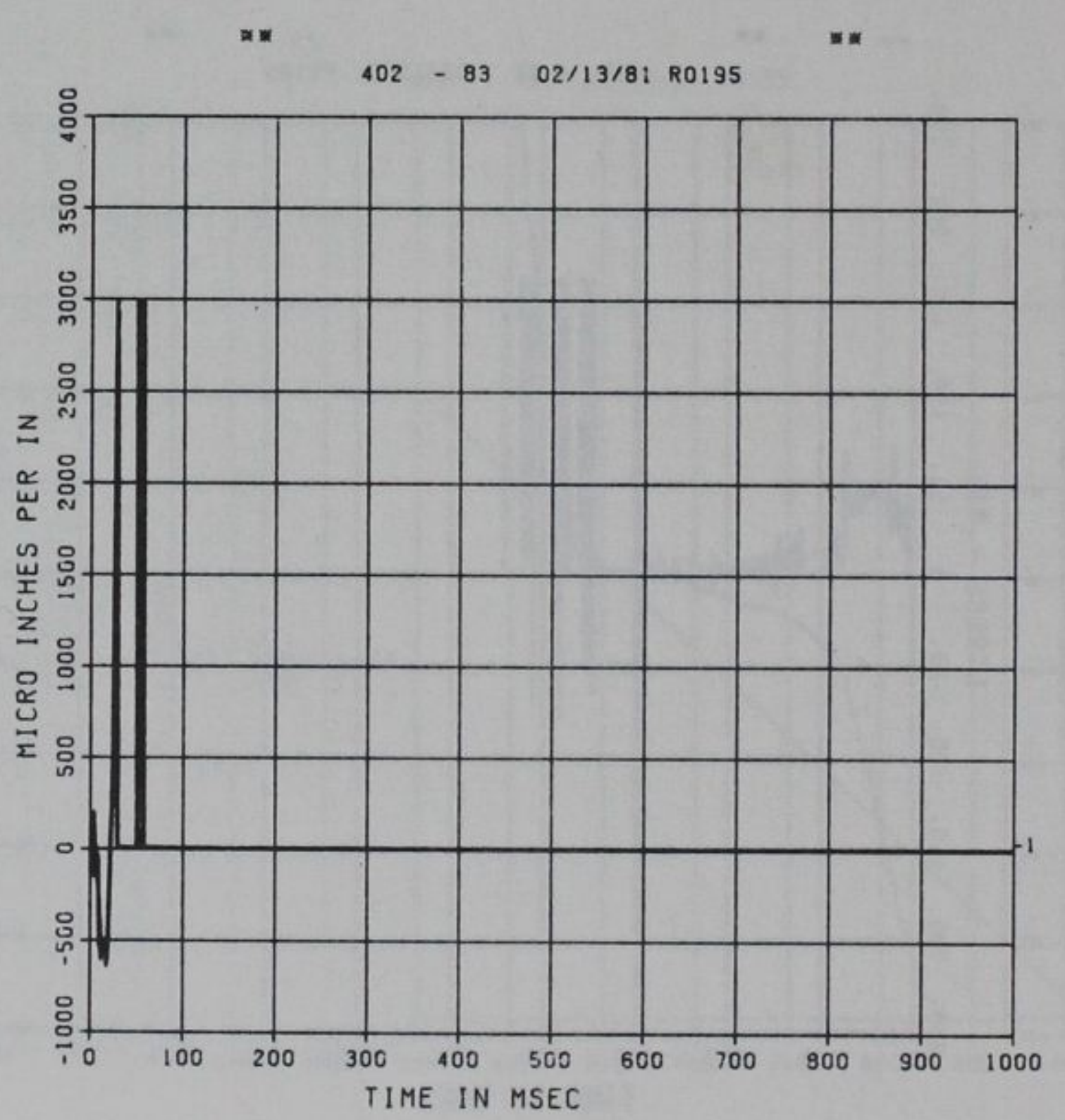

w* PEAK VALJe IS 37 \% OVER CALIBRGTION =" 
WAFFLE SLAB, DYN 2

$$
\text { 10000. } \mathrm{HZ} \quad \text { CAL }=2178 \text {. }
$$

FIGURE C.105

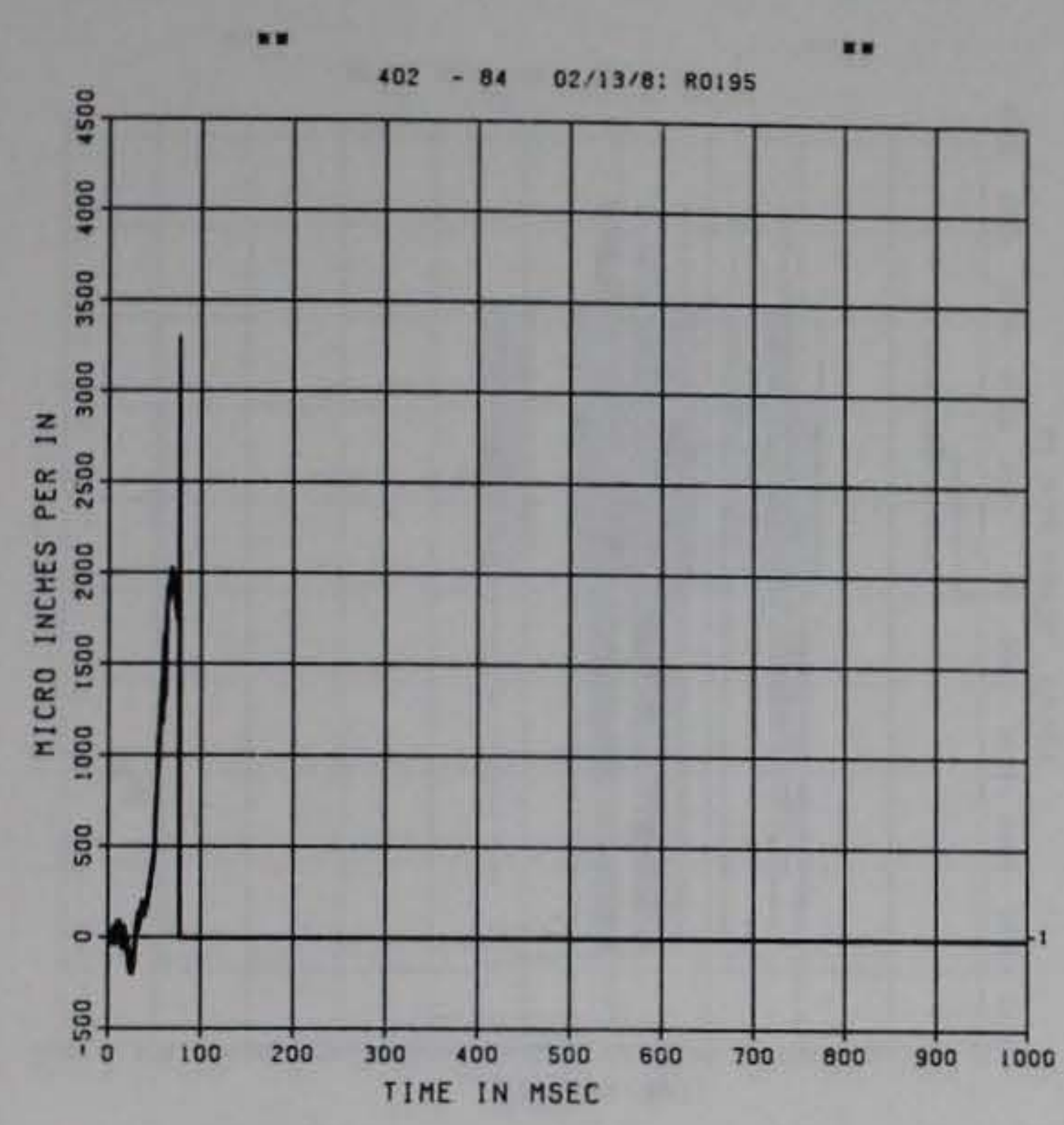

*. PEAK VaLUe IS 52 \% OVER CaLIBRation $\ldots$.

$$
\begin{gathered}
\text { WAFFLE SLAB, DYN } 2 \\
\text { BT-3 } \\
\text { 10000. } \mathrm{HZ} \quad \mathrm{CAL}=2178 .
\end{gathered}
$$

FIGURE C. 107

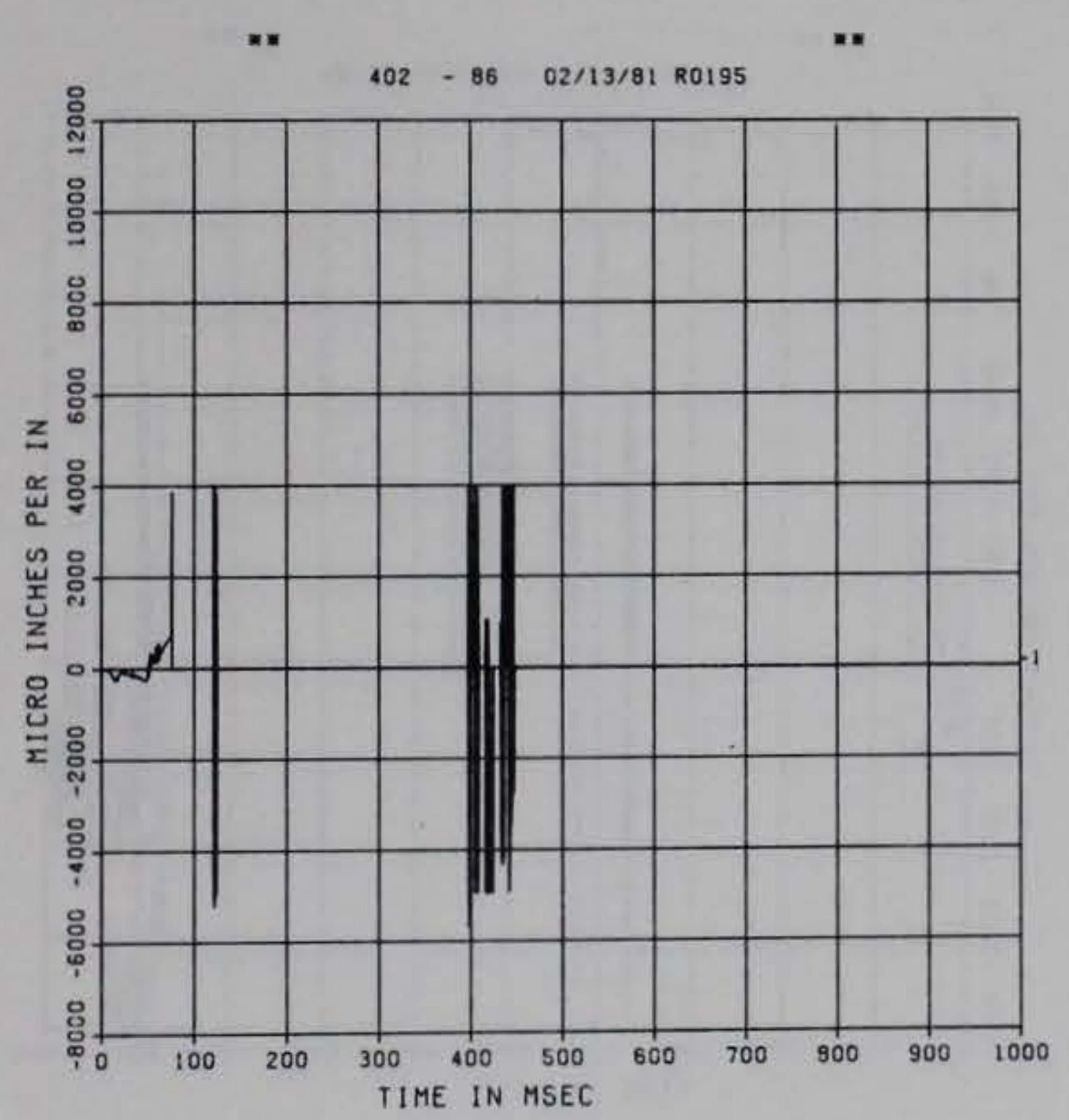

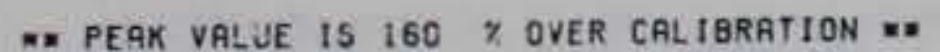

WAFFLE SLAB, DYN 2 $B B-3$

10000. $\mathrm{HZ} \quad \mathrm{CAL}=2178$.
FIGURE C.106

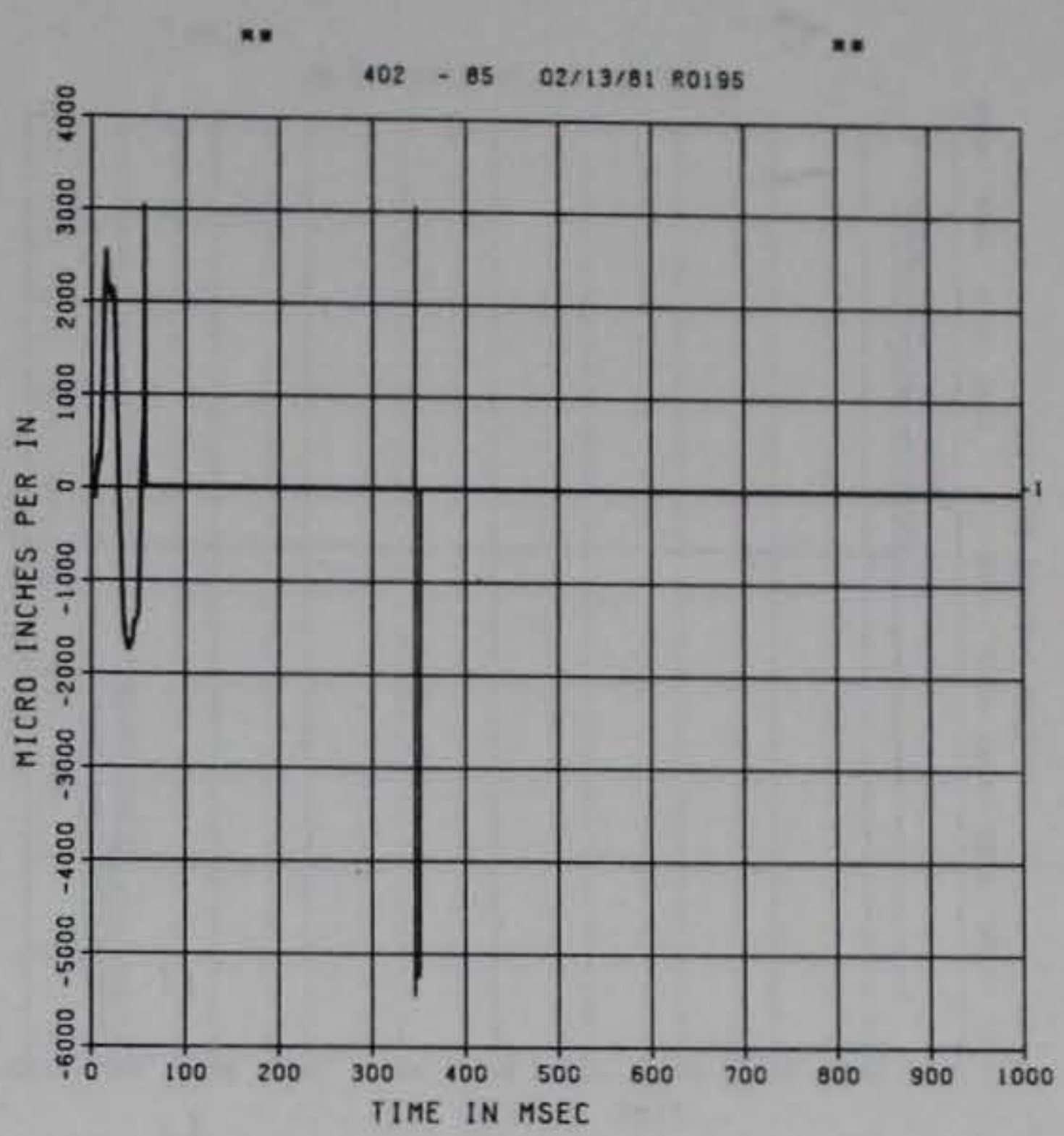

*. PEAK VALUE IS 150 \% OVER CALIBRATION $=$

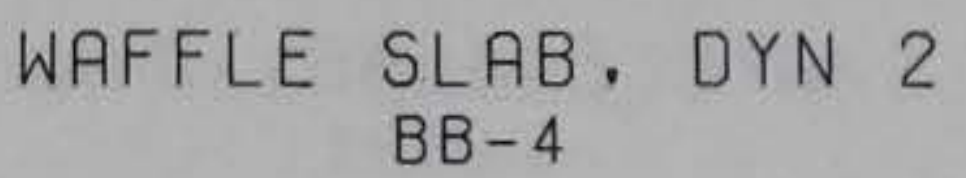

FIGURE C. 108

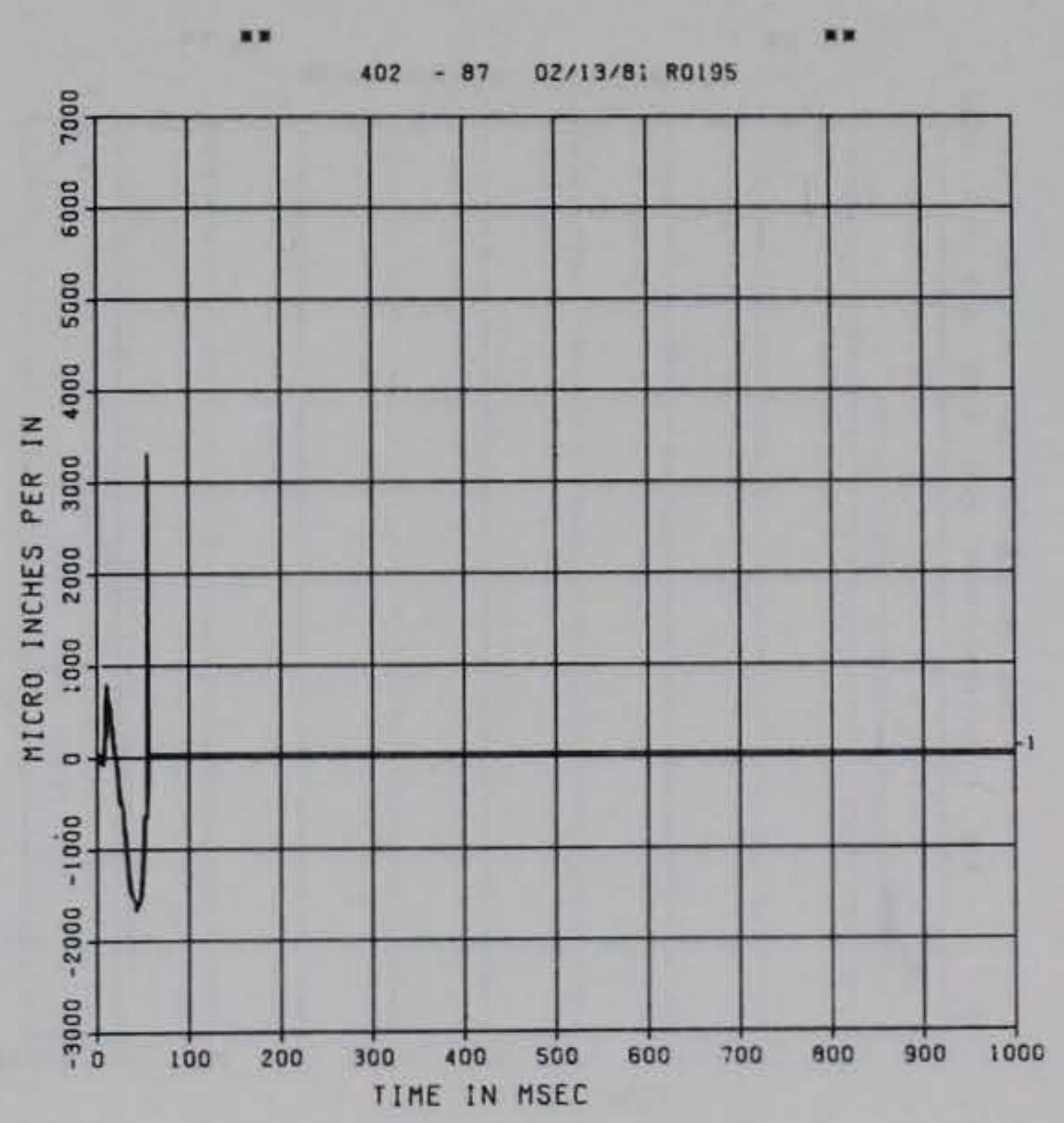

n. PEAK VALUE IS 52 \% OVER CaLIBration $\ldots$ 


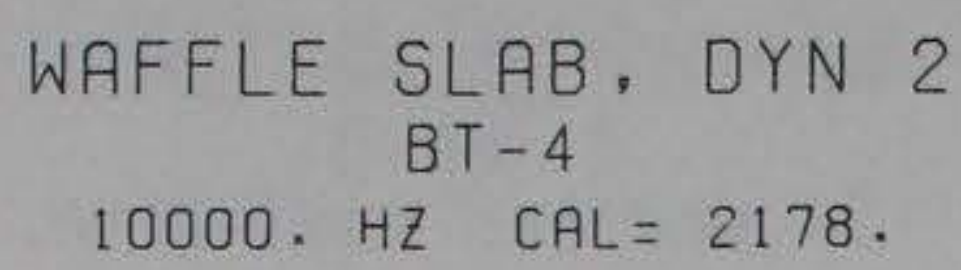

FIGURE C.109

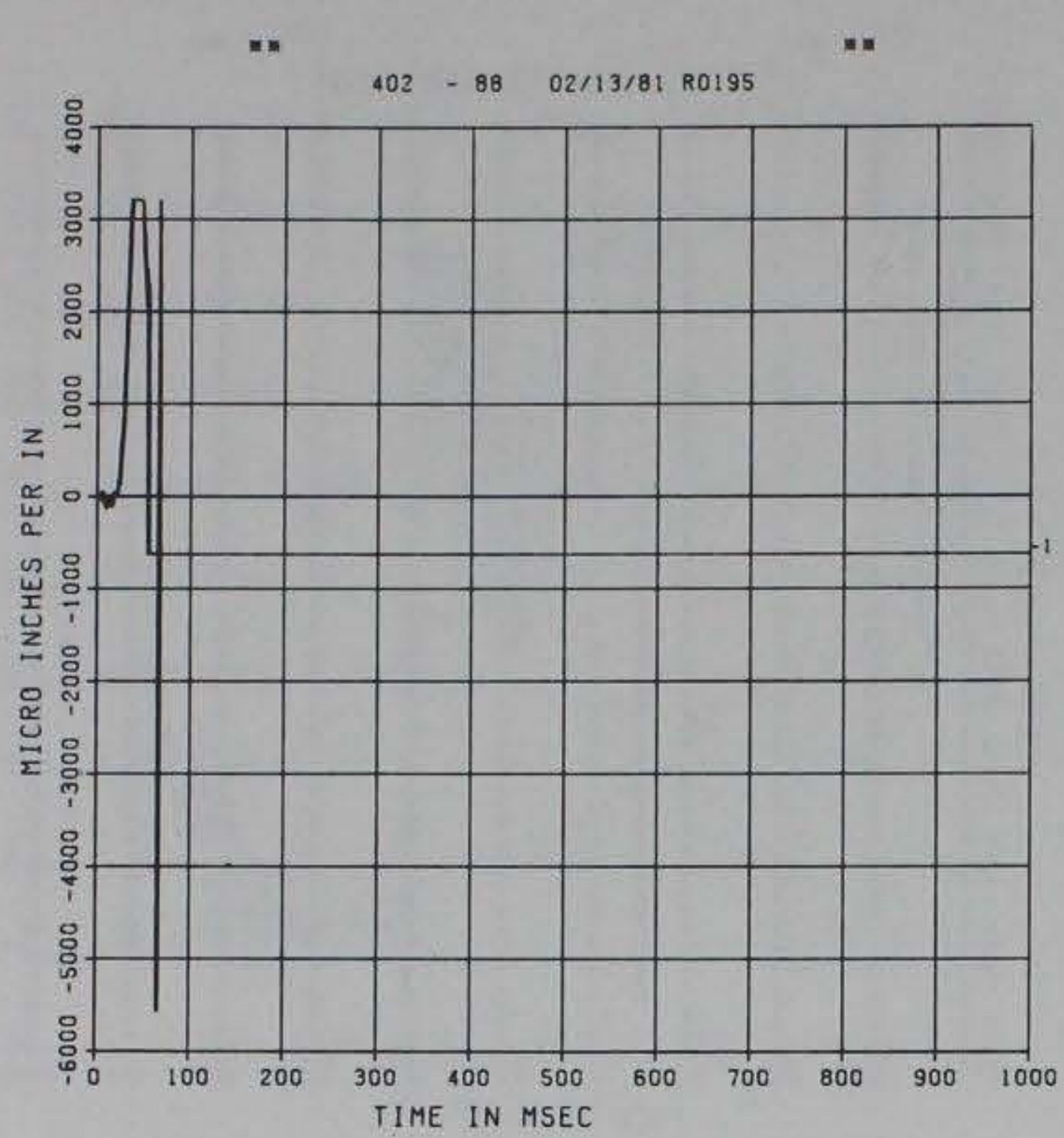

* PEAK VALUE IS 156 \% OVER CALIBRATION *

WAFFLE $\begin{gathered}\text { SLAB, DYN } 2 \\ \text { CT-1 }\end{gathered}$

10000. $\mathrm{HZ} \quad \mathrm{CAL}=2178$.

FIGURE C.111

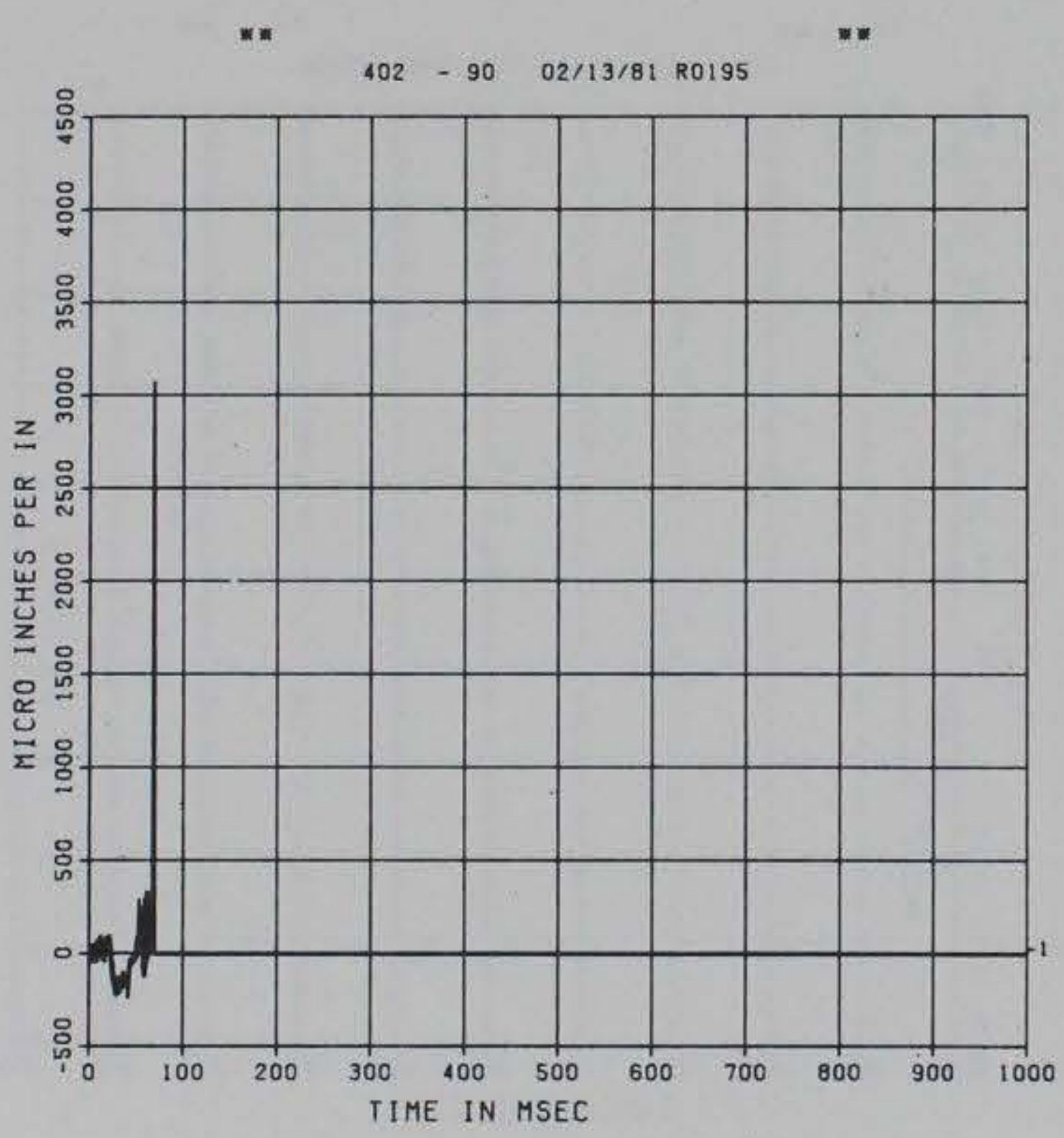

m* PEAK VALUE IS 41 \% OVER CALIBRation .\#
WAFFLE SLAB, DYN 2 $C B-1$

10000. $\mathrm{HZ} \quad \mathrm{CAL}=2178$.

FIGURE C. 110

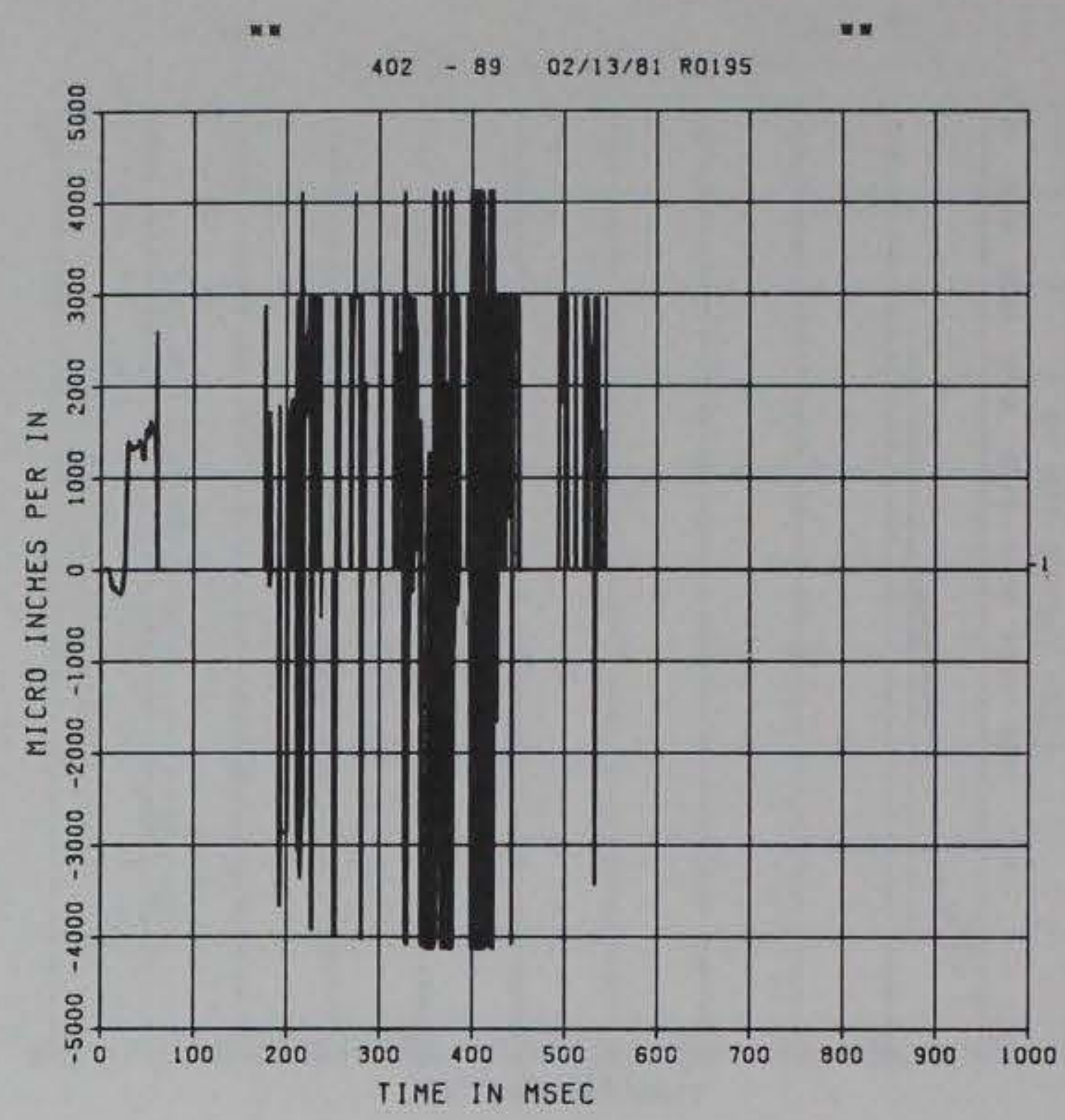

\footnotetext{
m. PEAK Value is 90 \% OVER CalibRation .

WAFFLE SLAB, DYN 2 $C B-2$

10000. $\mathrm{HZ} \quad \mathrm{CAL}=2178$.
}

FIGURE $C .112$

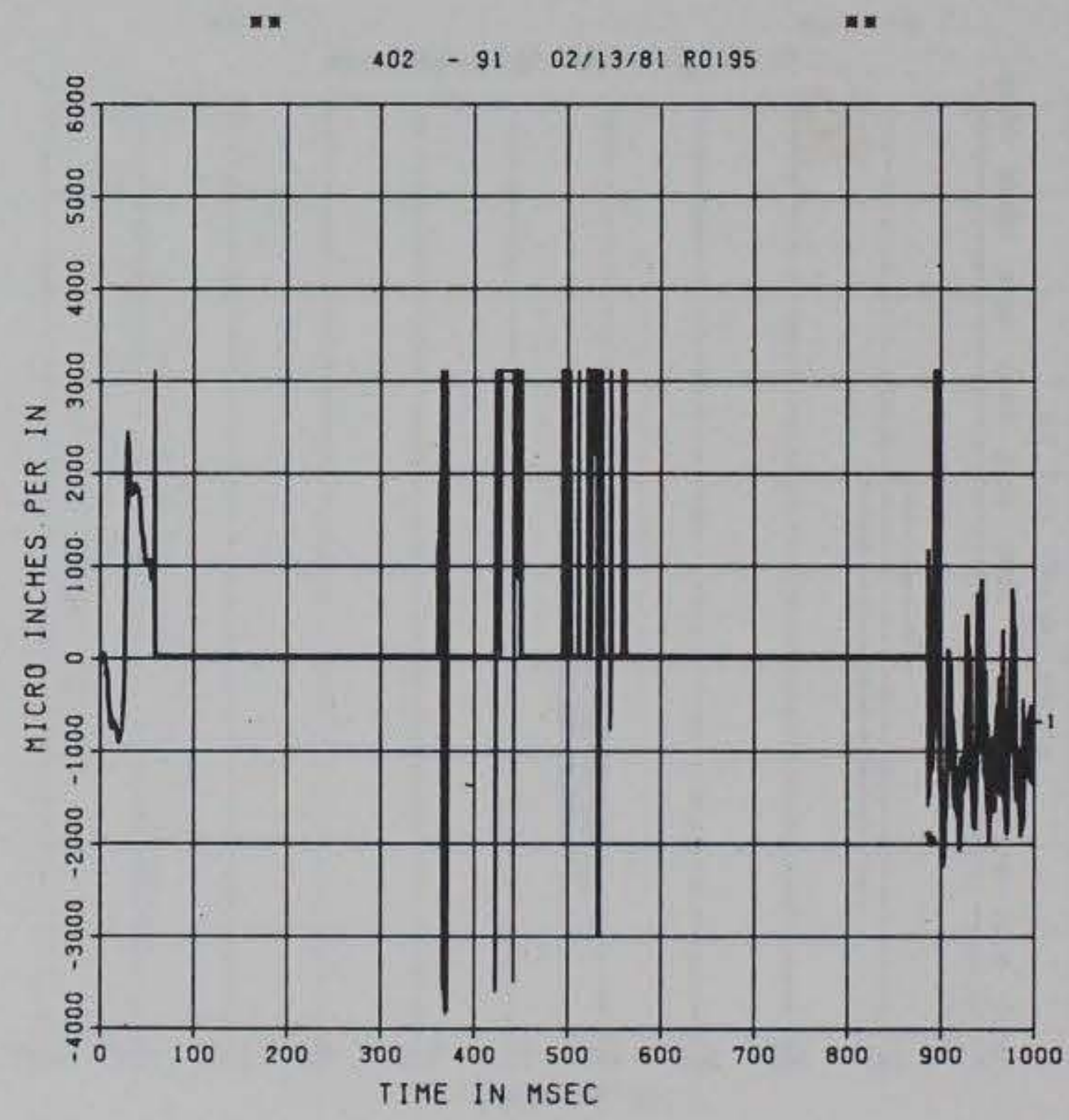

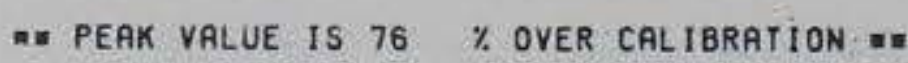


WAFFLE SLAB, DYN 2

10000. $\mathrm{HZ} \quad \mathrm{CAL}=2178$.

FIGURE C.113

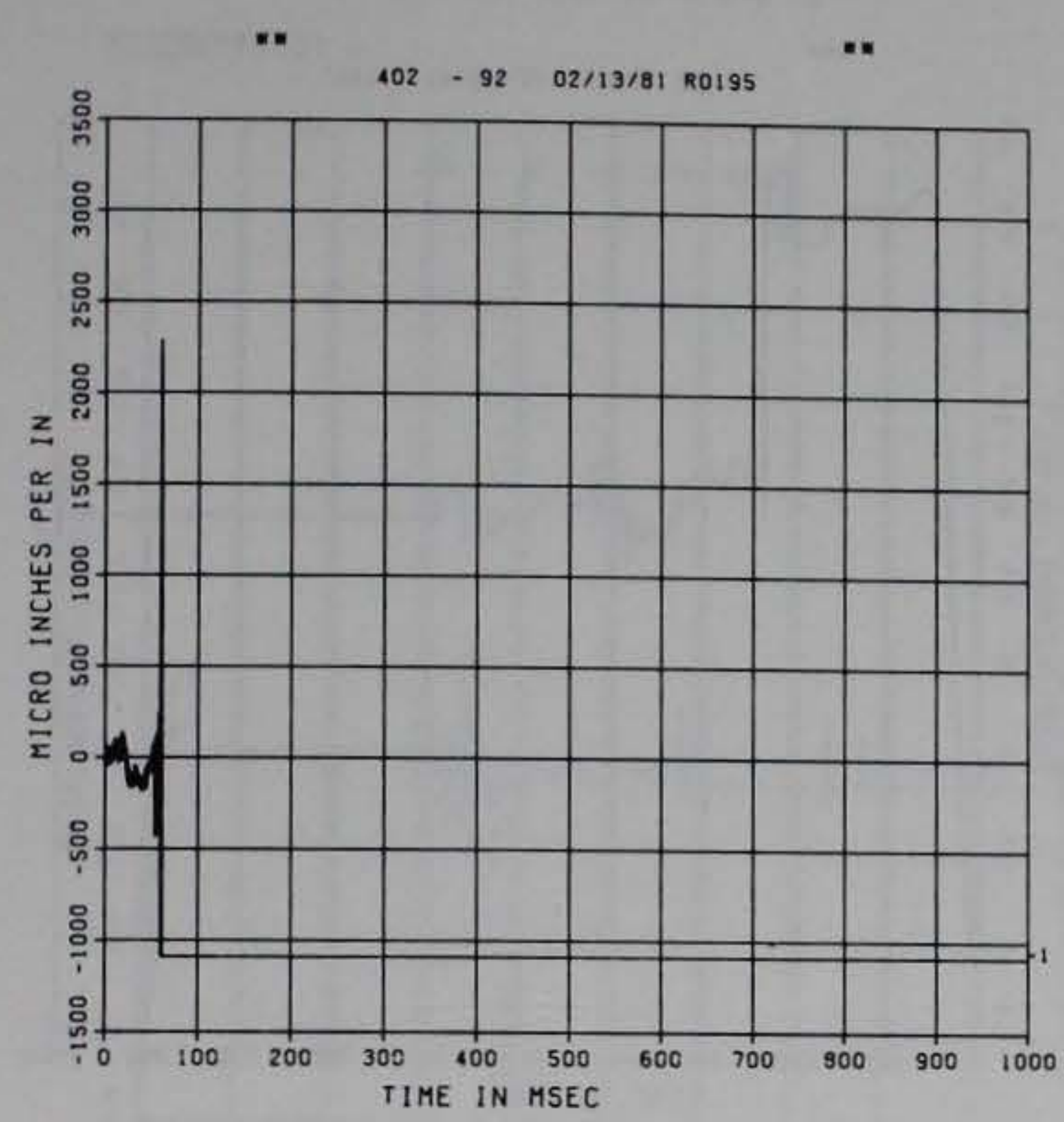

\#* peak value is 5 ₹ OVer cal ibration \#.

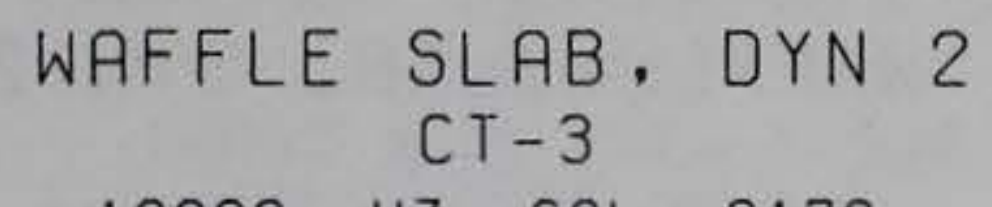

10000. $\mathrm{HZ} \quad \mathrm{CAL}=2178$.

FIGURE C.115

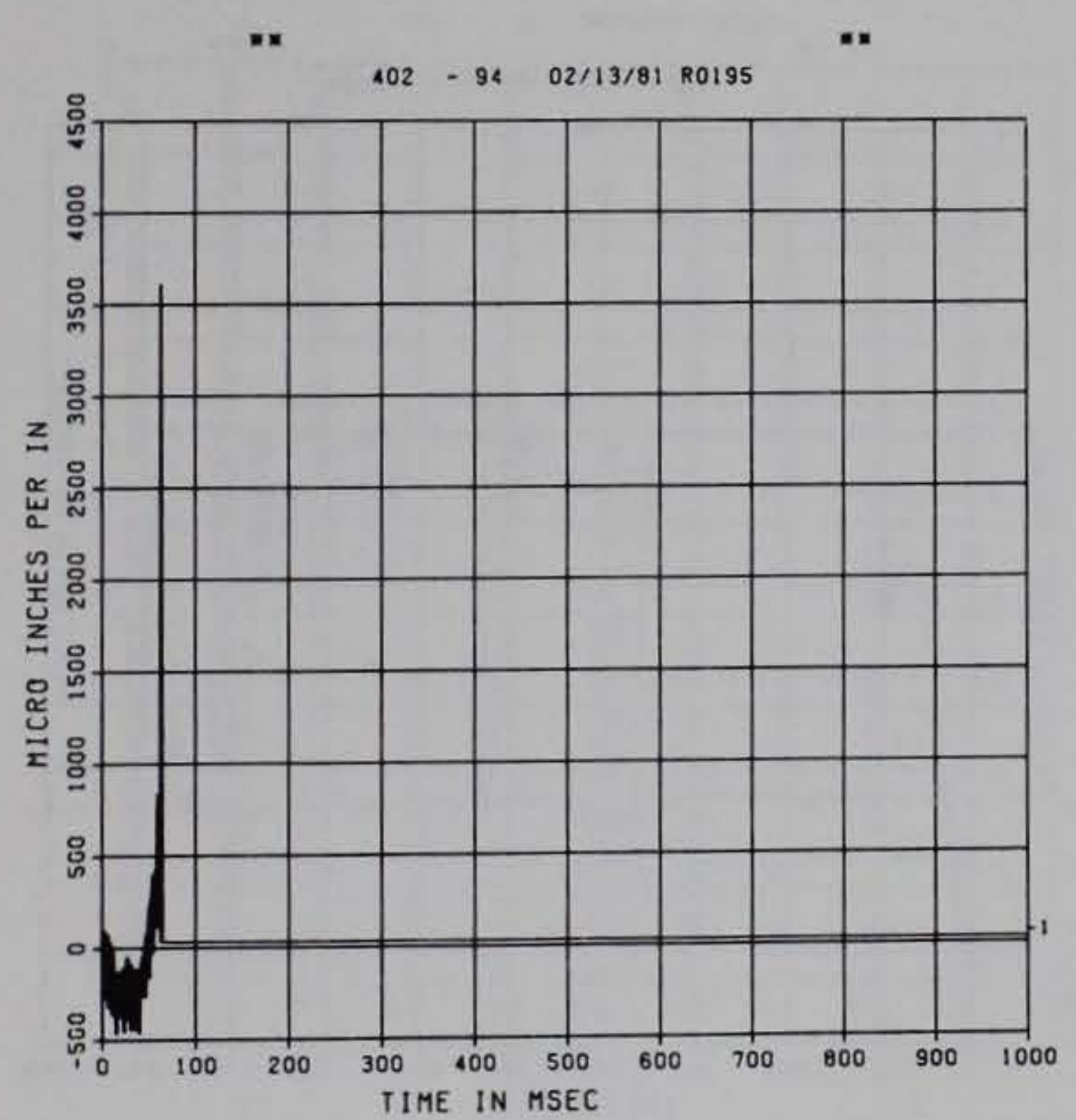

2* PEAK VALUE IS 66 \% OVER CALIBRATION \#"
WAFFLE SLAB, DYN 2

$$
C B-3
$$

10000. $\mathrm{HZ} \quad \mathrm{CAL}=2178$.

FIGURE C.114

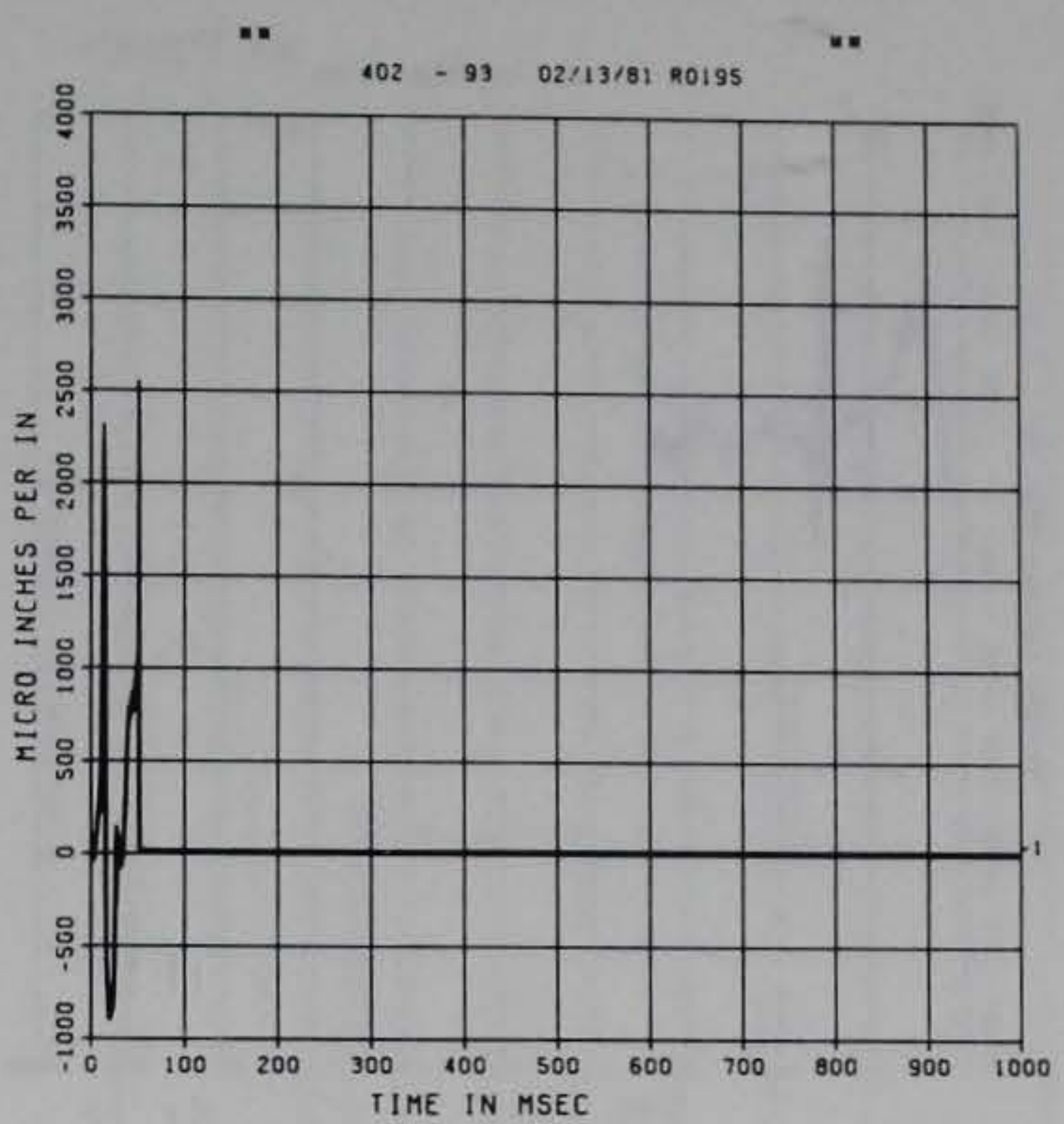

* peak value is 17 y over calibration ..

WAFFLE SLAB, DYN 2

$$
C B-4
$$

10000. $\mathrm{HZ} \quad \mathrm{CAL}=2178$.

FIGURE C.116

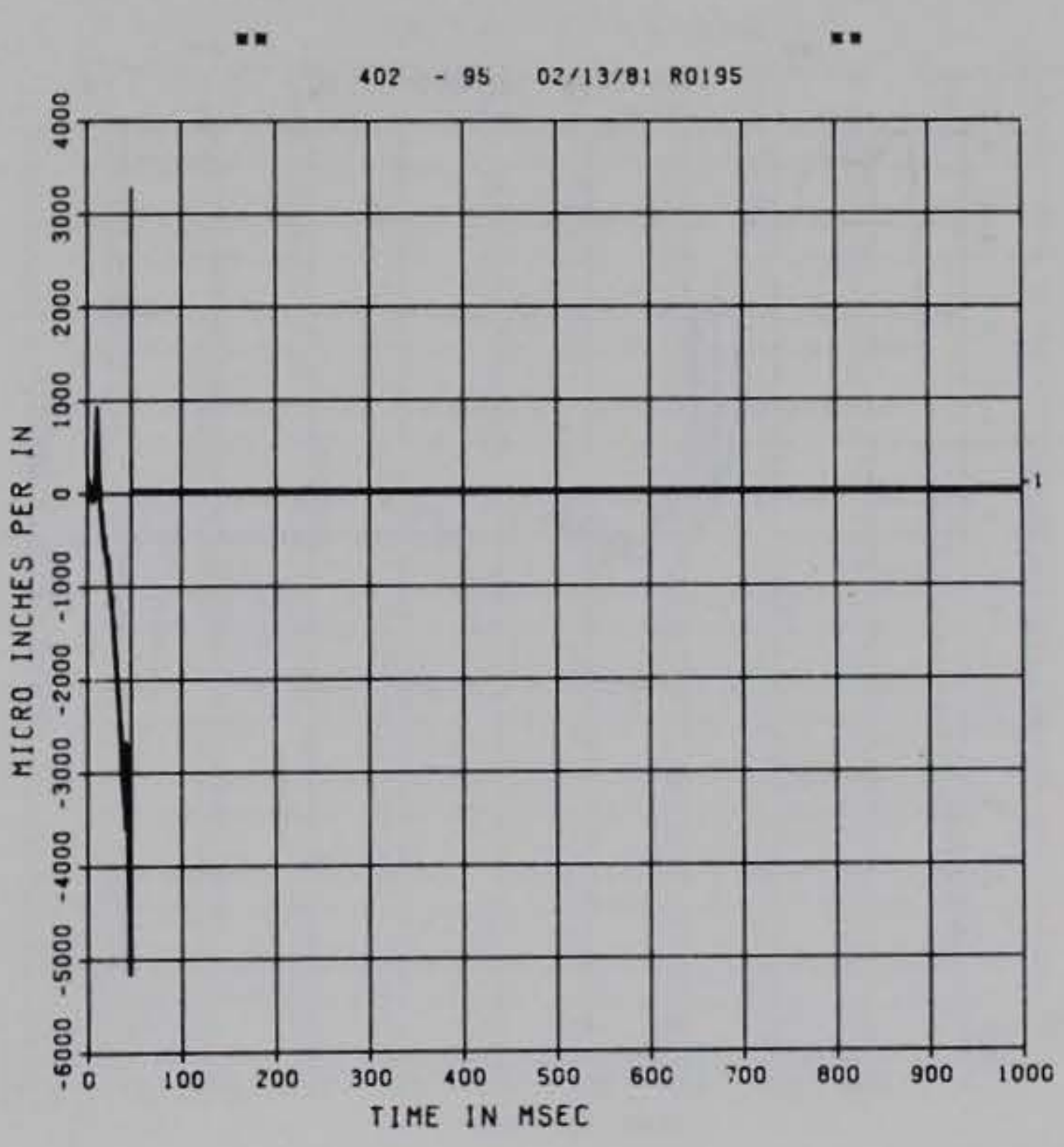

n. PEAK Value is 137 \% OVER CaLjBration .. 


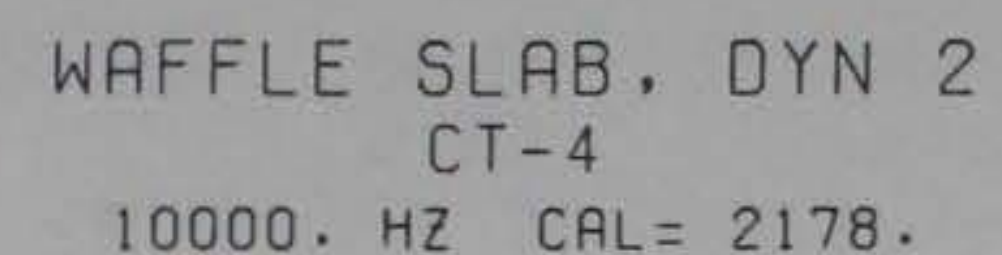

FIGURE C.117

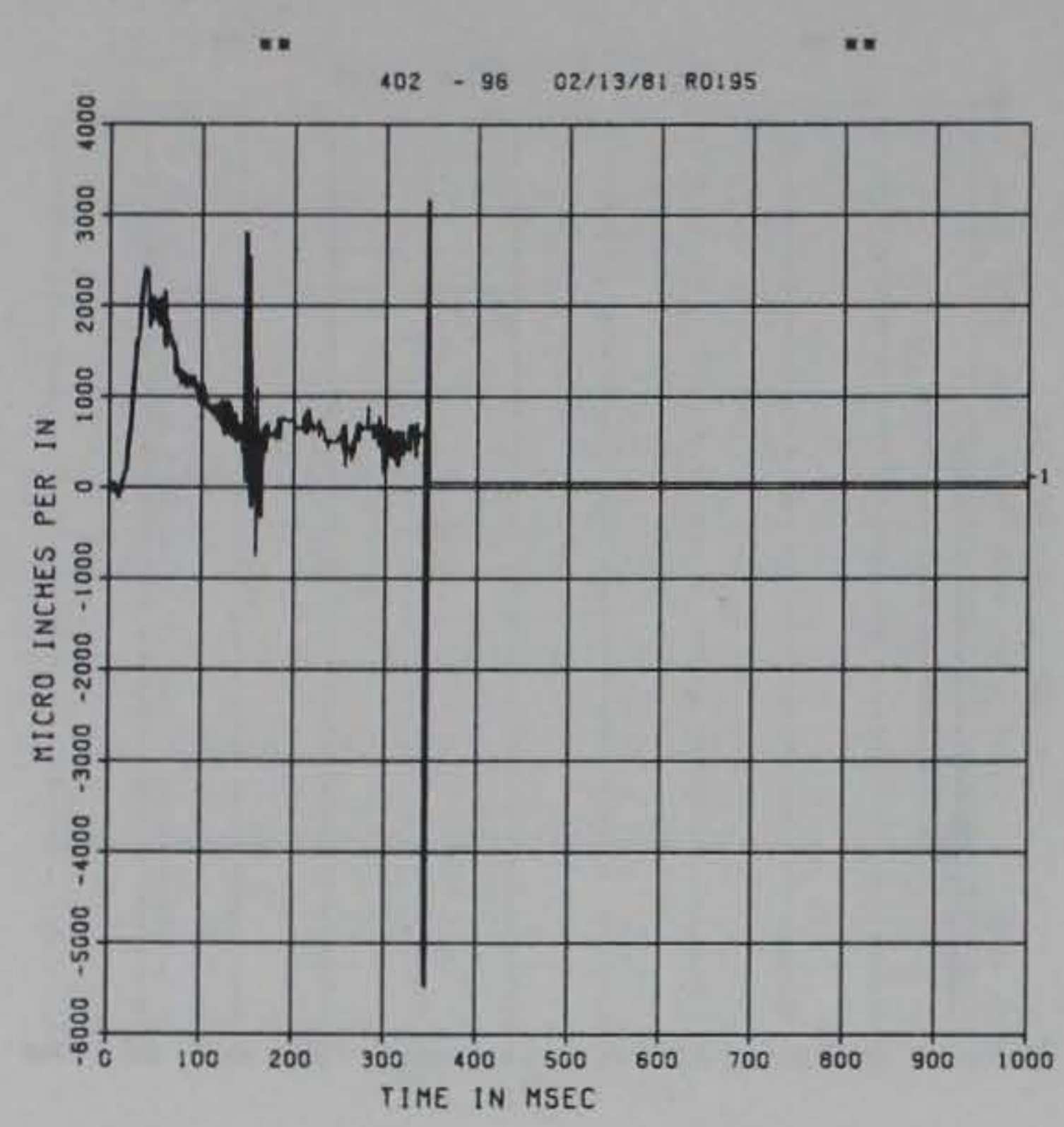

n. PEAK VALUE IS ISi \% OVER CaL IBRation \#.

$$
\begin{gathered}
\text { WAFFLE SLAB, DYN } 2 \\
D-2 \\
10000 . \mathrm{HZ} \quad \mathrm{CAL}=6.300 \\
\text { LP4 70\% CUTOFF }=450.0 \mathrm{~Hz}
\end{gathered}
$$

FIGURE C.119

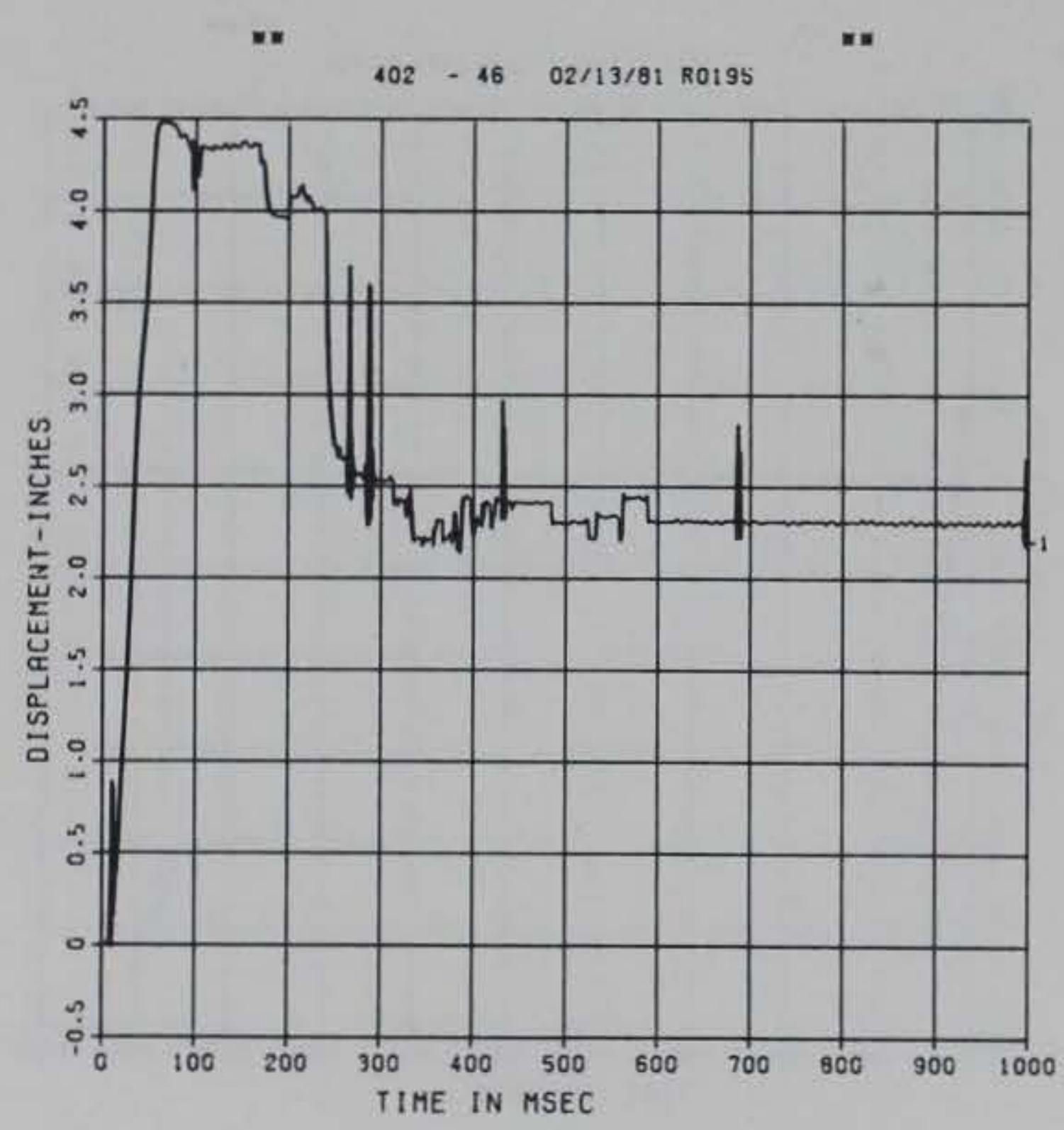

WAFFLE SLAB, DYN 2 $D-1$

10000. $\mathrm{HZ} \quad \mathrm{CAL}=6.300$

LP4 $70 \%$ CUTOFF $=450.0 \mathrm{HZ}$

FIGURE C.118

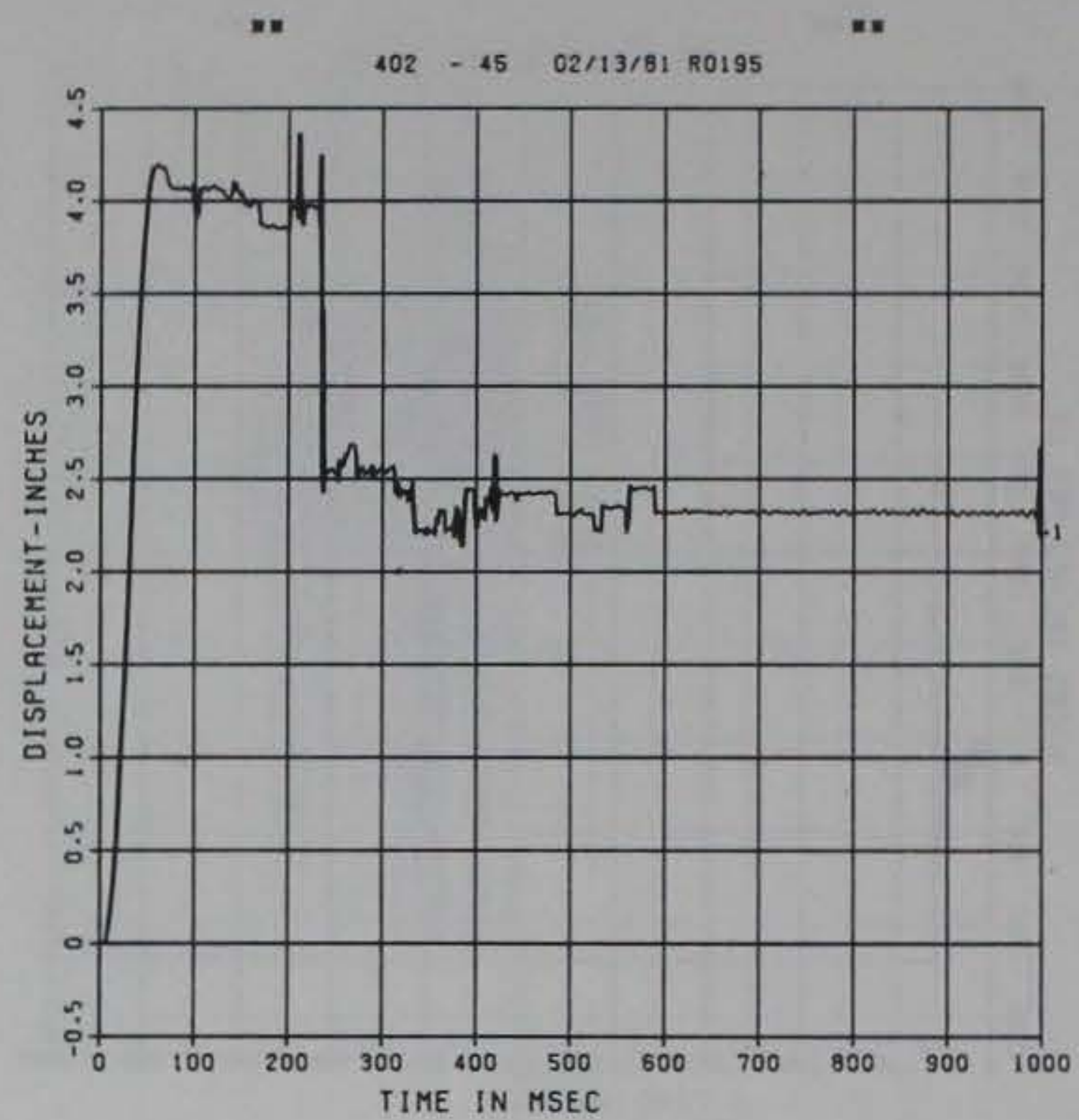

WAFFLE SLAB, DYN 2

$$
D-3
$$

10000. $\mathrm{HZ} \quad \mathrm{CAL}=4 \cdot 300$

LP4 $70 \%$ CUTOFF $=450.0 \mathrm{HZ}$

FIGURE C. 120

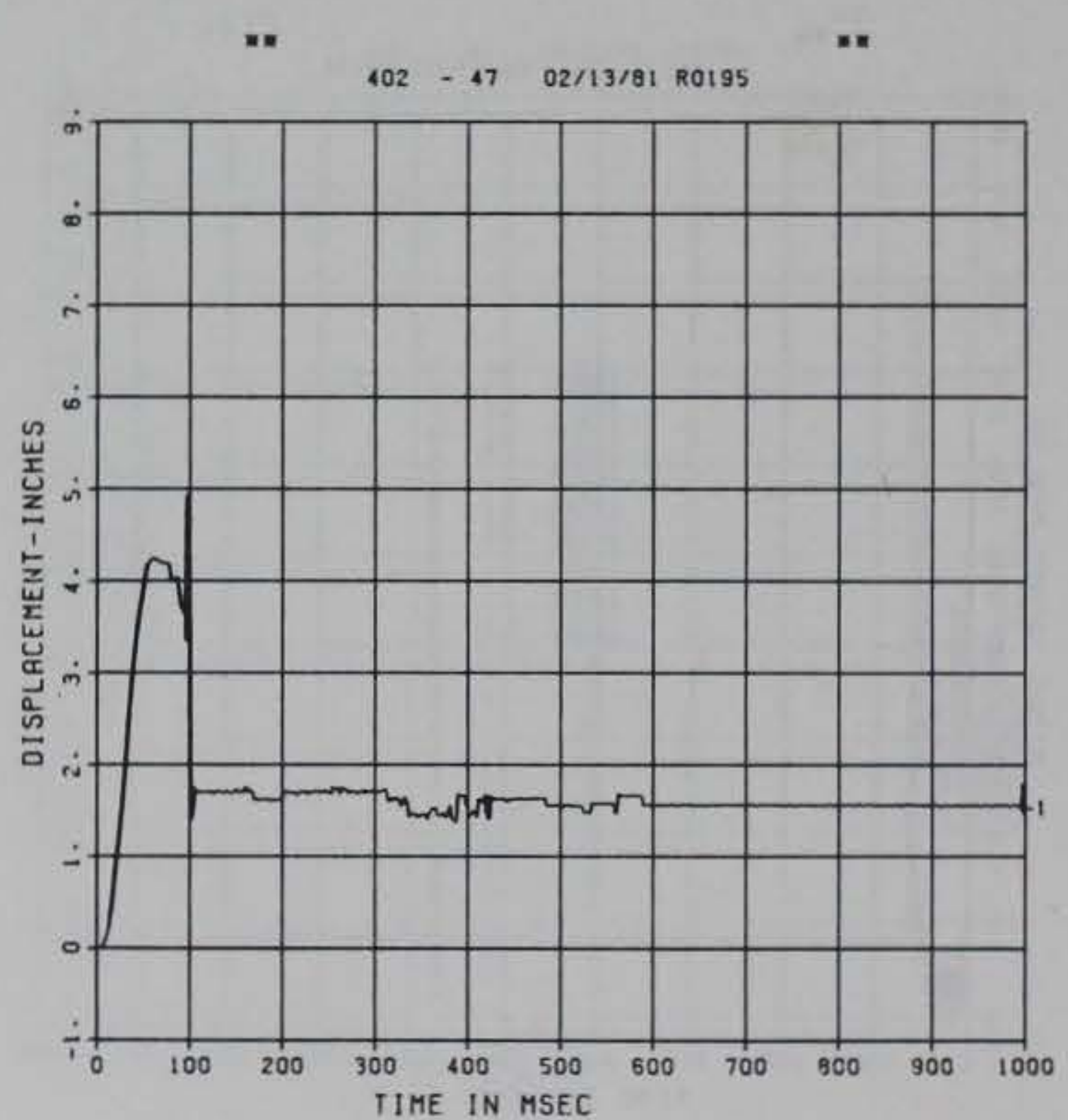

n. peak value is i5 x over calibration .. 
WAFFLE SLAB, DYN 2

10000. $\mathrm{HZ} \quad \mathrm{CAL}=3.500$

LP4 $70 \%$ CUTOFF $=450.0 \mathrm{HZ}$

FIGURE C.121

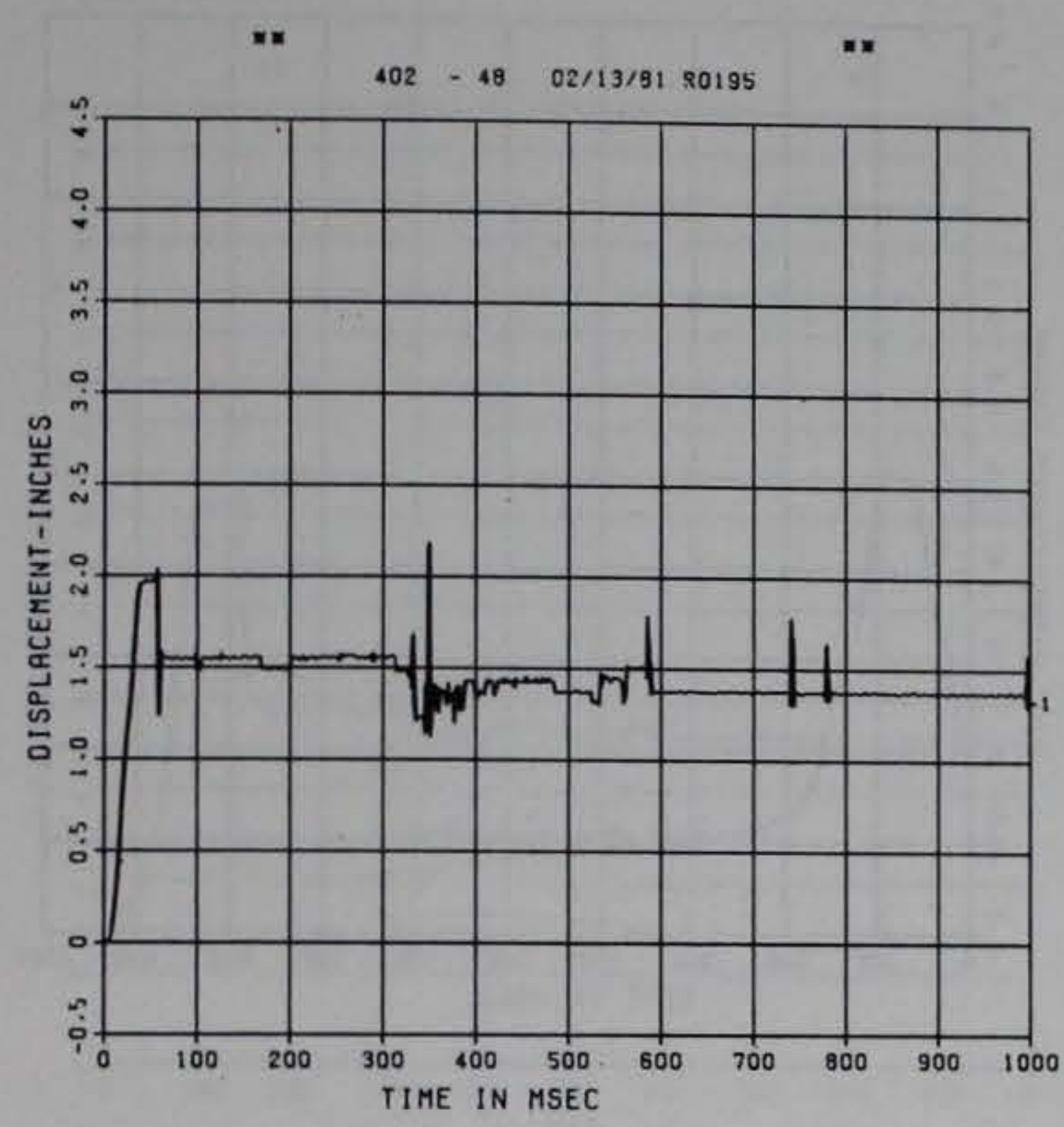

WAFFLE SLAB, DYN 2 $D-6$

10000. $\mathrm{HZ} \quad \mathrm{CAL}=1.300$

LP4 $70 \%$ CUTOFF $=450.0 \mathrm{HZ}$

FIGURE C. 123

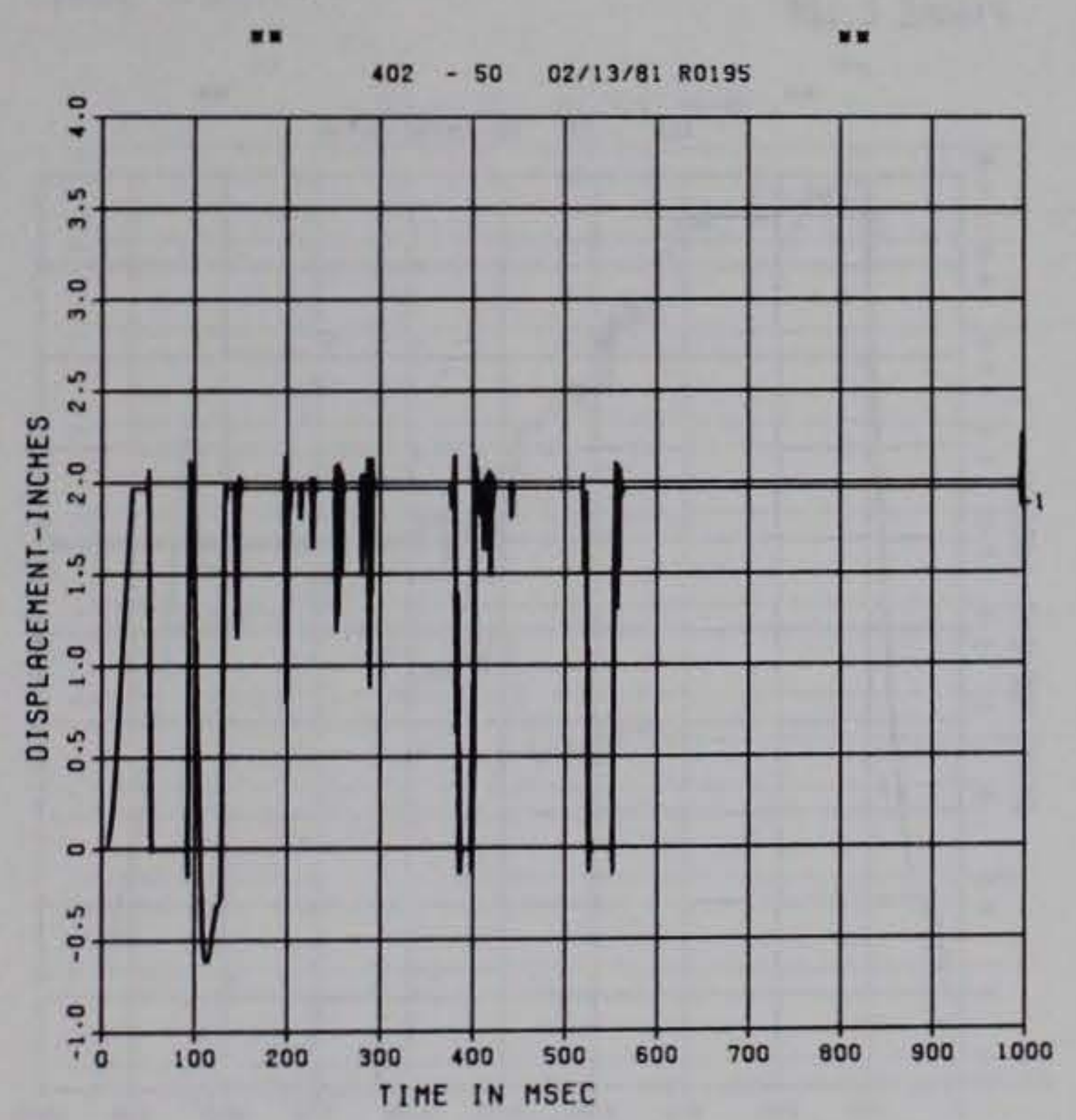

WAFFLE SLAB, DYN 2

$$
\text { D-5 }
$$

$10000 . \mathrm{HZ} \quad \mathrm{CAL}=4.300$

LP4 $70 \%$ CUTOFF $=450.0 \mathrm{~Hz}$

FIGURE C.122

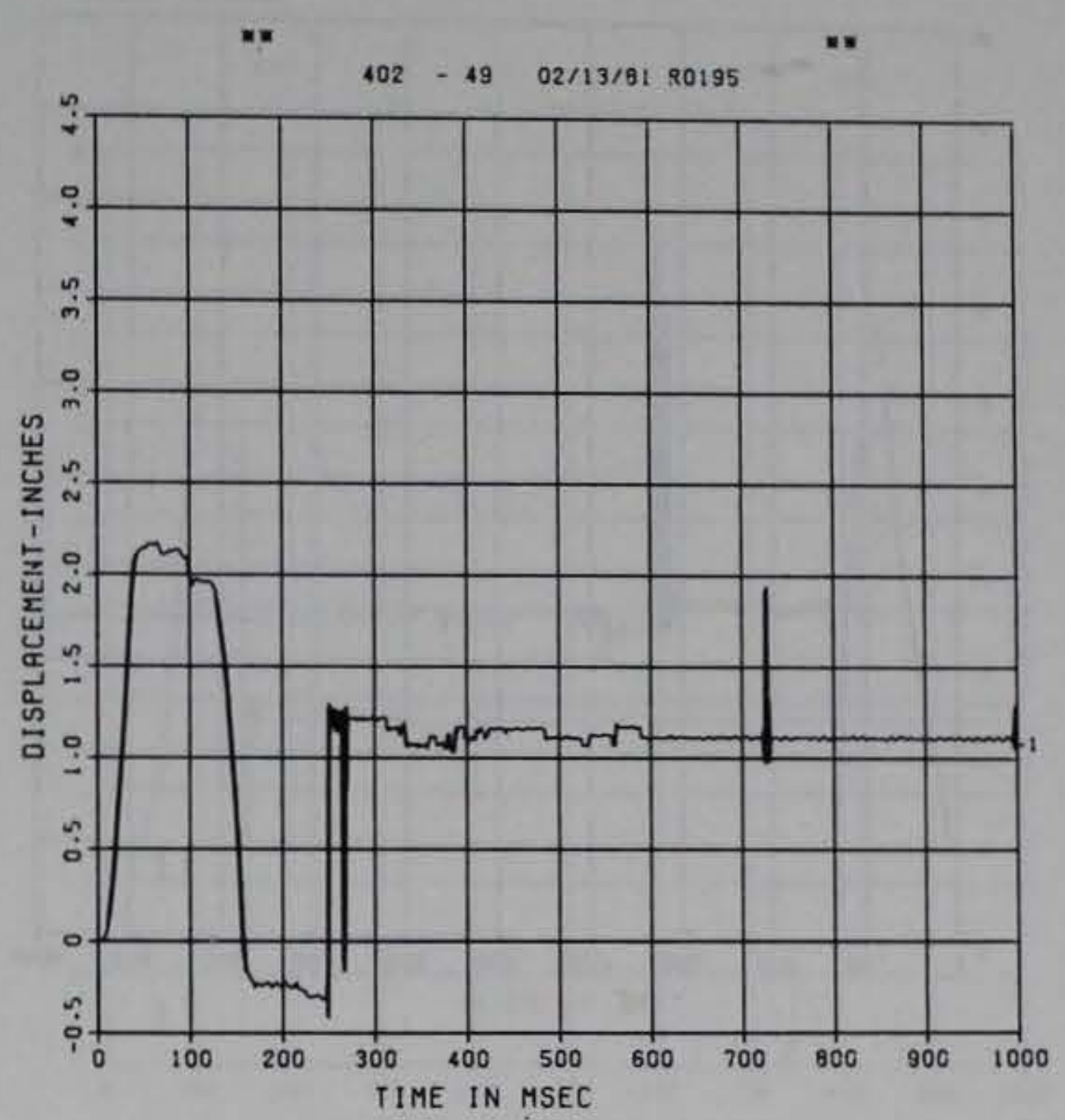

WAFFLE SLAB, DYN 2 D-7

10000. $\mathrm{HZ} \quad \mathrm{CAL}=6.300$

LP4 70\% CUTOFF $=450.0 \mathrm{HZ}$

FIGURE C. 124

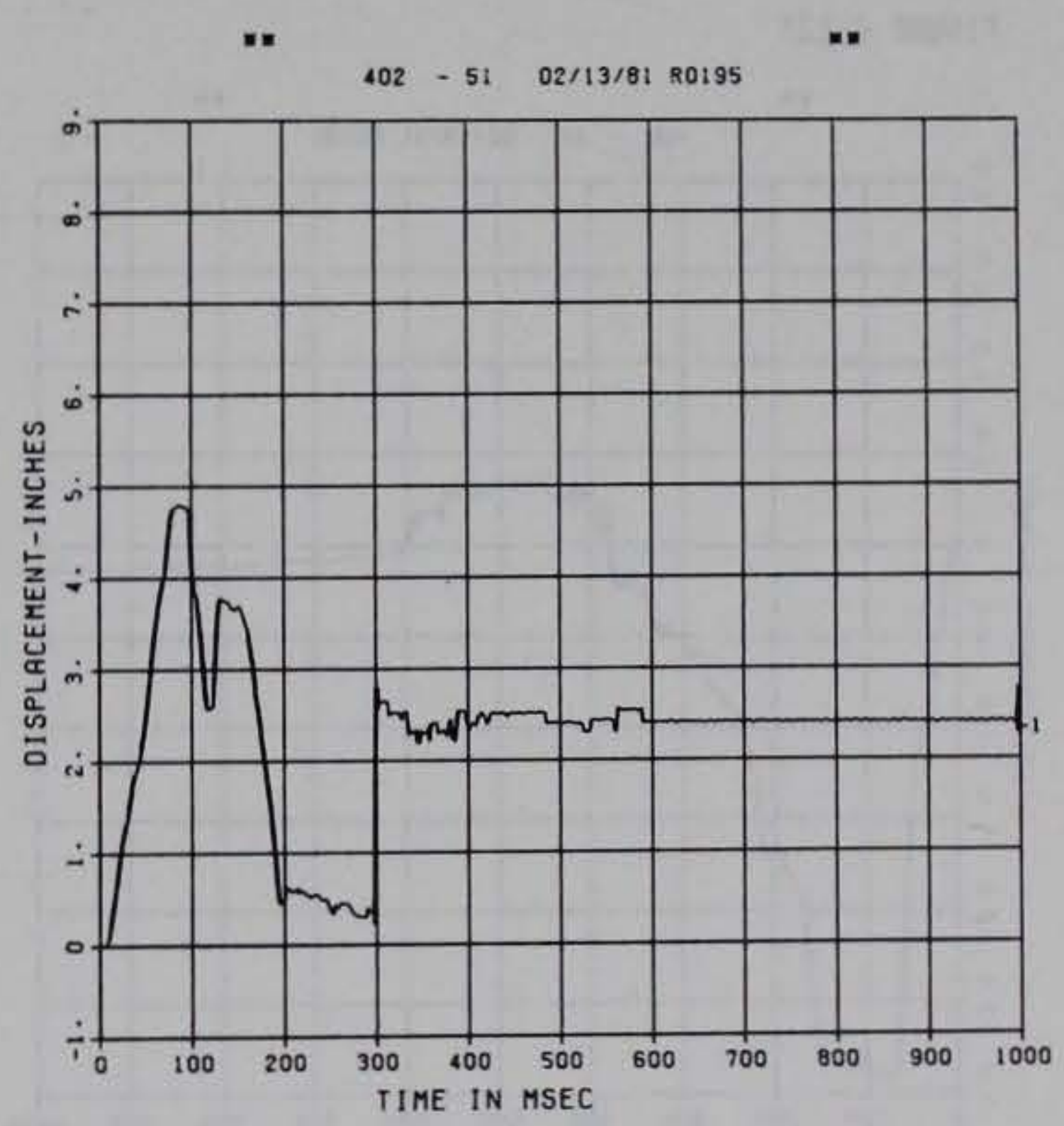


WAFFLE SLAB, DYN 2

$$
D-8
$$

10000. $\mathrm{HZ} \quad \mathrm{CAL}=6.300$ LP4 $70 \%$ CUTOFF $=450.0 \mathrm{HZ}$

FIGURE C. 125

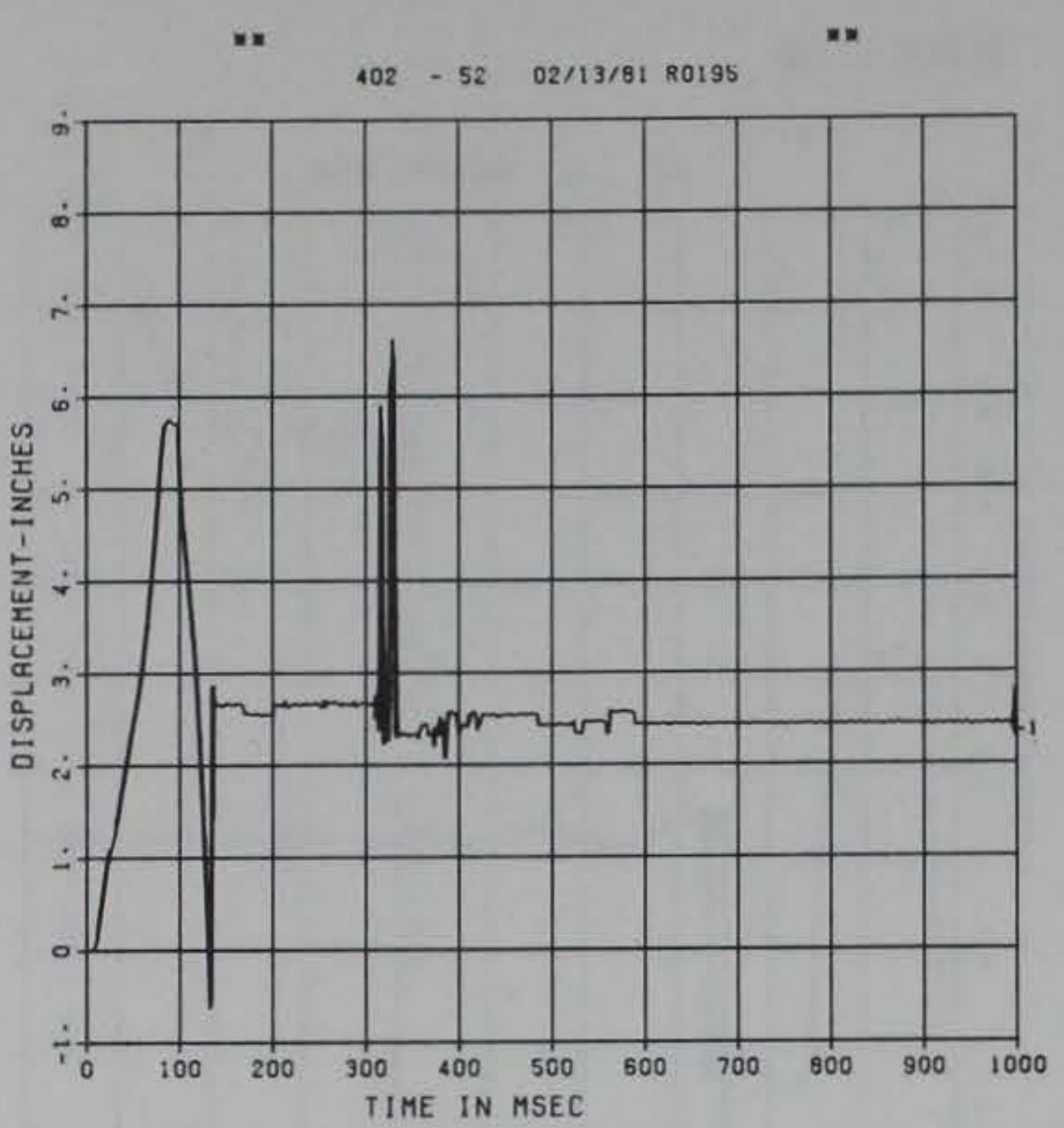

n. PEAK VALUE IS 5 \% OVER CALIBRATION $\ldots$

$$
\begin{gathered}
\text { WAFFLE SLAB, DYN } 2 \\
\text { D-10 } \\
\text { 10000. HZ CAL }=2.800
\end{gathered}
$$

LP4 70\% CUTOFF $=450.0 \mathrm{HZ}$

FIGURE C.127

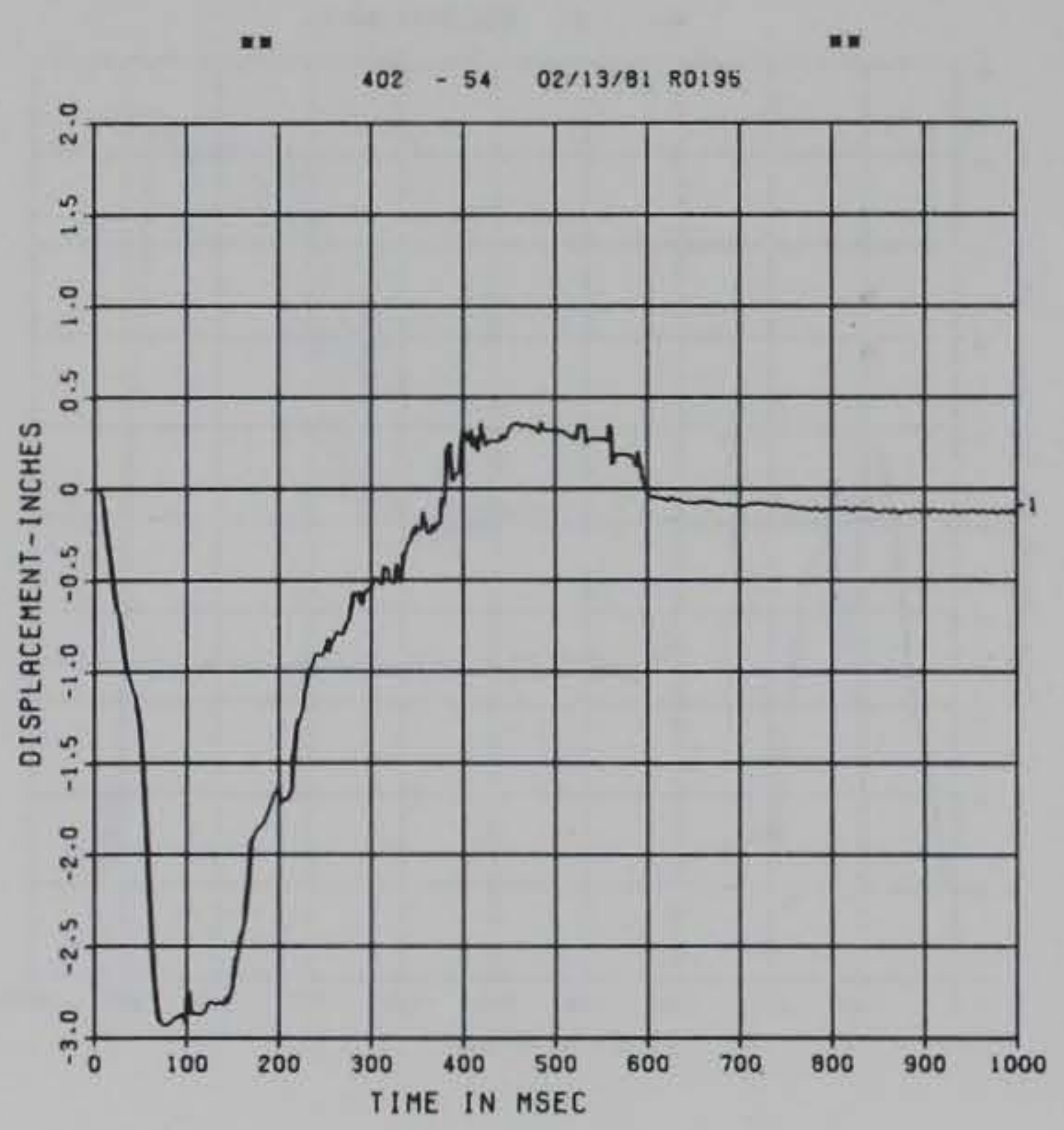

n* PEAK VALUE IS 5 \% OVER CALIBRATION \#
WAFFLE SLAB, DYN 2

$$
\text { D-9 }
$$

10000. $\mathrm{HZ} \quad \mathrm{CAL}=3.600$

LP4 $70 \%$ CUTOFF $=450.0 \mathrm{HZ}$

FIGURE C.126

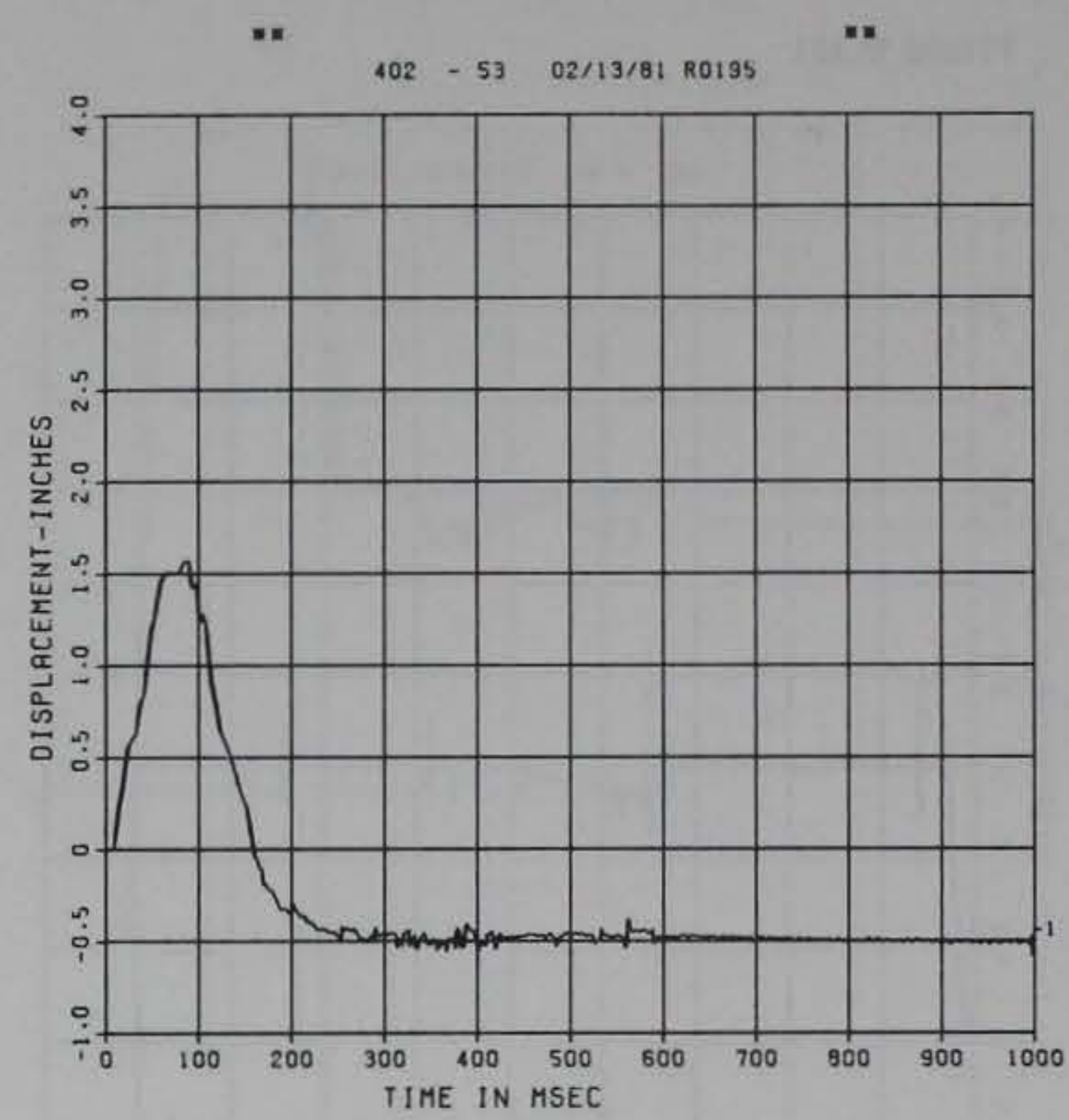

WAFFLE SLAB, DYN 2

$D-11$

10000. $\mathrm{HZ} \quad \mathrm{CAL}=4.300$

LP4 $70 \%$ CUTOFF $=450.0 \mathrm{HZ}$

FIGURE C. 128

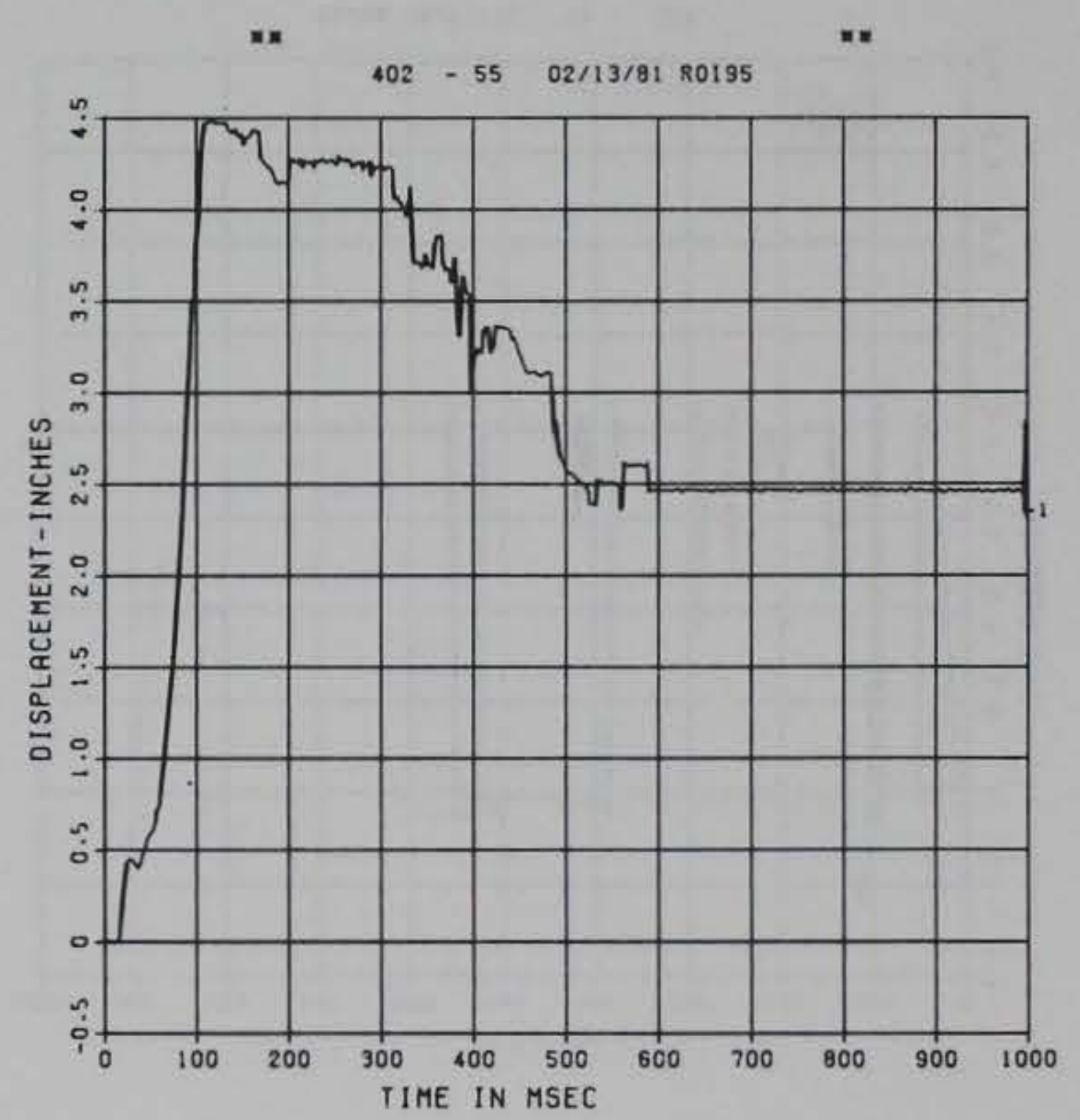

n. peak value is 4 x over calibration .. 
WAFFLE SLAB, DYN 2

10000. $\mathrm{HZ} \quad \mathrm{CAL}=6.300$

LP4 $70 \%$ CUTOFF $=450.0 \mathrm{HZ}$

FIGURE C. 129

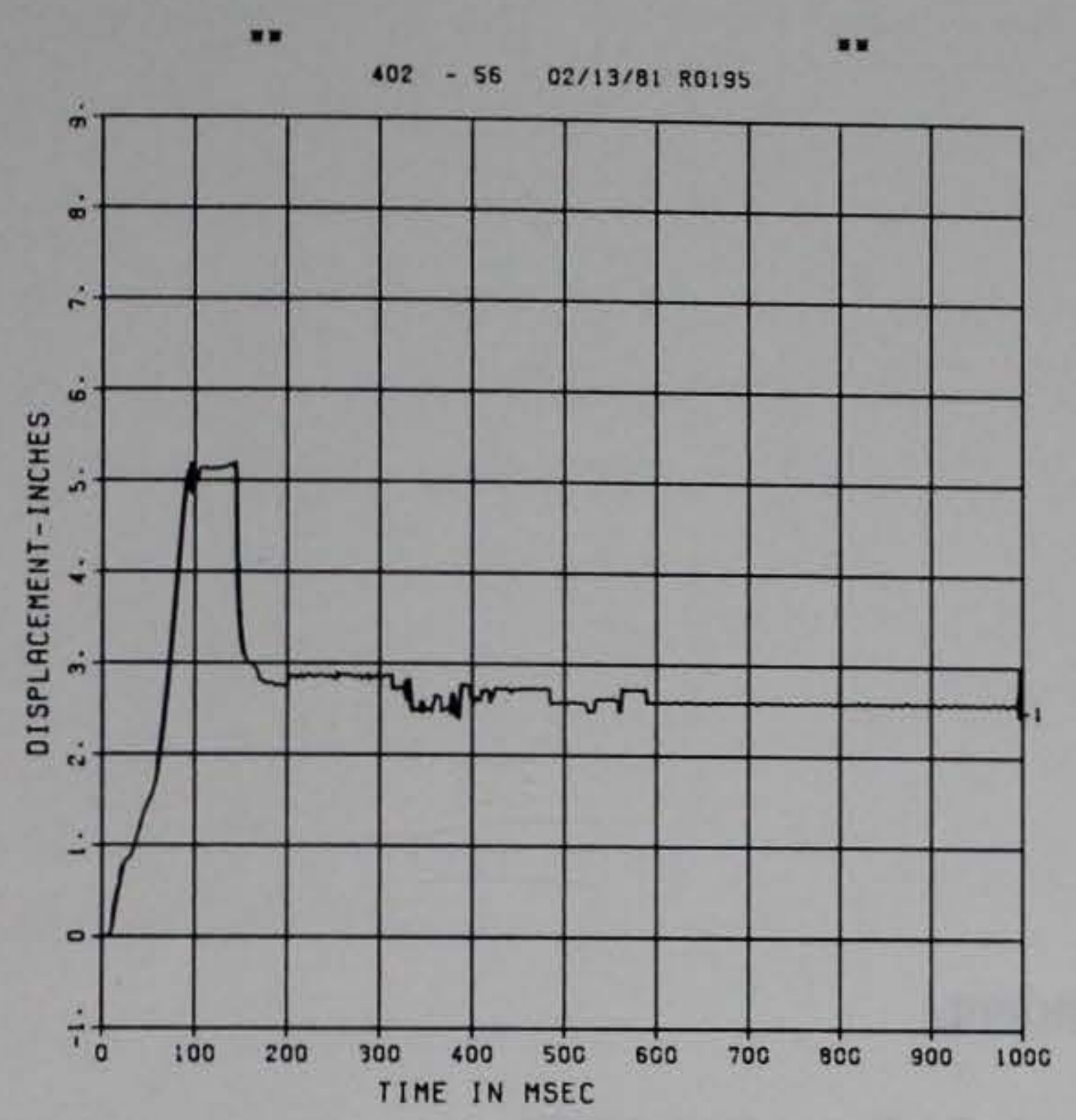

WAFFLE SLAB, DYN 2

$$
\text { D- } 14
$$

10000. $\mathrm{HZ} \quad \mathrm{CAL}=6.300$

LP4 $70 \%$ CUTOFF $=450.0 \mathrm{HZ}$

FIGURE C. 131

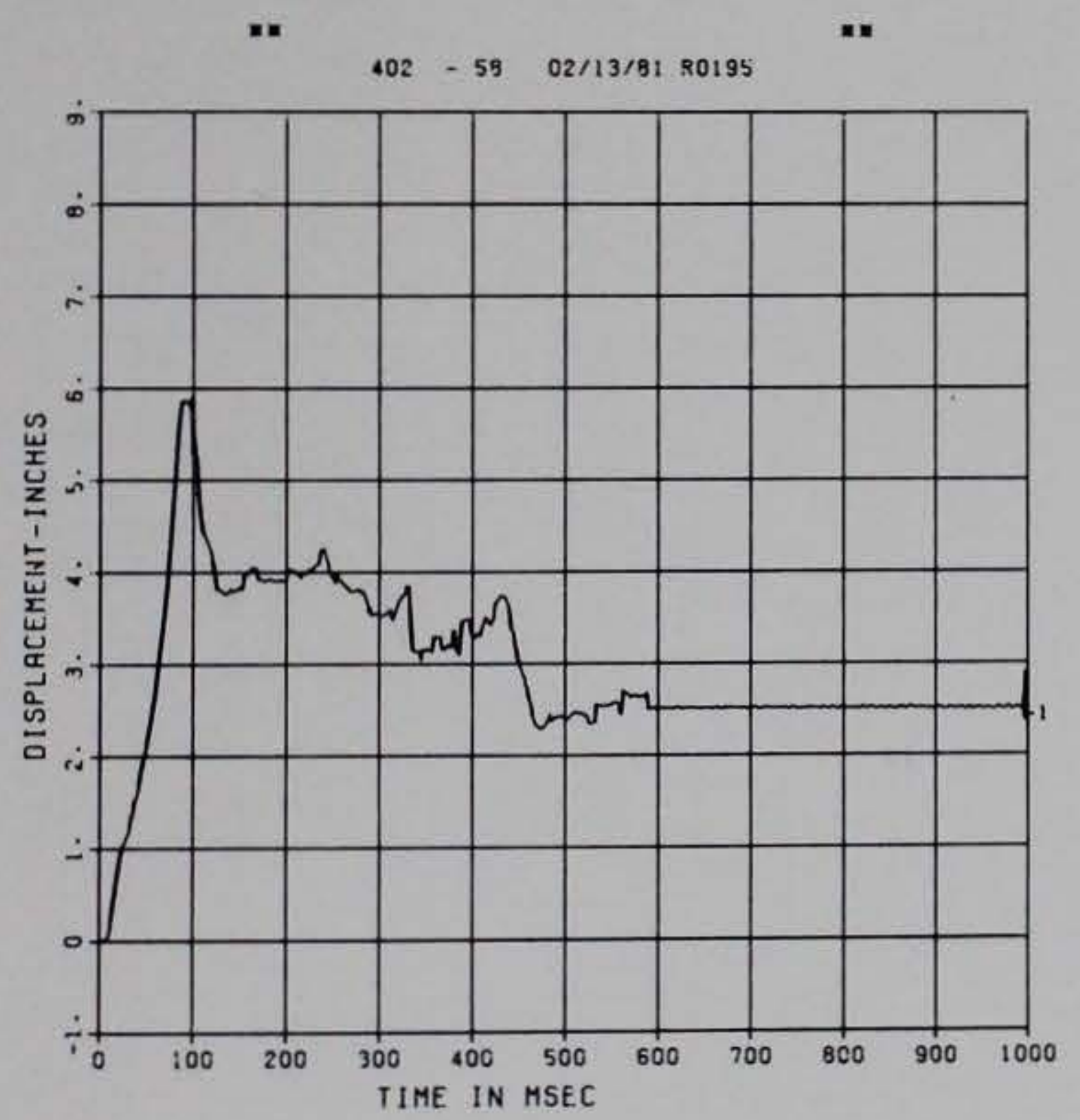

WAFFLE SLAB, DYN 2

$$
D-13
$$

10000. HZ CAL $=6.200$

LP4 $70 \%$ CUTOFF $=450.0 \mathrm{HZ}$

FIGURE C. 130

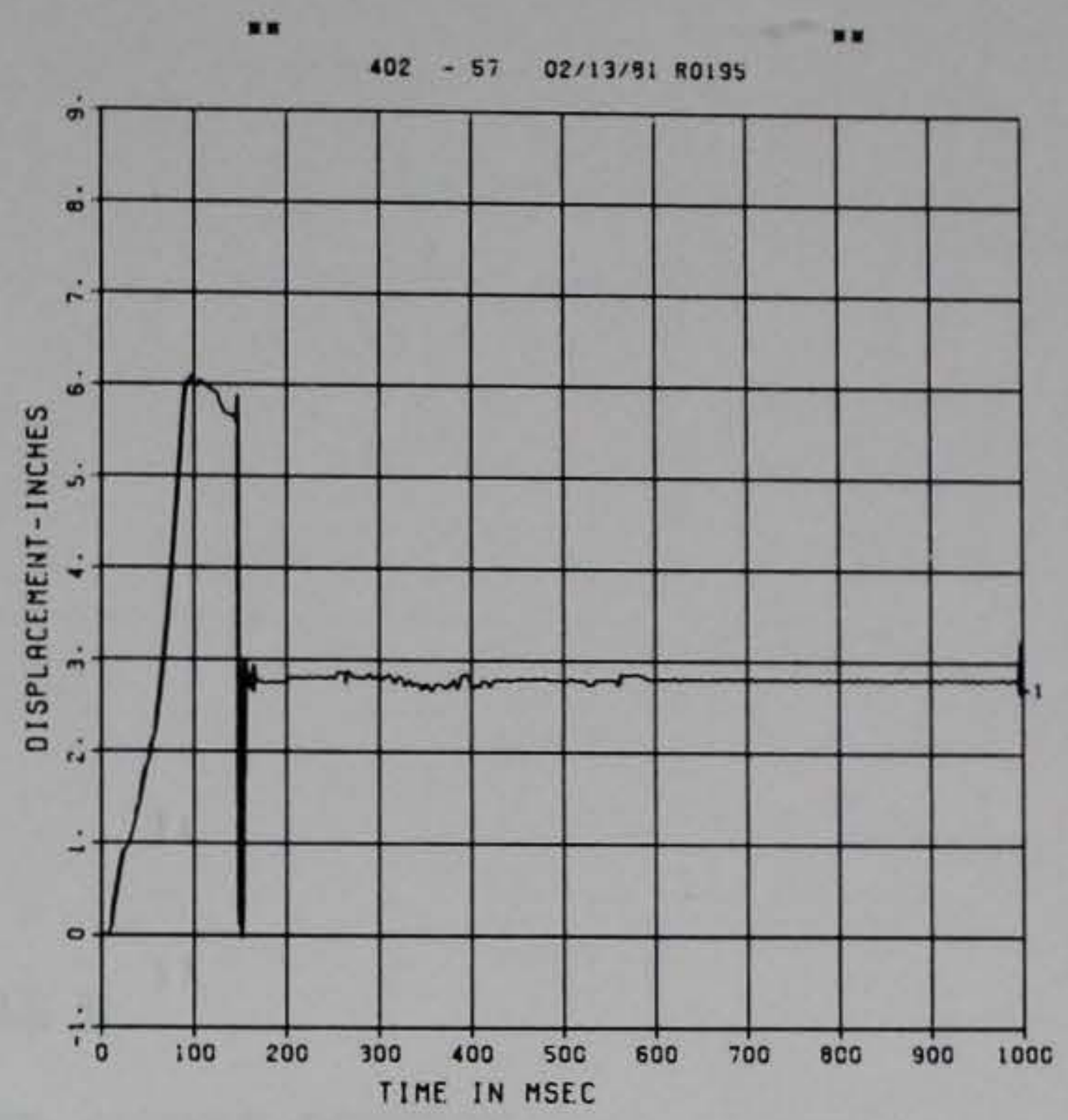


APPENDIX D

TEST DATA, FLAT PLATE CENTER PORTION 
Data from the tests on the flat plate center portion are presented in this appendix. Labels on the plots indicate the following:

Line 1: Test name

Line 2: Gage symbol

Line 3: Maximum value and calibration curve

Line 4: Filter (if any)

Lines 5 and 6: Bookkeeping data. 


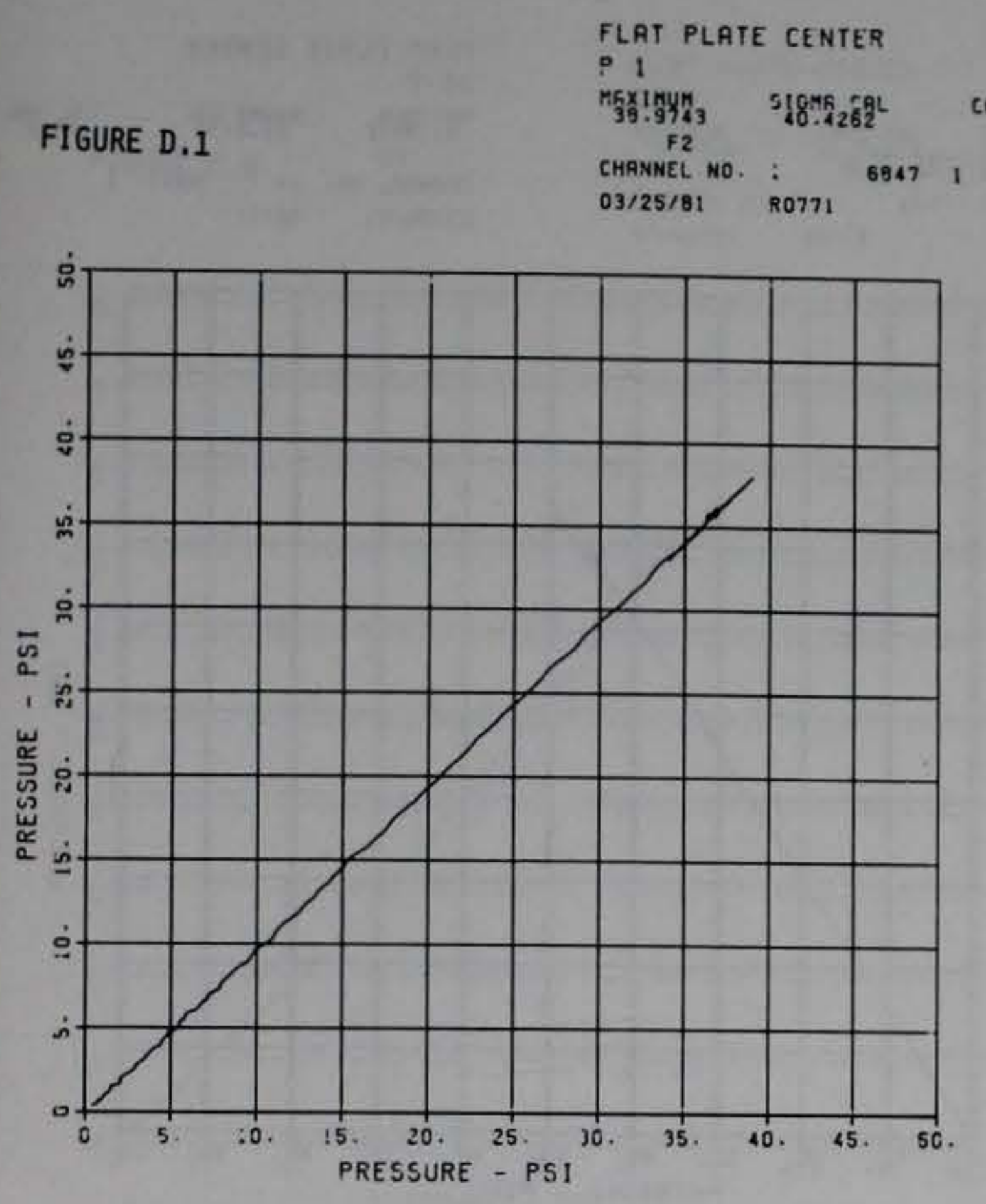

FLAT PLATE CENTER

$L-1$

FIGURE D.2

FLAT PLATE CENTER

$P-2$

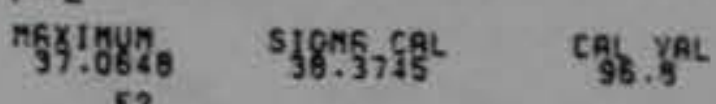

СHAN⿴囗2 NO = $6967 \quad 1$

$03 / 25 / 81 \quad 80771$

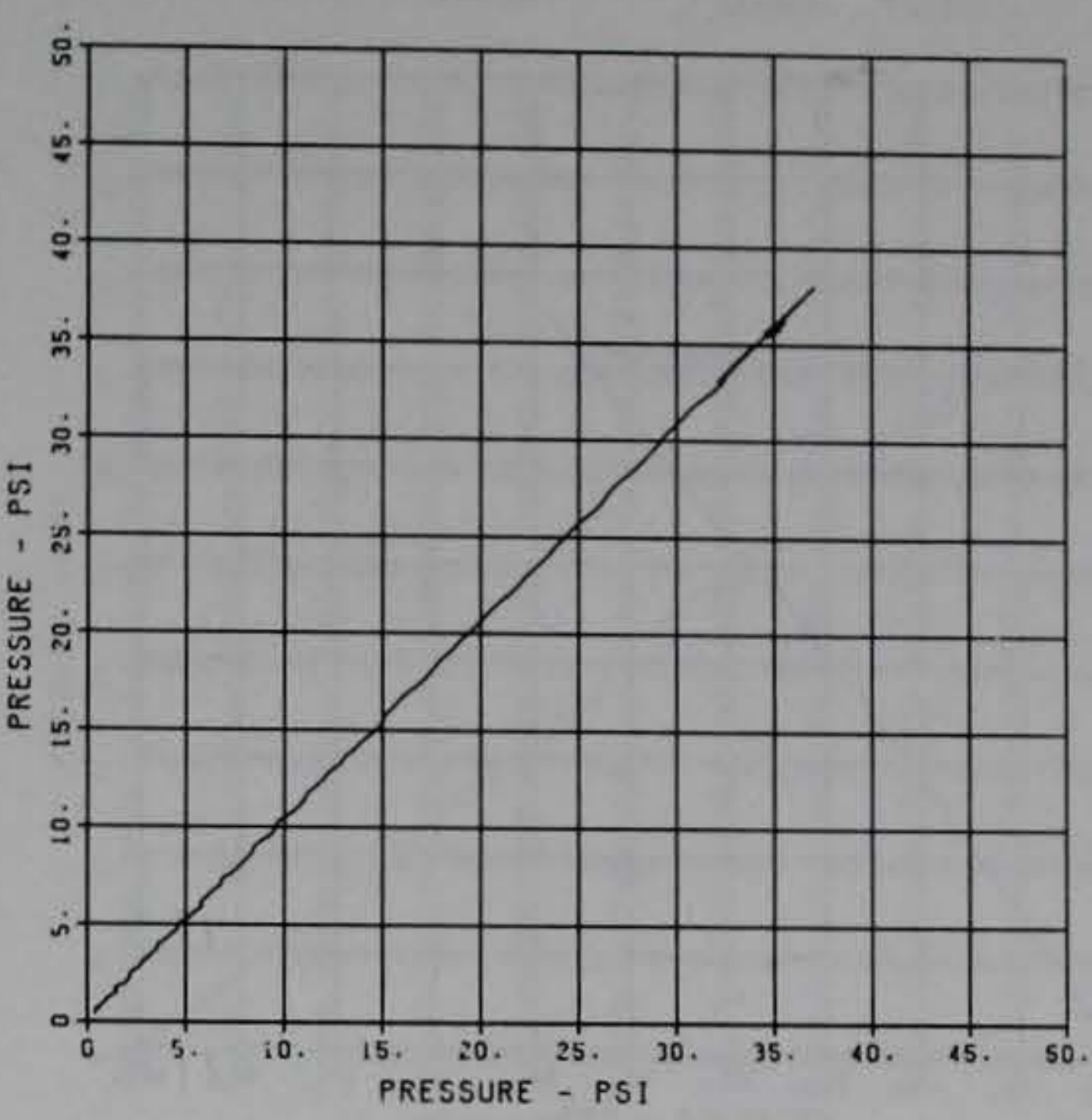

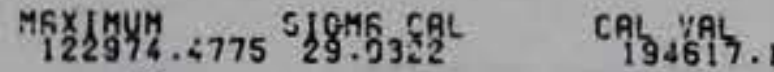

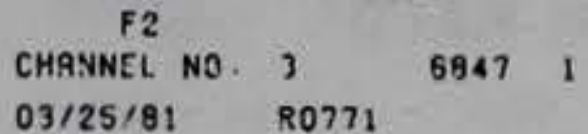

FIGURE D.4

FLAT PLATE CENTER

$L-2$

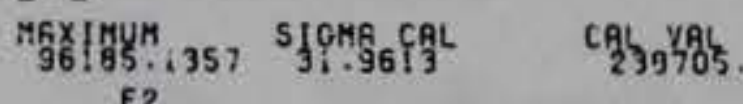

FIGURE D.3

CHANNEL NO. 4 6847 ।

$03 / 25 / 81 \quad R 0771$
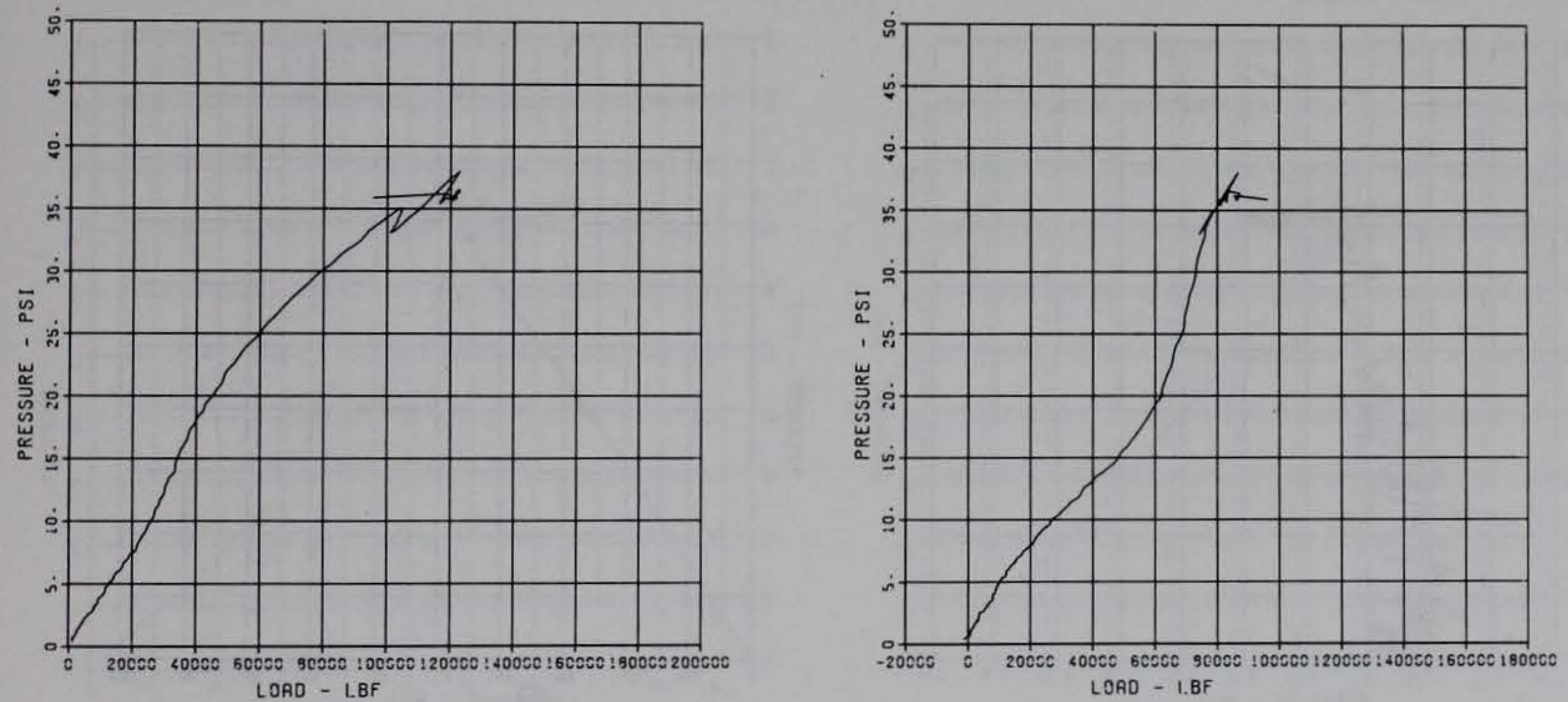


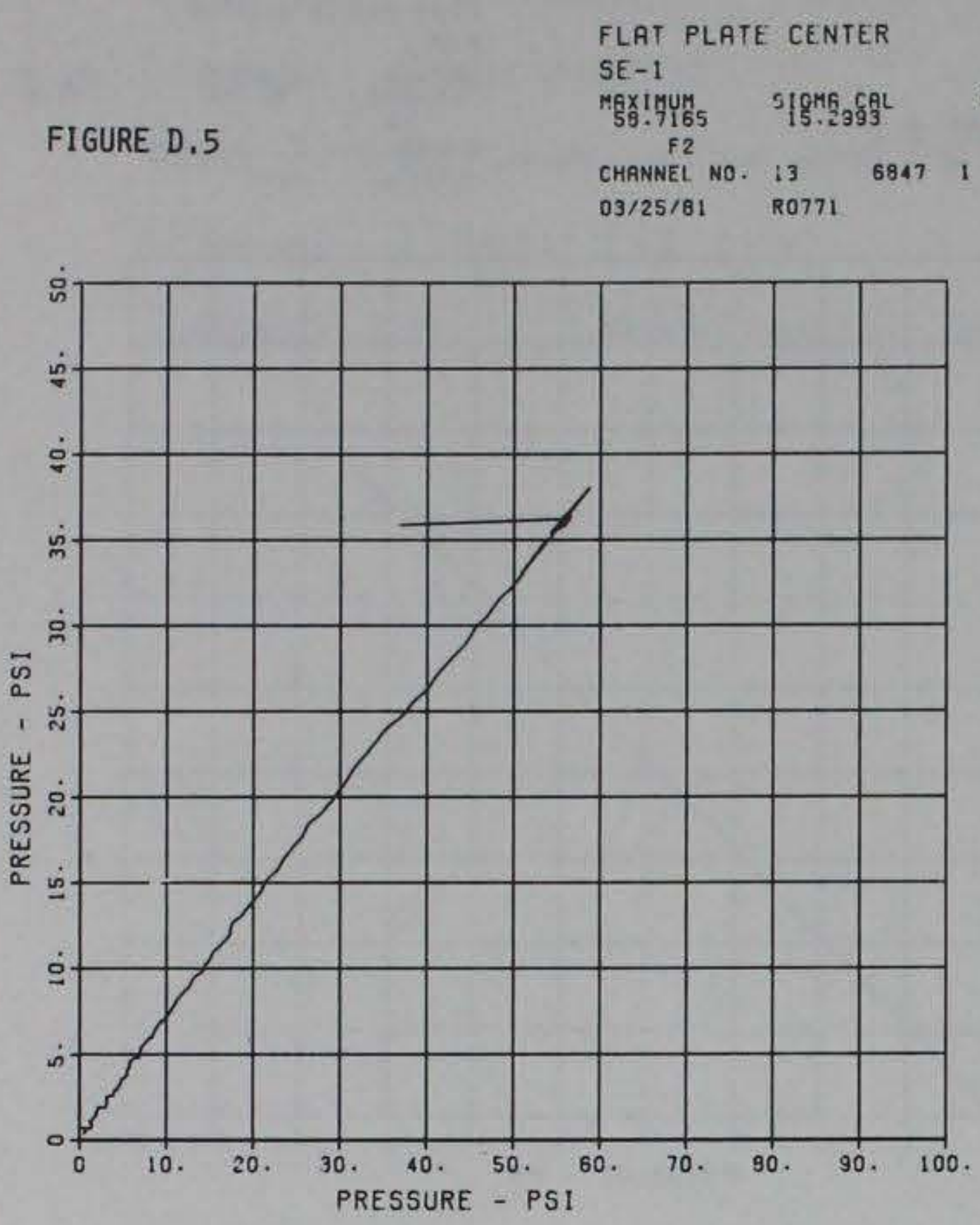

FIGURE D.6

FLAT PLATE CENTER

SE-2

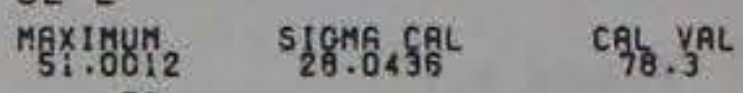

$\begin{array}{llll}\text { F2 } 2 & \\ \text { CHANNEL NO. I4 } 6847 & 1\end{array}$

03/25/81 RO771

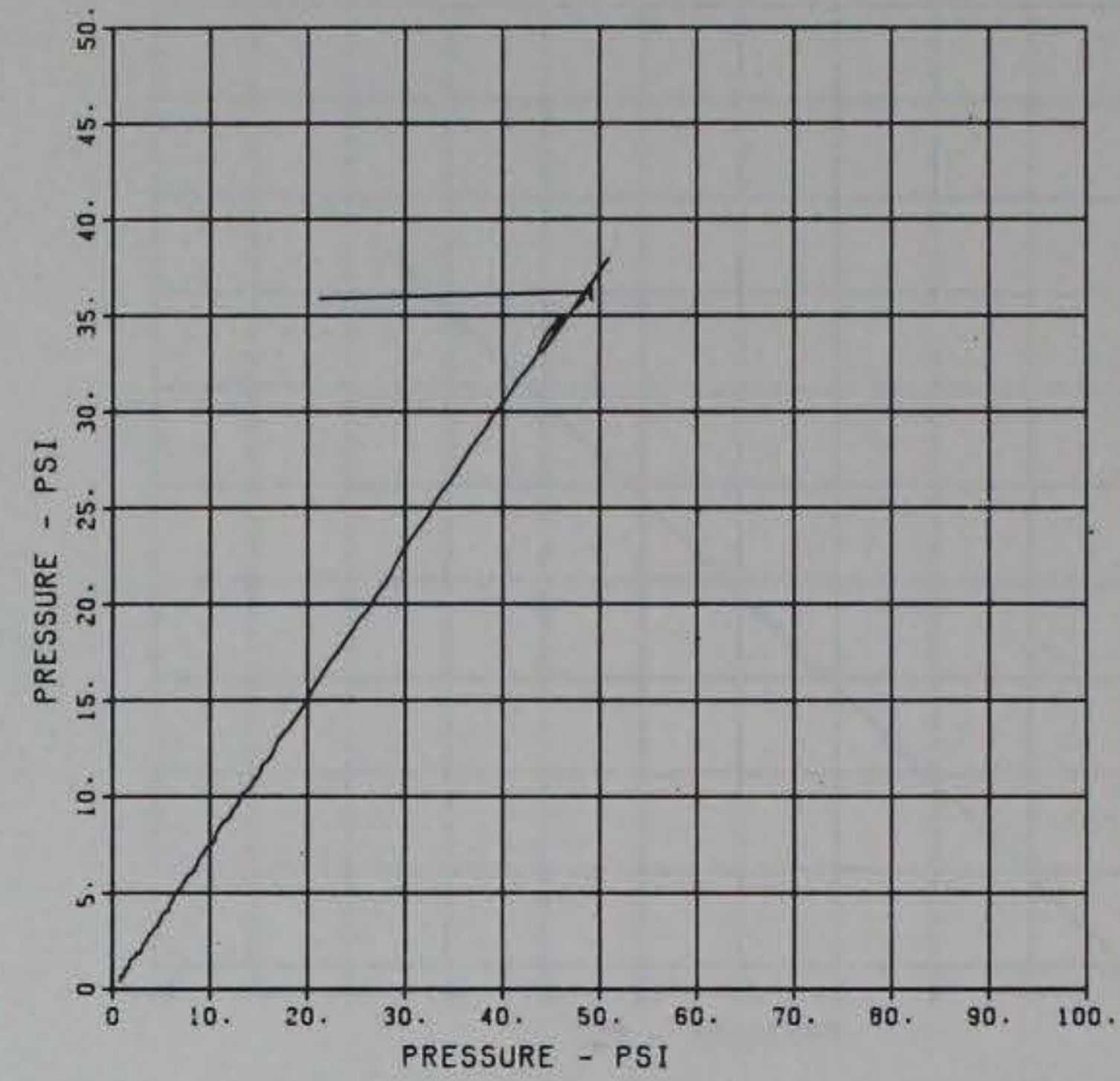

FLAT PLATE CENTER

SE-3

FIGURE D.7

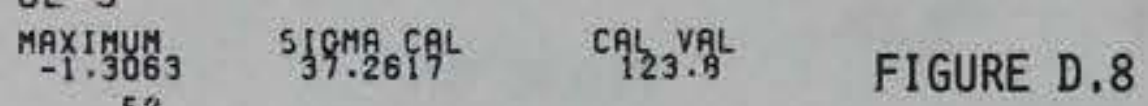

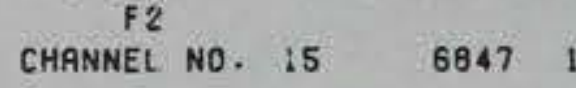

FLAT PLATE CENTER

SE-4

MAXIMUM SIOMG CAL C

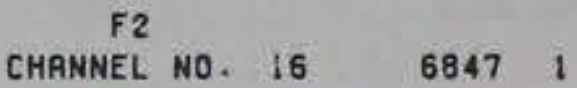

03/25/81 R0771

03/25/81 R0771.
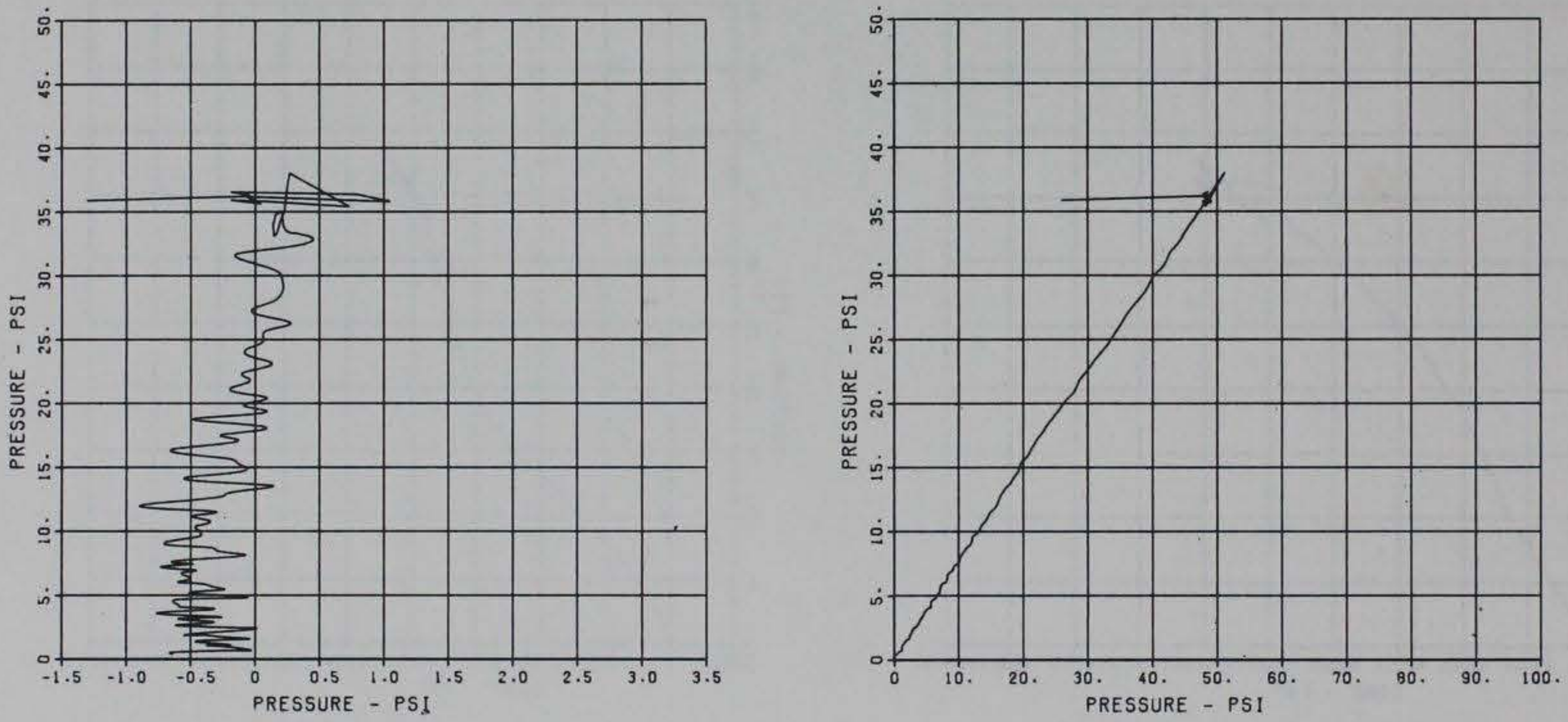


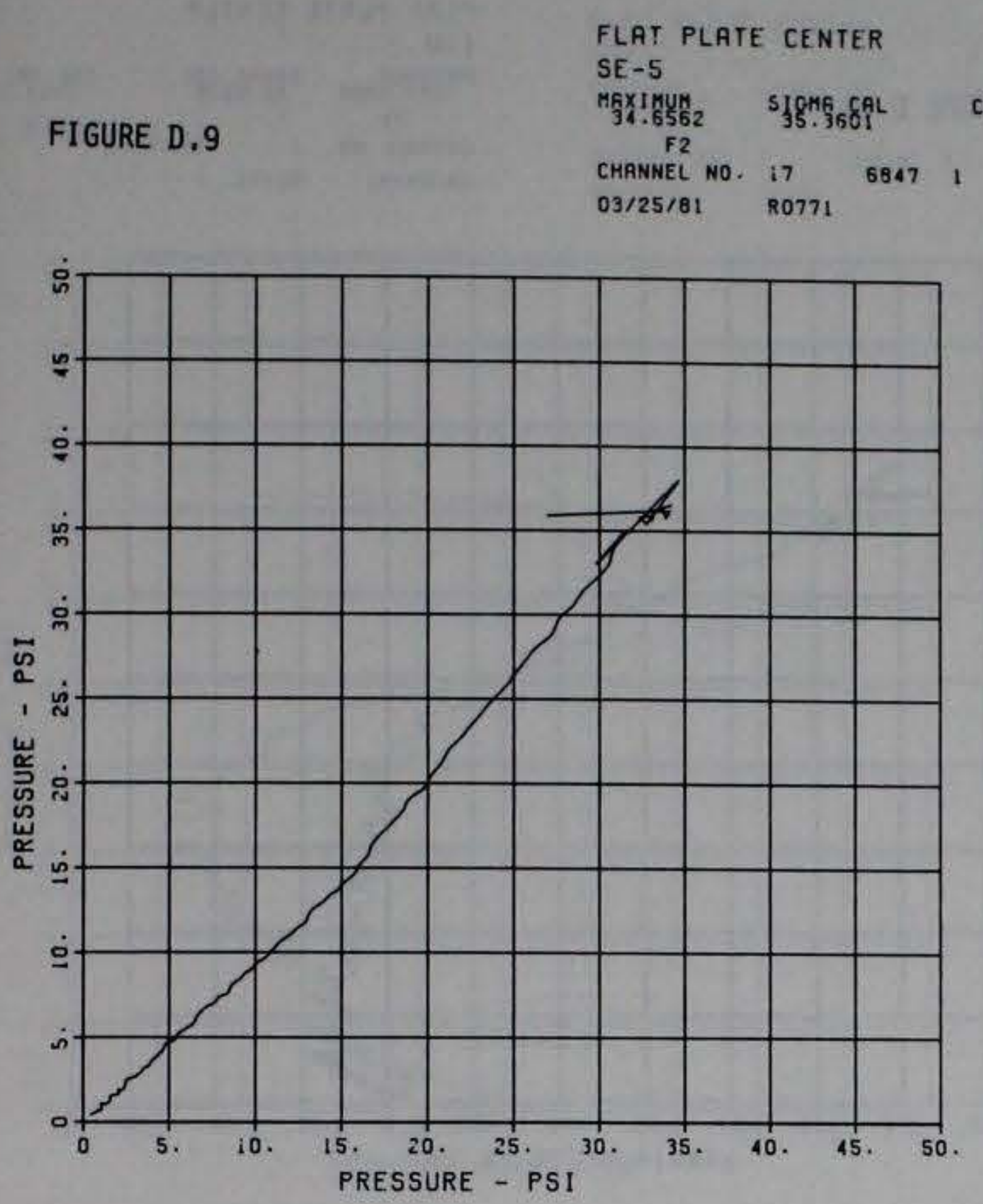

FLAT PLATE CENTER

SE -7

MGXIMUM S1GHG CRL CAL YAL

CHANNEL NO. $19 \quad 6847 \quad 1$

03/25/81 R0771

FIGURE D.10

FLAT PLATE CENTER

SE -6

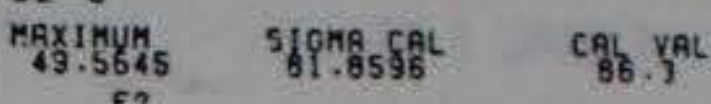

CHANNEL NO. IO 694?

03/25/81 RO771.

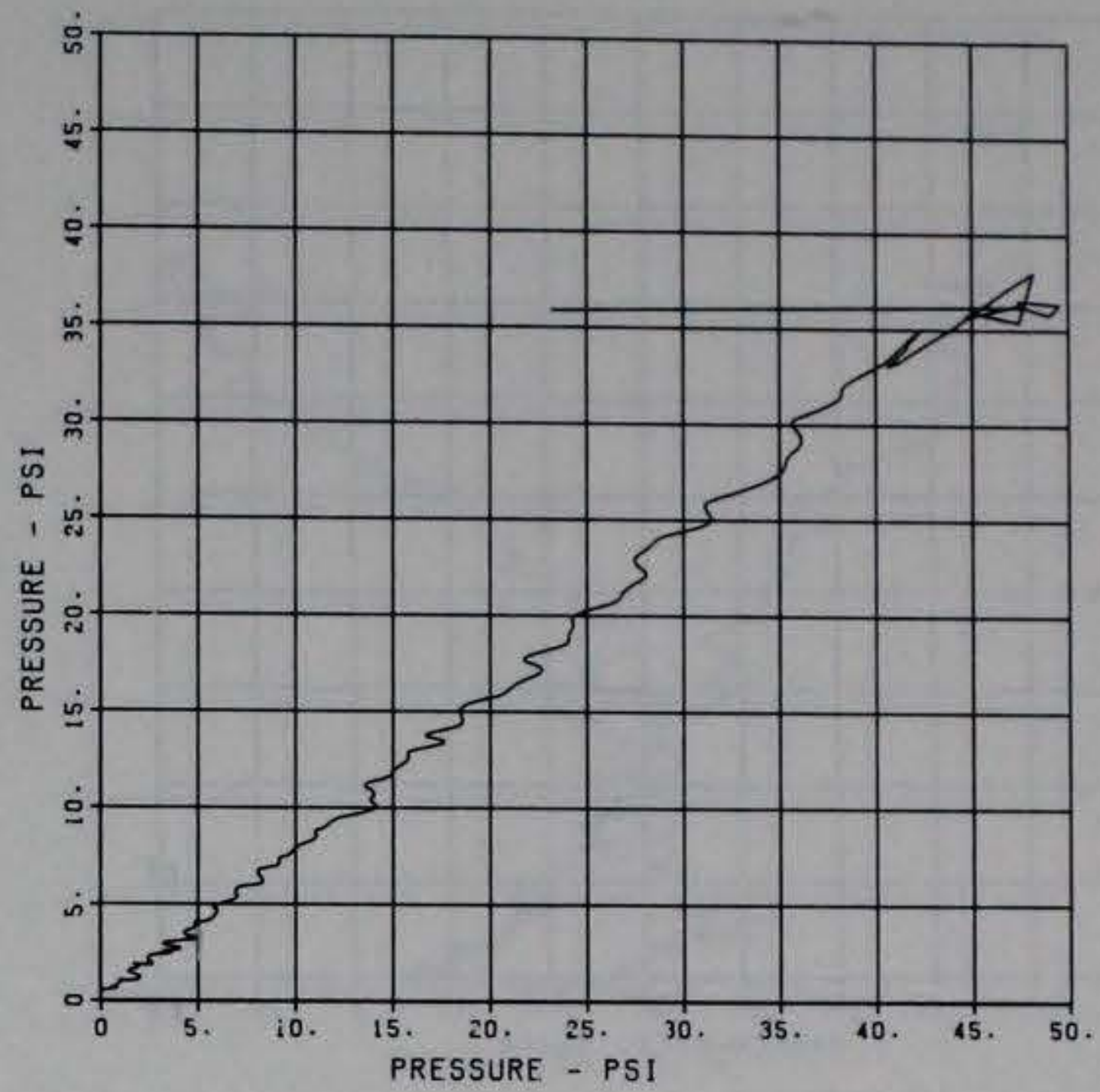

FIGURE D.11

FIGURE D.12

FLAT PLATE CENTER

SE - 8
MGXINUM SIOMG CAL CAL VAL
36.1528

$\begin{array}{cll}\text { F2 } & \\ \text { CHANNEL NO. } 20 \quad 6847 & 1\end{array}$

03/25/81 R0771
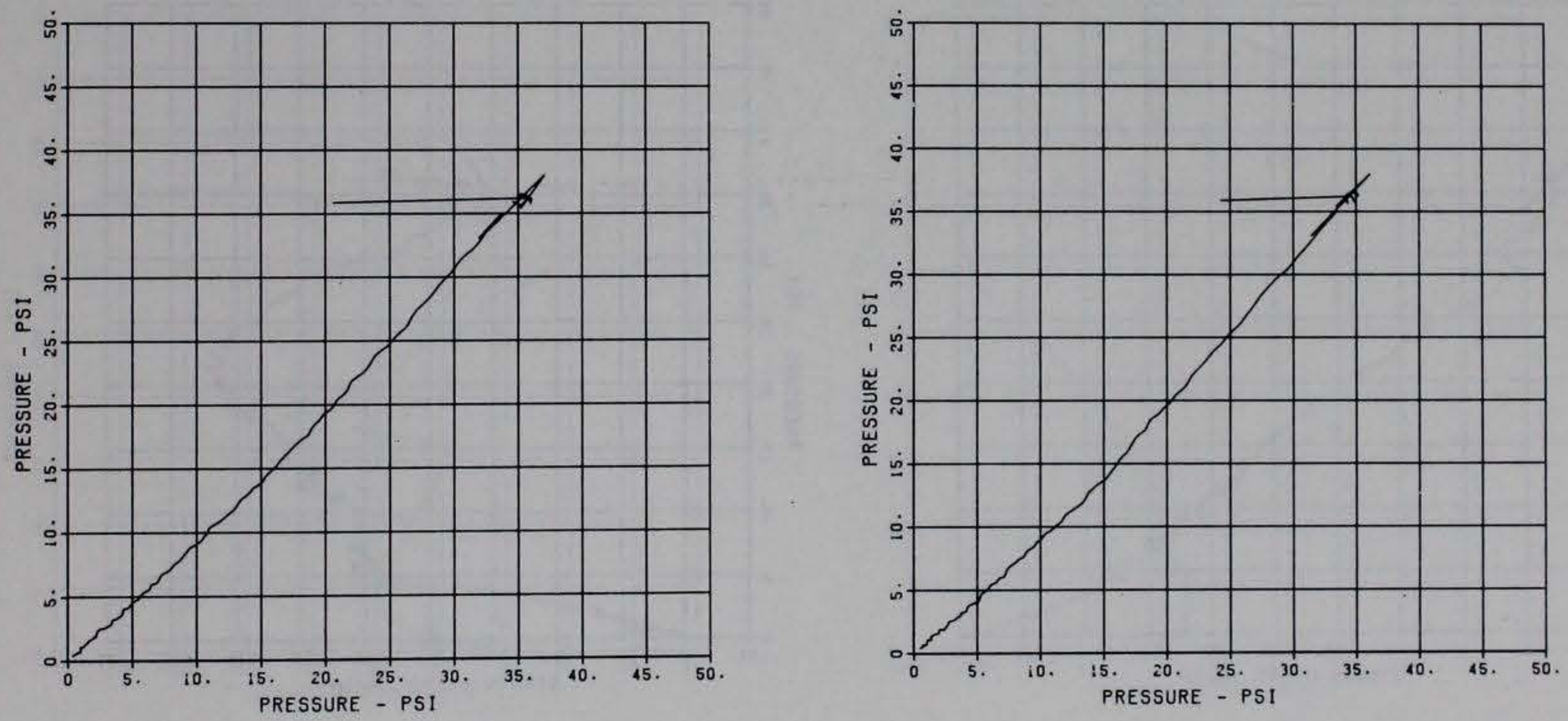
FLAT PLATE CENTER

MAXIMUM
-10.2165
SIGMG GQL

FIGURE D.13 $\begin{array}{cll}\text { F2 } 2 & \\ \text { CHANNEL NO. } 3 & 6847 \quad 2\end{array}$

03/25/81 R0771

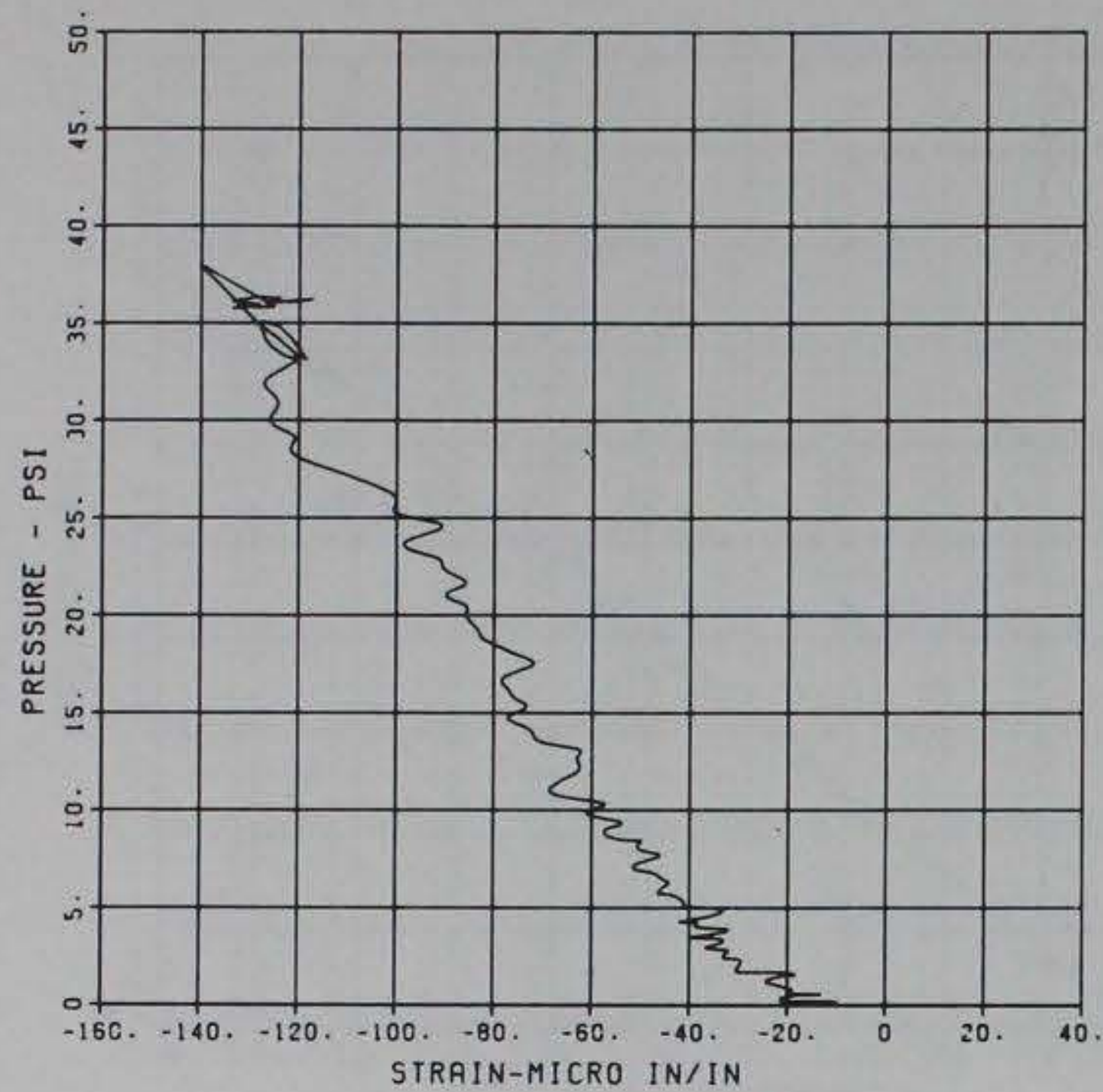

FLAT PLATE CENTER

E2T

MAXIMUM
-199.0348

FIGURE D.15

$\begin{array}{ccc}\text { F2 } & \\ \text { CHANNEL NO. } 5 & 6847 \quad 2\end{array}$

03/25/81 R0771

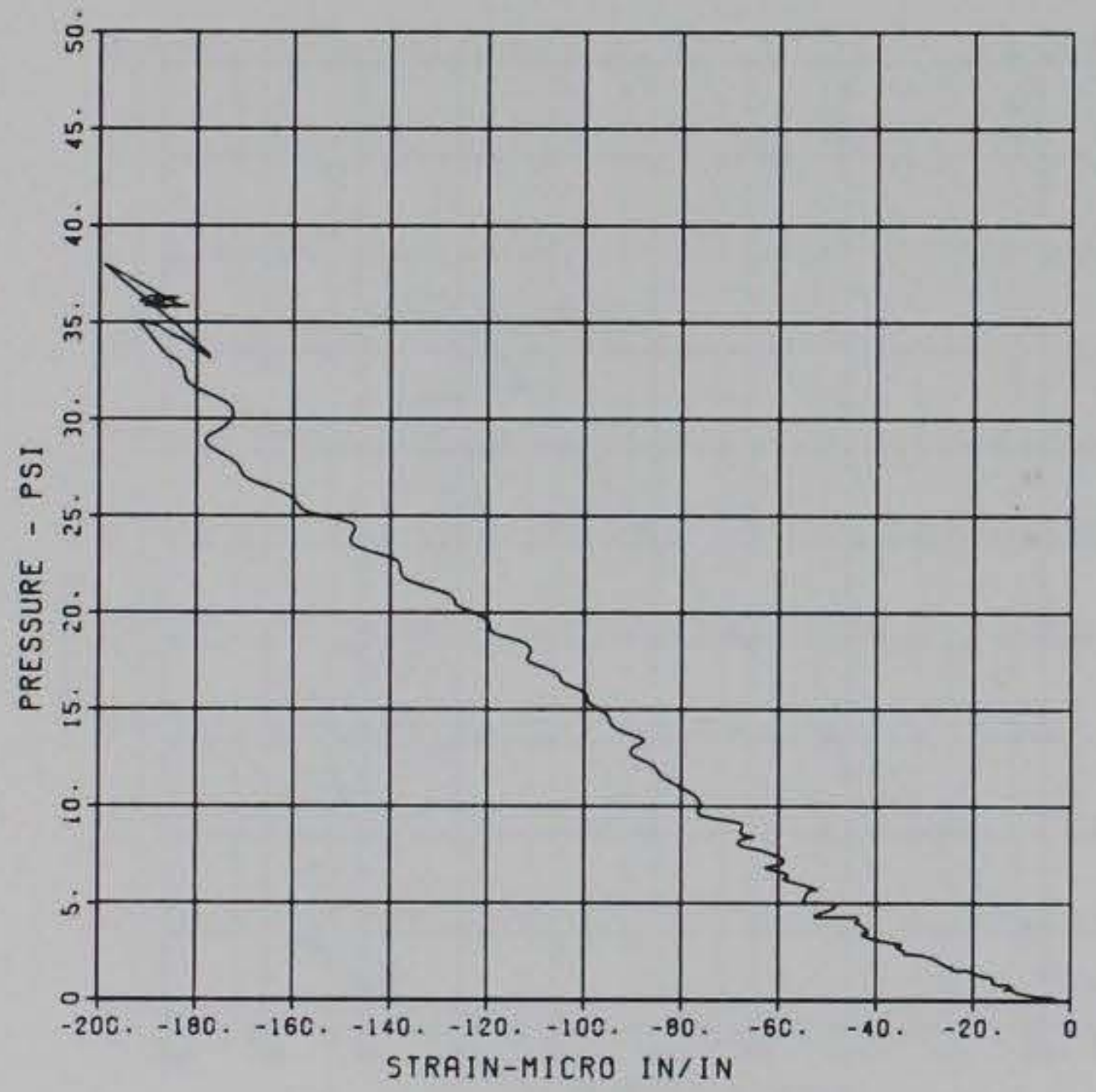

FLAT PLATE CENTER

\begin{tabular}{l} 
MRXIMUM \\
$-127.5350 \quad$ S18MA CER \\
\hline 8.6535
\end{tabular}

CHANMEL NO. 4 6847 2

03/25/81 RO271

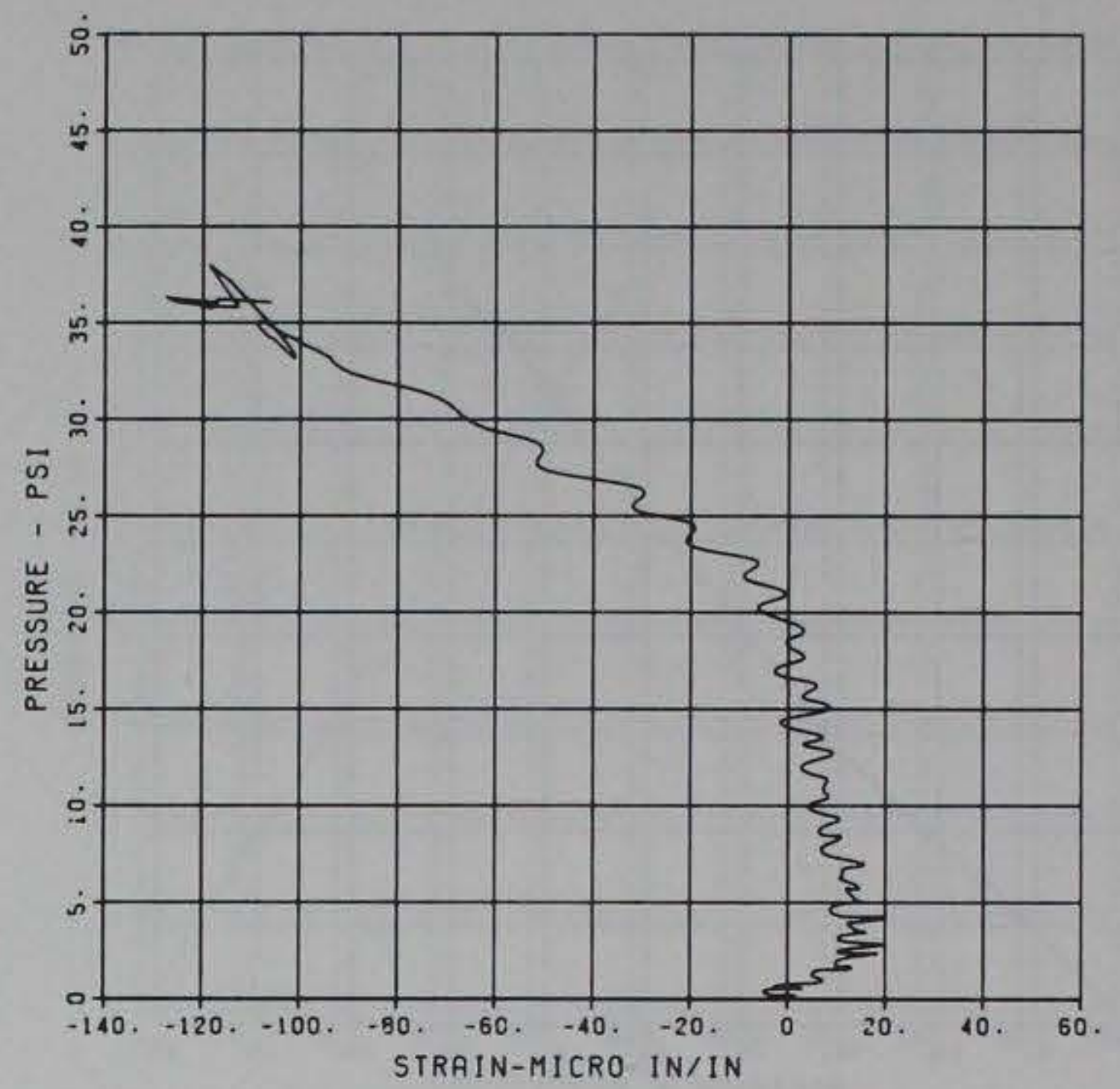

FLAT PLATE CENTER

E2 $B$

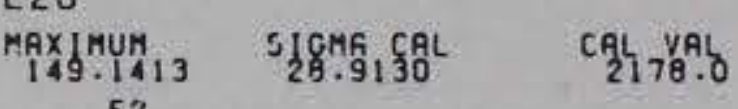

CHANNEL. NO. $6 \quad 6847 \quad 2$

03/25/81 R0771

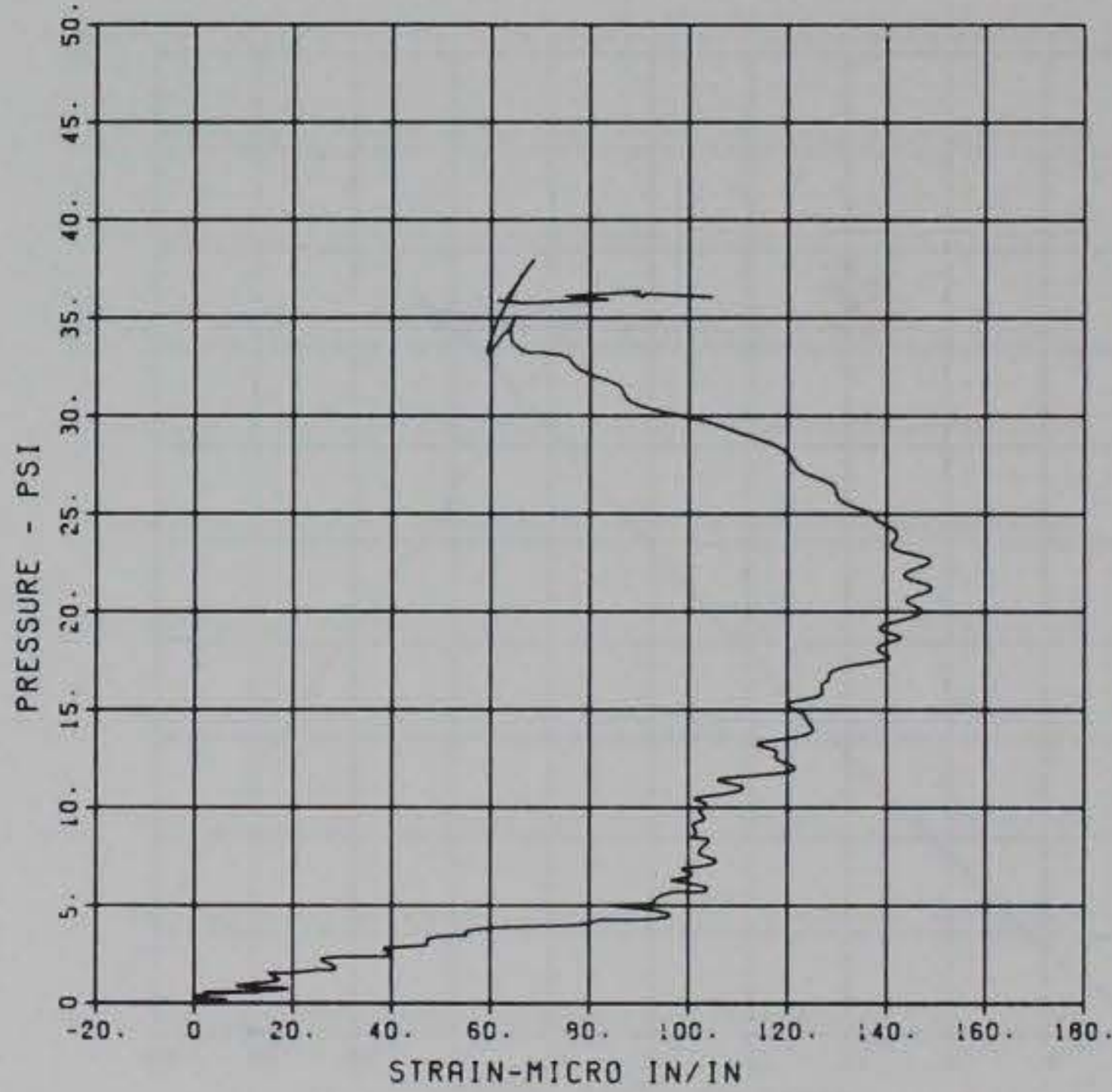



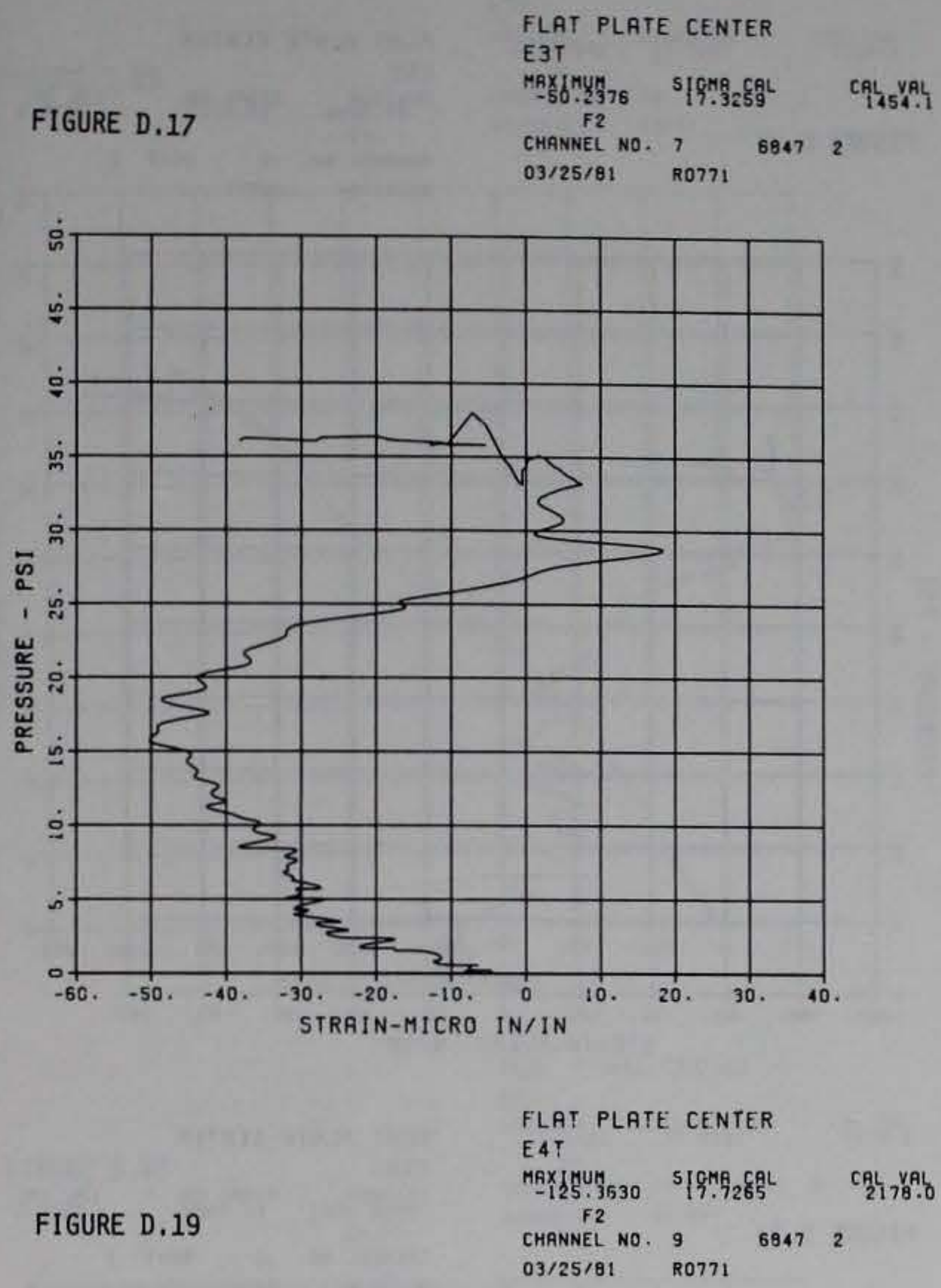

FIGURE D. 20

FLAT PLATE CENTER

E3B

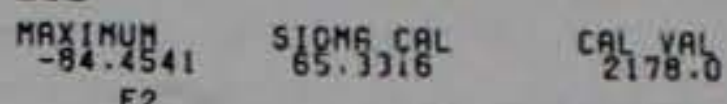

CHANNEL NO. a 69472

03/25/81 R0771

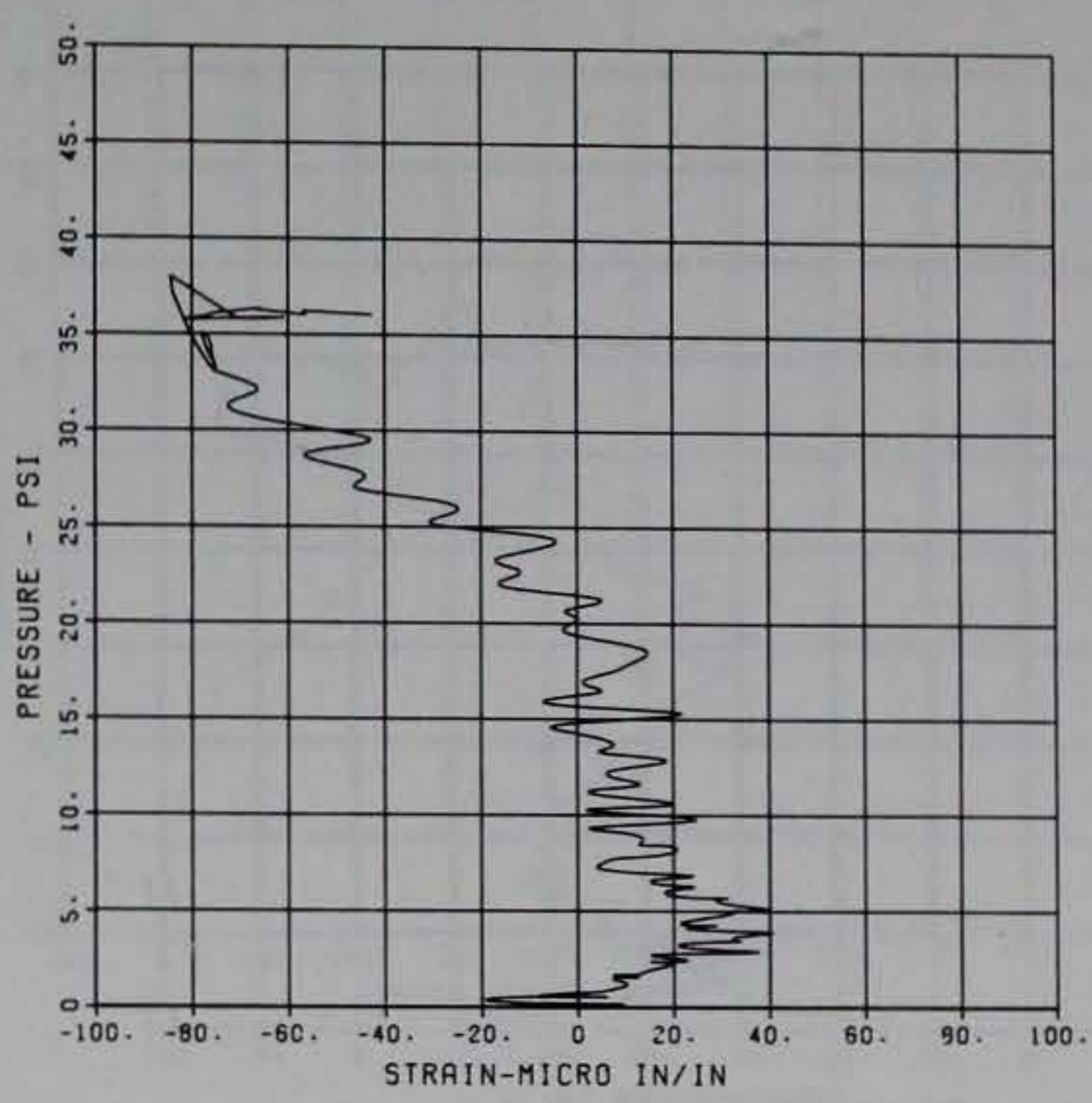

FLAT PLATE CENTER

E4B

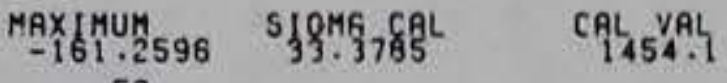

$\begin{array}{llll}\text { CHANNEL NO. } & 10 & 6847 & 2 \\ 03 / 25 / 81 & \text { R0771 } & & \end{array}$
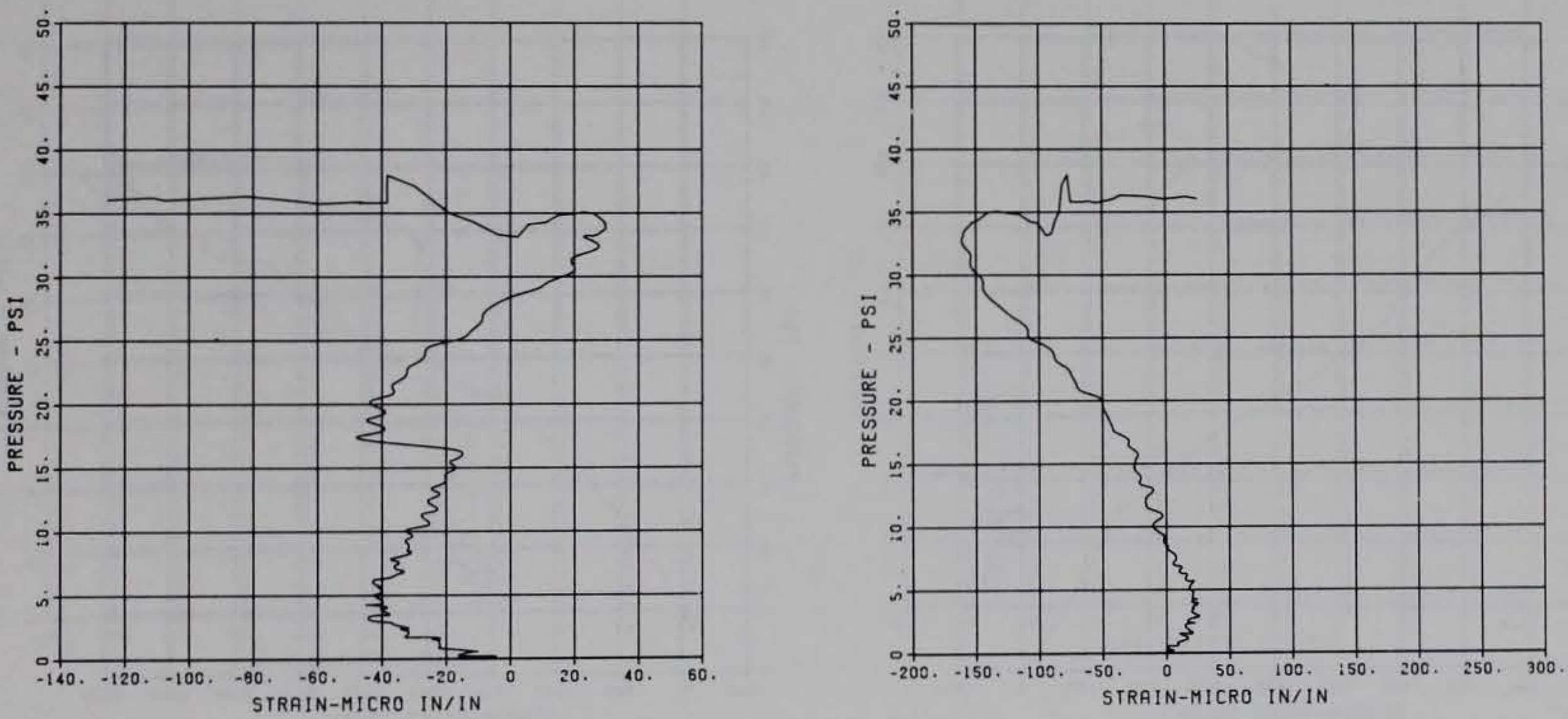

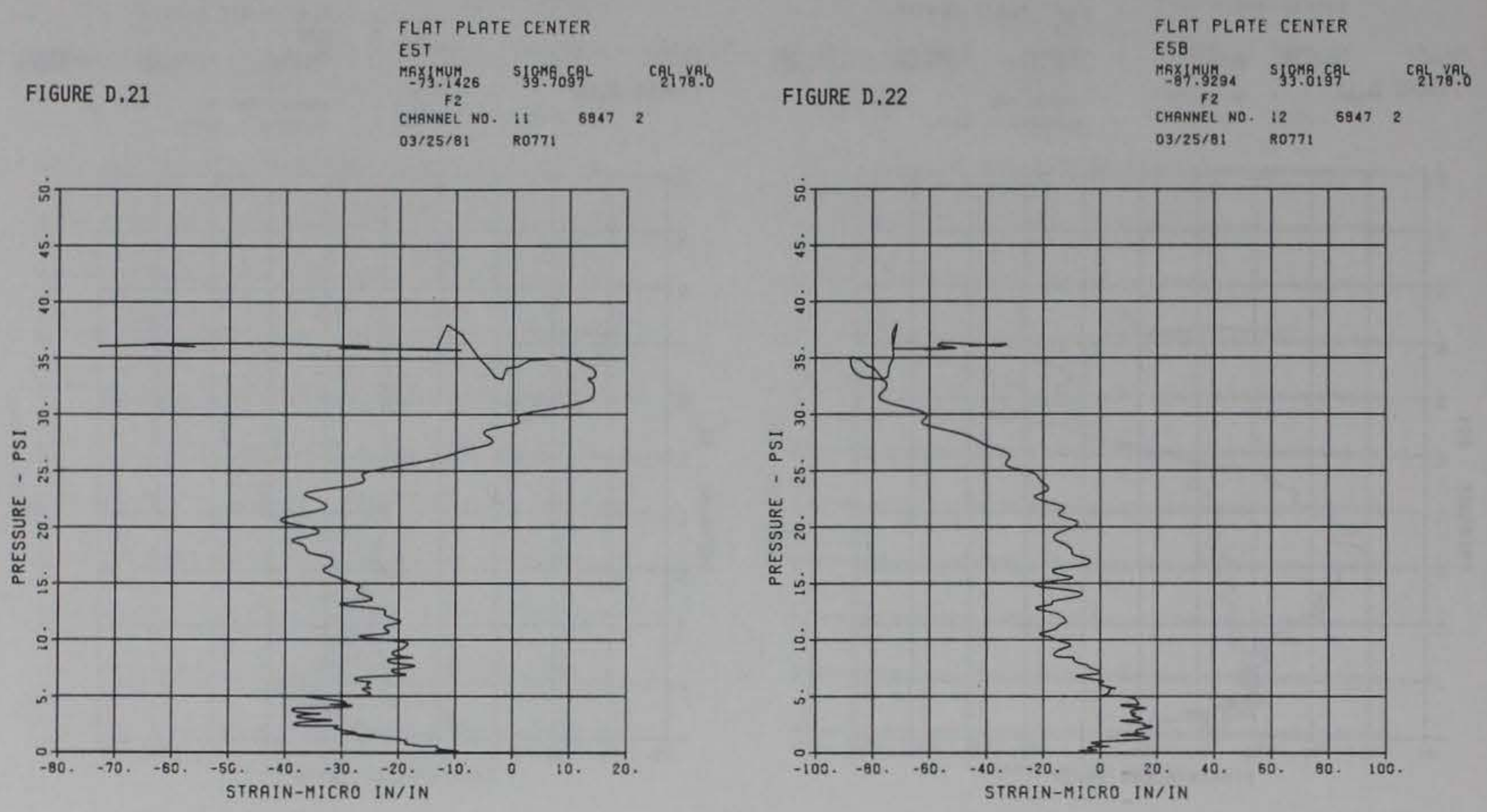

FLAT PLATE CENTER

EGT

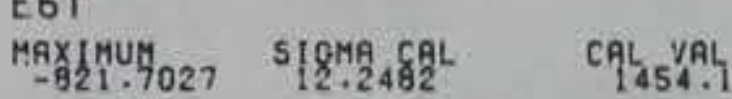

$\begin{array}{ccc}\text { F2 } & \\ \text { CHANNEL NO. } 3 \quad 6947 & 2\end{array}$

$\begin{array}{lll}\text { CHANNEL NO. } & \text { i3 } & 6947 \\ 03 / 25 / 81 & \text { R0771 }\end{array}$

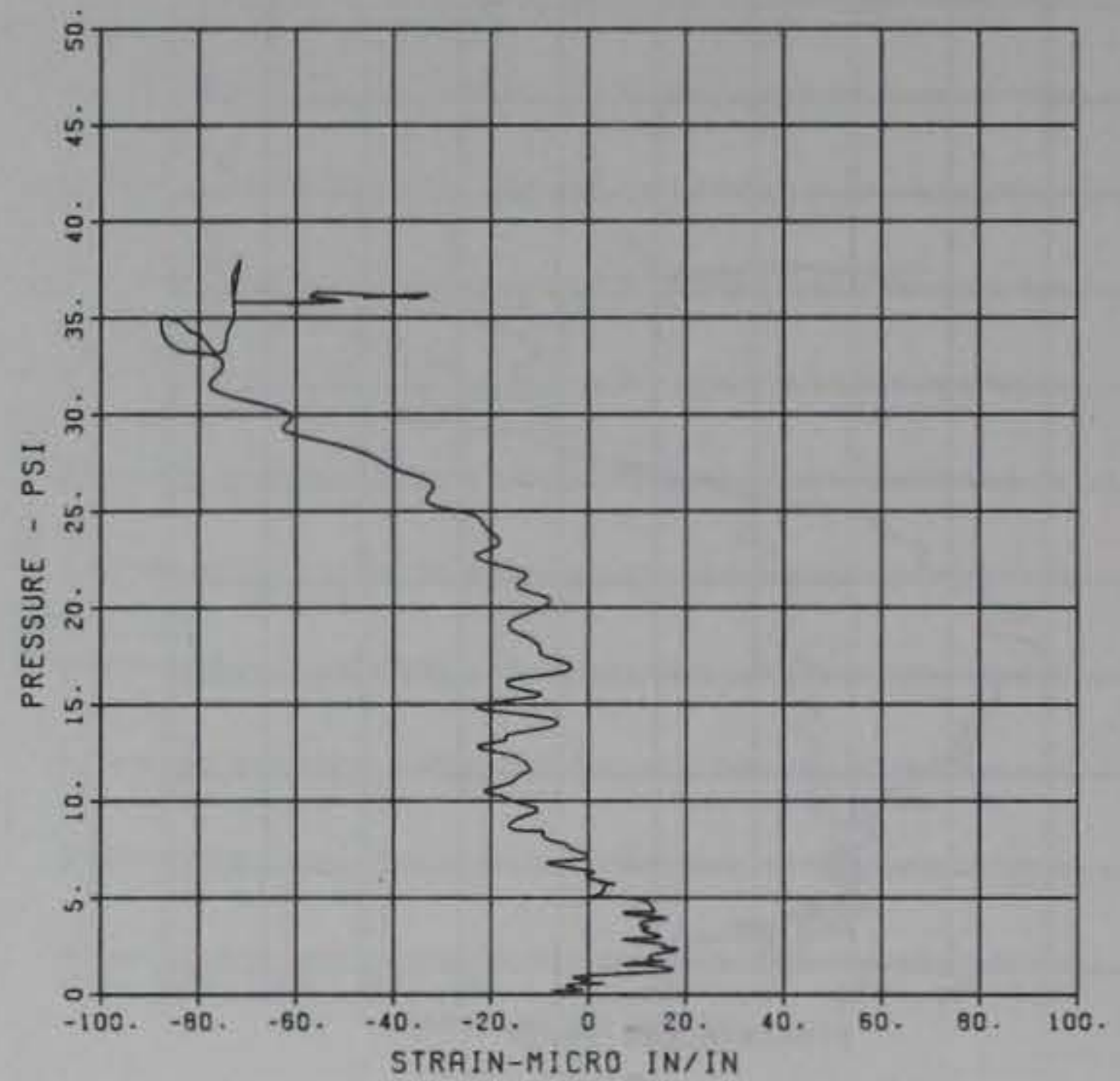

FIGURE D.23

FIGURE D.24

FLAT PLATE CENTER

E6B

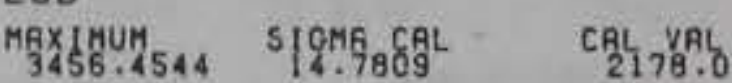

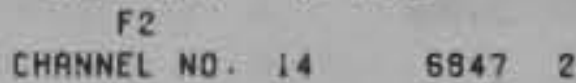

03/25/81 RO771
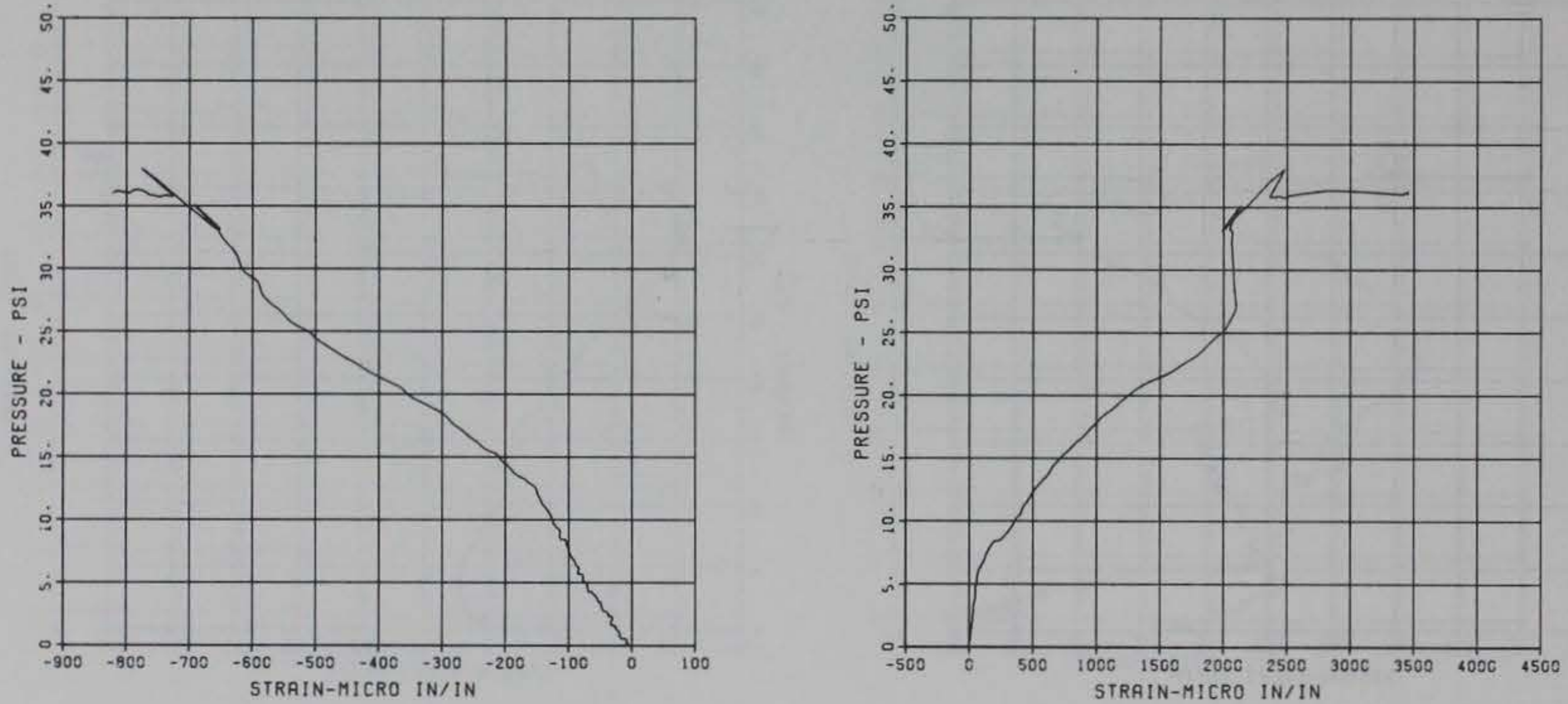


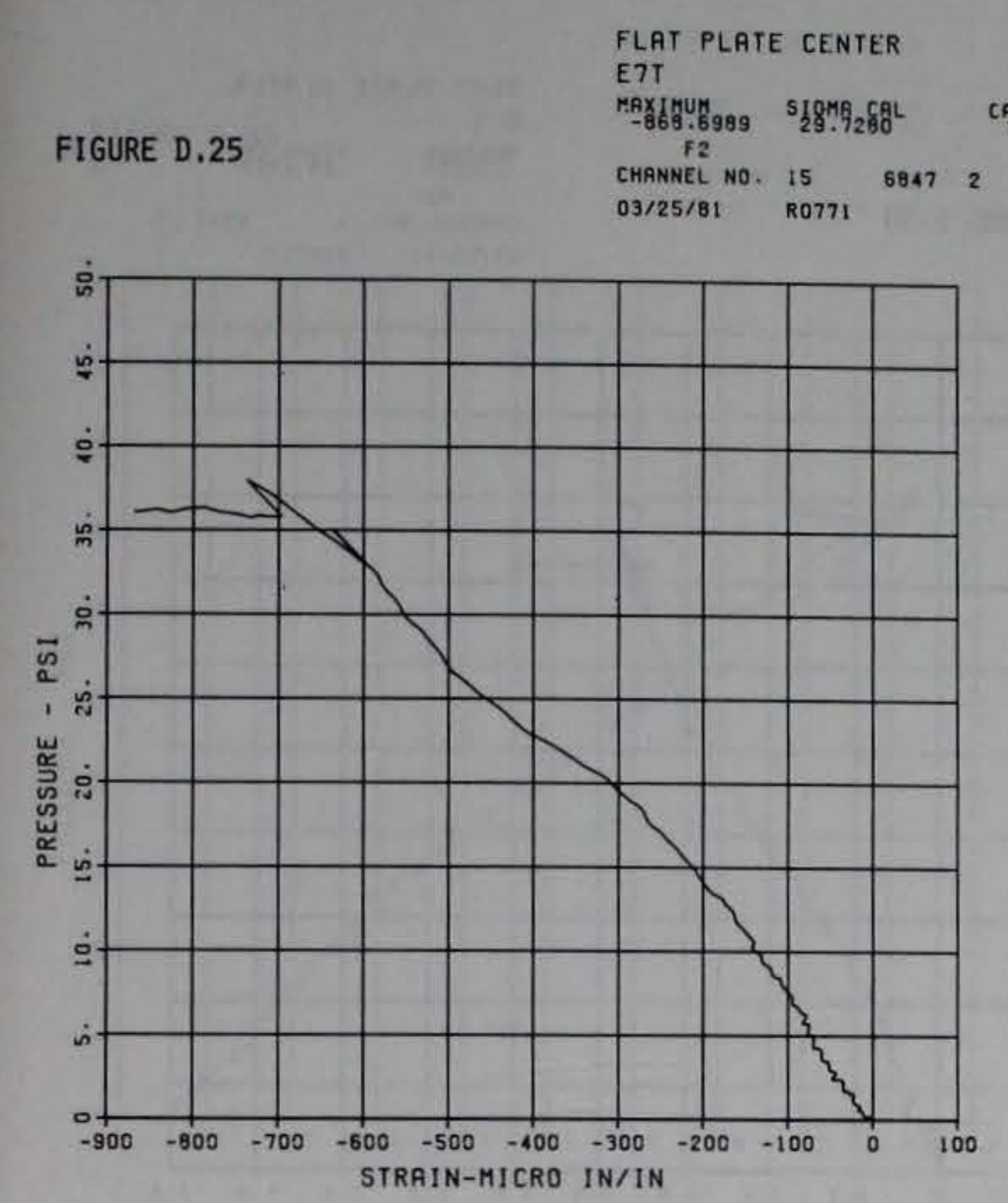

FIGURE D.26

FLAT PLATE CENTER

E7B

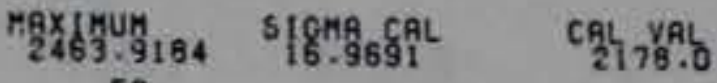

$\begin{array}{llll}\text { CHANNEL NO. } & \text { i6 } & 6847 & 2 \\ \text { O3/25/81 } & \text { R0771 } & & \end{array}$

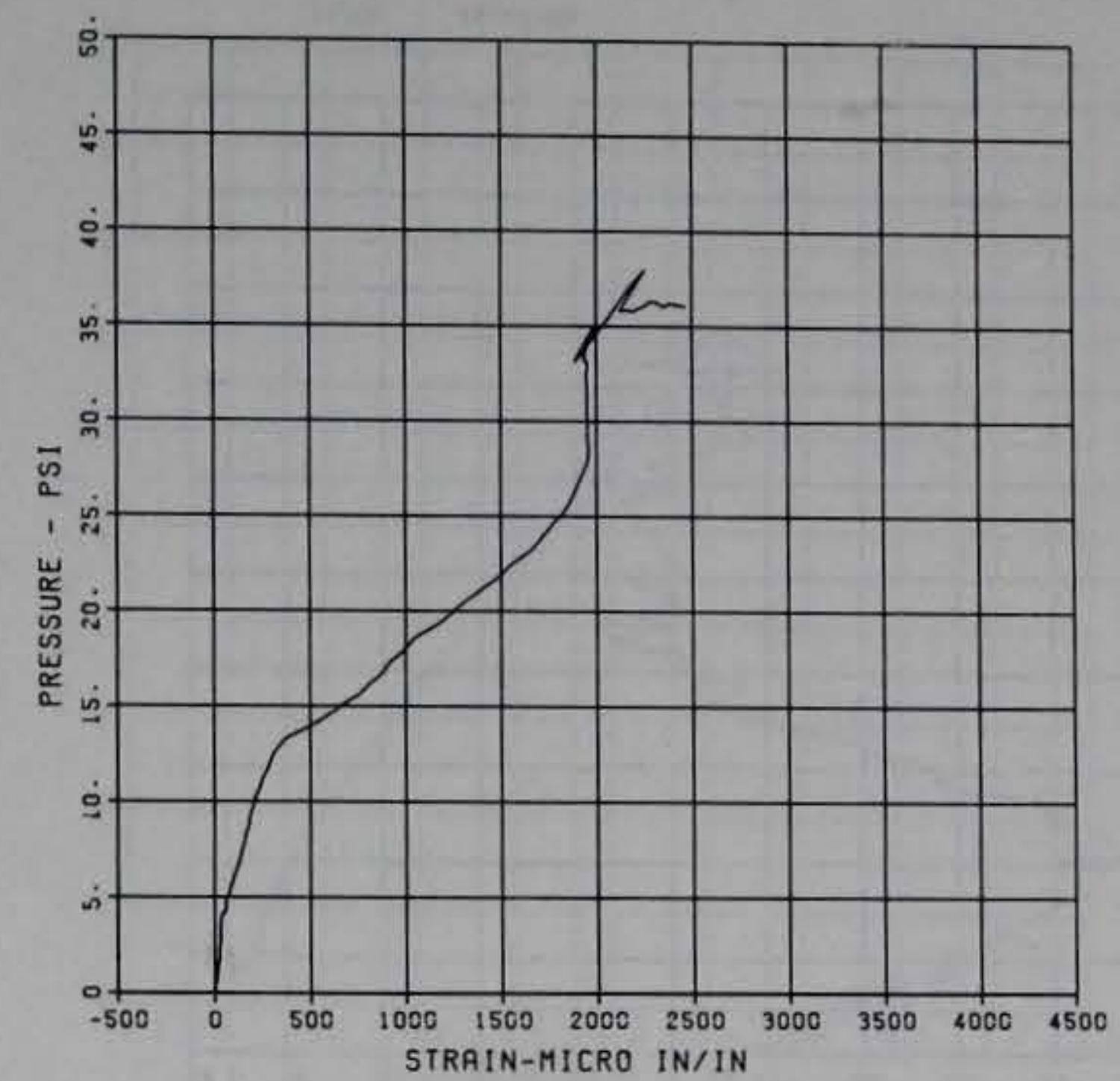

FLAT PLATE CENTER

EBT

FLAT PLATE CENTER

E8B

MAXInUM SIOHค CคL CAL YRL

FIGURE $D .27$

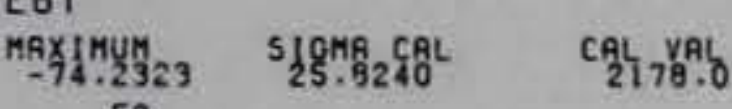

CHANNEL NO. :7 $6847=$

FIGURE D.28

$\begin{array}{llll}\text { F2 } 2 \text { NHANNEL NO. : } 8 & 6847 & 2\end{array}$

03/25/81 R0771

03/25/81 R0771
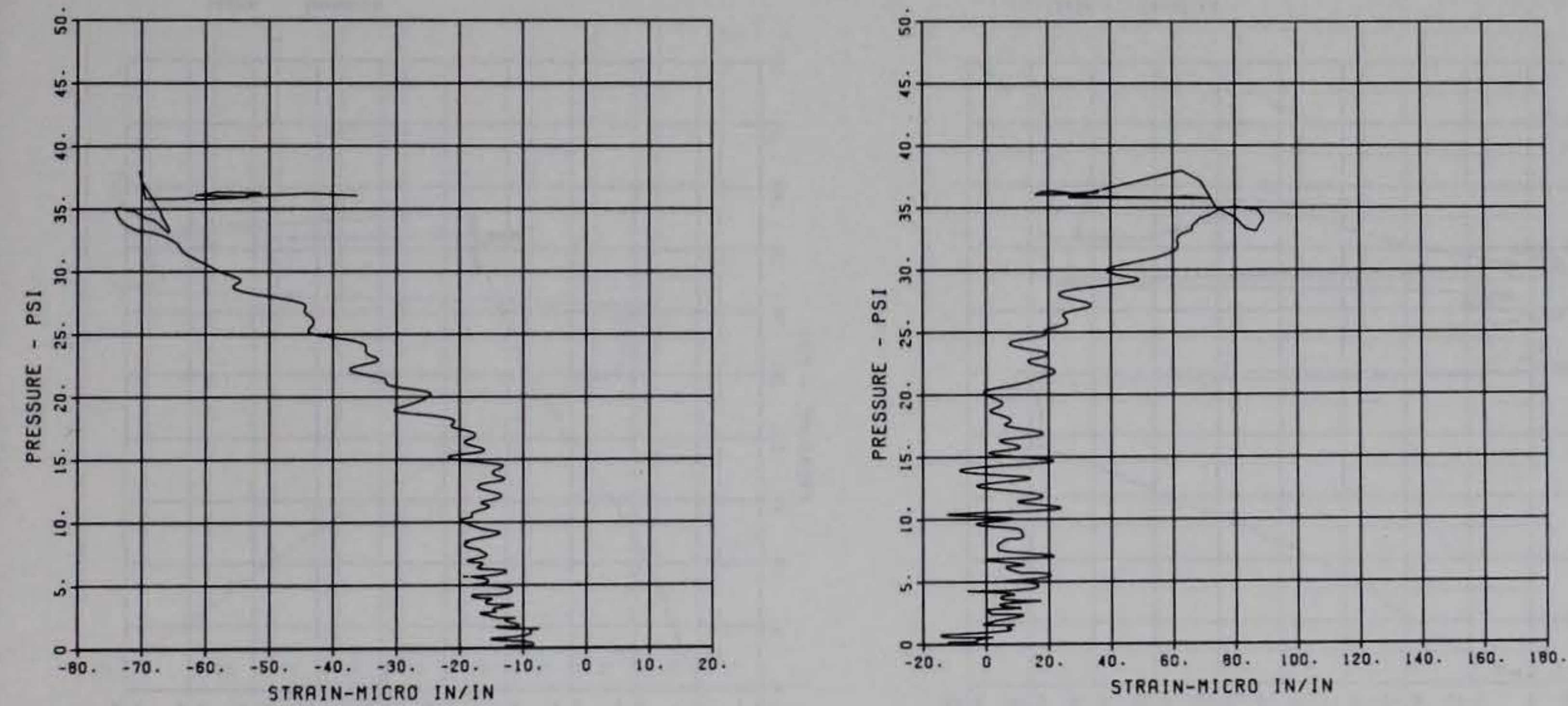
FLAT PLATE CENTER

EST

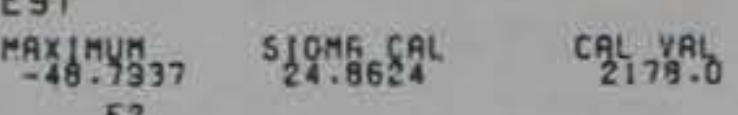

FIGURE D.29

F2
CHANNEL NO. I9 6847 ?

03/25/81 R0771

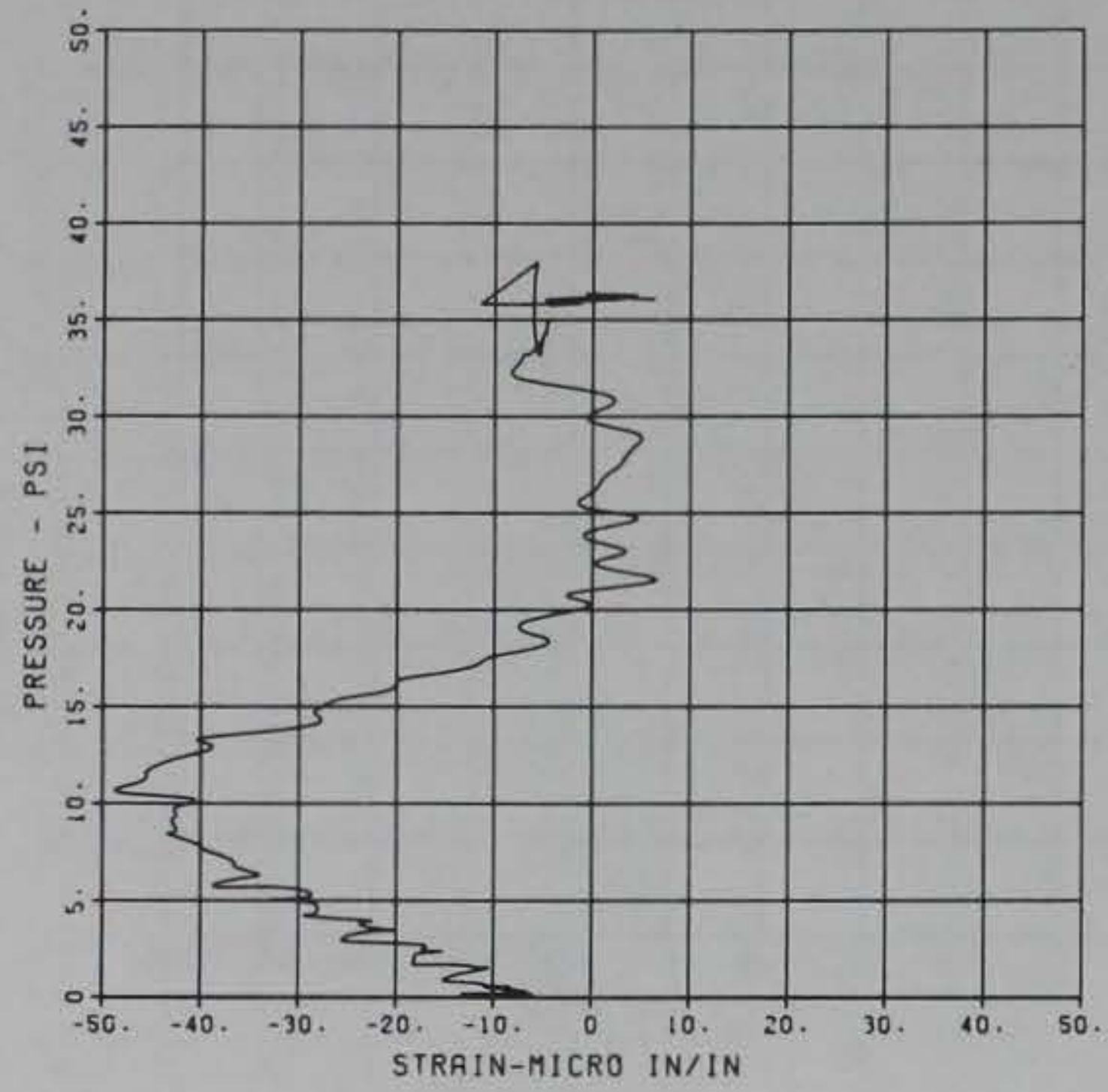

FLAT PLATE CENTER

$D-2$

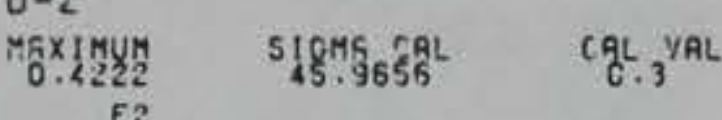

CHANNEL NO 5 6947

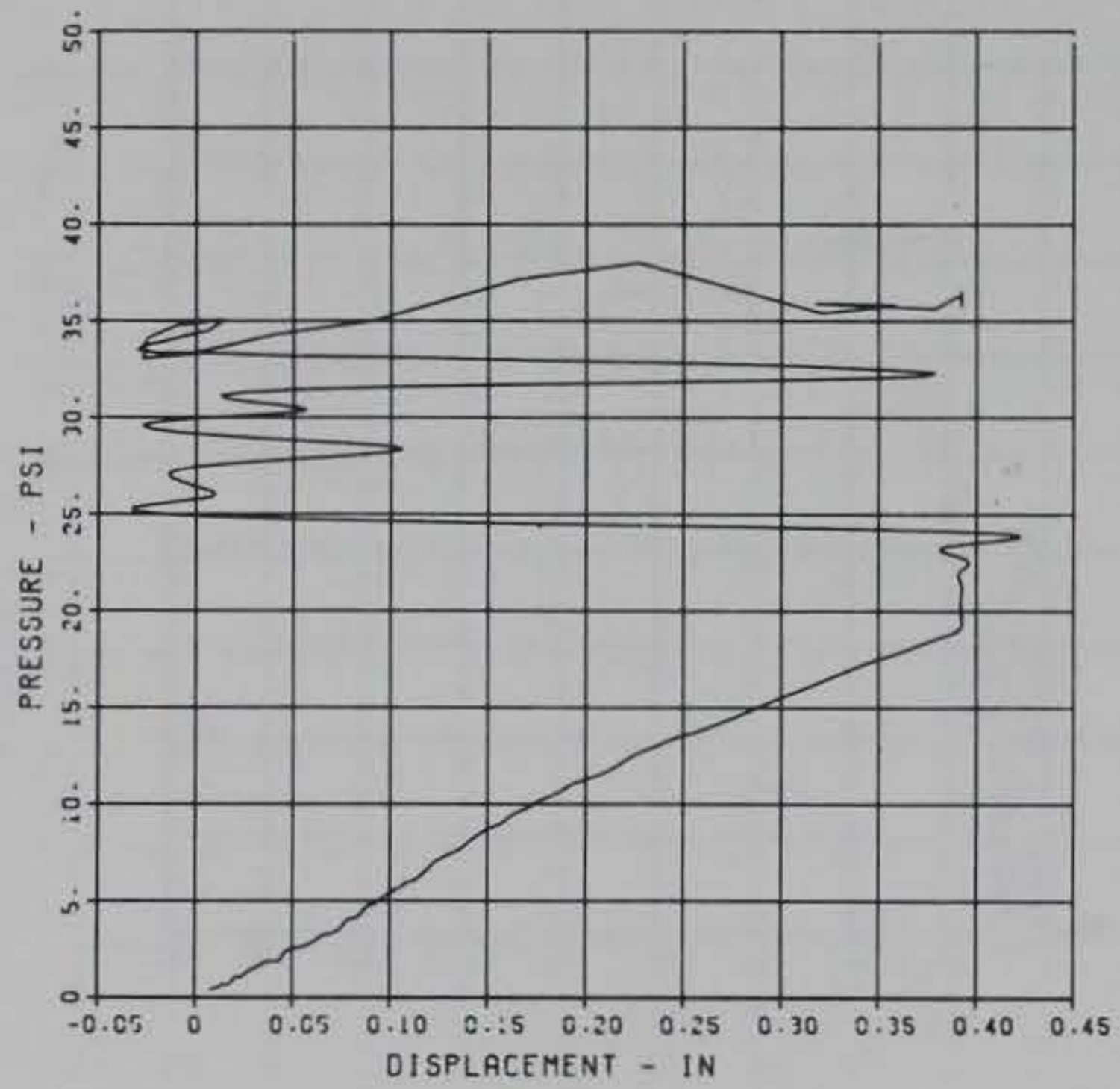

FLAT PLATE CENTES

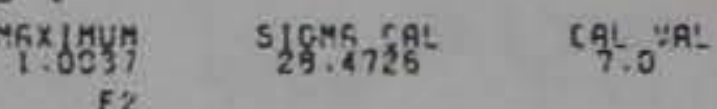

FIGURE D.30

CHONNEL N2 $5 \quad 6947$

03/25/8: R0771

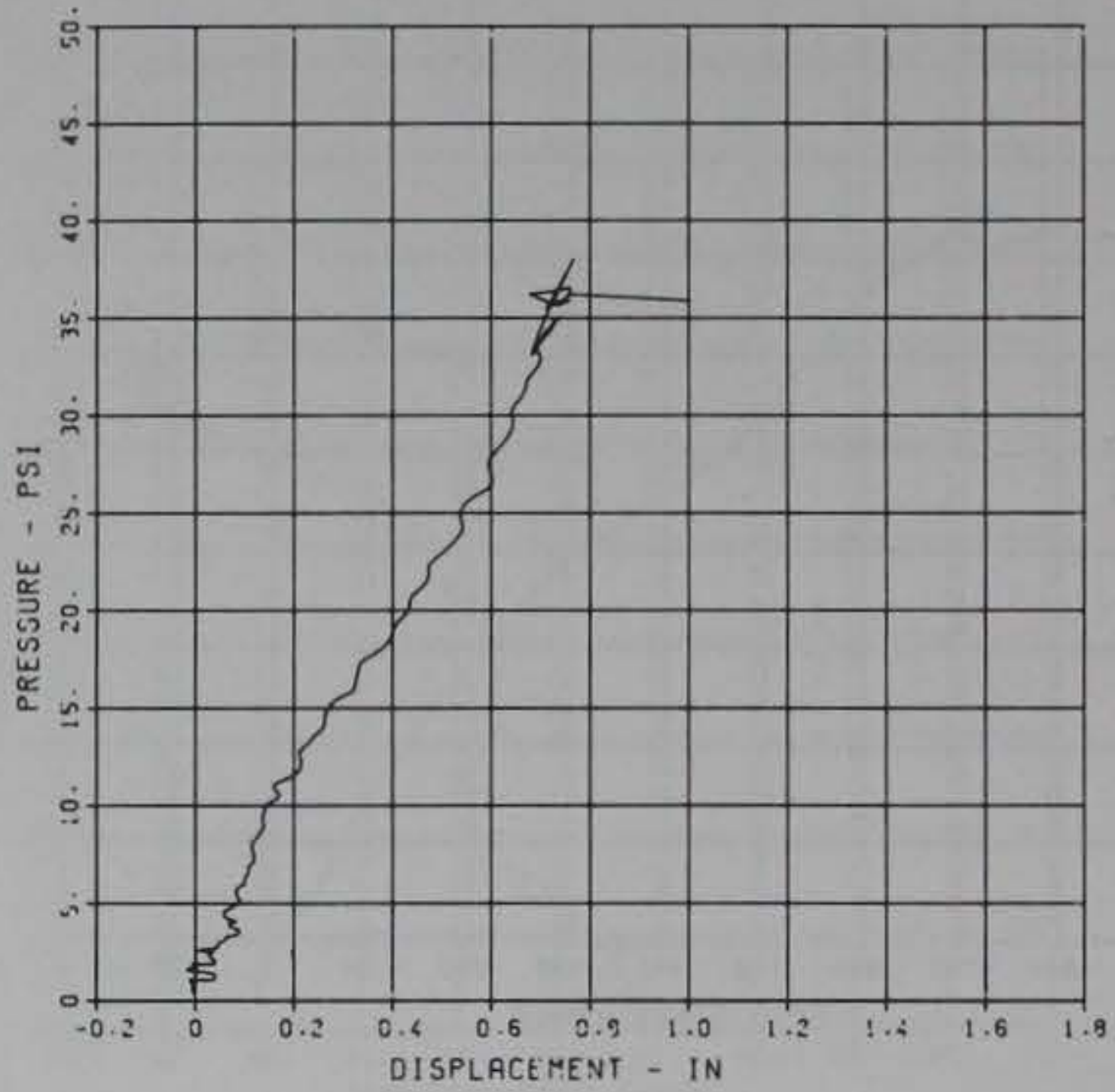

FLAT PLATE CENTER

$0-3$

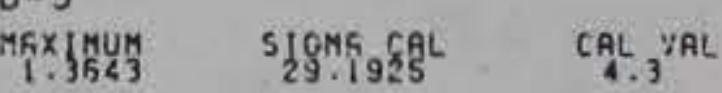

CHANNEL NO : 6947

03/25/81 2077

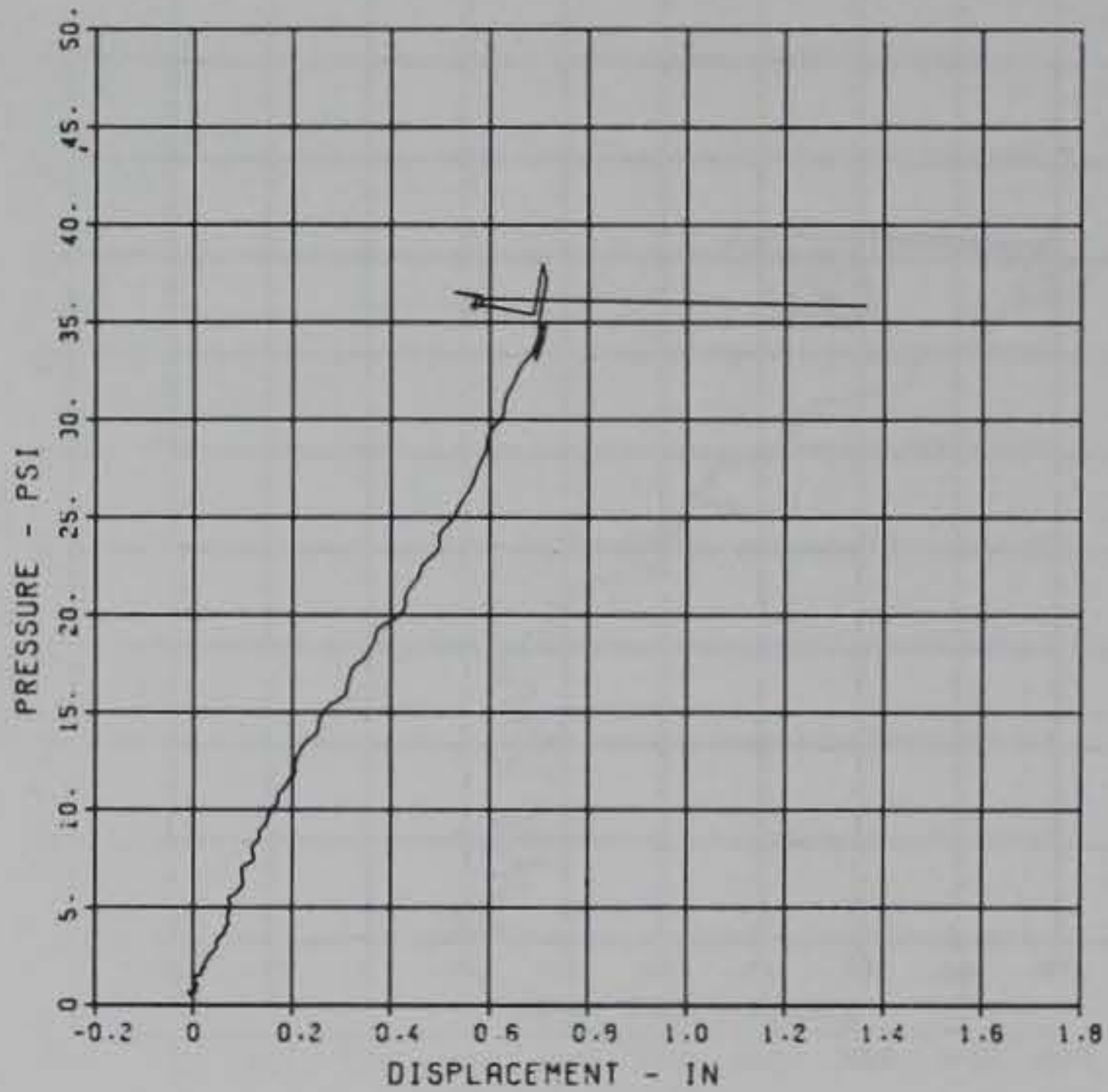




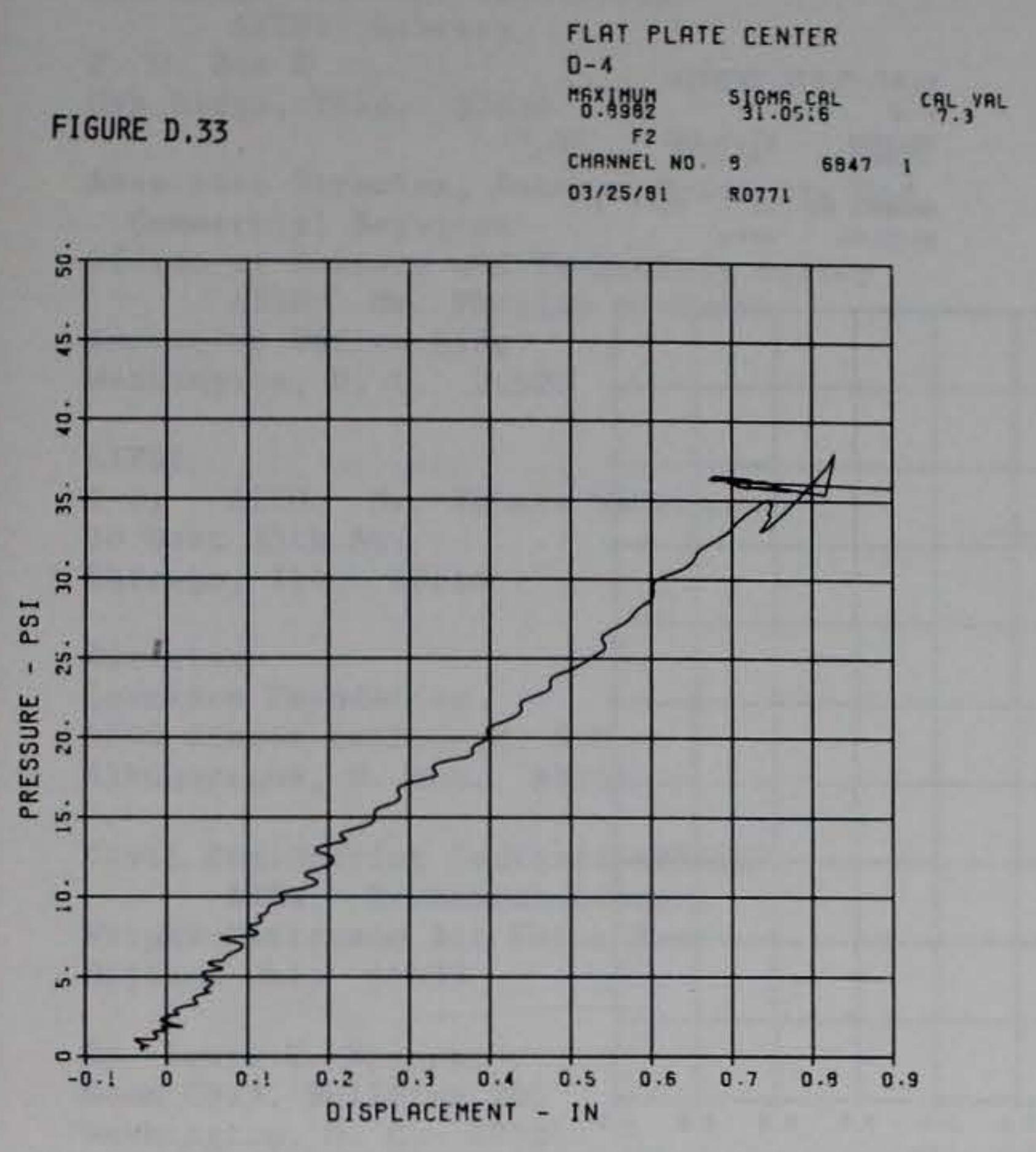

FIGURE D.34

FLAT PLATE CENTER

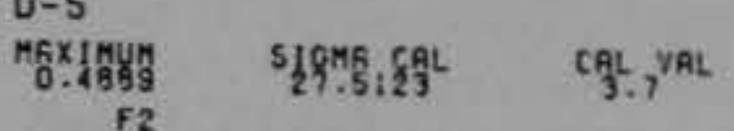

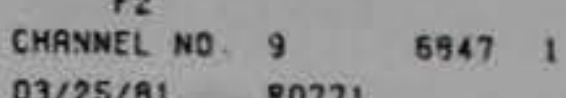

03/25/81 R0771

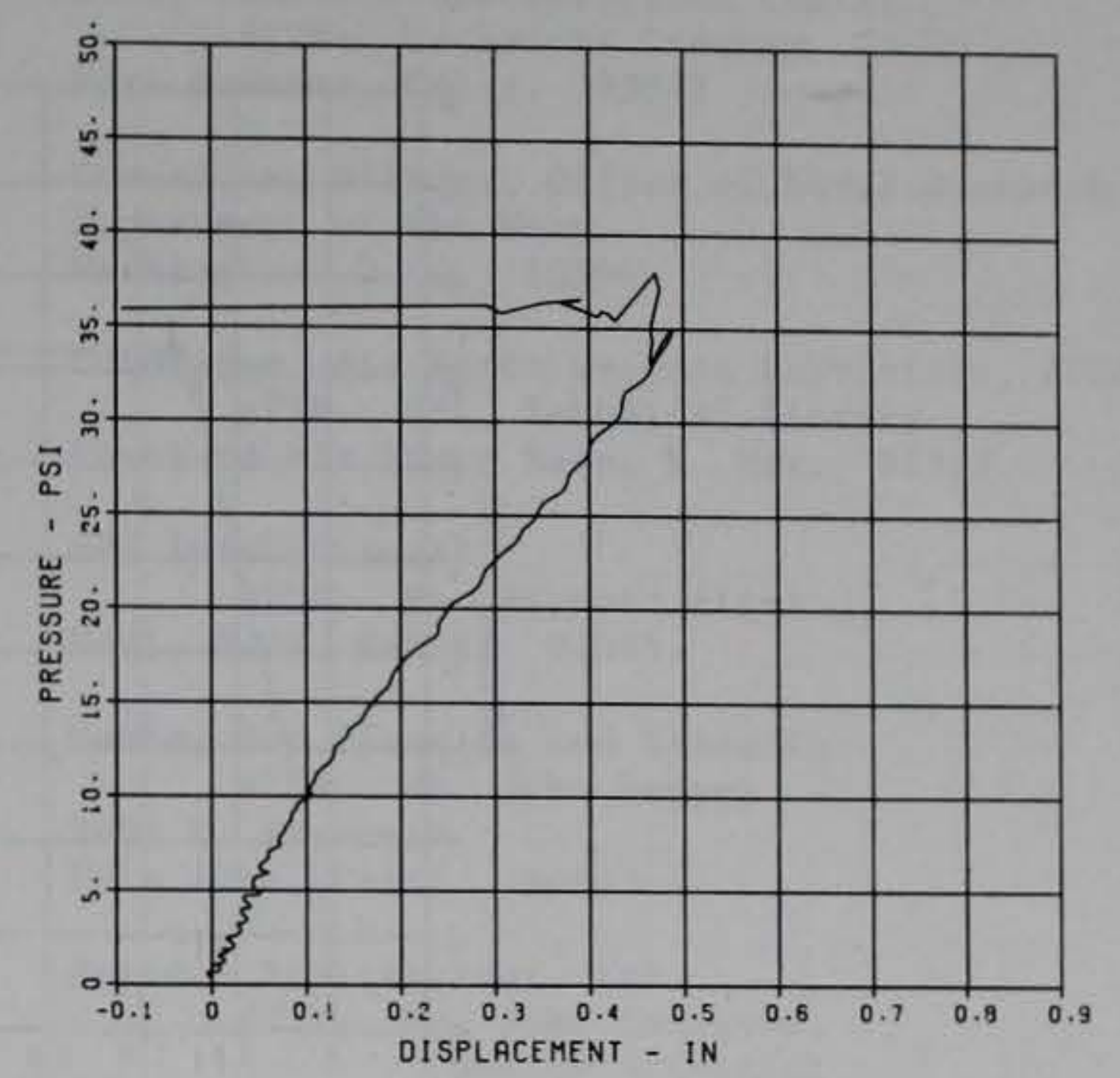

FLAT PLATE CENTER

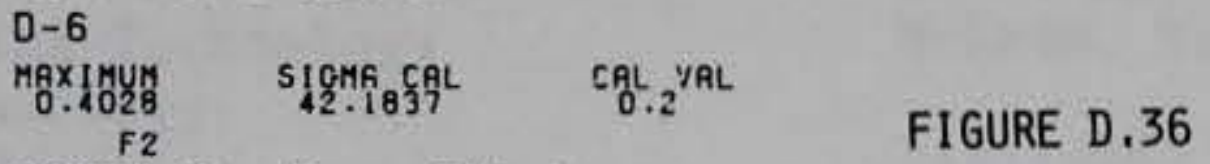

FIGURE D. 35

FLAT PLATE CENTER

D-7

MGXJMUM SIGHG CAL CQL VAL

F2
CHANEL NO. II $6947 \quad$ ।

CHANNEL. NO. : $0 \quad 6947$ ।

03/25/81 R0771
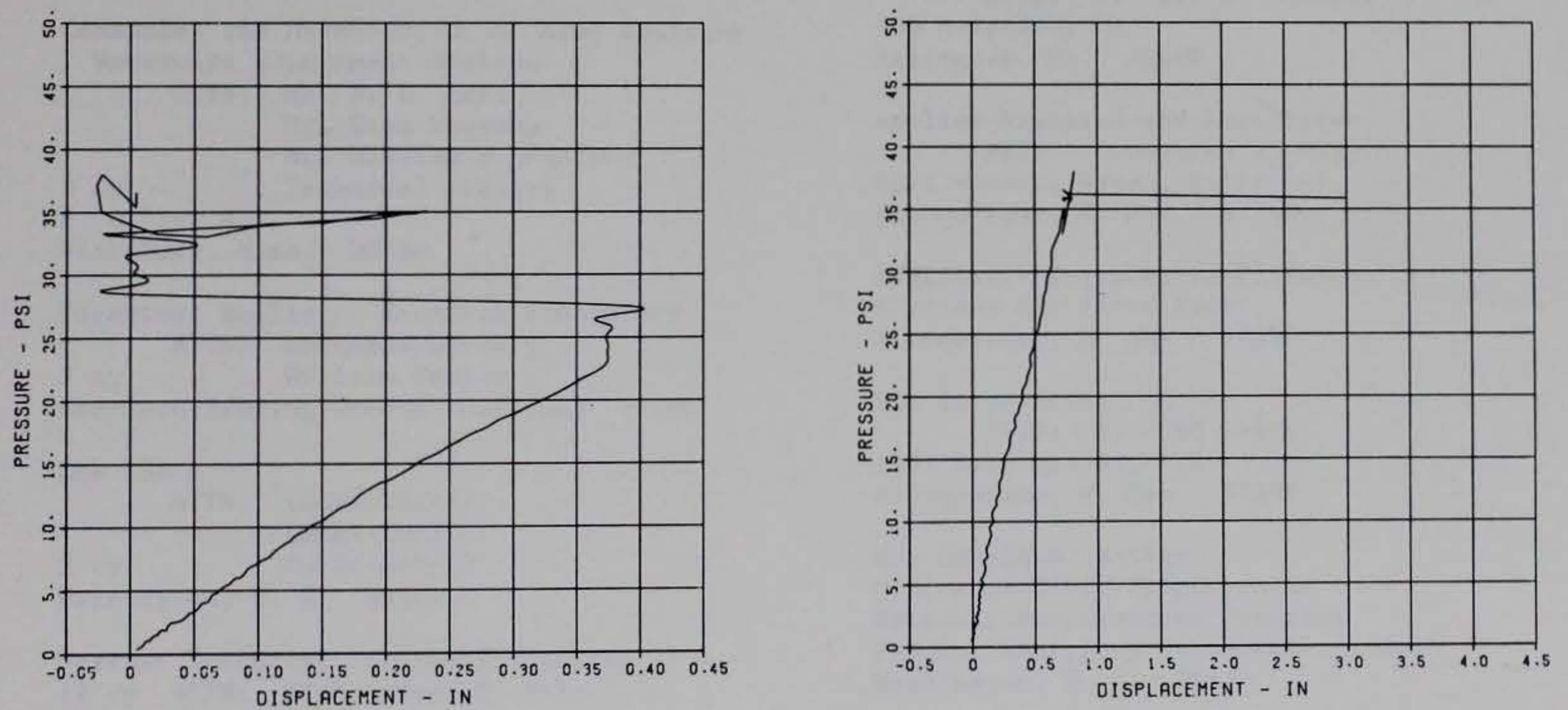
FLAT PLATE CENTER

$D-8$

FIGURE D. 37

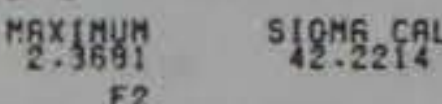

CHANEL NO $12 \quad 6847$

03/25/81 R0771

CRL Y YAL

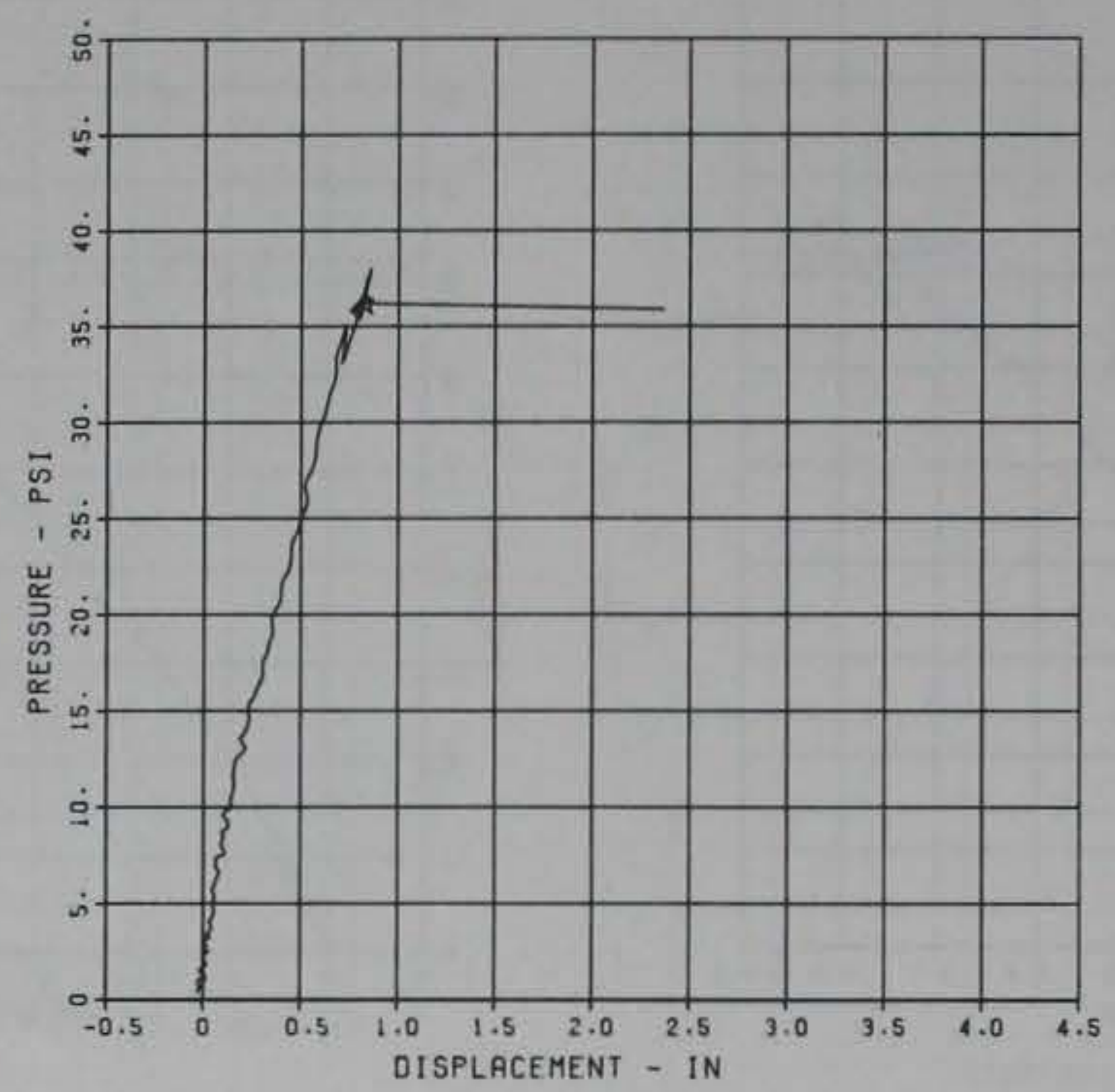

